\title{
Changing Lifeways along the Guadalupe Basin in South Texas: The Results of National Register Testing of a Stratified Multicomponent Prehistoric Site, 41DW277, DeWitt County, Texas
}

Mindy Bonine

Rachel Feit

Antonio E. Padilla

Raba Kistner

Robert Howells

Leslie L. Bush

Heritage Research Center, Stephen F. Austin State University

Follow this and additional works at: https://scholarworks.sfasu.edu/ita

Part of the American Material Culture Commons, Archaeological Anthropology Commons, Environmental Studies Commons, Other American Studies Commons, Other Arts and Humanities Commons, Other History of Art, Architecture, and Archaeology Commons, and the United States History Commons

Tell us how this article helped you.

This Article is brought to you for free and open access by the Center for Regional Heritage Research at SFA ScholarWorks. It has been accepted for inclusion in Index of Texas Archaeology: Open Access Gray Literature from the Lone Star State by an authorized editor of SFA ScholarWorks. For more information, please contact cdsscholarworks@sfasu.edu. 


\section{Changing Lifeways along the Guadalupe Basin in South Texas: The Results of National Register Testing of a Stratified Multicomponent Prehistoric Site, 41DW277, DeWitt County, Texas}

\section{Licensing Statement}

This is a work for hire produced for the Texas Department of Transportation (TxDOT), which owns all rights, title, and interest in and to all data and other information developed for this project under its contract with the report producer. The report may be cited and brief passages from this publication may be reproduced without permission provided that credit is given to TxDOT and the firm that produced it. Permission to reprint an entire chapter, section, figures or tables must be obtained in advance from the Supervisor of the Archeological Studies Branch, Environmental Affairs Division, Texas Department of Transportation, 125 East 11th Street, Austin, Texas, 78701 


\section{CHANGING LIFEWAYS ALONG THE GUADALUPE BASIN IN SOUTH TEXAS}

\section{THE RESULTS OF NATIONAL REGISTER TESTING OF A STRATIFIED MULTICOMPONENT PREHISTORIC SITE, 41DW277, DEWITT COUNTY, TEXAS}

by

Mindy Bonine, Rachel Feit, and Antonio E. Padilla

with contributions by

Robert Howells and Leslie L. Bush

Rachel Feit and Allen Bettis, Co-Principal Investigators

Texas Antiquities Permit 5460

CSJ: 0154-03-027

by

AmaTerra Environmental, Inc.

Austin, Texas

\section{AmaTerras}

Texas Department of Transportation

Environmental Affairs Division

Archeological Studies Program, Report No 143

February 2013 
Copyright () 2013

Texas Department of Transportation (TxDOT)

This is a work for hire produced for the Texas Department of Transportation (TxDOT), which owns all rights, title, and interest in and to all data and other information developed for this project under Contract 579145A006. Brief passages from this publication may be reproduced without permission provided that credit is given to TxDOT and AmaTerra Environmental, Inc. Permission to reprint an entire chapter, section, figures or tables must be obtained in advance from the Supervisor of the Archeological Studies Program, Environmental Affairs Division, Texas Department of Transportation, 125 East 11th Street, Austin, Texas 78701. Copies of this publication have been deposited with the Texas State Library in compliance with the State Depository Requirement.

Printed by Ginny’s Printing

published by:

Texas Department of Transportation

Environmental Affairs Division

Archeological Studies Program

Scott Pletka, Ph.D., Supervisor

Archeological Studies Program Report No 143

A. McGraw, Series Editor

and

AmaTerra Environmental, Inc.

4009 Banister Lane, Suite 300

Austin, Texas 78704

ISBN\# 978-1-935545-09-05

AmaTerra Project No. 062-034 


\section{Abstract}

AmaTerra Environmental (formerly Ecological Communications Corporation [EComm]) conducted archeological National Register eligibility testing at Site 41DW277 in December 2009. The site is located in the proposed right-of-way (ROW) for a new bridge along US 183 over the Guadalupe River, DeWitt County, Texas. Site 41DW277 was documented in 2009 by James Abbott and Allen Bettis of the Texas Department of Transportation (TxDOT) and at the time of survey it was thought to be potentially eligible for listing on the National Register of Historic Places (NRHP) or as a State Archeological Landmark (SAL). Due to expected impacts resulting from the proposed bridge construction, testing was recommended to determine NRHP/SAL eligibility. TxDOT hired AmaTerra to complete the work under Texas Antiquities Permit 5460. Testing consisted of excavation of five gradall trenches and 32 test units. AmaTerra found that the site consists of three stratified prehistoric components extending from 1-2 meters in depth and ranging from 2,800 years to 5,200 years BP in age. Three features were documented and artifacts recovered included lithic debris and tools, mussel shell, snail shell, a small amount of bone, and some modern household debris (from the top levels of the units). Burned rock was observed and documented but not collected. An interim report was submitted in January 2010 recommending that the upper components of the site are not eligible for NRHP/SAL listing but that lowest and oldest component is eligible. However, the report also recommended that no further work was needed since the lowest component was not within the area of potential effect (APE) for the bridge replacement. The Texas Historical Commission concurred with this recommendation in February 2010. This report documents the results of the testing and analysis for Site 41DW277. Records and artifacts generated during this project will be curated at the Center for Archaeological Studies at Texas State University. 


\section{TABLe of Contents}

ABSTRACT $\quad$..................................................................................................................................... ii

ACKNOWLEDGEMENTS ....................................................................................................... xiii

\section{CHAPTER 1}

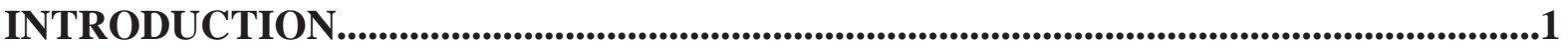

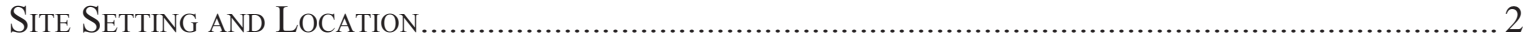

Description of Proposed Undertaking ANd APE ...................................................................... 3

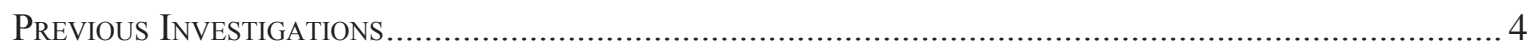

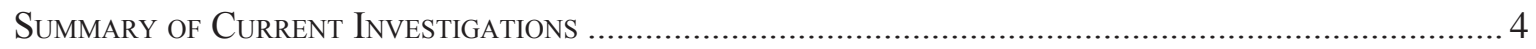

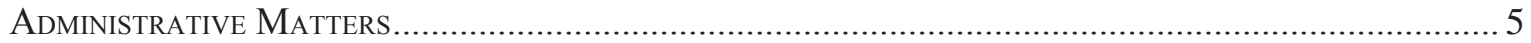

\section{CHAPTER 2}

ENVIRONMENTAL SETTING .................................................................................................

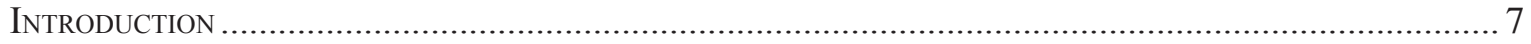

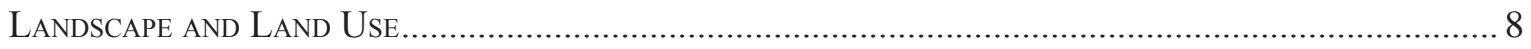

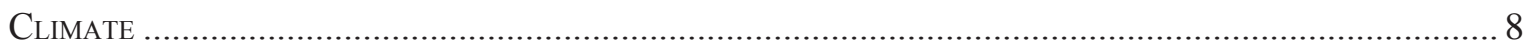

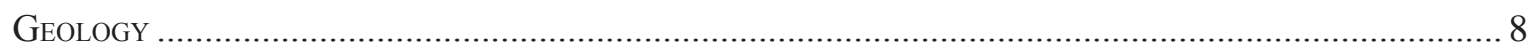

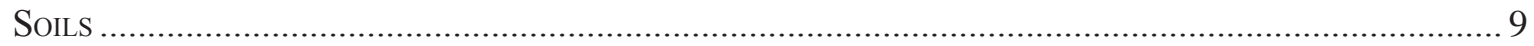

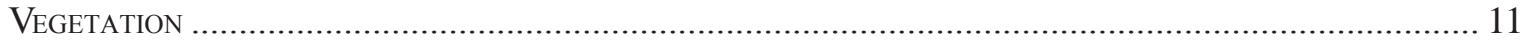

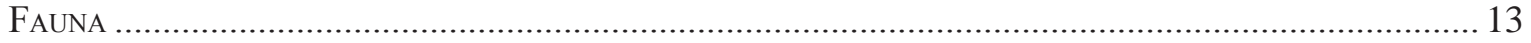

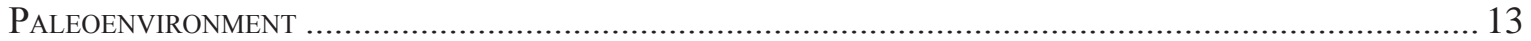

\section{CHAPTER 3}

CULTURAL HISTORY AND PREVIOUS INVESTIGATIONS ......................................15

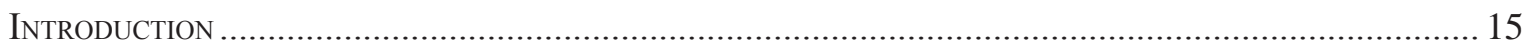

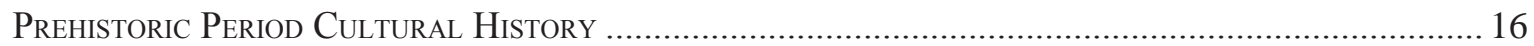

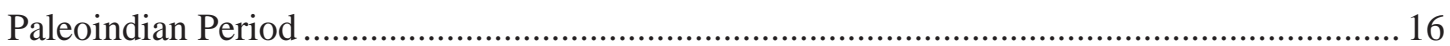

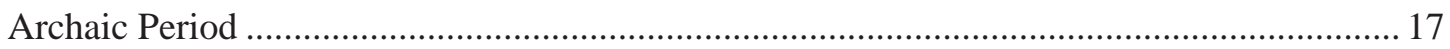

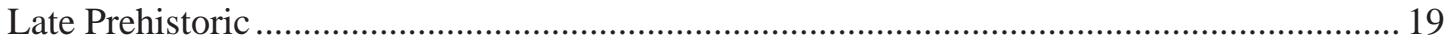

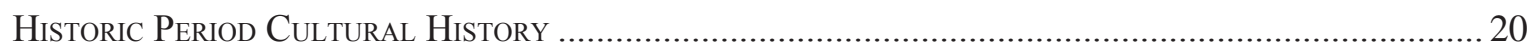

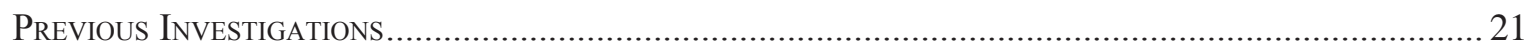




\section{CHAPTER 4}

RESEARCH DESIGN AND METHODOLOGY ...............................................................23

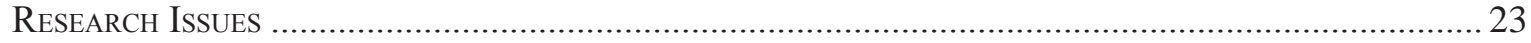

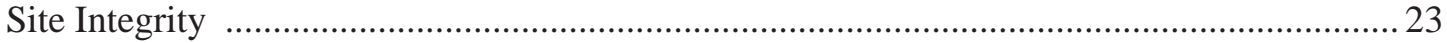

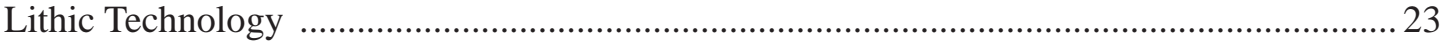

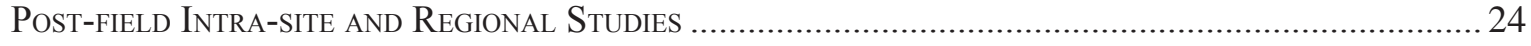

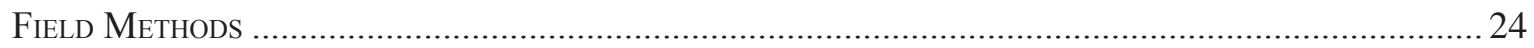

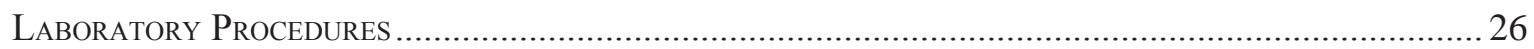

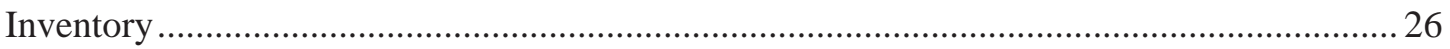

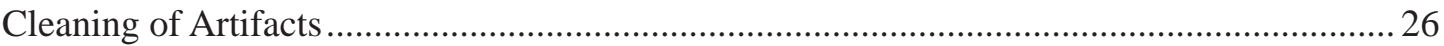

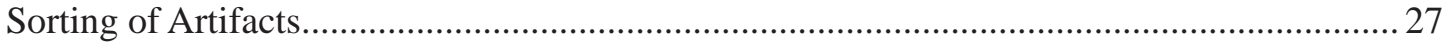

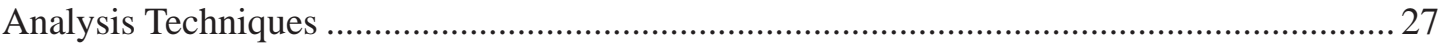

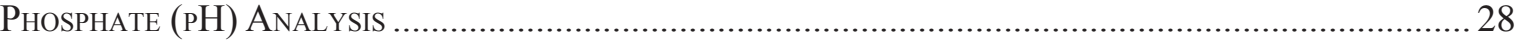

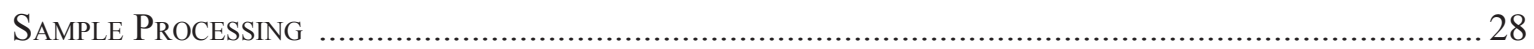

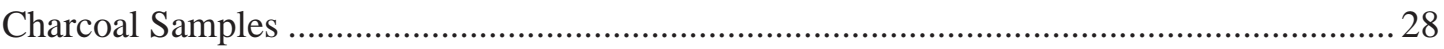

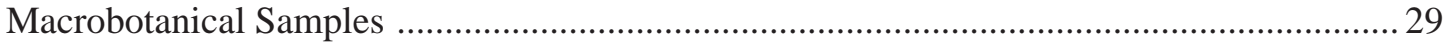

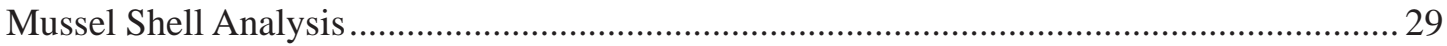

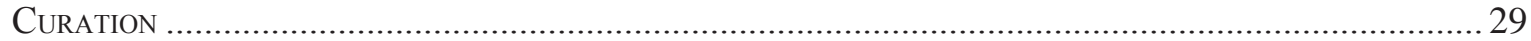

\section{CHAPTER 5}

RESULTS OF INVESTIGATIONS....................................................................................31

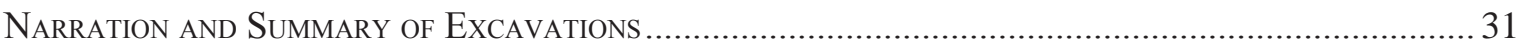

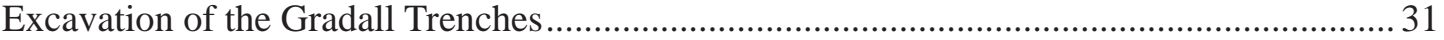

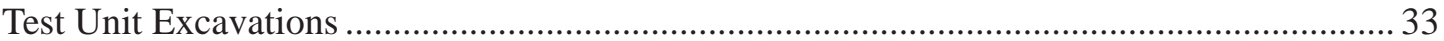

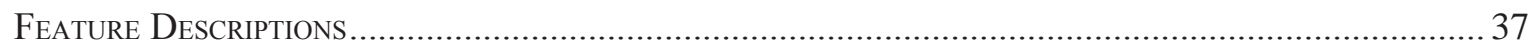

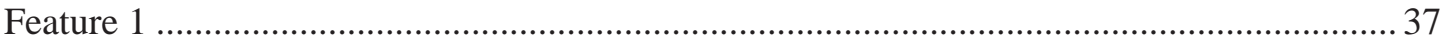

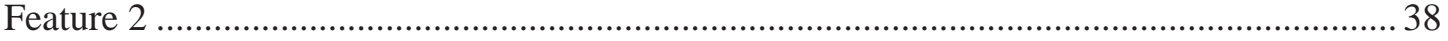

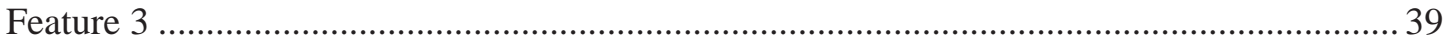

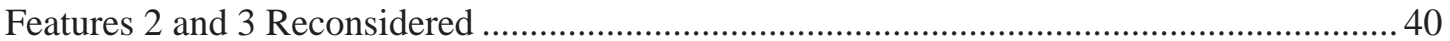

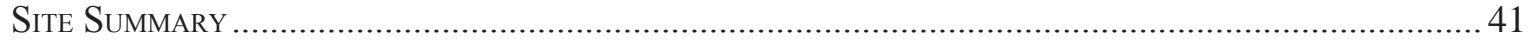

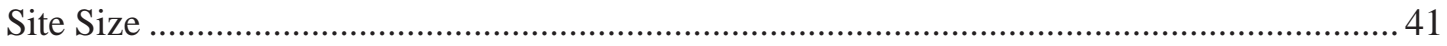

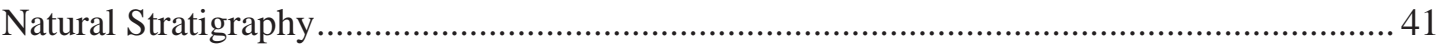

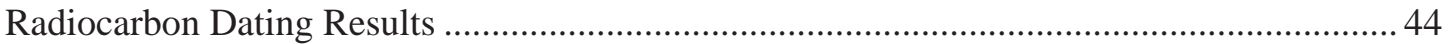

Summary of Observed Cultural Material................................................................................... 47

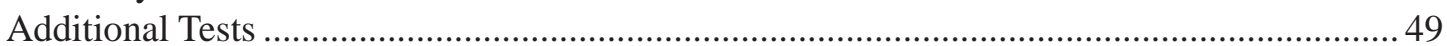

Cultural Components as Defined in Analytical Units ................................................................. 52

\section{CHAPTER 6}

RECOVERED CULTURAL MATERIAL_......................................................................57

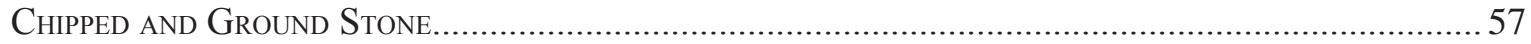

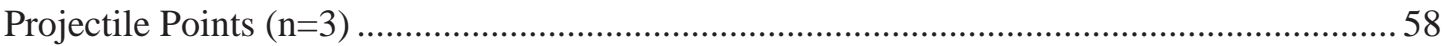




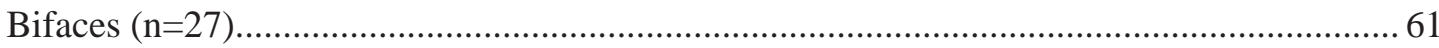

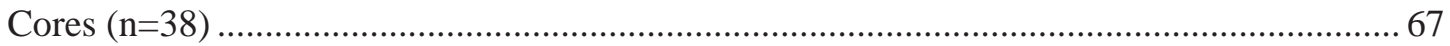

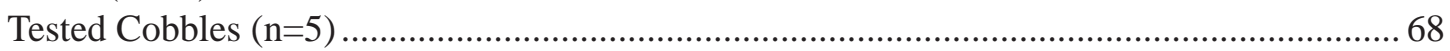

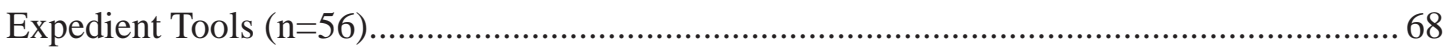

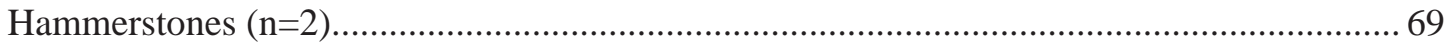

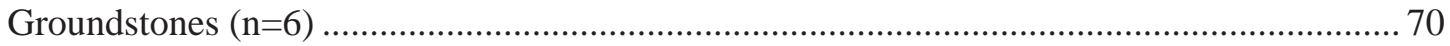

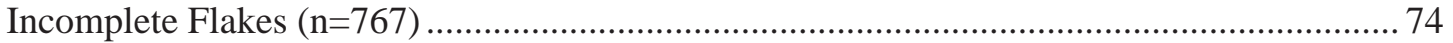

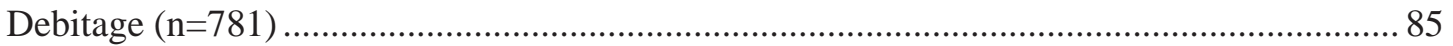

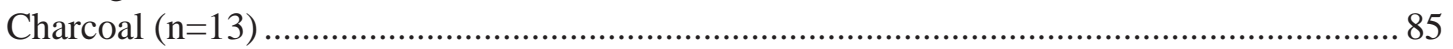

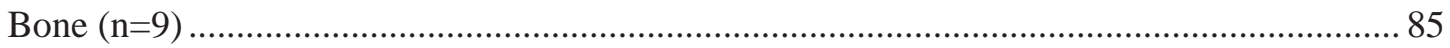

\section{CHAPTER 7}

DISCUSSION AND ANALYSIS ...............................................................................................87

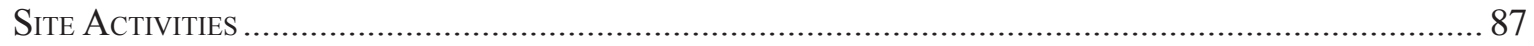

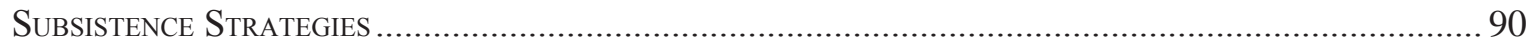

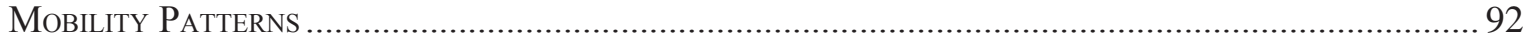

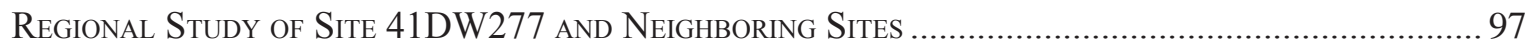

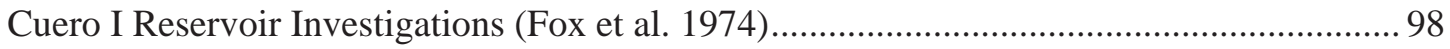

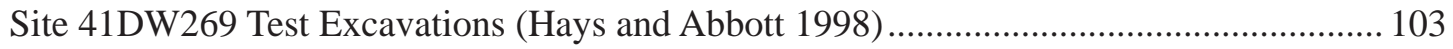

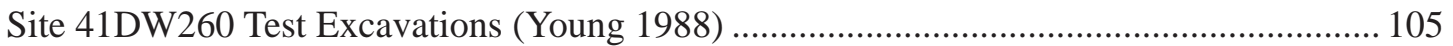

Site 41LC2 Text Excavations (Stahman et al. 2009) …........................................................... 105

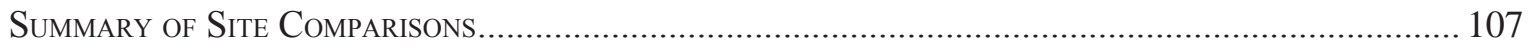

\section{CHAPTER 8}

SUMMARY, CONCLUSIONS, AND RECOMMENDATIONS .........................................109

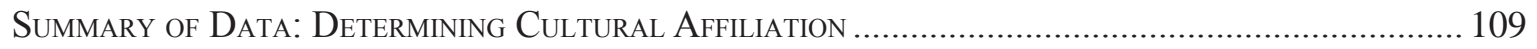

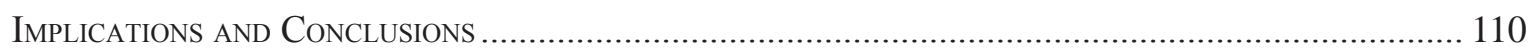

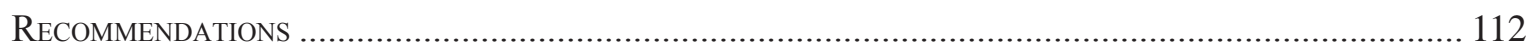

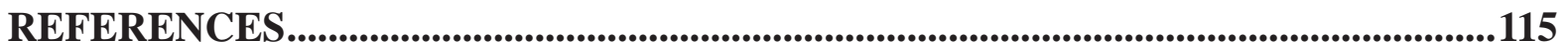

\section{APPENDICES:}

Appendix A

Appendix B

Appendix C

ApPendix D 


\section{List OF Figures}

Figure 1-1. Location of the project area in northern DeWitt County. 1

Figure 1-2. View of Site 41DW277 looking toward the US 183 bridge over the Guadalupe River....... 2

Figure 1-3. Aerial map of proposed undertaking and location of Site 41DW277............................... 3

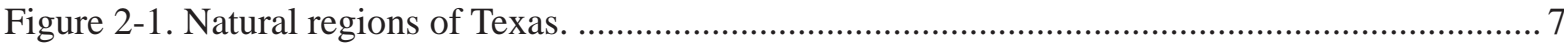

Figure 2-2. Map of the geological formations around the Guadalupe River valley and

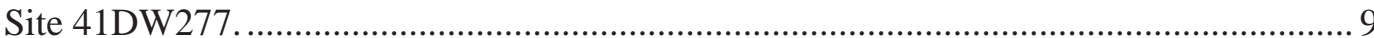

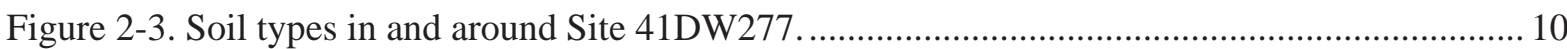

Figure 2-4. Various mapped natural regions and ecoregions around Site 41DW277. ....................... 12

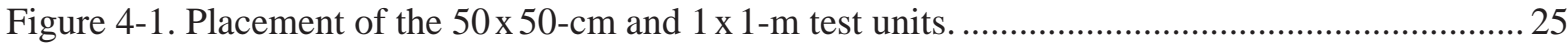

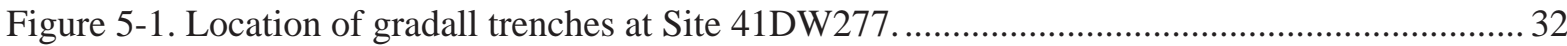

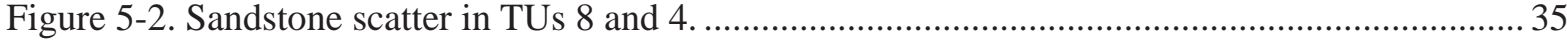

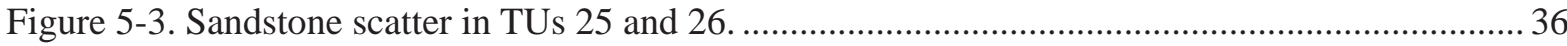

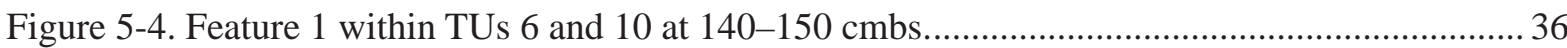

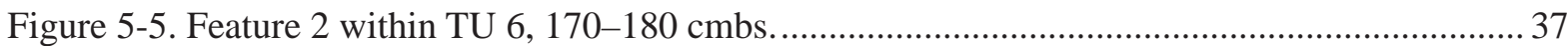

Figure 5-6. Feature 3 within TU 10, 170-180 cmbs......................................................................... 37

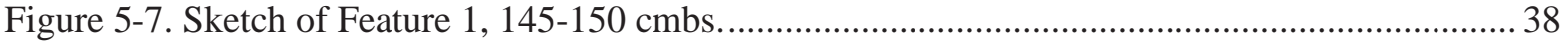

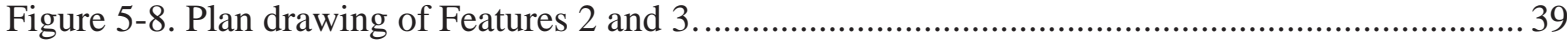

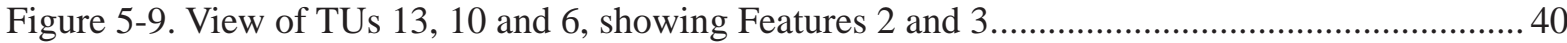

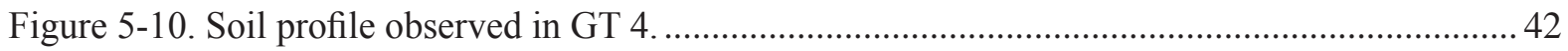

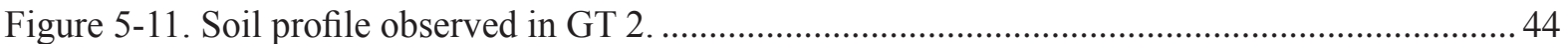

Figure 5-12. Spatial relationship of the soil profiles observed in GTs 2, 5, and 3 and changes in depths of the Ap-A-AB-Bw horizons.

Figure 5-13. Diagram of spacial-temporal relationships between radiocarbon dates at Site 41DW277.

Figure 5-14. Graph of observed burned rock in the hand excavation units. Ratios are based on actual excavated volume $\left(\mathrm{m}^{3}\right)$ per level.

Figure 5-15. Graph of recovered stone artifacts in the hand excavation units. Ratios are based on actual excavated volume $\left(\mathrm{m}^{3}\right)$ per level.

Figure 5-16. Graph of recovered mussel remains in the hand excavation units. Ratios are based on actual excavated volume $\left(\mathrm{m}^{3}\right)$ per level

Figure 5-17. Graph of recovered snail shells in the hand excavation units. Ratios are based on actual excavated volume $\left(\mathrm{m}^{3}\right)$ per level.............................................................................. 50

Figure 5-18. Graph of the mean $\mathrm{pH}$ values for GTs 2, 5, and 3 by elevation.................................... 50

Figure 5-19. Graph of mean soil susceptibility readings for GTs 2, 3, and 5 by elevation. ................. 51

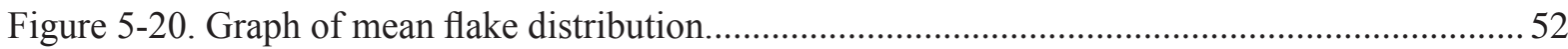

Figure 5-21. Test unit data and analytical units observed in GTs 2 and 3...................................... 54 
Figure 5-22. Test unit data and analytical units observed in GTs 4, 5, and 6................................. 54

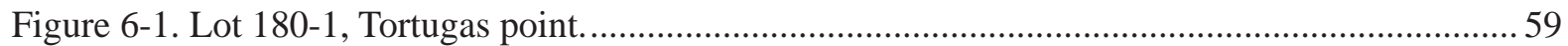

Figure 6-2. Lot 127-1, untypable lanceolate point............................................................................... 60

Figure 6-3. Lot 110-1, untypable lanceolate point. ........................................................................... 61

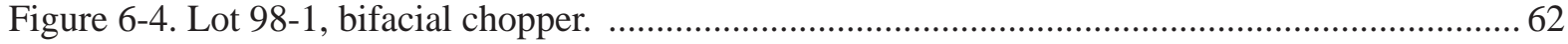

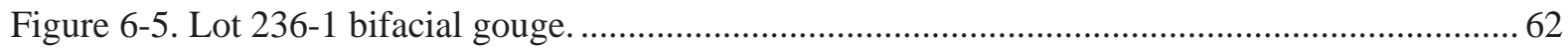

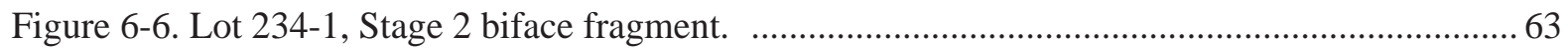

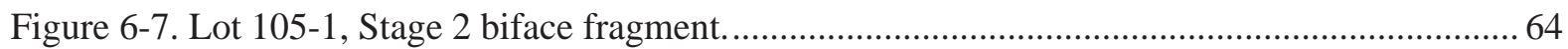

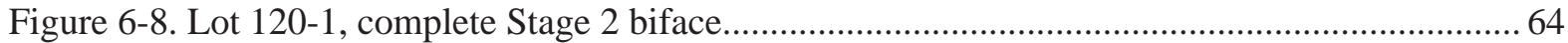

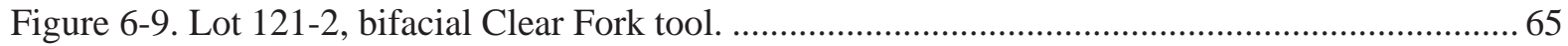

Figure 6-10. Lot 291-1, distal portion of a biface................................................................................ 65

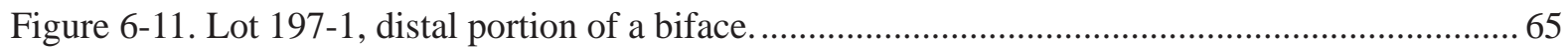

Figure 6-12. Lot 197-2, proximal-medial portion of a biface............................................................. 66

Figure 6-13. Lot 266-1, distal tip of a projectile point. .................................................................... 66

Figure 6-14. Lot 266-2, lateral edge fragment of projectile point. .................................................. 67

Figure 6-15. Lot 175-1, barb fragment of projectile point............................................................. 67

Figure 6-16. Lot 220-1, modified stem fragment of a projectile point. .............................................. 67

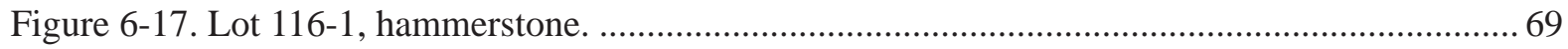

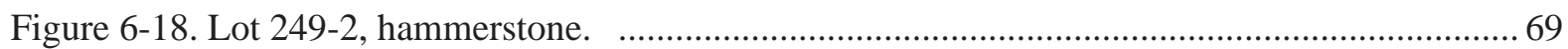

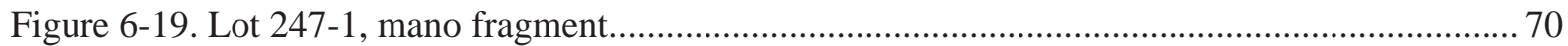

Figure 7-1. Lithic tools per excavated volume $\left(\mathrm{m}^{3}\right)$ in each analytical unit. ....................................... 88

Figure 7-2. Snail shell per excavated volume $\left(\mathrm{m}^{3}\right)$ in each analytical unit......................................... 90

Figure 7-3. Mussel shell per excavated volume $\left(\mathrm{m}^{3}\right)$ in each analytical unit. ..................................... 91

Figure 7-4. Bifaces vs. cores per excavated volume $\left(\mathrm{m}^{3}\right)$ for each analytical unit............................. 93

Figure 7-5. Formal vs. informal tools per excavated volume $\left(\mathrm{m}^{3}\right)$ for each analytical unit. ............... 93

Figure 7-6. Flake size percentages for each analytical unit........................................................... 94

Figure 7-7. Flake cortex percentages for each analytical unit........................................................... 95

Figure 7-8. Platform type percentages for each analytical unit. ...................................................... 95

Figure 7-9. Possible flake parent tool percentages for each analytical unit......................................... 96

Figure 7-10. Whole flake type percentages for each analytical unit................................................ 97

Figure 7-11. Whole flake parent tool percentages for each analytical unit.......................................97

Figure 7-12. Archeological sites and National Register Districts discussed in this chapter................ 99 


\section{LIST OF TABLES}

Table 3-1. Prehistoric Chronology for Central Texas, South Texas, and Coastal Texas 17

Table 5-1. Vertical Distribution of Artifacts within the Test Units and Identified Analytical Units..... 34

Table 5-2. Soil Descriptions of the Ap-AKss-ABss-Bw-Bss Soil Horizon in GT4 (derived from Abbott 2009). 42

Table 5-3. Soil Descriptions of the Ap-A-AB-Bw Soil Horizon (derived from Abbott 2009). .44

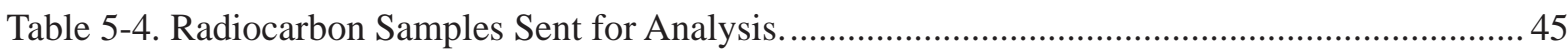

Table 5-5. Total Artifact Counts Observed at Site 41DW277 ................................................................ 47

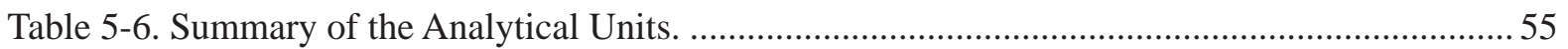

Table 6-1. Total Numbers of Artifacts Recovered from Site 41DW277.............................................. 57

Table 6-2. Technological Assessment of Whole Flakes from 100-200 cmbs...................................... 74

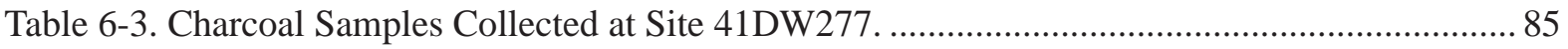

Table 6-4. Bone Fragments Collected from Site 41DW277. ............................................................ 85

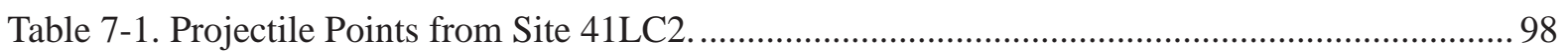

Table 7-2. All Artifacts Recovered During the Cuero I Reservoir Investigations. ............................. 100

Table 7-3. Biface Categories and Sub-categories of the Cuero I Reservoir Assemblage................... 101

Table 7-4. Distribution of Cores, Thick Bifaces, and Thin Bifaces, by Percent................................ 101

Table 7-5. Comparative Distribution of Multiple Small-Facet Tertiary Flakes, Thin Bifaces, and Comparable Diagnostics, by Percent. ............................................................................ 101

Table 7-6. Distribution of Specific Comparable Diagnostic Forms by Associated Chronological Period at Site.41LC2. 


\section{ACKNOWLEDGements}

The authors of this report would like to thank Allen Bettis of the Texas Department of Transportation's (TxDOT's) Environmental Affairs Division for facilitating the completion of this work. Allen Sharp and Allen Migl of TxDOT's Yoakum District were also instrumental during the fieldwork. They negotiated with the landowner at Site 41DW277 to gain access and permission to conduct the investigation, provided AmaTerra with a gradall for the investigation, and were generally patient and supportive while work was taking place. We would like to thank David Nickels for leading the fieldwork effort. Dave is true leader; and in spite of cold, rain, and less than optimal conditions, he went over and above the scope to get the best possible data from the site. Antonio Padilla conducted all the lithic analysis for this site and it is due to his effort that we are able to tease out significant intra-site patterns. Joel Butler, Dan Rose, and Emory Worrell helped prepare graphics; and Brittany McLain tackled the not-so-small job of preparing all the artifacts for curation. The authors are grateful to have had such skilled and professional staff working on this project. 


\section{Chapter 1}

\section{INTRODUCTION}

In November and December of 2009, AmaTerra Environmental, Inc. (AmaTerra) previously known and operated prior to 2012, as Ecological C o m m u n i c a t i o n s Corporation (EComm) —undertook National Register of Historic Places (NRHP) eligibility testing for Site 41DW277 in DeWitt County, Texas. Site 41DW277 is a stratified, multicomponent prehistoric campsite situated on an alluvial terrace on the east bank of the Guadalupe River where it intersects with United States Highway (US) 183 (Figure 1-1).

Site 41DW277 was first identified during an archeological survey conducted in advance of the US 183 bridge replacement over the Guadalupe River (CSJ 0154-03-027; Bettis and Abbott 2009). Archeological survey of the proposed new rightof-way (ROW) for the bridge replacement found abundant lithic debitage and burned rocks in three

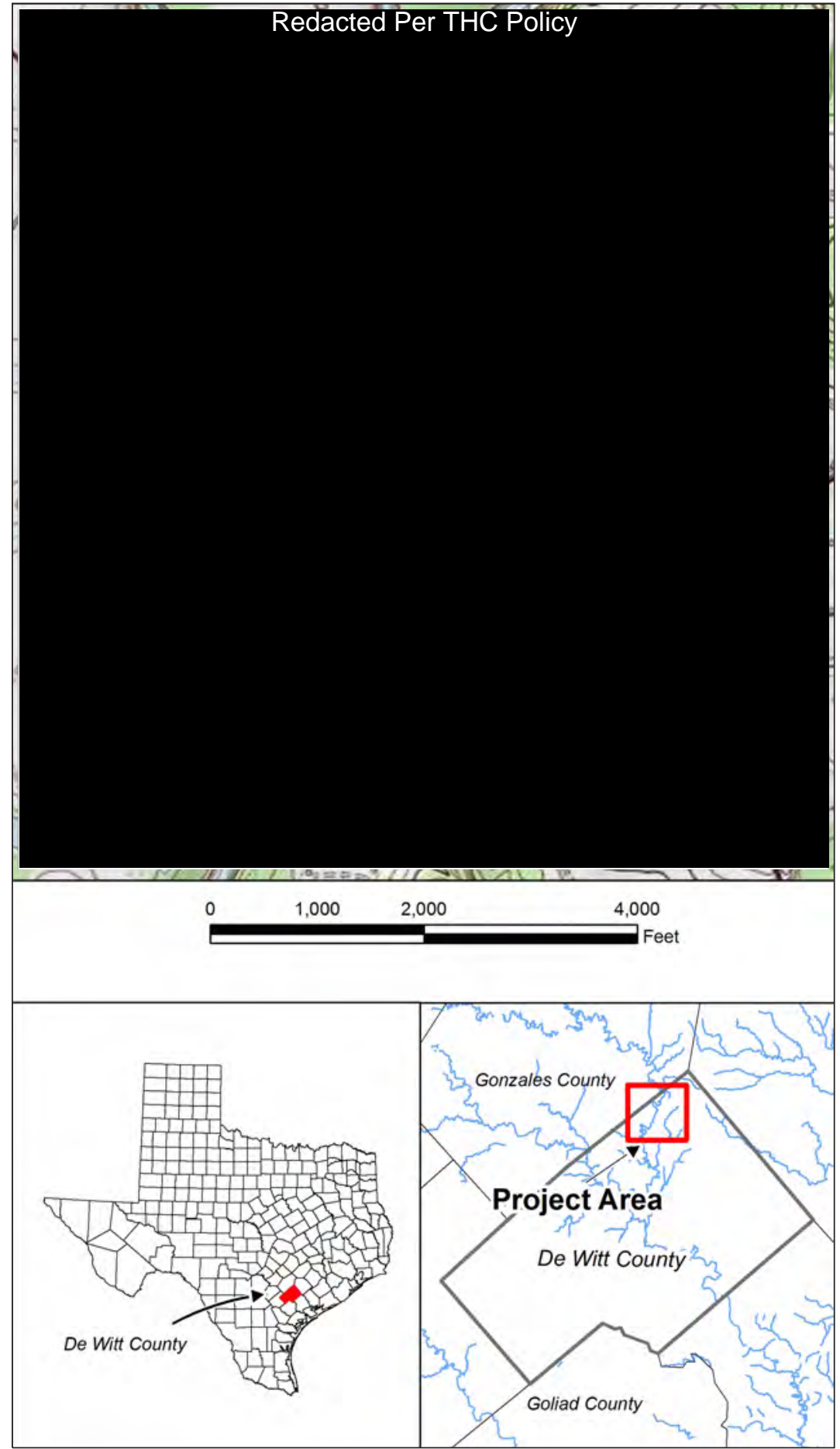

Figure 1-1. Location of the project area in northern DeWitt County. 
backhoe trenches within the proposed new ROW. Based on these investigations, Site 41DW277 was recommended for further testing to determine NRHP eligibility under Criterion D and State Archeological Landmark (SAL) eligibility. Under contract to the Texas Department of Transportation Environmental Affairs Division (TxDOT-ENV), AmaTerra conducted the eligibility testing of the site and found that while it may contain elements that could be considered worthy of inclusion in the NRHP, those elements are not within the area of potential effects (APE) for the bridge replacement project. Within the APE, the site does not exhibit any elements that merit inclusion in the NRHP or for listing as a SAL. This report documents the results of fieldwork and analysis for the NRHP eligibility testing of Site 41DW277.

\section{Site SetTing and Location}

Site 41DW277 is adjacent to US 183 approximately 12 miles south of Gonzales, Texas. The site is located on a wide alluvial floodplain situated on an outside bend of the Guadalupe River. From the river, the floodplain rises slightly to the east, abutting a line of prominent sandstone hills that rise more than 100 feet (ft) over the river basin. The landform that contains Site 41DW277 is entirely within the floodplain, and consists of agricultural and ranch land. It has been largely cleared of native bushes and trees, with the exception of strips of land immediately adjacent to the Guadalupe River and its drainages, a few windbreaks, and individual trees in large fields (Figure 1-2). The Guadalupe River in this area meanders considerably. Oxbow lakes are common, indicating former river channels and attest to an active hydrographic environment.

US 183 runs in a northwest to southeast direction. Site 41DW277 is located on the southwest side of the roadway, with the road and the river coming together in a point, which forms the northernmost extent of the site. Its western boundary is the river, the eastern boundary is the road, and it extends for approximately 100 meters (m [328 $\mathrm{ft}]$ ) to the south. It is likely that part of the site continues under the US 183 roadway itself. While sparse archeological remains were identified close to the river, the heart of the site, where

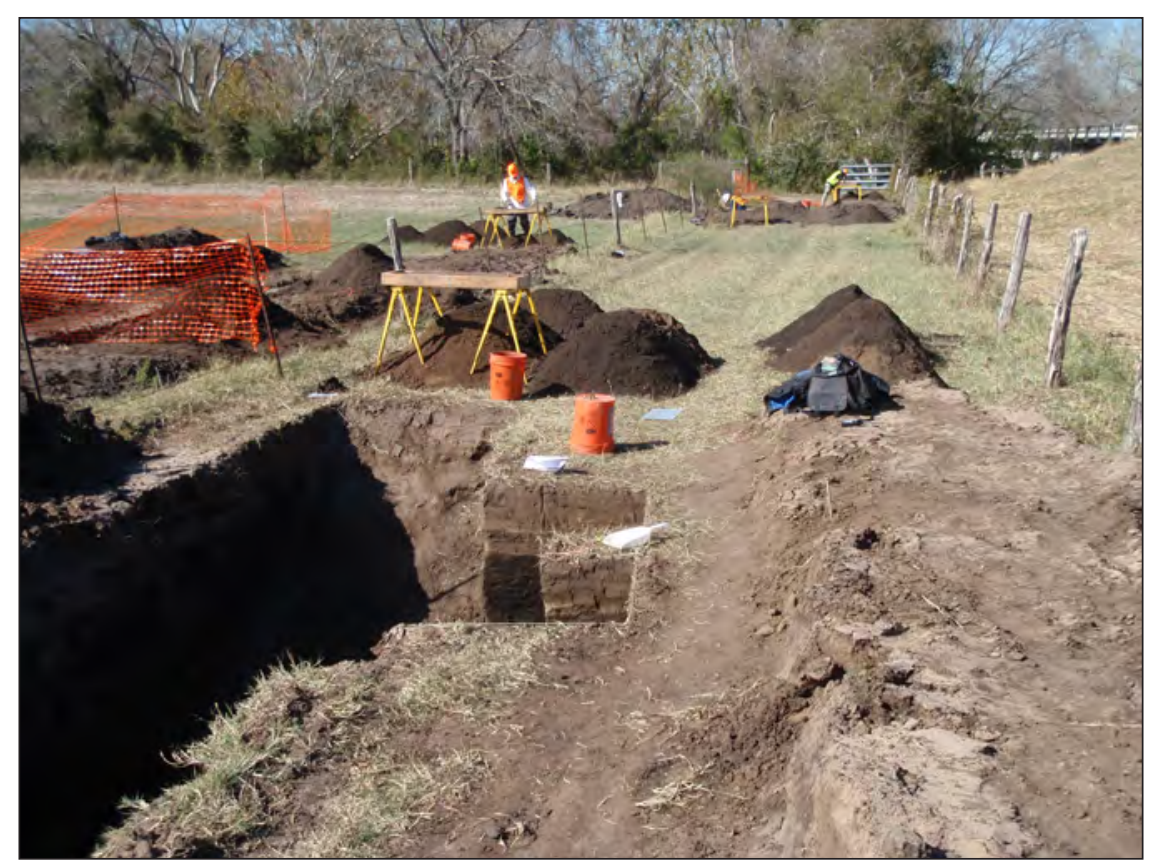

Figure 1-2. View of Site 41DW277 looking toward the US 183 bridge over the Guadalupe River. 


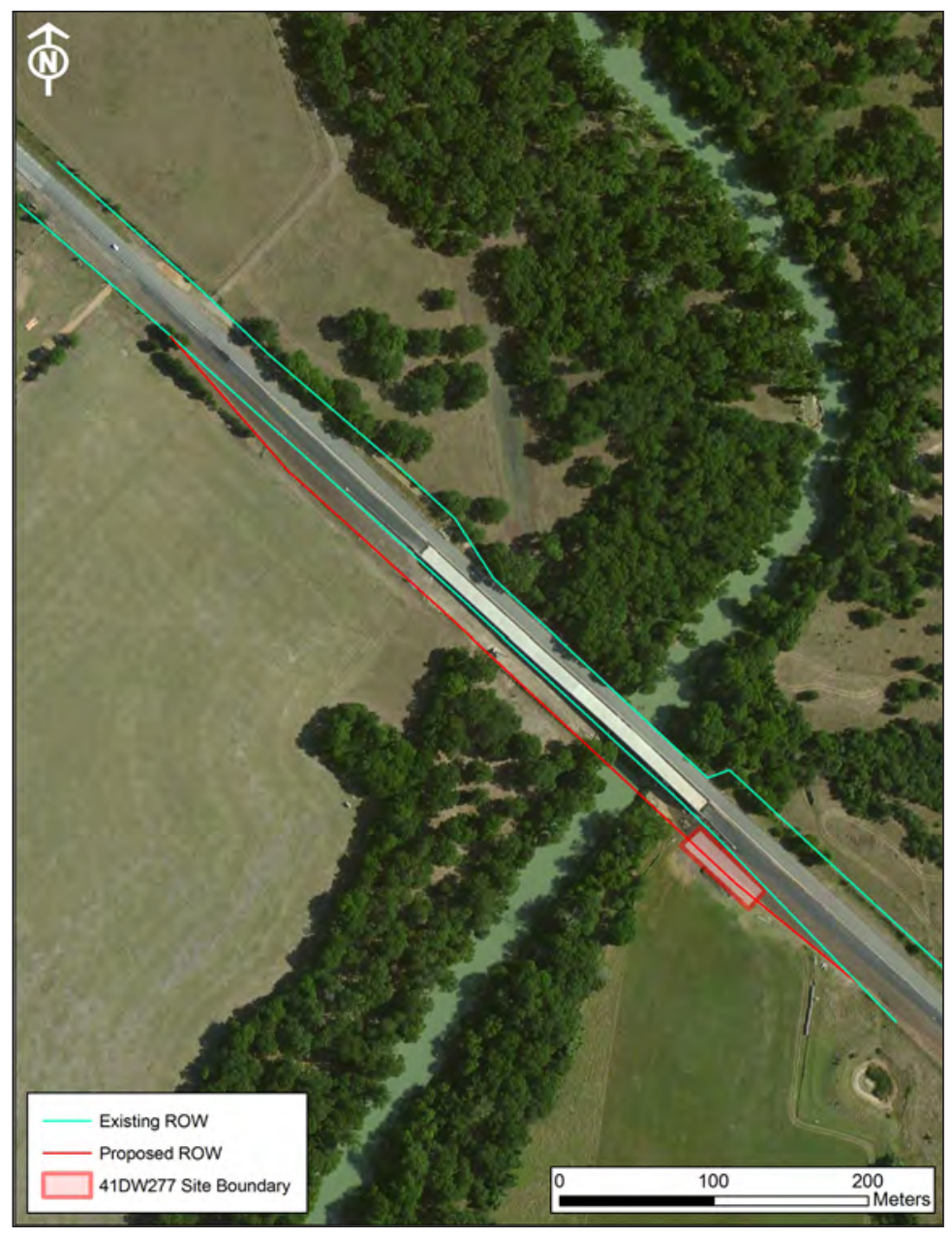

Figure 1-3. Aerial map of proposed undertaking and location of Site 41DW277.

the densest remains were identified, lays approximately 50-80 m (164-262 ft) south of the point where the road and river form a point.

\section{DESCRIPTION of Proposed UNDERTAKING AND APE}

The current US 183 bridge is a two-lane road atop a concrete slab bridge $30 \mathrm{ft}$ wide and $800 \mathrm{ft}$ long supported by steel beams and concrete pylons. The proposed bridge will be located slightly southwestward of the original, and will be expanded to $46 \mathrm{ft}$ in width (Figure 1-3). New ripraps will be constructed on both banks. The project limits for the improvements extend from approximately $1,500 \mathrm{ft}$ from the northwest end of the bridge to approximately $1,100 \mathrm{ft}$ from the southeast end of the bridge, covering a total linear distance of approximately 3,400 ft. The proposed undertaking will require 1.7 acres of new ROW on the southwest side of the existing roadway; 0.5 acres will be acquired on the left (west) bank of the Guadalupe River (facing downstream) and 1.2 acres will be needed from the right (east) bank, at the location of Site 41DW277. Combined, the total area (including existing and proposed ROW) of the APE for the bridge replacement will be about 6.9 acres.

At the location of Site 41DW277, project design plans call for acquisition of up to $50 \mathrm{ft}$ of new ROW from private property along the southwest side of the roadway (totaling 0.5 acres), making the total ROW at that location $160 \mathrm{ft}$ wide. It is within this 1.2 acres of proposed new ROW on private property that all of the test excavations were concentrated. The portions of the site within the existing ROW and under the current US 183 roadway were not investigated.

The proposed depth of impacts varies from more than $45 \mathrm{ft}$ near the river, where new bridge piers and abutments would be constructed, to less than $5 \mathrm{ft}$ as the road moves away from the river, where the roadway would be built on fill material. Thus, while the vertical APE at the 
river exceeds $45 \mathrm{ft}$, just $50 \mathrm{ft}$ east of the river the vertical APE is $5 \mathrm{ft}$ or less. Hence, at the heart of Site 41DW277, the major impacts would be less than 5 feet in depth and would consist primarily of soil compaction resulting from the fill material to raise the roadway level to the bridge elevation.

\section{Previous Investigations}

In June 2009, TxDOT archeologists Jim Abbott and Allen Bettis performed a survey consisting of mechanical trenching on both sides of the Guadalupe River within the APE for the proposed bridge replacement. They documented two new sites within the APE-41DW277 and 41DW278. Both sites fall within the Cuero I National Register Archeological District, which covers a wide area along the Guadalupe River in Dewitt and Gonzales counties, Texas. Site 41DW278, located on the northwest bank of the Guadalupe River, was determined to be ineligible for listing on the NRHP or as an SAL, and is not considered to be a contributing element to the Cuero I Archeological District; therefore, no further work was recommended at that site. At Site 41DW277, investigators discovered burned rocks, bifacial tools, stone tool manufacturing debris, and what appeared to be a fired clay ball in gradall trenches (GT) excavated on the east bank of the river within the area of proposed new ROW. These materials appeared to be part of an intact prehistoric occupation of an unknown date. Based on these findings, Bettis and Abbott (2009) recommended that additional test excavations were necessary to determine the site's overall integrity and research potential.

\section{Summary of CurRent InVestigations}

TxDOT hired AmaTerra to conduct further investigations. Following a scope of work prepared by Allen Bettis of TxDOT-ENV, testing excavations were initiated in November 2009. The work focused on the portion of Site 41DW277 within the APE, though the site almost assuredly extends outside the APE beyond the area investigated. Site 41DW277 falls within both public and private land within the APE. However, due to an inaccessible fill section within the existing ROW, the archeological testing at Site 41DW277 occurred exclusively on private land to which TxDOT had acquired a signed right-of-entry (ROE) from the landowner.

Excavations involved reopening two of the gradall trenches (GTs 2 and 3) excavated by Bettis and Abbott, plus excavation of three new gradall trenches (GTs 4, 5, and 6). Thirty two test units were excavated off of the side of the trenches. TUs $1-4,15,16$, and 18 were 50 x 50 -centimeter (cm) units dug into the sides of GTs 2-6. There was no GT 1 for this project, since GT 1 was excavated during the survey phase, and AmaTerra did not reopen it. The remaining units were $1 \times 1 \mathrm{~m}$ units. Not including the $50 \times 50-\mathrm{cm}$ units, a total of $26.15 \mathrm{~m}^{3}$ of sediments were hand excavated and screened through $1 / 4$-inch wire mesh. Archeologists excavated an additional 2.07 $\mathrm{m}^{3}$ through $50 \times 50$-cm units.

The excavations demonstrated the upper $80-100 \mathrm{~cm}$ of sediment was largely devoid of cultural material. The few pieces of lithic debris that were recovered lacked any context or feature associations. Through all test units, artifact density increased significantly across the site within 
a soil horizon beginning at about one meter below the surface. Artifact recovery continued to a depth of $1.9 \mathrm{~m}$ below the surface demonstrating stratified and relatively intact deposits. Investigations documented three distinct features during the field investigations. These were found in two adjacent units, TUs 6 and 10, at depths of 1.4-1.5 $\mathrm{m}$ and 1.7-1.8 $\mathrm{m}$ below the surface.

Overall, archeologists recorded 1,034 pieces (52.634 kg; 116.04 pounds) of burned or firecracked rocks, which were sorted by rock type and weighed, then discarded. The investigations recovered 2,823 stone artifacts in total. The artifacts found 1-2 $\mathrm{m}$ in depth were analyzed in detail (totaling 2,586 lithic artifacts). The remainder of the lithic debitage was simply catalogued, since the upper meter of the site lacked integrity. The breakdown of lithic artifacts from the 1-2 m depth includes 56 expedient tools or modified flakes, 27 whole or fragmented bifaces, 38 whole or fragmented cores, five tested cobbles, six pieces of ground stone, three projectile points, two hammerstones, 901 whole flakes, 767 incomplete flakes, and 781 pieces of unclassifiable debitage. Among the bifaces are a Clear Fork gouge and several artifacts that are broken and untypeable projectile points. A unifacial Clear Fork gouge is included among the expedient tool types. In addition, 1,513 freshwater mussel remains and 1,328 snails were collected, and these were interpreted as food remains.

Preserved macro-organic material recovered includes nine small bone fragments, most of which were recovered from the top meter of sediment. A significant number of mussel and snail shells were also recovered, and these are interpreted to be food remains. Charcoal from 13 different proveniences was collected. Five of these samples were submitted to Beta Analytic, Inc. for AMS dating and these yielded conventional radiocarbon dates ranging from 2590-5260 \pm 30 before present (BP). Four bulk sediment samples were also submitted for AMS dates and these yielded conventional dates of 3020-5030 \pm 30 years BP. The dates generally reinforce the idea that the site contains three intact, stratified occupation zones situated 1-2 $\mathrm{m}$ in depth that range in age from the early Middle Archaic to Transitional Archaic Periods.

At the request of Co-Principal Investigator Bettis, AmaTerra collected 104 bulk sediment samples (approximately 400 liters) from selected excavation units and levels for the purpose of estimating the quantity and types of microdebitage that likely were not caught in the $1 / 4$-inch screening process. Fifty of these samples were wet-screened, yielding 311 additional pieces of micro-debitage.

\section{Administrative MatTers}

AmaTerra performed the investigations under Texas Antiquities Permit 5460, with Rachel Feit of AmaTerra and Allen Bettis of TxDOT-ENV serving as co-principal investigators. David Nickels served as Project Archeologist during the field investigations, while Mindy Bonine assumed the role during the subsequent analysis and report preparation. David and Mindy were assisted by Antonio Padilla as Crew Chief. Crew members included Kevin Stone, Nathan Devito, Lynn Wack, Walker Van Item, and Emory Worrell. Noel Steinle, Molly Palmison, Brittany McClain, and Stacy Drake undertook the washing, sorting, and cataloging of artifacts back at the AmaTerra laboratory. 
AmaTerra conducted the test excavations during the period of November 30-December 22, 2009. Weather over the course of the investigations was predominantly drizzly and cold. At times, rain slowed progress considerably. The analysis and report preparation was undertaken over the course of several months, concluding in March 2012.

This report presents the results of AmaTerra's testing investigations at Site 41DW277. Chapter 2 describes the environmental setting, including the current landscape and climate, the geology and soils of the area, the vegetation and fauna, and the paleoenvironment. Chapter 3 presents the cultural history and previous investigations in DeWitt County. Chapter 4 contains our research design and methods of investigation, and Chapter 5 presents the results of the investigations. Chapter 6 provides a discussion and interpretation of the site, and Chapter 7 offers conclusions and management recommendations. The results of radiocarbon dating, lithic analysis data sheets, freshwater mussel shell analysis, flotation analysis and wet screening are presented in Appendices A-D. 


\section{Chapter 2}

\section{Environmental Setting}

\section{INTRODUCTION}

Site 41DW277 is located in southeastern Texas near the northern tip of DeWitt County. It is mapped within the southeasternmost band of the Blackland Prairie natural region of Texas, but is located very close to the Oak Woods and Prairies to the north, the Gulf Coast Prairie and Marshes of the Texas Coastal Plain to the southeast, and the South Texas Brush Country to the southwest (Figure 2-1). The Blackland Prairie region is comprised of gently rolling to nearly level terrain with deep, fertile black soils that once supported a tallgrass prairie. Today, much of the original prairie has been plowed to produce food and forage crops. Nearby, the Oak Woods and Prairies natural region is described as a gently sloping low

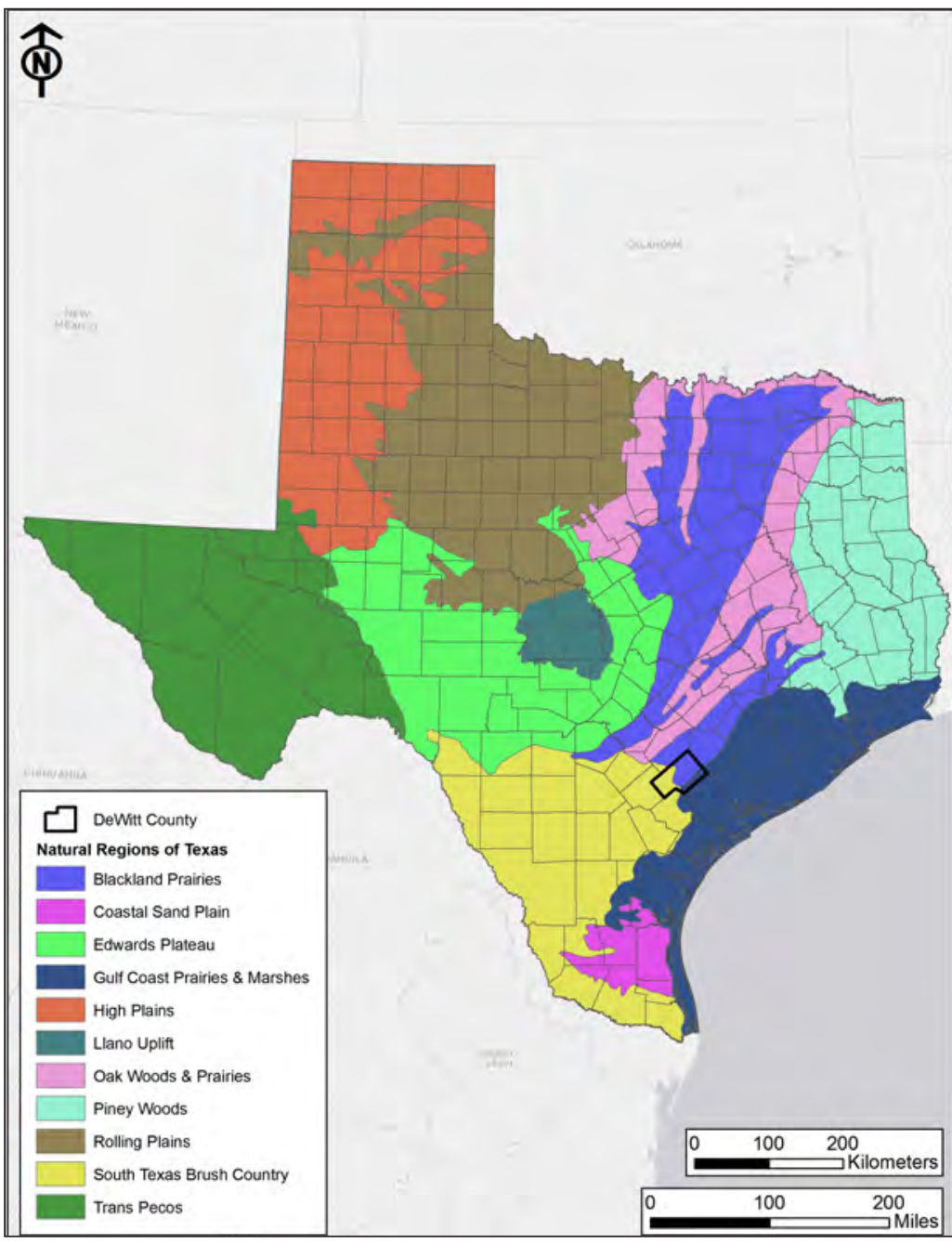

Figure 2-1. Natural regions of Texas. elevation area with a mix of oak and bunch grasses.

The Gulf Coast Prairie and Marshes region is a nearly level, low elevation, slowly draining plain dissected by streams and rivers flowing into the Gulf of Mexico. The South Texas Brush Country region is characterized by level, low elevation plains with thorny trees and bushes adapted to a low-rainfall, high-evaporation environment (Natural Heritage Policy Research Project [NHPRP] 1978).

The environment and climatic conditions of these regions have fluctuated considerably over the past 12,000 years, and the current conditions were not always prevalent in and around Site 
41DW277. Thus, the discussion below provides an overview of the present-day environmental setting, for which we have the most information, followed by a brief history of the regional paleoenvironmental record as it is currently understood. This discussion is based on the results of field investigations and a review of relevant literature.

\section{LANDSCAPE AND LAND USE}

DeWitt County is characterized by nearly level to gently sloping terrain, as is the portions of Gonzales and Lavaca counties adjacent to DeWitt County. Most of the county is contained within the Guadalupe River watershed, including the area where Site 41DW277 is located. The tributaries of the Guadalupe River include the various branches of Coleto Creek, and also Sandies, Salt, Smith, McCoy, Irish, Cuero, and Clear Creeks (Roell 2011).

Site 41DW277 lies within the valley of the Guadalupe River, at the base of a wide eastward bend in the river channel before it straightens out roughly southward. At this location the river bend abuts the base of a small hill to the east, gently rising $130 \mathrm{ft}$ above the valley floor. The river channel then peels away from the hill slope creating a very flat terrace between them. Site 41DW277 is located at the northern end of this semicircular terrace. The west side of the river channel consists of another wide flat terrace, which contains evidence that the river channel once flowed more westerly then it does currently. The actual site area is an improved agricultural pasture currently used for grazing and hay, as well as the location of the road ROW for US 183. The area tested is relatively flat, though it does slope up very slightly from the river to the southeast. Surface visibility is less than 10 percent due to grass cover.

\section{Climate}

The climate in DeWitt County is described as humid subtropical. Summers are hot and winters are mild. The average temperature ranges from a high of $96^{\circ} \mathrm{F}$ in July to an average low of $44^{\circ}$ in January; records of $2^{\circ}$ and $110^{\circ}$ were recorded in 1949 and 1954 respectively (Roell 2011). Rainfall averages 33.17 inches per year with the heaviest rainfall occurring in May and September (Miller 1978:75). Rainfall generally comes in the form of thunderstorms. Annual sunshine varies from around 50 percent in winter to 75 percent in summer, with a mean relative humidity at mid-day of 60-65 percent in winter and spring and 50-55 percent in summer and fall (Miller 1978). Freezing temperatures are rare and predominantly occur for a few hours before dawn. Thus, the warm season is calculated at 270 days per year.

\section{GEOLOGY}

The terrace on the east bank of the Guadalupe River upon which Site 41DW277 sits is comprised of recent alluvial deposits sandwiched between the modern river channel and the edge of the river valley, which is a hilly, upland sandstone outcrop of Miocene origin (Figure 2-2). The area around Site 41DW277 is mapped as Holocene Alluvium by the Bureau of Economic Geology (Barnes 1974). These include deposits made up of clay, silt, sand, gravel, and 
organic matter resulting from frequent flooding. The clay is calcareous, the sand generally comprises quartz, and gravels consist of chert, quartzite, and petrified wood. The fluviatile morphology is well preserved with point bars, oxbows, and abandoned channel segments (Barnes 1974). Directly east of the site location, the Oakville Sandstone formation consists of medium grained calcareous sandstone and clay with reworked Cretaceous fossils. Its thickness is between 200-500 $\mathrm{ft}$ and generally form smoothly rounded hills (Barnes 1974).

Geologically, the area around Site 41DW277 consists of northeast-southwest running bands of Eocene age sandstone formations (Manning, Wellborn, Caddell, Yegua, Cook Mountain, etc.) made of clay and sandstone mixed with various other inclusions such as

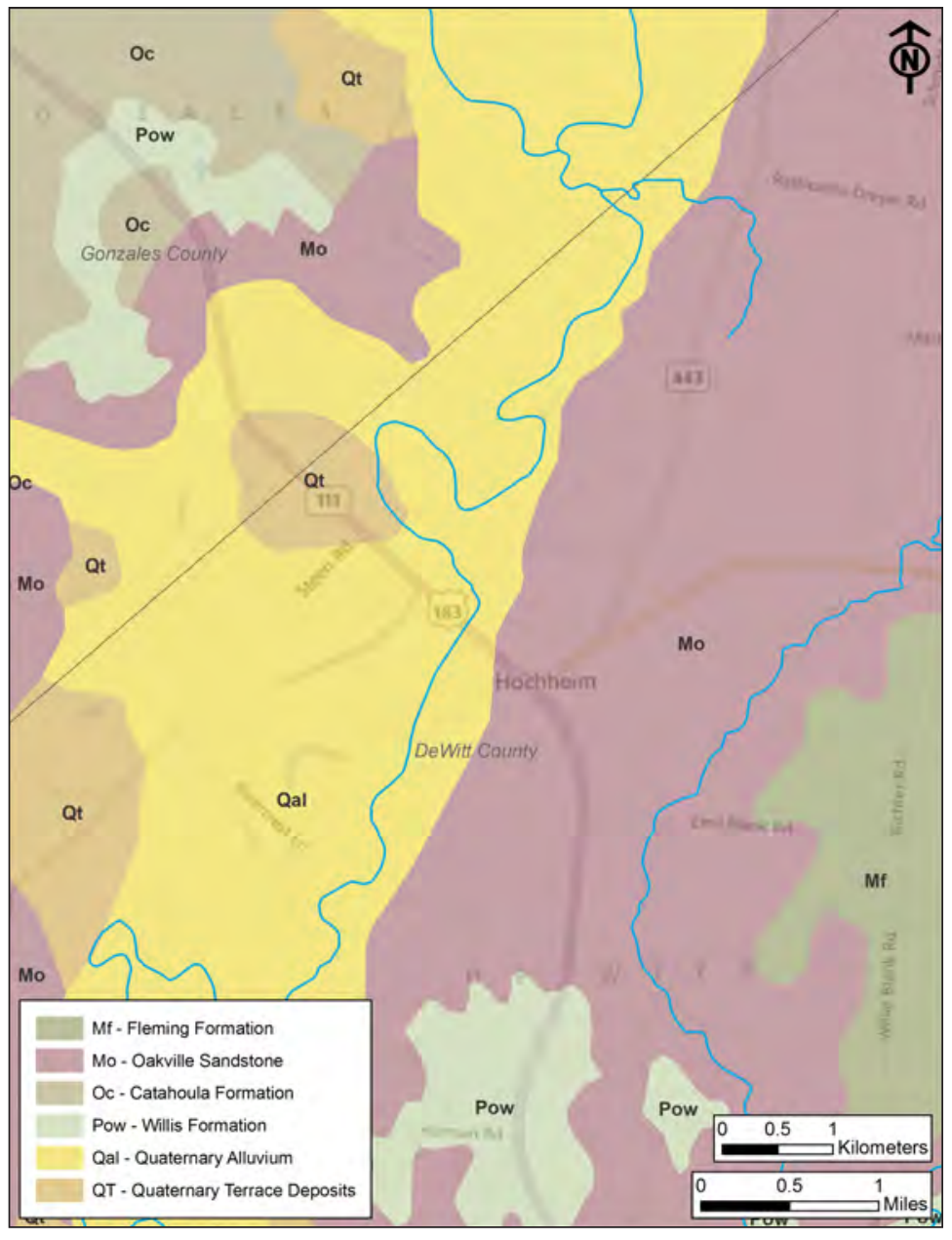

Figure 2-2. Map of the geological formations around the Guadalupe River valley and Site 41DW277. bentonite, quartz, and lignite. These narrow bands then meet much wider areas of Miocene (Fleming, Oakville, and Catahoula), Pliocene (Goliad), and Pleistocene (Willis) formations. All contain clay and sandstone with the occasional presence of chert gravels in the more recent formations (Barnes 1974). The Guadalupe River channel (as well as other large creek channels) cuts through all of these sandstone bands and contains the bulk of the alluvial deposits.

\section{$\underline{\text { SoILS }}$}

The excavated portion of Site 41DW277 is situated within a narrow area pinched by the Guadalupe River channel to the west and a slowly rising hill to the east. To the south, the terrace widens out to a broad flat plain. As such, the mapped soils are also pinched at the site location and widen out to the south. Nearest the Guadalupe River, the soils are mapped as Meguin soils, frequently flooded, then quickly change to Meguin silty clay loam, occasionally flooded, on the terrace, followed by Sarnosa fine sandy loam, five to eight percent slopes at the 
base of the hill (Figure 2-3). To the south, the broad plain is largely Meguin silty clay loam, occasionally flooded, with a small area of Buchel clay, occasionally flooded soils at the the center (Miller 1978).

Meguin series soils are described as deep, nearly level, calcareous loamy soils in bottomland areas. They are entirely alluvium that extend to a depth of approximately 62 inches $(1.59 \mathrm{~m})$. The soils are known to be well drained and have slow runoff. The soils nearest the river are frequently flooded and not suited for agricultural improvement, but the occasionally flooded soils are excellent for crops, improved pasture, rangeland, or pecan groves (Miller 1978:20). Buchel clay, occasionally flooded soils are reported to be nearly level calcareous clayey soils on low terraces. It is common to find them in association with Meguin soils (Miller 1978:7). Upslope from these soils, Sarnosa fine sandy loam, 5 to 8 percent slopes are deep,

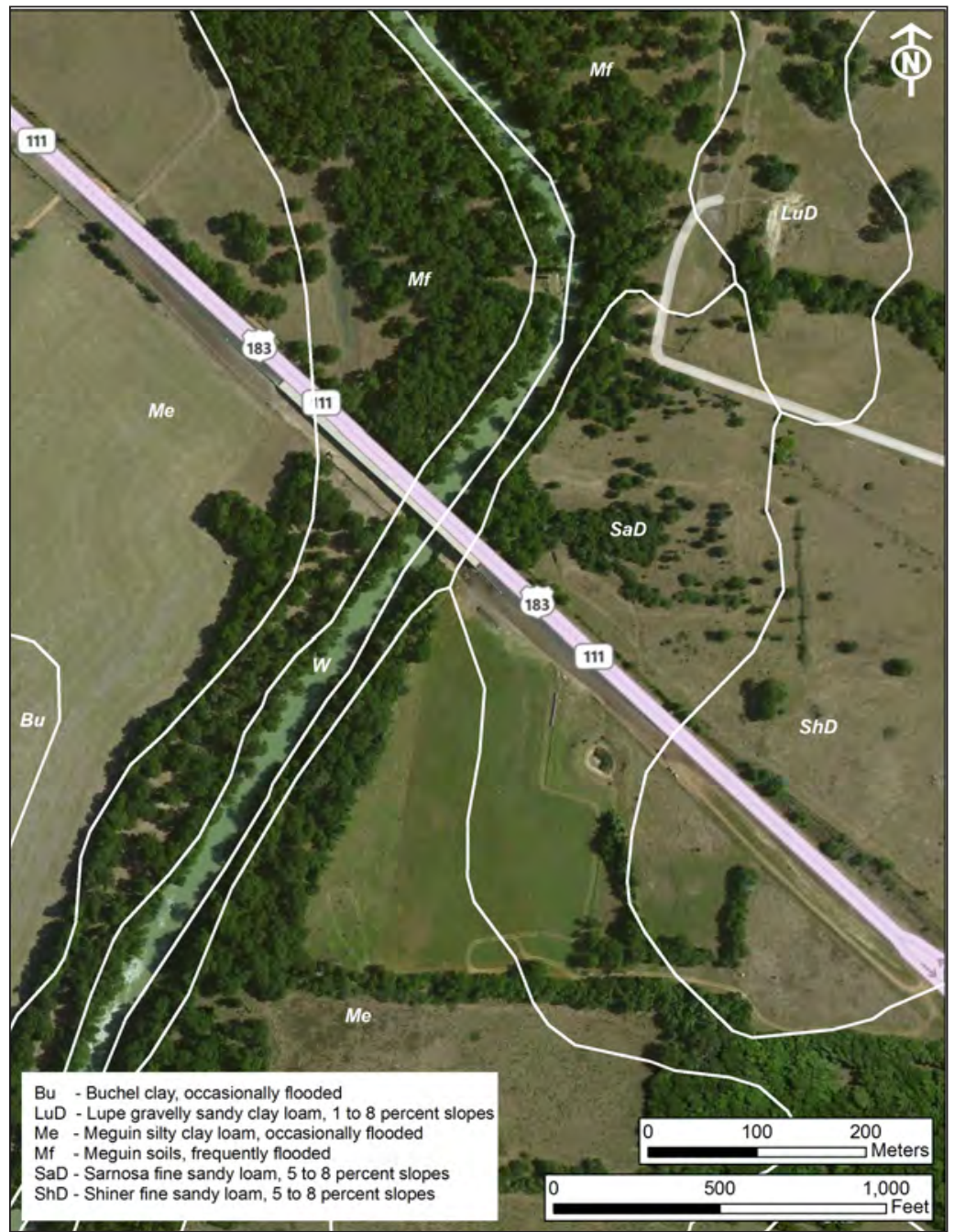

Figure 2-3. Soil types in and around Site 41DW277. slightly sloping calcareous loamy soils of the uplands.

They are often below Shiner soils on the ridgetops (e.g., shallow calcareous loamy soils on the uplands). Sarnosa series soils "formed in calcareous loamy material having thin strata of weakly cemented sandstone” (Miller 1978:27).

Site 41DW277 sits soundly in the Meguin-Trinity association (deep loamy and clayey soils) that surrounds the Guadalupe River, with loamy and loamy/clayey soils on the upland areas. However, only 12 miles to the south the land transitions to more sandy and gravely soils in the upland areas, with the loamy soils reserved for the river valley (Miller 1978). This corresponds roughly with the change in the geologic formations from older sandstone formations to more recent formations that contain chert gravels. 


\section{VEGETATION}

As mentioned above, Site 41DW277 is located in Blackland Prairie natural region of Texas and situated very near three other natural regions. However, there is some disagreement as to where the dividing lines are between these different regions in the vicinity of Site 41DW277 and DeWitt County in general (Figure 2-4). According to the NHPRP (1978), the area is part of the Blackland Prairie, with the Oak Woods and Prairies to the northwest, the South Texas Brush Country to the southwest, and the Gulf Coast Prairies and Marshes to the southeast. The Level III Ecoregions map also places Site 41DW277 within a narrow band of Blackland Prairie, but surrounded by East Central Texas Plains (i.e. post oak savanna) (U.S. Environmental Protection Agency [EPA] 2004, based on Omernik 1987). Gould et al. (1960) places the site area in the Post Oak Savannah, but with a Blackland Prairie band very close to the southeast. Bailey's ecoregions places the area in the Oak Woods and Prairies (U.S. Forest Service [USFS] 2004). Lastly, the site is mapped by Blair (1950) as part of the Texan biotic province. However, all of these researchers agree that the area around Site 41DW277 is near, but clearly outside of, the Texas Coastal Plain to the southeast, and the South Texas Brush Country to the southwest.

The Blackland Prairie natural region (or ecoregion) is described as a true prairie grassland community with a diverse assortment of annual and perennial grasses. The soil is considered some of the richest and most fertile in the world. As such, the vast majority of the Blackland Prairie has been under cultivation in recent history. The prairie is peppered with live oak trees, and they constitute the dominant form of large vegetation in this ecoregion. The northern and central portions of this area are predominately comprised of post oak, blackjack oak, American elm, winged elm, cedar elm, sugarberry, green ash, osage-orange, honey mesquite, and eastern redcedar. In addition to the species listed for the northern and central areas, the southern area is characterized by live oak and Ashe juniper. Pecan, black walnut, black willow, American sycamore, honey locust and bur oak are commonly found in the bottomland woodlands throughout this region (Texas Forest Service 2008a).

The Post Oak Savannah ecoregion is a transition zone between the Blackland Prairies to the west and the Pineywoods to the east, the Texas Coastal Plain to the southeast, and the South Texas Brush Country to the southwest. This ecosystem is part of a historic oak belt, which travels up though Oklahoma and the central United States. The Post Oak Savannah is dominated by native bunch grasses with scattered post oaks and some plateau live oak, black hickory, and blackjack oak. Historically, wide vistas of tall grass-little bluestem, Indiangrass, switchgrass and a myriad of wildflowers - were broken only by the occasional motte of trees giving the landscape a park like atmosphere. Peat bogs mingled amongst stands of flowering dogwood, sassafras, brumelia and yaupon are also found in this ecoregion. In recent times this historical vegetation has been replaced by cedar elm, sugarberry, and eastern red cedar. Upland areas are typically where bunch grasses are concentrated (Texas Forest Service 2008b).

Bailey's Oak Woods and Prairies are described as an oak-hickory forest, cross timbers, and juniper-oak savanna. The predominant vegetation type is cold-deciduous, broad-leaved forest. The oak-hickory cover type consists of scarlet, post, and blackjack oaks, and pignut and 

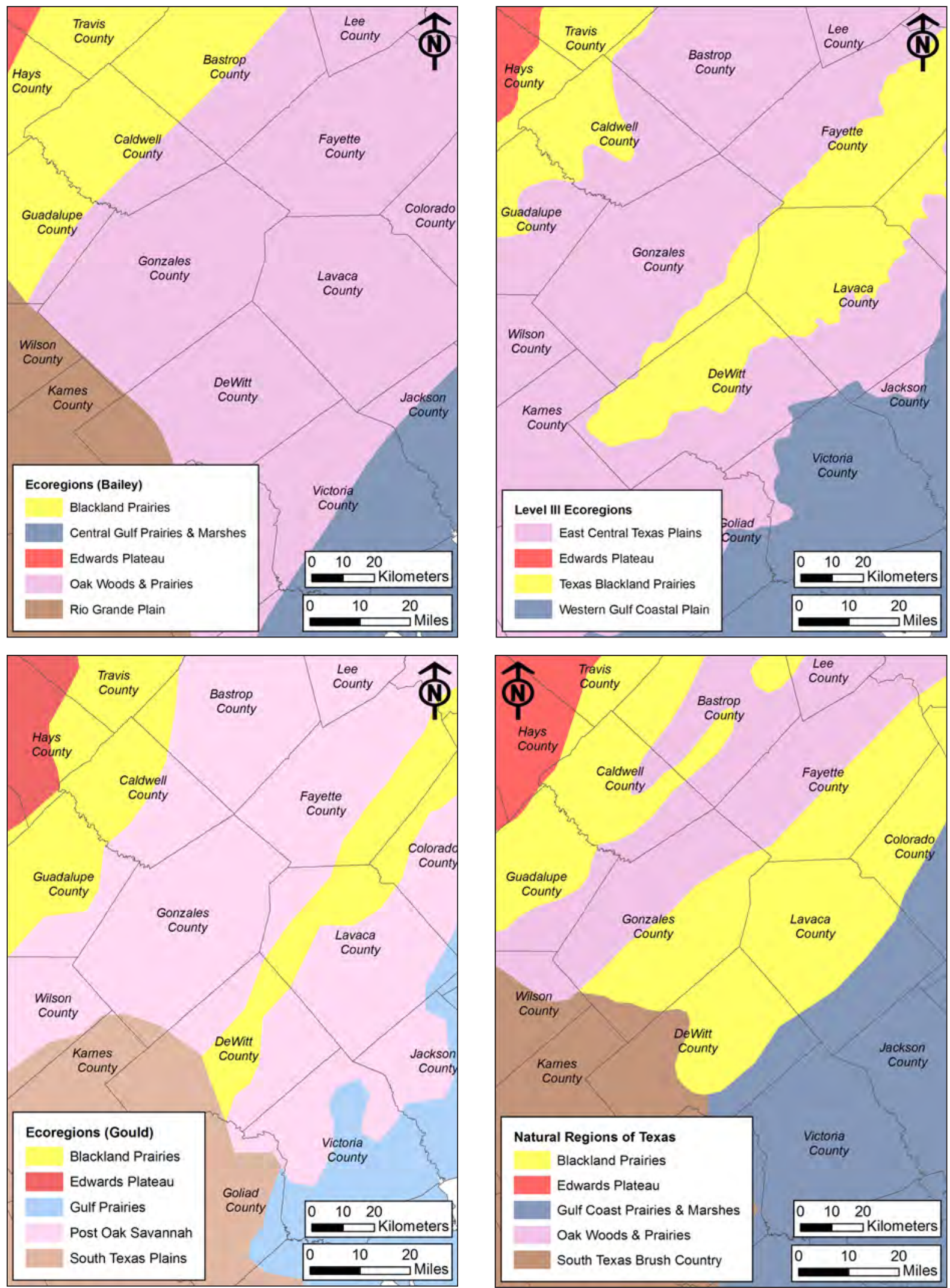

Figure 2-4. Various mapped natural regions and ecoregions around Site 41DW277. 
mockernut hickories. Forests of elm, pecan, and walnut are in bottomlands. Little bluestem is the dominant grass (USFS 2004).

During the test excavations at Site 41DW277, the local vegetation was observed to be a riparian setting consisting of pecan, elm, and live oak overstory, briar and brush understory, and short grasses in the open pastures.

\section{$\underline{\text { FAUNA }}$}

The faunal communities in the Blackland Prairie ecoregion are characterized by species associated with a prairie climate and vegetation. Typical large herbivores and carnivores include coyote, ringtail, and collared peccary. Smaller herbivores include plains pocket gopher, fulvous harvest mouse, and northern pygmy mouse. Ocelots were once common, but are now rare. The bison is historically associated with the Blackland Prairie. Birds species that inhabit grass and shrublands are typically found in this region; residents include many common species, such as turkey vulture, hairy woodpecker, cardinal, and yellow warbler. Smith's longspur, a bird of the Arctic tundra, winters in this area. Amphibians and reptiles typical of this area include eastern spadefoot toad, Great Plains narrow-mouthed frog, green toad, Texas toad, Gulf Coast toad, yellow mud turtle, Texas horned lizard, Texas spiny lizard, and Texas blind snake (McNab and Avers 1994).

The faunal communities of the Post Oak Savannah and Oak Woods and Prairies are characterized by species associated with a temperate, subhumid, forested environment. Common large herbivores and carnivores include coyote, ringtail, ocelot, and collared peccary. Smaller herbivores include plains pocket gopher, fulvous harvest mouse, northern pygmy mouse, southern short-tailed shrew, and least shrew. Jaguar and bison are historically associated with this region. Birds typical of this area include many wide-spread species, such as eastern bluebird, eastern meadowlark, grasshopper sparrow, mourning dove, Cooper's hawk, and mockingbird. Amphibians and reptiles include eastern spadefoot toad, Great Plains narrow-mouthed frog, green toad, yellow mud turtle, Texas horned lizard, Texas spiny lizard, and Texas blind snake (McNab and Avers 1994).

\section{PaLeoenVironMent}

Over the past 13,000 years the environmental and climatic conditions have changed considerably in south-central Texas. Although researchers rely on pollen and phytoliths studies to reconstruct the paleoenvironment, there are often contradictions between these two sources, as well as the data from different regions and time periods. Combined, most of the data can only indicate a general overview of the paleoenvironmental conditions. Hopefully, as the practice of collecting samples of pollen and phytoliths for paleoenvironmental data continues, a more concise and accurate reconstruction can be generated for each archeological region of the state. Currently, the pollen studies in the Central Texas archeological region (for which there is the most information at present) indicate a cool grassland environment was present roughly between 
17,000 BP and 15,500 BP with a trend towards a warmer or more arid climate after 15,000 BP (Bousman 1992, 1994, 1998; Camper 1991; Nickels and Mauldin 2001).

After 10,000 BP, changes in paleoclimatic conditions led to mass extinctions of megafauna across the region (Graham 1987; Graham and Lundelius 1984). Various pollen studies suggest a gradual and consistent warming and drying trend coupled with more seasonal climatic conditions throughout the Early to Middle Holocene (Bousman 1994, 1998; Nickels and Mauldin 2001). Woodland environments were in decline throughout most of the early to Middle Holocene and stopped around 6000-5000 BP. Arborial pollen then continued to decline after 5000 BP and slightly increased during a period of wetter weather (Bousman 1994). This arid interval is also represented at Applewhite Reservoir from 6000-4800 BP (Nordt et al. 1994), but Johnson and Goode's reconstruction does not correlate with Bousman's pollen data, and report the arid interval in central Texas as spanning 5000-2500 BP (Johnson and Goode 1994). Data from Hall's Cave in Kerr County indicate the arid episode occurred between 7000-2500 BP (Toomey and Stafford 1994). Phytolith analysis at Wilson-Leonard indicated a general expansion of grasslands throughout most of the Holocene beginning around 9500-4000 BP (Fredlund 1998). However, Hester (1981) points out that perennial river systems (such as the Guadalupe) have their own "micro-environments" that may have retained some of the woodland environment despite the general drying of the region and the grassland expansion. This is supported by the faunal evidence from the Smith Creek Bridge site (41DW270) in southwest DeWitt County, which found deer (who prefer woodlands) and antelope (who prefer grasslands) throughout the site's occupation period, 7000-910 BP (Hudler, Prilliman, and Gustavson 2002). Bison was only located in levels representing 2860-2130 BP; this and land snail data suggest that the area became more arid around $2500 \mathrm{BP}$, to the point where grassland prairie was preferred over woodlands (but both were present).

In the Late Holocene, Nordt et al. (1994) indicates a warm and dry period from 3000-1500 BP, and Hall's Cave shows a wet period around 2500 BP. Other studies from the Gulf Coast and Choke Canyon indicate a wetter climate around 3000 BP and 2450 BP, respectively (Ricklis 1994; Robinson 1982). Bousman's (1994) grass pollen frequencies indicate drying episodes around 1600-1500 BP and 500-400 BP. 


\section{Chapter 3 \\ Cultural History and Previous Investigations}

\section{INTRODUCTION}

Over the past several decades, researchers in Texas archeology have compiled information leading to the development of several archeological regions which divide the state. These archeological regions are arbitrarily defined areas with biogeographic and physiographic similarities that are thought to influence the lifeways of prehistoric and early historic inhabitants in distinctive and identifiable ways. Archeologists have found there is a connection between environmental setting and some aspects of cultural practice, particularly in terms of subsistence strategies and settlement patterns. If a hunter-gatherer habitation site is surrounded by one type of environment, then prehistoric peoples employed a specific set of tools to utilize the resources of that environment (called the "core" or "center"). However, if a habitation site is located near several different types of environmental conditions, then a different set of tools, perhaps sharing traits seen in neighboring "center" areas, would be employed. These areas are named the "periphery" or "transition zones." It appears that Site 41DW277 is located within one of these "transition zones." Some archeologists note that the cultural remains in the area of DeWitt County share traits with the South Texas archeological region (Perttula 2004; Hester 1991:2), while others indicate the area is more like the Central Coastal Plain archeological region (Hester 1991, quoting G. Hall). Still others have observed similarities with three different areas: Central Texas, South Texas, and Coastal Texas archeological regions (Bement and Robinson 1983). Unfortunately, the quantity and depth of archeological investigations thus far can only hint at these relationships.

According to Perttula (2004:7), DeWitt County and the location of Site 41DW277 is located at the edge of the mapped boundaries of the South Texas archeological region; it is geographically near the Central Texas, Savannah and Prairie, and Coastal Texas archeological regions. As currently defined, the South Texas archeological region extends northward from south Texas to the south central plains and includes the river valleys of the Rio Grande, Frio, Medina, San Antonio, and Guadalupe rivers. However, the region does not include the deltas of these rivers, which are situated in the coastal plain and the Coastal Texas archeological region. In addition to the South Texas Brush Country and Coastal Sand Plain natural regions, the South Texas archeological region includes the southernmost portions of the Blackland Prairie and the Oak Woods and Prairies natural regions.

Within these broad archeological regions, archeological investigations aim to identify and clarify broad-scale diachronic changes in the prehistoric archeological record, with a focus on environmentally-based behaviors. As is described in Chapter 2, Site 41DW277 is located near the edges of several types of environmental settings, and there is some discrepancy as to 
which environmental setting is more appropriate for the area around Site 41DW277. Likewise, the archeological region ascribed to the area might also be questionable; the cultural material found in northern DeWitt County may exhibit similarities with material found in one or more archeological regions, or none at all. The dominant cultural affiliation may have also changed over time. The difficulties in clarifying the regional prehistory is further complicated by the amount of archeological data from the area-DeWitt County has had 301 archeological sites recorded (as of December 2011) and very few have been investigated beyond the basic recording stage. As such, the cultural history described below is broad in both time and space and provides a basic foundation to the prehistory of the area. It is followed by a brief summary of the archeological research that has been conducted in the area thus far.

\section{Prehistoric Period Cultural History}

As part of a collaborative effort by the DeWitt County Historical Commission, a volume was published on the history of DeWitt County that includes a short "Prehistory" section written by Dr. Tom Hester (Hester 1991). The following cultural history draws from this account, and includes information from Perttula (2004), Fox et al. (1974), Bement and Robinson (1983), Hays and Abbott (1998), and other sources. The known prehistory of Texas begins around 11,000 BP and terminates in the early 1500s AD with the arrival of Spanish and French explorers to the area. Broad chronological subdivisions separate observed changes in the archeological record that are indications of changes in settlement patterns, subsistence strategies, and resource utilization.

\section{Paleoindian Period}

Paleoindian peoples are those who inhabited the area in the late Pleistocene and early Holocene who relied heavily on the hunting of now extinct megafauna. Other plant and animal resources were also utilized by these people for subsistence (Collins 1995). Three sites from DeWitt County are known to date to the Paleoindian period and some diagnostic projectile points, including Clovis and Scottsbluff, have been found in the area (Hester 1991). No intense archeological investigations have been conducted on Paleoindian sites in the county. Fox et al. (1974) observed that Paleoindian sites in DeWitt and Gonzales counties were found on older fossil floodplains and upland sandstone terraces, rather than colluvial gravel deposits or modern floodplains. This may be a result of geologic processes and alluvial changes in the Guadalupe River channel that have either destroyed or deeply buried these sites.

The Paleoindian period is represented in all the Texas archeological regions affiliated with the area of Site 41DW277, but the time periods vary somewhat. Within the South Texas and Savannah and Prairie archeological regions the Paleoindian period denotes the span from around 11,000-8000 BP, while within the Central Texas region the Paleoindian period spans 12,000-9000 BP (Perttula 2004:9) (Table 3-1). 
Table 3-1. Prehistoric Chronology for Central Texas, South Texas, and Coastal Texas*

\begin{tabular}{cccc}
\hline Period & Central Texas (years BP) & South Texas (years BP) & Coastal Texas (years BP) \\
\hline Paleoindian & $12,000-9,000$ & $11,000-8,000$ & Known from surface finds only \\
Early Archaic & $9,000-6,000$ & $8,000-4,500$ & $7,500-4,200$ \\
Middle Archaic & $6,000-4,000$ & $4,500-2,400$ & $4,200-3,000$ \\
Late Archaic & $4,000-1,200$ & $2,400-1,200$ & $3,000-900$ \\
Late Prehistoric & $1,200-350$ & $1,200-350$ & $1,200-350$ \\
\hline
\end{tabular}

*Source: Perttula 2004

\section{Archaic Period}

The Archaic period refers to a long time span of human occupation of central and south Texas focused on mobile hunting and gathering. Unlike Paleoindian sites, which are relatively rare and seem to have diagnostic projectile points scattered throughout several archeological regions, Archaic sites are far more numerous and temporally diagnostic points exhibit traits that are increasingly regional. The geology and soils of the Guadalupe River valley have settled into the forms we see today (with the notable exception of varying river channels), and the vegetation and fauna during the Archaic period appears to be represented in the current landscape, although to a more or less degree. For example, it is unknown how much mesquite (and their nutritious beans) or pecans were present in the area, but other plants were available, as well as whitetail deer, rabbits, buffalo, bear, wolf, antelope, and other game. The armadillo did not arrive until the 1830s, and the javelina arrived in the 1400s, so these resources were not present during the Archaic (Hester 1991).

The Archaic is generally divided into Early, Middle, and Late periods, which are represented in every archeological region in Texas. However, as with the Paleoindian period, different timeframes are ascribed to these periods within each region. Table 3-1 profiles the Archaic period for the regions discussed in this chapter.

Most of the archeological sites recorded in DeWitt County that have been ascribed to a specific time period are Archaic, and the majority of these dateable sites are from the Middle and Late Archaic periods. These sites are generally campsites (Hester 1991). As with the Paleoindian Period, most Early and Middle Archaic sites may have been destroyed or deeply buried by the changes in the Guadalupe River channel, as very few have been found near the surface in the modern floodplain (Fox et al. 1974). Examples of Archaic sites in the area include the Pat Dunn site in eastern DeWitt County, from which was recovered a Matamoros projectile point (Late Archaic to Late Prehistoric periods), a Refugio point (Archaic period), several dart points, and specialized adzes called Clear Fork tools. The site also contained a burial of a male of 15-25 years interred with shell ornaments from the gulf coast. Other such burials have been dated to 2900 BP or later (Hester 1991). Site 41DW247 is a quarry site west of the Guadalupe River and north of Cuero with a Tortugas point dating to Middle Archaic (Bement and Robinson 1983). 
Site 41DW243, the Kerlick site, has been dated to the Early and Middle Archaic, and contained food remains of deer and turtle bone. Deer bone was also found at Site 41DW244, as well as decorated bone and a disturbed burial; the site dated to Middle and Late Archaic (Hester 1991).

\section{Early Archaic}

Hester (1995) divides the Early Archaic into an earlier "Early Corner Notched" horizon and a later "Early Basal Notched" horizon in the South Texas archeological region. These horizons are associated with the presence in archeological assemblages of corner notched dart points (Martindale, Uvalde, etc.) and Guadalupe tools for the former, and basal notched points (Bell, Andice, etc.) and Clear Fork tools for the latter (Hester 1995; Hester 2004). The Early Triangular point, the most common Early Archaic point form in the South Texas archeological region, seemed to persist throughout the entire period. Based on the current evidence, these Early Archaic peoples utilized both terrestrial and aquatic resources for their subsistence (Hester 2004). In the Central Texas archeological region, the Early Archaic is well represented by the presence of three difference projectile point style intervals: the Angostura, the early split stem, and the Martindale-Uvalde (Collins 2004). Clear Fork and Guadalupe tools have been found in Central Texas as well, but sometimes in mixed or unknown contexts. The Coastal Texas archeological region in the Early Archaic exhibits dart points such as the Gower and Uvaldelike points; Bell, Andice, and Early Triangular points have also been found. Almost all were found in association with fish otoliths, an artifact ubiquitous in Coastal Texas (Ricklis 2004).

\section{Middle Archaic}

The Middle Archaic is indicated by a change in the artifact assemblage that in turn suggests a shift in the human occupation of Texas. This shift may have been a re-adaptation to a changing environment, a culturally-based alteration in general mobile hunter-gatherer settlement patterns and technology, or a result of the departure of one group(s) from the area and the arrival of another. The Middle Archaic in the South Texas archeological region is characterized by the appearance of unnotched triangular projectile points (i.e., Tortugas, Abasolo) and a suite of unifacial and bifacial beveled tools (i.e. Nueces tools and Dimmit tools). Researchers have observed a connection between these South Texas stone tools and stemmed points from the Central Texas archeological region (Pedernales, Bulverde, Lange, Travis, etc.) when one focuses on the area where these two regions meet (i.e. in the vicinity of DeWitt and neighboring counties) (Fox et al. 1974; Hays and Abbott 1998). In the Central Texas archeological region, the Middle Archaic marks the rise of the large burned rock midden sites that indicates a shift to heavy plant processing subsistence activities (Black et al. 1997; Johnson and Goode 1994). Others have suggested that a similar shift occurred in South Texas (Hall et al. 1986). Coastal Texas appears be largely unoccupied during the Middle Archaic, ca. 4200-3100 BP (Ricklis 2004).

Some particular attention has been paid to the distinctive Morhiss point, which seems to appear only in the Central Texas coast and the lower Guadalupe river valley and adjacent river drainages. Several sites with possible "Morhiss complex" components have been excavated (41GD21, 41GD30, and 41DW270), and have returned radiocarbon dates of 2860 $440 \mathrm{BP}$ and 
2670 \pm 370 BP, with a potential occupation period at Site 41DW270 of 2800-3100 BP (Brown 1983; Fox 1979; Hudler, Prilliman, and Gustavson 2002).

\section{Late Archaic}

The Late Archaic period in the South Texas archeological region appears to represent a continuation of the general subsistence strategies that had been used during the Middle Archaic, including the exploitation of a wide variety of plant and animal resources. Grinding implements increase in the archeological record during this period, and the presence of large bison herds may also have increased (Hays and Abbott 1998). Characteristic diagnostic projectile points include both stemmed points (e.g., Marcos, Frio, Ensor) and unstemmed points (e.g., Catan, Matamoros). The Tortugas and Abasolo points which appeared in the Middle Archaic also appear during the Late Archaic. Other diagnostic tools from the South Texas Late Archaic include Shumla points, Olmos bifaces, Ellis points, and Fairland points. Some burned rock middens and grinding tools have also been frequently located at Late Archaic sites. Large triangular bifaces made of Edwards chert (from Central Texas) have been found in South Texas, indicating a possible trade network with Central Texas peoples (Hester 2004). Large burned rock middens in the Central Texas archeological region persist through the Late Archaic, and a wide variety of stone tool forms are generally recovered from these sites, including Pedernales, Marshall, Marcos, Bulverde, Montell, Castroville, and Ensor points (Collins 2004). In the Coastal Texas archeological region, the diagnostic Late Archaic artifact assemblage includes Kent, Marcos, Godley, and Ensor dart points. Scrapers, knives, Clear Fork gouges, Olmos bifaces, and other such tools have been found at Late Archaic sites, but shell tools seem to have been used more often (Ricklis 2004). Shoreline fishing and the exploitation of aquatic resources seemed to have developed during the Late Archaic. In the Savannah and Prairie archeological region, a long period of apparently very sparse occupation was broken by the presence of Late Archaic and Woodland sites containing Dawson, Gary, Kent, Morrill, Trinity, Wesley, and Yarbrough points (Fields 2004). Ceramics were also found in Woodland contexts in the Post Oak Savannah.

\section{Late Prehistoric}

The period of time between the Archaic and Historic periods has been called various names in different regions of Texas, including the Late Prehistoric, Protohistoric, Woodland, Neoamerican, and Neoarchaic. Here, the term Late Prehistoric will be used to describe this time period, which is generally marked in the archeological record by the appearance of ceramics and arrow points. These new artifacts indicate a change in the lifeways of their makers, including the introduction of subsistence farming in some areas, a change in hunting practices (including an increased reliance on bison hunting in some areas), increased trade, and possible changes in cultural practices. See Table 3-1 for the time periods associated with the Late Prehistoric within each archeological region described here.

Several archeological regions exhibit evidence of two Late Prehistoric sub-periods marked by three distinct points, the Scallorn and Edwards (1,200-750 BP) and Perdiz (600-300 BP) (Collins 2004; Hester 1991). In the South Texas archeological region, the arrow points that 
define these different sub-periods are sometimes found mixed together, and several dart points such as Ensor, Matamoros, Catan, and Zavala are also found in Late Prehistoric contexts. Bone tempered pottery has been seen in South Texas at Late Prehistoric sites, but like the arrow points, only enough data has been gathered to pose more questions than answers. In DeWitt County, Late Prehistoric Site 41DW242 contained deer bones and a Scallorn point in close association, and another Scallorn point was found at Site 41DW243 (Hester 1991). The Toyah horizon (as indicated by Perdiz points, ceramics, beveled knives, end scrapers, and prismatic blades) is the best documented horizon in South Texas, although no Toyah sites have been found in DeWitt County (Hester 1991, 2004). The Toyah horizon is most strongly associated with bison hunting in the Central Texas archeological region (Collins 2004), but deer and antelope were also hunted, and these animals were perhaps more numerous in South and Coastal Texas. The Coastal Texas archeological region also contains several archeological sites of the Late Prehistoric, including those with Scallorn and Perdiz points, but another distinctive artifact, Rockport ceramics, has also been documented (Ricklis 2004). Ceramic sherds in the The Savannah and Prairie archeological region outnumber lithic artifacts by more than 2:1 in the Late Prehistoric period, which indicate the intense development of ceramic technology and a likely change in subsistence, including the utilization of maize along with a more traditional hunter-gatherer strategy (Fields 2004).

\section{Historic Period Cultural History}

The Historic period in DeWitt County begins with the arrival of Europeans to the area in the sixteenth century. Since Site 41DW277 dates only to the prehistoric period and has no historic component, only a brief description of DeWitt County in the Historic period is warranted here, and this will include only the early exploration of the area by the Spanish and French. Although no early European settlements of any kind were established in the land that would become DeWitt County, the location proved excellent for traveling between settled places in East Texas and New Spain, in what is now northern Mexico. The first European to travel through the area was Álvar Núñez Cabeza de Vaca in 1534, during his adventure through the Texas countryside after an ill-fated shipwreck off the gulf coast. Other explorers to the area include René Robert Cavelier, Sieur de La Salle and his French troops in 1685 (on reconnaissance missions from Fort St. Louis), and Governor Alonso De León in 1689 and 1690 (Foster 1991; Roell 2011).

Alonso De León made the Guadalupe River in northern Dewitt County his campground for two of his expeditions to the Texas gulf coast in 1689 and 1690. According to historian J. W. Williams, the De León base camp was located where U.S. 183 crosses the Guadalupe River (near Hochheim), in very close proximity to Site 41DW277 (Foster 1991). The broad valley on the west bank can be seen for over 20 miles from the high ridge near the river, and this area was interpreted to be the base camp. The first of the De León expeditions began on March 27, 1689 with a force of 114 men, including Fray Damián Massanet, soldiers, servants, muleteers, a French prisoner, and 700 horses. De León was seeking and eventually found the ruins of the French settlement, Fort St. Louis, established by La Salle in 1685. The 1690 expedition also used the same campground on the Guadalupe River en route to a site on San Pedro Creek to establish the first Texas mission, San Francisco de los Tejas, in the environs of present Augusta, 
Texas (Weddle 2011). The expedition also returned to Fort St. Louis and burned all the remains of the French fort.

Once established, other Europeans used the campground area as a river crossing. This included Governor Martín de Alarcón in 1718 on his way to establish the missions and presidio that would become San Antonio. Apparently, the crossing became known as Governor's Ford after Alarcón almost drowned there (Foster 1991). This part of the trail, part of a network of roads known as the Camino Real, was known as the The La Bahía, Opelousas, or Lower Road in the Spanish ranching period and used for cattle drives (Roell 2011). Fray Gaspar José de Solís also likely crossed the Guadalupe River near Hochheim on April 16, 1768 during his inspection tour of the Texas missions.

Part of DeWitt County was included in Green DeWitt's colony in 1825; 39 settlers were located in the area, almost all on farms along the Guadalupe River. DeWitt County was officially established in 1846 after the Texas Revolution (Foster 1991; Murphree 1962; Roell 2011). For an excellent history of DeWitt County, see The History of DeWitt County, Texas by the DeWitt County Historical Commission (1991).

\section{Previous Investigations}

Records at the Texas Archeological Research Laboratory (TARL) and the Texas Historic Sites Atlas indicate that just over 300 archeological sites have been recorded in DeWitt County as of December 2011. Before the archeological survey of large areas of the Guadalupe River valley in the early 1970s, only 12 sites had been recorded in DeWitt County. That survey, which was conducted in preparation for the proposed Cuero I Reservoir, recorded a total of 352 archeological sites in Gonzales and DeWitt counties (Fox et al. 1974). Only about 40 sites have been recorded in the last two decades (Hester 1991). A few of these sites were recorded during archeological surveys that had been conducted in recent years (Bement and Robinson 1983; Hays and Abbott 1998), and avocational archeologists have recorded several sites in the area, including Cecil Calhoun in the 1960s, Mark Hudgeons in the 1970s, and E.H. Schmeidlin in the 1980s (Hester 1991). Several of these sites are of interest as comparative studies to the current investigation, and the research concerning these sites will be discussed in more detail in Chapter 7. 


\section{Chapter 4 \\ Research Design and Methodology}

\section{RESEARCH ISSUES}

Original investigations of the site were conducted by Bettis and Abbot in 2009, and consisted of a pedestrian survey accompanied by mechanical trenching. During the mechanical excavation of three of their trenches (GT 1, GT 2, and GT 3), a thick deposit of prehistoric cultural material was encountered in all three ranging in depth from 50-160 cmbs. The lithic debitage from the deposits exhibited characteristics of thick bifacial reduction and hammer and anvil reduction techniques. In addition to the presence of debitage, one fire-cracked hearth feature and two scatters of fire-cracked rock were encountered. Based on information gathered from the previous investigations, a foundation was provided for research issues pertinent to the understanding of the site. The research issues addressed at the outset of the field investigations pertained to site integrity and lithic technology. Once the field investigations were complete, these topics were further refined into an intra-site comparison between the analytical units found during the excavations. In addition, a regional study was employed during the postfield analysis to assist in establishing a context into which Site 41DW277 can be placed. A description of the initial research issues are described below, followed by by a brief description of the post-field research topics. The full analysis is presented in Chapter 7.

\section{Site Integrity}

Establishing site integrity is vital to determining NRHP eligibility under Criterion D. Within an archeological site, good site integrity includes the presence of discrete zones of occupation that can be separated from the surrounding deposits, most often through an analysis of the natural soil strata. In addressing the integrity of the site during the field investigations, cultural deposits were examined by establishing a relationship between the natural strata and cultural deposits and features within the strata. The establishment of a relationship between the two was determined by the collection of several charcoal samples, diagnostic tools or points, soil susceptibility data, and soil $\mathrm{pH}$ data. Based on these data gathered from the excavations a chronological sequence of components present was identified.

\section{Lithic Technology}

As it is an integral aspect of prehistoric cultural adaptation, understanding the lithic technology employed at the site is important. By examining the remaining evidence of the types of lithic technology, an understanding of prehistoric lifeways such as hunter-gather mobility pattern/ strategies, raw material exploitation, and characterization of the regional assemblage can be established. To obtain the most comprehensive data set possible from the hand excavated units, which would provide the best provenance, all cultural lithic material was collected in 
the field. In addition, bulk soil samples were obtained from select excavation units to retrieve microdebitage in the laboratory. The bulk of the investigation into lithic technology was conducted in the laboratory once the field investigations were complete.

\section{Post-Field Intra-Site And Regional Studies}

The intra-site study developed after the field investigations include a comparative analysis of the defined analytical units to see if there is an observable difference between the subsistence strategies and site activities at different times of the site's occupation. Lithic technology, feature composition, and analysis of snail/mussel shell and organic remains were employed in the comparison. The regional study is also a comparative analysis of aspects of Site 41DW277 and other sites in the vicinity that have been investigated beyond the recording stage. As Site 41DW277 is located in a "transition zone" between more well-defined archeological regions, an obvious avenue of investigation is to see if this and neighboring sites have cultural traits similar to one of more archeological regions to the northwest, southwest, or southeast. These may include lithic technology, subsistence strategies, and site activities.

\section{Field Methods}

Prior to the NRHP eligibility investigations documented herein, two gradall trenches originally excavated by Bettis and Abbot (GTs 2 and 3) were re-opened. In addition to re-opening these two trenches, AmaTerra excavated an additional two new trenches (GTs 4 and 5). Subsequently, a third new trench (GT 6) was excavated just southwest of GT 5. Soil from the gradall trenches were not screened during excavation; however, spoils were piled adjacent to the trenches so that investigators could examine the excavated fill. Only soils from the newly excavated AmaTerra trenches were examined for cultural materials.

Once the trenches were excavated to their targeted depth of $150 \mathrm{cmbs}$, archeologists from AmaTerra re-identified the stratum according to Abbot's original interpretation. Each trench was then profiled and soil susceptibility readings were recorded using a hand-held Gf Instruments Magnetic Susceptibility Meter, Model SM-20, which records a sensitivity of 10-6 SI units. Soil magnetic susceptibility values were measured every $5 \mathrm{~cm}$ down the freshly exposed profile. In addition to measuring soil susceptibility, soil $(\mathrm{pH})$ values were also recorded. The $\mathrm{pH}$ values were measured in the exact area where the susceptibility values were collected. All values were recorded on standard forms designed for that purpose, and then entered into an Excel spreadsheet for purposes of analysis and modeling.

A $50 \times 50$-cm unit was excavated off the side of each trench. Each 50 x 50-cm unit was dug in 10-cm arbitrary levels, with soil screened though $1 / 4$-inch hardware cloth at each level in order to characterize artifact density, content, and context. These $50 \times 50-\mathrm{cm}$ units were then used to guide placement of larger $1 \times 1$-m test units (TUs), which were also placed off the sides of the trenches (Figure 4-1). 


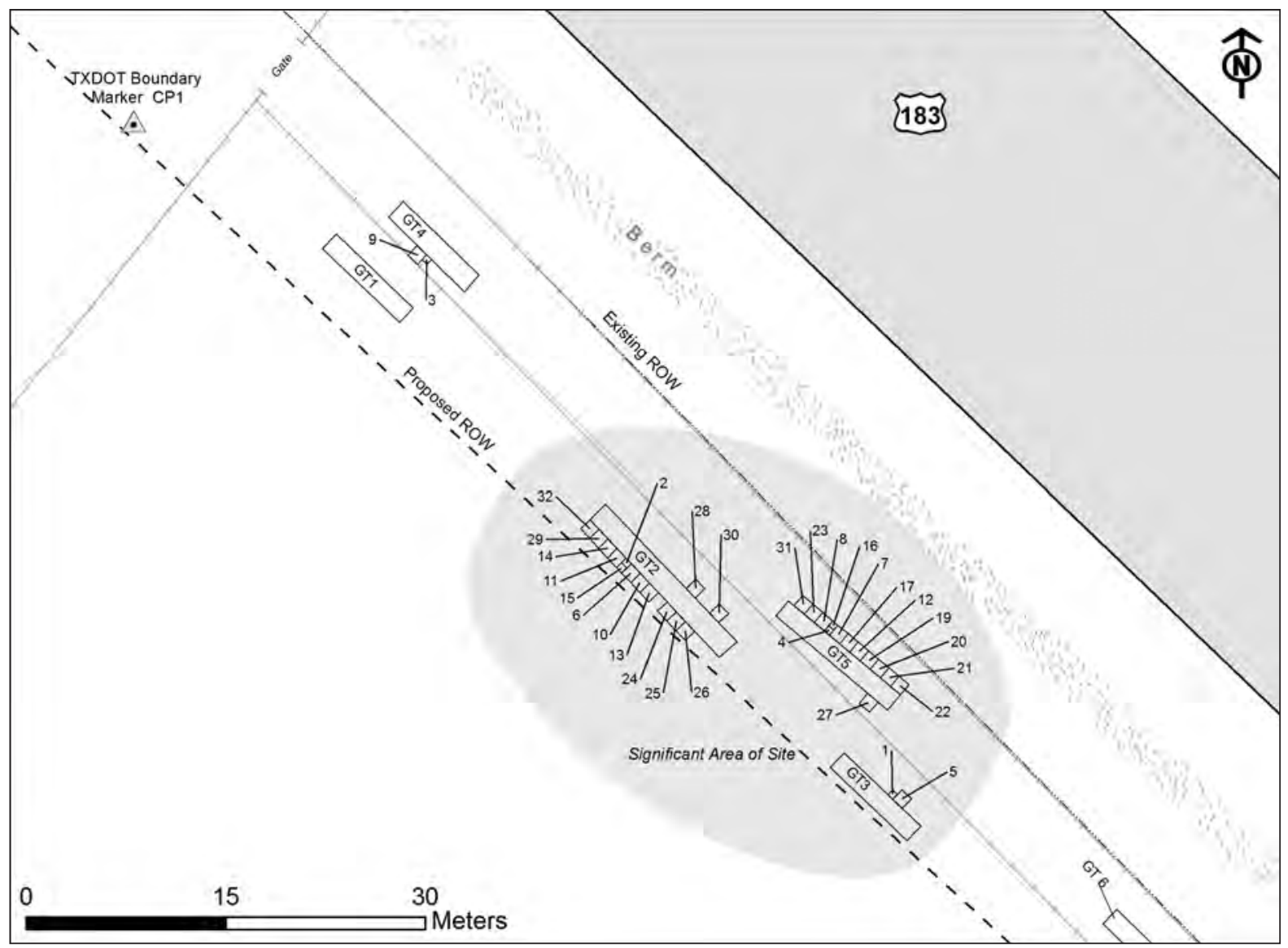

Figure 4-1. Placement of the $50 \times 50-\mathrm{cm}$ and $1 \times 1-\mathrm{m}$ test units.

Based on the results of the $50 \times 50-\mathrm{cm}$ units, the majority of the $1 \times 1-\mathrm{m}$ units were placed off of GTs 2 and 5. TUs 5-9, 23, and 27-32 were dug using shovels and trowels in 10-cm increments, except for the top $20 \mathrm{~cm}$ of each $1 \mathrm{x} 1$-m unit, which was dug as one level. This was done due to low artifact recovery from the top two levels and the fact that the upper 20 $\mathrm{cm}$ laid within the plow zone of the landform. Investigators anticipated that anything found within this upper $20 \mathrm{~cm}$ would lack context. Indeed, the unit excavations proved that almost the entire upper meter of sediment contained very little cultural material and lacked archeological integrity. Consequently, the excavation strategy was altered midway through investigations to target the cultural horizons more specifically. For TUs 10-17, 19-22, and 24-26, investigators simply removed the top meter of sediments (either by hand or by gradall stripping) without screening, and began excavation in $10 \mathrm{~cm}$ increments at a depth that typically varied from 80-100 cmbs. From that point, excavation in $10 \mathrm{~cm}$ intervals commenced, with soil screened through $1 / 4$-inch hardware cloth from each level down to the terminal depth of each unit, which typically varied from 140-190 cmbs. Each $10 \mathrm{~cm}$ screened level of each unit was documented using standardized field forms.

Features encountered during the excavation were carefully exposed and documented through field notes, sketches, maps, and photographs. Each feature was fully excavated to the extent feasible. All cultural materials and pertinent floral/faunal remains, including snails, 
were collected for later analysis. Charcoal samples for dating were collected as they were encountered during the course of investigations. Bulk sediment samples were taken from all feature contexts for purposes of eventual flotation and humate dating. In addition, part-way through investigations it was decided that a $10-\mathrm{cm}^{3}$ sediment sample should taken from test unit levels for eventual water screening in order to recover microdebitage that could contribute to analysis.

Vertical controls during excavation were taken from datum points established on the surface of each test unit. All datums, test unit corners, and gradall trenches were then mapped using a Total Data Station (TDS) with an arbitrary base elevation set at $100 \mathrm{~m}$, centered on a TxDOT monument located near the river. All TDS points collected were post-processed using ArcGIS and established within the universal trans mercator (UTM) grid system by geo-referencing various key data points (namely the block corners) with known survey markers. The site was basically flat; however, and for purposes of this report, the archeological team elected to maintain the elevations collected in the field. Therefore, all elevations discussed will be in centimeters or meters below surface.

\section{Laboratory Procedures}

All artifacts and samples collected during the course of our investigation were brought back to the AmaTerra laboratory. Lab analysts began by organizing the artifacts to prepare them for curation. This work consisted of bag cross checking, the creation of inventories, and the cleaning and sorting of artifacts. Artifacts were then prepared for final curation according to the Center for Archaeological Studies Standards.

\section{Inventory}

All bags collected containing artifacts and samples were logged in on an Artifact Inventory Sheet as they were collected in the field. All artifacts and samples from the site were stored in a large plastic container for transport to our offices. When the artifacts arrived at the offices of AmaTerra, technicians working in the laboratory went through the site's Artifact Inventory Sheet and accounted for each bag cited. Once all the bags were accounted for, the data recorded on the Artifact Inventory Sheet then transferred into an Excel file which established the basis of creating a Master Artifact List.

\section{Cleaning of Artifacts}

All artifacts brought into the lab were cleaned by means of washing and dry brushing. Artifacts consisting of lithics, marine shell, and bone were primarily cleaned by washing and brushing them in tap water with a toothbrush. However if any bone was noticed to be brittle and/or found to have been poorly preserved, the bone was cleaned using a dry toothbrush. All artifacts were then placed on drying racks and placed to dry for a day's time. 


\section{Sorting of Artifacts}

Once the artifacts had completely dried they were then sorted into separate categories: lithics, marine shell, bone, and rabdotus. As the artifacts were being separated a count of the artifacts of each kind for each field lot was documented on the Master Artifact Catalog. Once the artifacts were sorted and documented the artifacts were then placed in new bags labeled with their respective proveniences. In addition to the information written on the bag, a bag tag containing the same information was also inserted. After sorting the artifacts according to type (lithics, marine shell, bone, and rabdotus) they were brought to the Field Director for analytical purposes.

\section{Analysis Techniques}

Analysis of the artifacts and samples collected during our excavations were either processed in-house or sent out to agencies specializing in specific types of analysis. Artifacts and samples that were analyzed or processed in-house consisted of all lithic material collected, soil susceptibility, and $\mathrm{pH}$ samples. Artifacts and samples sent out to specialized agencies consisted of charcoal, marine shell, and macrobotanical samples. Various other samples that were not processed are to be curated with all the artifacts at Texas State University and will be available for processing at a later date.

\section{Lithic Analysis}

All lithic material collected during the excavations was entered in to a Master Catalog form. Only lithics from our analytical units were further separated into a distinctive taxonomic sequence as outlined in the TxDOT Chipped Stone Analytical Protocol. Because no protocol exists for groundstone, all groundstone encountered was separated from the chipped stone, weighed, measured and cataloged. All chipped stone was classified as either a core-derived tool or core-based tool. Lithics classified as core-based tools were further divided into a class as either biface or non-biface, followed by a subclass as either formal or informal, then into type based on function, and finally into a subtype based on identity/tradition. For each corebased tool, metric information, attributes, portion, failure/discard, alteration, edge morphology, flake scar pattern, edge construction type, proximal edge grinding, hafting evidence, and raw material were recorded.

Those lithics classified as core-derived tools such as flakes or blades were further divided based on raw material or individual package, then as whole and proximal flake, then by size grade (1-, 3/4-, $1 / 2-$, and $1 / 4$-inch). The two largest size grade flakes ( 1 and $3 / 4$ inch) were examined for utilization or use wear. Those that contained these attributes were removed and placed into the tool category. The remaining flakes, only those in the largest size grade, were then examined for thermal alteration. Each size grade was then separated based on the amount of dorsal cortex present. Finally each size grade was separated by platform type. Flaked material that did not fall into the categories identified in the TxDOT Chipped Stone Protocol were further divided into debitage or incomplete flakes with evidence of thermal alteration noted and cataloged. 
In addition to documenting the various attributes defined by the Chipped Stone Protocol, those flakes that were identified as whole or complete flakes were further examined and assigned a technical description based on the reduction technology. Not all whole/complete flakes were assigned a reduction technology, only those that displayed recognizable attributes. Reduction technology types identified consisted of: early/late bifacial manufacturing, blade, bi-polar, core reduction, distinctive expanding billet, "r," notching, sequence, thinning, and indeterminate flakes.

\section{Soil Susceptibility Analysis}

The purpose of collecting soil susceptibility readings was to evaluate the peaks in magnetic susceptibility of sediment at regular intervals from a vertical column from either a backhoe trench or unit profile and a horizontal column from a series of contiguous units containing evidence of burning. Ideally, information produced from the analysis of magnetic susceptibility values should reflect zones (vertically) in which high frequencies of cultural materials are found and evidence of sediments rich in organic materials.

\section{Phosphate (PH) Analysis}

Although soil $\mathrm{pH}$ (the measurement of hydrogen ion concentration in a soil solution) in archaeological contexts have been analyzed to obtain additional information on features that have ill-defined stratigraphic profiles (Deetz and Dethlefsen 1963), the primary use of $\mathrm{pH}$ measurements at an archeological site is to determine the likelihood that organic remains, particularly bone and shell, will be well preserved (Gordon and Buikstra 1981; Watson 1967). Soil $\mathrm{pH}$ is measured numerically, with values ranging from $0-14$, and categorized as either acidic, neutral, or alkaline (base). A neutral $\mathrm{pH}$ is valued at 7.0, and acidic soils are less than 7.0 and alkaline soils are more than 7.0. Most plants find it difficult to survive in soils with a $\mathrm{pH}$ outside the range of 4.5-8.0. Within archeological sites, a lower $\mathrm{pH}$ (higher acidity) indicates a poor environment for bone and shell preservation, while soils with a neutral or high $\mathrm{pH}$ are much more likely to preserve these artifacts, when present.

\section{Sample Processing}

Samples that were able to be processed at the lab before they were sent for specialized analysis were conducted by lab technicians employed by AmaTerra, under the supervision of the Lab Director. Other samples that needed a more specialized approach were sent directly to consultants specializing in processing and analysis. Charcoal samples, macrobotanical samples, and mussel shell samples were all sent to third-party technical specialists.

\section{Charcoal Samples}

All charcoal samples collected in the field were examined to identify the best possible specimens to be tested. Samples were selected based on the integrity of the context from which it was 
collected and the importance of information that could be provided by the sample. Samples selected for radio carbon assay were sent to Beta Analytic to be processed and analyzed.

\section{Macrobotanical Samples}

All soils collected for flotation were first processed in the lab at AmaTerra. The samples were collected using a chiffon cloth and were separated as light and heavy fractions. Prior to flotation of the samples a volume measurement was taken by the use of a graduated 5-gallon bucket. Once the floats were collected and dried, the light and heavy fractions were then combined and put into an envelope marked with the provenience of each float. Selected float samples were sent for microbotanical analysis to Leslie Bush.

\section{Mussel Shell Analysis}

All pieces of freshwater mussel shell $(1,513)$ collected were cleaned and processed by AmaTerra before being sent to Robert G. Howells to identify different species present at the site. Species identification will enable archeologists to see which species were harvested and give a glimpse in to the changing environmental conditions at the site.

\section{Curation}

Finally, all cultural material, field notes, forms, photographs, and drawings related to the project will be sent to the Center for Archaeological Studies, Texas State University for curation. All documents pertaining to this project will be stored there as well. 


\section{Chapter 5 \\ RESUlTS OF INVESTIGATIONS}

\section{Narration and Summary of Excavations}

During the original investigations of the site in August 2009, Abbott and Bettis excavated a total of seven gradall trenches on the east and west bank of the Guadalupe River. Three were located on the eastern bank of the river while four were located on the western bank of the river. Of the seven trenches excavated, the three (GTs 1-3) on eastern bank identified the prehistoric site of 41DW277. The site was identified based on the presence of cultural material encountered within each of the three trenches at various depths. Cultural material encountered consisted of lithic debitage, fire cracked rock, mussel shell fragments, two halves of a burnt clay ball and a possible hearth feature. The depths at which cultural material was encountered within the three trenches were between 50-160 cmbs. GT 1 revealed cultural material from 100-145 cmbs, GT 2 revealed cultural material from $50-140$ cmbs, and GT 3 contained cultural material from $100-160$ cmbs. The sandstone fire-cracked rock hearth feature was observed in GT 3 at a depth of $100 \mathrm{cmbs}$. Based on the cultural material encountered within the three trenches, Abbott and Bettis believed that the site warranted further testing for NRHP eligibility.

During the months of November and December 2009, archeologists from AmaTerra conducted NRHP-eligibility test excavations of Site 41DW277. The site is located on a $\mathrm{T}_{1}$ terrace along the east bank of the Guadalupe River and is situated in a riparian setting within an open pasture. Investigations of the site consisted of the excavation of five gradall trenches, two of which (GTs 2 and 3) were previously excavated during TxDOT's initial investigations in August 2009), seven 50 x $50-\mathrm{cm}$ test units, and $251 \times 1-\mathrm{m}$ test units. All units were placed abutting the sides of the gradall trenches. Termination depths of the test units varied. Seven units were terminated at less than $150 \mathrm{cmbs}, 17$ units were excavated to $150-170 \mathrm{cmbs}$, and eight units were excavated deeper than 170 cmbs. The deepest units, TUs 2, 6, 10, and 23, were excavated to 200 cmbs.

\section{Excavation of the Gradall Trenches}

Prior to hand excavation of the test units, archeologists monitored the mechanical excavation of four gradall trenches. As outlined in the scope of work, the four trenches were excavated within the proposed ROW on either side of a barbwire fence. Due to the cultural material encountered within the original trenches excavated by TxDOT, especially the presence of fire-cracked rock in GT 2 and a possible hearth feature in GT 3, excavations began with the re-opening of TxDOT's trenches GT 2 and GT 3. TxDOT's trench, GT 1, was not reopened during the testing. In addition to the re-opening of the two trenches, two more trenches (GTs 4 and 5) were placed within the proposed ROW. GT 4 was excavated approximately $17 \mathrm{~m}$ northwest from GT 2, and GT 5 was excavated parallel and staggered between GTs 2 and 3. Although the scope of work called for the excavation of only four new trenches, it was decided midway through the project that an additional trench, GT 6, be dug to further explore the site 
boundaries. GT 6 was excavated approximately $20 \mathrm{~m}$ southwest of GT 5 within the proposed ROW (Figure 5-1).

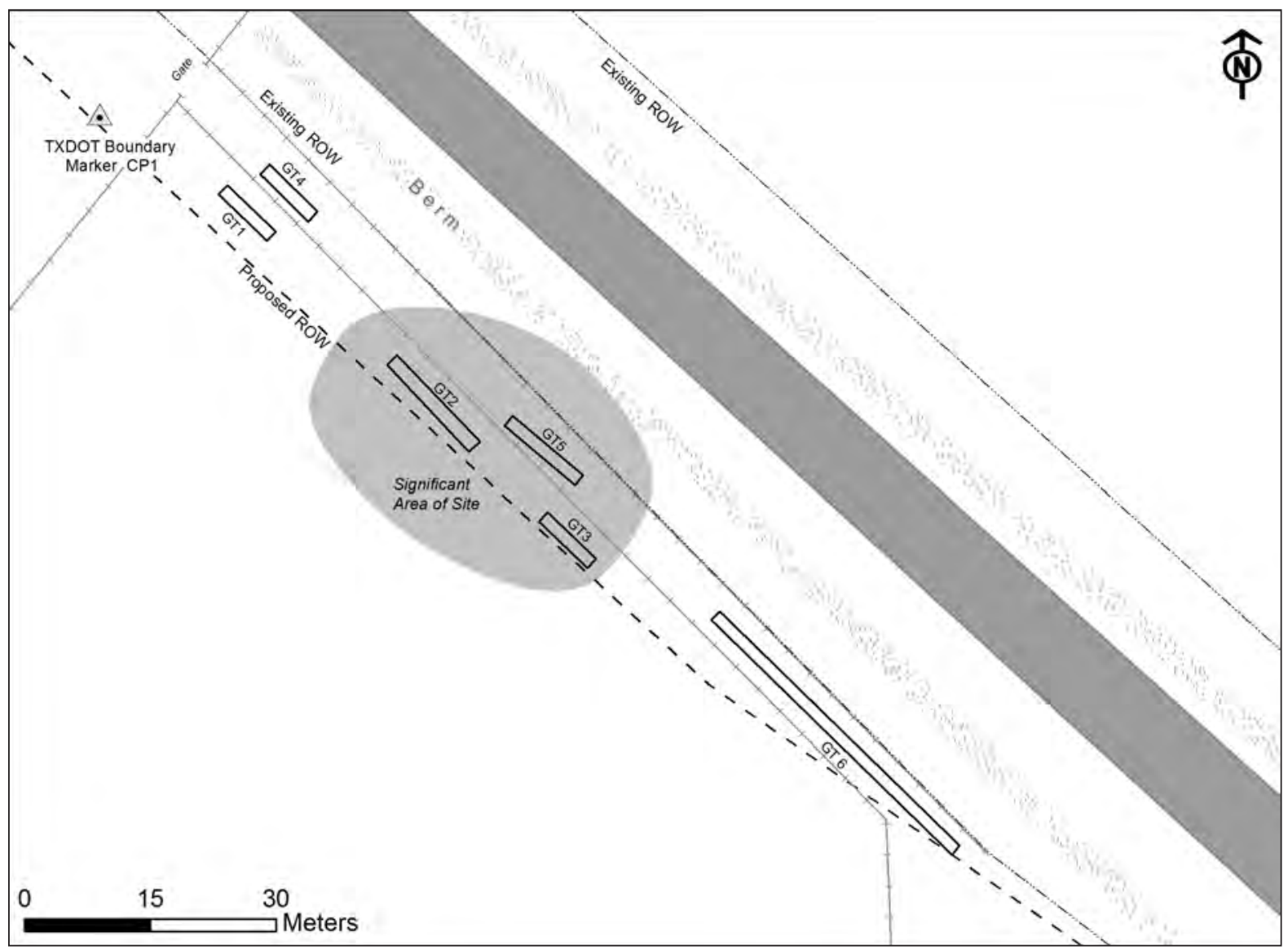

Figure 5-1. Location of gradall trenches at Site 41DW277.

During the original investigations, Abbott identified several different soil strata within the gradall trenches. These strata were re-identified within GT 2 and GT 3 by AmaTerra archeologists. Based on the identification of the strata within the two original trenches, strata observed within the three new trenches were identified and tied into the existing column description. Information gathered from the trench profiles was recorded and typical examples within each trench were sketched in the field. Major depositional units or strata soil were identified and referred to as "horizons," such as the Ap, A, AB, Bw horizons in GT 2, and minor variations within each horizon were identified as "strats." Major strata, horizons, and strats were given ascending numbers in profile from the ground surface down the trench wall. These numerical designations were also used to describe unit levels in subsequent hand excavations.

All five trenches excavated during the testing were at least $15 \mathrm{~m}$ in length and excavated to a depth of approximately $150 \mathrm{cmbs}$. GTs 2, 3, and 5 revealed similar profiles consisting of four basic strata. GT 6, which was placed farthest away from the river, contained a thick, alluvial/ colluvial Ap/A soil horizon. GT 4, placed closest to the Guadalupe River, also revealed a quite 
different profile than the other trenches. A complete description of the stratigraphy can be found below in the Natural Stratigraphy section.

\section{Test Unit Excavations}

After the excavation of the GTs 2-5, seven 50 x 50-cm and 251 x 1 -m test units were placed off the side of the trenches (see Figure 4-1). Excavation of the test units began with four $50 \times 50-\mathrm{cm}$ units off the sides of GTs 2-5. These were designated as TUs 1-4 and every subsequent unit, regardless of size, was assigned numbers corresponding to the order they were opened. The purpose of the four $50 \times 50$-cm test units was to identify any cultural components present within the trench profile based on the density of artifacts. TU 1 was placed on the northeast edge of GT 3, TU 2 was placed along the southwest edge of GT 2, TU 3 was placed along the southwest edge of GT 4, and TU 4 was placed along the northeast edge of GT 5. Additionally, when GT 6 was excavated a $50 \times 50-\mathrm{cm}$ test unit (TU 18) was placed along the northeast edge of that trench. Each of the $50 \times 50-\mathrm{cm}$ test units excavated within the five trenches began at ground surface $(0 \mathrm{cmbs})$, which was basically flat across the site, and was terminated at various depths based on the presence/absence of artifacts. TU 2 was the deepest $50 \times 50-\mathrm{cm}$ unit excavated at a depth of $200 \mathrm{cmbs}$, while TU 18 was the shallowest, ending at a depth of $160 \mathrm{cmbs}$. An additional two $50 \times 50$-cm test units were excavated to expand TUs 2 and 4 once it was found that artifact density in these units was generally high. Placement of the $1 \mathrm{x} 1-\mathrm{m}$ units was based on the distribution of artifacts encountered in the initial four $50 \times 50-\mathrm{cm}$ units.

Placement of the $1 \times 1-\mathrm{m}$ units also occurred along the edge the five gradall trenches. All $1 \times 1-m$ test units excavated stemmed from the originally excavated $50 \times 50-\mathrm{cm}$ test units within the trenches (see Figure 4-1). GTs 2 and 5 were the most productive in terms of artifact yield; consequently, most units were placed off of these two trenches. Excavation of the initial $1 \mathrm{x} 1$-m units began at the surface and proceeded downward, but overall, artifact recovery in the first meter was much lower than anticipated (Table 5-1). Though present, cultural material was very lightly scattered throughout the test units. The upper meter of sediments, corresponding to the sandy Ap and sandy clay loam A horizons, were largely devoid of cultural material, and what little was found lacked any sort of interpretable context. Rather, cultural material was largely confined to the $\mathrm{AB}$ and $\mathrm{Bw}$ horizons, which typically appeared at about $100 \mathrm{cmbs}$ in GTs 2, 3, and 5. Due to the paucity of artifacts encountered within the upper $100 \mathrm{~cm}$ of the site, the upper $90-110 \mathrm{~cm}$ of sediment in some of the subsequent $1 \mathrm{x} 1$-m units was removed without being screened to focus the level of effort on the lower horizons. Therefore, the screened and documented excavation of 15 test units (TUs 10-17, 19-22, and 24-26), began at 90-110 cmbs.

Based on debitage, snail, and shell collections, test unit excavations revealed what appeared to be three different intact occupation zones, or analytical units (AU). The first identified AU was centered around 100-110 cmbs (total extent is 100-130 cmbs). The second AU was situated at approximately 140-150 cmbs, and the third AU was situated at roughly 170-180 cmbs (see Table 5-1). Of the $26.15 \mathrm{~m}^{3}$ of soil that was hand-excavated, $14.23 \mathrm{~m}^{3}$ were not associated with an analytical unit, $8.575 \mathrm{~m}^{3}$ were part of AU1, $2.1 \mathrm{~m}^{3}$ contained AU2, and $1.25 \mathrm{~m}^{3}$ represented AU3. 


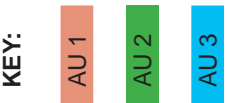

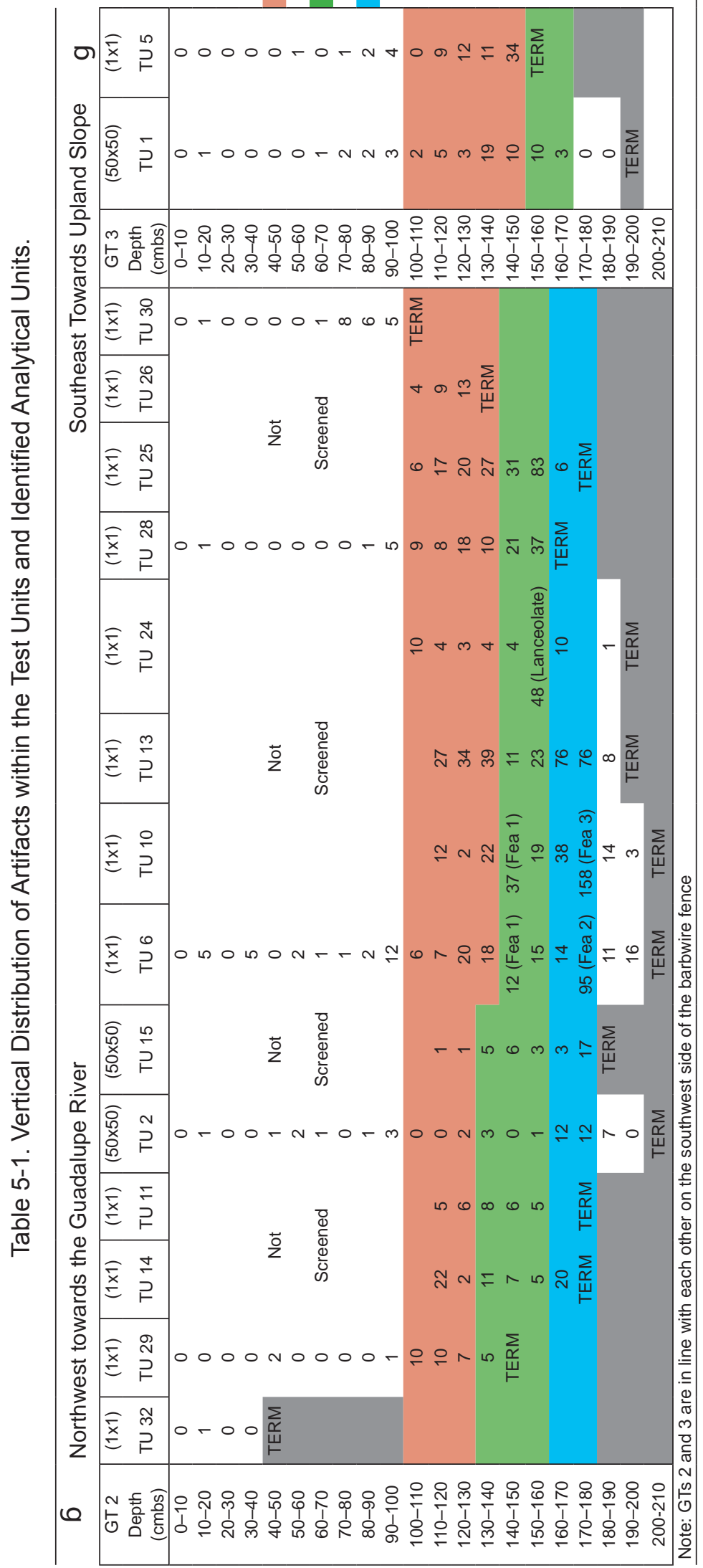

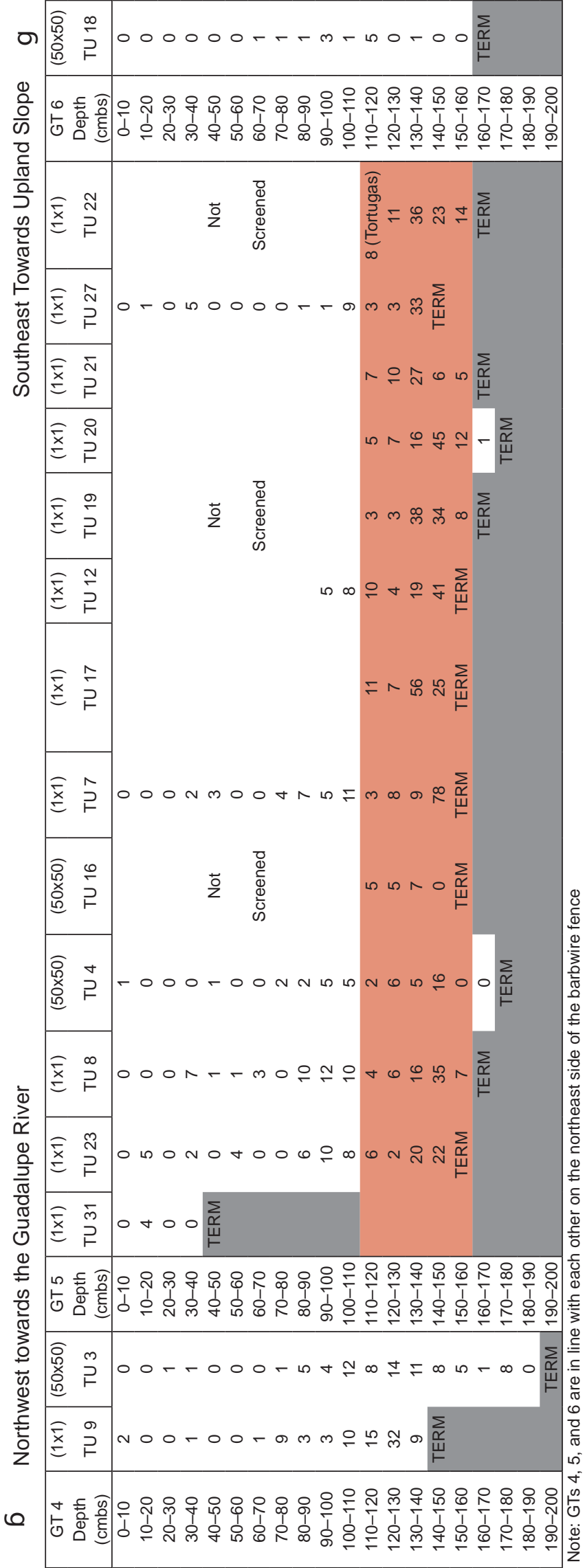


The uppermost analytical unit was spread across several vertical levels and contained no corresponding features. This analytical unit was most distinct in units placed off of GTs 2 and 5 , and roughly corresponded to the base of the A/AB horizon soils when sediments transition from sandy clay loam to lighter brown clay loam. At this transition point, debitage, mussel shell, and whole snail counts typically spiked. Investigators noted significant quantities of burned sandstone (and some chert) scattered throughout the matrix, as well as numerous crushed snail shells. A Tortugas point from TU 22 and a unifacial Clear Fork gouge from TU 12 were recovered at $110 \mathrm{cmbs}$. Field interpretation of this data suggested that the analytical unit represents a site occupation in the Late Middle to Late Archaic period, though Clear Fork tools are known from Early Archaic contexts as well (Hester 1995; Turner and Hester 1999).

No features were documented in this zone, though a notable scatter of tabular, very eroded sandstone (Figure 5-2) was documented at a consistent elevation of 110-120 cmbs in TUs 4 and 8 (GT 5). A second scatter (Figure 5-3) of burned sandstone was documented in TUs 25 and 26 (GT 2) at an elevation of 110-120 cmbs. Stratigraphically, these two rock clusters correspond to the base of the $\mathrm{AB}$ horizon with the soil matrix characterized by very dark gray (10YR 3/1) compact clay loam. Neither of these rock scatters were documented as features because they lacked identifiable patterning. Nonetheless, subsequent interpretation suggests that these were probably hearth or cooking feature remnants as they correspond to spikes in debitage, burned rocks, and mussel shells. An untypable point base (that has the appearance of something from the late Middle to Late Archaic period) was found just below the rock scatter in TU 25 at 120-130 cmbs, as was a second Clear Fork gouge from the same elevation in TU 7 which is adjacent to TUs 4 and 8 . This second Clear Fork tool was manufactured from petrified wood.

In the second analytical unit, field investigators noted a pronounced spike in debitage, mussel shell, and snail shell recovery along with a change to a Bw soil horizon marked by reddish brown sandy clay. Though scattered burned rocks (mainly sandstone) were noted in this zone, density was generally lower than at the 100-120 cmbs level, except in TUs 6 and 10, where Feature 1 was recorded.

Feature 1 was observed and excavated at 140-150 cmbs in TUs 6 and 10, located off of GT 2. The feature consisted of burned rocks set at a consistent level forming

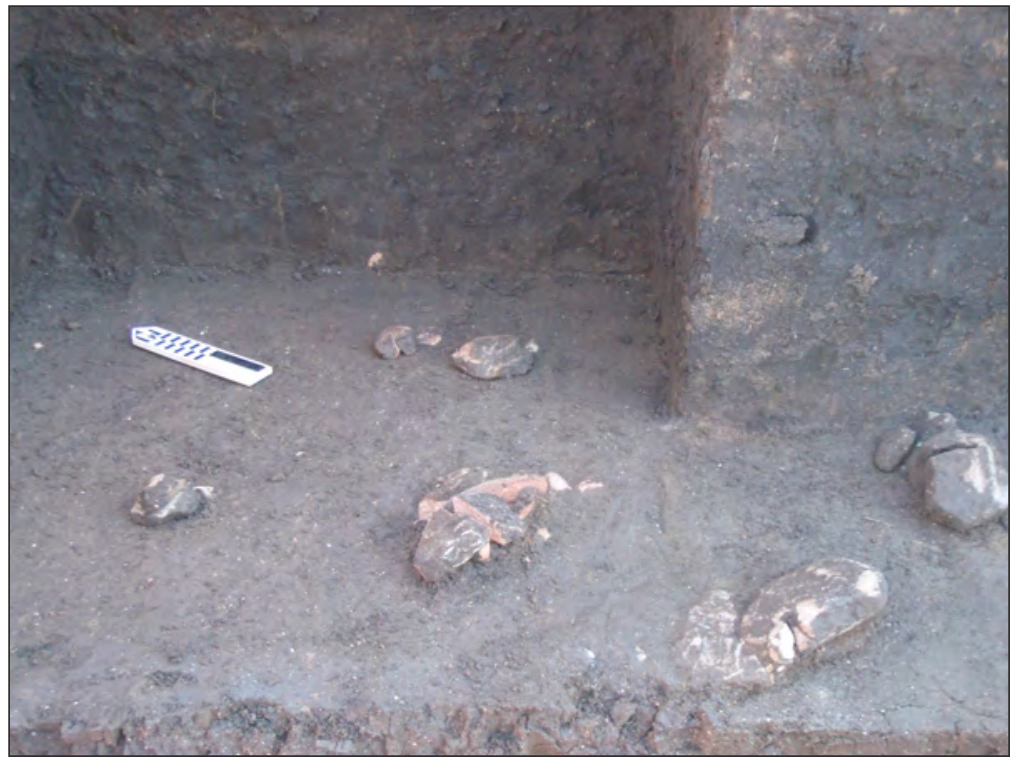

Figure 5-2. Sandstone scatter in TUs 8 and 4. 


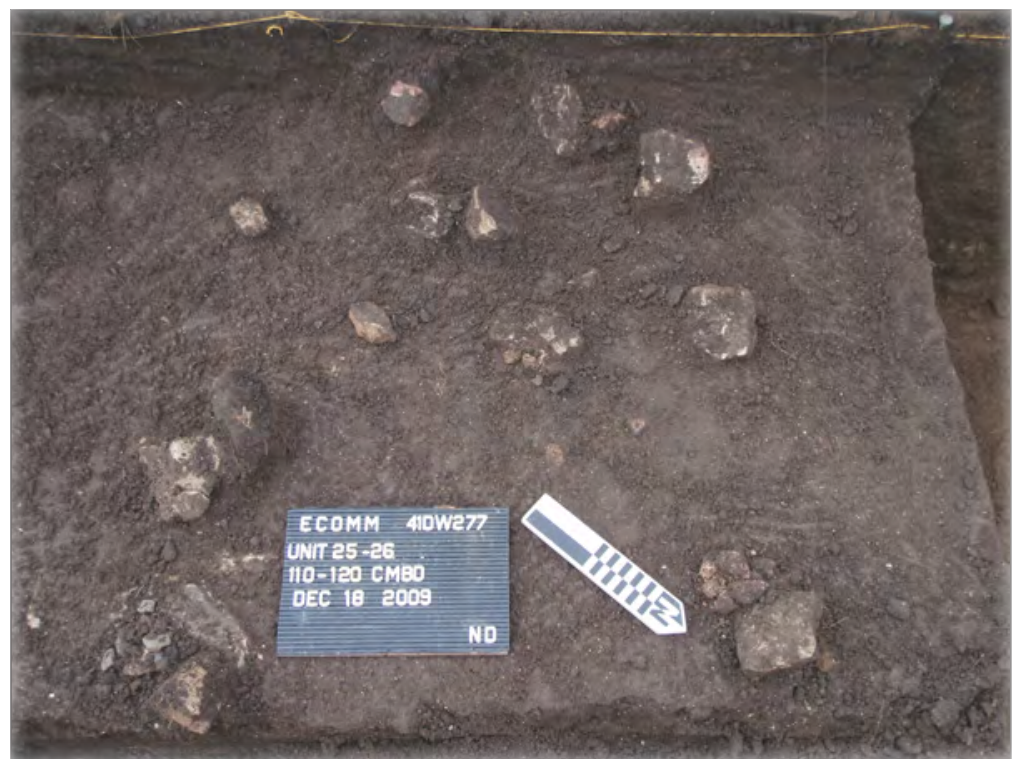

Figure 5-3. Sandstone scatter in TUs 25 and 26.

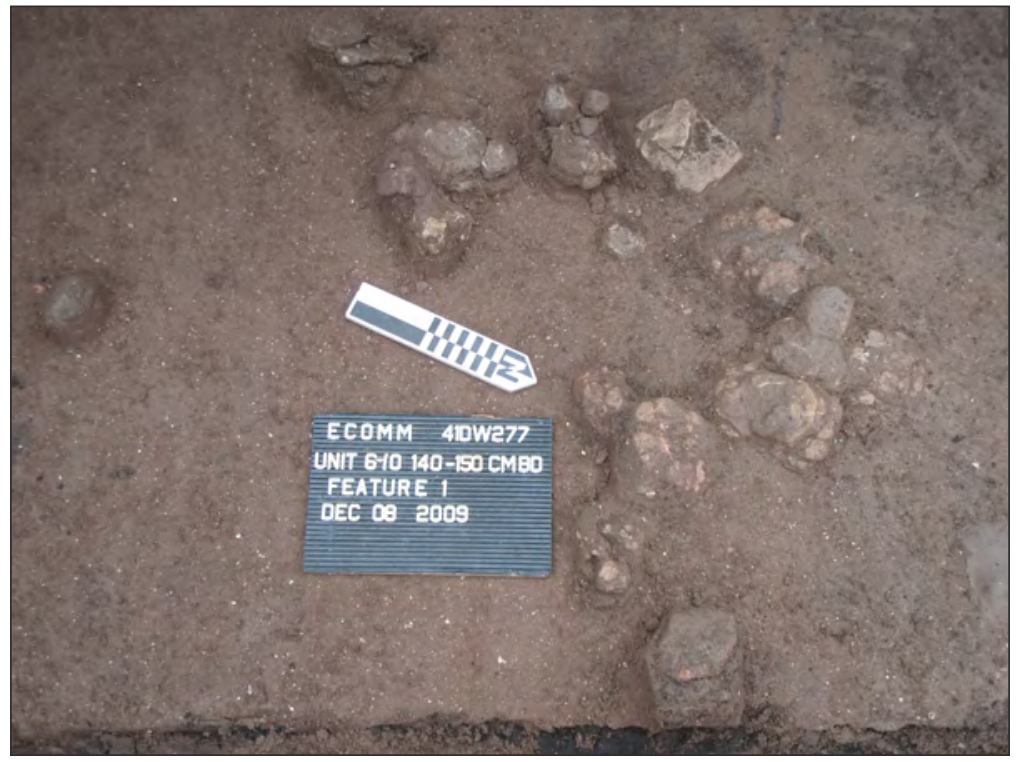

Figure 5-4. Feature 1 within TUs 6 and 10 at $140-150 \mathrm{cmbs}$. a semi-circle measuring approximately $35 \times 45 \mathrm{~cm}$ (Figure 5-4). This was interpreted to be a small hearth remnant. Investigators were able to recover two charcoal samples from within Feature 1.

Two untypable projectile points were found roughly at the same level as Feature 1, though not in direct association with the feature. The first, which superficially resembles a Pandale point, as it has a slight twist, was found in TU 7 at 140-150 cmbs. The second, which is heavily patinated, unstemmed, and with a single basal flake scar on its dorsal surface, was found in TU 24 at $150-160$ cmbs. It was found among a loose scatter of five tabular sandstone rocks that were featurelike, though ultimately not assigned a feature number. The point does not exhibit any evidence of retouching or reuse, and given its heavy patination, there was some field speculation about whether this point could represent an Early Archaic find. However, subsequent analysis and dating of this cultural zone suggests that this tool may be a curated manuport that was retouched and reused at a later date.

In GT 2, the third analytical unit was also situated within the Bw horizon at its base. The matrix is very hard and blocky with numerous fragmented snail shells and increasing calcium carbonate threads with depth. At this level, debitage, mussel shell, and snails spike again, as well as burned rock. Two features were documented at this level in TUs 6 and 10, below Feature 1. Feature 2 was located at 170-180 cmbs in TU 6, and Feature 3 was found at 170-180 
cmbs in TU 10 (Figures 5-5 and 5-6). Both features consisted primarily of medium-sized burned sandstone rocks arranged in small, loose, roughly circular clusters. Both features were only a single layer of rock deep. No diagnostic projectile points were recovered at this level, though in terms of associated artifact recovery, this zone was the most productive even in spite of the small cubic volume excavated for the AU. Investigators did, however, recover a charcoal sample from Feature 3, as well as matrix samples from Features 2 and 3.

\section{Feature Descriptions}

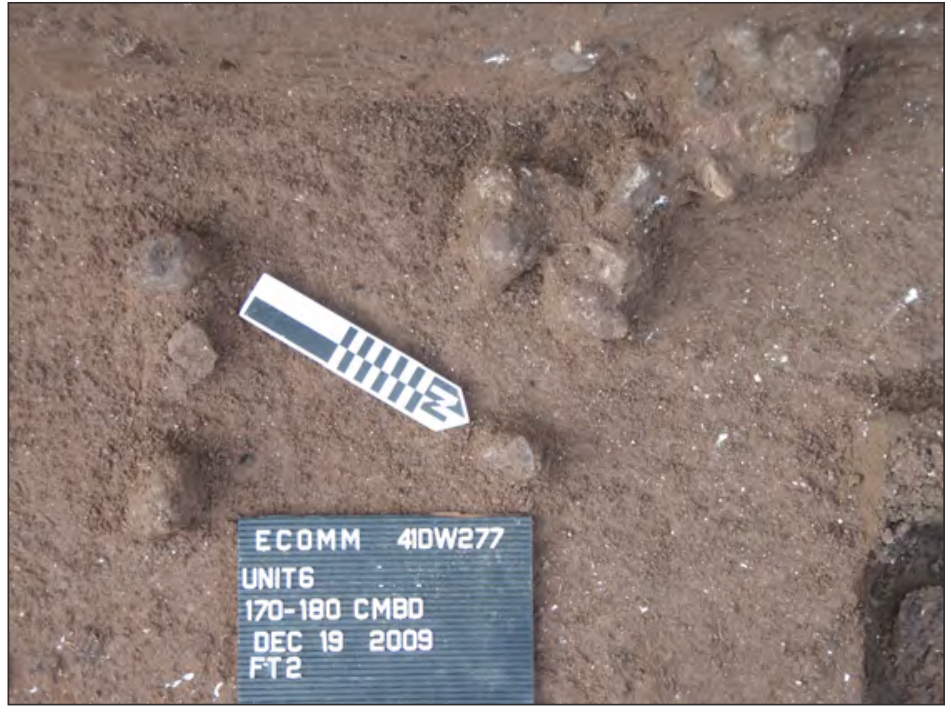

Figure 5-5. Feature 2 within TU 6, 170-180 cmbs.

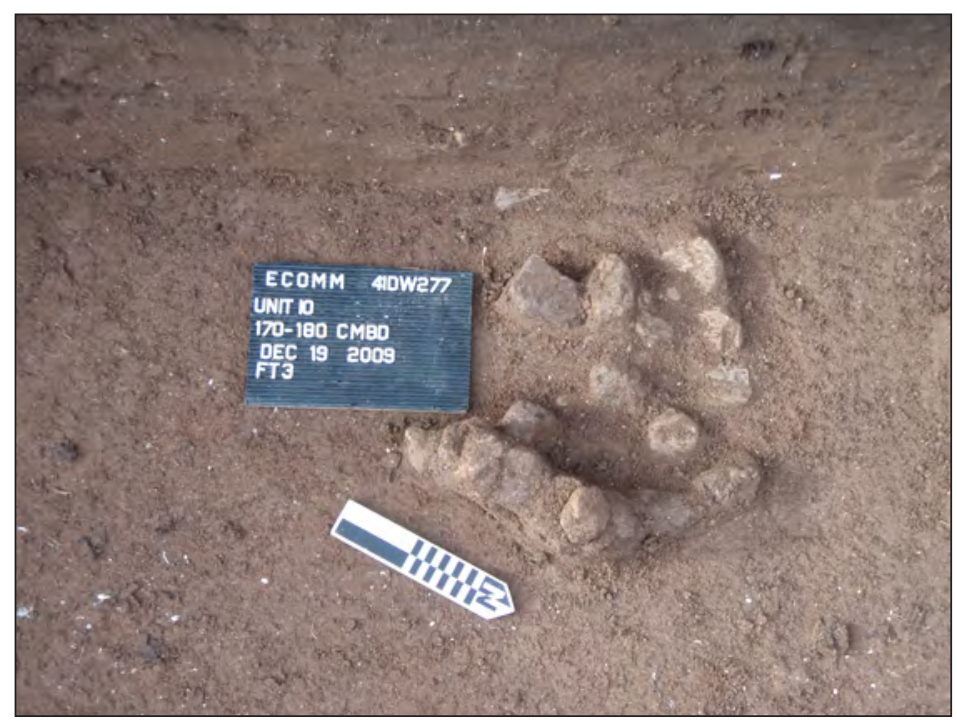

Figure 5-6. Feature 3 within TU 10, 170-180 cmbs.

\section{Feature 1}

Feature 1 was observed and excavated at $140-150$ cmbs in TUs 6 and 10, located adjacent to each other off of GT 2. The feature consisted of a group of tightly aligned burned rocks in an incomplete oval pattern in a pavement orientation (i.e. all at the same level and only one course thick). Feature rocks consisted of burned sandstone and chert of all different sizes and shapes. An abundance of snail shell was observed in and around the burned rocks. Some patchy oxidation of the soil surrounding the burned rocks was observed, but the feature was not associated with a thermal pit or basin and no charcoal lens or ash pit was observed in or near the burned rocks. When the units were fully excavated, Feature 1 was about 80 percent visible, consisting of 17 burned rocks spread across an area $35 \mathrm{~cm}$ (e-w) by $45 \mathrm{~cm}$ (n-s), and was about 10-15 cm thick. The total weight of burned rocks in the $10-\mathrm{cm}$ level containing Feature 1 was about 6,468.3 grams $(6.5 \mathrm{~kg})$. About 14 of the burned feature rocks created the semicircular shape, while the 


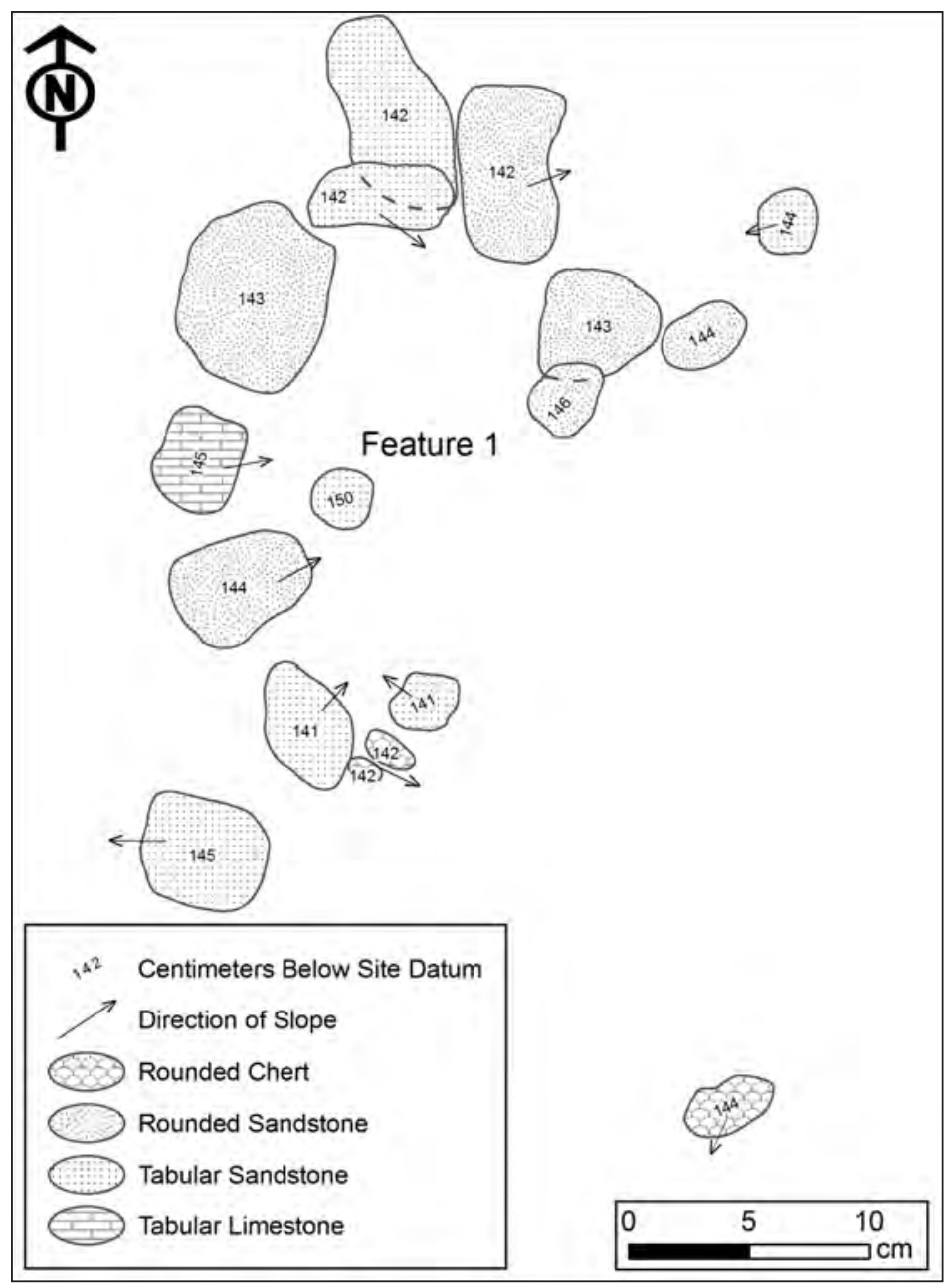

Figure 5-7. Sketch of Feature 1, 145-150 cmbs. other three were located nearby (Figure 5-7). The majority of the burned rocks were spaced slightly apart from each other, but a few touched and one rock overlaid another slightly. Eleven of the burned rocks were perfectly level or angled towards the center of the oval, and the remainder angled away from the feature. Some post-depositional processes seemed to have altered the feature components moderately, including krotovinas and some water derived erosion. The feature may have been formed from a single cooking episode rather than multiple episodes. The presence of the snail shell may give a clue as to what foods were being processed.

One core and an expedient tool were found associated with this feature. Two charcoal samples were collected from Feature 1 and these returned roughly comparable dates of $3820 \pm 30 \mathrm{BP}$ and $3840 \pm 30 \mathrm{BP}$.

\section{Feature 2}

Feature 2 was a small hearth remnant consisting of clustered, small fire-cracked rocks arranged at a uniform depth of about 173-177 cmbs (Figure 5-8). The feature was identified in TU 6 (GT 2) in the northwest corner of the unit and extended into the western wall of that same unit. Therefore, it was not fully uncovered. The exposed portion of the feature measured roughly 80 $\mathrm{cm}$ (n-s) by $50 \mathrm{~cm}$ (e-w) and was one course deep. Feature rocks consisted of sandstone (burned and unburned) and chert, and ranged in size from $2-5 \mathrm{~cm}$. Some rocks were rounded and others were tabular in shape. Several of the rocks appeared to be quite degraded, suggesting they may have been larger at one time. Feature 2 was very like Feature 1 in morphology and size (though Feature 2 consisted of smaller rocks), characterized by about 17 rocks, some tightly clustered, with a few outlying rocks. This arrangement suggests some loss of integrity to the feature. The total weight of burned rocks in the 10-cm level containing Feature 2 and the level above it was about 1,896 grams (1.9 kg). 
The level of Feature 2 corresponded to the base of the Bw horizon observed in GT 2. This soil zone consisted of compact brown (10YR 3/2) clay loam that was markedly different from the soil horizon above it. There was no observable anthropogenic modification in the form of abundant charcoal, ash, etc., to the surrounding matrix. However, both rabdotus and mussel shell spiked in this level, as did flake density. One expedient tool and one core were associated with this feature but no formal bifaces, points or other tools were recovered.

\section{Feature 3}

Feature 3 was identified at roughly the same depth as Feature 2, in an adjacent unit, TU 10 (see Figure 5-8). In terms of distance, it was separated from Feature 2 by less than $20 \mathrm{~cm}$. Feature 3 consisted of a circular arrangement of burned sandstone and chert at a depth ranging from 169-180 cmbs. Its diameter measured approximately $50 \mathrm{~cm}$. The rocks in this feature were more tightly clustered than in Feature 2 and mounded slightly to form a profile that was more than one rock deep. Tabular rocks were documented in TU 10 under the visible portion of Feature 3 at a depth of 187 and 190 cmbs. Rocks ranged in size from less than a centimeter to $5 \mathrm{~cm}$ with most of the rocks falling in the 1-3-cm range. Nonetheless, Feature 3 contained more rocks in the 3-5-cm range than Feature 2. The 19 rocks were mapped and the total weight

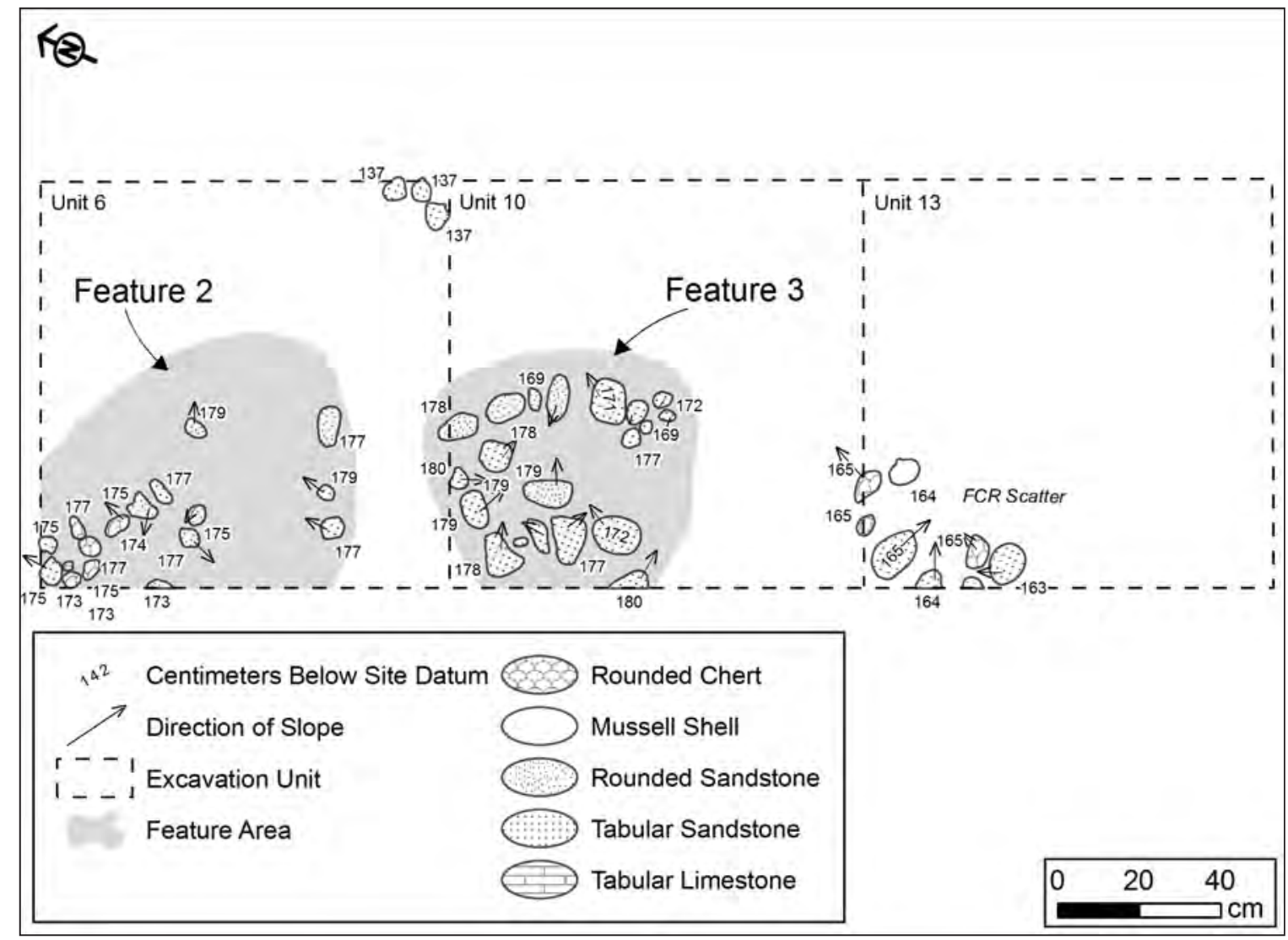

Figure 5-8. Plan drawing of Features 2 and 3. 
of burned rocks in the 10-cm level containing Feature 3 and the level above it was about 3,879 grams (3.9 kg).

Like Feature 2, there was an observable spike in snail and mussel shell density at this elevation. Debitage density was correspondingly high as well, demonstrating a prominent spike over previous and subsequent levels. Three expedient tools and two tested cobbles were associated with this feature, but no formal bifaces, points, or other tools were noted. One charcoal sample was collected from Feature 3 and it yielded a date of 5260 \pm 30 BP.

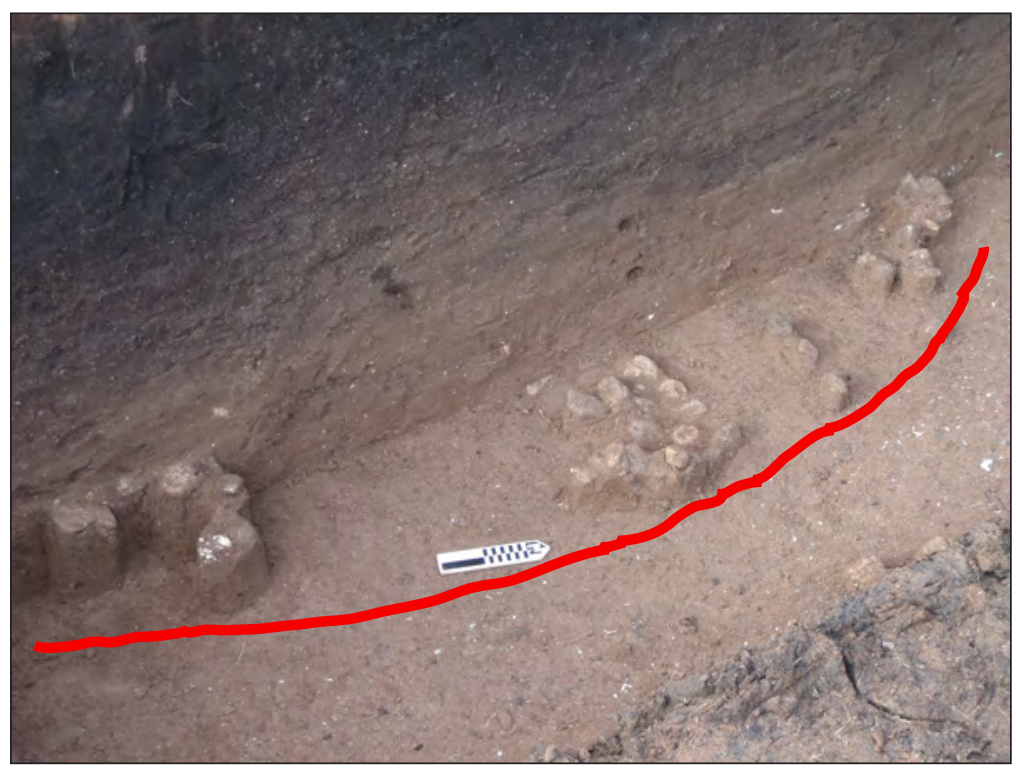

Figure 5-9. View of TUs 13, 10 and 6, showing Features 2 and 3.

\section{Features 2 and 3 Reconsidered}

A small scatter of burned rocks was also recorded in adjacent TU 13 at the same approximate level as Features 2 and 3, though this cluster was not recorded as a unique feature. This cluster consisted of a tabular sandstone and rocks arranged in a loose semicircular pattern at a depth of 164 cmbs. The distance between this cluster of rocks and Feature 3 was only about $40 \mathrm{~cm}$ (Figure 5-9).

Stratigraphically, this rock cluster occupied the same soil horizon as Features 2 and 3, and it consisted of comparably sized rocks. TU 13 at this elevation (160-180 cmbs) exhibited corresponding spikes in debitage, mussel shell, and rabdotus and burned rock (742.1 g of burned rock). Viewed on a larger scale, it seems likely that this scatter of tabular rocks was, in fact, associated with Feature 3, which was probably part of the same overall cooking hearth as Feature 2. This was probably a larger, basin-shaped hearth feature at one time. The deepest part of the feature was at the center, where tabular rocks were recorded under Feature 3 at a maximum depth of 190 cmbs. The rocks at the edges of the basin, represented by Feature 2 and the TU 13 rock cluster, were all shallower, occurring at a depth of 167-177 cmbs. Time and natural processes likely eroded its original integrity, leaving large gaps in the central portion of the feature.

Viewed as a single feature, all the rocks at this level form a roughly circular arrangement that extend into the western wall of TUs 6, 10 and 13. The total combined size of Features 2, 3, and the adjacent rock cluster is about $2.4 \mathrm{~m}$ in diameter, but only about 30 percent of the probable entirety of the feature was excavated. 


\section{SITe Summary}

\section{Site Size}

As the current investigations of Site 41DW277 were limited to the APE for the bridge replacement project over the Guadalupe River, the horizontal limits of the site have clearly not been fully defined as a result of the testing excavations. The excavated portion of the site extends only about $15 \mathrm{~m}$ (sw-ne) by $90 \mathrm{~m}$ (nw-se). Within this area, the stratigraphy of GT 4 nearest the Guadalupe River and GT 6 furthest away from the river indicates that the northwest-southeast extent had been identified for the site, which totals about $60 \mathrm{~m}$ in length. However, the southwest-northeast extent of the site is far from clear, and the cultural deposits may extend northeastward under the roadway for US 183, as well as southwestward into the agricultural field. The level topography of the field makes it a likely candidate for additional subsurface cultural deposits.

The vertical extent of Site 41DW277 within the excavated area appears to be confined to the area below $100 \mathrm{cmbs}$ and above $200 \mathrm{cmbs}$. Although no excavations took place below 200 cmbs, the drop in artifact recovery and change in stratigraphy suggests the terminus of the cultural deposits in this area.

\section{Natural Stratigraphy}

The stratigraphy at Site 41DW277 was derived from an examination of each gradall trench excavated within the site area, including GTs 1-3 examined by Jim Abbott of TxDOT during the archeological survey of the proposed US 183 bridge replacement project at the Guadalupe River; and GTs 4-6 examined by AmaTerra archeologists during the NRHP-eligibility investigations. The identification of the soil horizons and general morphology were initially made by Abbott (Bettis and Abbott 2009: Appendix I), and confirmed and refined where needed by AmaTerra archeologists.

Site 41DW277 is located on a Holocene $\mathrm{T}_{1}$ terrace sandwiched between a narrow modern floodplain ( $\mathrm{T}_{0}$ surface) at the Guadalupe River and a colluvial slope to the southeast ( $\mathrm{T}_{2}$ surface). The $\mathrm{T}_{1}$ terrace sits at about 223-227 ft above mean sea level (amsl), which is slightly higher than the opposite side of the river. Abbott (2009:3) believes this is due to lateral migration of the river rather than stream cutting and filling. The terrace within the APE is narrow, less than $50 \mathrm{~m}$, which roughly corresponds with the northwest-southeast extent of Site 41DW277. The rear of the terrace fades into the base of the colluvial slope, and the elevation rises upland to a prominent hill towards the southeast.

Flooding of the lower $\mathrm{T}_{0}$ surface appears to be common, occurring every $3-5$ years, and larger floods have been known to cover the $\mathrm{T}_{1}$ terrace as well, but much less frequently. Thus, the burial of archeological sites on the $\mathrm{T}_{1}$ terrace from flooding is possible in this area, but those on the lower surface are much more likely to be scoured by flood events (Abbott 2009:5). 
Each gradall trench excavated at Site 41DW277 is shown in Figure 5-1. As the figure shows, gradall trenches were positioned in a slightly staggered pattern parallel to US 183 and perpendicular to the Guadalupe River. GT 4 and GT 1, excavated roughly adjacent to each other, were located nearest the river, followed by GTs 2, 5, and 3. GT 6 was situated the furthest from the river near the base of the colluvial slope.

Beginning at GT 4 nearest the river, the stratigraphic profile revealed in the trench showed upper sediments of strong, blocky, dark brown clays and clay loams largely free of cultural material (Ap, AKss, and ABss horizons; 0-90 cmbs), followed by hard blocky clays containing some cultural material (Bw horizon; 90-140 cmbs). The lowest stratum was marked by very dark, hard, grayish brown clay with decreasing amounts of cultural material (Bss horizon; 140-160 cmbs). The soil profile for GT 4 is shown in Figure 5-10, and descriptions of each soil are found in Table 5-2. GT 1

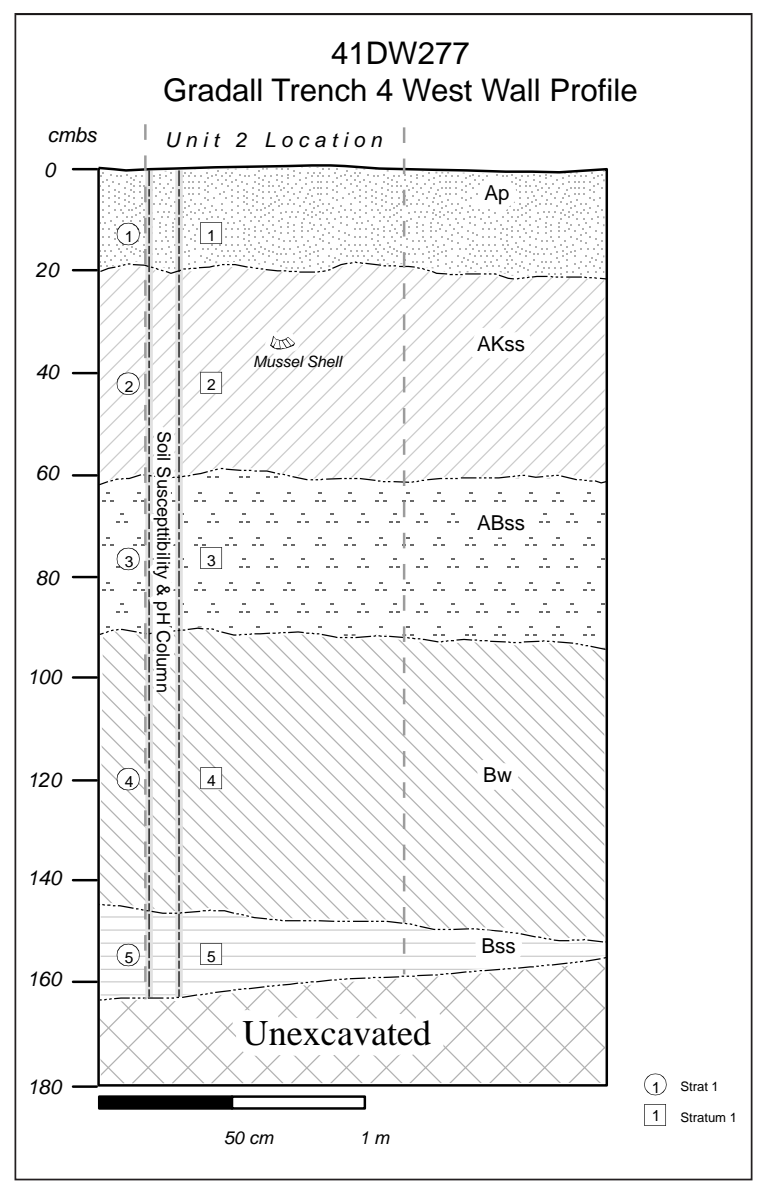

Figure 5-10. Soil profile observed in GT 4. mirrored the profile found in GT 4 with an

Table 5-2. Soil Descriptions of the Ap-AKss-ABss-Bw-Bss Soil Horizon in GT4 (derived from Abbott 2009).

\begin{tabular}{|c|c|c|}
\hline Depth & Horizon & Description \\
\hline $0-20$ & Ap & $\begin{array}{l}\text { Clay loam; moderate to strong medium angular blocky structure; hard; common grass roots; } \\
\text { strong effervescence; very dark grayish brown (10YR 3/2); clear smooth boundary. }\end{array}$ \\
\hline $20-60$ & Akss & $\begin{array}{l}\text { Clay loam; strong medium blocky structure; common pressure faces on peds; no } \\
\text { slickensides noted; hard to very hard; somewhat sticky; plastic; strong effervescence; very } \\
\text { dark gray (10YR 3/1); common to abundant carbonate filaments (mycellial carbonate) } \\
\text { concentrated on ped faces; common fine roots; smooth gradual boundary. }\end{array}$ \\
\hline $60-90$ & ABss & $\begin{array}{l}\text { Clay loam to clay; strong medium blocky structure; common pressure faces on peds; } \\
\text { occasional short slickensides; very hard; somewhat sticky; plastic; strong effervescence; } \\
\text { very dark grayish brown (10YR 3/2); few carbonate filaments concentrated on ped } \\
\text { faces; common fine roots; few mussel shells; smooth gradual boundary. }\end{array}$ \\
\hline 90-140 & Bw & $\begin{array}{l}\text { Clay; weak medium subangular to angular blocky structure; very firm; not sticky; plastic; } \\
\text { strong effervescence; faint coarse bioturbation mottles; very dark grayish brown (10YR } \\
\text { 3/2); common mussel shell clusters; common chert flakes and shatter; occasional } \\
\text { burned/thermally shattered rock; one fired clay ball noted; gradual boundary. }\end{array}$ \\
\hline 140-190 & Bss & $\begin{array}{l}\text { Clay, moderate medium angular blocky structure; moderately developed pressure faces; } \\
\text { occasional short slickensides; very firm; not sticky; slightly plastic to plastic; strong } \\
\text { effervescence; very dark grayish brown (10YR 3/2); moderate volumes of cultural material } \\
\text { (mussel shells, thermally fractured rocks; lithic debitage) decreasing in frequency with depth. }\end{array}$ \\
\hline
\end{tabular}

*Taken from Abbott (2009:13). 
Ap-AKss-ABss-Bw-Bss horizon of clay loam transitioning to clay with increased depth. Cultural material from GT 1 was abundant from the base of ABss to the top of Bss (90-160 cmbs), but no recognizable artifacts were found below $170 \mathrm{cmbs}$.

GTs 2, 5, and 3 all exhibited very similar profiles to each other, but differed slightly from GTs 1 and 4 . These were also located in the area of the site that contained the most cultural material. The four basic strata found in these trenches began with an upper zone of loose dark brown, coarse, sandy sediments (Ap horizon), followed by a sandy clay loam (A horizon). These soils are interpreted as alluvial overbank deposits from the river mixing with colluvial slopewash from higher elevations. These soils overlay harder, blockier, alluvial, brown clay loam (AB horizon). This stratum faded into a very hard, lighter brown, blocky clay (Bw horizon). This Bw horizon was only seen in GTs 2 and 3 within the excavated depths; it was not seen in GT 3 although it may still be present at greater depths. A visual example of these strata can be found in Figure 5-11, and Table 5-3 contains descriptions of each soil type. The soil horizons do not appear to be vertic, and the structural development is described as moderate. The most similar soil association to the examples found in these three trenches is the Sinton series, which are Cumulic Haplustolls (Abbott 2009:9). Cultural material spikes at the base of the A horizon and into the B horizon, which suggests that the human occupation of the area occurred during the period of "waning deposition, before the surface stabilized locally and the soil began to form in earnest" (Abbott 2009:9). The stratigraphic evidence indicates that the cultural deposits represent several discrete occupations over a long period of time.

A possible fifth horizon was observed below the Bw horizon within the hand-excavated units TUs 2, 6, and 10, all located adjacent to each other on the southwest side of GT 2. These units were dug to the greatest depth, terminating at $200 \mathrm{cmbs}$. This horizon was not seen in any of the gradall trenches, as they were not excavated to such depths. At $190 \mathrm{cmbs}$, the soil exhibited markedly increased amounts of calcium carbonate filaments, abundant mussel shell fragments were present, and the soil showed some soil mottling with a lighter yellow brown sandy clay. Some cultural material was observed in the excavation units at this depth. In all other respects, the soil appeared similar to the Bw horizon, and for the purposes of this discussion is called the Bw2 horizon. As only a small portion of this horizon was investigated, very little is known about its morphology and attributes.

The depth of the Ap-A-AB-Bw horizons varied from GT 2 southeast to GT 3, and there were several instances where the soils faded into each other over a depth of 10-15 cm. In general, though, the Ap horizon thickened with increased distance from the river; the A horizon narrowed slightly from $45 \mathrm{~cm}$ thick in GT 2 to $40 \mathrm{~cm}$ thick in GT 3, but thickened in GT 5 closer to the roadway; the $\mathrm{AB}$ horizon maintained an even thickness of about $50 \mathrm{~cm}$ throughout the soil profiles; and the Bw horizon was observed to be at least $55 \mathrm{~cm}$ in thickness before the bottom of the gradall trenches were reached. Figure 5-12 shows the change in depths for each stratum.

GT 6 was located furthest from the Guadalupe River and closest to the colluvial slope. It exhibited a significantly different soil profile than any of the other gradall trench profiles. The trench contained a thick alluvial/colluvial Ap-A soil horizon similar to the gradall trenches to the northwest (0-70 cmbs), but the culturally rich AB horizon was completely absent. Instead, 
the A horizon sat atop a reddish brown, blocky clay loam containing abundant calcium carbonate strings, which were noticeably absent or minimal in other trenches. The $\mathrm{A} / \mathrm{Bk}$ transition zone extended from 70-95 cmbs, followed by the $\mathrm{Bk}$ horizon from $95 \mathrm{cmbs}$ to the bottom of the trench at $160 \mathrm{cmbs}$. This soil contained almost no cultural material.

\section{Radiocarbon Dating Results}

Nine samples from Site 41DW277 were submitted to Beta Analytic, Inc., for radiocarbon assay; five were derived from charcoal remains collected during the hand excavations, and four were portions of bulk soil samples collected from different depths within the excavation units (Appendix A; Table 5-4). The research strategy utilized in the selection of these samples from the pool of collected charcoal and soil samples was intended to accurately date each analytical unit (and thus the periods of occupation) defined during the excavations. Dating the features found at the site was seen as a priority in this effort,

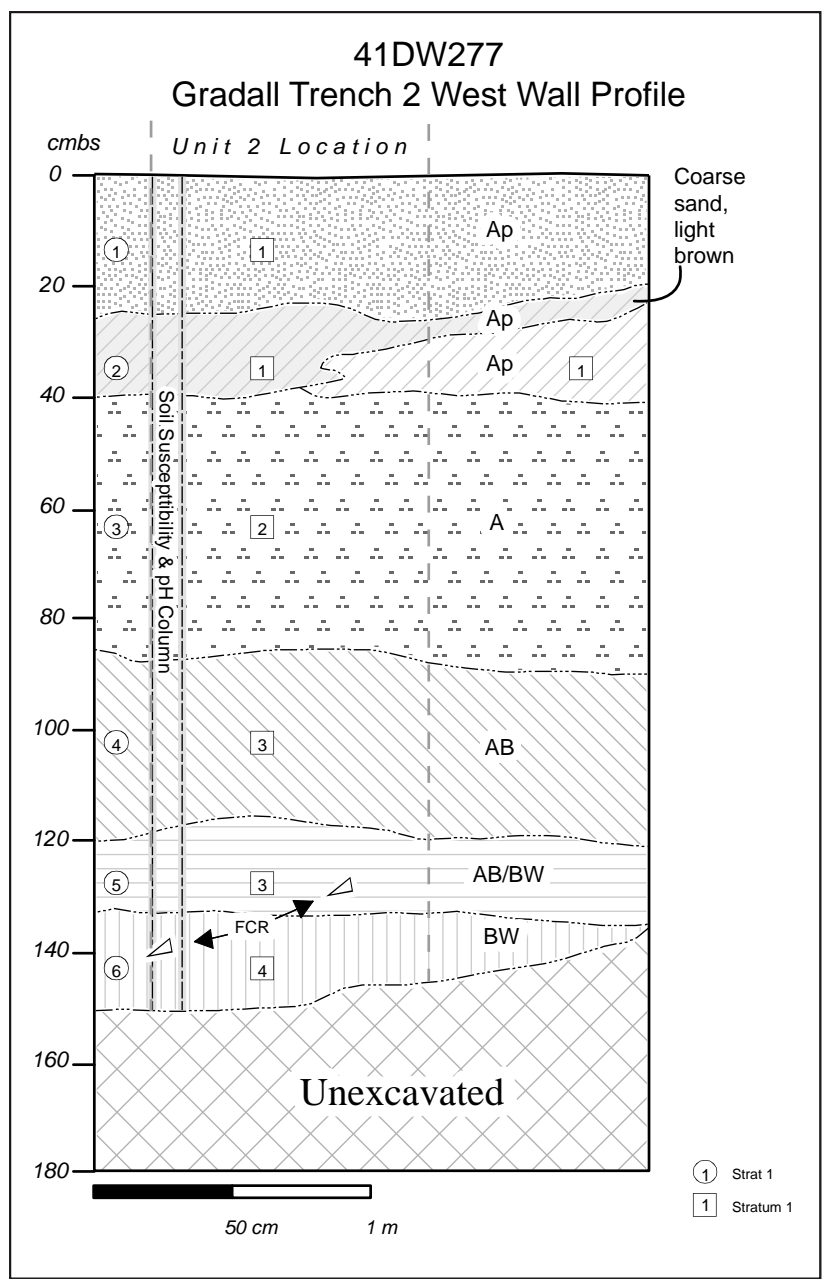

Figure 5-11. Soil profile observed in GT 2.

Table 5-3. Soil Descriptions of the Ap-A-AB-Bw Soil Horizon (derived from Abbott 2009).

\begin{tabular}{|c|c|c|}
\hline $\begin{array}{l}\text { Depth } \\
\text { (cmbs) }\end{array}$ & Horizon & Description \\
\hline $0-30$ & Ap & $\begin{array}{l}\text { Sandy loam; massive; soft to slightly hard; strong effervescence; common faint mottles; dark } \\
\text { yellowish brown (10YR 4/4); common reworked carbonate fragments and crushed mussel } \\
\text { shell; few fine roots; very dark brown (10YR 3/3); clear to abrupt broken boundary. }\end{array}$ \\
\hline $30-85$ & Ap & $\begin{array}{l}\text { Sandy clay loam; weak fine to medium blocky structure; slightly hard to hard; strong } \\
\text { effervescence; slightly hard to hard; black (10YR } 2 / 1) \text {; fragments of shell has and lithic } \\
\text { debris below approximately } 60 \mathrm{cmbs} \text {; few fine roots; smooth gradual contact. }\end{array}$ \\
\hline 85-135 & $A B$ & $\begin{array}{l}\text { Clay loam; weak fine to medium subangular blocky; very hard; very dark gray } \\
\text { (10YR 3/1) to very dark grayish brown (10YR 3/2); strong effervescence; } \\
\text { abundant distinct to prominent dark mottles; abundant cultural material (lithic } \\
\text { debitage, thermally-fractured rock, mussel shell); gradual boundary. }\end{array}$ \\
\hline $135-180$ & BW & $\begin{array}{l}\text { Clay; massive; very hard; not sticky; slightly plastic; strong effervescence; few faint brown } \\
\text { and black bioturbation mottles; very dark grayish brown (10YR 3/2); abundant snail } \\
\text { shells and snail shell hash distributed throughout the horizon; no evidence of dissolution/ } \\
\text { reprecipitation; occasional thermally shattered rock fragments between } 135 \text { and } 160 \mathrm{cmbs} \text {. }\end{array}$ \\
\hline
\end{tabular}

*Taken from Abbott (2009:13). 


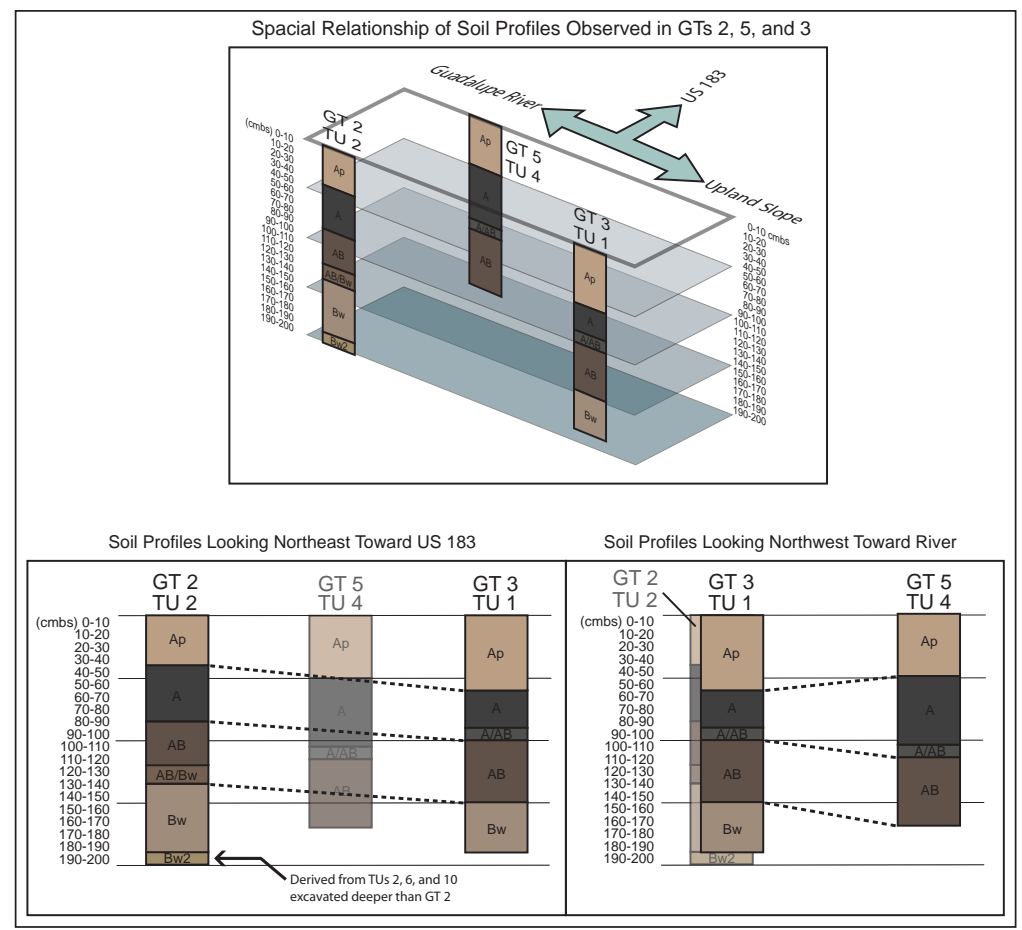

Figure 5-12. Spatial relationship of the soil profiles observed in GTs 2, 5, and 3 and changes in depths of the Ap-A-AB-Bw horizons. particularly as no temporally diagnostic tools were found at the same levels. As such, all of the charcoal samples from feature contexts were selected for radiocarbon dating, including two from Feature 1 and one from Feature 3 (no samples were found at Feature 2).

The other samples were selected from areas of the site close to, but outside of, the feature zones. The goal of this sampling selection was to attempt to date the soil horizons slightly above, parallel with, and below the level at which the bulk of the cultural material and features were located. These nonfeature samples would then be compared to the featurebased samples to see if there are similarities. Three soil samples were taken from TU 13, located adjacent to the units where the features were recorded, and one soil sample was obtained from TU 6 at the very bottom if the excavation unit, below Feature 2. A charcoal sample was taken from TU 4, some distance away from the feature locations but within an area of high artifact concentrations, and the final charcoal sample was selected from TU 25 just below a loose cluster of sandstone rocks that was probably a feature remnant.

Table 5-4. Radiocarbon Samples Sent for Analysis.

\begin{tabular}{cccccccccc}
\hline Lot & Horizon & AU & Unit & Level & $\begin{array}{c}\text { Depth } \\
\text { (cmbs) }\end{array}$ & Type & Feature & AMS Date & $\begin{array}{c}\text { Beta Analytic } \\
\text { Lab Number }\end{array}$ \\
\hline 77 & AB & 1 & 4 & 12 & $110-120$ & charcoal & n/a & $3750+/-30$ BP & Beta-302688 \\
220 & AB & 1 & 25 & 3 & $120-130$ & charcoal & n/a & $2590+/-30$ BP & Beta-302687 \\
158 & AB/Bw & 1 & 13 & 3 & $130-140$ & soil & n/a & $3020+/-30$ BP & Beta-302695 \\
128 & Bw & 2 & 10 & 4 & $140-150$ & charcoal & Feature 1 & $3820+/ 30$ BP & Beta-302690 \\
134 & Bw & 2 & 10 & 5 & $150-155$ & charcoal & Feature 1 & $3840+/-30$ BP & Beta-302686 \\
145 & Bw & 2 & 13 & 4 & $140-150$ & soil & n/a & $3460+/-30$ BP & Beta-302696 \\
216 & Bw & 3 & 10 & 7 & $170-180$ & charcoal & Feature 3 & $5260+/-30$ BP & Beta-302691 \\
218 & Bw & 3 & 13 & 7 & $170-180$ & soil & n/a & $5030+/-40$ BP & Beta-302694 \\
234 & Bw2 & Below 3 & 6 & 18 & $190-200$ & soil & n/a & $4720+/-40$ BP & Beta-302693 \\
\hline
\end{tabular}


The radiocarbon dating of the features indicates at least two distinct periods of occupation at Site 41DW277, separated by about 1,400 years. The Feature 1 samples returned dates of $3820 \pm 30$ years BP and 3840 \pm 30 years BP, and the Feature 3 appears to have been used about $5260 \pm 30$ years BP. Feature 2, being at the same level as Feature 3, is also likely to date to this earlier time. The three samples from TU 13, adjacent to the feature areas, also returned very satisfying and consistent dates. The level above Feature 1 in the $\mathrm{AB} / \mathrm{Bw}$ horizon returned a date of $3020 \pm 30$ years BP, the level at Feature 1 was $3460 \pm 30$ years BP, and the level at Features 2 and 3 returned a date of $5030 \pm 40$ years BP.

The timeline mapped by the radiocarbon dates above is supported by one of the three remaining samples from a location about $4 \mathrm{~m}$ away from this cluster. The sample from TU 25 below the rock cluster, at the bottom of the $\mathrm{AB}$ horizon retuned a date of $2590 \pm 30$ years $\mathrm{BP}$. The next sample date below it in the AB/Bw horizon is $3020 \pm 30$ years BP (from TU 13), which is about 430 years older.

However, the last two dates from the radiocarbon samples do not fit so neatly into the linear timeline indicated by the samples above (Figure 5-13). The most notable non-conforming result comes from the soil sample from TU 6 at the very bottom of the level (190-200 cmbs; the Bw2 horizon) below Feature 2. This sample retuned a date of $4720 \pm 40$ years BP, about 300-500 years younger then the samples above it. As a bulk matrix sample, this could be the result of a contamination error.

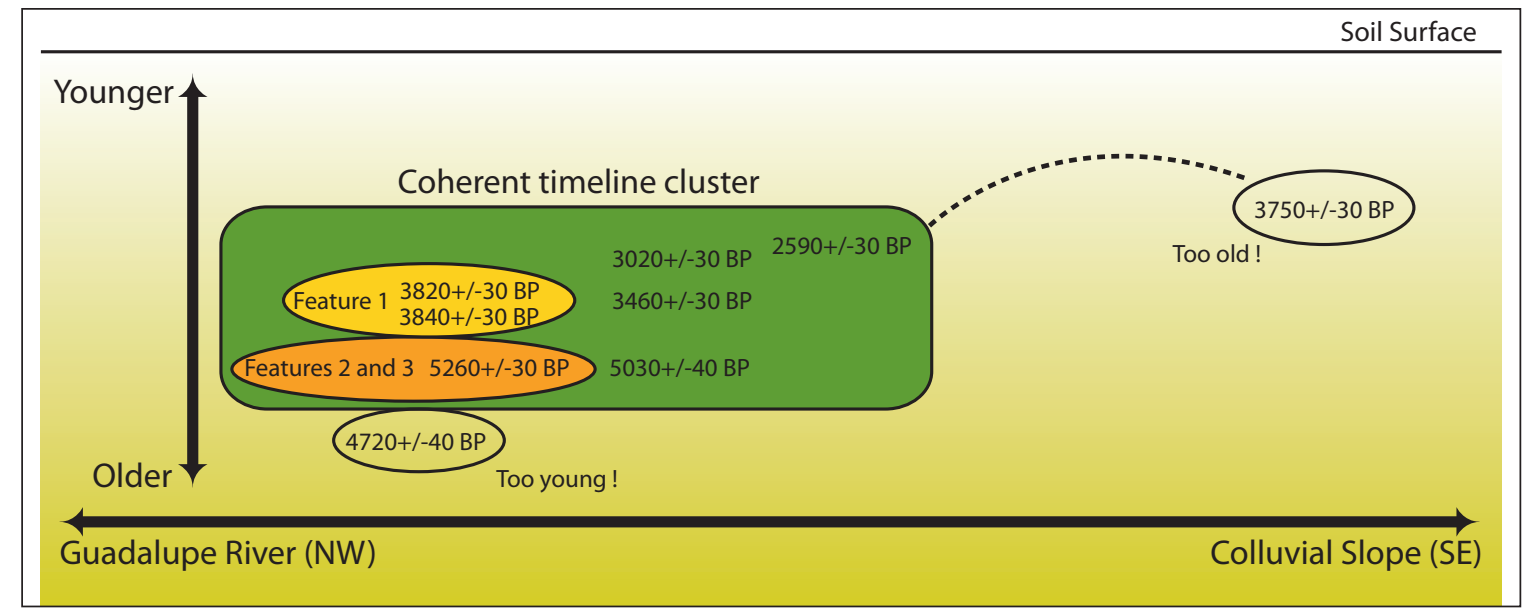

Figure 5-13. Diagram of spacial-temporal relationships between radiocarbon dates at Site 41DW277.

One other nonconformity also presents a challenge. The charcoal sample taken from the top of the AB horizon in TU 4 resulted in a date of $3750 \pm 30$ years BP, about 1,160 years older than the next sample below it at the bottom of the AB horizon. Again, there is no traceable contamination error in this sample as well. However, all charcoal samples recovered from Site 41DW277 were very small, and it is possible the small sample size resulted in dating error. While these non-conformities do exist, the bulk of the dates appear to fall within a 
linear stratigraphic sequence relative to each of the defined AUs; and we have chosen to base chronometric associations for AUs 1-3 on those consistent dates.

\section{Summary of Observed Cultural Material}

The artifact recovery at Site 41DW277 was not as robust as initially expected. Organic remains such as bone were extremely sparse, and human-made stone tools (both formal and informal tools) were present but not in great numbers. Interestingly, no Morhiss points, typically considered a hallmark of Archaic sites in this region, were located at the site. The bulk of the observed cultural material was firecracked rocks, lithic flakes and debitage, mussel remains, and snail shell (Table 5-5). Complete descriptions of the recovered artifacts are presented in Chapter 6, but a summary of all of the observed artifacts (as some were not collected) is presented here.

Overall, archeologists recorded 1,045 pieces (52.688 kg) of burned or fire-cracked rocks from the hand excavation units, which were sorted by rock type, size, and weight, and were then discarded. The burned rock observed and recorded consisted of burned sandstone (92.3 percent), chert (7.4 percent), and ironstone (0.3 percent). As with much of the cultural material found at the site, very minimal amounts were found in the upper meter of soil. However, burned rock increased significantly below $1 \mathrm{~m}$, and the amounts (by weight) spiked at 100-110 cmbs, 140-150 cmbs (at the depth of Feature 1), and 170-180 cmbs (at the depth of Features 2 and 3) (Figure 5-14). As a small hearth cluster of burned sandstone was recorded in GT 3 at $100 \mathrm{cmbs}$ by Bettis and Abbott (2009:10) during the survey investigations, it is possible that they found the loci of a burned rock feature at that level and the (a)
Table 5-5. Total Artifact

Counts Observed at Site 41DW277.

\begin{tabular}{cc}
\hline Type & Number \\
\hline FCR & 1045 \\
Modified Flakes & 56 \\
Bifaces & 27 \\
Cores & 38 \\
Tested Cobbles & 6 \\
Groundstone & 6 \\
Projectile Points & 4 \\
Hammerstones & 2 \\
Flakes and Shatter & 2686 \\
Mussel Shell & 1513 \\
Snail Shell & 1328 \\
Bone & 9 \\
Charcoal Samples & 13 \\
\hline Observed by TxDOT \\
\hline FCR & 14 \\
Flakes and Shatter & 9 \\
Bifaces & 5 \\
Cores & 2 \\
\hline
\end{tabular}


remaining burned rocks found at that depth during the test excavations were associated, but peripheral, scattered material. The size of the observed burned rocks was also recorded, with no specimens larger than $22.9 \mathrm{~cm}$ in diameter. The breakdown consisted of 11.9 percent of 17.8-22.9 cm in diameter, 12.5 percent of $12.7-17.8 \mathrm{~cm}$ in diameter, 39.6 percent of 7.6-12.7 $\mathrm{cm}$ in diameter, 28.6 percent $2.5-7.6 \mathrm{~cm}$ in diameter, and 7.4 percent of less than $2.5 \mathrm{~cm}$ in diameter. The burned rocks associated with features will be described in more detail during the discussion of the analytical units below.

The hand excavation of $26.15 \mathrm{~m}^{3}$ of soil recovered 2,823 individual chipped stone artifacts. All but one of the artifacts were recovered from the hand excavation units or known proveniences in the wall of the gradall trenches; however, one biface was recovered from the bottom of GT 5, which fell from an unknown elevation, that was observed to be a possible knife blade. This was collected as well. The artifact recovery rate remained minimal until about $70-80 \mathrm{cmbs}$ where the number of chipped stone artifacts recovered increased slightly. The artifact counts increased throughout the remainder of the excavation process, with a small increase between 130-150 cmbs and a sharp increase at 170-180 cmbs (Figure 5-15). Of the chipped stone artifacts recovered from the upper meter, the flaking material and shatter was cataloged but not analyzed in detail ( $\mathrm{n}=237)$, as these lacked clear contextual integrity and the researchers decided to focus more on the lower meter of excavations. One biface and one core fragment were also recovered from the upper meter, and these were included in the more detailed analysis of the stone artifacts. Thus, the number of chipped stone artifacts recovered from the upper meter totaled 240 specimens. All of the lithic artifacts found $1-2 \mathrm{~m}$ in depth $(n=2,583)$, the tools from the upper meter $(n=2)$, and the biface from GT $5(n=1)$ were analyzed in more detail. The breakdown of lithic artifacts from the 1-2 m depth includes 56 expedient flake tools, 25 whole or fragmented bifaces, 37 whole or fragmented cores, 5 tested cobbles, 6 pieces of groundstone, 3 projectile points, 2 hammerstones, 901 whole flakes, 767 incomplete flakes, and 781 pieces of unclassifiable debitage. The Clear Fork gouges and the broken, untypable projectile points recovered from the site were classified by morphology, thus they were included in the biface category or the expedient tool types. For more information on the collected chipped stone artifacts see Chapter 6 . A comparative analysis of the chipped stone artifacts from the $1-2 \mathrm{~m}$ range is presented in Chapter 7.

In addition to the artifacts listed above, $\quad 1,513$ freshwater mussel remains and 1,328 snail shells were collected. All of the collected mussel remains were sent for a more detailed analysis conducted by Robert

\section{Ratio of Stone Artifacts (\#) per $1 \mathrm{~m}^{3}$ Within Each Level (cmbs)}

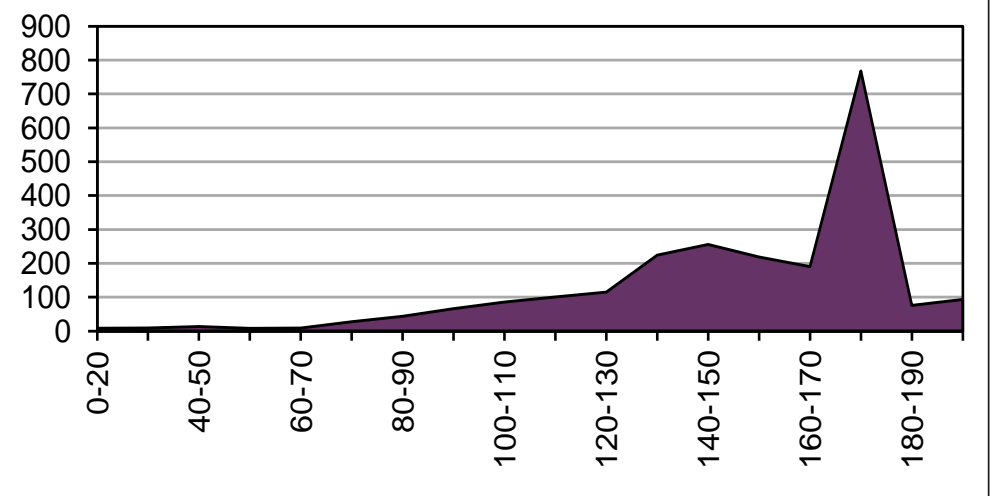

Figure 5-15. Graph of recovered stone artifacts in the hand excavation units. Ratios are based on actual excavated volume $\left(\mathrm{m}^{3}\right)$ per level. 
Howells, and the results are presented in Appendix C. Howells study identified 427 of the shell fragments to species and found nine mussel species and two other taxa represented in the assemblage. These various species are all common to the Guadalupe River drainage area and most have been documented at other nearby sites (such as Site 41DW270). Overall the species collected and discarded at Site 41DW277 were among those that grow to relatively small size. Most of the mussel shell species identified at Site 41DW277 occurred throughout the soil column from 100-200 cmbs. The most numerous species occurring at Site 41DW277 were threeridge (Amblema plicata), Tampico pearlymussel (Cyrtonaias tampicoensis), washboard, and unidentified quadrulid fragments (most probably southern mapleleaf or golden orb, but possibly pistolgrip or Texas pimpleback $Q$. petrina). These occurred regularly between 100-200 cmbs. However, a few species occurred only in certain levels. This was the case with Golden Orb Louisiana fatmucket (Lampsilis hydiana), yellow sandshell (L. teres), an unidentified lampsiliid (either Louisiana fatmucket or yellow sandshell), southern mapleleaf (Quadrula apiculata), golden orb ( $Q$. aurea), false spike ( $Q$. mitchelli), and pistolgrip ( $Q$. verrucosa). The southern mapleleaf, the unidentified lampsiliid, and the Louisiana fatmucket occurred only in the lowest levels of the site, while the yellow sandshell, golden orb, false spike, and pistolgrip occurred only in the upper levels of the site. A total of twelve specimens were burned and none of them show any other signs of additional manipulation.

The snail shell was analyzed by AmaTerra staff for signs of burning, but none could be observed on any of the samples. A graph of the mussel remains shows two spikes in the number of specimens recovered, one reaching its height at 110-120 cmbs and the other at 170-180 cmbs (Figure 5-16). The graph of the snail shell shows only one spike in number of specimens recovered at 160-170 cmbs (Figure 5-17). Both graphs show a minimal recovery rate for both types of shell in the upper meter.

\section{Additional Tests}

Two field tests of the soil within Site 41DW277 were conducted, and the results were tabulated and returned to the AmaTerra laboratory for processing and analysis. Soil $\mathrm{pH}$ and magnetic susceptibility readings were obtained from each gradall trench in a vertical column from top to bottom in $5 \mathrm{~cm}$ intervals immediately after the trench was excavated. Soil probes were inserted into the matrix at these intervals and the readings were recorded on the appropriate

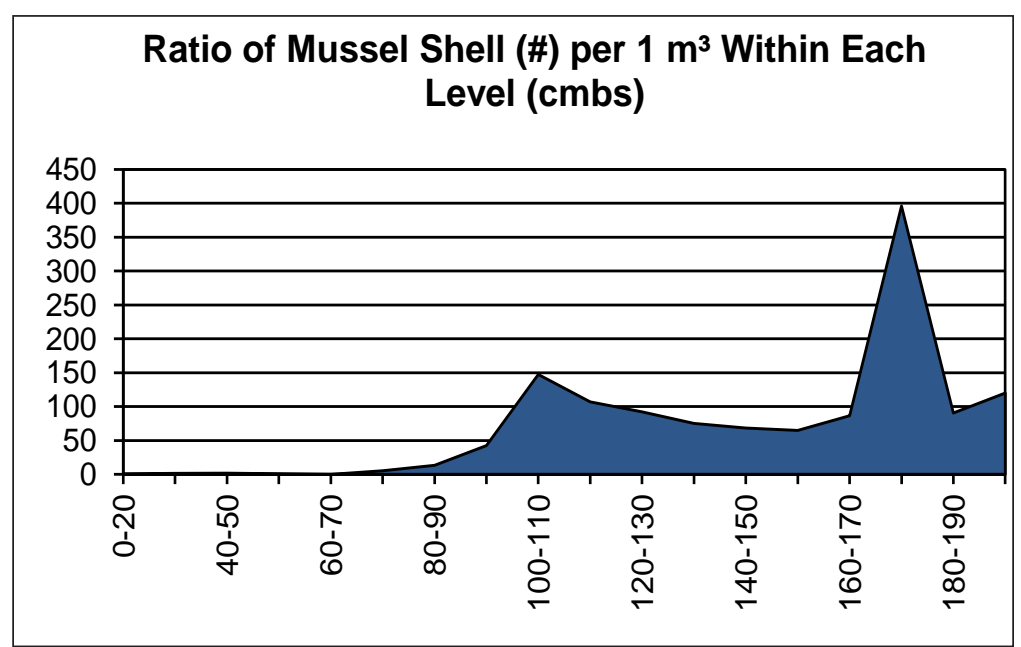

Figure 5-16. Graph of recovered mussel remains in the hand excavation units. Ratios are based on actual excavated volume $\left(\mathrm{m}^{3}\right)$ per level. 


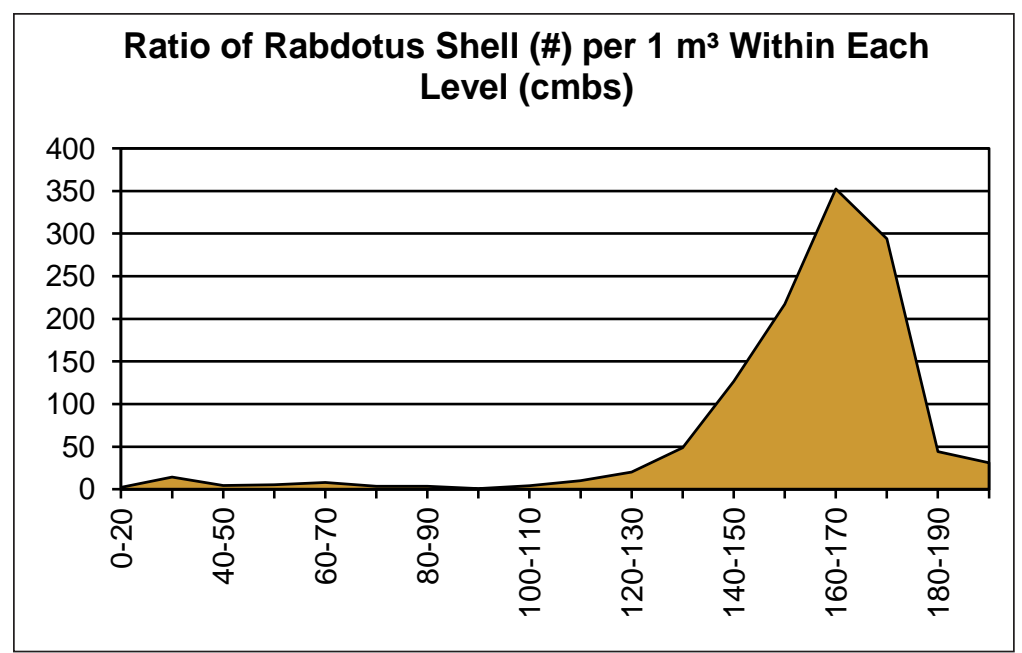

Figure 5-17. Graph of recovered snail shells in the hand excavation units. Ratios are based on actual excavated volume $\left(\mathrm{m}^{3}\right)$ per level. forms. The data was then analyzed and compared with the information obtained from the observed cultural material.

\section{(pH) Readings}

Soil acidity comes from increased hydrogen $(\mathrm{H})$ and aluminum (Al) ions contained in the soil solution (Al reacts with water to release even more $\mathrm{H}$ ions into the soil), and alkaline soil solutions contain large amounts of base cations: potassium (K), calcium (Ca), magnesium (Mg), sodium (Na), and carbonates (Brady and Weil 2002; Sparks 2003). Numerous factors are involved in the determination of $\mathrm{pH}$ in any particular soil sample, including rainfall, fertilizer (either manmade or naturally occurring decomposing organic matter), plant root activity, weathering of minerals, depth of the soil sample, and the initial chemical composition of the soil when formed. It has been demonstrated that acidic soils have an adverse effect on the phosphates and calcium that largely comprise bone and shell, and low $\mathrm{pH}$ soils rarely contain un-compromised faunal remains (Gordon and Buikstra 1981; Watson 1967). Although soil acidity is not the only cause of bone degradation in soil, it is a known and quantifiable factor, and can be easily tested with a simple $\mathrm{pH}$ reader in typical field conditions.

Analysis if the resulting data showed wild variations in the pH values in GT 3 and GT 6, which showed an elevated $\mathrm{pH}$ value in the upper $40 \mathrm{cmbs}$ and a significant drop in $\mathrm{pH}$ (increased acidity) below $110 \mathrm{cmbs}$, respectively. The remaining trenches appeared to have a relatively level $\mathrm{pH}$ between 7.0 and 8.0, which is slightly alkaline (Figure 5-18). Thus, with the exception of the area around GT 6, the shell and bone remains associated with the occupation surfaces within the excavated area of Site 41DW277 have not been adversely affected by highly acidic soils.

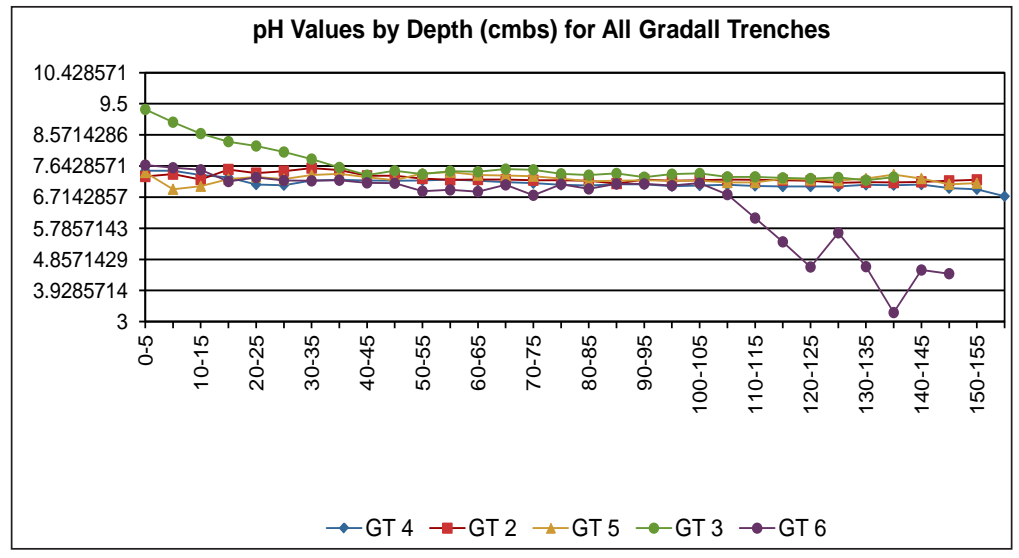

Figure 5-18. Graph of the mean $\mathrm{pH}$ values for GTs 2, 5, and 3 by elevation. 


\section{Soil Susceptibility Readings}

Soils acquire a magnetic charge from the Earth's ambient magnetic field. Changes to this magnetic field as represented in the soil can be altered by both soil formation processes and culturally derived activities. The initial research into this area indicates that wood ash and charcoal add magnetic minerals to the existing soil, and multiple heating events increase the magnetism of these minerals. They can be discernible through an analysis of soil susceptibility readings in a vertical soil profile (Collins et al. 1994; Gose and Nickels 1998; Heller and Evans 1995). Ideally, the peaks in magnetic susceptibility of the soil should coincide with the areas in which high frequencies of cultural material were located, and may indicate locations of highheat or prolonged-duration cooking activities.

Interpretation of the susceptibility readings taken at Site 41DW277 were focused on those from GTs 2, 3, and 5, which was the location of the most observable occupation surfaces. The data was largely inconclusive. The most pronounced spike occurs around the $75 \mathrm{cmbs}$ level, well above the artifact bearing zones. Smaller spikes are observable at various points along the combined soil column, but generally there is no one zone that stands out with respect to spikes in soil susceptibility (Figure 5-19).

The soil susceptibility readings were then compared to the distribution of $3 / 4$ - and 1 -inch sized flakes by level within GTs 2, 3 and 5. The mean count of flakes within the analytical units were tallied and plotted. Figure 5-20 shows distribution of flakes from the analytical units at a depth from 1-2 m below the surface. A general trend can be seen within the distribution of flakes. Flake counts peaked at a depth of 140-150 cmbs and 170-180 cmbs, nowhere near the peaks for magnetic

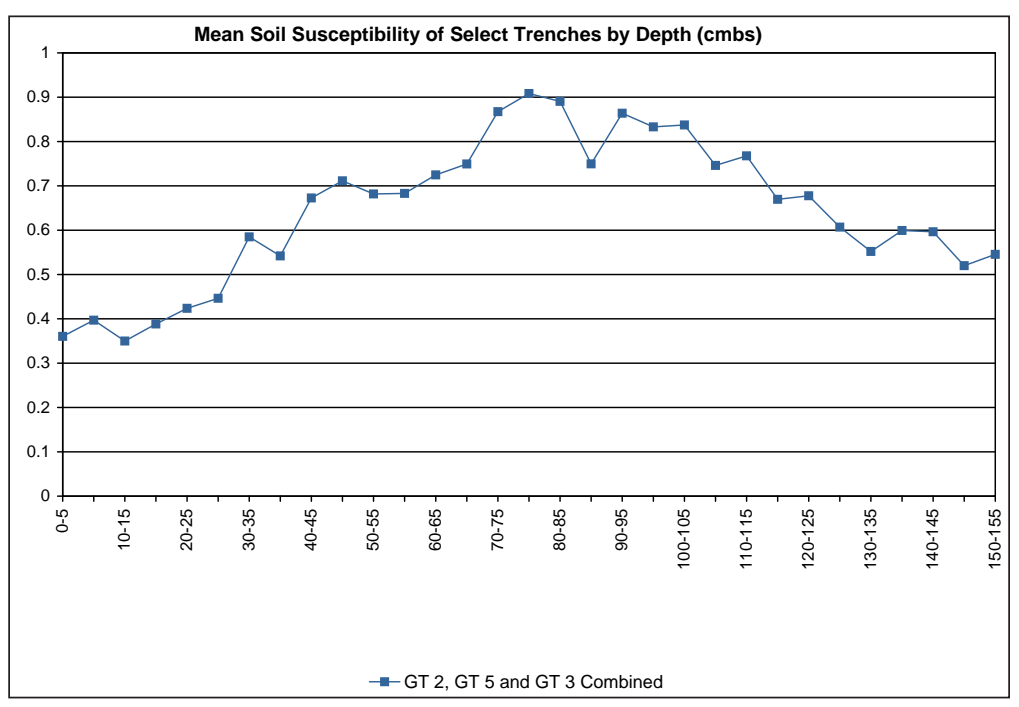

Figure 5-19. Graph of mean soil susceptibility readings for GTs 2, 3, and 5 by elevation. susceptibility. Overall, the soil susceptibility readings do not exactly contradict flake and other artifact data, but data does little to enhance the other site elements analyzed. Therefore, we conclude that for this site, soil susceptibility readings were not a particularly productive line of analysis. 


\section{Mean Flake Count by Depth (cmbs)}

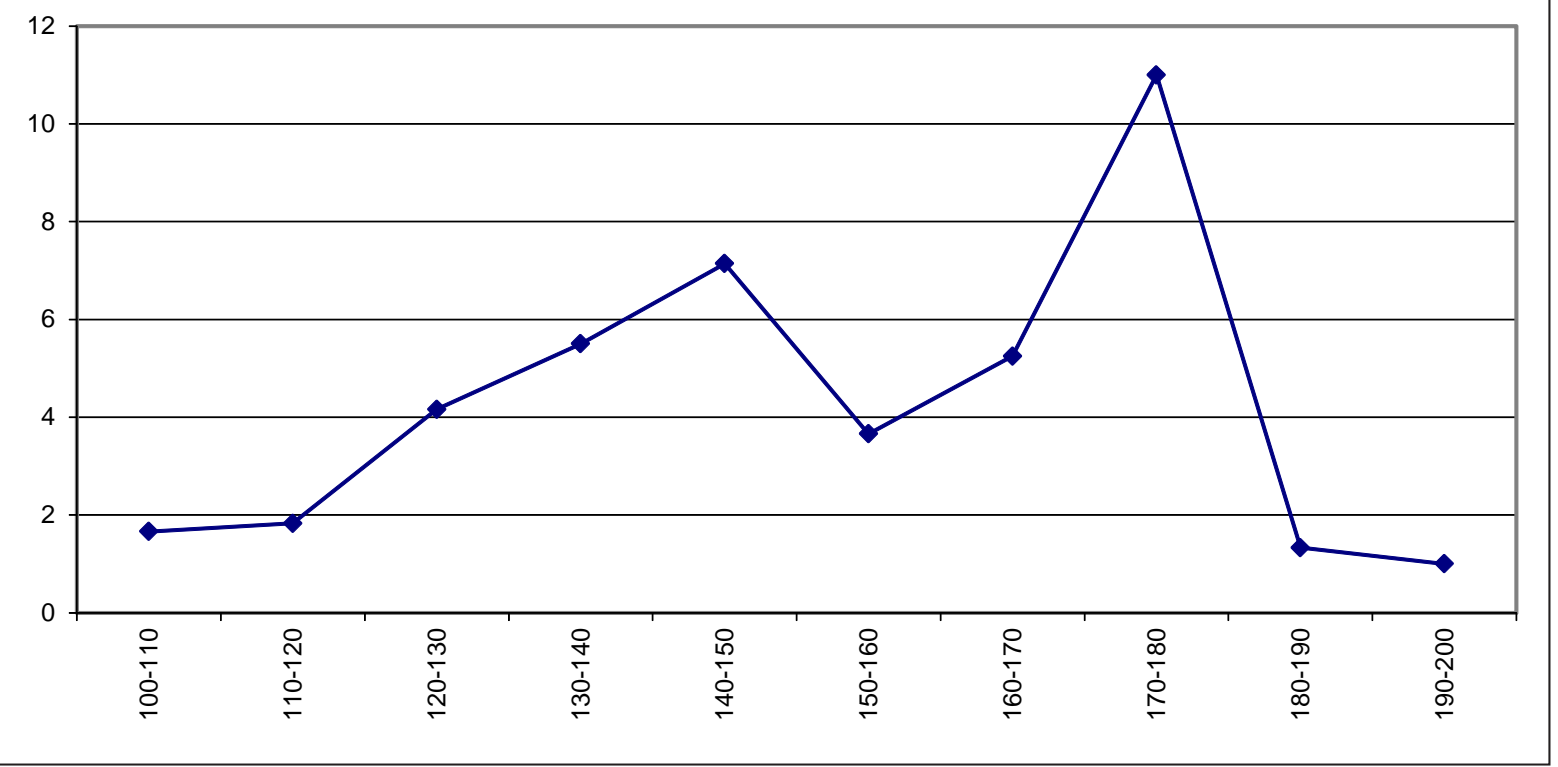

Figure 5-20. Graph of mean flake distribution.

\section{Cultural Components as Defined in Analytical Units}

During the field excavation of Site 41DW277, it became clear that the site was inhabited by prehistoric peoples at different points over a long period of time (i.e. thousands of years), and each time the site was occupied, they left traces of their presence on the ground in the form of cultural debris and features. In between these periods of habitation, soil deposits had a chance to form over occupation surfaces. Post-depositional processes, of course, altered the stratigraphy of these layers, but it appears that in large part Site 41DW277 remained somewhat stable. As such, the stratigraphic layers revealed by the site excavation were able to be analyzed and divided into analytical units, representing different periods of occupation in prehistoric times. Actual occupation surfaces were almost impossible to define given the level of preservation, so the analytical units were limited to broader time periods perhaps representing more than one habitation event.

Soil stratigraphy was the principal means by which the analytical units were defined, but radiocarbon dates, diagnostic artifacts, feature locations, and the quantities of artifacts found within certain layers were also used to further refine them. The soil susceptibility readings were also analyzed, but the results were not as conclusive as other avenues of research.

In the field, the three identified analytical units were most clearly observed in GT 2, and the interpretation of this information was the way in which the analytical units were initially defined. The uppermost analytical unit, AU 1, was seen from 100-130 cmbs, the middle analytical unit, AU 2, was observed from 140-150 cmbs, and the lowest analytical unit, AU 
3, was documented at 170-190 cmbs. Just above AU 1, the soil changed from an A (or A/ $\mathrm{AB}$ ) horizon to an $\mathrm{AB}$ horizon, and that analytical unit was marked by an increase in artifact recovery. Between AU 1 and AU 2, the soil transitioned from an AB horizon to a Bw horizon. AU 2 was marked by increased artifact recovery and the presence of Feature 1. There was no obvious change in soil morphology between AU 2 and AU 3, but Features 2 and 3 were revealed directly below Feature 1, and this was interpreted to be a separate analytical unit, AU 3. The greatest concentration of artifacts was seen at this level. In the test units excavated below $180 \mathrm{cmbs}$, the number of artifacts recovered dropped off significantly, and the investigators concluded the bottom of AU 3 had been reached.

During the subsequent analysis of the data from the site, the analytical units were refined and expanded a bit more. AU 1 was defined as beginning at $100 \mathrm{cmbs}$ across the site, but the bottom of the analytical unit was altered to follow the transition line between the AB horizon and the Bw horizon. Thus, in GT 2 the analytical unit terminated at 130-140 cmbs, and GT 3 saw the analytical unit terminate at $150 \mathrm{cmbs}$. As the bottom of the AB horizon was not reached in GT 5, the bottom of AU 1 was defined by a significant drop in artifact recovery below 160 cmbs. Thus, AU 1 as seen in GT 5 extended from 100-160 cmbs (Figures 5-21 and 5-22). As the stratigraphy observed in GTs 4 and 6 at the edges of the site were so different than the stratigraphy seen in the center, and they did not contain any information that could be directly tied to any particular analytical unit, there were no analytical units assigned to either the trenches or their associated hand excavation units.

The Bw horizon that contained the evidence of AUs 2 and 3 was only observed in GTs 2 and 3. At first, these two analytical units were narrowly defined by the depth and location of the features and associated artifacts. However, the review of the artifact recovery of the $10 \mathrm{~cm}$ between the bottom of AU 1 and Feature 1 and the $20 \mathrm{~cm}$ between Feature 1 and Features 2 and 3 revealed a pretty significant number of artifacts. Rather than limit the subsequent analysis of the site through narrowly defined analytical units (which, granted, might have represented some small portion of actual habitation surfaces), a research decision was made to expand the analytical units to include the levels in between in order to capture the most amount of data recovered at the site. Thus, AU 2 is redefined as being located just below AU 1 at 130-140 cmbs and extending to $160 \mathrm{cmbs}$ in GT 2 and $170 \mathrm{cmbs}$ in GT 3, and AU 2 was redefined to include the information from the excavated test units at 160-190 cmbs.

To more easily present the summary of the analytical units to the reader, the following information is presented in table format rather than a narrative (Table 5-6). 


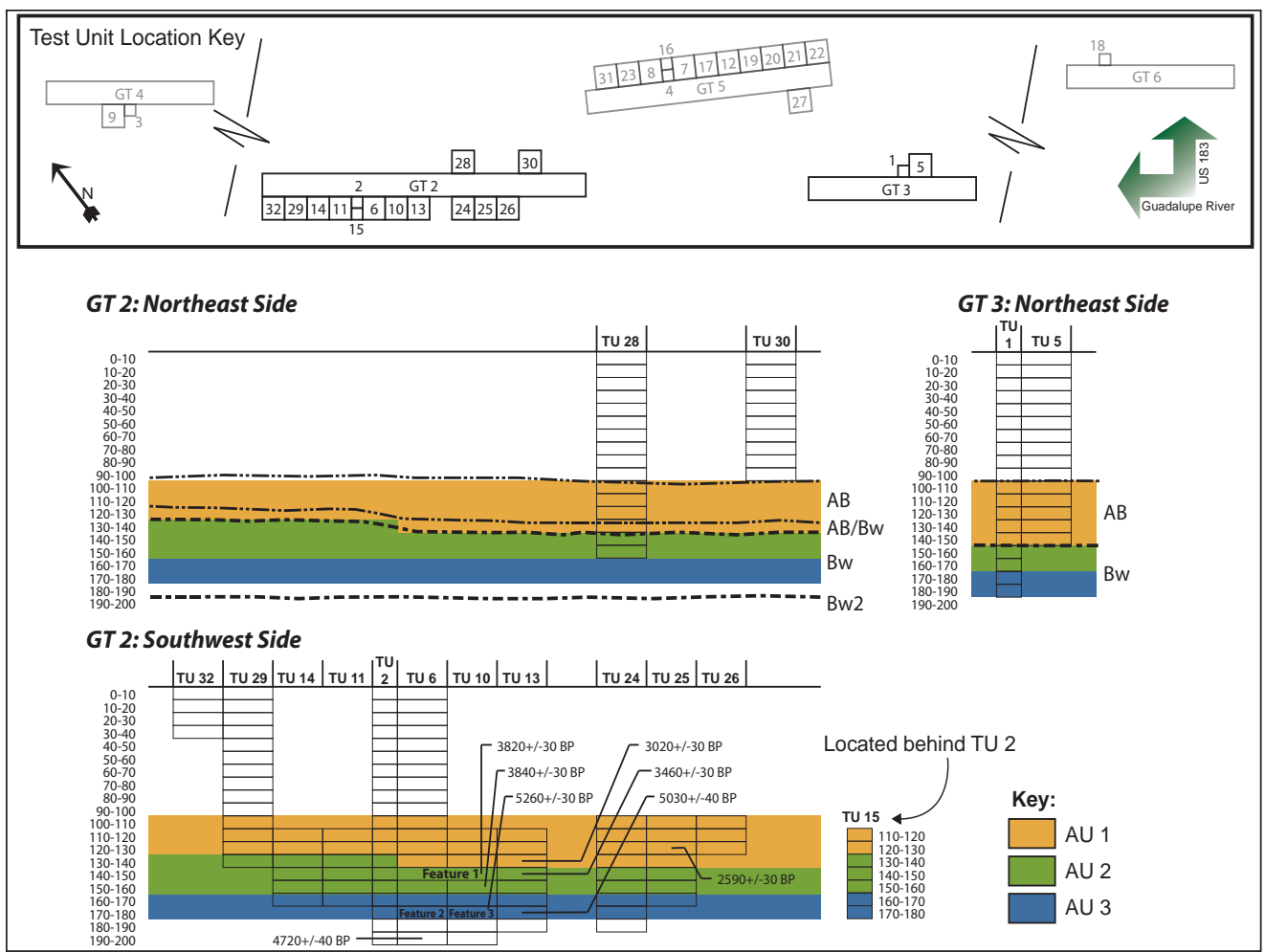

Figure 5-21. Test unit data and analytical units observed in GTs 2 and 3.

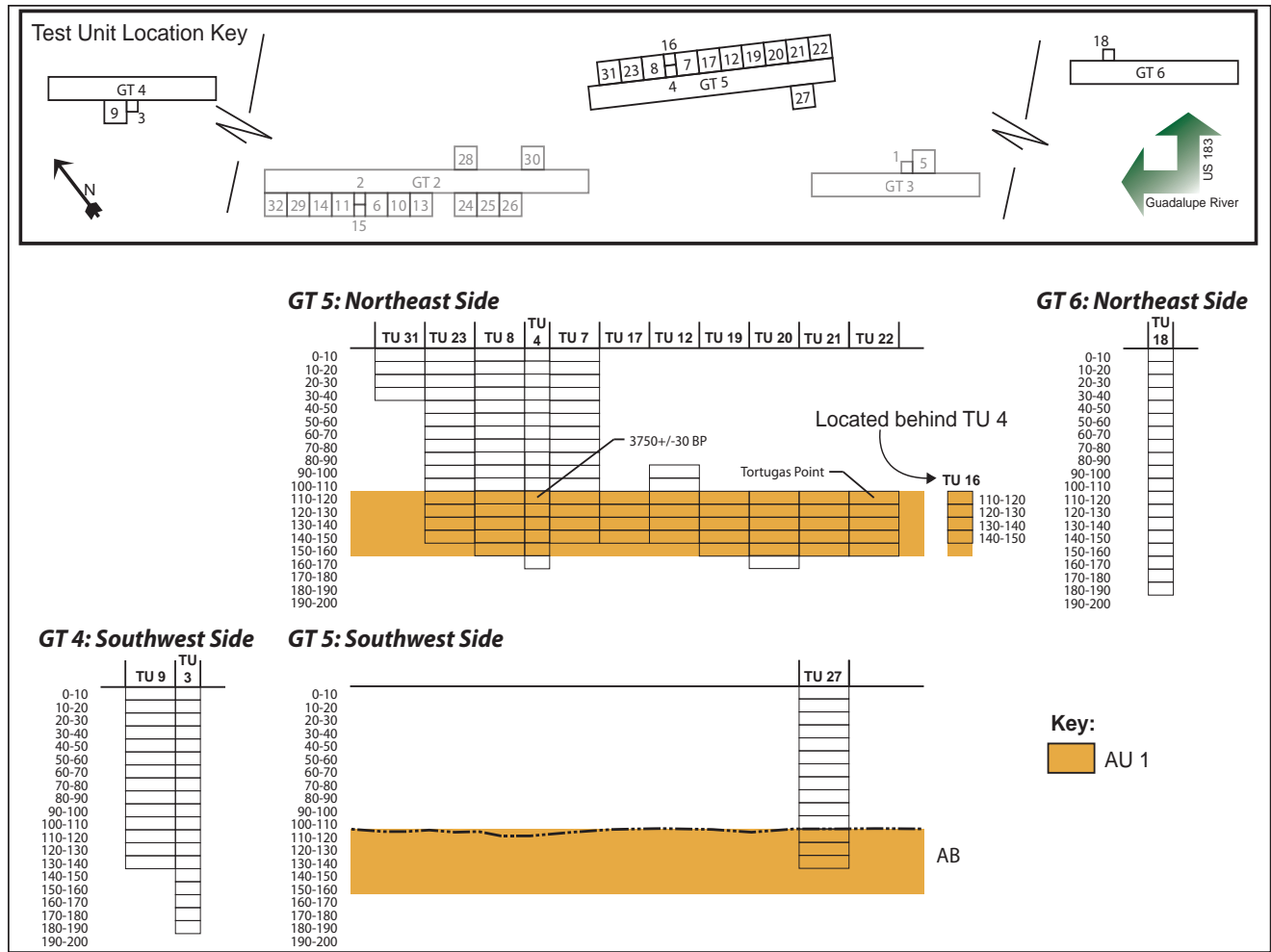

Figure 5-22. Test unit data and analytical units observed in GTs 4, 5, and 6. 
Table 5-6. Summary of the Analytical Units.

Analytical Unit:

Observed in Gradall Trenches:

Observed at Depths:

Defined Top Boundary:

Defined Bottom Boundary:

Excavated Volume:

Associated Features:

Associated Soil Horizon:

Associated Radiocarbon Dates:

Associated Diagnostic Artifacts:

Periods of Occupation:
1

2,3 , and 5

See Figures 5-21 and 5-22

$100 \mathrm{cmbs}$, when artifact recovery increased

Transition between $\mathrm{AB}$ horizon to Bw horizon

$$
\begin{gathered}
8.575 \mathrm{~m}^{3} \\
\text { None }
\end{gathered}
$$$$
A B
$$

$2590 \pm 30 \mathrm{BP}, 3020 \pm 30 \mathrm{BP}$, (accepted) 3750 $\pm 30 \mathrm{BP}$ (rejected)

Tortugas Point (TU 22 at 110-120 cmbs), two Clear Fork gouges (TU 12 at 110-120 cmbs; TU 7 at 120-130 cmbs)

Middle Archaic (South Texas); Late Archaic (Central Texas, Savannah and Prairie, and Coastal Texas)

Analytical Unit:

Observed in Gradall Trenches:

Observed at Depths:

Defined Top Boundary:

Defined Bottom Boundary:

Excavated Volume:

Associated Features:

Associated Soil Horizon:

Associated Radiocarbon Dates:

Associated Diagnostic Artifacts:

Periods of Occupation:

Analytical Unit:

Observed in Gradall Trenches:

Observed at Depths:

Defined Top Boundary:

Defined Bottom Boundary:

Excavated Volume:

Associated Features:

Associated Soil Horizon:

Associated Radiocarbon Dates:

Associated Diagnostic Artifacts:

Periods of Occupation:
2 and 3

See Figure 5-21

Transition between $\mathrm{AB}$ horizon to $\mathrm{Bw}$ horizon

Radiocarbon date locations

$2.1 \mathrm{~m}^{3}$

1

Bw

$3460 \pm 30 \mathrm{BP}, 3820 \pm 30 \mathrm{BP}, 3840 \pm 30 \mathrm{BP}$ (accepted)

None

Middle Archaic (South Texas and Savanna and Prairie); Late Archaic (Central Texas and Coastal Texas)

\section{3}

2 and 3

See Figure 5-21

Radiocarbon date locations

At bottom of features, number of recovered artifacts dropped

$1.25 \mathrm{~m}^{3}$

2 and 3

Bw

$5030 \pm 40$ BP, $5260 \pm 30$ BP (accepted)

None

Early Archaic (South Texas and Coastal Texas); Middle Archaic (Central Texas and Savannah and Prairie) 


\section{Chapter 6 \\ Recovered Cultural Material}

The hand excavation of $26.15 \mathrm{~m}^{3}$ of soil recovered 2,823 individual chipped or ground stone artifacts, 1,513 pieces of mussel shell, 1,328 pieces of snail shell, 9 bone fragments, and 13 charcoal samples. About 1,045 pieces of burned rock were observed and recorded, but not collected. Of these artifacts, about 7 percent were recovered from the upper meter of hand excavations, and 93 percent were collected from the lower meter of excavations (Table 6-1). All but one of the artifacts were recovered from the hand excavation units or known proveniences in the wall of the gradall trenches; however, one biface was recovered from the bottom of GT 5, which fell from an unknown elevation, and was observed to be a possible knife blade. This was recovered and included in the collection as well (included in the bifaces category). All of the snail shell collected was analyzed in the AmaTerra laboratory, and all of the mussel shell was sent for detailed analysis by Robert Howells. The results of these analyses are reported elsewhere in this report (see Chapters 5 and 7 for the snail shell analysis and Chapters 5, 7, and Appendix $\mathrm{C}$ for the mussel shell report). This chapter will focus on a description of the chipped and ground stone, charcoal, and bone.

Table 6-1. Total Numbers of Artifacts Recovered from Site 41DW277.

\begin{tabular}{ccccc}
\hline Type & $\begin{array}{c}\text { Upper } \\
\text { Meter }\end{array}$ & $\begin{array}{c}\text { Lower } \\
\text { Meter }\end{array}$ & $\begin{array}{c}\text { Unknown } \\
\text { Provenience }\end{array}$ & Total \\
\hline Projectile Points & 0 & 3 & 0 & 3 \\
Bifaces & 1 & 25 & 1 & 27 \\
Cores & 1 & 37 & 0 & 38 \\
Tested Cobbles & 0 & 5 & 0 & 5 \\
Expedient & 0 & 56 & 0 & 56 \\
Flake Tools & 0 & 6 & 0 & 6 \\
Groundstone & 0 & 2 & 0 & 2 \\
Hammerstones & 237 & 2449 & 0 & 2686 \\
Flakes and Shatter & 82 & 1431 & 0 & 1513 \\
Mussel Shell & 73 & 1255 & 0 & 1328 \\
Snail Shell & 5 & 4 & 0 & 9 \\
Bone & 4 & 9 & 0 & 13 \\
Charcoal Samples & & & & 5686 \\
\hline Total & & &
\end{tabular}

CHIPPED AND Ground Stone

The majority of lithic materials recovered at Site 41DW277 came from the levels below one meter in depth. Of the some 2,800 lithic artifacts recorded at the site only, 237 (less than 10 percent) pieces of lithic flaking material and shatter came from the upper meter of sediments. Virtually none of this was found in an intact or interpretable context. Consequently, analysis and research focused on the lower meter

of excavations. Artifacts from upper meter were cataloged but not analyzed in detail in the laboratory and are not included in the analysis below. However, two exceptions are a biface and a core fragment. These were included in the detailed analysis, but they are not included in the artifact descriptions to follow. Also included in the artifact analysis is an unprovenienced knife from GT 5. The total number of chipped or ground stone analyzed in detail includes three 
projectile points, 27 whole or fragmented bifaces, 38 whole or fragmented cores, five tested cobbles, 56 expedient flake tools, six pieces of groundstone, two hammerstones, 901 whole and proximal flakes, 767 incomplete flakes, and 781 pieces of unclassifiable debitage.

The lithic analysis followed the Chipped Stone Analytical Protocol prepared by the staff of the Archeological Studies Program at TxDOT. The protocol is an effort to standardize much of the details of basic lithic analysis to more easily compare one site's data set with another, while still maintaining the flexibility to pursue individualized avenues of analysis based on unique research questions. For instance, AmaTerra conducted additional analysis on whole flakes from AUs 1-3, in an attempt to explore questions about lithic tool manufacturing processes and group mobility among the occupants of Site 41DW277. There will be more on this topic below.

In general, the basic theory behind prehistoric lithic analysis is the idea that stone tool manufacture follows the same pattern as almost every other kind of stone processing, in that the maker has an idea of the final form and takes away (reduces) stone material in a methodical way to produce that final form. Once that form was achieved (or was close enough), the tool was used and possibly reused until it was no longer useful (or was lost). The tool was then discarded and something else took its place. Extensive studies of prehistoric stone tools and their methods of manufacture have provided a template for the general way in which prehistoric stone tools were made and used (Black et al. 1997; Collins 1975; Crabtree 1966, 1972; Goode 2002; Patterson 1977; Shafer 1983, 1985; Sollberger 1977; Tsirk 1979; Whittaker 1994). Thus, subsequent analysis of both the tools themselves and the discarded waste debris can indicate what stage in the manufacturing process the tool was in, what the tool was used to do, if the tool was reused as something else, and the possible reasons the tool was abandoned. With this in mind, specific observations were made and recorded for each class of chipped stone artifact, according to the TxDOT protocol. For lithic tools that were not made by reduction, such as hammerstones and groundstones, the observations made and recorded for each artifact differed slightly, but the same "use life” theory was utilized in the analysis.

The following stone artifact descriptions are organized by class: projectile points, bifaces, cores, tested cobbles, expedient tools, hammerstones, groundstones, whole and proximal flakes, incomplete flakes, and unclassifiable debitage. The descriptions include the attributes observed and recorded for each class during the laboratory analysis, followed by a brief discussion.

\section{Projectile Points $(n=3)$}

All of the projectile points recovered from Site 41DW277 were found 1-2 m below the ground surface. These artifacts received the most attention in the laboratory, with 12 different attributes observed and recorded. First, basic metrics were measured, including the maximum length, maximum width, maximum thickness, weight, and the working edge angle. Then, several attributes were observed and recorded based on the TxDOT protocol. The first attribute considered by the lithic analyst was the stage of manufacture. The process of manufacture from a cobble to a finished tool was divided into five stages for this analysis, beginning at the initial reduction, followed by a blank, a preform, the final stage (the finished product), and ending with a rejuvenated or reworked tool. The initial reduction is marked by cortex removal, mass 
thinning, and initial shaping. Hard hammer percussion is generally used to take away large chunks of material at this stage. A blank is a more refined piece with the initial shaping required to reach the final form in the maker's mind. There is little if any cortex remaining on the tool, and this shape generally marks the end of the hard hammer percussion and the beginning of soft hammer. A preform is even more refined, with a much thinner form and the overall shape is complete. A soft hammer is almost exclusively used in this stage. The final stage completes the tool with the final refinement of the lateral edges and minor facial thinning. Notching, edge grinding, and stem preparation are completed through pressure flaking and indirect percussion. Finally, a rejuvenated tool is a completed tool that has been reworked - the edge may have been sharpened or altered, the tool may have been adapted to a different use, or the tool may have been modified after a breakage.

The lithic analyst then identified what portion of the tool was recovered. If the tool was broken and only a portion was recovered, the analyst attempted to determine if the break was during the use life of the tool or if it was post-depositional. With this information and other features of the tool, the analyst attempted to determine why the artifact was discarded, either through a production flaw or failure, breakage from use, or an incidental (or accidental) discard. The analyst also recorded staining, patina, evidence of heat treatment on the tool, the shape of the working edge (edge morphology), flake scar patterns, and edge construction (unifacial or bifacial and unilateral or bilateral). Then the tool was studied to see if any edge grinding was present, if there was any evidence of hafting, and finally the type of stone the tool was made from (lithology).

\section{Tortugas}

Lot $180-1$ is a Tortugas point that was encountered in Unit 22 at a depth of 110-120 cmbs (Figure 6-1). The point is made of a finegrained grayish brown chert and is relatively complete. This specimen has a thick midsection that consists of non-patterned flaking and a gently concave base that is basally thinned. The lateral edges are gently convex and are alternately beveled. The distal tip of the point had been

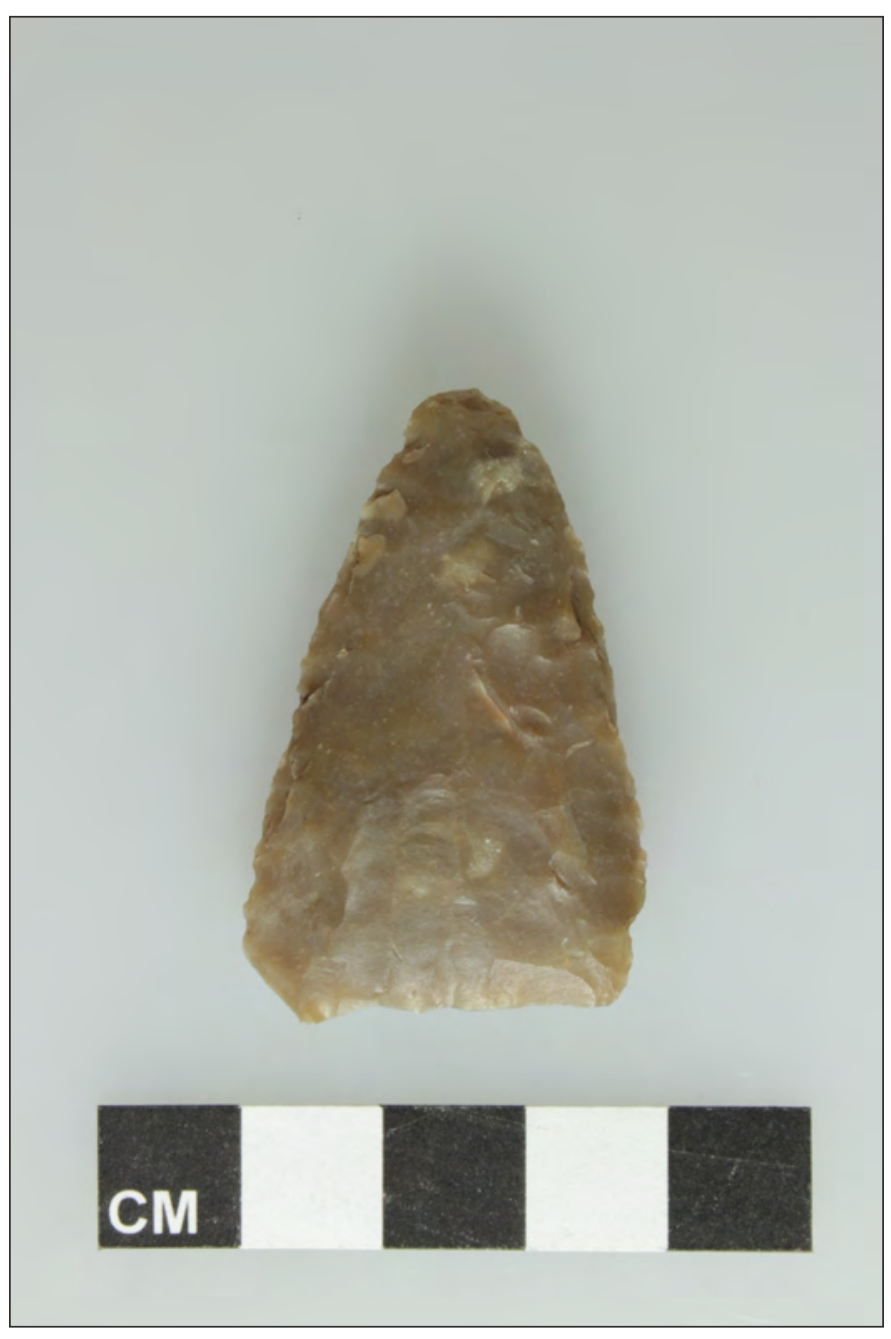

Figure 6-1. Lot 180-1, Tortugas point. 
broken; however, it shows evidence of attempts at resharpening the tip. Evidence of resharpening can also be seen along the lateral edges of the point. During the resharpening of the lateral edges, both corners of the base were removed. The base also showed evidence of reworking, and possibly some rejuvenation.

Tortugas poins are generally found in the South Texas archaeological region and date to the Middle Archaic (4500-2400 BP). They are part of the unnotched triangular projectile point tradition beginning with the Early Triangular point and ending with the Matamoros point (Turner and Hester 1999).

\section{Untypable Lanceolate Points}

Lot $127-1$ is an untypable lanceolate point that was encountered in TU 7 at a depth of 140-150 cmbs (Figure 6-2). The point appears to be made from heat treated chert that is gray in color and heavily patinated. The specimen consists of only the

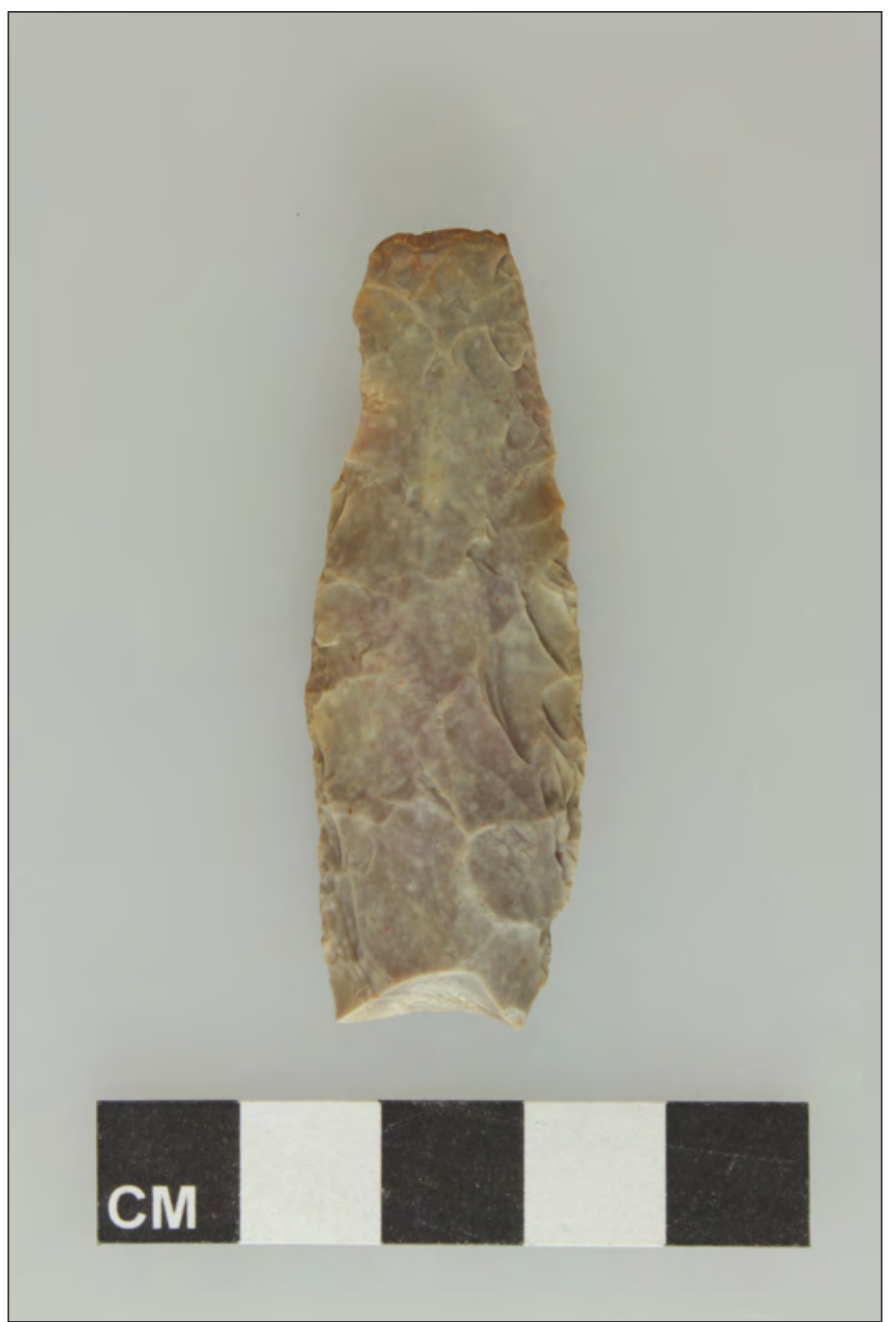

Figure 6-2. Lot 127-1, untypable lanceolate point. proximal and medial sections. Due to impurities within the chert the distal portion of the specimen is missing along with a portion of the dorsal medial section along the right lateral edge. Cortex is still visible along the dorsal side of the point near the base and is present along the straight constricting base. The flaking observed on the projectile point is non-patterned.

Lot 110-1 is an untypable lanceolate point that was encountered in TU 5 at a depth of 130$140 \mathrm{cmbs}$ (Figure 6-3). The point is made from a fine grained light gray chert with a quartz inclusion near the distal tip along the dorsal side. The specimen has a straight constricting base that has been basally thinned. The lateral edges of the point show evidence of reworking and large flakes are seen to have been removed along the right lateral edge during resharpening. The distal tip of the point has been removed and resharpening along the tip has occurred. The flaking patterning on the point is random; however, flaking along the lateral edges of the point appears to be somewhat parallel. 


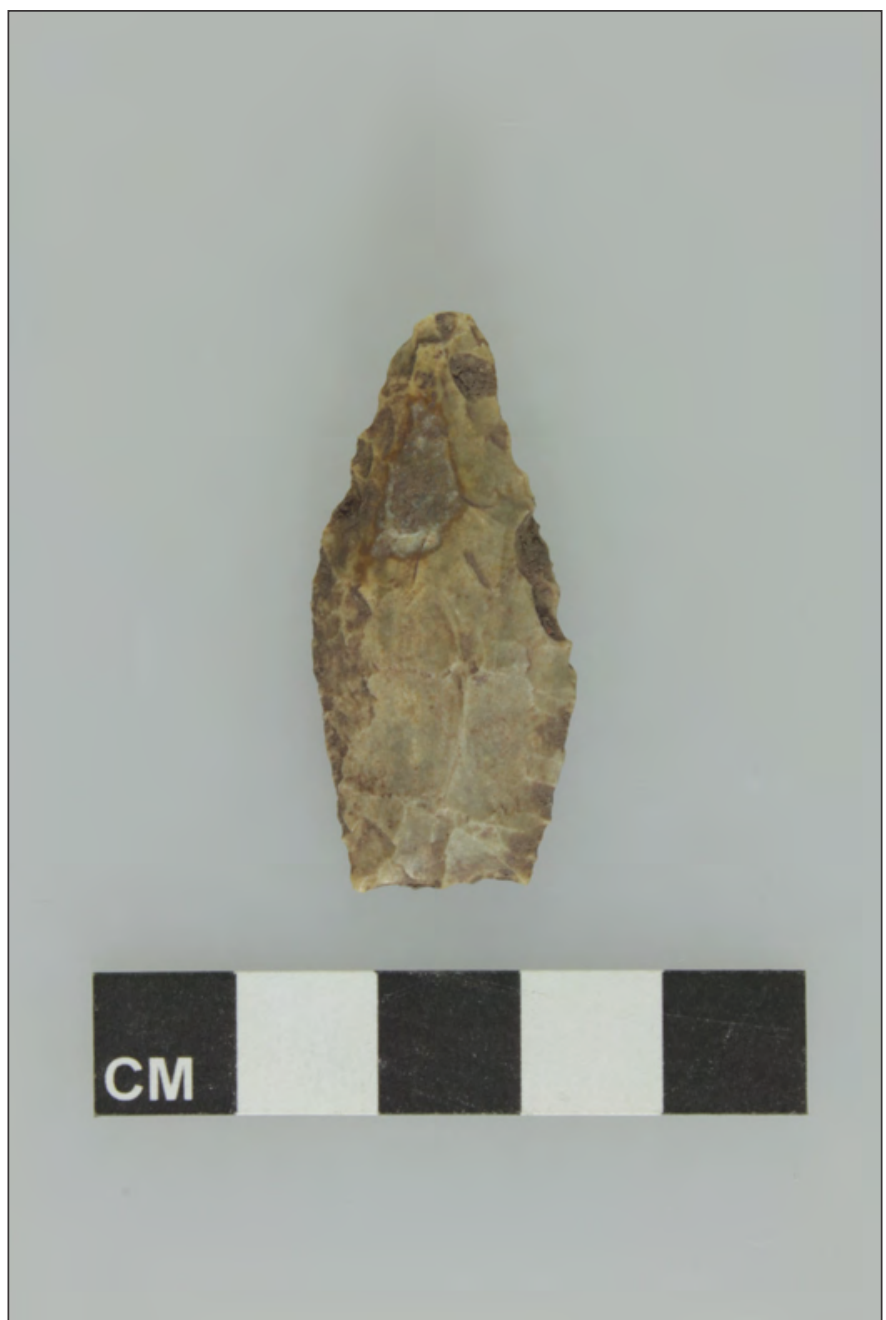

Figure 6-3. Lot 110-1, untypable lanceolate point.

\section{Bifaces (n=27)}

Of the 27 bifaces analyzed, one biface was recovered from between 0-100 cmbs, and 25 were recovered from between 100-200 cmbs in the hand excavation units. One additional biface was recovered from an unknown depth within GT 5. The lithic analyst measured eight different attributes based on the TxDOT protocol, and in addition, attempted to determine the use of the biface, either as a gouge, chopper, scraper, knife, or a fragment of a projectile point. First, basic metrics were measured, including the maximum length, maximum width, maximum thickness, weight, and the working edge angle. Then, several attributes were observed and recorded based on the TxDOT protocol. The first attribute considered was the stage of manufacture. The process of manufacture from a cobble to a finished tool was divided into five stages for this analysis, beginning at the initial reduction (Stage 1), followed by a blank (Stage 2), a preform (Stage 3), the final stage (Stage 4, the finished product), and ending with a rejuvenated or reworked tool (Stage 5).

Further analysis on the bifaces followed the same template established for the projectile points and considered a range of attributes, such as heat treatment, edge morphology and type, hafting evidence, and lithology.

\section{Stage 1 Bifaces (n=9): Initial Reduction}

A total of nine Stage 1 bifaces were encountered during the test excavations. Only one of these demonstrated any evidence of heat alteration (Lot 253-1) in the form of pot-lidding or "greasy" surfaces. Of the Stage 1 bifaces collected, three were incomplete and six were complete. All were made from chert. Further examination of the bifaces within this category showed that the bifaces could be further classified into three different categories based on function and use wear: formal, informal, and indeterminate. Formal Stage 1 bifaces are defined as being minimally reduced into a basic biface form, but are viewed as completed tools with a certain 
established design and a specific function. Informal Stage 1 bifaces are minimally reduced bifaces that have been used as tools. Indeterminate Stage 1 bifaces do not contain evidence of use as a tool. Two bifaces can be categorized as formal tools, six are considered to be informal tools that show evidence of use as a gouge, and one is categorized as being indeterminate. The formal tool Stage 1 bifaces consist of a complete chopper (Lot 98-1) and gouge (Lot 236-1) (Figures 6-4 and 6-5). The informal tool Stage 1 bifaces consist of three biface fragments used as gouges (Lots 173-1, 216-1, and 218-1) and three complete bifaces also used as gouges (Lots 222-1, 253-1, and 261-1). The biface considered to be indeterminate (Lot 121-1) is a small fragment with no expedient use wear observed. The bifaces identified as formal and informal are described below.

\section{Formal Stage 1 Biface Tools $(n=2)$}

Lot 98-1 is a bifacial chopper made from a yellowish to dark yellowish brown fine grained chert. The specimen is bifacially flaked along the lateral and distal edges with approximately 20 percent of cortex remaining on the dorsal, ventral, and proximal faces of the biface. The distal edge of the biface shows evidence of bashing with heavily stepped fractured-crushed faces that appear to be heavily worn.

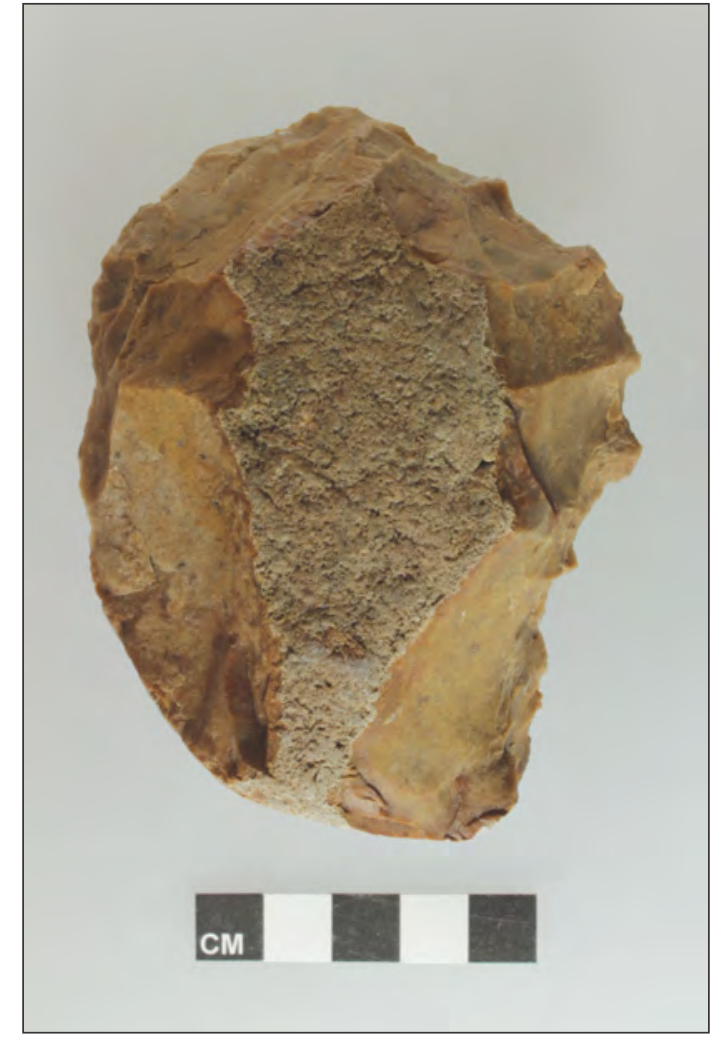

Figure 6-4. Lot 98-1, bifacial chopper.

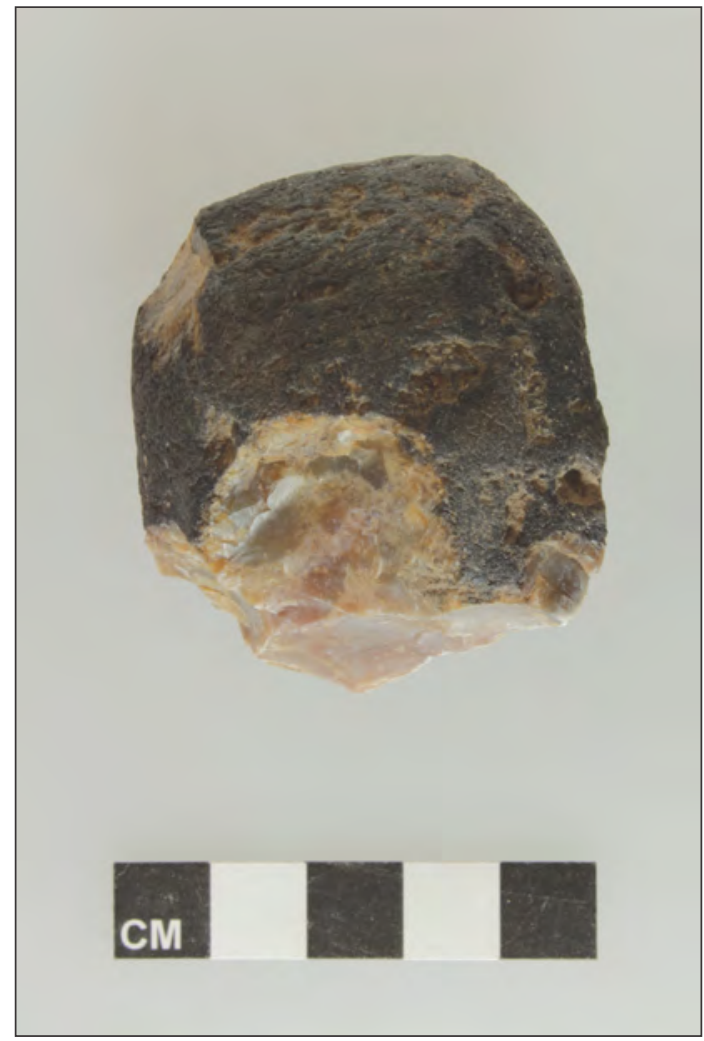

Figure 6-5. Lot 236-1 bifacial gouge. 
Lot 236-1 is a bifacial gouge made from a brown fine grained chert with white specks. The specimen is bifacially flaked on the distal edge with approximately 50 percent of cortex remaining along the lateral and proximal edges. The distal end has been flaked to provide a bit used for gouging. Evidence of gouge use is observed on the distal edge with numerous step fractures and some crushing.

\section{Informal Stage 1 Biface Tools $(n=6)$}

The informal Stage 1 biface tools include incomplete and complete bifaces. Both types contain cortex ranging from 20-50 percent and are characterized as "informal" based on form and function evident by expedient use wear. All bifaces in this category show evidence of use as a gouge with either a portion of the distal or lateral edges (usually directly above a semi-flat flake scar) formed as a bit. The areas used as a gouge on the bifaces are isolated and contain small flakes forming teeth which have been destroyed by stepped fractures from use.

\section{Stage 2 Bifaces $(n=5):$ Blank}

During the test excavations a total of five Stage 2 bifaces were encountered and collected. Of these, one will not be discussed in detail, as it was collected from 0-20 cmbs, and does not fall within the analytical units discussed in this report.

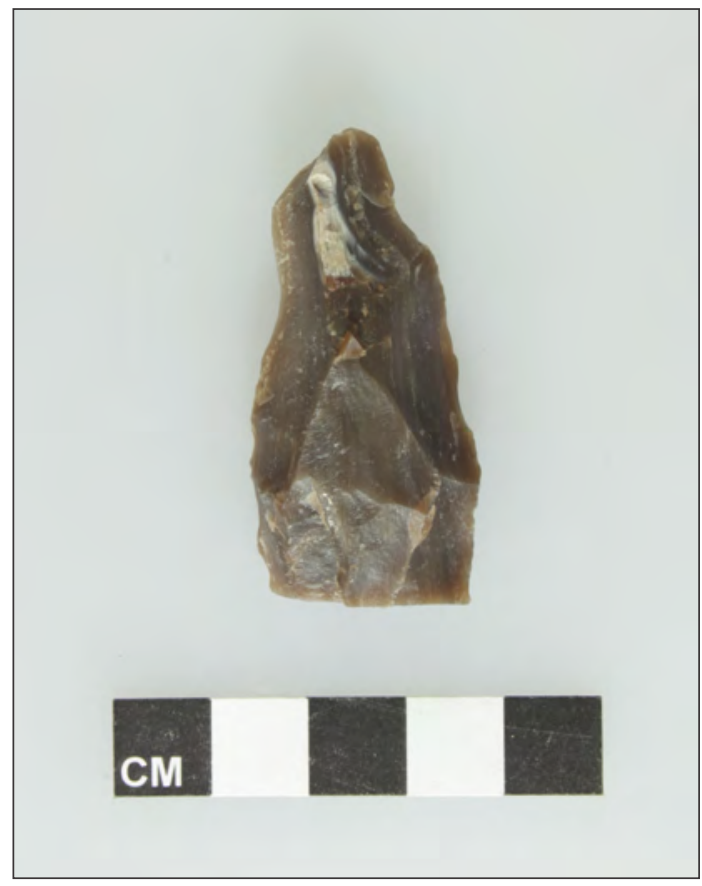

Figure 6-6. Lot 234-1, Stage 2 biface fragment.
The remaining four Stage 2 bifaces consist of three biface fragments and only one complete biface. None of them demonstrated any potlidding or a "greasy" surface appearance, which would suggest heat-treating. The three Stage 2 biface fragments (Lots 105-1, 234-1, and 2901) are thick and contain 1-5 percent cortex (Figures 6-6 and 6-7). The shape of the three fragments are indeterminate; however, they appear lanceolate-like and have been shaped entirely by hard hammer percussion. Lot 234-1 is made from a very dark grayish brown fine grained petrified wood while the Lots 105-1 and 290-1 are made from a brown fine grained chert with white speckling.

The complete Stage 2 biface collected (Lot 1201 ) is made of a pale yellow fine grained chert with white and brown speckling (Figure 6-8). The specimen is round in shape and devoid of any cortex. The medial section of the specimen is thick, flake scars are large, and they appear to have been made by hard hammer percussion. Three areas along the edge of the specimen 


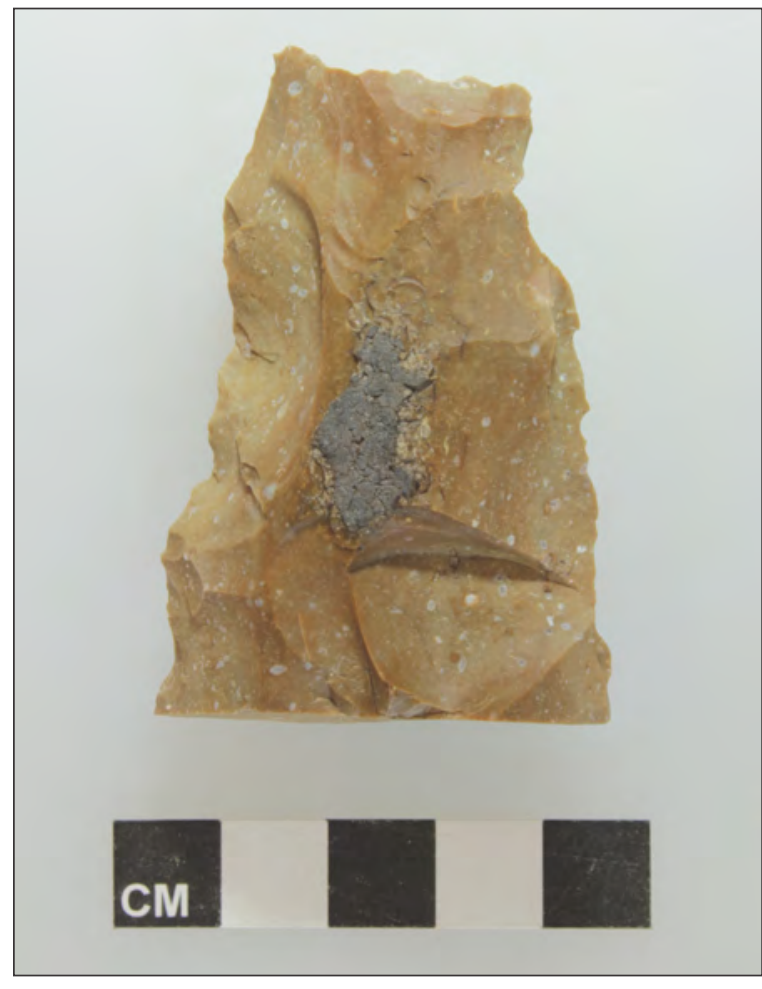

Figure 6-7. Lot 105-1, Stage 2 biface fragment.

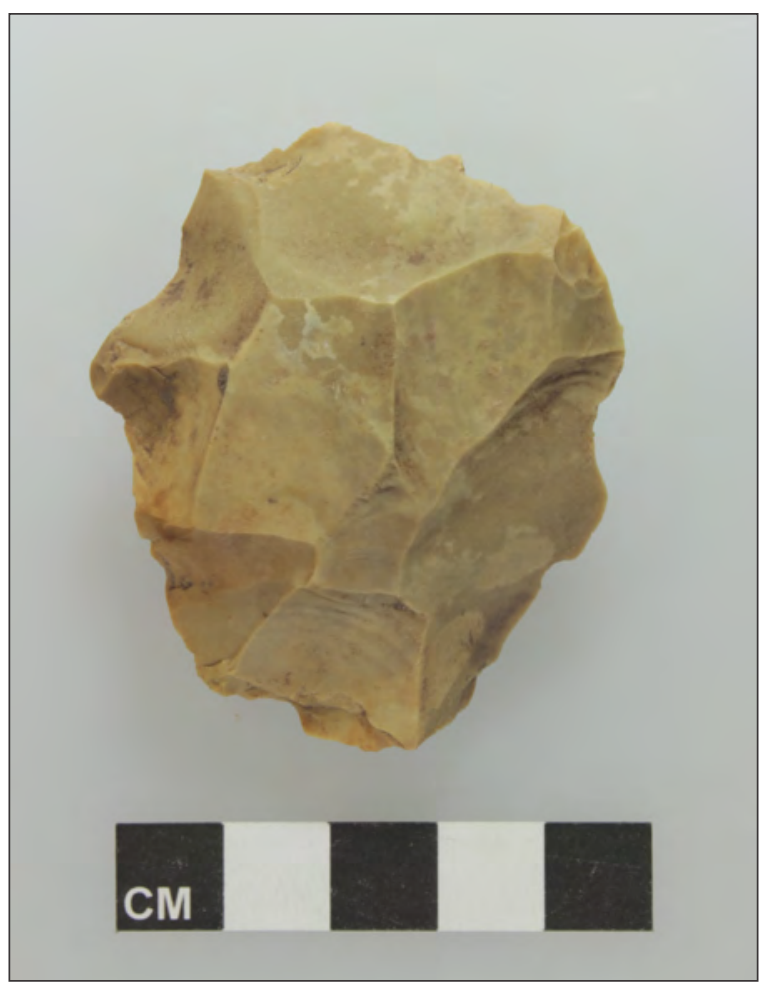

Figure 6-8. Lot 120-1, complete Stage 2 biface.

appear to have been used as a scraper or gouge. The areas displaying use wear vary and are concentrated on both the dorsal and ventral surfaces of the tool. Each area has a semi-flat base and a heavily stepped or crushed working edge. In some cases the working edge is heavily worn.

\section{Stage 3 Bifaces ( $n=3)$ : Preform}

Only three fragments of Stage 3 bifaces were collected. All three fragments were made from chert, have been thinned, and contain no cortex. The portions of the three specimens analyzed (Lots 158-1, 158-2, and 73-1) are indeterminate and in shape.

\section{Stage 4 Bifaces ( $n=6)$ : Final Stage}

A total of six Stage 4 bifaces were encountered during the test excavations. Of the six collected, one was obtained from GT 5 at an unknown depth. The provenience was not recorded for the specimen, and will not be discussed further. The remaining five bifaces analyzed consisted of one complete specimen, three distal fragments, and one proximal-medial fragment. Of the three distal fragments one is heavily burned (Lot 122-1), and two appear to be portions of knives. The complete specimen is a bifacial Clear Fork gouge and the proximal-medial fragment is that of a knife. The possible knife fragments and the bifacial Clear Fork gouge are individually described below. 
Lot 121-2 is a bifacial Clear Fork gouge made of gray to dark gray fine grained petrified wood (Figure 6-9). The tool was flaked against the grain and each wood line is defined by small fractures that appear white in color. The flaking pattern is random, however the specimen is finely made. The distal bit appears to be in good condition with only a little bit of crushing.

Clear Fork gouges have been found at sites spanning the Archaic Period in South and Central Texas (8000-1200 BP), but are most often associated with the Early Archaic (8000-4500 BP). They are linked to the "Early Basal Notched" horizon of the Early Archaic in the South Texas archaeological region (Hester 1995, 2004).

Lot 291-1 is a distal portion of a biface made from a yellowish brown fine grained chert with gray speckling and veins (Figure 6-10). The specimen is serrated along the right lateral edge which is curved with no serration on the opposing lateral edge which is straight. For these reasons, we speculate that the artifact may have been used as a knife. However, since what would have been the hafted end has been snapped off, the specimen's function remains speculative. The tip of the specimen still has some cortex; serration is worked into it. The flaking pattern is random.

Lot 197-1 is a distal portion of a biface made from a dark yellowish brown fine grained chert and is heavily patinated (Figure 6-11). Like the Lot 291-1 specimen, the right lateral edge of the specimen is slightly serrated with no serration along the opposing lateral edge. Like Lot 291-1, this may also have been used as a knife, though the hafted end has been broken. The tip of the specimen has a snap fracture. Flaking of the specimen is non-patterned.

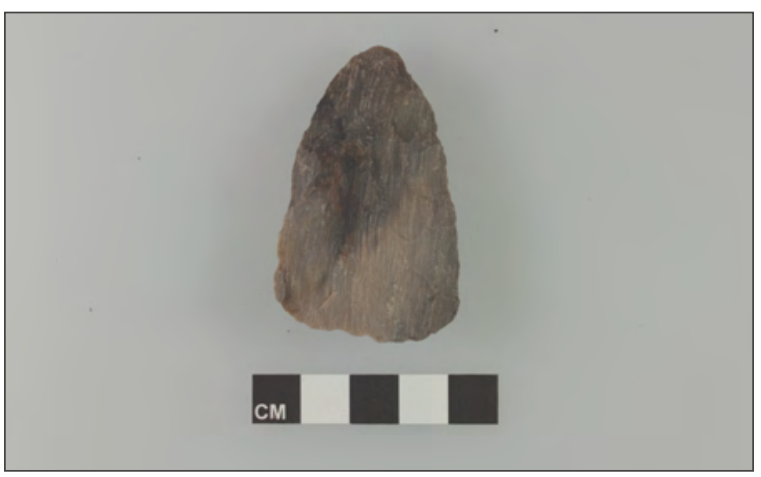

Figure 6-9. Lot 121-2, bifacial Clear Fork tool.

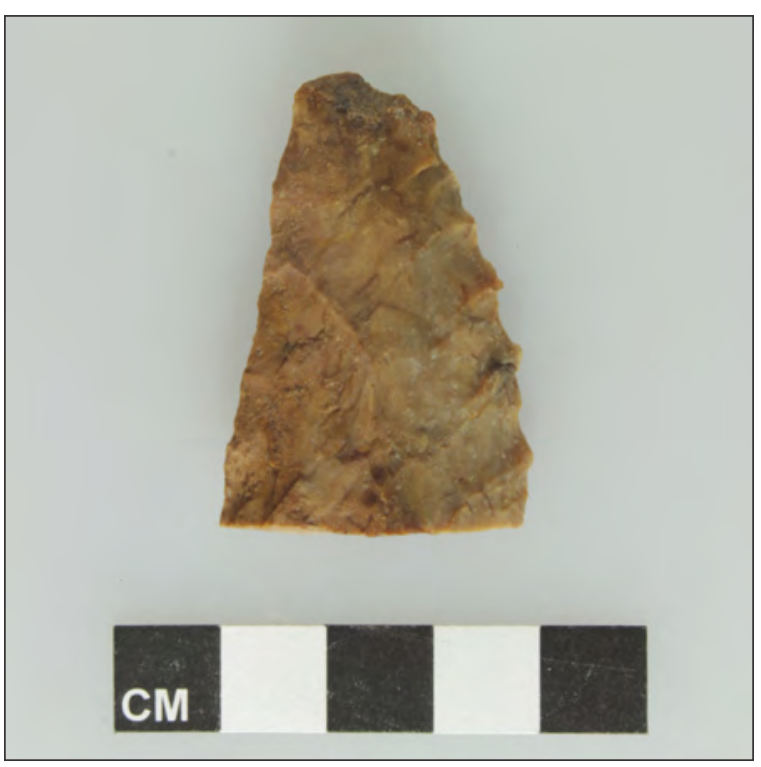

Figure 6-10. Lot 291-1, distal portion of a biface.

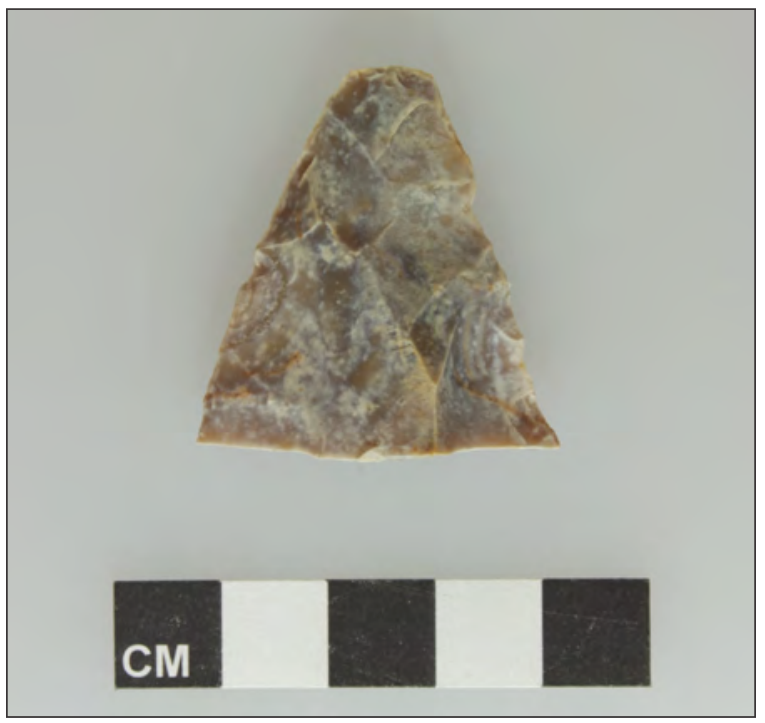

Figure 6-11. Lot 197-1, distal portion of a biface. 
Lot $197-2$ is a proximal-medial portion of a biface made from a dark reddish gray fine grained chert and is heavily patinated (Figure 6-12). The lateral edges of the specimen are not serrated like the other two knife fragments; however, evidence of hafting is present. The missing distal portion of the specimen is snapped, and the flaking pattern of the specimen is random.

\section{Stage 5 Bifaces $(n=4)$ : Rejuvenated}

During the test investigations, four projectile point fragments were collected which are classified as Stage 5 bifaces. All specimens were either broken during resharpening or use. Three specimens were broken during manufacturing and one was broken during use and reworked into a scraper. The specimens are described below.

Lot 266-1 is the distal tip of a projectile point made from a dark gray fine grained chert (Figure 6-13). The flaking pattern of the specimen is random and it appears that the specimen was in the process of being resharpened. The left lateral edge is beveled. It appears that an overshot flake was removed from the right lateral edge and the specimen snapped.

Lot 266-2 is a lateral edge fragment of a projectile point made from a light gray fine grained chert (Figure 6-14). The portion is too small to determine the lateral side;

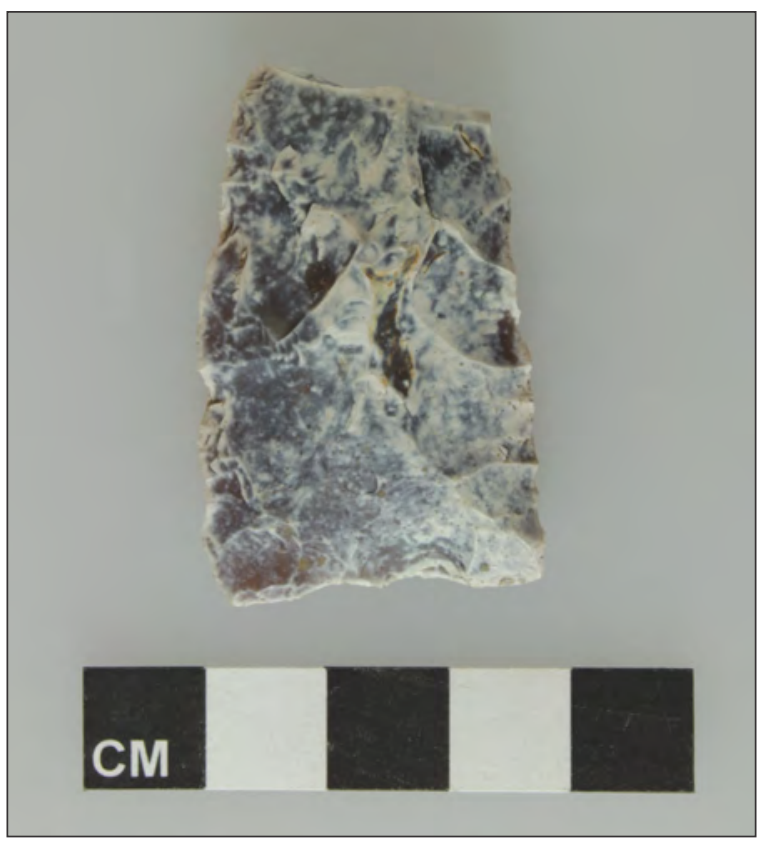

Figure 6-12. Lot 197-2, proximalmedial portion of a biface.

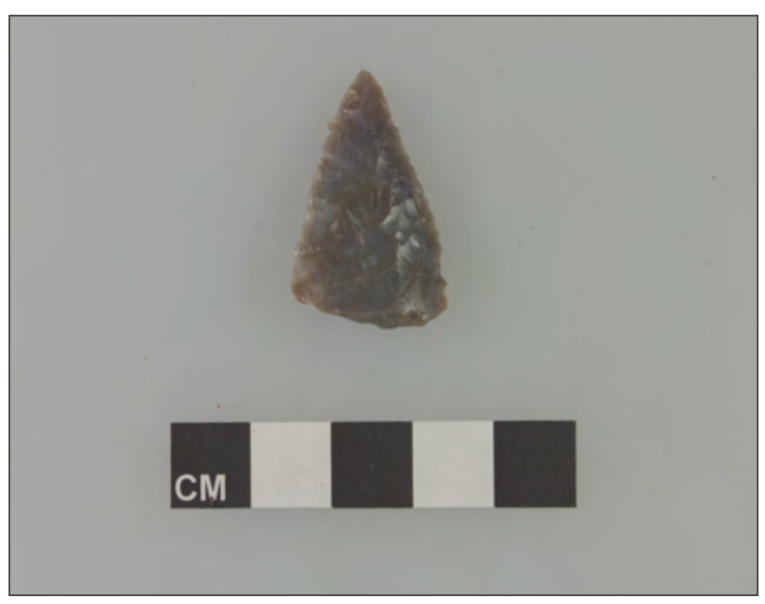

Figure 6-13. Lot 266-1, distal tip of a projectile point. however, an overshot scar was observed.

Lot 175-1 is a barb fragment of a projectile point made from a light yellowish brown fine grained chert (Figure 6-15). The specimen is the result of an overshot notching flake which removed the barb. This was likely a barb from a Middle to Late Archaic period Marshall or Marcos point.

Lot 220-1 is a stem fragment of a projectile point made from a dark grayish brown fine grained chert (Figure 6-16). The specimen has an expanding base with finely flaked grounded edges. 


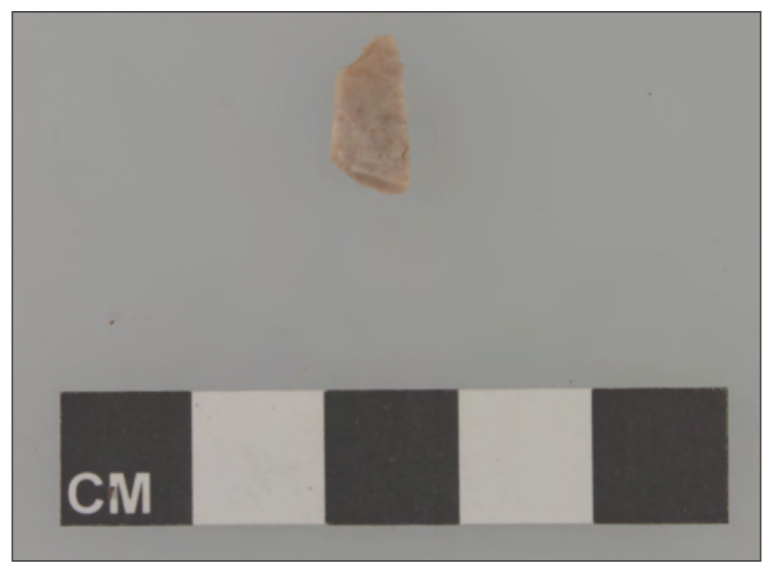

Figure 6-14. Lot 266-2, lateral edge fragment of projectile point.

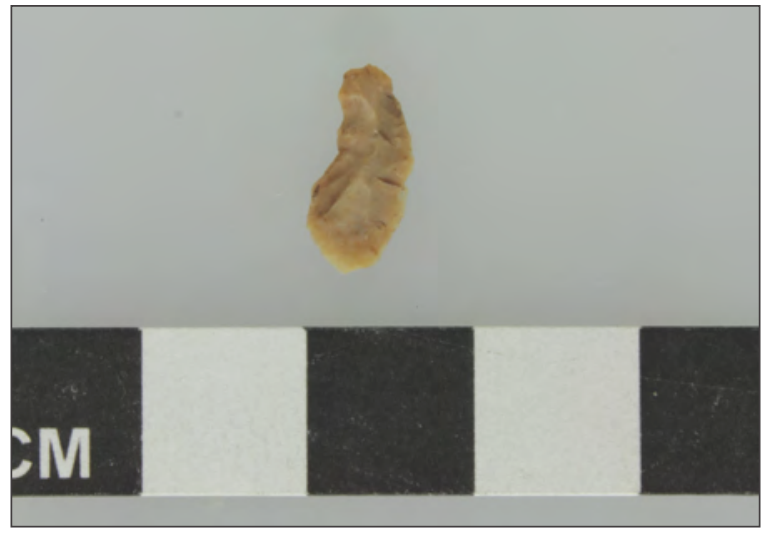

Figure 6-15. Lot 175-1, barb fragment of projectile point.

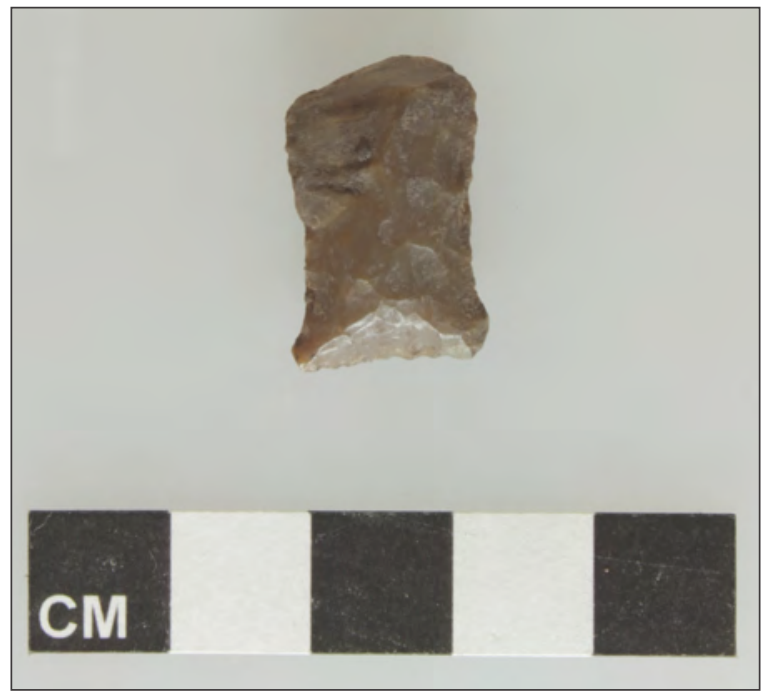

Figure 6-16. Lot 220-1, modified stem fragment of a projectile point.
The body of the point was broken and flaking along the break was observed. It appears that flakes were removed to form a scraper edge.

\section{Cores $(\mathbf{n}=38)$}

Thirty-seven cores were recovered from between 100-200 cmbs in the hand excavation units, and one core was recovered from between $0-100$ cmbs. This specimen was included in the lithic analysis but is not described below. The lithic analyst measured four different attributes. First, basic metrics were measured, including the maximum length, maximum width, maximum thickness, and weight. Following this analysis, the tool was then studied to evaluate flake scar patterns, lithology, the number of flake scars present, and whether or not the core was heat treated.

Cores collected from the identified analytical units were encountered in d epths ranging from 100-180 cmbs. The vertical distribution of cores are as follows: two were collected from 100-110 cmbs, two from 110-120 cmbs, eight from 120-130 cmbs, 11 from 130-140 cmbs, three from 140-150 cmbs, seven from 150-160 cmbs, three from 160-170 cmbs, and one from 170-180 cmbs.

Flaking patterns on the cores varied somewhat; 30 cores displayed a unidirectional flaking pattern while seven displayed a multidirectional flaking pattern. The number of scars observed on the cores ranged from 2-9, with one exhibiting two flake scars, two with three scars, nine with four flake scars, eight with five flake scars, nine with six flake scars, five with seven flake scars, two with eight flake scars, and one with nine flake scars. Only one core examined (Lot 221-2) was exhausted with five flake scars. Core sizes ranged from 
76-31 mm. Of the 37 specimens of cores collected, 10 were heat treated while 27 showed no evidence of thermal alteration.

\section{Tested Cobbles $(\mathbf{n}=5)$}

A total of five tested cobbles were recovered from the hand excavation units, all between 100-200 cmbs. The lithic analyst measured five different attributes. First, basic metrics were measured, including the maximum width, maximum thickness, and weight. Following the metrics, the analyst recorded the type of stone the tool was made from (lithology), the number of flake scars present, and whether or not the core was heat treated.

All tested cobbles were chert and varied in size from 19-64 mm. Unlike the cores, these tested cobbles were discarded after the removal of 1-3 flakes. Based on examination of the tested cobbles, the cobbles appear to be discarded due to poor quality of material, numerous inclusions, and/or because the stone was too small to produce a usable product. Of the five specimens collected, three showed evidence of thermal alteration.

\section{Expedient Tools $(\mathrm{n}=56)$}

Only the flakes from the lower meter of excavations were analyzed and discussed below. Any expedient tools within the upper meter of excavations were not identified since these deposits lacked integrity and interpretability. The lithic analyst measured seven different attributes along with basic metrics, including maximum length, maximum width, maximum thickness, weight, and the working edge angle. All of the expedient tools are flake derived.

The lithic analyst then identified what portion of the tool was recovered. Next, staining, patina, or evidence of heat treatment on the tool, the shape of the working edge, lithology, and edge construction type were recorded. .

A total of 56 unifacial expedient flake tools were recovered from the hand excavation units. According to the protocols outlined by TxDOT, these artifacts are classified as chipped stone tools that are simple detachment-based flakes that have been modified and expediently used. The characterization of these types of tools are broad and do not consider the degree to which these tools have been modified and used. An analysis of the working edge of this tool type suggests that they can be further subdivided based on stage of manufacture and use. Thus, unifacial tools were further separated into three categories based on modification of the working edge. The three categories identified are expedient, minimally retouched, and formal. The classification of expedient refers to the lack of preparation of a working edge, meaning the flake was used as is with no intentional sharpening of the working edge. The classification of minimally retouched refers to an effort made to sharpen a working edge by intentionally removing flakes to provide a cutting or scraping edge. The classification of formal refers to formal tool types with an intended design and function, such as scrapers and gouges, and to flakes with edges that have been heavily worked to provide a scraping or cutting edge. In all, the assemblage includes 11 expedient flakes with evidence of use on one or more lateral edges, 
22 minimally retouched flakes with minimal flaking along one or both lateral edges and in some cases along the distal edge, and 23 formal tools and flakes. The formal tools encountered include a unifacial Clear Fork tool $(n=1)$, scrapers $(n=4)$, gouges $(n=1)$, and one gouge/scraper.

\section{Hammerstones $(n=2)$}

Only two hammerstones were recovered from the test excavations, both of which were in the lower meter. As there is no official protocol for analyzing hammerstones, only one attribute was measured in addition to the maximum length and weight. The hammerstones were observed to see if they were heat treated.

The hammerstones consist of quartzite river cobbles varying in size from $58 \mathrm{~mm}-95 \mathrm{~mm}$ in length and weight from 137-406 grams. Neither were heat-treated. The smaller hammerstone (Lot 116-1) has evidence of pitting and crushing on two edges of the stone (Figure 6-17). One edge is smaller in size and not as bulbous as the opposing edge. Evidence of pitting and crushing on this edge is faint. The opposing edge with pitting and crushing also displays evidence of grinding and is more apparent.

Lot 249-2 is the larger of the two hammerstones collected (Figure 6-18). The specimen shows evidence of pitting and crushing along the lateral edge; however, the use wear is minimal. Unlike the previously described hammerstone, no evidence of grinding was observed.

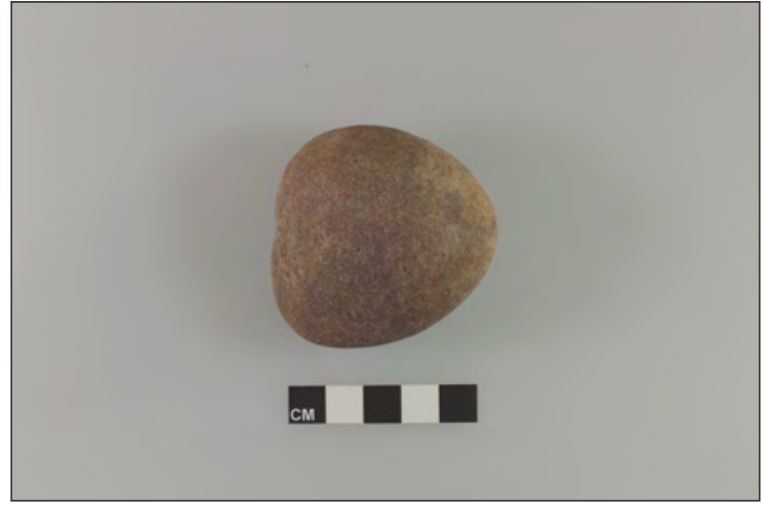

Figure 6-17. Lot 116-1, hammerstone.

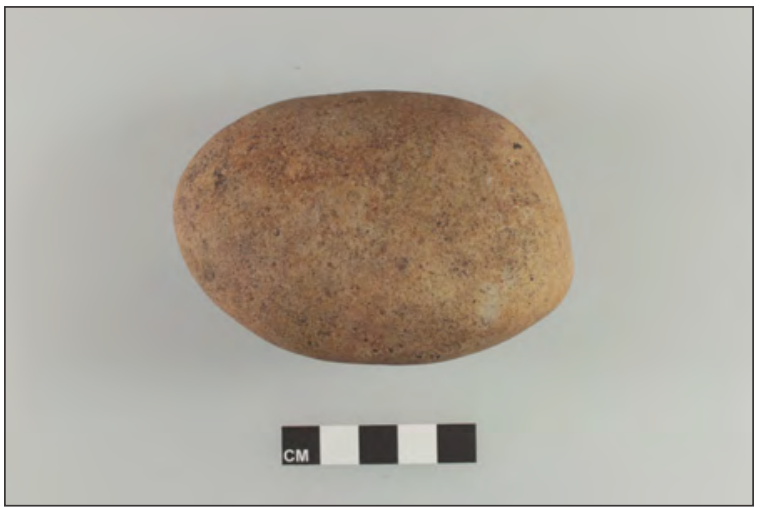

Figure 6-18. Lot 249-2, hammerstone.

\section{Groundstones $(n=6)$}

Six groundstone fragments were recovered from the test excavations, all of which were found in the lower meter. Analysis of groundstone included notations about lithic material, weight, size, shape, and any evidence of smoothing, etching, or abrasion. 
All the groundstone collected consisted of sandstone and were found at various depths from $110-150$ cmbs. One fragment was encountered at a depth of $110-120 \mathrm{cmbs}$, four fragments were encountered at a depth of 120-130 cmbs, and one was encountered at a depth of 140-150 cmbs. The majority of groundstone consisted of tabular sandstone metate fragments while one, Lot 247-1, appears to be a semi-rounded sandstone mano fragment weighing $60.4 \mathrm{~g}$. The tabular sandstone metates show a shallow concave face with evidence of abrasion and etching. It was encountered in Unit 28 from 110-120 cmbs (Figure 6-19). The portion collected is a lateral-medial section that has evidence of etching and striations from grounding on the ventral side and a grounded grove along the dorsal and lateral edge.

\section{Whole and Proximal Flakes $(\mathbf{n}=901)$}

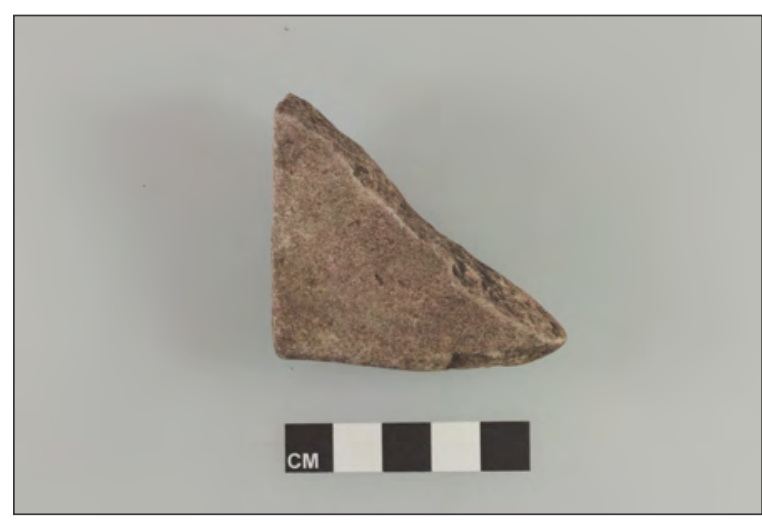

Figure 6-19. Lot 247-1, mano fragment.
All of the whole and proximal flaking material from between 100-200 cmbs was separated from the total assemblage and analyzed in more detail. A total of 901 pieces were analyzed, with eight attributes observed and recorded. Basic metrics such as maximum length and maximum width were not measured for each specimen. Instead, the lithic analyst determined the raw material type, whether it was a whole or proximal flake, the size grade based on passing the flakes through graduated sieves of $1,3 / 4,1 / 2$, and $1 / 4$ inch sizes, whether or not

the specimen was thermally altered, the amount of cortex by percentage, the platform type, the total count and weight, and the likely minimum number of nodules (MNN) that contributed to the assemblage. MNN values were based on the similarity of raw material type and material properties, as well as the effects of patination and thermal alteration.

The platform type attribute was categorized into eight types for this analysis, based on the TxDOT protocols. Those flakes that could not be classified into other categories were labeled indeterminate. Cortical flakes are those with cortex observed on striking platforms and have been produced in the initial stage of package reduction. A flat platform type is a single facet caused by a single previous flake removal. Flat platforms are common in the early stages of decortification and core reduction. A faceted platform indicates two intersecting facets have been observed on the platform. Assemblages dominated by flakes with double faceted platforms are generally produced in early stage blank production. Multifaceted platforms contain multiple facets observed on the platform. Assemblages dominated by flakes with multifaceted platforms are generally produced through work on later stage preforms. The abraded platform type exhibits platform edge smoothing/rounding that obliterate facet ridges, and complex platforms exhibit pressure or light percussion scars originating from the platform edge. These features generally indicate of late stage biface manufacture. Rejuvenated platforms are indicative of recycling and will typically exhibit worn edges and remnant polish. If the flake is missing 
the segment that includes the point of fracture initiation, the flake was identified as having a missing platform.

The flat platform type is the most prevalent in the flake assemblage, with 35.8 percent of the total represented. The multifaceted type is next, with 25.0 percent of the total assemblage, and cortical flakes consist of 14.8 percent of all whole and proximal flakes analyzed. The remaining platform types were encountered in much smaller percentages; faceted flakes account for 10.4 percent of the total, abraded flakes comprise 8.6 percent of the total, and complex flakes comprise 1.2 percent of the assemblage. Indeterminate and missing flakes are 4.2 percent of the assemblage, and no rejuvenated flakes were encountered at all.

Only about 11 percent of the assemblage showed signs of thermal alteration. Interestingly, no whole or proximal flakes in the assemblage exhibited 100 percent cortex on the dorsal surface, and only one flake was seen to have 51-75 percent cortex. All of the remaining flakes had either less than 50 percent cortex (50.6 percent of the total) or no cortex at all (49.4 percent of the total).

\section{Whole Flake Analysis}

In addition to documenting the various attributes defined by the Chipped Stone Protocol, those flakes that were identified as whole or complete flakes were further examined and assigned a technical description based on the reduction technology. Not all whole/complete flakes were assigned a reduction technology, only those that displayed recognizable attributes. Reduction technology types identified consisted of: early/late bifacial manufacturing, blade, bi-polar, core reduction, distinctive expanding billet, notching, sequence, thinning, and indeterminate flakes.

\section{Early or Late Biface Manufacture Flakes}

These flakes are defined as primary and secondary flakes having moderate to large dorsal flake scar ridges and with minimal to considerable longitudinal curvature. The striking platforms on this type range from single to multi-faceted, although single and double faceting is most common. These flakes are usually removed with a hard hammerstone or large billet, and the dorsal flake scarring is indicative of sequential flake removals and flake removals from opposite edges (Mehalchick et al. 1996).

\section{Blades}

Generally, a blade is defined as a flake that is twice as long as it is wide (Mehalchick et al. 1996), although in this study, the definition is restricted to flakes removed from a blade core. These flakes are characterized by single or multiple dorsal ridges that are roughly parallel to the longitudinal axis of the flake. These ridges are indicative of earlier blade removals. The longitudinal curvature of blades is slight to moderate. Striking platforms are generally single or corticate faceted, although double and multiple-faceted platforms occur as well (Mehalchick et al. 1996). 


\section{Bi-polar Flakes}

The process involving the creation of bi-polar flakes consists of an anvil and another stone implement. The lithic implement intended to be split or fractured would be placed on an anvil and then struck by with another stone implement. The force induced from both the hammerstone and anvil produces cones of force at both ends causing the core material to fracture and split. Although the impact of the hammerstone and anvil produce cones of percussions at both ends, usually only one is present in the end result and may be sheared or shattered (Crabtree 1982).

\section{Core Reduction Flakes}

Core reduction flakes are highly variable in size, shape, amount of dorsal cortex, and platform faceting, but they all represent an attempt to prepare a platform or core for subsequent flake removals. Size and platform faceting are dependent upon the stage of reduction during which they were removed and the size of the parent material which may be a core or artifact. Likewise, shape is dependent on the type of core from which they were removed. The amount of dorsal cortex is also highly variable, ranging from 0 to $100 \%$, depending on the stage of reduction (Mehalchick et al. 1996).

\section{Distinctive Expanding Billet (DEB) and " $r$ ” Flakes}

In experiments conducted by Hayden and Hutchings (1989) two flakes were identified as being inductive of softhammer percussion or billet flakes. In their experiments one expanding flake continually appeared to be exclusive with billet flaking. These flakes exhibited expanding lateral edges measuring over one half of the length of the flake. In addition to the expanding lateral edges these flakes were relatively thin with pronounced curvature and a small platform area. These flake types were referred to as DEB flakes (Hayden and Hutchings 1989).

The other flake identified directly associated with billet flaking was typed as a " $r$ " flake. These " $r$ " flakes characteristically appear to have been overshot flakes with a very broad area of the lithic implement being struck. The lithic implement is struck behind the platform edge producing a bending fracture on the ventral surface. In profile the flake has a $r$ shaped appearance (Hayden and Hutchings 1989).

\section{Notching Flakes}

These small flakes are usually 5-15 $\mathrm{mm}$ long, and are removed by pressure flaking during the creation of notches on projectile points or other notched tools. The flakes have distinctive U-shaped platforms and scalloped dorsal surfaces indicative of prior notching flake removals (Mehalchick et al. 1996).

\section{Sequence Flakes}

Sequence flakes are indicative of a particular core reduction strategy in which a cobble is first split lengthwise and then flakes are removed in sequence beginning at one end of the core. These flakes can be recognized by a double-negative bulb centered above or on the platform 
with a tabular surface. Sequence flakes are unique to a particular type of core technology, but without a series of them, they are most likely accidental in nature (Jelinek et al. 1971). This method of flake removal may have been useful in an environment where raw material was commonly available as tubular cobbles rather than as tabular or spherical cobbles.

\section{Thinning Flakes}

Thinning flakes can be created either in biface manufacturing or uniface manufacturing. These flakes are created by the removal of flakes from a perform either by percussion or pressure flaking. The platforms of these flakes are usually well prepared (Crabtree 1982).

\section{Indeterminate Flakes}

If a flake could not be assigned with certainty to one of the types described above, it was coded as indeterminate. Generally, flakes displaying attributes associated with two or more different types were included in the incomplete category.

Table 6-2 shows the reduction technology results of the whole flake analysis. A total of 476 flakes were analyzed. About 38.3 percent of the specimens could not be assigned a reduction technology and were dubbed "indeterminate," but the remainder were identified as one of the types described above. Core reduction flakes dominate the assemblage at 26.5 percent of the total, followed by late bifacial manufacturing flakes (13.0 percent), thinning flakes (12.4 percent), "r" flakes (3.3 percent), early bifacial manufacturing flakes (3.2 percent), and sequence flakes (2.1 percent). About 1.1 percent of the assemblage, only one specimen each, of notching flakes, DEB flakes, bipolar (anvil) flakes, bipolar (split cobble) flakes, and blades were observed.

\section{Incomplete Flakes $(n=767)$}

The analysis of incomplete flakes focused on those collected from the lower meter of hand excavations. Incomplete flakes were fragments of lithic flakes that did not possess any features that would allow for further analysis. The lithic analyst counted and weighed the specimens from each unit and level, and determined if the specimens were heat treated. A total of 767 incomplete flakes were analyzed in this manner. About 49 percent were observed to be heat treated. In other words, they demonstrated thermal alteration in the form of pot-lidding, cracked surfaces, or "greasy" appearing surfaces.

\section{Debitage $(n=781)$}

The analysis of debitage was conducted in a similar way as the incomplete flakes. Debitage was used as the catch-all category for non-burned rock lithic debris that was not identifiable as flakes or flake fragments. The lithic analyst counted and weighed the specimens from each unit and level, and determined if the specimens were heat treated. A total of 781 pieces of debitage were analyzed, and about 70 percent of them were heat treated. 
Table 6-2. Technological Assessment of Whole Flakes from 100-200 cmbs.

\begin{tabular}{|c|c|c|c|c|c|c|}
\hline Unit & Level & Lot & $\begin{array}{c}\text { Depth } \\
\text { (cmbs) }\end{array}$ & $\begin{array}{c}\text { Size } \\
\text { grade }\end{array}$ & Flake Type & Comments \\
\hline 1 & 12 & 64 & $110-120$ & $3 / 4$ & core reduction flake & \\
\hline 1 & 16 & 83 & $150-160$ & 1 & core reduction flake & \\
\hline 1 & 12 & 64 & $110-120$ & $1 / 4$ & indeterminate & \\
\hline 1 & 12 & 64 & $110-120$ & $1 / 2$ & indeterminate & \\
\hline 1 & 15 & 76 & $140-150$ & $1 / 2$ & indeterminate & \\
\hline 1 & 15 & 76 & $140-150$ & $3 / 4$ & indeterminate & \\
\hline 1 & 16 & 87 & 160-170 & 1 & indeterminate & \\
\hline 1 & 11 & 61 & $100-110$ & $3 / 4$ & late bifacial manufacturing flake & \\
\hline 1 & 15 & 76 & $140-150$ & $3 / 4$ & late bifacial manufacturing flake & \\
\hline 1 & 16 & 87 & 160-170 & $1 / 2$ & late bifacial manufacturing flake & \\
\hline 2 & 17 & 114 & $160-170$ & $3 / 4$ & core reduction flake & \\
\hline 2 & 19 & 119 & 180-190 & $3 / 4$ & core reduction flake & \\
\hline 2 & 17 & 114 & 160-170 & 1 & indeterminate & \\
\hline 2 & 18 & 116 & 170-180 & $1 / 4$ & indeterminate & \\
\hline 2 & 17 & 114 & 160-170 & $1 / 2$ & late bifacial manufacturing flake & \\
\hline 2 & 18 & 116 & 170-180 & $3 / 4$ & late bifacial manufacturing flake & \\
\hline 2 & 18 & 116 & 170-180 & $3 / 4$ & sequence flake & \\
\hline 3 & 12 & 40 & $100-110$ & $3 / 4$ & "r" flake (bifacial manufacturing flake) & billet flake \\
\hline 3 & 15 & 55 & $130-140$ & $1 / 4$ & "r" flake (bifacial manufacturing flake) & billet flake \\
\hline 3 & 16 & 58 & $140-150$ & $1 / 4$ & "r" flake (bifacial manufacturing flake) & billet flake \\
\hline 3 & 12 & 40 & $100-110$ & $3 / 4$ & indeterminate & \\
\hline 3 & 15 & 55 & $130-140$ & $1 / 4$ & indeterminate & \\
\hline 3 & 15 & 55 & $130-140$ & $1 / 2$ & indeterminate & \\
\hline 3 & 16 & 58 & $140-150$ & $1 / 2$ & indeterminate & \\
\hline 3 & 16 & 58 & $140-150$ & $1 / 2$ & indeterminate & \\
\hline 3 & 17 & 99 & $150-160$ & 1 & indeterminate & \\
\hline 3 & 19 & 107 & 170-180 & $1 / 4$ & indeterminate & \\
\hline 3 & 19 & 107 & 170-180 & $1 / 2$ & indeterminate & \\
\hline 3 & 15 & 55 & $130-140$ & 1 & late bifacial manufacturing flake & \\
\hline 4 & 13 & 79 & $120-130$ & 1 & bipolar (split cobble) & \\
\hline 4 & 12 & - & $110-120$ & 1 & core reduction flake & \\
\hline 4 & 13 & 79 & $120-130$ & 1 & core reduction flake & \\
\hline 4 & 13 & 79 & $120-130$ & 1 & core reduction flake & \\
\hline 4 & 13 & 79 & $120-130$ & 1 & core reduction flake & \\
\hline 4 & 15 & 86 & $140-150$ & 1 & core reduction flake & \\
\hline 4 & 11 & 25 & 100-110 & $1 / 2$ & indeterminate & \\
\hline 4 & 14 & 84 & $130-140$ & 1 & indeterminate & \\
\hline 4 & 13 & 79 & $120-130$ & $3 / 4$ & late bifacial manufacturing flake & \\
\hline 4 & 15 & 86 & $140-150$ & 1 & late bifacial manufacturing flake & \\
\hline 5 & 10 & 109 & $120-130$ & 1 & core reduction flake & \\
\hline 5 & 12 & 115 & 140-150 & $3 / 4$ & core reduction flake & \\
\hline 5 & 12 & 115 & 140-150 & 1 & core reduction flake & \\
\hline
\end{tabular}




\begin{tabular}{|c|c|c|c|c|c|c|}
\hline Unit & Level & Lot & $\begin{array}{c}\text { Depth } \\
\text { (cmbs) }\end{array}$ & $\begin{array}{c}\text { Size } \\
\text { grade }\end{array}$ & Flake Type & Comments \\
\hline 5 & 12 & 115 & $140-150$ & 1 & DEB (bifacial manufacturing flake) & billet flake \\
\hline 5 & 11 & 110 & $130-140$ & $1 / 4$ & indeterminate & \\
\hline 5 & 12 & 115 & $140-150$ & $1 / 4$ & indeterminate & \\
\hline 5 & 12 & 115 & $140-150$ & $3 / 4$ & indeterminate & \\
\hline 5 & 10 & 109 & $120-130$ & 1 & late bifacial manufacturing flake & \\
\hline 5 & 10 & 109 & $120-130$ & 1 & late bifacial manufacturing flake & \\
\hline 5 & 11 & 110 & $130-140$ & $1 / 2$ & late bifacial manufacturing flake & \\
\hline 5 & 11 & 110 & $130-140$ & 1 & sequence flake & \\
\hline 5 & 11 & 110 & $130-140$ & $1 / 2$ & thinning flake & \\
\hline 6 & 16 & 217 & 170-180 & $3 / 4$ & "r" flake (bifacial manufacturing flake) & billet flake \\
\hline 6 & 15 & - & $150-160$ & 1 & core reduction flake & \\
\hline 6 & 16 & 217 & 170-180 & $1 / 2$ & core reduction flake & \\
\hline 6 & 16 & 217 & 170-180 & $1 / 2$ & core reduction flake & \\
\hline 6 & 16 & 217 & $170-180$ & 1 & core reduction flake & \\
\hline 6 & 16 & 217 & 170-180 & 1 & core reduction flake & \\
\hline 6 & 16 & 217 & $170-180$ & 1 & core reduction flake & \\
\hline 6 & 16 & 217 & 170-180 & 1 & core reduction flake & \\
\hline 6 & 16 & 217 & 170-180 & 1 & core reduction flake & \\
\hline 6 & 16 & 217 & 170-180 & 1 & core reduction flake & \\
\hline 6 & 14 & 103 & $140-150$ & 1 & early bifacial manufacturing flake & \\
\hline 6 & 15 & - & $150-160$ & 1 & early bifacial manufacturing flake & \\
\hline 6 & 16 & 217 & 170-180 & $1 / 2$ & early bifacial manufacturing flake & \\
\hline 6 & 11 & 82 & $110-120$ & $1 / 4$ & indeterminate & \\
\hline 6 & 11 & 82 & $110-120$ & 1 & indeterminate & \\
\hline 6 & 15 & 174 & $160-170$ & 1 & indeterminate & \\
\hline 6 & 15 & 174 & $160-170$ & $1 / 2$ & indeterminate & \\
\hline 6 & 15 & 174 & 160-170 & $3 / 4$ & indeterminate & \\
\hline 6 & 15 & - & $150-160$ & $1 / 4$ & indeterminate & \\
\hline 6 & 16 & 217 & 170-180 & $1 / 4$ & indeterminate & \\
\hline 6 & 16 & 217 & 170-180 & $1 / 4$ & indeterminate & \\
\hline 6 & 16 & 217 & 170-180 & $1 / 4$ & indeterminate & \\
\hline 6 & 16 & 217 & 170-180 & $1 / 4$ & indeterminate & \\
\hline 6 & 16 & 217 & 170-180 & $1 / 2$ & indeterminate & \\
\hline 6 & 16 & 217 & 170-180 & $1 / 2$ & indeterminate & \\
\hline 6 & 16 & 217 & 170-180 & $1 / 2$ & indeterminate & \\
\hline 6 & 16 & 217 & 170-180 & 1 & indeterminate & \\
\hline 6 & 16 & 217 & 170-180 & $3 / 4$ & indeterminate & \\
\hline 6 & 16 & 217 & 170-180 & $3 / 4$ & indeterminate & \\
\hline 6 & 17 & 229 & 180-190 & $1 / 4$ & indeterminate & \\
\hline 6 & 10 & 75 & $100-110$ & $1 / 2$ & late bifacial manufacturing flake & \\
\hline 6 & 13 & 94 & $130-140$ & $3 / 4$ & late bifacial manufacturing flake & \\
\hline 6 & 15 & 174 & $160-170$ & $1 / 2$ & late bifacial manufacturing flake & \\
\hline 6 & 16 & 217 & 170-180 & $1 / 2$ & late bifacial manufacturing flake & \\
\hline 6 & 16 & 217 & 170-180 & $1 / 2$ & late bifacial manufacturing flake & \\
\hline
\end{tabular}




\begin{tabular}{|c|c|c|c|c|c|c|}
\hline Unit & Level & Lot & $\begin{array}{l}\text { Depth } \\
\text { (cmbs) }\end{array}$ & $\begin{array}{c}\text { Size } \\
\text { grade }\end{array}$ & Flake Type & Comments \\
\hline 6 & 18 & 234 & 190-200 & $1 / 2$ & late bifacial manufacturing flake & \\
\hline 6 & 16 & 217 & $170-180$ & $1 / 4$ & sequence flake & \\
\hline 6 & 16 & 217 & $170-180$ & $1 / 4$ & sequence flake & \\
\hline 7 & 13 & 127 & $140-150$ & 1 & core reduction flake & \\
\hline 7 & 9 & 59 & $100-110$ & $1 / 4$ & indeterminate & \\
\hline 7 & 11 & 121 & $120-130$ & $1 / 2$ & indeterminate & \\
\hline 7 & 12 & 125 & $130-140$ & $1 / 2$ & indeterminate & \\
\hline 7 & 12 & 125 & $130-140$ & $1 / 2$ & indeterminate & \\
\hline 7 & 13 & 127 & $140-150$ & $1 / 2$ & indeterminate & \\
\hline 7 & 13 & 127 & $140-150$ & $1 / 4$ & indeterminate & \\
\hline 7 & 13 & 127 & $140-150$ & $3 / 4$ & indeterminate & \\
\hline 7 & 13 & 127 & $140-150$ & $1 / 2$ & late bifacial manufacturing flake & \\
\hline 7 & 13 & 127 & $140-150$ & $1 / 2$ & late bifacial manufacturing flake & \\
\hline 7 & 13 & 127 & $140-150$ & $3 / 4$ & late bifacial manufacturing flake & \\
\hline 7 & 13 & 127 & $140-150$ & $3 / 4$ & late bifacial manufacturing flake & \\
\hline 7 & 13 & 127 & $140-150$ & $3 / 4$ & thinning flake & \\
\hline 8 & 13 & 120 & $140-150$ & 1 & core reduction flake & \\
\hline 8 & 13 & 120 & $140-150$ & 1 & core reduction flake & \\
\hline 8 & 14 & 117 & $150-160$ & $3 / 4$ & core reduction flake & \\
\hline 8 & 12 & 105 & $130-140$ & 1 & early bifacial manufacturing flake & \\
\hline 8 & 13 & 120 & $140-150$ & 1 & early bifacial manufacturing flake & \\
\hline 8 & 13 & 120 & $140-150$ & $3 / 4$ & early bifacial manufacturing flake & \\
\hline 8 & 11 & 97 & $120-130$ & $1 / 2$ & indeterminate & \\
\hline 8 & 12 & 105 & $130-140$ & $1 / 2$ & indeterminate & \\
\hline 8 & 12 & 105 & $130-140$ & $3 / 4$ & indeterminate & \\
\hline 8 & 13 & 120 & $140-150$ & $1 / 2$ & indeterminate & \\
\hline 8 & 14 & 117 & $150-160$ & $1 / 2$ & indeterminate & \\
\hline 8 & 9 & 73 & $100-110$ & $1 / 2$ & thinning flake & \\
\hline 8 & 9 & 73 & $100-110$ & $1 / 2$ & thinning flake & \\
\hline 9 & 12 & 108 & $120-130$ & $3 / 4$ & core reduction flake & \\
\hline 9 & 12 & 108 & $120-130$ & $3 / 4$ & core reduction flake & \\
\hline 9 & 10 & 96 & $100-110$ & $1 / 2$ & indeterminate & \\
\hline 9 & 12 & 108 & $120-130$ & $1 / 2$ & indeterminate & \\
\hline 9 & 13 & 111 & $130-140$ & $1 / 4$ & indeterminate & \\
\hline 9 & 12 & 108 & $120-130$ & $3 / 4$ & late bifacial manufacturing flake & \\
\hline 9 & 12 & 108 & $120-130$ & 1 & thinning flake & \\
\hline 10 & 6 & - & $160-170$ & 1 & blade & \\
\hline 10 & 4 & 128 & $140-150$ & 1 & core reduction flake & \\
\hline 10 & 5 & 134 & $150-160$ & $1 / 2$ & core reduction flake & \\
\hline 10 & 6 & - & $160-170$ & $3 / 4$ & core reduction flake & \\
\hline 10 & 6 & - & $160-170$ & $3 / 4$ & core reduction flake & \\
\hline 10 & 6 & - & $160-170$ & $3 / 4$ & core reduction flake & \\
\hline 10 & 6 & - & $160-170$ & $3 / 4$ & core reduction flake & \\
\hline 10 & 6 & - & $160-170$ & 1 & core reduction flake & \\
\hline
\end{tabular}




\begin{tabular}{|c|c|c|c|c|c|c|}
\hline Unit & Level & Lot & $\begin{array}{c}\text { Depth } \\
\text { (cmbs) }\end{array}$ & $\begin{array}{c}\text { Size } \\
\text { grade }\end{array}$ & Flake Type & Comments \\
\hline 10 & 6 & - & $160-170$ & 1 & core reduction flake & \\
\hline 10 & 7 & 216 & $170-180$ & $1 / 2$ & core reduction flake & \\
\hline 10 & 7 & 216 & 170-180 & $3 / 4$ & core reduction flake & \\
\hline 10 & 7 & 216 & $170-180$ & $3 / 4$ & core reduction flake & \\
\hline 10 & 7 & 216 & $170-180$ & $3 / 4$ & core reduction flake & \\
\hline 10 & 7 & 216 & $170-180$ & $3 / 4$ & core reduction flake & \\
\hline 10 & 7 & 216 & $170-180$ & $3 / 4$ & core reduction flake & \\
\hline 10 & 7 & 216 & $170-180$ & $3 / 4$ & core reduction flake & \\
\hline 10 & 7 & 216 & $170-180$ & 1 & core reduction flake & \\
\hline 10 & 7 & 216 & $170-180$ & 1 & core reduction flake & \\
\hline 10 & 7 & 216 & $170-180$ & 1 & core reduction flake & \\
\hline 10 & 7 & 216 & $170-180$ & 1 & core reduction flake & \\
\hline 10 & 7 & 216 & $170-180$ & 1 & core reduction flake & \\
\hline 10 & 7 & 216 & $170-180$ & 1 & core reduction flake & \\
\hline 10 & 7 & 216 & $170-180$ & 1 & core reduction flake & \\
\hline 10 & 7 & 216 & $170-180$ & 1 & core reduction flake & \\
\hline 10 & 8 & 219 & $180-190$ & $3 / 4$ & core reduction flake & \\
\hline 10 & 9 & 228 & 190-200 & 1 & core reduction flake & \\
\hline 10 & 3 & 126 & $130-140$ & $3 / 4$ & early bifacial manufacturing flake & \\
\hline 10 & 7 & 216 & $170-180$ & $3 / 4$ & early bifacial manufacturing flake & \\
\hline 10 & 7 & 216 & $170-180$ & $3 / 4$ & early bifacial manufacturing flake & \\
\hline 10 & 3 & 126 & $130-140$ & $1 / 2$ & indeterminate & \\
\hline 10 & 4 & 128 & $140-150$ & $1 / 2$ & indeterminate & \\
\hline 10 & 4 & 128 & $140-150$ & $1 / 2$ & indeterminate & \\
\hline 10 & 4 & 128 & $140-150$ & $1 / 2$ & indeterminate & \\
\hline 10 & 6 & - & $160-170$ & $1 / 2$ & indeterminate & \\
\hline 10 & 7 & 216 & $170-180$ & $1 / 4$ & indeterminate & \\
\hline 10 & 7 & 216 & $170-180$ & $1 / 4$ & indeterminate & \\
\hline 10 & 7 & 216 & $170-180$ & $1 / 4$ & indeterminate & \\
\hline 10 & 7 & 216 & $170-180$ & $1 / 2$ & indeterminate & \\
\hline 10 & 7 & 216 & $170-180$ & $1 / 2$ & indeterminate & \\
\hline 10 & 7 & 216 & $170-180$ & $1 / 2$ & indeterminate & \\
\hline 10 & 6 & - & $160-170$ & $3 / 4$ & late bifacial manufacturing flake & \\
\hline 10 & 7 & 216 & $170-180$ & $1 / 2$ & late bifacial manufacturing flake & \\
\hline 10 & 7 & 216 & $170-180$ & $1 / 2$ & late bifacial manufacturing flake & \\
\hline 10 & 7 & 216 & $170-180$ & $1 / 2$ & late bifacial manufacturing flake & \\
\hline 10 & 7 & 216 & $170-180$ & $3 / 4$ & late bifacial manufacturing flake & \\
\hline 10 & 7 & 216 & $170-180$ & $3 / 4$ & late bifacial manufacturing flake & \\
\hline 10 & 6 & - & $160-170$ & $1 / 2$ & sequence flake & \\
\hline 10 & 4 & 128 & $140-150$ & 1 & thinning flake & \\
\hline 10 & 4 & 128 & $140-150$ & $1 / 2$ & thinning flake & \\
\hline 10 & 4 & 128 & $140-150$ & $1 / 2$ & thinning flake & \\
\hline 10 & 7 & 216 & $170-180$ & $1 / 2$ & thinning flake & \\
\hline 10 & 7 & 216 & $170-180$ & $1 / 2$ & thinning flake & \\
\hline
\end{tabular}




\begin{tabular}{|c|c|c|c|c|c|c|}
\hline Unit & Level & Lot & $\begin{array}{c}\text { Depth } \\
\text { (cmbs) }\end{array}$ & $\begin{array}{c}\text { Size } \\
\text { grade }\end{array}$ & Flake Type & Comments \\
\hline 10 & 7 & 216 & $170-180$ & $1 / 2$ & thinning flake & \\
\hline 10 & 7 & 216 & $170-180$ & $1 / 2$ & thinning flake & \\
\hline 10 & 7 & 216 & $170-180$ & $1 / 2$ & thinning flake & \\
\hline 11 & 5 & 155 & $150-160$ & 1 & early bifacial manufacturing flake & \\
\hline 11 & 1 & 130 & $110-120$ & $1 / 2$ & indeterminate & \\
\hline 11 & 2 & 132 & $120-130$ & $3 / 4$ & thinning flake & \\
\hline 11 & 3 & 135 & $130-140$ & $1 / 4$ & thinning flake & \\
\hline 12 & 2 & 131 & $100-110$ & $1 / 2$ & core reduction flake & \\
\hline 12 & 3 & 133 & $110-120$ & 1 & core reduction flake & \\
\hline 12 & 5 & 138 & $130-140$ & $3 / 4$ & core reduction flake & \\
\hline 12 & 5 & 138 & $130-140$ & 1 & core reduction flake & \\
\hline 12 & 5 & 138 & $130-140$ & 1 & core reduction flake & \\
\hline 12 & 6 & 139 & $140-150$ & $3 / 4$ & core reduction flake & \\
\hline 12 & 6 & 139 & $140-150$ & 1 & core reduction flake & \\
\hline 12 & 2 & 131 & $100-110$ & $1 / 2$ & indeterminate & \\
\hline 12 & 2 & 131 & $100-110$ & $1 / 4$ & indeterminate & \\
\hline 12 & 4 & 136 & $120-130$ & $1 / 2$ & indeterminate & \\
\hline 12 & 5 & 138 & $130-140$ & $1 / 4$ & indeterminate & \\
\hline 12 & 5 & 138 & $130-140$ & $1 / 4$ & indeterminate & \\
\hline 12 & 6 & 139 & $140-150$ & $1 / 2$ & indeterminate & \\
\hline 12 & 6 & 139 & $140-150$ & $3 / 4$ & indeterminate & \\
\hline 12 & 2 & 131 & $100-110$ & $1 / 4$ & thinning flake & \\
\hline 12 & 6 & 139 & $140-150$ & 1 & thinning flake & \\
\hline 12 & 6 & 139 & $140-150$ & 1 & thinning flake & \\
\hline 12 & 6 & 139 & $140-150$ & 1 & thinning flake & \\
\hline 12 & 6 & 139 & $140-150$ & $1 / 2$ & thinning flake & \\
\hline 12 & 6 & 139 & $140-150$ & $3 / 4$ & thinning flake & \\
\hline 13 & 1 & 146 & $110-120$ & $1 / 4$ & "r" flake (bifacial manufacturing flake) & billet flake \\
\hline 13 & 6 & 184 & $160-170$ & $1 / 4$ & "r" flake (bifacial manufacturing flake) & billet flake \\
\hline 13 & 6 & 184 & $160-170$ & $1 / 2$ & "r" flake (bifacial manufacturing flake) & billet flake \\
\hline 13 & 6 & 184 & $160-170$ & 1 & "r" flake (bifacial manufacturing flake) & billet flake \\
\hline 13 & 3 & 158 & $130-140$ & $1 / 2$ & core reduction flake & \\
\hline 13 & 3 & 158 & $130-140$ & $3 / 4$ & core reduction flake & \\
\hline 13 & 3 & 158 & $130-140$ & $3 / 4$ & core reduction flake & \\
\hline 13 & 3 & 158 & $130-140$ & 1 & core reduction flake & \\
\hline 13 & 5 & 170 & $150-160$ & 1 & core reduction flake & \\
\hline 13 & 6 & 184 & $160-170$ & 1 & core reduction flake & \\
\hline 13 & 6 & 184 & $160-170$ & 1 & core reduction flake & \\
\hline 13 & 7 & 218 & $170-180$ & $3 / 4$ & core reduction flake & \\
\hline 13 & 2 & 150 & $120-130$ & 1 & early bifacial manufacturing flake & \\
\hline 13 & 1 & 146 & $110-120$ & $1 / 4$ & indeterminate & \\
\hline 13 & 1 & 146 & $110-120$ & $1 / 4$ & indeterminate & \\
\hline 13 & 2 & 150 & $120-130$ & $3 / 4$ & indeterminate & \\
\hline 13 & 2 & 150 & $120-130$ & $1 / 4$ & indeterminate & \\
\hline
\end{tabular}




\begin{tabular}{|c|c|c|c|c|c|c|}
\hline Unit & Level & Lot & $\begin{array}{c}\text { Depth } \\
\text { (cmbs) }\end{array}$ & $\begin{array}{c}\text { Size } \\
\text { grade }\end{array}$ & Flake Type & Comments \\
\hline 13 & 3 & 158 & $130-140$ & $1 / 4$ & indeterminate & \\
\hline 13 & 3 & 158 & $130-140$ & 1 & indeterminate & \\
\hline 13 & 4 & 163 & 140-150 & $3 / 4$ & indeterminate & \\
\hline 13 & 4 & 163 & 140-150 & $1 / 2$ & indeterminate & \\
\hline 13 & 5 & 170 & $150-160$ & $1 / 2$ & indeterminate & \\
\hline 13 & 5 & 170 & $150-160$ & $3 / 4$ & indeterminate & \\
\hline 13 & 6 & 184 & 160-170 & $1 / 2$ & indeterminate & \\
\hline 13 & 6 & 184 & 160-170 & $1 / 2$ & indeterminate & \\
\hline 13 & 6 & 184 & 160-170 & $3 / 4$ & indeterminate & \\
\hline 13 & 6 & 184 & 160-170 & $3 / 4$ & indeterminate & \\
\hline 13 & 6 & 184 & 160-170 & $3 / 4$ & indeterminate & \\
\hline 13 & 7 & 218 & 170-180 & $1 / 4$ & indeterminate & \\
\hline 13 & 7 & 218 & 170-180 & $1 / 4$ & indeterminate & \\
\hline 13 & 7 & 218 & 170-180 & $1 / 4$ & indeterminate & \\
\hline 13 & 7 & 218 & 170-180 & $1 / 4$ & indeterminate & \\
\hline 13 & 7 & 218 & 170-180 & $1 / 4$ & indeterminate & \\
\hline 13 & 7 & 218 & 170-180 & $1 / 2$ & indeterminate & \\
\hline 13 & 2 & 150 & $120-130$ & 1 & late bifacial manufacturing flake & \\
\hline 13 & 7 & 218 & 170-180 & $1 / 2$ & late bifacial manufacturing flake & \\
\hline 13 & 7 & 218 & 170-180 & $1 / 2$ & late bifacial manufacturing flake & \\
\hline 13 & 7 & 218 & 170-180 & $1 / 2$ & late bifacial manufacturing flake & \\
\hline 13 & 7 & 218 & 170-180 & $3 / 4$ & late bifacial manufacturing flake & \\
\hline 13 & 8 & 277 & $180-190$ & $3 / 4$ & late bifacial manufacturing flake & \\
\hline 13 & 7 & 218 & 170-180 & $1 / 4$ & notching flake & \\
\hline 13 & 1 & 146 & $110-120$ & 1 & sequence flake & \\
\hline 13 & 5 & 170 & $150-160$ & $1 / 2$ & thinning flake & \\
\hline 13 & 6 & 184 & $160-170$ & $1 / 2$ & thinning flake & \\
\hline 13 & 7 & 218 & 170-180 & $1 / 4$ & thinning flake & \\
\hline 13 & 7 & 218 & 170-180 & $3 / 4$ & thinning flake & \\
\hline 14 & 5 & 193 & $150-160$ & 1 & core reduction flake & \\
\hline 14 & 6 & 205 & $160-170$ & 1 & core reduction flake & \\
\hline 14 & 1 & 156 & $110-120$ & $1 / 2$ & indeterminate & \\
\hline 14 & 1 & 156 & $110-120$ & $1 / 4$ & indeterminate & \\
\hline 14 & 4 & 192 & 140-150 & $1 / 2$ & indeterminate & \\
\hline 14 & 6 & 205 & $160-170$ & $1 / 2$ & indeterminate & \\
\hline 14 & 6 & 203 & $160-170$ & $1 / 2$ & indeterminate & \\
\hline 14 & 3 & 179 & $130-140$ & 1 & late bifacial manufacturing flake & \\
\hline 14 & 4 & 192 & $140-150$ & $1 / 2$ & late bifacial manufacturing flake & \\
\hline 14 & 4 & 192 & $140-150$ & $3 / 4$ & late bifacial manufacturing flake & \\
\hline 14 & 4 & 192 & $140-150$ & $3 / 4$ & late bifacial manufacturing flake & \\
\hline 14 & 6 & 203 & $160-170$ & 1 & late bifacial manufacturing flake & \\
\hline 15 & 7 & 188 & 170-180 & $1 / 2$ & "r" flake (bifacial manufacturing flake) & billet flake \\
\hline 15 & 7 & 188 & 170-180 & $1 / 2$ & "r" flake (bifacial manufacturing flake) & billet flake \\
\hline 15 & 2 & 148 & $120-130$ & $3 / 4$ & core reduction flake & \\
\hline
\end{tabular}




\begin{tabular}{|c|c|c|c|c|c|c|}
\hline Unit & Level & Lot & $\begin{array}{c}\text { Depth } \\
\text { (cmbs) }\end{array}$ & $\begin{array}{c}\text { Size } \\
\text { grade }\end{array}$ & Flake Type & Comments \\
\hline 15 & 5 & 154 & $150-160$ & 1 & early bifacial manufacturing flake & \\
\hline 15 & 7 & 188 & $170-180$ & $1 / 2$ & indeterminate & \\
\hline 15 & 3 & 150 & $130-140$ & $1 / 4$ & thinning flake & \\
\hline 15 & 5 & 154 & $150-160$ & $1 / 4$ & thinning flake & \\
\hline 16 & 1 & 141 & $110-120$ & 1 & core reduction flake & \\
\hline 16 & 2 & 142 & $120-130$ & 1 & core reduction flake & \\
\hline 16 & 3 & 143 & $130-140$ & $1 / 4$ & thinning flake & \\
\hline 17 & 1 & 153 & $120-130$ & 1 & core reduction flake & \\
\hline 17 & 3 & 157 & $130-140$ & $3 / 4$ & core reduction flake & \\
\hline 17 & 3 & 157 & $130-140$ & $3 / 4$ & early bifacial manufacturing flake & \\
\hline 17 & 1 & 153 & $120-130$ & $1 / 2$ & indeterminate & \\
\hline 17 & 3 & 157 & $130-140$ & $1 / 4$ & indeterminate & \\
\hline 17 & 3 & 157 & $130-140$ & $1 / 4$ & indeterminate & \\
\hline 17 & 3 & 157 & $130-140$ & $1 / 2$ & indeterminate & \\
\hline 17 & 4 & 159 & $140-150$ & $1 / 4$ & indeterminate & \\
\hline 17 & 4 & 159 & $140-150$ & $1 / 2$ & indeterminate & \\
\hline 17 & 4 & 159 & $140-150$ & $1 / 2$ & indeterminate & \\
\hline 17 & 3 & 157 & $130-140$ & $1 / 2$ & sequence flake & \\
\hline 17 & 3 & 157 & $130-140$ & $1 / 2$ & thinning flake & \\
\hline 17 & 3 & 157 & $130-140$ & $3 / 4$ & thinning flake & \\
\hline 18 & 12 & 167 & $110-120$ & $1 / 2$ & indeterminate & \\
\hline 18 & 11 & 166 & $100-110$ & 1 & late bifacial manufacturing flake & \\
\hline 19 & 5 & - & $150-160$ & $1 / 2$ & "r" flake (bifacial manufacturing flake) & billet flake \\
\hline 19 & 3 & - & $130-140$ & $3 / 4$ & core reduction flake & \\
\hline 19 & 3 & - & $130-140$ & 1 & core reduction flake & \\
\hline 19 & 4 & - & $140-150$ & $3 / 4$ & core reduction flake & \\
\hline 19 & 4 & - & $140-150$ & 1 & core reduction flake & \\
\hline 19 & 3 & - & $130-140$ & $1 / 4$ & indeterminate & \\
\hline 19 & 3 & - & $130-140$ & $1 / 2$ & indeterminate & \\
\hline 19 & 3 & - & $130-140$ & $1 / 2$ & indeterminate & \\
\hline 19 & 3 & - & $130-140$ & $3 / 4$ & indeterminate & \\
\hline 19 & 4 & - & $140-150$ & $1 / 4$ & indeterminate & \\
\hline 19 & 4 & - & $140-150$ & $1 / 2$ & indeterminate & \\
\hline 19 & 4 & - & $140-150$ & $3 / 4$ & indeterminate & \\
\hline 19 & 5 & - & $150-160$ & $1 / 2$ & indeterminate & \\
\hline 19 & 5 & - & $150-160$ & $1 / 2$ & indeterminate & \\
\hline 19 & 3 & - & $130-140$ & $3 / 4$ & late bifacial manufacturing flake & \\
\hline 19 & 4 & - & $140-150$ & $3 / 4$ & sequence flake & \\
\hline 19 & 3 & - & $130-140$ & $1 / 2$ & thinning flake & \\
\hline 19 & 4 & - & $140-150$ & $1 / 2$ & thinning flake & \\
\hline 19 & 4 & - & $140-150$ & $1 / 2$ & thinning flake & \\
\hline 19 & 4 & - & $140-150$ & 1 & thinning flake & \\
\hline 19 & 5 & - & $150-160$ & $1 / 4$ & thinning flake & \\
\hline 20 & 2 & - & $120-130$ & 1 & core reduction flake & \\
\hline 20 & 3 & 189 & $130-140$ & $3 / 4$ & core reduction flake & \\
\hline
\end{tabular}




\begin{tabular}{|c|c|c|c|c|c|c|}
\hline Unit & Level & Lot & $\begin{array}{l}\text { Depth } \\
\text { (cmbs) }\end{array}$ & $\begin{array}{l}\text { Size } \\
\text { grade }\end{array}$ & Flake Type & Comments \\
\hline 20 & 4 & 191 & $140-150$ & $1 / 2$ & core reduction flake & \\
\hline 20 & 4 & 191 & $140-150$ & $3 / 4$ & core reduction flake & \\
\hline 20 & 5 & 195 & $150-160$ & $3 / 4$ & core reduction flake & \\
\hline 20 & 5 & 195 & $150-160$ & 1 & core reduction flake & \\
\hline 20 & 2 & - & $120-130$ & $1 / 4$ & indeterminate & \\
\hline 20 & 2 & - & $120-130$ & $3 / 4$ & indeterminate & \\
\hline 20 & 3 & 189 & $130-140$ & $1 / 4$ & indeterminate & \\
\hline 20 & 3 & 189 & $130-140$ & $1 / 2$ & indeterminate & \\
\hline 20 & 3 & 189 & $130-140$ & $1 / 2$ & indeterminate & \\
\hline 20 & 3 & 189 & $130-140$ & $3 / 4$ & indeterminate & \\
\hline 20 & 4 & 191 & $140-150$ & $1 / 4$ & indeterminate & \\
\hline 20 & 4 & 191 & $140-150$ & $1 / 2$ & indeterminate & \\
\hline 20 & 4 & 191 & $140-150$ & $1 / 2$ & indeterminate & \\
\hline 20 & 4 & 191 & $140-150$ & $1 / 2$ & indeterminate & \\
\hline 20 & 4 & 191 & $140-150$ & $1 / 2$ & indeterminate & \\
\hline 20 & 5 & 195 & $150-160$ & $1 / 2$ & indeterminate & \\
\hline 20 & 5 & 195 & $150-160$ & $1 / 2$ & indeterminate & \\
\hline 20 & 5 & 195 & $150-160$ & $1 / 2$ & late bifacial manufacturing flake & \\
\hline 20 & 1 & - & $110-120$ & $3 / 4$ & sequence flake & \\
\hline 20 & 1 & - & $110-120$ & $1 / 4$ & thinning flake & \\
\hline 20 & 4 & 191 & $140-150$ & $1 / 4$ & thinning flake & \\
\hline 21 & 5 & 177 & $150-160$ & $1 / 4$ & "r" flake (bifacial manufacturing flake) & billet flake \\
\hline 21 & 4 & 176 & $140-150$ & $1 / 2$ & core reduction flake & \\
\hline 21 & 2 & 168 & $120-130$ & $3 / 4$ & indeterminate & \\
\hline 21 & 2 & 168 & $120-130$ & 1 & indeterminate & \\
\hline 21 & 3 & 175 & $130-140$ & $1 / 4$ & indeterminate & \\
\hline 21 & 3 & 175 & $130-140$ & $1 / 2$ & indeterminate & \\
\hline 21 & 3 & 175 & $130-140$ & $1 / 2$ & indeterminate & \\
\hline 21 & 3 & 175 & $130-140$ & $1 / 2$ & indeterminate & \\
\hline 21 & 3 & 175 & $130-140$ & 1 & indeterminate & \\
\hline 21 & 5 & 177 & $150-160$ & $1 / 2$ & indeterminate & \\
\hline 22 & 2 & 190 & $120-130$ & $1 / 4$ & core reduction flake & \\
\hline 22 & 3 & 194 & $130-140$ & $3 / 4$ & core reduction flake & \\
\hline 22 & 3 & 194 & $130-140$ & 1 & core reduction flake & \\
\hline 22 & 3 & 194 & $130-140$ & 1 & core reduction flake & \\
\hline 22 & 4 & 196 & $140-150$ & $1 / 2$ & core reduction flake & \\
\hline 22 & 4 & 196 & $140-150$ & $1 / 2$ & core reduction flake & \\
\hline 22 & 4 & 196 & $140-150$ & $3 / 4$ & core reduction flake & \\
\hline 22 & 4 & 196 & $140-150$ & 1 & core reduction flake & \\
\hline 22 & 4 & 196 & 140-150 & 1 & core reduction flake & \\
\hline 22 & 1 & 181 & $110-120$ & $1 / 2$ & indeterminate & \\
\hline 22 & 2 & 190 & $120-130$ & $1 / 4$ & indeterminate & \\
\hline 22 & 3 & 194 & $130-140$ & $1 / 4$ & indeterminate & \\
\hline 22 & 3 & 194 & $130-140$ & $3 / 4$ & indeterminate & \\
\hline 22 & 3 & 194 & $130-140$ & $3 / 4$ & indeterminate & \\
\hline
\end{tabular}




\begin{tabular}{|c|c|c|c|c|c|c|}
\hline Unit & Level & Lot & $\begin{array}{l}\text { Depth } \\
\text { (cmbs) }\end{array}$ & $\begin{array}{c}\text { Size } \\
\text { grade }\end{array}$ & Flake Type & Comments \\
\hline 22 & 4 & 196 & $140-150$ & $1 / 4$ & indeterminate & \\
\hline 22 & 4 & 196 & $140-150$ & $1 / 4$ & indeterminate & \\
\hline 22 & 4 & 196 & $140-150$ & $1 / 4$ & indeterminate & \\
\hline 22 & 1 & 181 & $110-120$ & $1 / 2$ & late bifacial manufacturing flake & \\
\hline 22 & 1 & 181 & $110-120$ & $3 / 4$ & late bifacial manufacturing flake & \\
\hline 22 & 2 & 190 & $120-130$ & $1 / 2$ & late bifacial manufacturing flake & \\
\hline 22 & 3 & 194 & $130-140$ & $3 / 4$ & late bifacial manufacturing flake & \\
\hline 22 & 4 & 196 & $140-150$ & $1 / 2$ & late bifacial manufacturing flake & \\
\hline 22 & 4 & 196 & $140-150$ & $1 / 2$ & late bifacial manufacturing flake & \\
\hline 22 & 3 & 194 & $130-140$ & $1 / 4$ & thinning flake & \\
\hline 22 & 3 & 194 & $130-140$ & $1 / 4$ & thinning flake & \\
\hline 22 & 3 & 194 & $130-140$ & $1 / 2$ & thinning flake & \\
\hline 23 & 9 & 242 & $100-110$ & $1 / 2$ & indeterminate & \\
\hline 23 & 10 & 244 & $110-120$ & $1 / 2$ & indeterminate & \\
\hline 23 & 11 & 248 & $120-130$ & $3 / 4$ & indeterminate & \\
\hline 23 & 12 & 255 & $130-140$ & $1 / 4$ & indeterminate & \\
\hline 23 & 12 & 255 & $130-140$ & $1 / 4$ & indeterminate & \\
\hline 23 & 13 & 259 & $140-150$ & $1 / 2$ & late bifacial manufacturing flake & \\
\hline 23 & 13 & 259 & $140-150$ & $1 / 4$ & thinning flake & \\
\hline 24 & 5 & 183 & $130-140$ & $1 / 4$ & "r" flake (bifacial manufacturing flake) & billet flake \\
\hline 24 & 2 & 172 & $110-120$ & 1 & core reduction flake & \\
\hline 24 & 4 & 182 & $120-130$ & $1 / 2$ & core reduction flake & \\
\hline 24 & 5 & 183 & $130-140$ & 1 & core reduction flake & \\
\hline 24 & 6 & 197 & $140-150$ & $1 / 2$ & core reduction flake & \\
\hline 24 & 6 & 197 & $140-150$ & $1 / 2$ & core reduction flake & \\
\hline 24 & 6 & 197 & $140-150$ & $3 / 4$ & core reduction flake & \\
\hline 24 & 6 & 197 & $140-150$ & $1 / 4$ & indeterminate & \\
\hline 24 & 6 & 197 & $140-150$ & $1 / 2$ & indeterminate & \\
\hline 24 & 6 & 197 & $140-150$ & $1 / 2$ & indeterminate & \\
\hline 24 & 6 & 197 & $140-150$ & $1 / 2$ & indeterminate & \\
\hline 24 & 6 & 197 & $140-150$ & $1 / 2$ & indeterminate & \\
\hline 24 & 6 & 197 & $140-150$ & $1 / 2$ & indeterminate & \\
\hline 24 & 7 & 198 & $160-170$ & $1 / 4$ & indeterminate & \\
\hline 24 & 9 & 211 & $180-190$ & $3 / 4$ & indeterminate & \\
\hline 24 & 6 & 197 & $140-150$ & $3 / 4$ & late bifacial manufacturing flake & \\
\hline 24 & 2 & 172 & $110-120$ & $1 / 4$ & thinning flake & \\
\hline 24 & 7 & 198 & $160-170$ & $1 / 4$ & thinning flake & \\
\hline 25 & 6 & 235 & $150-160$ & $1 / 2$ & "r" flake (bifacial manufacturing flake) & billet flake \\
\hline 25 & 2 & 201 & $110-120$ & $1 / 2$ & core reduction flake & \\
\hline 25 & 2 & 201 & $110-120$ & 1 & core reduction flake & \\
\hline 25 & 4 & 221 & $130-140$ & $3 / 4$ & core reduction flake & \\
\hline 25 & 4 & 221 & $130-140$ & $3 / 4$ & core reduction flake & \\
\hline 25 & 4 & 221 & $130-140$ & $3 / 4$ & core reduction flake & \\
\hline 25 & 4 & 221 & $130-140$ & $3 / 4$ & core reduction flake & \\
\hline 25 & 4 & 221 & $130-140$ & $3 / 4$ & core reduction flake & \\
\hline
\end{tabular}




\begin{tabular}{|c|c|c|c|c|c|c|}
\hline Unit & Level & Lot & $\begin{array}{c}\text { Depth } \\
\text { (cmbs) }\end{array}$ & $\begin{array}{c}\text { Size } \\
\text { grade }\end{array}$ & Flake Type & Comments \\
\hline 25 & 4 & 221 & $130-140$ & 1 & core reduction flake & \\
\hline 25 & 5 & 222 & $140-150$ & 1 & core reduction flake & \\
\hline 25 & 5 & 222 & $140-150$ & 1 & core reduction flake & \\
\hline 25 & 5 & 222 & $140-150$ & 1 & core reduction flake & \\
\hline 25 & 6 & 235 & $150-160$ & $1 / 2$ & core reduction flake & \\
\hline 25 & 6 & 235 & $150-160$ & $3 / 4$ & core reduction flake & \\
\hline 25 & 6 & 235 & $150-160$ & 1 & core reduction flake & \\
\hline 25 & 6 & 235 & $150-160$ & $1 / 2$ & early bifacial manufacturing flake & \\
\hline 25 & 6 & 235 & $150-160$ & 1 & early bifacial manufacturing flake & \\
\hline 25 & 2 & 201 & $110-120$ & $1 / 2$ & indeterminate & \\
\hline 25 & 2 & 201 & $110-120$ & $1 / 2$ & indeterminate & \\
\hline 25 & 4 & 221 & $130-140$ & $1 / 4$ & indeterminate & \\
\hline 25 & 4 & 221 & $130-140$ & $3 / 4$ & indeterminate & \\
\hline 25 & 4 & 221 & $130-140$ & $1 / 2$ & indeterminate & \\
\hline 25 & 5 & 222 & $140-150$ & $1 / 4$ & indeterminate & \\
\hline 25 & 5 & 222 & $140-150$ & $1 / 4$ & indeterminate & \\
\hline 25 & 5 & 222 & $140-150$ & $1 / 2$ & indeterminate & \\
\hline 25 & 6 & 235 & $150-160$ & $1 / 2$ & indeterminate & \\
\hline 25 & 6 & 235 & $150-160$ & $1 / 2$ & indeterminate & \\
\hline 25 & 7 & 236 & $160-170$ & $1 / 4$ & indeterminate & \\
\hline 25 & 5 & 222 & $140-150$ & 1 & late bifacial manufacturing flake & \\
\hline 25 & 5 & 222 & $140-150$ & 1 & late bifacial manufacturing flake & \\
\hline 25 & 6 & 235 & $150-160$ & $3 / 4$ & late bifacial manufacturing flake & \\
\hline 25 & 6 & 235 & $150-160$ & $3 / 4$ & late bifacial manufacturing flake & \\
\hline 25 & 6 & 235 & $150-160$ & $3 / 4$ & late bifacial manufacturing flake & \\
\hline 25 & 6 & 235 & $150-160$ & $3 / 4$ & late bifacial manufacturing flake & \\
\hline 25 & 7 & 236 & $160-170$ & $1 / 2$ & sequence flake & \\
\hline 25 & 3 & 220 & $120-130$ & $1 / 4$ & thinning flake & \\
\hline 25 & 4 & 221 & $130-140$ & $1 / 4$ & thinning flake & \\
\hline 25 & 5 & 222 & $140-150$ & $1 / 4$ & thinning flake & \\
\hline 25 & 5 & 222 & $140-150$ & 1 & thinning flake & \\
\hline 25 & 5 & 222 & $140-150$ & 1 & thinning flake & \\
\hline 25 & 6 & 235 & $150-160$ & $1 / 4$ & thinning flake & \\
\hline 25 & 6 & 235 & $150-160$ & $1 / 4$ & thinning flake & \\
\hline 26 & 3 & 202 & $120-130$ & $1 / 2$ & core reduction flake & \\
\hline 26 & 3 & 202 & $120-130$ & $1 / 2$ & indeterminate & \\
\hline 26 & 2 & 186 & $110-120$ & $1 / 2$ & late bifacial manufacturing flake & \\
\hline 27 & 9 & 249 & $100-110$ & $3 / 4$ & core reduction flake & \\
\hline 27 & 11 & 256 & $120-130$ & $1 / 2$ & core reduction flake & \\
\hline 27 & 12 & 266 & $130-140$ & $1 / 2$ & core reduction flake & \\
\hline 27 & 12 & 266 & $130-140$ & $1 / 2$ & core reduction flake & \\
\hline 27 & 12 & 266 & $130-140$ & $3 / 4$ & core reduction flake & \\
\hline 27 & 12 & 266 & $130-140$ & 1 & core reduction flake & \\
\hline 27 & 12 & 266 & $130-140$ & 1 & core reduction flake & \\
\hline
\end{tabular}




\begin{tabular}{|c|c|c|c|c|c|c|}
\hline Unit & Level & Lot & $\begin{array}{c}\text { Depth } \\
\text { (cmbs) }\end{array}$ & $\begin{array}{c}\text { Size } \\
\text { grade }\end{array}$ & Flake Type & Comments \\
\hline 27 & 10 & 252 & $110-120$ & $1 / 2$ & indeterminate & \\
\hline 27 & 12 & 266 & $130-140$ & $1 / 2$ & indeterminate & \\
\hline 27 & 12 & 266 & $130-140$ & $3 / 4$ & indeterminate & \\
\hline 27 & 12 & 266 & $130-140$ & $1 / 2$ & late bifacial manufacturing flake & \\
\hline 27 & 12 & 266 & $130-140$ & $1 / 2$ & late bifacial manufacturing flake & \\
\hline 27 & 9 & 249 & $100-110$ & $1 / 4$ & thinning flake & \\
\hline 27 & 9 & 249 & $100-110$ & $1 / 4$ & thinning flake & \\
\hline 27 & 12 & 266 & $130-140$ & $1 / 4$ & thinning flake & \\
\hline 27 & 12 & 266 & $130-140$ & $1 / 4$ & thinning flake & \\
\hline 27 & 12 & 266 & $130-140$ & $1 / 4$ & thinning flake & \\
\hline 28 & 14 & 262 & $150-160$ & $1 / 2$ & "r" flake (bifacial manufacturing flake) & billet flake \\
\hline 28 & 14 & 262 & $150-160$ & $3 / 4$ & bipolar (anvil) & \\
\hline 28 & 10 & 247 & $110-120$ & $1 / 2$ & core reduction flake & \\
\hline 28 & 11 & 253 & $120-130$ & $3 / 4$ & core reduction flake & \\
\hline 28 & 13 & 261 & $140-150$ & $3 / 4$ & core reduction flake & \\
\hline 28 & 12 & 254 & 130-140 & $3 / 4$ & indeterminate & \\
\hline 28 & 13 & 261 & $140-150$ & $1 / 2$ & indeterminate & \\
\hline 28 & 13 & 261 & 140-150 & $1 / 2$ & indeterminate & \\
\hline 28 & 13 & 261 & $140-150$ & $3 / 4$ & indeterminate & \\
\hline 28 & 14 & 262 & $150-160$ & $1 / 4$ & indeterminate & \\
\hline 28 & 14 & 262 & 150-160 & $3 / 4$ & indeterminate & \\
\hline 28 & 14 & 262 & 150-160 & $3 / 4$ & indeterminate & \\
\hline 28 & 14 & 262 & $150-160$ & $1 / 2$ & late bifacial manufacturing flake & \\
\hline 28 & 14 & 262 & $150-160$ & $1 / 2$ & late bifacial manufacturing flake & \\
\hline 28 & 10 & 247 & $110-120$ & $1 / 2$ & thinning flake & \\
\hline 28 & 11 & 253 & $120-130$ & $1 / 4$ & thinning flake & \\
\hline 28 & 14 & 262 & $150-160$ & $1 / 4$ & thinning flake & \\
\hline 28 & 14 & 262 & $150-160$ & $1 / 4$ & thinning flake & \\
\hline 28 & 14 & 262 & $150-160$ & $1 / 4$ & thinning flake & \\
\hline 29 & 10 & 258 & $110-120$ & $3 / 4$ & core reduction flake & \\
\hline 29 & 9 & 251 & $100-110$ & $1 / 4$ & indeterminate & \\
\hline 29 & 11 & 260 & $120-130$ & $1 / 4$ & indeterminate & \\
\hline 29 & 11 & 260 & $120-130$ & $1 / 4$ & indeterminate & \\
\hline 29 & 10 & 258 & $110-120$ & $1 / 2$ & late bifacial manufacturing flake & \\
\hline $6 / 10$ & Fea. 1 & - & - & $3 / 4$ & indeterminate & \\
\hline
\end{tabular}




\section{Charcoal $(n=13)$}

Thirteen charcoal samples were collected during the hand excavations at Site 41DW277. Five of those samples were sent for radiocarbon assay along with four specimens obtained from bulk soil sediment samples. The locations from which the charcoal samples were obtained is presented in Table 6-3.

\section{Bone (n=9)}

A total of nine pieces of bone were recovered from the hand excavation units, five of which were encountered below $1 \mathrm{~m}$. All were too small to make an identification to taxa. Two bone fragments, encountered at a depth between 110-130 cmbs, were heavily burned. Table 6-4 presents the provenience information for each specimen.
Table 6-3. Charcoal Samples

Collected at Site 41DW277.

\begin{tabular}{cccc}
\hline Unit & Level & $\begin{array}{c}\text { Depth } \\
\text { (cmbs) }\end{array}$ & Notes \\
\hline 4 & 7 & $60-70$ & $\mathrm{n} / \mathrm{a}$ \\
4 & 12 & $110-120$ & $\mathrm{n} / \mathrm{a}$ \\
7 & 10 & $110-120$ & $\mathrm{n} / \mathrm{a}$ \\
8 & 6 & $70-80$ & $\mathrm{n} / \mathrm{a}$ \\
10 & 4 & $140-150$ & Feature 1 \\
10 & 5 & $150-160$ & Feature 1 \\
10 & 7 & $170-180$ & Feature 3 \\
12 & 5 & $130-140$ & $\mathrm{n} / \mathrm{a}$ \\
17 & 4 & $140-150$ & $\mathrm{n} / \mathrm{a}$ \\
23 & 4 & $50-60$ & $\mathrm{n} / \mathrm{a}$ \\
25 & 3 & $120-130$ & $\mathrm{n} / \mathrm{a}$ \\
26 & 3 & $120-130$ & $\mathrm{n} / \mathrm{a}$ \\
GT3 & - & 68 & $\mathrm{n} / \mathrm{a}$ \\
\hline
\end{tabular}

Table 6-4. Bone Fragments Collected from Site 41DW277.

\begin{tabular}{cccc}
\hline Unit & Level & $\begin{array}{c}\text { Depth } \\
\text { (cmbs) }\end{array}$ & Notes \\
\hline 7 & 7 & $80-90$ & $\mathrm{n} / \mathrm{a}$ \\
8 & 4 & $50-60$ & $\mathrm{n} / \mathrm{a}$ \\
13 & 5 & $150-160$ & $\mathrm{n} / \mathrm{a}$ \\
13 & 6 & $160-170$ & $\mathrm{n} / \mathrm{a}$ \\
23 & 2 & $20-40$ & $\mathrm{n} / \mathrm{a}$ \\
26 & 2 & $110-120$ & burned \\
26 & 3 & $120-130$ & burned \\
27 & 6 & $70-80$ & $\mathrm{n} / \mathrm{a}$ \\
28 & 11 & $120-130$ & $\mathrm{n} / \mathrm{a}$ \\
\hline
\end{tabular}




\section{Chapter 7 \\ Discussion ANd Analysis}

In Chapters 5 and 6, we presented the results of the archeological test investigations at Site 41DW277. In this chapter, a preliminary analysis will be conducted to attempt to answer meaningful research questions relating to site activities, mobility, and to a lesser extent, subsistence. This will be done through an intra-site study of the lithic material, features, and snail/mussel shell remains found at the site. In addition, an attempt will be made to place Site 41DW277 within a particular regional archeological tradition through a basic comparative study of the site's cultural material and cultural material found at neighboring sites, most notably those found during the Cuero I Reservoir survey investigations.

As described in Chapter 1, the area of Site 41DW277 that was investigated was limited to the APE of the proposed bridge replacement project, and it is very likely that the site extends beyond the APE. Thus, the horizontal extent of the site was not fully investigated, and the remains of specific activity areas such as knapping stations, large cooking or food processing areas, locations of shelters, etc., may still be present but were not clearly identified during the current investigations. It should also be noted that vertically, the sampling size varied dramatically among the AUs. For instance, while more than $8 \mathrm{~m}^{3}$ were excavated from AU 1, just $1.25 \mathrm{~m}^{3}$ were excavated from AU 3 and only $2.1 \mathrm{~m}^{3}$ excavated from AU 2. With this in mind, any interpretation of site activities will be generally limited to the presence of certain activities based on the artifacts recovered, rather than a more thorough discussion of the exact nature, importance, or frequency of those activities. Caution must also be maintained in answering research questions about subsistence, particularly as very little faunal material was recovered from the area investigated, and none of it was identifiable to taxon. Similarly, research questions about the mobility patterns of the site's inhabitants is also limited to a very rough sketch based on the cultural material recovered, and the conclusions reached here may be refutable if the site were investigated further.

However, even with these disclaimers, there are some interesting patterns resulting from an analysis of the cultural material found at Site 41DW277. The following analysis was conducted in attempt to answer three research questions:

1) What activities occurred at Site 41DW277, and do they differ between the different periods of occupation?

2) What were the subsistence strategies employed at the site, and do they differ between the different periods of occupation?, and

3) Can the mobility patterns of the site's inhabitants be determined as they relate to Site 41DW277, including the length of general site occupation over time? 


\section{Site Activities}

The majority of the cultural material found at Site 41DW277 consisted of burned or fire-cracked rock and chipped stone material. Thus, two obvious activities that took place at the site was the manufacture of stone tools and the cooking of foodstuffs, either animal, plant, or both. The burned rock features found in AUs 2 and 3 attest to food cooking, and although no feature was found in AU 1, the presence of substantial quantities of burned rock and burned rock scatters indicates that hot rock use took place during that period of occupation as well. Additionally, all of the groundstone recovered at the site, suggesting food processing, was found in AU 1 (Figure 7-1), though it should be noted that the sample size of AU1 was much larger than that of AUs 2 and 3. Although evidence of hot rock cooking was present in each analytical unit, there is some difficulty in determining what kind of cooking was taking place. Feature 1 was a small flat cooking hearth that was likely used for a very short time before being abandoned. Feature 2-3the remnants of a basin-shaped hearth — was probably utilized for either a longer period of time or was used to cook a much larger quantity of food. Unfortunately, the hearth remnants have been modified through post depositional processes and somewhat poor organic preservation. Other than a small amount of oxidation around Feature 1, there was no observed thermal

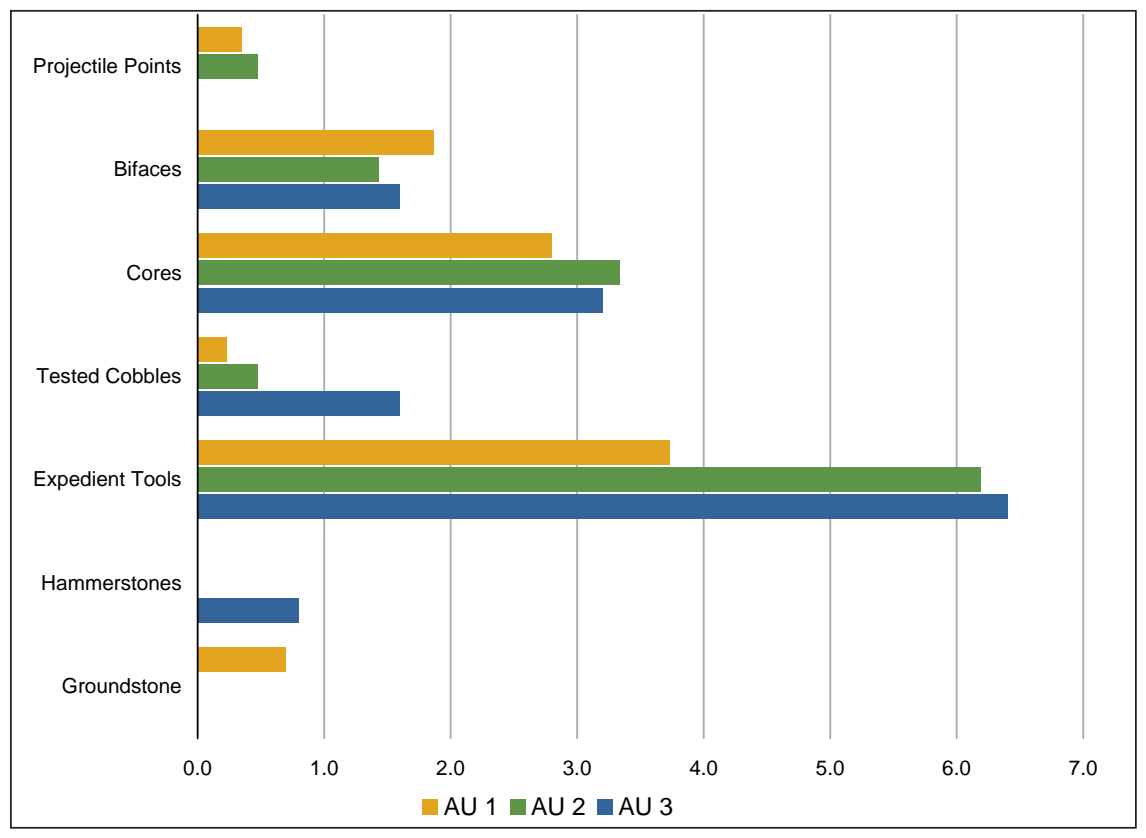

Figure 7-1. Lithic tools per excavated volume $\left(\mathrm{m}^{3}\right)$ in each analytical unit. alteration to the soil surrounding the features. As a result, the particular type of cooking conducted with these hearths, either broiling, baking, steaming, boiling, or roasting, can only be guessed (Ellis 1997:61). If the lack of charcoal or evidence of thermal alteration to the surrounding soil is not a result of post depositional processes, then the type of cooking that might have been used by the site inhabitants

in each analytical unit was either earth oven cooking (roasting) or stone boiling where the burned rocks have been placed in a secondary discard context (Black et al. 1997; Collins 2011; Quigg et al. 2001). However, there are several more possibilities that open up if the burned rocks were found in their primary context, albeit with some post depositional alterations. Earthoven roasting and stone boiling are still likely candidates for the type of cooking employed, but broiling, steaming, baking, or grilling could also have been conducted. 
The lithic tools found at the site attest to what types of tools were being made, as well as what activities those tools were facilitating. Tested cobbles, biface blanks, cores, and flaking debris were recovered that indicate the act of lithic tool manufacture itself, and examples were found in each analytical unit. Projectile points, general use bifaces, scrapers (categorized under bifaces or expedient tools), knives, hammerstones, and flake-based expedient tools were all found at the site, suggesting hunting, woodworking, and possible non-lithic tool stone working (pecking), as well as general use cutting, slicing, scraping, and mending. The quantities of lithic tools in different categories do not point to a specific large-scale activity conducted at the site during any of the occupation periods, such as boat making or intense hot rock cooking or lithic procurement, but a diversity of activities needed for conducting daily life.

Within this broad spectrum of activities, there are some observable differences between the analytical units. It is unknown if these differences are representative of the entire site, but it appears that the way in which certain activities were conducted in this area of the site changed over time. Most notable is the number of expedient tools (per excavated volume) recovered in AUs 2 and 3, which are much higher than AU 1. A large number of cores, from which the expedient tools were derived, were also found within each analytical unit in about the same quantities, though their density was greater in AUs 2 and 3 than AU 1. Tested cobbles, which are generally considered parent material from which cores (and other tools) are made, are much higher in AU 3 (by over 50 percent) than AUs 1 and 2. Thus, one possible interpretation is that the people who inhabited the site during the earliest occupation period tried more frequently to use the local lithic material (assuming that they picked up a cobble and tested it right away), and subsequent inhabitants used the local material far less often. This also has implications for overall mobility, suggesting that earlier occupants of the site resided there for longer periods of time, while later occupants were simply passing through (more discussion on this topic below). Another view suggests that the subsequent inhabitants knew which rocks were suitable for use and had fewer discards. In any event, tested cobbles were subsequently turned into cores and bifaces, which are represented in each analytical unit though are most numerous in AU 1 . The change in tool use to increased formality over time can be seen once the cores were produced and expedient tools were struck from them. Indeed, a slightly increased number of bifaces can be observed in AU 1 from previous analytical units corresponding to a slightly decreased number of cores in the same analytical unit.

Projectile points, considered to be the most labor intensive tool form, were few in number throughout the site, and in very poor condition. The fact that none were found in AU 3 does not necessarily indicate the absence of hunting during that period of occupation. However, the small number of recovered points does suggest that these tools were valuable to their owners during all periods of occupation, and they were not likely to discard them easily.

Hammerstones and groundstones were also found in very small numbers, and not in every analytical unit. As with the projectile points, this does not indicate an absence of certain activities in certain periods of occupation, but an indication that either these tools were not used as much as others, or they were quite valuable and some effort was taken to keep track of them. Hammerstones are generally considered to be part of any knapper's toolkit and toolmakers may be inclined to hold on to the hammerstones they like best. They are sturdy and unlikely 
to break easily, and are generally quite portable. Another use of hammerstones can be the modification of other stones by pecking to create a certain useful form. Groundstones in the mano/metate form are generally not very portable, break relatively easily given the amount of force applied to their surfaces, but as a single-use item are often found in small numbers unless a lot of plant/seed processing is undertaken. Thus, these artifacts do represent certain activities, but further interpretation is limited.

One possible activity comes from the results of the macrobotanical analysis (Appendix D). Very few plant remains were able to be identified due to the very poor organic preservation at the site, but one of the two identified wood charcoal fragments was from the species Condalia, known as bluewood condalia, found in AU 2. This thicket-forming shrub is not generally known as good firewood, but proves to be a very suitable dye plant, with the berries and wood tissue producing green-gold and blue colors. The decorative arts is generally not well understood in prehistoric cultures without pottery or known rock art associations, but the utilization of this plant to make paint or dye is a possibility.

\section{Subsistence Strategies}

The direct evidence recovered from Site 41DW277 of the subsistence strategies employed by the inhabitants is quite sparse. As mentioned above, almost no faunal material was recovered from the hand excavated units at the site, and the small pieces that were collected were too small and badly decomposed to make a taxonomic identification. Additionally, the macrobotanical samples obtained from bulk soil samples collected at the site and processed through flotation contained only one example of a plant that could have been used as a food source (the berries from bluewood condalia). Thus, the principal direct evidence of the types of food processed at any time at Site 41DW277 is the snail shell and mussel shell remains.

An analysis by analytical unit of the snail shell and mussel shell recovered presents a similar picture (Figures 7-2 and 7-3). The highest percentages of both types of shell were found in AU 3, and the mussel shell remains were more than double those of AUs 1 and 2. Thus, the earliest inhabitants of the site appeared to utilize this food resource much more than later inhabitants. All of the inhabitants collected mussel shell species common to the Guadalupe River drainage (and most likely adjacent

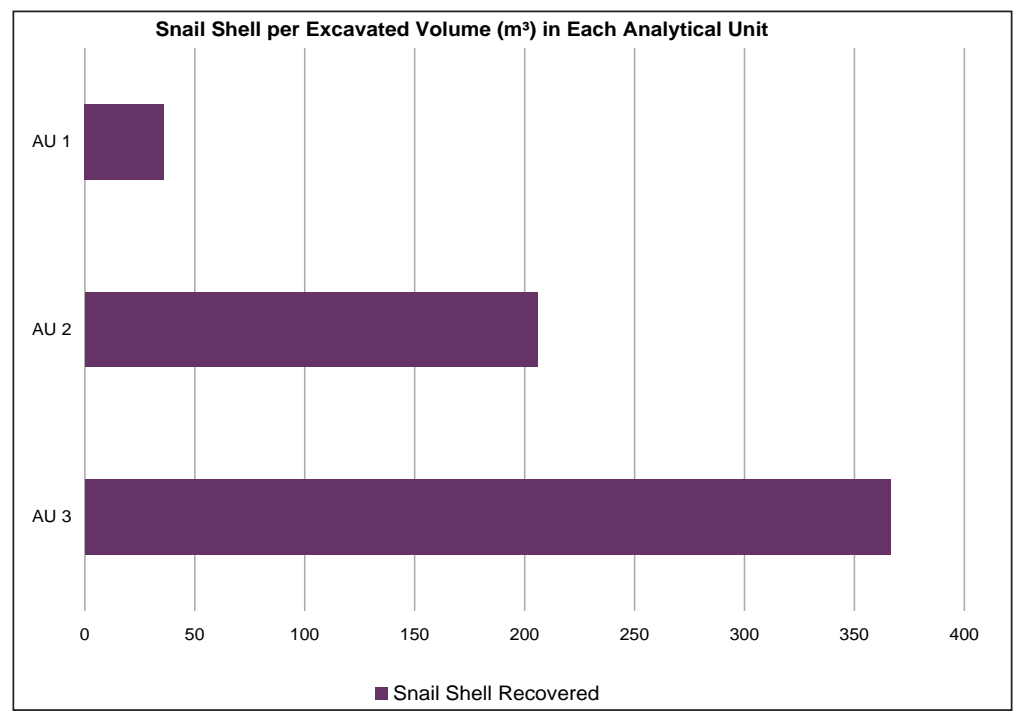

Figure 7-2. Snail shell per excavated volume $\left(\mathrm{m}^{3}\right)$ in each analytical unit. 


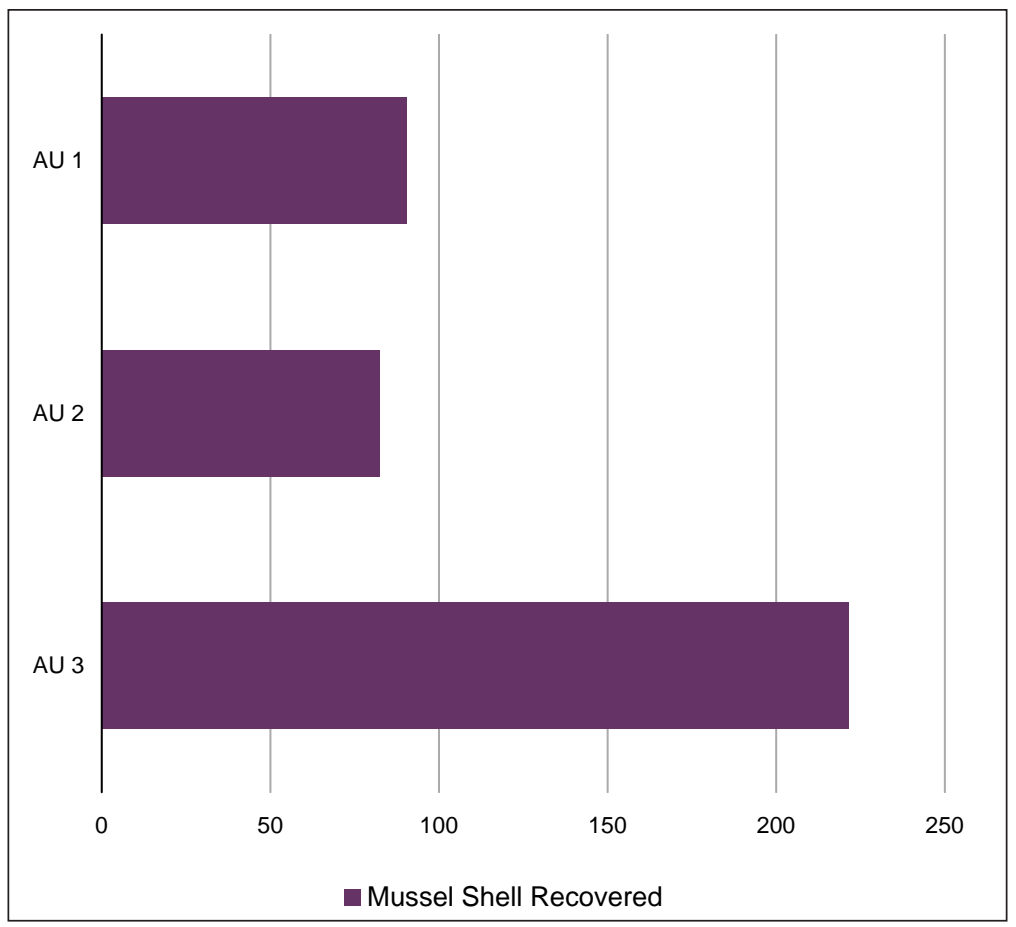

Figure 7-3. Mussel shell per excavated volume $\left(\mathrm{m}^{3}\right)$ in each analytical unit. to the site) in substrates of firm mud, sand, and light to moderately large gravels. The most common species (Threeridge, Washboard, and Quadrulid) were found in all of the analytical units, but the more unique species were only found in AUs 1 and 3. With these species a very small number, between 1 and 4 specimens, were recovered. It appears that sub-adult or smaller species of mussels were preferred, as these types of shell remains are present in much higher quantities in the recovered material than would be present in normal populations (Appendix C). Very few of the samples were burned (0.8 percent), and no

samples showed any evidence of drilling, carving, or edge modification. These factors indicate that mussels were cooked using an indirect heating method such as boiling or steaming, or perhaps even eaten raw.

The snail shell remains were most predominantly found in AU 3, with 44 percent less in AU 2, and 90 percent less in AU 1. All of the shell was identified as the rabdotus species. As with the mussel shell, the snail shell showed virtually no evidence of burning. Some debate as to the reason for the presence of large quantities of rabdotus at archeological sites, particularly in south Texas, has been present in the archeological literature (Baker 1993:39-41). The two main interpretations have been that the snails were used as a food source by the prehistoric inhabitants, or the snails were attracted by the refuse left once the site was abandoned and lived their natural life cycle at the site location. We agree with the conclusions presented by Ken Brown in his analysis of the snail shell from the Smith Creek Bridge site (41DW270) that the rabdotus shell found in archeological contexts are a combination of both scenarios, but the high incidence of larger sized specimens in and around hearth features indicate that snails were used as a food source, and that most of the shell was derived from the harvesting and cooking of the snails (Brown 2002:242-251). They were most likely parboiled or boiled.

The indirect evidence of subsistence activities at Site 41DW277 consists of the feature remains. If the features were used for roasting or stone boiling, then the possible foodstuffs cooked might have been meat, roots or bulbs, cactus pads, nuts, acorns, berries, meat, small insects, eggs, fish, shellfish, or land snails (Ellis 1997:Table 3). However, beyond mollusk procurement, the types 
of foods that were cooked and eaten at Site 41DW277 can only be guessed at. Preservation at the site was simply too lean to make decisive statements about subsistence practices.

\section{Mobility Patterns}

Kelly (1992:54-57) points out several avenues to study mobility in prehistoric societies, including the study of resource abundance in a particular area, the stone tool technology employed, the spatial organization of a site, and the presence and type of constructed dwellings. Unfortunately, the excavated portion of Site 41DW277 does not contain sufficient information to study resource abundance, spatial organization, or the presence or absence of houses. Thus, the only avenue of research open with the current dataset is an analysis of the lithic technology. Even with this information the conclusions reached are only tentative, as the numbers of chipped stone tools recovered from the site are relatively small.

Several topics within the field of stone tool technology and mobility have been studied in recent years. For example, an analysis of the raw material stone tools were made from and the possible sources of that material is a frequently-used strategy to study mobility, as someone had to transport the tool from its source to the place where it was finally discarded (Kelly 1992). Also, there have been some suggestions that an inverse relationship between the technological diversity and residential mobility exists (Shott 1986). Unfortunately, time and funding did not permit a lithic sourcing study at Site 41DW277 to determine the possible sources of the lithic material used to make the debris found at the site, and the quantity of recovered artifacts did not provide a suitable dataset to determine the technological diversity at the site, or lack thereof. As a result, the analysis tool that could be used to discuss mobility at Site 41DW277 is a comparison between lithic tool types within and between analytical units.

This method of analysis concerns the ratio of the types of tools found at archeological sites as an indicator of mobility. In general, the hypothesis stipulates that bifacial tools or bifaces used as cores (i.e., formal tools that require time to make) are associated with frequent movement by prehistoric inhabitants, and expedient flake tools and bipolar core reduction (i.e. informal tools that take almost mo time at all) are associated with more infrequent residential movement (Andrefsky 1994; Bramforth and Becker 2000; Cowan 1999; Kelly 1988, 1992). The researchers who propose this relationship between tool forms and mobility argue that bifaces are multi-use tools, more portable due to the decreased weight, and can be easily reworked to meet a specific (but as yet unknown) need. Expedient tools, on the other hand, are more often single-use tools, easily discarded because more can be struck from one of many cores close at hand, and can be slightly altered to complete most required tasks. This argument generally gets summed-up in a biface-to-core ratio, which is then used to make observations and comparisons about the overall mobility of the inhabitants of a site at a particular time. Some have argued that this biface-to-core relationship is more complicated, and factors such the availability and quality of raw material also has an impact on the ratio (Andrefsky 1994). In addition, the quantity and type of the discarded artifacts may not necessarily correspond with what was present in the knapper's toolkit, and the assumption that the biface-to-core ratios of tools at archeological sites are representative of the tools that were actually used may be in error (Bramforth and Becker 2000). As these and other arguments have some validity, and the concerns raised cannot 
be entirely explained with the information currently at hand in this analysis, the following discussion is to be taken as a preliminary one only.

To begin, the biface-tocore chart at Site 41DW277 appears to show a higher percentage of cores to bifaces present in each analytical unit, with AU 1 showing the smallest ratio of $1: 1.5$, and AUs 2 and 3 showing similar results of $1: 2.3$ and $1: 2$, respectively (Figure $\mathbf{7 - 4}$ ). According to the hypothesis, the inhabitants of the site throughout its occupation were more sedentary, using flake/core technology at least half as much to twice as often as biface technology. A comparison of these numbers with those of Bramforth and Becker's study of the Great Plains (2000) confirms that they fall within the range of more sedentary behavior. If projectile points were combined with the bifaces to encapsulate all formal tools found at the site for each analytical unit, and these numbers were compared with the flakebased informal tools, the differences are even more pronounced (Figure 7-5). Again, informal tools far outweigh formal tools in each analytical unit, with AU 1 having the smallest ratio

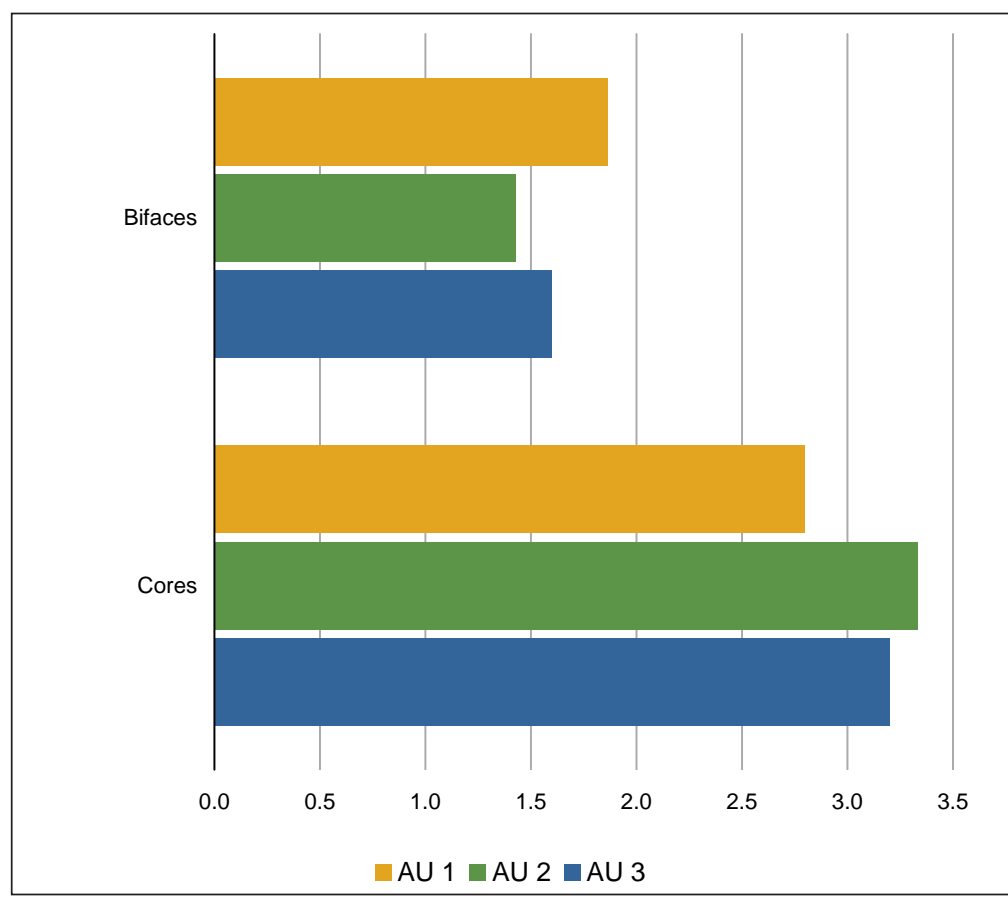

Figure 7-4. Bifaces vs. cores per excavated volume $\left(\mathrm{m}^{3}\right)$ for each analytical unit.

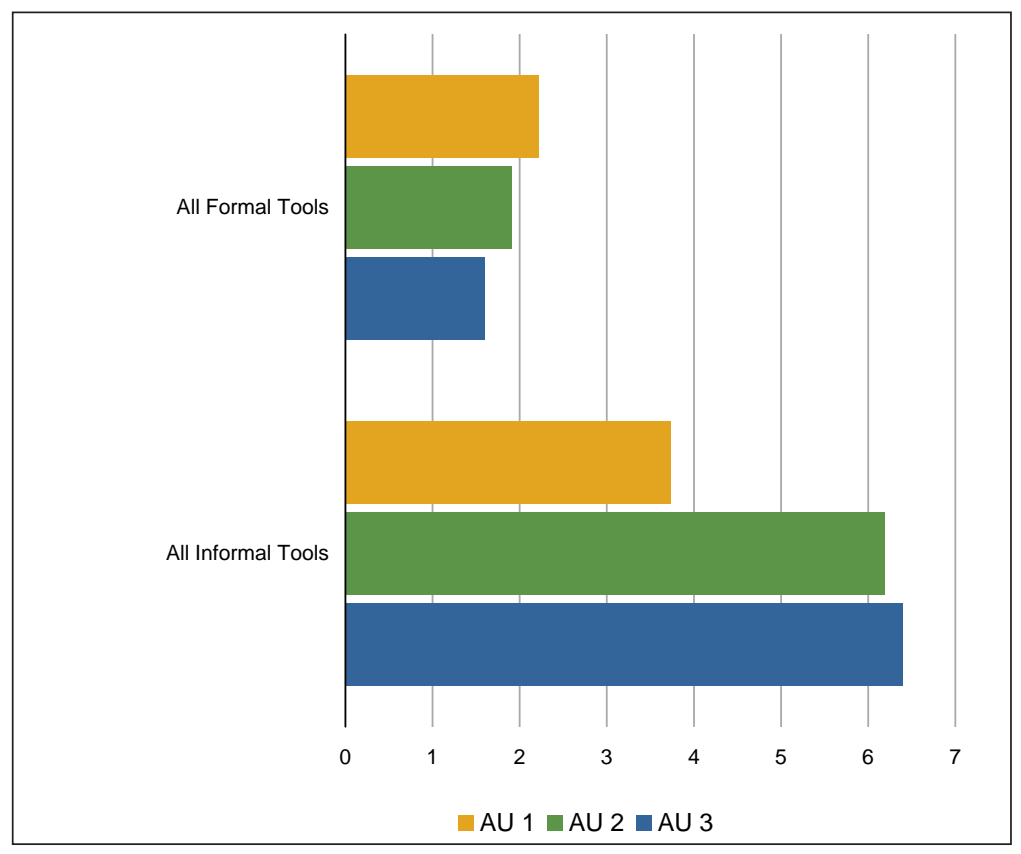

Figure 7-5. Formal vs. informal tools per excavated volume $\left(\mathrm{m}^{3}\right)$ for each analytical unit. 
of formal-to-informal tools of 1:1.7, and AUs 2 and 3 showing much larger differences of $1: 3.25$ and $1: 4$, respectively.

If the number of features found during the excavations or the quantity of artifacts recovered were the only things used to analyze the mobility of the inhabitants of Site 41DW277, the paucity of each would point to a temporary campsite used for single resource utilization (obtaining and cooking mussels and snails). However, the lithic analysis above indicates the possibility of a much longer occupation of the site during each of the occupation periods, but particularly during the earliest periods, with mobility tending to increase over time. This presents an interesting question: if the site was occupied for a long period at any point in time, where are the artifacts and features one would expect to find? One likely answer is that these remains are still present at the site, but were not excavated within the APE. Another quite probable explanation is that much of the feature and related occupational debris has been scoured over time by repeated flood incidents and various other degenerative processes. We have already observed that preservation at the site is quite poor, with almost no faunal and organic material still intact. It may be that what we observe today at Site 41DW277 is simply remnant material from a poorly preserved base-camp. Alternatively, the biface-to-core ratio may be in error, and the features recorded and artifacts recovered are more accurately representative of a short-term stay.

To shed some light on the possible legitimacy of the biface-to-core ratio and the mobility patterns of Site 41DW277's inhabitants, the whole and proximal flaking debris was also analyzed to determine if the pattern continues. The types of flaking debris recovered from archeological contexts are assumed to be representative of the tools produced at the site, since the tools themselves may have been ultimately used and discarded somewhere else entirely, but flakes were probably left where they fell from the knapping process. For the purposes of this study, the lithic analyst used the categories outlined in the Chipped Stone Analytical Protocol developed by TxDOT. The analysis used flake size, amount of cortex, and platform type for flake comparison between the analytical units. The flake size chart and the cortex chart indicate two things: the stage of tool manufacture appears to be remarkably similar between the analytical units, and seem to lean towards later-stage tool manufacturing rather than early stage manufacturing (Figures 7-6 and 7-7). The

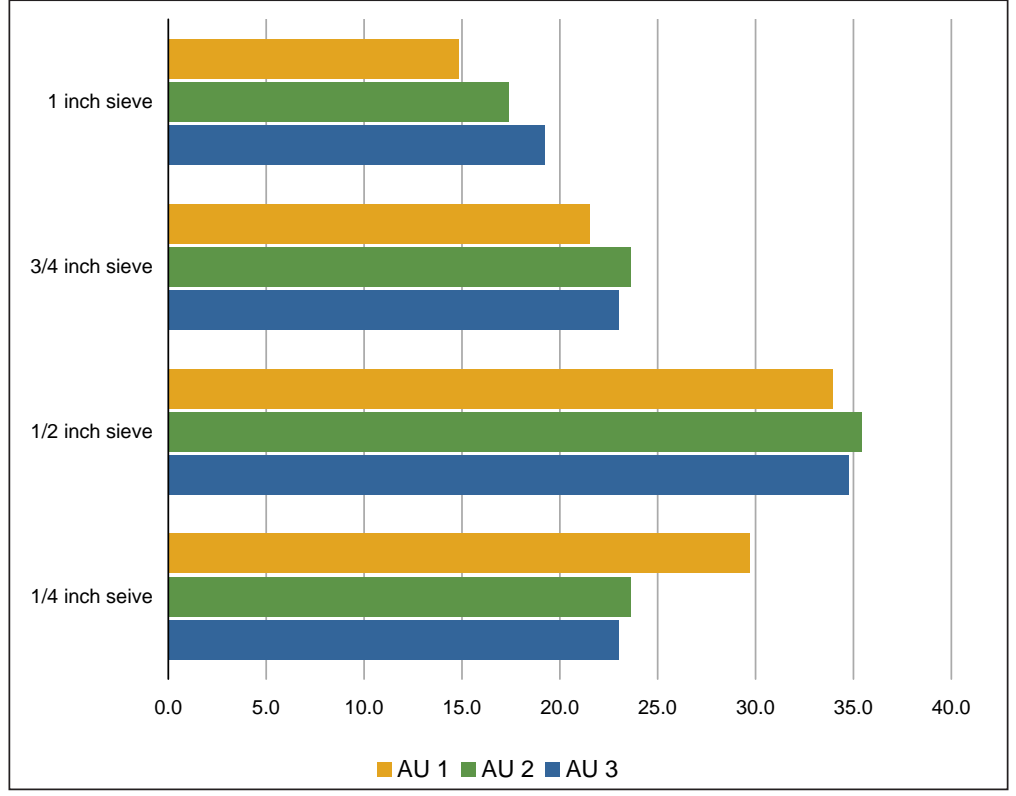

Figure 7-6. Flake size percentages for each analytical unit. 


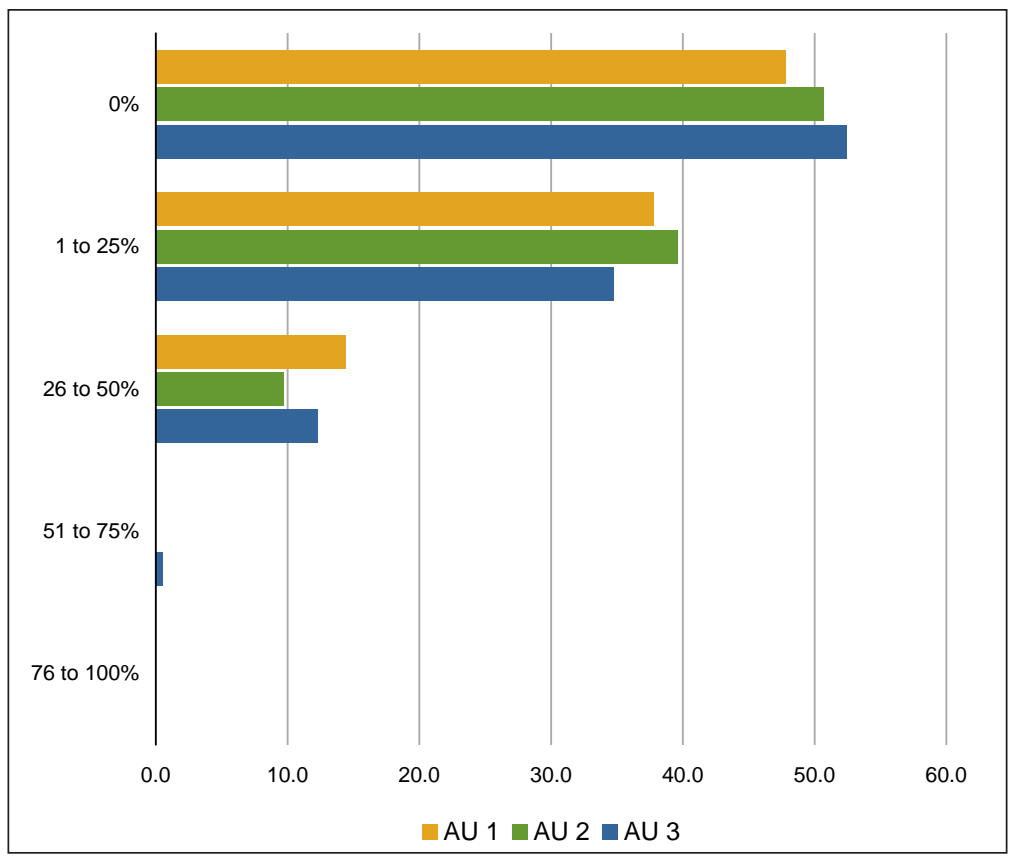

Figure 7-7. Flake cortex percentages for each analytical unit.

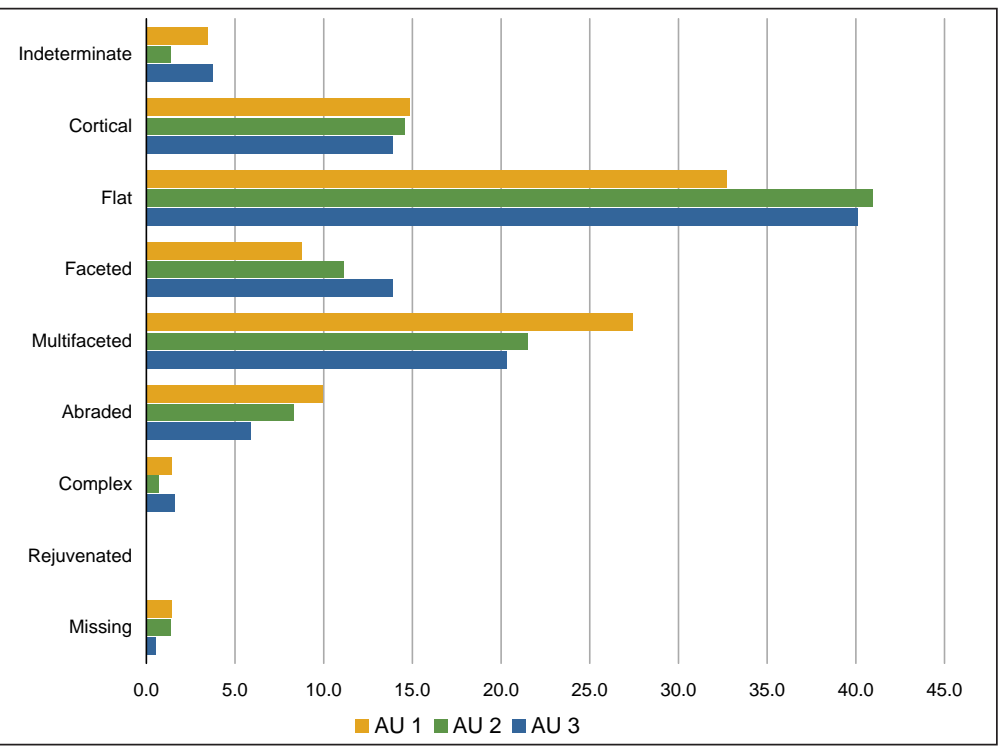

Figure 7-8. Platform type percentages for each analytical unit. majority of flakes exhibited no cortex (around 50 percent), roughly 35-40 percent of flakes exhibited $1-25$ percent cortex, between 10-15 percent of flakes showed 26-50 percent cortex, and only 0.5 percent of flakes exhibited 51-75 percent cortex. No flakes were found with 76-100 percent cortex. Flake sizes leaned towards smaller end (around 1/2 inch), and AU 1 exhibited a larger percentage of very small flakes than the other analytical units, but all flakes sizes were well represented in the samples analyzed.

The platform type for the flakes was then charted for comparison between the analytical units (Figure 7-8). Again, there appeared to be remarkable similarity between the analytical units, with the most extreme deviation exhibited in AU 1. In this analytical unit, there is about 7-8 percent fewer flat platforms and 7-8 percent more multifaceted platforms than AUs 2 and 3. Interestingly, no rejuvenated flakes were found in any of the analytical units, and thus Site 41DW277 has no evidence of tool

resharpening. The relatively high percentage of multifaceted flakes indicate a higher incidence of late-stage tool manufacture, but flakes produced in the early stages of manufacture, such as cortical, flat, and faceted flakes, are also well represented. To attempt to see if the flaking debris can give an indication of the degree of biface vs. core technology, the platform types were combined into "Cobble Reduction," consisting of cortical flakes, "Core Reduction," consisting of the flat platform type, and "Biface Reduction," combining the faceted, multifaceted, abraded, 
and complex platform types

(Figure 7-9). Understanding that these may be gross generalizations, the preliminary results from this comparison shows remarkable similarity in flake composition between AUs 2 and 3, while AU 1 differs slightly. There are 7-8 percent fewer core reduction flakes and 6 percent more biface reduction flakes. Also, the gap between core reduction flakes and biface reduction flakes is extremely small, quite unlike the bifaceto-core and the informalto-formal tool ratios. If this data accurately represents the behavior exhibited by the inhabitants of the site, then one possible explanation for

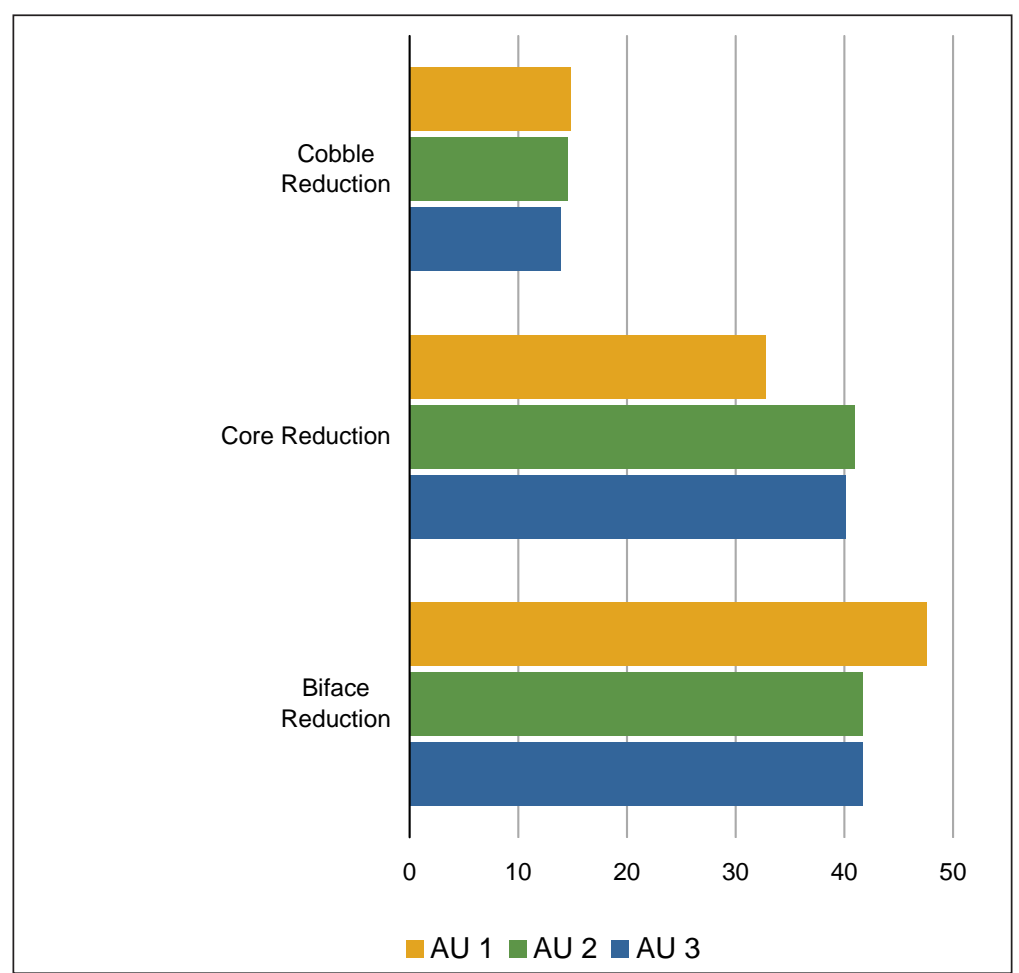

Figure 7-9. Possible flake parent tool percentages for each analytical unit. the difference is exemplified by the concern raised by Bramforth and Becker (2000), in that the tools recovered may not necessarily be like the ones manufactured and used on site, at least statistically speaking. One feature does stand out, however, between the analysis of the tools and the flake analysis. AU 1 seems to have a higher percentage of both bifacial tools and bifacially derived flakes than the other analytical units. This may indicate a comparatively shorter duration of occupation during the later period of site use, and correspondingly greater mobility.

One last type of analysis was conducted between the analytical units, which included a comparison between the flake types among the whole flakes only. For this analysis multiple technical attributes were used to determine reduction technology, including early/late biface manufacture flakes, blades, bi-polar flakes, core reduction flakes, DEB and "r" flakes, notching flakes, sequence flakes, thinning flakes, and indeterminate flakes. These categories can be more directly associated with reduction technology than the analysis of platform type alone. Theoretically, one could then infer into the types of activities that occurred at the site, which could then be linked to group mobility patterns. Figure 7-10 shows the types of flakes for each analytical unit. In this analysis, significant differences appear between the analytical units. AU 2 appears to have the greatest deviation, in that there are a greater number of early biface and late biface thinning flakes than the other AUs. AU 2 also has fewer core reduction flakes, and more thinning flakes than AUs 1 and 3. When the flake types are combined into core derived, biface derived, and unknown, the same differences appear for AU 2, with a higher percentage of biface derived flakes than core derived flakes (Figure 7-11). What this suggests is that group 
mobility may have been highest during the AU 2 occupation. The results are somewhat inconsistent with the previous analyses. Based on these data, it would appear that AUs 1 and 3 are more similar in terms of mobility than AU 2; whereas, the parent tool type analyses suggests an overall increase in mobility over time.

Regardless of this inconsistency, the flake type analysis still supports the idea that the AU 3 peoples were the least mobile. This is best supported by the sheer number of all flakes found in each of the AUs (Table 7-1). If one looks at whole flakes alone, the ratio of whole flakes to excavated sediment is highest by far in $\mathrm{AU} 3$ and lowest in AU 1. Again, this supports the theory that occupation was most intense during the earliest period and less intense over time.

\section{Regional StUdy OF SITE 41DW277 AND NeIGHboring Sites}

In order to place Site 41DW277 in a wider prehistoric context, the information obtained from the test excavations was compared to other archeological sites in the region to attempt to determine similarities

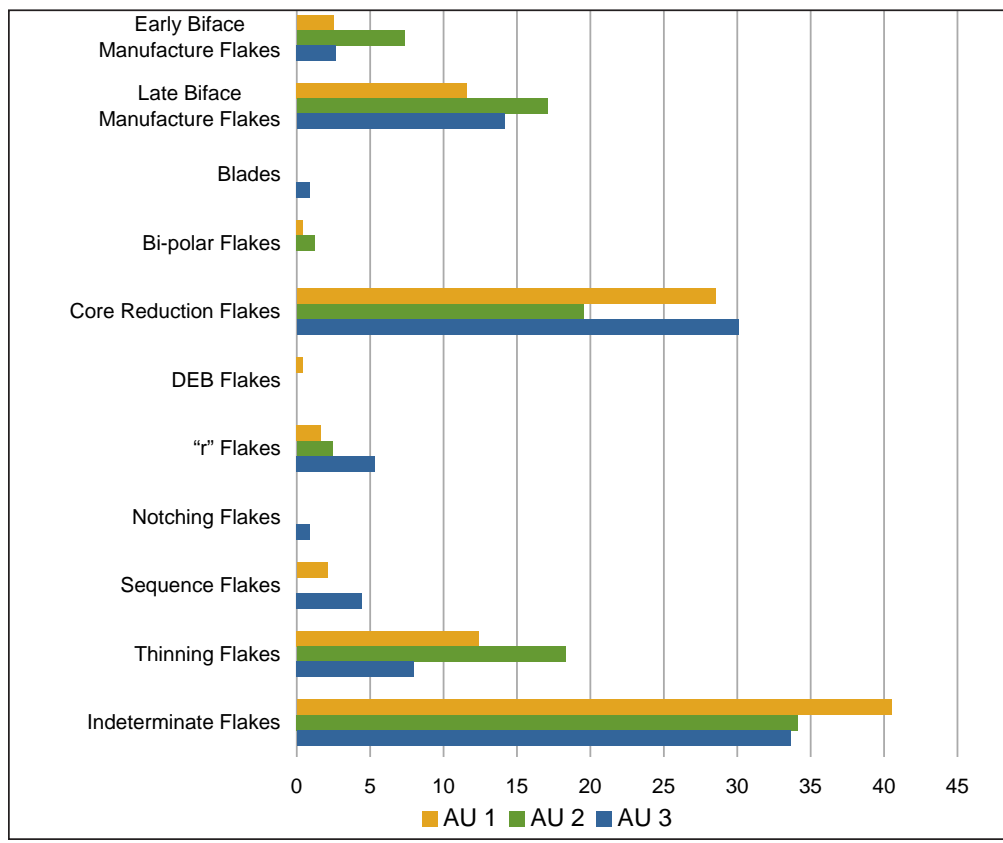

Figure 7-10. Whole flake type percentages for each analytical unit.

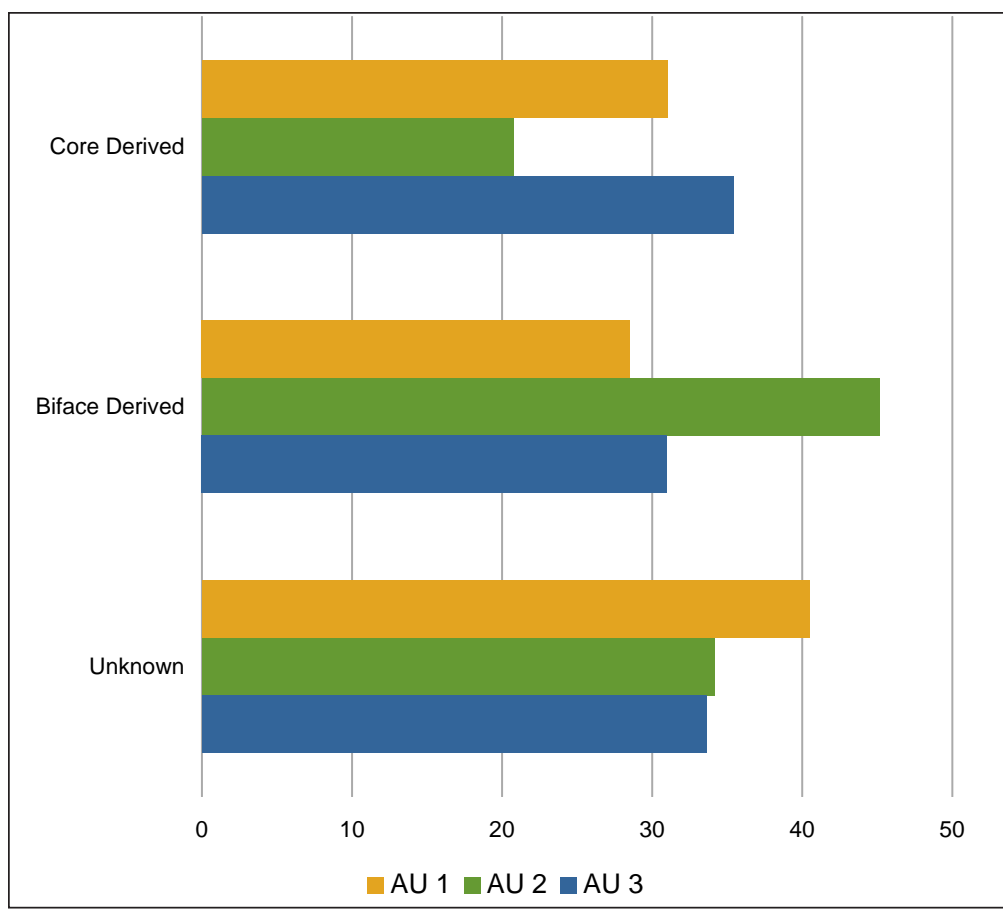

Figure 7-11. Whole flake parent tool percentages for each analytical unit. 
Table 7-1. Projectile Points from Site 41LC2.

\begin{tabular}{cccc}
\hline & AU 1 & AU 2 & AU 3 \\
\hline $\begin{array}{c}\text { Early Biface } \\
\text { Manufacture Flakes }\end{array}$ & 6 & 6 & 3 \\
Late Biface Manufacture & 28 & 14 & 16 \\
Flakes & 0 & 0 & 1 \\
Blades & 1 & 1 & 0 \\
Bi-polar Flakes & 69 & 16 & 34 \\
Core Reduction Flakes & 1 & 0 & 0 \\
DEB Flakes & 4 & 2 & 6 \\
"r" Flakes & 0 & 0 & 1 \\
Notching Flakes & 5 & 0 & 5 \\
Sequence Flakes & 30 & 15 & 9 \\
Thinning Flakes & 98 & 28 & 38 \\
Indeterminate Flakes & 242 & 82 & 113 \\
\hline Total & 28 & 39 & 90 \\
\hline Average Number of Flakes & & &
\end{tabular}

and differences between them. The comparative analysis used both sites that have been investigated beyond the survey stage, as well as the synthesis of surveyed sites during the archeological investigations of the proposed Cuero I Reservoir, conducted in 1972 and 1973. Normally, survey-level investigations do not provide enough information to conduct a suitable comparative analysis, but the researchers of the proposed Cuero I Reservoir used the sheer quantity of sites recorded to make some regional interpretations that is useful for comparison. The other archeological sites used in this comparative analysis were all tested for their eligibility for inclusion into the NRHP, and the subsequent reports

also provided enough information for a basic comparison. These include Sites 41DW269, 41DW260, and 41LC2, all located within approximately $40 \mathrm{~km}$ of Site 41DW277 (Figure 7-12). The Smith Creek Bridge site, 41DW270, is also located in the same county as Site 41DW277 and was investigated quite thoroughly, but the five occupation zones analyzed at that site were primarily younger than the ones found at Site 41DW277. Thus, while general comparisons with respect to resource procurement and utilization choices can be made between sites, it will be important to note that the assemblages represent occupations separated by hundreds, if not thousands of years.

\section{Cuero I Reservoir Investigations (Fox et al. 1974)}

The Cuero I Reservoir Investigations consisted of an intensive archeological survey of the entire proposed Cuero I Reservoir location (totaling about 57,400 acres) in DeWitt and Gonzales counties, by the Texas Historical Commission (THC) at the behest of the Texas Water Development Board (TWDB). The survey resulted in the recording of 352 archeological sites, ranging in occupation from the Late Paleoindian to the Early Historic periods. A few test excavations were also conducted at select sites $(n=20)$ to answer specific research questions. The researchers then compiled this information into a study of the changes in technology over time and concurrent subsistence patterns, as well as the compilation of the overall view of landscape utilization and settlement patterns in the region. As a result of their investigations the Cuero I National Register District was formed (see Figure 7-12).

The majority of the archeological sites recorded by the survey team were found through surfacelevel manifestations of cultural material. A total of 18,892 lithic specimens were collected from the surface of 293 prehistoric archeological sites in the project area, which were then categorized into morphological type indicating either a tool type or by-product of lithic tool 


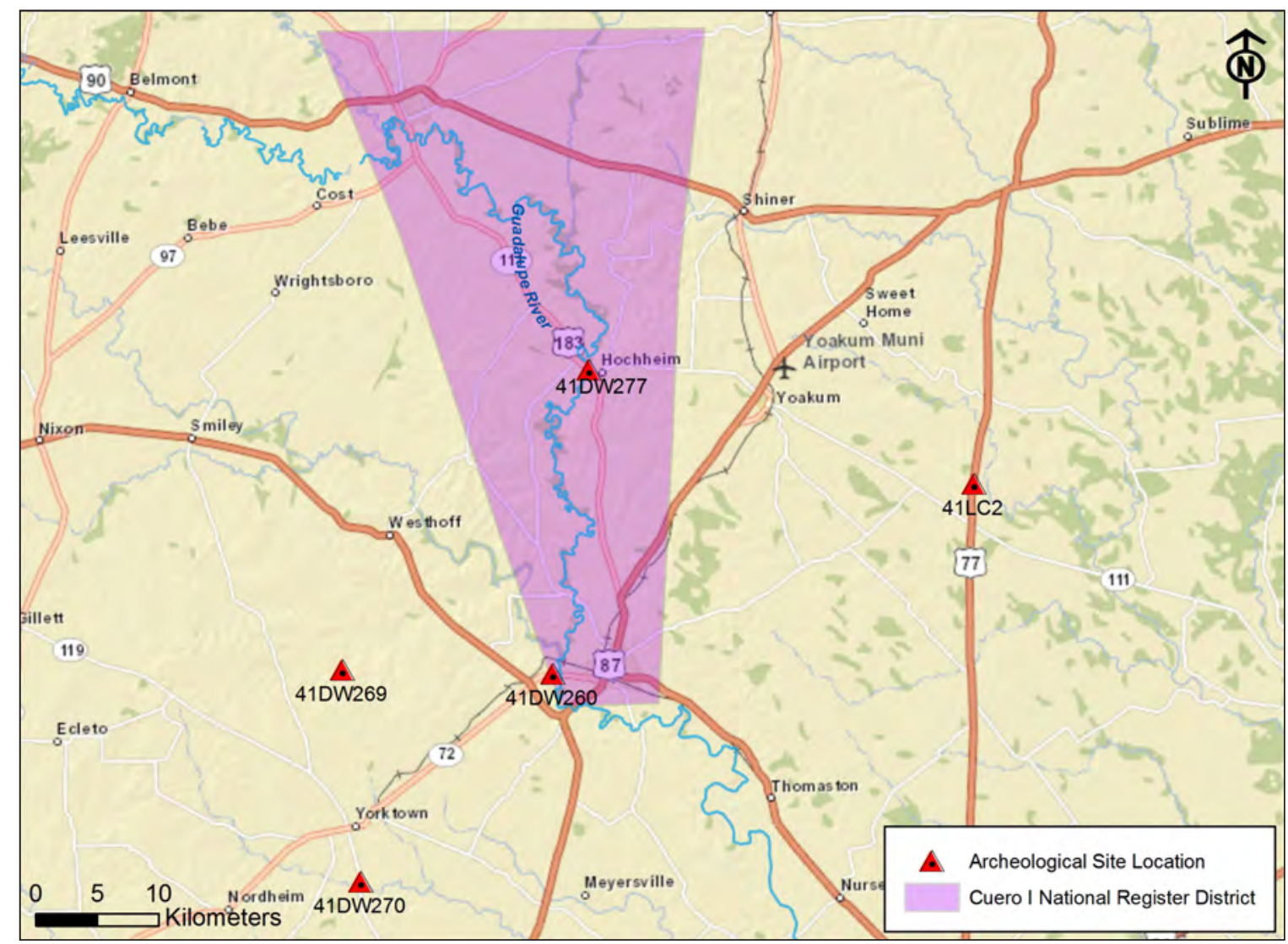

Figure 7-12. Archeological sites and National Register Districts discussed in this chapter.

production. These categories included cores, core tools, bifaces, flakes, chips, hammerstones, burned debris, and groundstone. These major categories were sub-categorized into groups showing specific diagnostic characteristics (Tables 7-2 and 7-3).

The site locations were then divided into four types, upland sandstone sites $(n=28)$, sites on thick gravel deposits $(n=102)$, sites on eroded caliche terraces and the fossil floodplain $(n=106)$, and sites on active floodplains $(n=57)$. Using these site types, the researchers looked at the lithic technology found within each type of site for clues as to site use. Cores appeared to be in similar quantities across all types of sites, but primary and secondary flakes had higher percentages on gravel-bearing sites, and tertiary flakes and chips had higher percentages on fossil floodplain ( $\mathrm{T}_{1}$ terraces) and modern floodplain sites ( $\mathrm{T}_{0}$ terraces). This is to be expected if the gravel deposits were used as the primary source of lithic procurement. Similarly, lithic tool production, based on the number of cores vs. thick and thin bifaces, appeared to begin at the upland gravel deposits and end on the lowland terrace sites, although all tool types were at least represented in the assemblages from each site location (Table 7-4). Diagnostic tools were then analyzed to determine both their prevalence within each site type and to provide possible time periods when certain types sites were occupied more than other types (Table 7-5). The analysis showed that lithic specimens clearly indicating late stage tool manufacture were also most prevalent on fossil floodplain sites, followed by modern floodplain sites. Gravel deposit 
Table 7-2. All Artifacts Recovered During the Cuero I Reservoir Investigations.

\begin{tabular}{|c|c|c|c|c|}
\hline Biface & Group & Form & Count & Description \\
\hline \multirow[t]{8}{*}{ Thick } & & & 252 & \\
\hline & 1 & & 204 & Percussion flaked, sinuous edges, core bifaces or triangular/oval shaped \\
\hline & II & & 34 & Percussion flaked, sharp beveled end \\
\hline & & 1 & 9 & Triangular shaped, Clear Fork gouge \\
\hline & & 2 & 6 & Elliptical, Guadalupe adze \\
\hline & & 3 & 19 & Oval shaped, sharply beveled, convex distal end \\
\hline & III & & 3 & Percussion flaked, oval shaped, plano-convex \\
\hline & IV & & 11 & $\begin{array}{l}\text { Round or oval shaped, plano-convex, cortex } \\
\text { present, flake scars with hinge fractures }\end{array}$ \\
\hline \multirow[t]{34}{*}{ Thin } & & & 456 & \\
\hline & Irregular & & 49 & Nonuniform edges, beveled, formed from flakes \\
\hline & Pointed-Ovate & & 29 & Percussion thinned, pointed distal end and rounded proximal end \\
\hline & & 1 & 14 & Large \\
\hline & & 2 & 7 & Medium \\
\hline & & 3 & 8 & Small, Abasolo-like \\
\hline & Subtriangular & & 45 & Percussion and pressure flaked, triangular with rounded corners \\
\hline & & 1 & 30 & Thin \\
\hline & & 2 & 3 & Thick, Pandora-like \\
\hline & & 3 & 12 & Thick, Granbury-like \\
\hline & Triangular & & 31 & Percussion and pressure flaked, triangular with pointed corners \\
\hline & & 1 & 14 & Long \\
\hline & & 2 & 4 & Short \\
\hline & & 3 & 11 & Beveled, Early Triangular-like \\
\hline & & 4 & 1 & Parallel flake scars \\
\hline & & 5 & 1 & Pressure flaked fragment, Spanish Colonial Period form? \\
\hline & $\begin{array}{l}\text { Contracting } \\
\text { Stem }\end{array}$ & & 8 & $\begin{array}{c}\text { Broadest below midsection, tapers toward base, } \\
\text { base straight with rounded corners }\end{array}$ \\
\hline & & 1 & 5 & Steeply beveled \\
\hline & & 2 & 1 & Nearly bipointed, Lerma-like \\
\hline & & 3 & 2 & Slight pointed shoulders, Refugio-like \\
\hline & Straight Stem & & 20 & Shoulders and straight-sided stems \\
\hline & & 1 & 5 & Pedernales-like \\
\hline & & 2 & 4 & Convex sides, unbarbed shoulders, straight bases with squared corners \\
\hline & & 3 & 1 & Barbed shoulders, Bulverde-like \\
\hline & & 4 & 1 & $\begin{array}{l}\text { Narrow blade with slight unbarbed shoulders, } \\
\text { base straight with pointed corners }\end{array}$ \\
\hline & & 5 & 2 & Slight barbs, prominent shoulders \\
\hline & & 6 & 2 & Slightly convex sides and unbarbed shoulders, truncated at base \\
\hline & & 7 & 5 & Prominent barbed shoulders, stems long and straight, Perdiz-like \\
\hline & $\begin{array}{l}\text { Expanding } \\
\text { Stem }\end{array}$ & & 38 & Expanding outward stems from shouldered blades \\
\hline & & 1 & 4 & Concave stem edges and subtle shoulders \\
\hline & & 2 & 1 & Triangular blade with pointed shoulders, concave sides, Lange-like \\
\hline & & 3 & 3 & Long flat barbs and slightly expanding stems, Castroville-like \\
\hline & & 4 & 4 & Triangular blade with slight barbs, straight sided stem, Montell-like \\
\hline & & 5 & 2 & Triangular blade with pointed unbarbed shoulders \\
\hline
\end{tabular}


Table 7-2. All Artifacts Recovered During the Cuero I Reservoir Investigations. (continued)

\begin{tabular}{ccccc}
\hline Biface & Group & Form & Count & Description \\
\hline 6 & 3 & Long thin blades with pointed unbarbed shoulders, straight bases \\
& 7 & 11 & $\begin{array}{c}\text { Side-notched, slightly barbed shoulders, convex } \\
\text { base, common Central Texas form }\end{array}$ \\
8 & & $\begin{array}{c}\text { Deep corner notches and prominent barbs, concave base } \\
\text { Corner notched and prominent barbs, pointed corners }\end{array}$ \\
9 & 10 & & Corner notched and prominent barbs, straight base, Scallorn-like \\
\hline Miscellaneous & & 236 & Otherwise unidentifiable \\
\hline
\end{tabular}

From Fox et al. (1974), pp. 24-61.

Table 7-3. Biface Categories and Sub-categories

of the Cuero I Reservoir Assemblage.

\begin{tabular}{ccccc}
\hline & $\begin{array}{c}\text { Sandstone } \\
\text { Terraces } \\
\%\end{array}$ & $\begin{array}{c}\text { Gravel } \\
\text { Deposits } \\
\%\end{array}$ & $\begin{array}{c}\text { Fossil } \\
\text { Floodplains } \\
\%\end{array}$ & $\begin{array}{c}\text { Modern } \\
\text { Floodplain } \\
\%\end{array}$ \\
\hline Cores & 76 & 88 & 51 & 56 \\
Thick Bifaces & 11 & 6 & 13 & 9 \\
Thin Bifaces & 13 & 6 & 35 & 36 \\
\hline Total Specimens & 359 & 523 & 875 & 187 \\
\hline
\end{tabular}

From Fox et al. (1974), pp. 24-61.

Table 7-4. Distribution of Cores, Thick Bifaces, and Thin Bifaces, by Percent.

\begin{tabular}{cccccc}
\hline & Count & $\begin{array}{c}\text { Sandstone } \\
\text { Terraces } \\
\%\end{array}$ & $\begin{array}{c}\text { Gravel } \\
\text { Deposits } \\
\%\end{array}$ & $\begin{array}{c}\text { Fossil } \\
\text { Floodplains } \\
\%\end{array}$ & $\begin{array}{c}\text { Modern } \\
\text { Floodplain } \\
\%\end{array}$ \\
\hline $\begin{array}{c}\text { Multiple Small- } \\
\text { Facet Tertiary } \\
\text { Flakes }\end{array}$ & 1067 & 13 & 11 & 49 & 27 \\
$\begin{array}{c}\text { Thin Bifaces } \\
\text { Comparable }\end{array}$ & 456 & 28 & 5 & 48 & 19 \\
Diagnostics & 98 & 20 & 4 & 49 & 27 \\
\hline
\end{tabular}

From Fox et al. (1974), pp. 24-61.

Table 7-5. Comparative Distribution of Multiple Small-Facet Tertiary

Flakes, Thin Bifaces, and Comparable Diagnostics, by Percent.

\begin{tabular}{cccccc}
\hline & Count & $\begin{array}{c}\text { Sandstone } \\
\text { Terraces } \\
\%\end{array}$ & $\begin{array}{c}\text { Gravel } \\
\text { Deposits } \\
\%\end{array}$ & $\begin{array}{c}\text { Fossil } \\
\text { Floodplains } \\
\%\end{array}$ & $\begin{array}{c}\text { Modern } \\
\text { Floodplain } \\
\%\end{array}$ \\
\hline Neo-American & 39 & 13 & 2 & 35 & 51 \\
Late Archaic & 16 & 0 & 6 & 73 & 21 \\
$\begin{array}{c}\text { Early and } \\
\text { Middle Archaic }\end{array}$ & 27 & 37 & 8 & 46 & 9 \\
Early Archaic & 6 & 0 & 0 & 100 & 0 \\
Paleoindian & 10 & 29 & 0 & 71 & 0 \\
\hline
\end{tabular}

From Fox et al. (1974), pp. 24-61. 
sites, where early stage tool manufacture was likely to take place, had the least amount of late stage flakes, bifaces, and diagnostic tools.

Using diagnostic tool forms as a guide, principally projectile points, Table 7-5 shows that within the survey area, sites located on the modern floodplain were occupied during the Middle Archaic to Neo-American (Late Prehistoric) periods, as were sites on gravel deposits. The fossil floodplain, alternatively, was heavily occupied during the Paleoindian, Early Archaic, and Late Archaic, and less so during the Middle Archaic and Late Prehistoric periods. Fox et al. suggest that the lack of sites in the modern floodplain in these early periods of occupation may be a result of geologic and climatic change (1974:76). Quite simply, the modern floodplain did not exist during the Paleoindian to Early Archaic period. Additional observations made by the researchers include the higher percentages of Group I trimmed flakes and chips (end scrapers) and Group II trimmed flakes and chips (gravers) on gravel deposit sites, and correspondingly lower percentages of thin bifaces. Also, Group II core tools (boring tools) and Form 2 pointedovate thin bifaces occurred only at sandstone terrace and fossil floodplain sites suggesting an association with the Early Archaic or even Paleoindian, as did Form 2 Group II thick bifaces (Guadalupe gouges) and Form 3 Group II thick bifaces (a similar form). These tool forms generally are present in the Early and Middle Archaic. Similarly, these tool forms may indicate as specific use of that tool for activities conducted on sandstone terrace sites.

One last discussion on the dataset obtained by the investigations at the proposed Cuero I Reservoir included a comparison of the diagnostic forms found in the project area and those found in Central, Coastal, and Southwestern Texas. It was observed first that diagnostic tool forms indicative of all three geographic areas were represented in the lithic assemblage found in the project area. Central Texas tool forms, including the Pedernales, Bulverde or Bell, Lange, Castroville, Montell, Ensor, Scallorn, and Granbury were all seen in the lithic assemblage, indicating a strong association with Central Texas peoples, even to the extent that the project area was considered part of the subsistence region of these peoples at certain periods of time. A strong relationship between the artifacts found in the Cuero I project area and those found in Coastal Texas (Morhiss, Tortugas, Catan, Desmuke, Pandora, Refugio, and Lerma) as well as the presence of asphaltum on some of the recovered artifacts in the area showed a possible connection between the coastal region as well. Some vague associations concerning the Guadalupe gouge from South Texas and shell "gouges" from Coastal Texas were suggested, but no definitive evidence was present in the artifact assemblages from the Cuero I project area.

If Site 41DW277 is placed in this context, it would certainly fall within the fossil floodplain type of site, the most prevalent type of site recorded by the investigators. Unfortunately, there were no subsurface investigations conducted during the survey of the proposed Cuero I Reservoir, and there may be even more sites of this type along the Guadalupe River with no surface manifestations. Site 41DW277 also conforms to the observation that sites of this type generally have debris from late stage tool manufacture. On fossil floodplain sites analyzed during the Cuero I study, cores outnumber bifaces, but only by a small margin (51.3 percent vs. 48.7 percent), as opposed to other types of sites where the differences are wider. This is also true of Site 41DW277 whose earliest dated component dates to around 5260 \pm 30 BP. 
(This date falls within the Early Archaic period using the Savannah \& Prairie and Coastal Texas chronologies and the Middle Archaic period using the Central Texas chronology). The analysis of fossil floodplain sites over time does show that these types of sites were occupied throughout prehistory, and there is some evidence that they were the only ones utilized during the Early Archaic, but this may be a result of sampling error. Thus, in placing Site 41DW277 in the context of the utilization of the landscape and possible settlement patterns over time, one is hesitant to make conclusions until more chronometric evidence can be obtained. This is particularly true for floodplain sites that likely contain subsurface deposits. Nonetheless, the data from Site 41DW277 do support the idea that the site was used more intensively during the Early to Middle Archaic periods than during the Middle to Late Archaic periods.

As mentioned above, artifacts similar to those from Central Texas, South Texas, and Coastal Texas were all found in the Cuero I Reservoir project area. Although the researchers placed the Tortugas diagnostic point type in the Coastal Texas region, current research places the point type into a typical South Texas assemblage (Turner and Hester 1999). In any event, there seems to be a strong relationship with the Central Texas archeological region and the Cuero I project area, but the scant evidence obtained for Site 41DW277 indicates a connection with the South Texas archeological region. There are several possible explanations for this difference. The Cuero I project area is quite large, and perhaps there are differences between the northern sections of the area and the southern sections, were Site 41DW277 is located. In addition, there was no time element specifically incorporated into this analysis of the Cuero I assemblage, and the area, known to be a transition zone already, was influenced by peoples of different regions at different times. The Cuero I researchers mention this possibility specifically. It must be admitted, though, that due to the extremely low number of temporally and regionally diagnostic tools found during the test excavations, it may be that Site 41DW277 is a poor example to be compared with other archeological regions for any associations with them.

\section{Site 41DW269 Test Excavations (Hays and Abbott 1998)}

Site 41DW269 is described as a multi-component site with extant cultural material ranging in age from the Early Archaic through the Late Archaic, situated on a terrace above Clear Creek in northern DeWitt County. Two distinct cultural strata and a single pit-like feature were observed during the test excavations. The first strata contained mineralized bone and lithic material about 120-180 cmbs dating to the Early Archaic, based on a Guadalupe tool found in the strata and one radiocarbon date. The second strata contained cultural material from 10-110 cmbs dating to the Middle to Late Archaic.

The site was found by TxDOT archeologists in 1996 and tested in 1997, in advance of a bridge replacement project on County Road (CR)122. The site was seen to be eroding out of a cutbank of Clear Creek. Three mechanical trenches, two 1 x $1 \mathrm{~m}$ test units, two shovel tests and nine auger holes were dug at the site. The tested area was limited to the existing and proposed ROW for CR 122.

One snail shell recovered from $150 \mathrm{cmbs}$ obtained a radiocarbon date of $7450 \pm 70 \mathrm{BP}$. The pitlike feature consisted of a $12 \mathrm{~cm}$ diameter area of dark soil about 70-90 cmbs containing a few 
fragmented burned rocks, charcoal, and bone fragments. It was contextually determined to be of Late Archaic age.

About 599 pieces of lithic debitage, 138 pieces of faunal material, and 10 lithic tools were recovered from the test excavations. About 438 rabdotus snail shell, 13 mussel shell fragments, and 4,545 grams of burned rocks were also recovered. All of the temporally diagnostic artifacts with the exception of two Guadalupe tools were found during surface collection or eroding out of the cutbank. These included one possible Late Archaic proximal fragment of a projectile point, one Morhiss point, one Lange-like specimen, and one Lerma- or Refugio-like specimen. The researchers could only comfortably date these latter "like" specimens to the Archaic period. Three temporally diagnostic gouges were also located, including a Middle/Late Archaic bifacial gouge, a Clear Fork/Guadalupe tool, and a Guadalupe tool found in association with a mass of bone identified as white-tailed deer. This bone mass was radiocarbon dated to $7450 \pm 70$ BP, the Early Archiac.

Three hammerstones were recovered, and 11 sandstone metate fragments and one mano were found. About 18 edge modified flakes were recovered. One mussel shell fragment showed evidence of being used as a digging implement. Faunal remains of white-tailed deer, bison, cottontail rabbit, jackrabbit, opossum, turtle, large bird, and rattlesnake were all found. Much of the bone was broken into small pieces, indicating human-based processing. Cut marks and green fractures were present in 14 percent of the assemblage.

In comparing Sites 41DW269 and 41DW277, a few obvious similarities and differences appear. Both sites are on terraces above waterways, and both have Early Archaic components (although they are almost 2,200 years apart). The Middle Archaic components of Site 41DW277 may also partially correspond to the Middle/Late Archaic component of Site 41DW269, but the lack of radiocarbon dates at Site 41DW269 make this association tentative. The types of artifacts recovered from the sites are similar, but some of the quantities are vastly different. The faunal recovery at Site 41DW269 was much better than Site 41DW277, but the mussel shell recovery at Site 41DW277 is much higher than Site 41DW269. In addition, for the small amount of soil excavated at Site 41DW269, quite a few more pieces of groundstone were recovered than the much larger excavations at Site 41DW277. No mention of cores was made in the Site 41DW269 report, but numerous cores were found at Site 41DW277. The remainder of the artifact categories have much smaller numbers at Site 41DW269, including burned rock, lithic tools, debitage, and snail shell, but this is most likely a result of a much smaller quantity of excavated soil during the test investigations.

The faunal vs. mussel shell assemblages may indicate resource utilization at each location, rather than a simple difference in organic preservation. The bone mass of white-tailed deer at Site 41DW269 clearly shows the utilization of this resource for food in the Early Archaic. Extensive mussel and snail processing is seen in the Early Archaic at Site 41DW277. Geographically, this difference would make sense (see Figure 7-12). Also, it appears that plant resources that required grinding were utilized much more heavily at Site 41DW269 than Site 41DW277. This suggests that the location of Site 41DW277 was really used for gathering and processing specific food resources, namely mussels and snails. The chipped stone assemblage 
at Site 41DW269 is quite small, and although some comparisons with Site 41DW277 could be posited, the possibility for those conclusions to be in error (based on the existing dataset) is too large to provide any useful information.

\section{Site 41DW260 Test Excavations (Young 1988)}

Site 41DW260, a shallowly buried prehistoric campsite, was excavated by the State Department of Highways and Public Transportation (SDHPT) in late 1988 and early 1989, in anticipation of road improvements to Farm-to-Market (FM) 3402. The site remains were observed to extend 20-25 cmbs below the surface, where the site activities appeared to be early stage lithic production and the collection of freshwater mussel shell. The site is located on a flat secondlevel terrace above the Guadalupe River. Lost Creek, a tributary of the Guadalupe, is located about $150 \mathrm{~m}$ from the site. The site had been disturbed by blading of the top $10 \mathrm{~cm}$, which was how the site was discovered and recorded, but the blading did not seem to have caused significant damage.

A total of six shovel tests and sixteen 1 x 1-m excavation units were excavated in the ROW of FM 3402, recovering a large quantity of lithic material and shell debris. Twelve of those units were excavated as three $2 \times 2$-m blocks in the areas of the site with the highest potential for artifact recovery. No diagnostic artifacts or features were encountered, but some burned flint cobbles were observed with the other artifacts. Three thin biface fragments, eight thick biface fragments, two scrapers, five cores, and 12 modified flakes were collected from the test excavations. About 6,064 unmodified flakes were collected, with about 26.4 percent of the samples representing early lithic reduction, based on the amount of cortex on the flakes. Bifacial thinning flakes were rare, only about one percent of the assemblage. About 6,064 fragments, or 1,838 grams, of mussel shell were recovered and recorded. Although no diagnostic artifacts were found, the density of artifacts recovered in the vertical excavation column indicated a possible compression of multiple occupation components, with the earlier emphasizing mussel shell procurement, and the later lithic collection and reduction.

At first glance, Site 41DW260 would be an excellent site for comparison due to its location on a terrace above the Guadalupe River floodplain. However, the lack of features, diagnostic artifacts, or radiocarbon dates limits the comparison to gross generalities. Site 41DW260 appears to be the extreme example of dual-resource procurement-mussels as food and large gravels for lithic tools. The "earlier" occupation seemed to rely on the mussels, as with the earliest occupations at Site 41DW277, but it is unknown if these two components are at all related temporally. These two sites do differ in terms of the lithic debris-Site 41DW277 shows evidence of later lithic processing, and Site 41DW260 is more clearly a site where early lithic reduction took place.

\section{Site 41LC2 Test Excavations (Stahman et al. 2009)}

Site 41LC2 was excavated in 2007 in anticipation of the roadway improvements of US 77 by PBS\&J on behalf of TxDOT. The site was initially recorded in 1970 by Ken Bishop when 
he observed what was possibly a human burial eroding out of a cutbank of a drainage ditch just south of Supplejack Creek. In addition, artifacts were observed on both sides of US 77 within the ROW. The test excavations consisted of the excavation of five gradall trenches, two scraped areas totaling $51 \mathrm{~m}^{2}$, the hand excavation of 17 shovel tests, and the hand excavation of five 1 x 1-m test units. Surface collection was also conducted prior to the excavations. Analysis of the artifacts suggests a periodic occupation of the site from the Late Paleoindian to the Late Prehistoric periods. No radiocarbon samples were sent for analysis, as the subsurface investigations revealed that any occupation surfaces that were present in the ROW had been extensively disturbed and redeposited, mixing both cultural zones and possible features.

The gradall trenches ranged in depth form 137-200 cmbs. The soil from the scraped areas was removed $10 \mathrm{~cm}$ at a time until sterile soil was reached. A partial deer skeleton was encountered in one scraped area, but was found in association with a piece of clear modern glass. No prehistoric artifacts were found with the skeleton. The hand excavations revealed the presence of prehistoric artifacts from the surface to $104.5 \mathrm{cmbs}$, and some evidence of disturbed feature material, burned rock and burned matrix, was found 24.5-34.5 cmbs.

The artifacts collected during the test excavations included 1,565 pieces of debitage, 33 tools, 40 cores, 2 groundstone manos, 2,083 pieces of fire-cracked rock, 4,448.16 g of burned matrix, 483 faunal bone fragments, 1 prehistoric ceramic sherd, and 1,440 snail shells. About $0.61 \mathrm{~g}$ of charcoal was also recovered. Of the chipped stone tools, the assemblage included seven projectile points, six bifaces, 19 modified flakes, and one core tool. The diagnostic projectile points were used to identify the periods of occupation, and included an Angostura, Kinney-like, Palmillas, and Scallorn (Table 7-6). Of the six bifaces recovered, four were Stage 2 bifaces and two were Stage 3. None were completed, nor were they in their initial stages of manufacture.

Five of the modified flakes

Table 7-6. Distribution of Specific Comparable Diagnostic Forms by Associated Chronological Period at Site.41LC2.

\begin{tabular}{|c|c|c|c|}
\hline $\begin{array}{l}\text { Test } \\
\text { Unit }\end{array}$ & $\begin{array}{c}\text { Depth } \\
\text { (cmbs) }\end{array}$ & Type & Time Range \\
\hline 5 & $0-22$ & Angostura & Late Paleoindian \\
\hline 1 & $84.5-94.5$ & unidentified & Early Archaic \\
\hline \multicolumn{2}{|c|}{ Surface } & Kinney-like & Middle Archaic \\
\hline 1 & $44.5-54.5$ & unidentified & Middle Archaic \\
\hline 2 & $54-64$ & Palmillas & Middle/Late Archaic \\
\hline 3 & $40-50$ & unidentified & Late Prehistoric \\
\hline 3 & $70-80$ & Scallorn & Late Prehistoric \\
\hline
\end{tabular}

From Stahman, et al. (2009), pp. 34 were unifacially modified, 11 were just utilized, and 3 were used as perforators. Most of the fakes were used as scrapers, but spokeshaves and knives were also present. The core tool was used as both a scraper and chopper. The single ceramic sherd found at the site appeared to be similar to bone-tempered ceramics of the Central Coastal Bend area.

Of the faunal material recovered from Site 41LC2, the condition of the remains was considered poor. The assemblage exhibited extensive burning, extensive erosion, animal gnawing, and post-depositional breakage. About 224 bones could be identified to taxa, and included white-tailed deer, deer-sized artiodactyls, opossum, Mustelid (skunk or weasel), pocket gopher, hispid cotton rat, cottontail rabbit, large and small bird bones, 
turtle, and colubrid snake. Some of these species were determined to be post-depositionally invasive. The only evidence of cultural modification to the assemblage was burning.

The lack of clear occupation surfaces or intact stratigraphy severely hampers a comparative analysis, as does the diagnostic artifacts that indicate a periodic occupation from the Late Paleoindian to Late Prehistoric. Thus, the only comparison that can be conducted is the totality of artifacts recovered and their similarities and differences. As with Site 41DW269, the faunal recovery was much higher than at Site 41DW277, which might be significant. The variety of diagnostic artifacts was much higher as well, but the number of cores recovered is more in line with Site 41DW277's assemblage. The number of perforators found in Site 41LC2 was higher than at Site 41DW277, and that may indicate a specific site activity at one site that was not conducted at the other. The number of cores and modified flakes clearly indicates the use of a core-based tool technology in use at some point, as was also found at Site 41DW277 (see below). As no intact Late Prehistoric components were identified at Site 41DW277, one would not expect to see ceramic artifacts, as was found at Site 41LC2.

\section{Summary of Site Comparisons}

Review of the available literature on sites close to Site 41DW277 provides some general points of comparison with respect to lithic tool types, dietary resources, and site distribution. However, what is most striking about all of the sites examined in the region is how few actually contain intact stratified components, especially components associated with the Early to Middle Archaic periods. There are few sites with intact components older than 5,000 years that have been investigated near the Guadalupe Basin in the inland South Texas/Coastal region. The best comparative data comes from Site 41DW269 (Hays and Abbott 1998), but this site was only minimally investigated and the report is largely descriptive rather than interpretive. This makes the data offered by Site 41DW277 of particular value in that three distinct components are present, with the earliest potentially pre-dating 5,200 years old. The implications for this, and avenues for further research are discussed in the following chapter. 


\section{Chapter 8 \\ Summary, Conclusions, AND \\ RECOMMENDATIONS}

\section{Summary of Data: Determining Cultural Affiliation}

Site 41DW277 is a multicomponent prehistoric site on the Guadalupe River. Archeological testing of Site 41DW277 consisted of excavation of five gradall trenches and 32 test units to a maximum depth of $200 \mathrm{cmbs}$. The site's earliest identified component (AU 3) dates to $5260 \pm 30$ - a date that corresponds to the Early Archaic for the South Texas and Coastal Texas regions, and the Middle Archaic for the Prairies and Savannah and Central Texas cultural regions. This component was buried roughly 170-190 cmbs at the base of the Bw soil horizon. Researchers identified two other components at Site 41DW277, AU 1 and AU 2, and have dated them to 2900-3000 BP and 3400-3800 BP respectively. These components are buried at a depth of about 100-140 cmbs for AU 1 and 140-160 cmbs for AU 2 (though the depth of each component varies among trenches, and is based on proximity to the river itself) and correspond to the base of the $\mathrm{AB}$ soil horizon and the top of the Bw horizon respectively. In terms of integrity, all three analytical units appear to be relatively well delineated and in context, though it is not clear to what extent various natural processes have affected overall organic material preservation. Though lithic, snail and mussel shell recovery was moderate, almost no bone or charcoal was observed or collected during the investigations. Only three features were recorded.

AmaTerra tested the site within the proposed ROW for a bridge replacement along US 183 over the Guadalupe River. We believe that only a small portion of the site was investigated during AmaTerra's 2009 testing, and it is likely that the site extends to the northeast and southwest, and that additional elements could be identified if further archeological investigations were to occur on private property outside the US 183 ROW. Indeed, it is possible that the portion of the site investigated represents only its periphery, rather than its core. Supporting this are the soil susceptibility, which when graphed, returned relatively random readings throughout the various soil columns. While the susceptibility results may simply be inconclusive, it may also be the case that the most intensely utilized portion of the site was not the area tested. Hence, the susceptibility readings did not demonstrate the expected spikes corresponding to the various analytical units. Being at the site's periphery could also account for the low number of features, bone, and charcoal recovered at the site.

One of the issues to come out of the subsequent analysis of the archeological data is cultural affiliation. Does the site exhibit more affinity to Central Texas sites, Coastal sites, or South Texas sites? Geographically, it falls along the cusp of all three culture areas, and going into the testing, it was unclear whether the site is better-related to one cultural tradition over another. Earlier research from the Cuero I project suggests that sites along the Guadalupe Basin in this 
region exhibit a strong connection to Central Texas, though influences from other neighboring cultural areas were also observed. We contend that Site 41DW277 resembles a Coastal/South Texas site more than a Central Texas site. This is based on the recovery of primarily triangular and unstemmed tool types (the Tortugas point, the Clear Fork gouges, and unstemmed basally notched tools) over bifurcate-stem tools that are prevalent among Central Texas assemblages of the Archaic period. One Clear Fork gouge from Site 41DW277 was made from petrified wood, a material more commonly associated with the eastern portions of Texas than Central Texas, and while cultural affiliation cannot be determined from one tool specimen, it does suggest contact with the eastern and coastal regions. In addition, the presence of small, dispersed single-lens sandstone features rather than well-constructed formal hearths and thick midden deposits shares resemblances to Coastal/South Texas sites. Finally, the strong reliance on snail and freshwater marine resources over land animals is commonly seen in Coastal/South Texas. While all of these individual elements can be found on sites from other regions, the aggregation of them here does suggest that the peoples who inhabited the site had greater affiliation and contact with South Texas and the coast than other adjacent culture areas.

In terms of how this site fits into Coastal/South Texas chronology, then, it appears to fall into the Early Archaic through Late Archaic periods, with AU 1 falling at the end of the Middle Archaic to beginning of the Late Archaic, AU 2 in the Middle Archaic, and AU 3 at the end of the Early Archaic. The stratified nature of the deposits, despite the paucity of the actual recovery, makes this site among the few Coastal/South Texas that have interpretable components from the entire Archaic period. For this reason the site is potentially important, particularly the lowest component, which also happens to be the richest in terms of cultural material.

\section{IMPLICATIONS AND CONCLUSIONS}

Overall recovery of organic material was markedly sparse in all levels, with very little charcoal, charred macrobotanical material, or bone recovered during the excavations. There are several possible explanations for this. The first was alluded to above and could simply be a result of sampling the wrong part of the site. Though plausible, this hypothesis is impossible to test without further investigations outside of the US $183 \mathrm{ROW}$. The second possible explanation is that site formation conditions did not favor organic preservation. Situated within the Guadalupe River floodplain, the site was undoubtedly subject to recurring floods which may have scoured surfaces and washed away remains that were once more plentiful. This would help explain the fragmentary and diffuse aspects of the rock features observed at the site. Finally, a third explanation for poor organic recovery could simply have to do with site activities. For instance, it is possible that faunal recovery in particular was poor because Site 41DW277's prehistoric inhabitants were not engaging in hunting activities. Ultimately, we propose that the poor organic recovery during the testing may have been some combination of all three possibilities. At least soil pH levels were shown to be in the range where good organic preservation was possible, and soil acidity was not a factor in the poor organic preservation.

Despite the relatively small number of artifacts and features documented at the site, the data and analysis from Site 41DW277 do highlight several important conclusions about site activities over time, with implications that could direct future research. The first and most obvious is 
that (based on the current site sample) the site was much more intensively utilized during the earliest period of occupation (AU 3) than the latter. Though by volume investigators excavated far less of AU 3 than any other component (only $1.25 \mathrm{~m}^{3}$ ), this same analytical unit contained greater numbers and weight of lithic debris, burned rock, mussel, and snail shells than any other component. If we measure the ratio of artifacts to volume excavated, there were nearly twice as many artifacts in AU 3 than AU 2, and nearly three times the number in AU 1. This is a significant change over time that has implications for the choices inhabitants made about this place throughout prehistory. The snail, mussel shell, and limited bone recovery also suggest differing subsistence foci over time. Freshwater mussel shell was generally plentiful in all levels, but it was highest in AU 3, followed by much lower numbers in AUs 2 and 1. Similarly, rabdotus snail shells prominently spiked in AU 3 and gradually decreased in numbers, with the lowest density in AU 1. Meanwhile, the small quantity of bone that was recovered from the site came entirely from the upper levels, with no bone found in AU 3. We have already suggested that low faunal recovery could be attributable to poor organic preservation and maintain that was probably the case for Site 41DW277. However, it is also worthwhile to point out that there does appear to be a stronger correspondence between faunal recovery and AU 1 than any other component, and this is probably meaningful. It suggests that during its earliest period of use, protein subsistence among occupants of Site 41DW277 was based on snail and mussel shell gathering, while subsistence during later periods relied less on snail and mussel shell gathering in favor of hunting.

Further evidence that site foci changed over time comes from lithic tools and lithic flake analysis, both of which hint at greater mobility among site occupants during the Middle to Late Archaic periods. This observation, in turn, harmonizes with the perceived changes in subsistence discussed above. Tools and flake analysis of the lithic assemblage demonstrates greater reliance on expedient tools and core-derived tools (typically an indicator of increased sedentism) during the AU 3 period, with more emphasis on bifaces and formal tools (generally linked to greater mobility) during the AU 2 and AU 1 periods. Thus, overall it would appear that the inhabitants of Site 41DW277 occupied the area for longer periods of time and engaged in more sedentary activities such as lithic resource procurement and gathering 5,200 years ago, while they were more mobile and used the area less intensively 3,000 years ago. In short, prehistoric peoples exploited this area differently and perhaps for longer periods of time during the Early Archaic period than in the Middle and Late Archaic periods.

When compared with data from other sites this observation may fit into a regional pattern. For instance, data from the proposed Cuero I Reservoir archeological survey does suggest that people of the Late Archaic preferred a slightly greater variety of site environments, including upland gravel deposits and modern floodplain areas. Middle Archaic sites were found in the greatest numbers on sandstone terraces as well as fossil floodplains, while Early Archaic sites were confined to fossil floodplain areas similar to the geomorphic setting of Site 41DW277. Despite these differences, the type of geographic location most utilized by prehistoric peoples throughout prehistory is the fossil floodplains, such as the location of Site 41DW277.

A comparative analysis of Sites 41DW277 and 41DW269, 41DW260, and 41LC2 provided more information on subsistence issues than any other topic, followed by some data on lithic 
technology. The better faunal recovery at Sites 41DW269 and 41LC2 indicates possible site-specific resource utilizations, particularly a dichotomy between medium-sized mammal protein sources and freshwater marine protein sources. It is likely that the locations of Sites 41DW269 and 41LC2 away from major river drainages such as the Guadalupe River helped influence the resource utilization strategy of the site inhabitants as well as increased the faunal preservation. This includes data from the Early Archaic (at Sites 41DW269 and 41DW277), as well as other time periods. A comparison between Sites 41DW277 and 41DW260 provided remarkably similar data on mussel shell procurement (although it is unknown if the timeframes are similar), but quite different data on lithic technology. Site 41DW260 was a site for lithic procurement and early stage tool manufacturing, while Site 41DW277 was a locale for late stage tool manufacturing. On the other hand, Sites 41DW277 and 41LC2 did indicate that late stage tool manufacturing as well as a core-based tool technology was used at each location.

One conclusion that could be drawn from data from Site 41DW277 and other nearby sites could be that prehistoric peoples regionally used this area more intensively and stayed at campsites for longer periods of time, relying heavily freshwater marine resources (and presumably plants) during the Early to Middle Archaic period. The data from Site 41DW277 certainly suggests more intensive freshwater marine shell utilization in the lower (Early to Middle Archaic) levels than in higher levels (Late Archaic). Data from Site 41DW269 also supports this idea. Thus, it could be that over time the peoples who entered this region were more mobile in general and more reliant on hunting for subsistence during the Late Archaic than during the Early Archaic, where people tended to focus more heavily on gathering freshwater marine resources. This is indeed a broad generalization - especially given the small sample size of AU 3-and one that requires more vigorous research and testing of other sites. Nonetheless, it is a worthwhile avenue for future research to follow in order to understand the long term patterns of the lifeways in this still poorly understood aspect of Texas prehistory.

\section{RECOMMENDATIONS}

AmaTerra prepared an interim report of excavations in January 2010 (Feit and Nickels 2010). In it, the Principal Investigators recommended that the upper portions of the site (AUs 1 and 2) were not eligible for listing on the NRHP under 36 CFR 60.4, or as a SAL under 13 TAC 26 because they did not exhibit any unique or unusual characteristics with potential to contribute new data or understanding of the prehistory of the region. The lowest component (AU 3), however, was recommended as possibly eligible for inclusion to the NRHP and listing as a SAL due to its Early Archaic age and integrity. Under Criterion D outlined in 36 CFR 60.4, it does have potential to contribute new data to the study of Texas prehistory. No further work was recommended, though, because the depth of the component was outside of the APE, which extends less than five feet in depth where AU 3 was documented. Therefore, construction of the new bridge would not impact the AU 3 component of Site 41DW277. The THC concurred with this recommendation in February 2010 and bridge construction has proceeded.

AU 3 currently remains intact under the new US 183 bridge over the Guadalupe River, and potentially in areas outside the existing road ROW. Should future construction affect the AU 3 deposits of Site 41DW277 within or adjacent to the currently defined site limits, AmaTerra 
recommends that further archeological investigations may be warranted to target possible Early Archaic components. This report has been prepared in partial fulfillment of the requirements of Antiquities Permit 5460. 


\section{REFERENCES}

Abbott, J. T.

2009 "Appendix I: Geoarcheological Observations at US 183 and the Guadalupe River, DeWitt County, Texas,” In Letter Report: Archeological Survey of Proposed Right-of-Way for US Highway 183 at the Guadalupe River, DeWitt County, Texas. CSJ: 0154-03-027. Archeological Studies Program, Environmental Affairs Division, Texas Department of Transportation. Austin.

Andrefsky, W., Jr.

1994 Raw Material Availability and the Organization of Technology. American Antiquity 59:1, pp. 21-34.

Baker, B. W.

1993 A Review of Central Texas Archaic Subsistence Patterns. In Archaeological Investigations in Bull Branch: Results of the 1990 Summer Archaeological Field School, edited by D. L. Carlson, pp. 35-45. Research Report 19. Archaeological Resource Management Series, United States Army Fort Hood.

Barnes, V. E.

1974 Geological Atlas of Texas, Seguin Sheet. Bureau of Economic Geology, the University of Texas at Austin.

Bement, L. C., and D. G. Robinson

1983 A Cultural Resource Survey and Assessment of the Proposed Gonzales to Cuero Transmission Corridor, Gonzales and DeWitt Counties, Texas. Texas Archeological Survey Technical Bulletin No. 64, Submitted to the Lower Colorado River Authority, TAC Permit Number 252. Austin, Texas.

Bettis, A., and J. T. Abbott

2009 Archeological Survey of Proposed Right-of-Way for US Highway 183 at the Guadalupe River; DeWitt County, Texas. Letter Report, CSJ: 0154-03-027. Prepared August 2009 by Archeological Studies Program, Environmental Affairs Division, Texas Department of Transportation, Austin.

2009 Letter Report: Archeological Survey of Proposed Right-of-Way for US Highway 183 at the Guadalupe River, DeWitt County, Texas. CSJ: 0154-03-027. Archeological Studies Program, Environmental Affairs Division, Texas Department of Transportation. Austin.

Black, S. L., L. W. Ellis, D. G. Creel, and G. T. Goode

1997 Hot Rock Cooking on the Greater Edwards Plateau: Four Burned Rock Midden Sites in West Central Texas. 2 vols. Studies in Archeology 22, Texas Archeological Research Laboratory, University of Texas at Austin. Archeology Studies Program, Report 2, Texas Department of Transportation, Austin. 
Blair, W. F.

1950 The Biotic Provinces of Texas. The Texas Journal of Science 2(1):93-117. Map compiled by the Texas Parks and Wildlife Department, online at http://www.tpwd.state.tx.us/landwater/ land/maps/gis/map_downloads/map_gallery/bio/.

Brady, N. and R. Weil

2002 The Nature and Properties of Soils. 13th Edition. Prentice Hall, New Jersey.

Bousman, C. B.

1992 Preliminary Oxygen-Isotope Evidence for Late Pleistocene-Early Holocene Climatic Change. Current Research in the Pleistocene 9:78-80.

1994 Central Texas Pollen Record: A Reinterpretation. Current Research in the Pleistocene 11:79-81.

1998 Paleoenvironmental Change in Central Texas: The Palynological Evidence. Plains Anthropologist (43) 164:201-219.

Bramforth, D. B., and M. S. Becker

2000 Core/Biface Ratios, Mobility, Refitting, and Artifact Use-lives: A Paleoindian Example. The Plains Anthropologist 45:173, pp. 273-290.

Brown, D. O.

1983 The Berger Bluff Site (41GD30A): Excavations in the Upper Deposits, 1979. Archaeological Survey Report No. 115, Center for Archeological Research, the University of Texas at San Antonio.

Brown, K.

2002 “Appendix F: Snails from the Quarter-inch and Eight-inch Screens.” In The Smith Creek Bridge Site (41DW270), a Terrace Site in DeWitt County, Texas, buy Dale Hudler, Keith Prilliman, and Thomas Gustavson. Studies in Archeology 35, Texas Archaeological Research Laboratory, the University of Texas at Austin, and Archeology Studies Program, Report No. 17, Environmental Affairs Division, Texas Department of Transportation.

Camper, H. A.

1991 Pollen Analysis of Patschke Bog. Unpublished MS Thesis, Department of Botany, Texas A\&M University, Bryan, Texas.

Collins, M. B.

1975 Lithic Technology as a Means of Processual Inference. In Lithic Technology: Making and Using Stone Tools, edited by E. H. Swanson, pp. 15-34. Mouton Publishers, The Hague, The Netherlands.

1995 Forty Years of Archeology in Central Texas. Bulletin of the Texas Archeological Society 66:361-400. 
2004 Archeology in Central Texas. In The Prehistory of Texas, edited by Timothy Perttula. Texas A\&M University Press, College Station.

2011 Heated Rocks as Evidence of Prehistoric Hunter-Gatherer Adaptations in Texas. Bulletin of the Texas Archeological Society 82, pp. 181-191.

Collins, M.B., W. B. Gose, and S. Shaw

1994 Preliminary Geomorphological Findings at Dust and Nearby Caves. Journal of Alabama Archeology 40:35-56.

Cowan, F. L.

1999 Making Sense of Flake Scatters: Lithic Technological Strategies and Mobility. American Antiquity 64:4, pp. 593-607.

Crabtree, D. E.

1966 A Stoneworker's Approach to Analyzing and Replicating the Lindenmeire Folsome. Tebiwa 9(1):3-39.

1972 An Introduction to Flintworking. Occasional Papers of the Idaho State University Museum, Pocatello, ID. Fullagar, R. L. K.

1982 An Introduction to Flintworking. In Occasional Papers of the Idaho Museum of Natural History, No. 28, 2nd ed. Pocatello, Idaho.

Deetz, J. and E. Dethlefsen

1963 Soil pH as a Tool in Archaeological Site Interpretation. American Antiquity 29(2):242-243.

Ellis., L.

1997 Chapter 3: Hot Rock Technology. In Hot Rock Cooking on the Greater Edwards Plateau: Four Burned Rock Midden Sites in West Central Texas, by Stephen L. Black, Linda W. Ellis, Darrell G. Creel, and Glen T. Goode. Studies in Archeology 22, Texas Archeological Research Laboratory, the University of Texas at Austin, and Archeology Studies Program, Report No. 2, Environmental Affairs Division, Texas Department of Transportation.

Feit, R., and D. Nickels

2010 Interim Report for Archeological Testing of Site 41DW277, DeWitt County, Texas. Ecological Communications Corporation, Austin, Texas.

Fields, R.C.

2004 The Archeology of the Post Oak Savanna of East-Central Texas. In The Prehistory of Texas, edited by Timothy Perttula. Texas A\&M University Press, College Station.

Foster, W.

1991 Spanish and French Explorers. In The History of DeWitt County, Texas by the DeWitt County Historical Commission. Curtis Media Corporation. Dallas, Texas. 
Fox, D. E.

1979 Archaeological Investigations of Two Prehistoric Sites on the Coleto Creek Drainage, Goliad County, Texas. Archaeological Survey Report 69, Center for Archeological Research, the University of Texas at San Antonio.

Fox, D. E., R. J. Mallouf, N. O’Malley, and W. M. Sorrow

1974 Archeological Resources of the Proposed Cuero I Reservoir, DeWitt and Gonzales Counties, Texas. Texas Historical Commission Archeological Survey Report No. 12. Austin, Texas.

Fredlund, G.

1998 Phytolith Analysis. In Wilson Leonard, An 11,000-year Archeological Record of Hunter Gatherers in Central Texas, Volume V: Special Studies, edited by M. B. Collins, pp. 1637-1651. Studies in Archeology 31, Texas Archeological Research Laboratory, the University of Texas at Austin. Archeology Studies Program, Report 10, Environmental Affairs Division, Texas Department of Transportation, Austin.

Goode, G.

2002 The Anthon Site: A Prehistoric Encampment in Southern Uvalde County, Texas. Report 8, TxDOT ENV Archeological Studies Program.

Gordon, C. C., and J. E. Buikstra

1981 Soil pH, Bone Preservation, and Sampling Bias at Mortuary Sites. American Antiquity 46(3):566-571.

Gose, W. A. and D. L. Nickels

1998 Archaeomagnetic and Magnetic Susceptibility Analyses. In Test Excavations at the Culebra Creek Site, 41BX126, Bexar County, Texas, by D. L. Nickels, C. B. Bousman, J. D., Leach, and D. A. Cargill, pp. 204-214 (reprinted in 2001). Archaeological Survey Report No. 265, Center for Archeological Research, the University of Texas at San Antonio, Archeological Studies Program Report 3, Environmental Affairs Division, Texas Department of Transportation, Austin.

Gould, F. W., Hoffman, G. O., and C. A. Rechenthin

1960 Vegetational Areas of Texas. Texas A\&M University, Texas Agricultural Experiment Station, Leaflet No. 492. Map compiled by the Texas Parks and Wildlife Department, online at http:// www.tpwd.state.tx.us/landwater/land/maps/gis/map_downloads/map_gallery/bio/.

Graham, R. W.

1987 Late Quarternary Fauna and Paleoenvironments of the Southwestern Plains of the United States. In Late Quaternary Mammalian Biogeography and Environments of the Great Plains and Prairies, edited by R. W. Graham, H. A. Semken Jr., and M. A. Graham, pp. 24-86. Scientific Papers Volume 22, Illinois State Museum, Springfield. 
Graham, R. W. and E. L. Lundelius, Jr.

1984 Coevolutionary Disequilibrium and Pleistocene Extinctions. In Quarternary Extinctions: A Prehistoric Revolution, edited by P. S. Martin and R. G. Klein, pp. 223-249. University of Arizona Press, Tuscon.

Hall, G. D., T. R. Hester, and S. L. Black

1986 The Prehistoric Sites at Choke Canyon Reservoir, Southern Texas: Results of Phase II Archaeological Investigations. Choke Canyon Series, No. 10, Center for Archeological Research, the University of Texas at San Antonio.

Hayden, B. and W. K. Hutchings

1982 Wither the Billet Flake. In Experiments in Lithic Technology, edited by Daniel S. Amick and Raymond P. Mauldin, pp. 235-257. BAR International Series 528, British Archaeological Reports, Oxford.

Hays, S. H., and J. T. Abbott

1998 Results of Significance Testing at 41DW269, DeWitt County, Texas. Texas Department of Transportation, Environmental Affairs Division, Cultural Resource Management Section, Archeology Studies Program. Austin, Texas.

Heller, F. and M. E. Evans

1995 Loess Magnetization. Reviews of Geophysics 33:211-240.

Hester, T. R.

1981 Tradition and Diversity among the Prehistoric Hunters and Gatherers of Southern Texas. The Plains Anthropologist 26(92):119-128.

1991 Prehistory of DeWitt County. In The History of DeWitt County, Texas by the DeWitt County Historical Commission. Curtis Media Corporation. Dallas, Texas.

1995 The Prehistory of South Texas. Bulletin of the Texas Archeological Society 66:427-459.

2004 The Prehistory of South Texas. In The Prehistory of Texas, edited by Timothy Perttula. Texas A\&M University Press, College Station.

Hudler, D., K. Prilliman, and T. Gustavson

2002 The Smith Creek Bridge Site (41DW270), A Terrace Site in DeWitt County, Texas. Studies in Archeology 35, Texas Archeological Research Laboratory, the University of Texas at Austin. Archeology Studies Program, Report No. 17, Environmental Affairs Division, Texas Department of Transportation, Austin.

Jelinek, A. J., B. Bradley, and B. Huckell

1971 The Production of Secondary Multiple Flakes. American Antiquity 36:198-200.

AmaTerra Environmental, Inc. 
Johnson, L., Jr., and G. T. Goode

1994 A New Try at Dating and Characterizing Holocene Climates, as Well as Archeological Periods, on the Eastern Edwards Plateau. Bulletin of the Texas Archeological Society 65:1-51.

Kelly, R. L.

1988 The Three Sides of a Biface. American Antiquity 53:4, pp. 717-734.

1992 Mobility/Sedentism: Concepts, Archaeological Measures, and Effects. Annual Review of Anthropology 21, pp. 43-66.

McNab, W. Henry and P. E. Avers

1994 Ecological Subregions of the United States. WO-WSA-5, Prepared in cooperation with Regional Compilers and the ECOMAP Team of the Forest Service. Online at http://www.fs.fed.us/land/ pubs/ecoregions/index.html.

Mehalchick, G. K., D. K. Boyd, S. A. Tomka, and K. W. Kibler

1996 National Register Testing of 19 Prehistoric Archeological Sites on Fort Hood, Texas: The 1995 Season. United States Army Fort Hood Archeological Resource Management Series, Research Report No. 37. Prewitt and Associates, Austin, Texas.

Miller, W. T.

1978 Soil Survey of De Witt County, Texas. Soil Conservation Service, United States Department of Agriculture, Washington, DC.

Murphree, N.

1962 A History of DeWitt County. Edited by Robert W. Shook. Victoria, Texas.

Natural Heritage Policy Research Project

1978 Preserving Texas' Natural Heritage. Natural Heritage Policy Research Project, Lyndon B. Johnson School of Public Affairs, the University of Texas at Austin. Policy Research Project Report Number 31.

Nickels, D.L. and R. P. Maudlin

2001 An Archaeological Survey of Twin Buttes Reservoir, Tom Green County, Texas. Archaeological Survey Report, No. 300, Center for Archeological Research, The University of Texas at San Antonio.

Nordt, L. C., T. W. Boutton, J. S. Jacob, and R. Mandel

1994 Late Quarternary Climates of Central Texas Based on the Stable Isotope Composition of Organic Carbon. Program and Abstracts, 52nd Plains Conference, 65th Annual Meeting of the Texas Archeological Society, Lubbock, Texas. 
Omernik, J.M.

1987 Ecoregions of the Conterminous United States. Map. Annals of the Association of American Geographers 77(1):118-125.

Patterson, $\mathrm{P}$.

1977 A Lithic Reduction Sequence: A Test Case in the North Fork Reservoir Area, Williamson County, Texas. Bulletin of the Texas Archeological Society 48: 44-54.

Perttula, T. K. (editor)

2004 The Prehistory of Texas. Texas A\&M University Press, College Station.

Quigg, J. M., M. E. Malainey, R. Przybylski, and G. Monks

2001 No Bones About It: Using Lipid Analysis of Burned Rock and Groundstone Residues to Examine Late Archaic Subsistence Practices in South Texas. Plains Anthropologist 46:177 pp. 283-303.

Ricklis, R. A.

1994 Toyah Components: Evidence for Occupation in the Project Area during the Later part of the Late Prehistoric. In Archaic and late Prehistoric Human Ecology in the Middle Onions Creek Valley, Hays County, Texas. Studies in Archeology 19, Texas Archeology Research Laboratory, the University of Texas at Austin.

2004 Prehistoric Occupation of the Central and Lower Texas Coast. In The Prehistory of Texas, edited by Timothy Perttula. Texas A\&M University Press, College Station.

Robinson, R. L.

1982 Biosilica Analysis of Three Prehistoric Archaeological SItes in the Choke Canyon Reservoir, Live Oak County, Texas: Preliminary Summary of Climatic Implications. In Archaeological Investigations at Choke Canyon Reservoir, South Texas: Phase I Findings, edited by G. D. Hall, S. L. Black, and C. Graves, pp. 597-610. Choke Canyon Series, No. 5, Center for Archeological Research, the University of Texas at San Antonio.

Roell, C. H.

2011 “DEWITT COUNTY,” Handbook of Texas Online (http://www.tshaonline.org/handbook/ online/articles/hcd07), accessed November 21, 2011. Published by the Texas State Historical Association.

Shafer, H. J.

1983 The Lithic Artifacts of the Pulltrouser Area: Settlements and Fields. In Pulltrouser Swamp: Ancient Maya Habitat, Agriculture, and Settlement in Northern Belize, edited by P. D. Harrison and B. L. Turner, pp. 212-245. University of Texas Press, Austin.

1985 A Technological Study of Two Maya Workshops at Colhá, Belize. In Stone Tool Analysis: Essays in Honor of Don E. Crabtree, edited by M. G. Plew, J. C. Woods and M. G. Pavesic, pp. 277-315. University of New Mexico Press, Albuquerque. 
Shott, M. J.

1986 Technological Organization and Settlement Mobility: an Ethnographic Examination. Journal of Anthropological Research 42:15-51.

Sollberger, J. B.

1977 Fracture Theory, Applied to Flaking Forces and Lithic Analysis. Paper presented at the Conference for Use-Wear, Simon Fraser University, Burnaby, British Columbia, Canada.

Smyrl, V. E.

2011 “GUADALUPE RIVER,” Handbook of Texas Online (http://www.tshaonline.org/handbook/ online/articles/rng01), accessed August 31, 2011. Published by the Texas State Historical Association.

Sparks, D.

2003 Environmental Soil Chemistry. Academic Press, London.

Stahman, Andrea, Michael Nash, Ruth Marie, and Linda W. Ellis

2009 National Register Eligibility Testing of Site 41LC2, Lavaca County, Texas. Prepared for the Texas Department of Transportation, Environmental Affairs Division, by PBS\&J, Austin.

Texas Forest Service

2008a Blackland Prairie Eco-Region. Member Texas A\&M System http:/texastreeid.tamu.edu/ content/texasEcoRegions/BlacklandPrairies/

2008b Post Oak Savannah Eco-Region. Member Texas A\&M System http:/texastreeid.tamu.edu/ content/texasEcoRegions/PostOakSavanah/

Toomey, R. S., III, and T. W. Stafford, Jr.

1994 Paleoenvironmental and Radiocarbon Study of the Deposits from Hall's Cave, Kerr County, Texas. Program and Abstracts, 52nd Plains Conference, 65th Annual Meeting of the Texas Archeological Society, Lubbock, Texas.

Tsirk, A.

1979 Regarding Fracture Initiations. In Lithic Use-wear Analysis, edited by B. Hayden, pp. 83-96. Academic Press, New York.

Turner, E., and T. R. Hester

1999 A Field Guide to Stone Artifacts of Texas Indians. 3rd ed. Gulf Publishing, Latham, Maryland. 
U.S. Environmental Protection Agency

2004 Level III Ecoregions of the Continental United States. Map compiled by the Texas Parks and Wildlife Department, online at http://www.tpwd.state.tx.us/landwater/land/maps/gis/ map_downloads/map_gallery/bio/.

U.S. Forest Service

2004 Bailey's Ecoregions and Subregions of the United States, Puerto Rico, and the U.S. Virgin Islands: National Atlas of the United States. Map compiled by the Texas Parks and Wildlife Department, online at http://www.tpwd.state.tx.us/landwater/land/maps/gis/map_downloads/ map_gallery/bio/.

Watson, J. P.

1967 A Termite Mound in an Iron Age Burial ground in Rhodesia. Journal of Ecology 55(3):663-669.

Weddle, R. S.

2011 “SAN FRANCISCO DE LOS TEJAS MISSION," Handbook of Texas Online (http://www. tshaonline.org/handbook/online/articles/uqs15), accessed December 04, 2011. Published by the Texas State Historical Association.

Whittaker, J. C.

1994 Flintknapping: Making and Understanding Stone Tools. 1st ed., University of Texas Press, Austin.

Young, Wayne C.

1988 Archaeological Testing of Site 41DW260, Dewitt County, Texas. State Department of Highways and Public Transportation, Highway Design Division. 


\section{Appendix A Radiocarbon Dating Results}




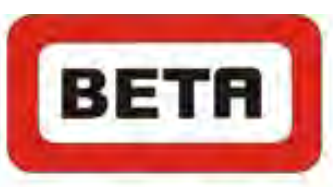

Consistent Accuracy... ... Delivered On-time

July 29, 2011

\section{Dr. James Abbott}

Texas Department of Transportation

Cultural Resource Management

Environmental Affairs Division

125 East 11th Street

Austin, TX 78701

RE: Radiocarbon Dating Results For Samples DW277U10L5F1, DW277U25L3, DW277U4L12, DW277U10L4F1, DW277U10L7F3, DW277U6L18, DW277U13L7, DW277U13L3, DW277U13L4

Dear Dr. Abbott:

Enclosed are the radiocarbon dating results for nine samples recently sent to us. They each provided plenty of carbon for accurate measurements and all the analyses proceeded normally. As usual, the method of analysis is listed on the report with the results and calibration data is provided where applicable.

As always, no students or intern researchers who would necessarily be distracted with other obligations and priorities were used in the analyses. We analyzed them with the combined attention of our entire professional staff.

If you have specific questions about the analyses, please contact us. We are always available to answer your questions.

Our invoice is enclosed with the mailed report copy. Please, forward it to the appropriate officer or send VISA charge authorization. Thank you. As always, if you have any questions or would like to discuss the results, don't hesitate to contact me.

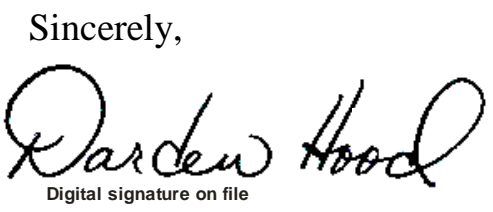




\section{REPORT OF RADIOCARBON DATING ANALYSES}

Dr. James Abbott

Report Date: 7/29/2011

Texas Department of Transportation

Material Received: 7/20/2011

Sample Data

Measured
Radiocarbon Age

$3830+/-30 \mathrm{BP}$

Beta - 302686

SAMPLE : DW277U10L5F1

ANALYSIS : AMS-Standard delivery

MATERIAL/PRETREATMENT : (charred material): acid/alkali/acid

2 SIGMA CALIBRATION : $\quad$ Cal BC 2450 to 2200 (Cal BP 4400 to 4150)
$13 \mathrm{C} / 12 \mathrm{C}$
Ratio

$-24.4 \mathrm{o} / \mathrm{oo}$

$3840+/-30$ BP
Conventional

Radiocarbon Age $\left(^{*}\right)$
Beta - 302687

SAMPLE : DW277U25L3

ANALYSIS : AMS-Standard delivery

MATERIAL/PRETREATMENT : (charred material): acid/alkali/acid

2 SIGMA CALIBRATION : $\quad$ Cal BC 810 to 760 (Cal BP 2760 to 2720)
$-23.8 \mathrm{o} / \mathrm{oo}$

$2590+/-30$ BP
Beta - 302688

SAMPLE : DW277U4L12

ANALYSIS : AMS-Standard delivery

MATERIAL/PRETREATMENT : (charred material): acid/alkali/acid

2 SIGMA CALIBRATION : $\quad$ Cal BC 2280 to 2250 (Cal BP 4230 to 4200) AND Cal BC 2220 to 2120 (Cal BP 4160 to 4070 ) Cal BC 2090 to 2040 (Cal BP 4040 to 3990)
$3750+/-30 \mathrm{BP}$

$-25.2 \mathrm{o} / \mathrm{oo}$

$3750+/-30 \mathrm{BP}$
Beta - 302690

SAMPLE : DW277U10L4F1

ANALYSIS : AMS-Standard delivery

MATERIAL/PRETREATMENT : 2 SIGMA CALIBRATION : 


\section{REPORT OF RADIOCARBON DATING ANALYSES}

Dr. James Abbott

Report Date: 7/29/2011

$$
\text { Sample Data }
$$

\author{
Measured \\ Radiocarbon Age
}

$13 \mathrm{C} / 12 \mathrm{C}$
Ratio
Conventional

Radiocarbon Age $\left.{ }^{*}\right)$

Beta - 302691

$5240+/-30$ BP

$-23.6 \mathrm{o} / \mathrm{oo}$

$5260+/-30$ BP

SAMPLE : DW277U10L7F3

ANALYSIS : AMS-Standard delivery

MATERIAL/PRETREATMENT : (charred material): acid/alkali/acid

2 SIGMA CALIBRATION : $\quad$ Cal BC 4230 to 4200 (Cal BP 6180 to 6150) AND Cal BC 4170 to 3980 (Cal BP 6120 to 5930)

Beta - 302693

$4610+/-40$ BP

$-18.2 \mathrm{o} / \mathrm{oo}$

$4720+/-40 \mathrm{BP}$

SAMPLE : DW277U6L18

ANALYSIS : AMS-Standard delivery

MATERIAL/PRETREATMENT : (organic sediment): acid washes

2 SIGMA CALIBRATION : $\quad$ Cal BC 3630 to 3490 (Cal BP 5580 to 5440) AND Cal BC 3470 to 3370 (Cal BP 5420 to 5320)

Beta - 302694

$4930+/-40$ BP

$-19.0 \mathrm{o} / \mathrm{oo}$

$5030+/-40 \mathrm{BP}$

SAMPLE : DW277U13L7

ANALYSIS : AMS-Standard delivery

MATERIAL/PRETREATMENT : (organic sediment): acid washes

2 SIGMA CALIBRATION : $\quad$ Cal BC 3950 to 3710 (Cal BP 5900 to 5660)

Beta -302695

$2910+/-30$ BP

$-18.3 \mathrm{o} / \mathrm{oo}$

$3020+/-30$ BP

SAMPLE : DW277U13L3

ANALYSIS : AMS-Standard delivery

MATERIAL/PRETREATMENT : (organic sediment): acid washes

2 SIGMA CALIBRATION : $\quad$ Cal BC 1380 to 1200 (Cal BP 3330 to 3150)

Dates are reported as RCYBP (radiocarbon years before present, "present" = AD 1950). By international convention, the modern reference standard was $95 \%$ the $14 \mathrm{C}$ activity of the National Institute of Standards and Technology (NIST) Oxalic Acid (SRM 4990C) and calculated using the Libby $14 \mathrm{C}$ half-life (5568 years). Quoted errors represent 1 relative standard deviation statistics (68\% probability) counting errors based on the combined measurements of the sample, background, and modern reference standards. Measured $13 \mathrm{C} / 12 \mathrm{C}$ ratios (delta 13C) were calculated relative to the PDB-1 standard.
The Conventional Radiocarbon Age represents the Measured Radiocarbon Age corrected for isotopic fractionation, calculated using the delta $13 \mathrm{C}$. On rare occasion where the Conventional Radiocarbon Age was calculated using an assumed delta $13 \mathrm{C}$, the ratio and the Conventional Radiocarbon Age will be followed by "**". The Conventional Radiocarbon Age is not calendar calibrated. When available, the Calendar Calibrated result is calculated from the Conventional Radiocarbon Age and is listed as the "Two Sigma Calibrated Result" for each sample. 


\section{REPORT OF RADIOCARBON DATING ANALYSES}

$$
\text { Sample Data }
$$

\author{
Measured \\ Radiocarbon Age
}

$13 \mathrm{C} / 12 \mathrm{C}$
Ratio

$-18.6 \mathrm{o} / \mathrm{oo}$
Conventional

Radiocarbon Age $\left(^{*}\right)$

Beta - 302696

$3360+/-30$ BP

$3460+/-30$ BP

Dates are reported as RCYBP (radiocarbon years before present, "present" = AD 1950). By international convention, the modern reference standard was $95 \%$ the $14 \mathrm{C}$ activity of the National institute of Standards and Technology (NIST) Oxalic Acid (SRM 4990C) and calculated using the Libby $14 \mathrm{C}$ half-life (5568 years). Quoted errors represent 1 relative standard deviation statistics (68\% probability) counting errors based on the combined measurements of the sample, background, and modern reference standards. Measured $13 \mathrm{C} / 12 \mathrm{C}$ ratios (delta 13C) were calculated relative to the PDB-1 standard.
The Conventional Radiocarbon Age represents the Measured Radiocarbon Age corrected for isotopic fractionation, calculated using the delta $13 \mathrm{C}$. On rare occasion where the Conventional Radiocarbon Age was calculated using an assumed delta $13 \mathrm{C}$, the ratio and the Conventional Radiocarbon Age will be followed by "**". The Conventional Radiocarbon Age is not calendar calibrated. When available, the Calendar Calibrated result is calculated from the Conventional Radiocarbon Age and is listed as the "Two Sigma Calibrated Result" for each sample. 


\section{CALIBRATION OF RADIOCARBON AGE TO CALENDAR YEARS}

\section{(V ariables: C13/C12=-24.4:lab. mult $=1$ )}

\section{Laboratory number: Beta-302686}

\section{Conventional radiocarbon age: $\quad 3840 \pm 30$ B P}

2 Sigma calibrated result: Cal BC 2450 to 2200 (Cal BP 4400 to 4150) (95\% probability)

Intercept data

Intercept of radiocarbon age

with calibration curve:

Cal BC 2290 (Cal BP 4240)

1 Sigma calibrated results: Cal BC 2340 to 2280 (Cal BP 4290 to 4230) and

(68\% probability) Cal BC 2250 to 2220 (Cal BP 4200 to 4160 )

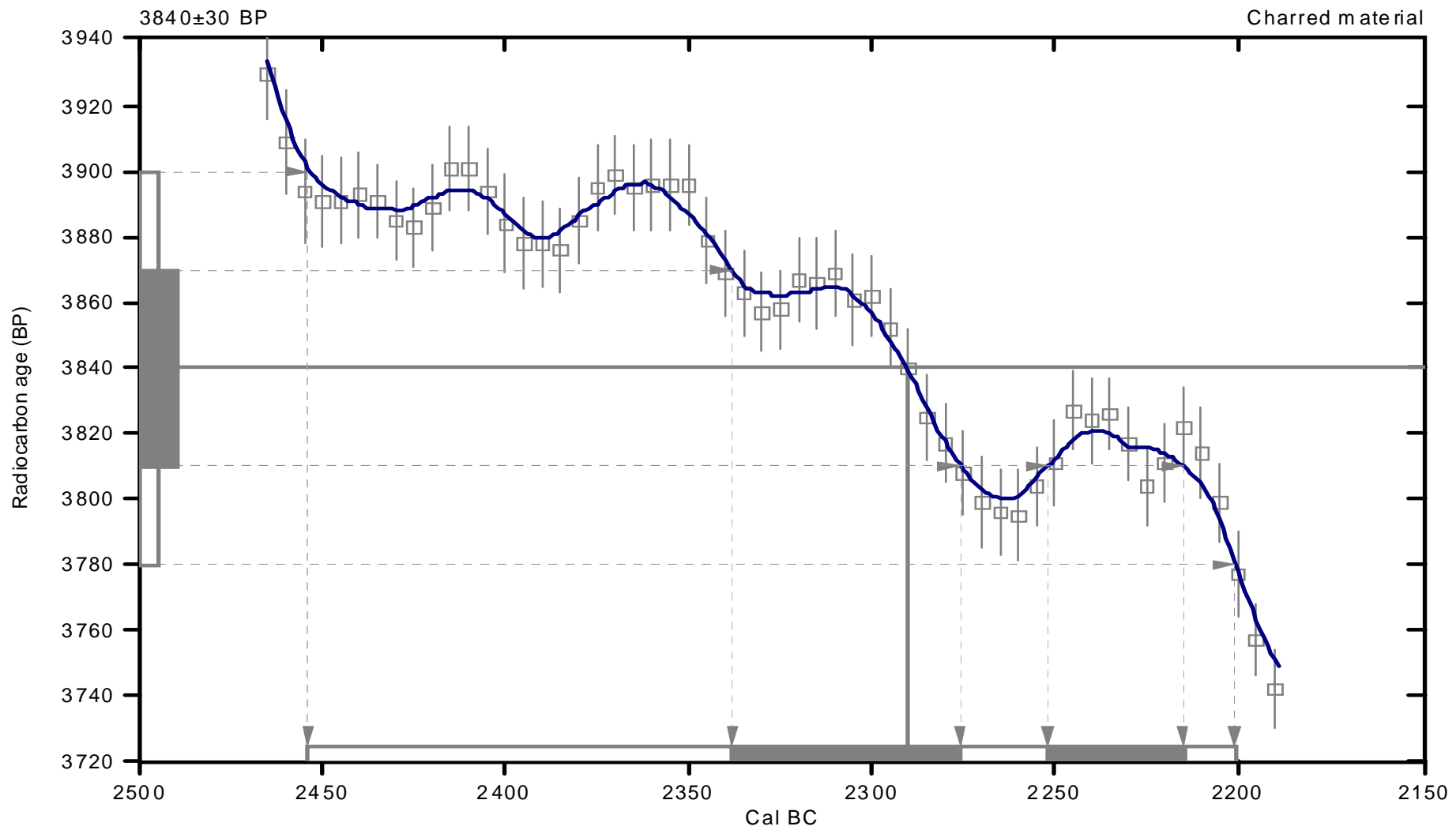

References:

Database used INTCALO 4

Calibration Database

IN TCALO4 Radiocarbon Age Calibration

IntCal04: Calibration Issue of Radiocarbon (Volume 46, $\mathrm{nr} 3$, 2004).

Mathematics

A Simplified Approach to Calibrating C14 Dates Talma, A. S., Vogel, J. C., 1993, Radiocarbon 35(2), p317-322 


\section{CALIBRATION OF RADIOCARBON AGE TO CALENDAR YEARS}

\section{(V ariables: C13/C12=-23.8:lab. mult $=1$ )}

Laboratory number: Beta-302687

Conventional radiocarbon age: $2590 \pm 30$ B P

2 Sigma calib rated result: Cal BC 810 to 760 (Cal BP 2760 to 2720) (95\% probability)

Intercept data

Intercept of radiocarbon age

with calibration curve: Cal BC 790 (Cal BP 2740)

1 Sigma calibrated result: Cal BC 800 to 780 (Cal BP 2750 to 2730)

(68\% probability)

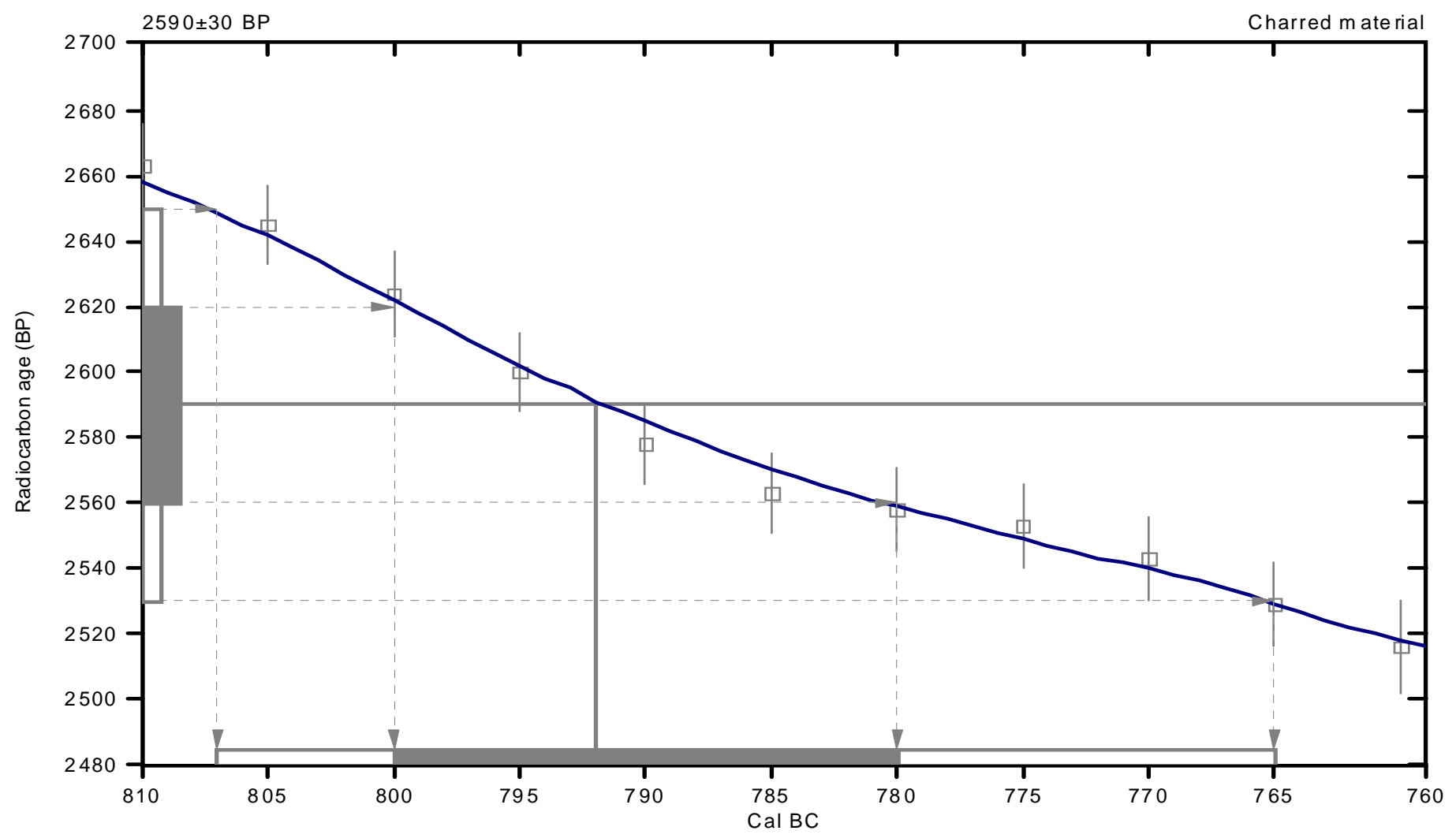

References:

Database used INTCALO 4

Calibration Database

IN TCAL04 Radiocarbon Age Calibration

IntCal04: Calibration Issue of Radiocarbon (Volume 46, nr 3, 2004).

Mathematics

A Simplified Approach to Calibrating C14 Dates Talma, A. S., Vogel, J. C., 1993, Radiocarbon 35(2), p317-322 


\section{CALIBRATION OF RADIOCARBON AGE TO CALENDAR YEARS}

\section{(V ariables: C13/C12=-25.2:lab. mult $=1$ )}

Laboratory number: Beta-302688

Conventional radiocarbon age: $\quad 3750 \pm 30$ B P

2 Sigma calib rated results: Cal BC 2280 to 2250 (Cal BP 4230 to 4200 ) and (95\% probability) Cal BC 2220 to 2120 (Cal BP 4160 to 4070) and

Cal BC 2090 to 2040 (Cal BP 4040 to 3990)

In tercept data

Intercepts of radiocarbon age

with calibration curve: Cal BC 2190 (Cal BP 4140) and

Cal BC 2180 (Cal BP 4120) and

Cal BC 2140 (Cal BP 4100)

1 Sigma calibrated result: Cal BC 2200 to 2130 (Cal BP 4150 to 4080)

(68\% probability)

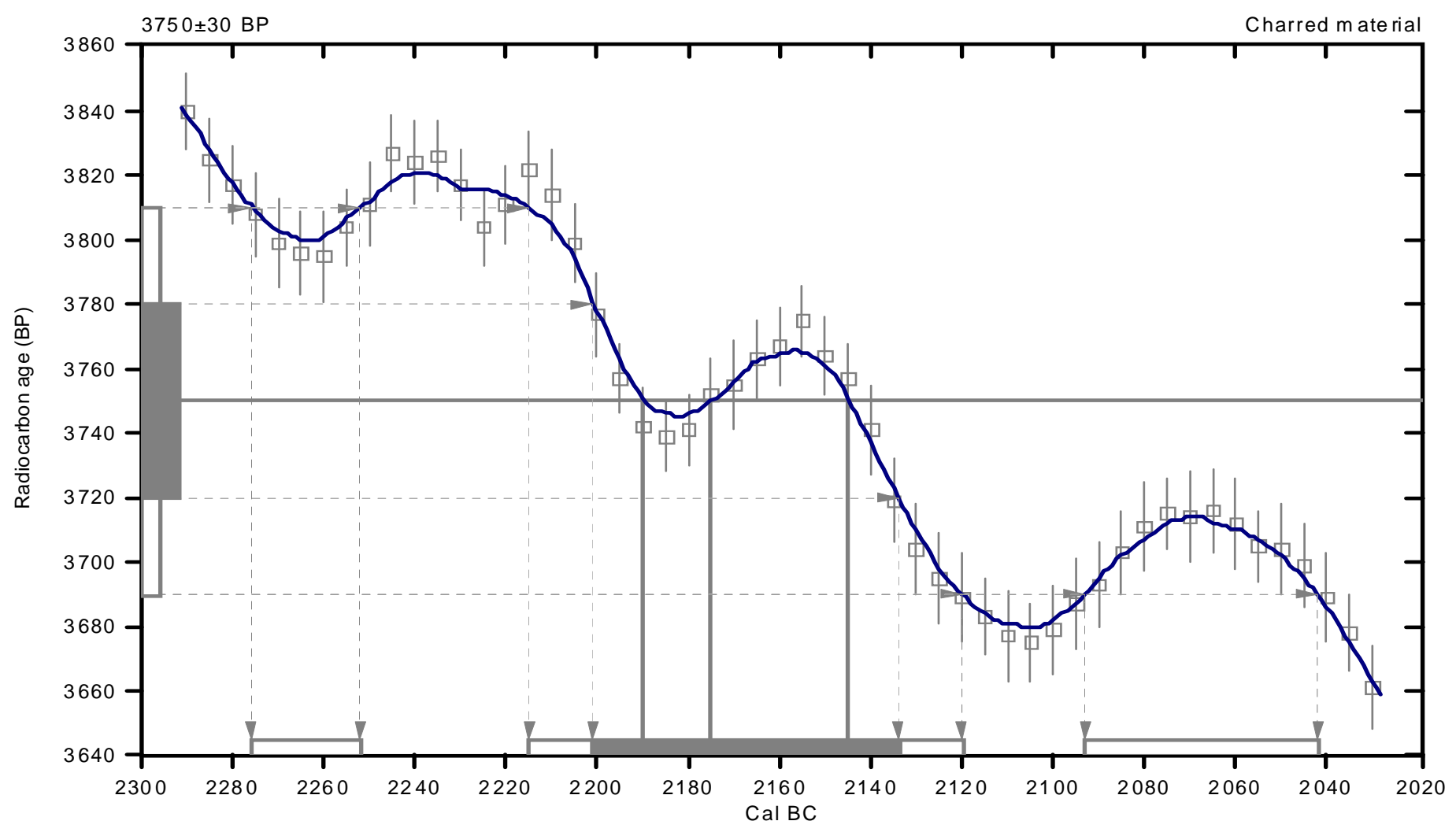

References:

Database used INTCALO 4

Calibration Database

IN TCALO4 Radiocarbon Age Calibration

IntCal04: Calibration Issue of Radiocarbon (Volume 46, $\mathrm{nr} 3$, 2004).

Mathematics

A Simplified Approach to Calibrating C14 Dates Talma, A. S., Vogel, J. C., 1993, Radiocarbon 35(2), p317-322 


\section{CALIBRATION OF RADIOCARBON AGE TO CALENDAR YEARS}

\section{(V ariables: C13/C12=-23.3:lab. mult $=1$ )}

Laboratory number: Beta-302690

Conventional radiocarbon age: $\quad 3820 \pm 30$ B P

2 Sigma calib rated results: Cal BC 2390 to 2390 (Cal BP 4340 to 4340 ) and (95\% probability) Cal BC 2340 to 2190 (Cal BP 4290 to 4140 ) and

Cal BC 2170 to 2150 (Cal BP 4120 to 4100 )

In tercept data

Intercepts of radiocarbon age

with calibration curve: Cal BC 2280 (Cal BP 4230) and

Cal BC 2240 (Cal BP 4190) and

Cal BC 2240 (Cal BP 4190)

1 Sigma calibrated result: Cal BC 2300 to 2200 (Cal BP 4250 to 4150 )

(68\% probability)

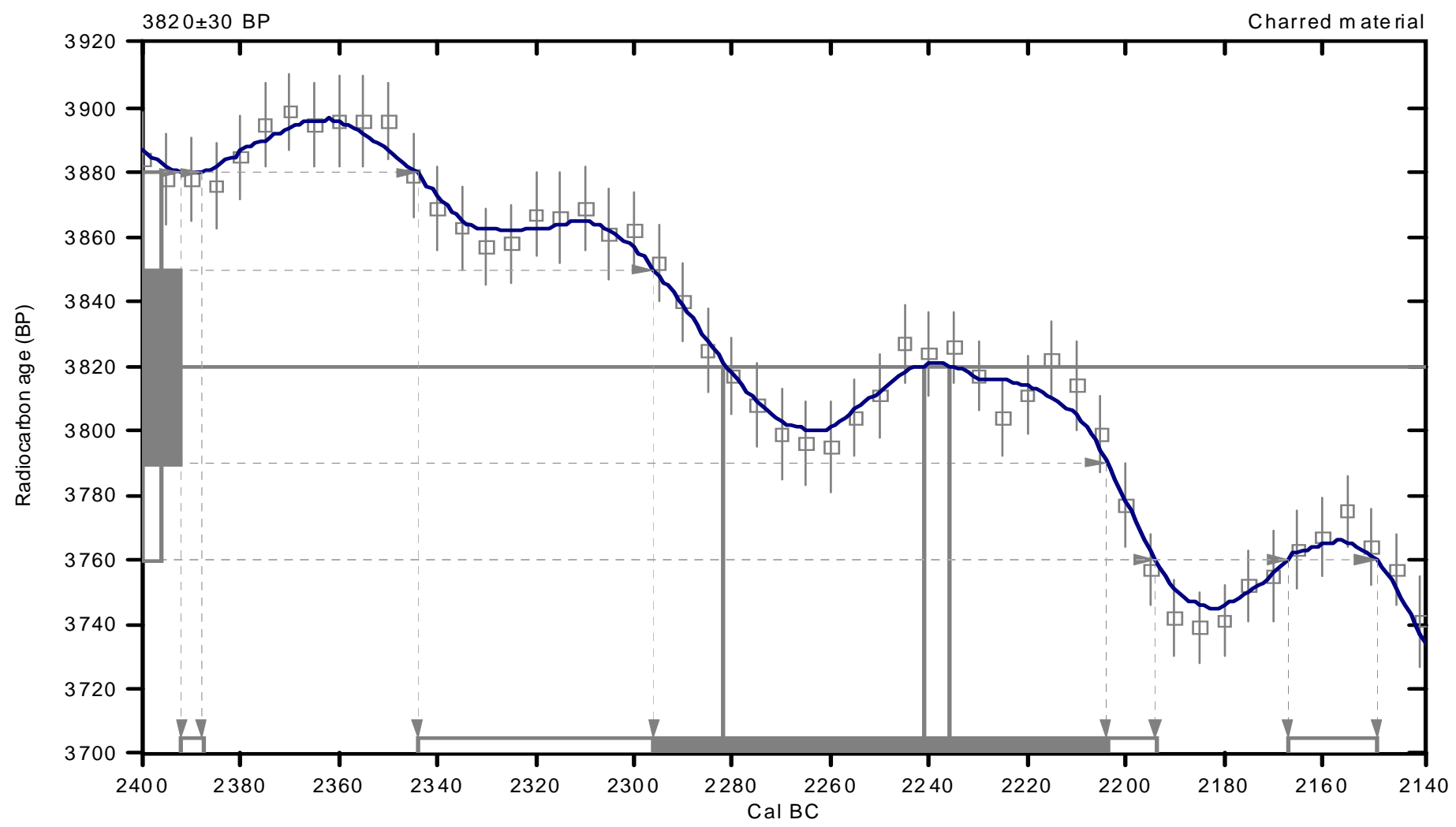

References:

Database used INTCALO 4

Calibration Database

IN TCALO4 Radiocarbon Age Calibration

IntCal04: Calibration Issue of Radiocarbon (Volume 46, $\mathrm{nr} 3$, 2004).

Mathematics

A Simplified Approach to Calibrating C14 Dates Talma, A. S., Vogel, J. C., 1993, Radiocarbon 35(2), p317-322 


\section{CALIBRATION OF RADIOCARBON AGE TO CALENDAR YEARS}

\section{(V ariables: C13/C12=-23.6:lab. mult $=1$ )}

\section{Laboratory number: Beta-302691}

\section{Conventional radiocarbon age: $\quad 5260 \pm 30$ B P}

2 Sigma calibrated results: Cal BC 4230 to 4200 (Cal BP 6180 to 6150) and (95\% probability) Cal BC 4170 to 3980 (Cal BP 6120 to 5930)

Intercept data

Intercept of radiocarbon age with calibration curve:

1 Sigma calibrated results:

(68\% probability)
Cal BC 4040 (Cal BP 6000)

Cal BC 4140 to 4140 (Cal BP 6100 to 6090) and Cal BC 4060 to 4040 (Cal BP 6010 to 5990) and Cal BC 4010 to 4000 (Cal BP 5960 to 5950)

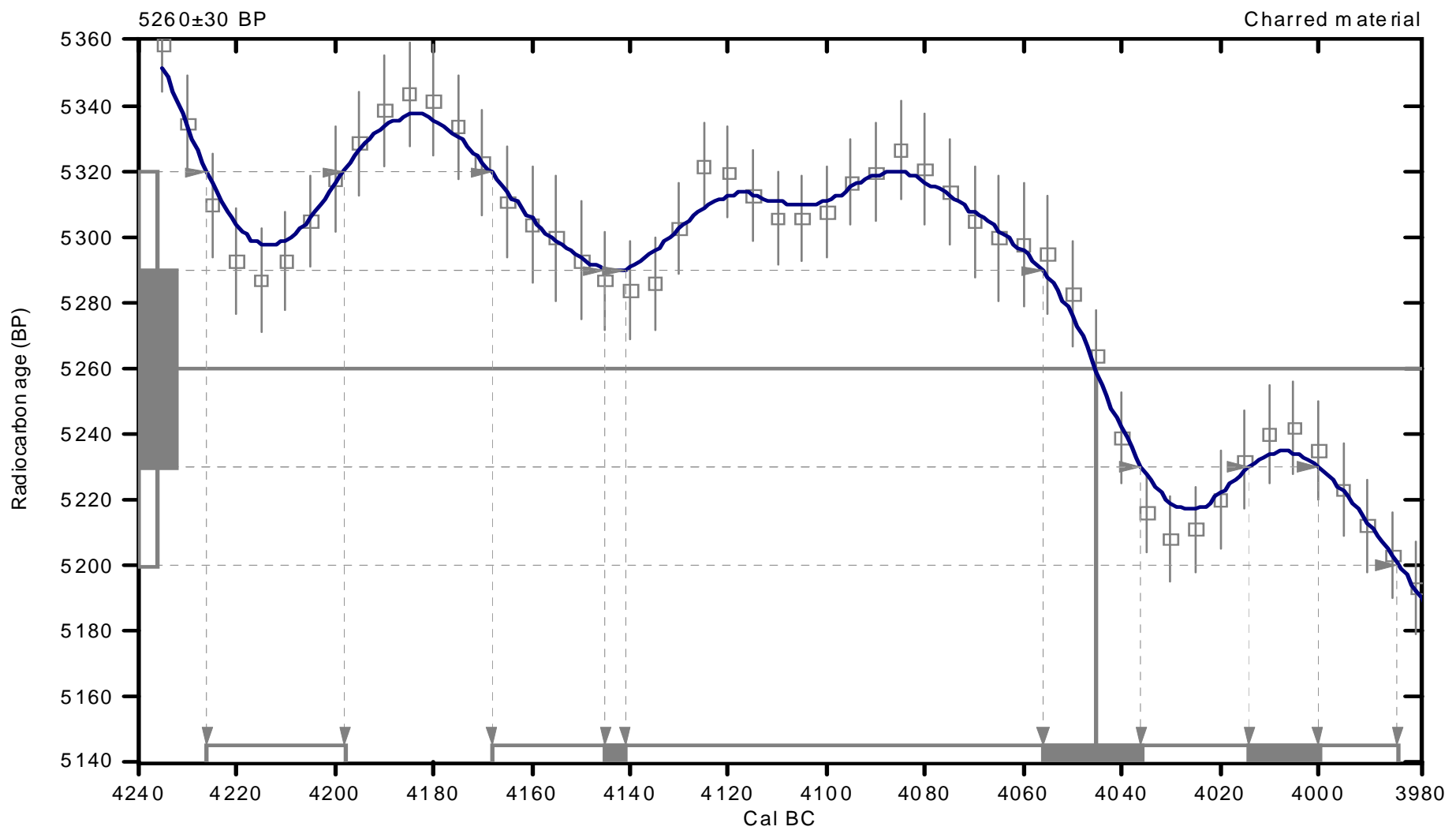

References:

Database used INTCALO4

Calibration Database

IN TCALO4 Radiocarbon Age Calibration

Int Cal04: Calibration Issue of Radiocarbon (Volume 46, $n r$ 3, 2004).

Mathematics

A Simplified Approach to Calibrating C14 Dates Talma, A. S., Vogel, J. C., 1993, Radiocarbon 35(2), p317-322 


\section{CALIBRATION OF RADIOCARBON AGE TO CALENDAR YEARS}

\section{(V ariables: C13/C12=-1 8.2:lab. mult $=1$ )}

\section{Laboratory number: Beta-302693}

\section{Conventional radiocarbon age: $\quad 4720 \pm 40$ B P}

2 Sigma calibrated results: Cal BC 3630 to 3490 (Cal BP 5580 to 5440) and (95\% probability) Cal BC 3470 to 3370 (Cal BP 5420 to 5320)

Intercept data

Intercept of radiocarbon age with calibration curve:

1 Sigma calibrated results:

(68\% probability)
Cal BC 3520 (Cal BP 5470)

Cal BC 3630 to 3580 (Cal BP 5580 to 5530) and Cal BC 3530 to 3500 (Cal BP 5480 to 5450) and Cal BC 3430 to 3380 (Cal BP 5380 to 5330)

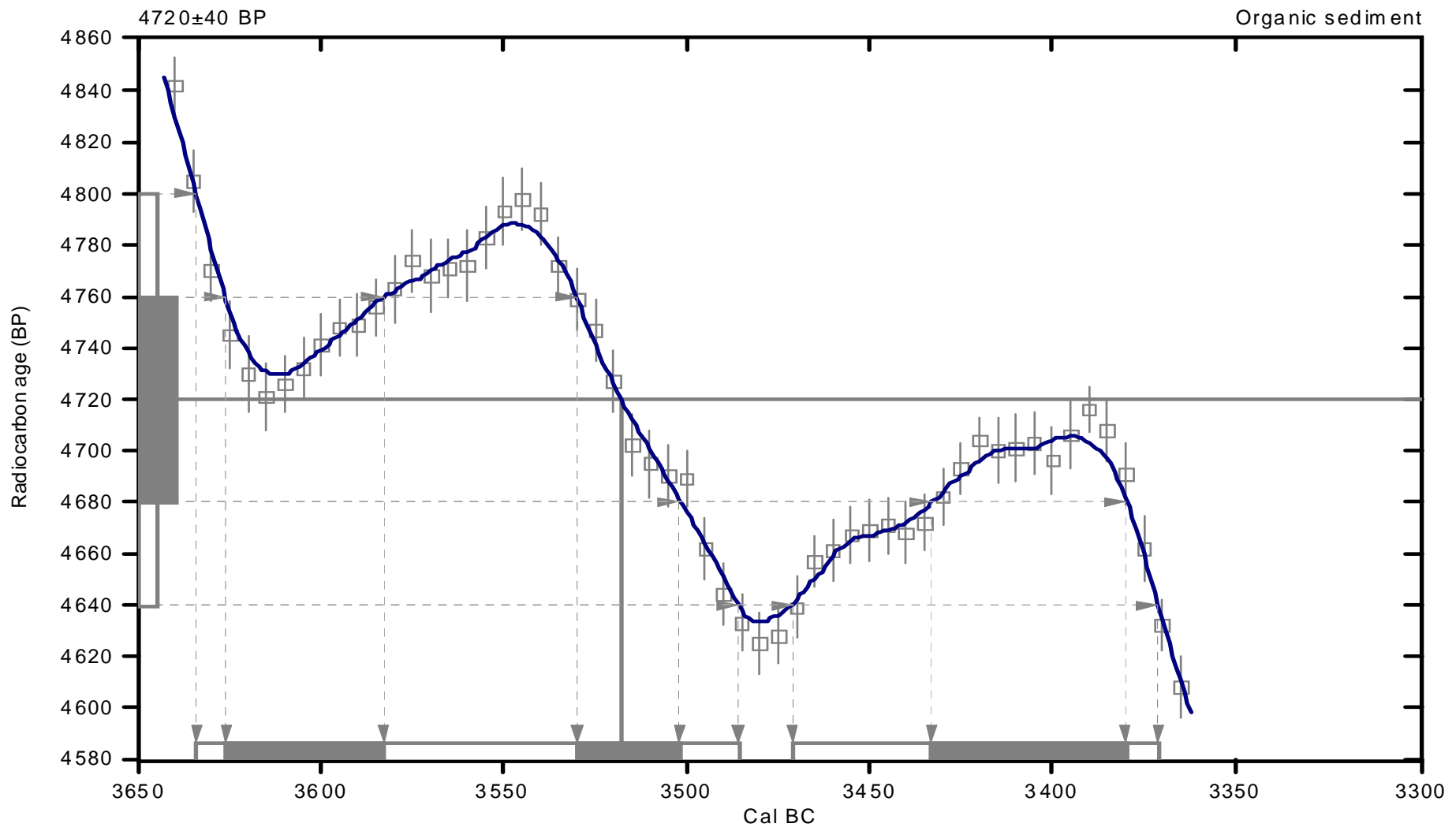

References:

Database used INTCALO 4

Calibration Database

IN TCALO4 Radiocarbon Age Calibration

Int Cal04: Calibration Issue of Radiocarbon (Volume 46, $\mathrm{nr} 3$, 2004).

Mathematics

A Simplified Approach to Calibrating C14 Dates Talma, A. S., Vogel, J. C., 1993, Radiocarbon 35(2), p317-322 


\section{CALIBRATION OF RADIOCARBON AGE TO CALENDAR YEARS}

\section{(V ariables: C13/C12=-19:1ab. mult=1)}

\section{Laboratory number: Beta-302694}

\section{Conventional radiocarbon age: $\quad 5030 \pm 40 \mathrm{BP}$}

\section{Sigma calib rated result: Cal BC 3950 to 3710 (Cal BP 5900 to 5660)}

(95\% probability)

In tercept data

Intercept of radiocarbon age

with calibration curve:

Cal BC 3800 (Cal BP 5740)

1 Sigma calibrated results: Cal BC 3940 to 3860 (Cal BP 5890 to 5810) and

(68\% probability) Cal BC 3810 to 3770 (Cal BP 5760 to 5720)

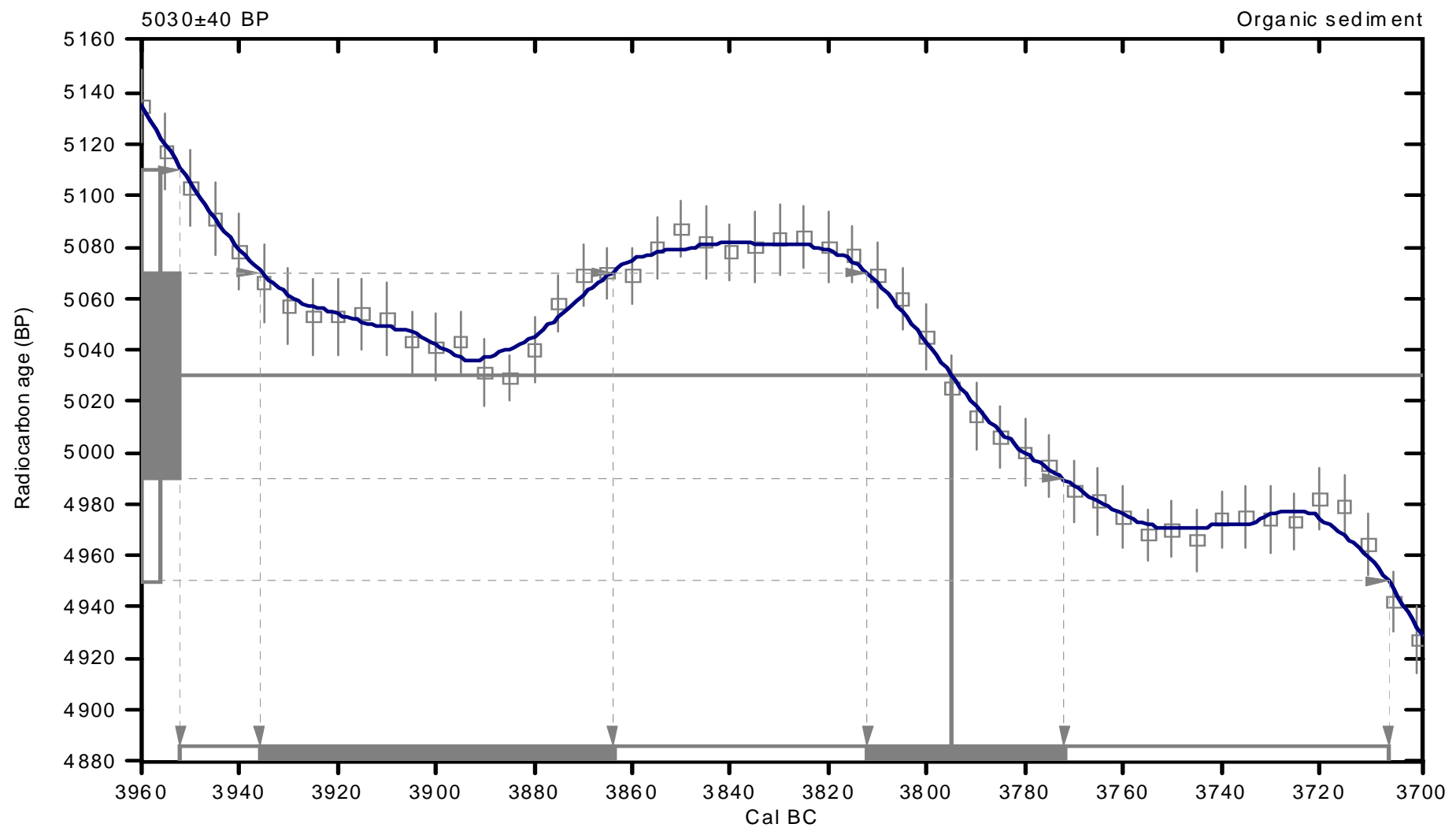

References:

Database used INTCALO4

Calibration Database

IN TCALO4 Radiocarbon Age Calibration

IntCal04: Calibration Issue of Radiocarbon (Volume 46, $\mathrm{nr} 3$, 2004).

Mathematics

A Simplified Approach to Calibrating C14 Dates Talma, A. S., Vogel, J. C., 1993, Radiocarbon 35(2), p317-322

\section{Beta Analytic Radiocarbon Dating Laboratory}




\section{CALIBRATION OF RADIOCARBON AGE TO CALENDAR YEARS}

\section{(V ariables: C13/C12=-18.3:lab. mult $=1$ )}

\section{Laboratory number: Beta-302695}

\section{Conventional radiocarbon age: $\quad 3020 \pm 30$ B P}

2 Sigma calib rated result: Cal BC 1380 to 1200 (Cal BP 3330 to 3150 ) (95\% probability)

In tercept data

Intercept of radiocarbon age

with calibration curve:

Cal BC 1280 (Cal BP 3230)

1 Sigma calibrated results: Cal BC 1360 to 1350 (Cal BP 3310 to 3300) and

(68\% probability) Cal BC 1310 to 1260 (Cal BP 3260 to 3210 )

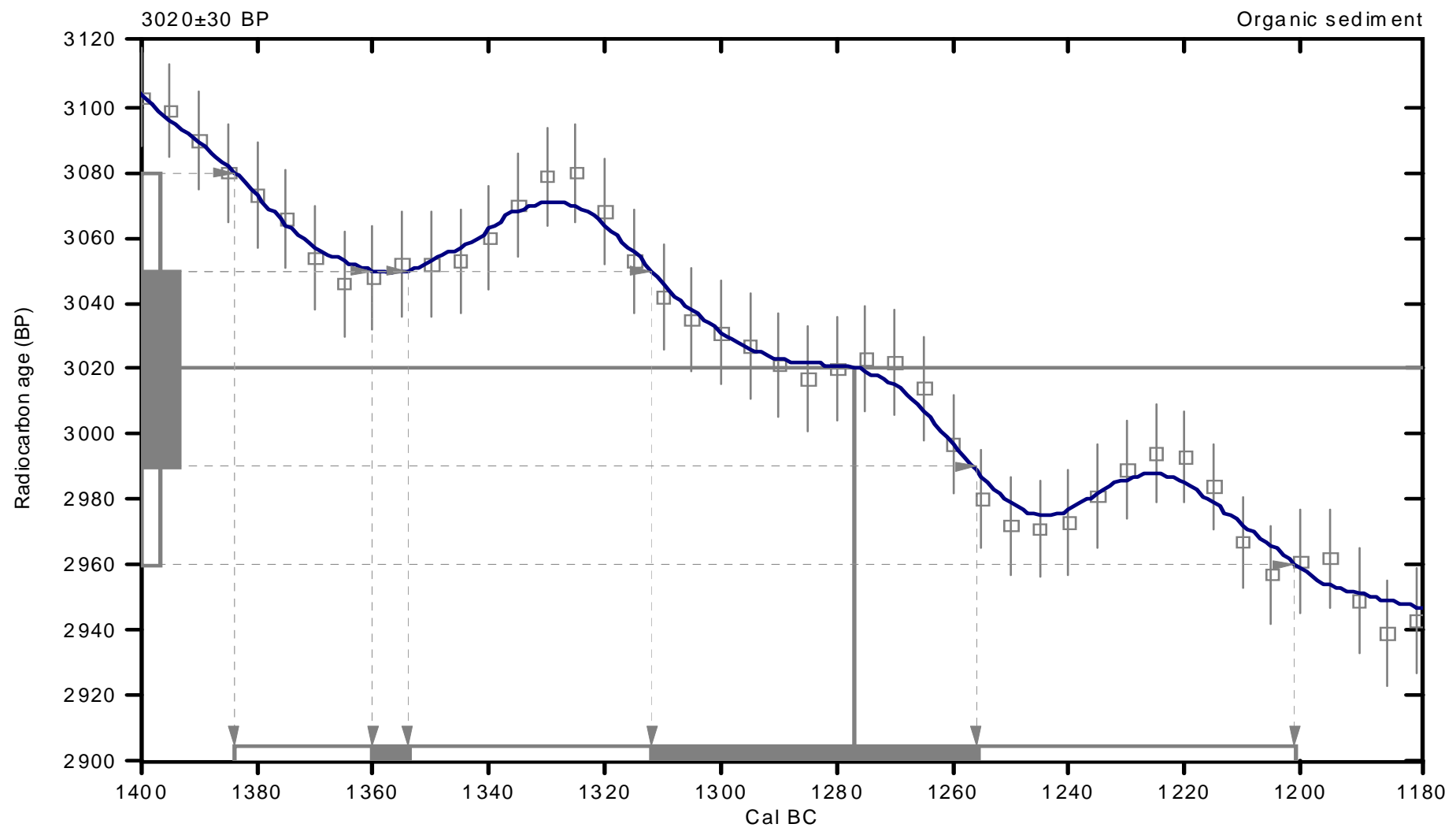

References:

Database used INTCALO 4

Calibration Database

IN TCAL04 Radiocarbon Age Calibration

IntCal04: Calibration Issue of Radiocarbon (Volume 46, nr 3, 2004).

Mathematics

A Simplified Approach to Calibrating C14 Dates Talma, A. S., Vogel, J. C., 1993, Radiocarbon 35(2), p317-322

\section{Beta Analytic Radiocarbon Dating Laboratory}




\section{CALIBRATION OF RADIOCARBON AGE TO CALENDAR YEARS}

\section{(V ariables: C13/C12=-1 8.6:lab. mult $=1$ )}

Laboratory number: Beta-302696

Conventional radiocarbon age: $\quad 3460 \pm 30$ B P

2 Sigma calib rated result: Cal BC 1880 to 1690 (Cal BP 3830 to 3640 ) (95\% probability)

Intercept data

Intercept of radiocarbon age

with calibration curve:

Cal BC 1750 (Cal BP 3700)

1 Sigma calibrated results: Cal BC 1870 to 1850 (Cal BP 3820 to 3800) and

(68\% probability) Cal BC 1780 to 1740 (Cal BP 3730 to 3690 )

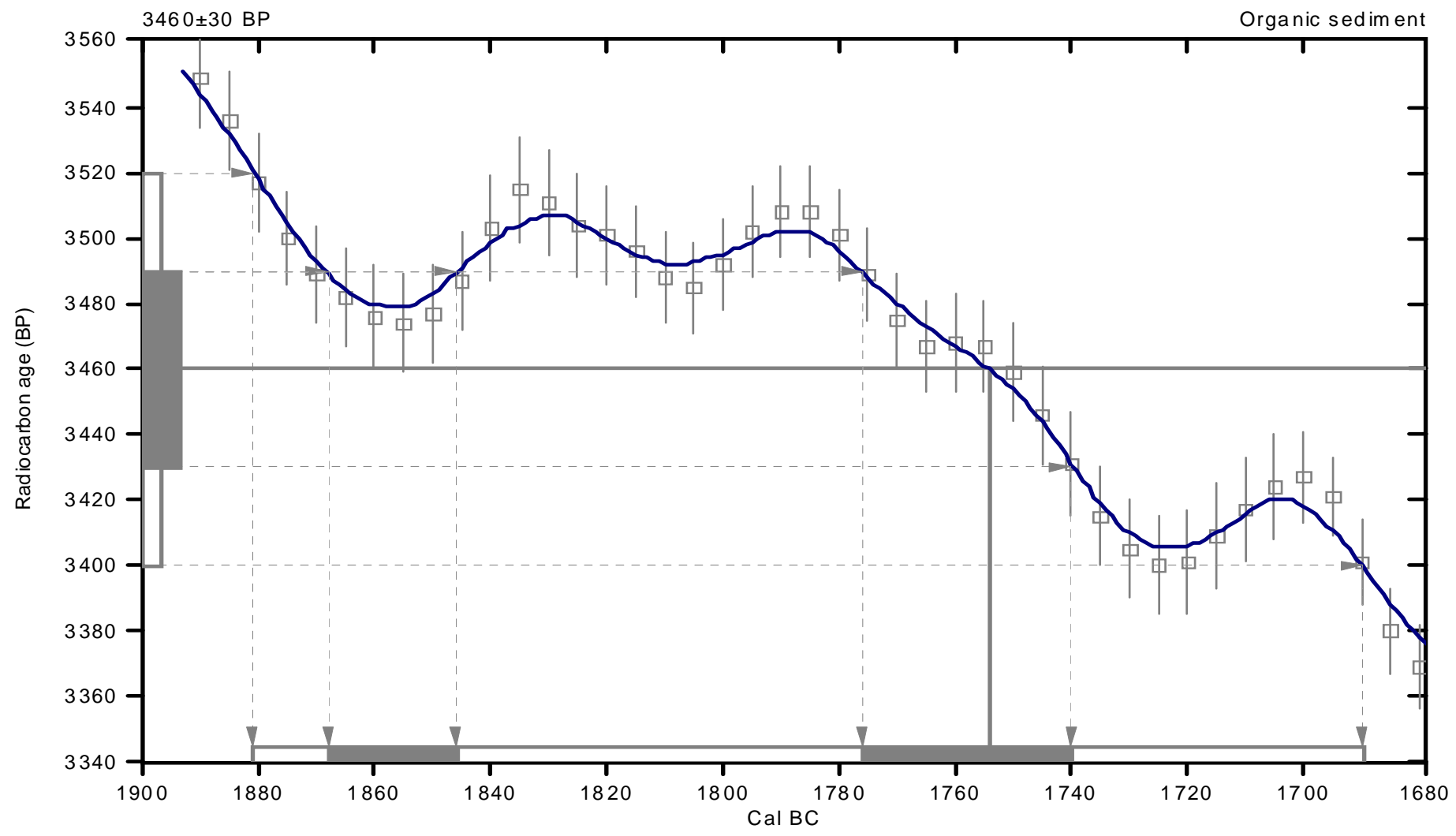

References:

Database used INTCALO 4

Calibration Database

IN TCAL04 Radiocarbon Age Calibration

IntCal04: Calibration Issue of Radiocarbon (Volume 46, nr 3, 2004).

Mathematics

A Simplified Approach to Calibrating C14 Dates Talma, A. S., Vogel, J. C., 1993, Radiocarbon 35(2), p317-322

\section{Beta Analytic Radiocarbon Dating Laboratory}




\section{Appendix B}

\section{Lithic Analysis Data Sheets}




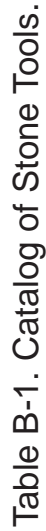
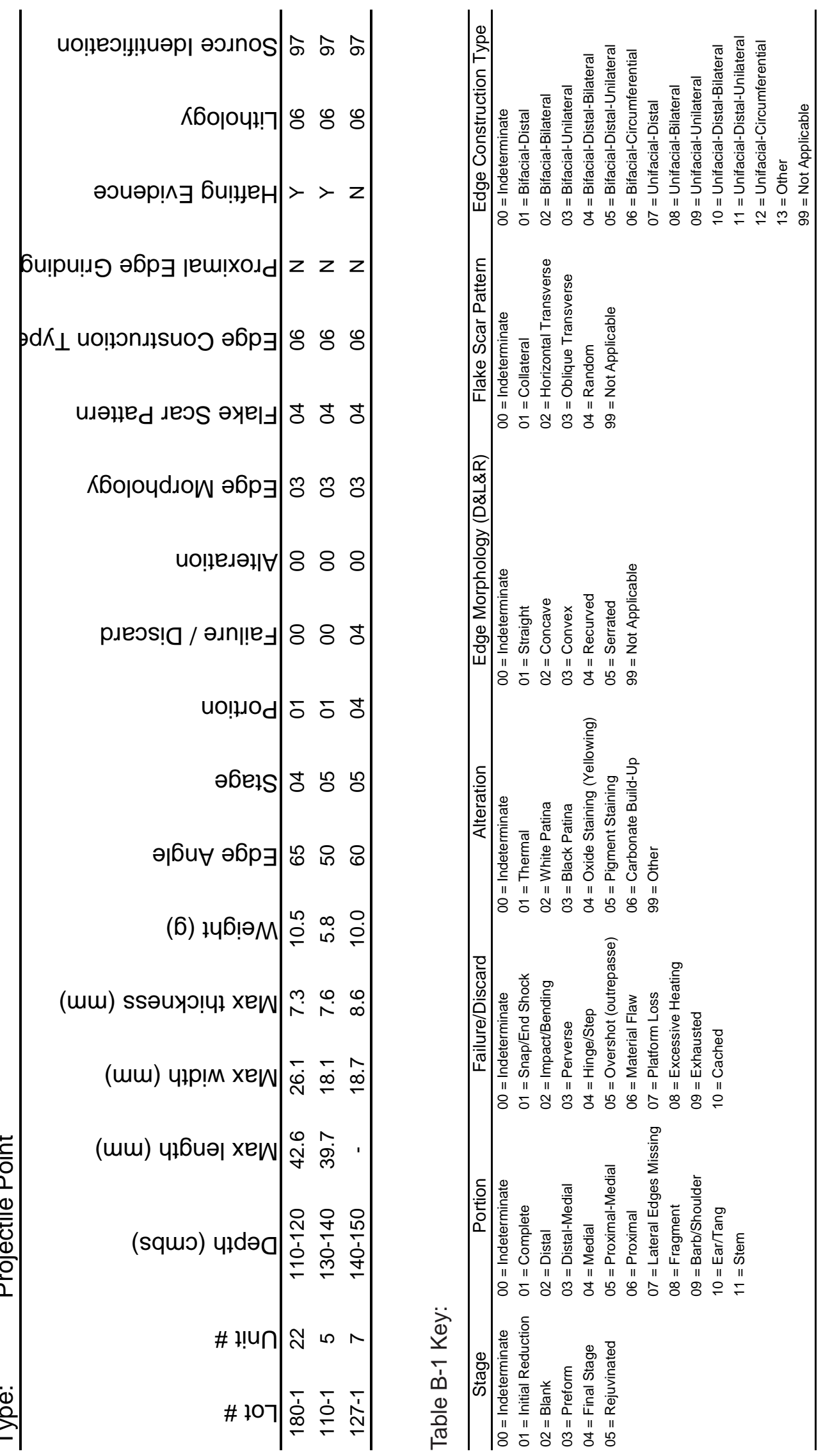
Table B-2. Catalog of Bifaces.

\begin{tabular}{|c|c|c|c|c|c|c|c|c|c|c|c|c|c|c|c|c|}
\hline $\begin{array}{l}\# \\
\text { \# }\end{array}$ & $\begin{array}{l}\stackrel{\#}{\stackrel{*}{ \pm}} \\
\stackrel{5}{J}\end{array}$ & 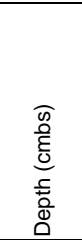 & 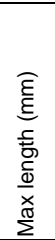 & 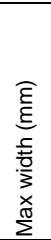 & 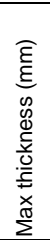 & $\begin{array}{l}\text { क् } \\
\frac{ \pm}{5} \\
\frac{0}{0} \\
3\end{array}$ & 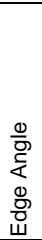 & $\begin{array}{l}\stackrel{0}{8} \\
\text { ஸे } \\
\text { ஸे }\end{array}$ & 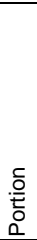 & 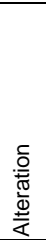 & $\begin{array}{l}\text { তे } \\
\text { 응 } \\
\frac{0}{0} \\
\sum_{0}^{0} \\
\text { D } \\
\text { एँ }\end{array}$ & 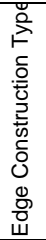 & 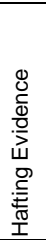 & $\begin{array}{l}\text { 하 } \\
\text { 응 } \\
\text { ․ㅗㅂ }\end{array}$ & 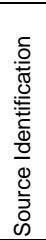 & Notes \\
\hline $98-1$ & 5 & $100-110$ & 97.6 & 75.9 & 39.0 & 325.8 & 65 & 01 & 01 & 00 & 03 & 06 & $\mathrm{~N}$ & 06 & 97 & chopper \\
\hline 234-1 & 6 & $190-200$ & - & 21.7 & 8.2 & 13.0 & 60 & 02 & 04 & 00 & 03 & 06 & $\mathrm{~N}$ & 10 & 97 & - \\
\hline $121-1$ & 7 & $120-130$ & - & 33.5 & 11.7 & 10.5 & 55 & 01 & 00 & 00 & 03 & 03 & $\mathrm{~N}$ & 06 & 97 & fragment no use observed \\
\hline $121-2$ & 7 & $120-130$ & 58.3 & 36.3 & 13.1 & 31.4 & 65 & 04 & 01 & 00 & 03 & 06 & $\mathrm{~N}$ & 10 & 97 & bifacial clear fork gouge \\
\hline $73-1$ & 8 & $100-110$ & - & 35.4 & 7.0 & 7.3 & 40 & 03 & 08 & 00 & 03 & 06 & $\mathrm{~N}$ & 06 & 97 & - \\
\hline $105-1$ & 8 & $130-140$ & - & 42.0 & 19.4 & 51.4 & 55 & 02 & 08 & 00 & 03 & 06 & $\mathrm{~N}$ & 06 & 97 & - \\
\hline $120-1$ & 8 & $140-150$ & 53.1 & 47.1 & 20.5 & 44.3 & 50 & 02 & 01 & 00 & 03 & 06 & $\mathrm{~N}$ & 06 & 97 & used as scraper and gouge \\
\hline $122-1$ & 10 & $110-120$ & - & - & 6.0 & 2.9 & 45 & 04 & 02 & 01 & 03 & 04 & $\mathrm{~N}$ & 06 & 97 & - \\
\hline $216-1$ & 10 & $170-180$ & 47.5 & 48.1 & 20.1 & 43.5 & 65 & 01 & 00 & 00 & $01 / 02$ & 01 & $\mathrm{~N}$ & 06 & 97 & used as gouge \\
\hline $158-1$ & 13 & $130-140$ & - & 21.3 & 7.3 & 2.7 & 45 & 03 & 06 & 00 & 00 & 00 & $\mathrm{~N}$ & 06 & 97 & - \\
\hline $158-2$ & 13 & $130-140$ & - & - & 6.4 & 8.1 & 50 & 03 & 08 & 00 & 00 & 00 & $\mathrm{~N}$ & 06 & 97 & - \\
\hline 218-1 & 13 & $170-180$ & - & 31.3 & 17.3 & 27.7 & 70 & 01 & 00 & 00 & 03 & 06 & $\mathrm{~N}$ & 06 & 97 & fragment used as gouge \\
\hline 273-1 & 19 & $140-150$ & - & 29.2 & 11.6 & 12.8 & 50 & 04 & 02 & 00 & 05 & 03 & $\mathrm{~N}$ & 06 & 97 & knife \\
\hline $175-1$ & 21 & $130-140$ & - & 5.6 & 1.2 & 0.1 & 25 & 05 & 09 & 00 & 04 & 03 & $\mathrm{~N}$ & 06 & 97 & projectile point shoulder \\
\hline 173-1 & 24 & $120-130$ & - & 48.8 & 31.3 & 99.4 & 80 & 01 & 00 & 00 & 03 & 05 & $\mathrm{~N}$ & 06 & 97 & fragment used as gouge \\
\hline $197-1$ & 24 & $150-160$ & - & 32.9 & 10.1 & 9.4 & 40 & 04 & 02 & 02 & 00 & 06 & $\mathrm{~N}$ & 06 & 97 & knife \\
\hline $197-2$ & 24 & $150-160$ & - & 27.7 & 10.7 & 11.7 & 50 & 04 & 05 & 02 & 03 & 06 & Y & 06 & 97 & knife \\
\hline $220-1$ & 25 & $120-130$ & - & 13.6 & 6.2 & 2.4 & 80 & 05 & 11 & 00 & 02 & 06 & $\mathrm{~N}$ & 06 & 97 & projectile pt. base reworked into scrape \\
\hline $222-1$ & 25 & $140-150$ & 65.7 & 37.0 & 17.8 & 37.6 & 55 & 01 & 01 & 00 & 03 & 06 & $\mathrm{~N}$ & 06 & 97 & used as gouge \\
\hline 236-1 & 25 & $160-170$ & 48.1 & 47.9 & 30.9 & 95.5 & 85 & 01 & 01 & 00 & 01 & 01 & $\mathrm{~N}$ & 06 & 97 & gouge \\
\hline 266-1 & 27 & $130-140$ & - & 19.2 & 4.8 & 2.9 & 40 & 05 & 02 & 01 & 00 & 06 & $\mathrm{~N}$ & 06 & 97 & projectile pt. distal tip \\
\hline $266-2$ & 27 & $130-140$ & - & - & 1.7 & 0.1 & 35 & 05 & 00 & 00 & 00 & 00 & $\mathrm{~N}$ & 06 & 97 & projectile pt. lateral edge \\
\hline 253-1 & 28 & $120-130$ & 65.7 & 45.2 & 32.4 & 78.5 & 70 & 01 & 01 & 01 & 03 & 03 & $\mathrm{~N}$ & 06 & 97 & used as gouge \\
\hline $261-1$ & 28 & $140-150$ & 68.4 & 45.4 & 33.5 & 104.0 & 70 & 01 & 01 & 00 & 03 & 06 & $\mathrm{~N}$ & 06 & 97 & used as gouge \\
\hline $267-1$ & 31 & $0-20$ & - & 47.5 & 15.6 & 27.9 & 70 & 02 & 08 & 00 & 03 & 03 & $\mathrm{~N}$ & 06 & 97 & - \\
\hline $291-1$ & GT 5 & - & - & 27.3 & 6.9 & 7.2 & 55 & 04 & 02 & 06 & 00 & 06 & $\mathrm{~N}$ & 06 & 97 & knife \\
\hline $290-1$ & GT 5 & $130-140$ & - & 43.4 & 16.6 & 25.2 & 65 & 02 & 02 & 00 & 03 & 06 & $\mathrm{~N}$ & 06 & 97 & - \\
\hline
\end{tabular}

Table B-2 Key:

\begin{tabular}{|c|c|c|c|c|c|c|}
\hline Stage & Portion & Alteration & Edge Morphology (D\&L\&R) & Edge Construction Type & Lithology & Source Identification \\
\hline $00=$ Indeterminate & $00=$ Indeterminate & $00=$ Indeterminate & $00=$ Indeterminate & $00=$ Indeterminate & $06=$ Chert & $97=$ Unidentified local \\
\hline $01=$ Initial Reduction & $01=$ Complete & $01=$ Thermal & $01=$ Straight & $01=$ Bifacial-Distal & & \\
\hline $02=$ Blank & $02=$ Distal & $02=$ White Patina & $02=$ Concave & $02=$ Bifacial-Bilateral & & \\
\hline $03=$ Preform & $03=$ Distal - Medial & $03=$ Black Patina & $03=$ Convex & $03=$ Bifacial-Unilateral & & \\
\hline $04=$ Final Stage & $04=$ Medial & $04=$ Oxide Staining (Yellowing) & $04=$ Recurved & $04=$ Bifacial-Distal-Bilateral & & \\
\hline \multirow[t]{10}{*}{$05=$ Rejuvinated } & $05=$ Proximal-Medial & $05=$ Pigment Staining & $05=$ Serrated & $05=$ Bifacial-Distal-Unilateral & & \\
\hline & $06=$ Proximal & $06=$ Carbonate Build-Up & $99=$ Not Applicable & $06=$ Bifacial-Circumferential & & \\
\hline & $07=$ Lateral Edges Missing & $99=$ Other & & $07=$ Unifacial-Distal & & \\
\hline & $08=$ Fragment & & & $08=$ Unifacial-Bilateral & & \\
\hline & $09=$ Barb $/$ Shoulder & & & $09=$ Unifacial-Unilateral & & \\
\hline & $10=$ Ear $/$ Tang & & & $10=$ Unifacial-Distal-Bilateral & & \\
\hline & $11=$ Stem & & & $11=$ Unifacial-Distal-Unilateral & & \\
\hline & & & & $12=$ Unifacial-Circumferential & & \\
\hline & & & & $13=$ Other & & \\
\hline & & & & $99=$ Not Applicable & & \\
\hline
\end{tabular}


Table B-3. Catalog of Cores.

\begin{tabular}{|c|c|c|c|c|c|c|c|c|c|c|c|}
\hline 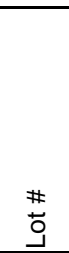 & $\begin{array}{l}\text { \# } \\
\stackrel{+}{\mathrm{c}} \\
\mathrm{J}\end{array}$ & 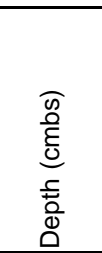 & 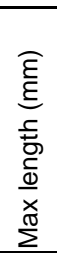 & 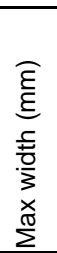 & 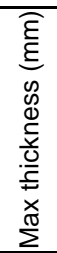 & 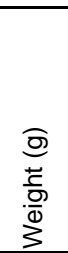 & 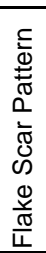 & $\begin{array}{l}\text { 하 } \\
\text { 응 } \\
\text { 톨 }\end{array}$ & 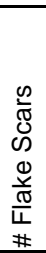 & 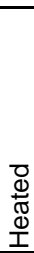 & Notes \\
\hline $64-1$ & 1 & $110-120$ & 47.3 & 39.2 & 32.2 & 64.9 & 00 & 06 & 4 & $\mathrm{Y}$ & - \\
\hline $109-1$ & 5 & $120-130$ & 38.7 & 42.2 & 17.2 & 33.0 & 00 & 06 & 5 & $Y$ & - \\
\hline $115-1$ & 5 & $140-150$ & 68.6 & 50.4 & 22.4 & 77.0 & 00 & 06 & 6 & $\mathrm{~N}$ & - \\
\hline $137-1$ & 6 & $150-160$ & 57.1 & 55.2 & 40.0 & 106.0 & 00 & 06 & 8 & $\mathrm{~N}$ & - \\
\hline $174-1$ & 6 & $160-170$ & 66.7 & 48.0 & 41.1 & 137.7 & 00 & 06 & 3 & $Y$ & - \\
\hline $121-3$ & 7 & $120-130$ & 63.8 & 43.4 & 32.2 & 100.3 & 00 & 06 & 7 & $\mathrm{Y}$ & - \\
\hline $73-2$ & 8 & $100-110$ & 45.5 & 41.2 & 27.6 & 80.4 & 00 & 06 & 6 & $\mathrm{~N}$ & - \\
\hline $105-2$ & 8 & $130-140$ & 63.4 & 39.5 & 34.2 & 120.8 & 00 & 06 & 5 & $\mathrm{Y}$ & - \\
\hline $105-3$ & 8 & $130-140$ & 75.8 & 56.3 & 38.8 & 138.1 & 00 & 06 & 6 & $\mathrm{~N}$ & - \\
\hline $128-1$ & 10 & $140-150$ & 47.2 & 43.3 & 14.0 & 31.5 & 00 & 06 & 4 & $\mathrm{~N}$ & - \\
\hline $158-4$ & 13 & $130-140$ & 54.5 & 32.6 & 26.7 & 51.8 & 00 & 06 & 4 & $\mathrm{~N}$ & - \\
\hline 163-1 & 13 & $140-150$ & 30.1 & 40.4 & 53.7 & 70.2 & 00 & 06 & 7 & $\mathrm{~N}$ & - \\
\hline $184-1$ & 13 & $160-170$ & 75.8 & 46.8 & 24.9 & 80.6 & 01 & 06 & 4 & $\mathrm{~N}$ & - \\
\hline $218-2$ & 13 & $170-180$ & 64.6 & 50.6 & 39.8 & 154.5 & 01 & 06 & 9 & $\mathrm{~N}$ & - \\
\hline 203-1 & 14 & $160-170$ & 76.7 & 54.5 & 30.7 & 137.0 & 01 & 06 & 4 & $\mathrm{~N}$ & - \\
\hline $157-1$ & 17 & $130-140$ & 41.1 & 38.4 & 22.3 & 35.4 & 00 & 06 & 6 & $\mathrm{~N}$ & - \\
\hline $161-1$ & 18 & $70-80$ & 45.2 & 42.0 & 23.2 & 52.8 & 00 & 06 & 8 & $\mathrm{~N}$ & Outside analytical units (Exhausted) \\
\hline $168-1$ & 21 & $120-130$ & 31.4 & 40.3 & 25.7 & 57.5 & 00 & 06 & 7 & $\mathrm{Y}$ & - \\
\hline $175-2$ & 21 & $130-140$ & 46.6 & 39.1 & 29.4 & 59.6 & 00 & 06 & 4 & $\mathrm{Y}$ & - \\
\hline $175-3$ & 21 & $130-140$ & 37.3 & 39.0 & 25.9 & 47.3 & 01 & 06 & 3 & $\mathrm{Y}$ & - \\
\hline $177-1$ & 21 & $150-160$ & 62.2 & 45.7 & 29.7 & 79.0 & 00 & 06 & 6 & $\mathrm{~N}$ & - \\
\hline $190-1$ & 22 & $120-130$ & 39.7 & 26.1 & 26.4 & 37.1 & 00 & 06 & 4 & $\mathrm{~N}$ & - \\
\hline $190-2$ & 22 & $120-130$ & 50.8 & 28.8 & 18.8 & 29.9 & 00 & 06 & 5 & $\mathrm{~N}$ & - \\
\hline $207-1$ & 22 & $150-160$ & 51.3 & 45.9 & 25.7 & 65.2 & 00 & 06 & 5 & $\mathrm{~N}$ & - \\
\hline $172-1$ & 24 & $110-120$ & 66.1 & 56.9 & 45.0 & 158.2 & 00 & 06 & 6 & $\mathrm{~N}$ & - \\
\hline $197-3$ & 24 & $150-160$ & 58.4 & 51.1 & 25.9 & 92.7 & 00 & 06 & 4 & $\mathrm{Y}$ & - \\
\hline $220-2$ & 25 & $120-130$ & 39.1 & 40.6 & 23.2 & 43.3 & 00 & 06 & 5 & $\mathrm{~N}$ & - \\
\hline $220-3$ & 25 & $120-130$ & 57.6 & 42.8 & 26.0 & 38.4 & 00 & 06 & 6 & $\mathrm{~N}$ & - \\
\hline $220-4$ & 25 & $120-130$ & 48.9 & 32.7 & 25.9 & 32.1 & 00 & 06 & 7 & $\mathrm{~N}$ & - \\
\hline $221-1$ & 25 & $130-140$ & 62.6 & 44.9 & 25.2 & 77.8 & 00 & 06 & 4 & $\mathrm{~N}$ & - \\
\hline $221-2$ & 25 & $130-140$ & 40.1 & 31.6 & 14.8 & 21.2 & 01 & 06 & 5 & $\mathrm{~N}$ & Exhausted \\
\hline $235-1$ & 25 & $150-160$ & 76.1 & 47.8 & 33.4 & 124.5 & 01 & 06 & 2 & $\mathrm{~N}$ & - \\
\hline $235-2$ & 25 & $150-160$ & 69.5 & 44.5 & 28.0 & 110.6 & 01 & 06 & 5 & $\mathrm{~N}$ & - \\
\hline $249-1$ & 27 & $100-110$ & 58.3 & 45.3 & 27.8 & 66.9 & 00 & 06 & 6 & $\mathrm{~N}$ & - \\
\hline $254-1$ & 28 & $130-140$ & 68.7 & 56.2 & 49.8 & 187.0 & 00 & 06 & 5 & $\mathrm{Y}$ & - \\
\hline $254-2$ & 28 & $130-140$ & 50.4 & 47.5 & 34.3 & 92.2 & 00 & 06 & 6 & $\mathrm{~N}$ & - \\
\hline $254-3$ & 28 & $130-140$ & 73.4 & 48.2 & 29.1 & 158.6 & 00 & 06 & 8 & $\mathrm{~N}$ & - \\
\hline $262-1$ & 28 & $150-160$ & 60.5 & 47.4 & 38.6 & 127.4 & 00 & 06 & 7 & $\mathrm{~N}$ & - \\
\hline
\end{tabular}

Table B-3 Key:

\begin{tabular}{|c|c|}
\hline Flake Scar Pattern & Lithology \\
\hline $00=$ Indeterminate & $06=$ Chert \\
\hline $01=$ Collateral & \\
\hline $02=$ Horizontal Transverse & \\
\hline $03=$ Oblique Transverse & \\
\hline $04=$ Random & \\
\hline $99=$ Not Applicable & \\
\hline
\end{tabular}


Table B-4. Catalog of Tested Cobbles.

\begin{tabular}{|c|c|c|c|c|c|c|c|c|c|c|}
\hline $\begin{array}{l}\# \\
\text { \# }\end{array}$ & 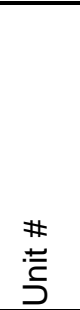 & 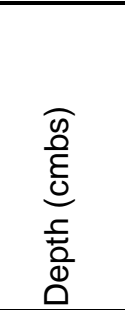 & 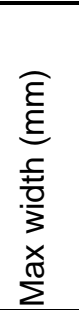 & 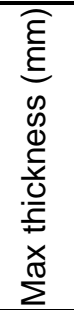 & 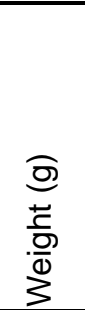 & 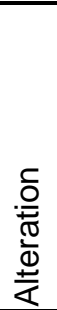 & $\begin{array}{l}\text { 긍 } \\
\text { 응 } \\
! \equiv \\
\vdots\end{array}$ & 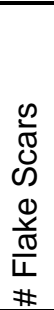 & $\begin{array}{l}\text { D } \\
\stackrel{\Phi}{\mathbb{D}} \\
\stackrel{\Phi}{I}\end{array}$ & Notes \\
\hline $105-4$ & 8 & $130-140$ & 19.6 & 21.4 & 32.4 & 02 & 01 & 2 & $\mathrm{~N}$ & small \\
\hline $140-1$ & 10 & $160-170$ & 64.0 & 31.3 & 186.1 & 01 & 01 & 3 & $\mathrm{Y}$ & impurities \\
\hline $228-1$ & 10 & $190-200$ & 25.0 & 12.4 & 15.6 & 02 & 01 & 1 & $\mathrm{~N}$ & impurities \\
\hline $146-1$ & 13 & $110-120$ & 39.6 & 31.0 & 81.1 & 01 & 01 & 3 & $Y$ & heavily fractured \\
\hline $103-1$ & $6 / 10$ & - & 56.6 & 21.8 & 60.1 & 02 & 01 & 2 & $\mathrm{~N}$ & Feature 1 / impurities \\
\hline
\end{tabular}

Table B-4 Key:

\begin{tabular}{ll}
\hline \multicolumn{1}{c}{ Alteration } & \multicolumn{1}{c}{ Lithology } \\
\hline $00=$ Indeterminate & $01=$ Unidentified Silex \\
$01=$ Thermal & \\
$02=$ White Patina & \\
$03=$ Black Patina & \\
(Yellowing) & \\
$05=$ Pigment Staining & \\
06 & $=$ Carbonate Build-Up \\
99 & $=$ Other
\end{tabular}


Table B-5. Catalog of Expedient Tools.

\begin{tabular}{|c|c|c|c|c|c|c|c|c|c|c|c|c|c|c|}
\hline $\begin{array}{l}\# \\
\text { \# } \\
\end{array}$ & $\begin{array}{l}\# \\
\text { \# } \\
\text { 志 } \\
\text { D }\end{array}$ & 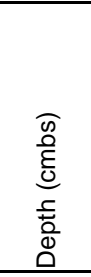 & 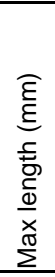 & 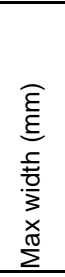 & 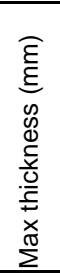 & 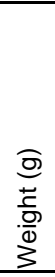 & 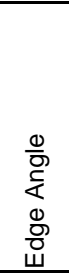 & $\begin{array}{l}\text { 을 } \\
\stackrel{ }{\mathrm{t}} \\
0 \\
\end{array}$ & 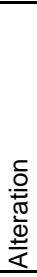 & 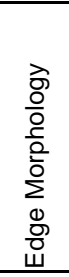 & 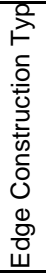 & 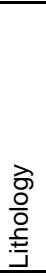 & 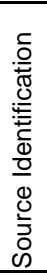 & Notes \\
\hline $71-1$ & 1 & $130-140$ & 51.9 & 31.8 & 11.1 & 6.1 & 60 & 01 & 01 & 03 & 09 & 06 & 97 & Minimally retouched \\
\hline $119-1$ & 2 & $180-190$ & 25.8 & 18.1 & 3.3 & 1.2 & 45 & 01 & 00 & 01 & 11 & 06 & 97 & Formal \\
\hline $40-1$ & 3 & $100-110$ & - & 32.8 & 7.8 & 10.3 & 45 & 05 & 00 & 03 & 09 & 06 & 97 & Minimally retouched \\
\hline $49-1$ & 3 & $120-130$ & 28.6 & 18.7 & 2.9 & 1.6 & 25 & 01 & 01 & 03 & 09 & 06 & 97 & Expediently used \\
\hline $102-1$ & 5 & $110-120$ & - & - & 15.4 & 23.8 & 75 & 00 & 00 & 01 & 07 & 06 & 97 & Formal (scraper) \\
\hline $102-2$ & 5 & $110-120$ & - & 18.3 & 3.2 & 2.0 & 55 & 03 & 00 & 03 & 11 & 06 & 97 & Minimally retouched \\
\hline $109-2$ & 5 & $120-130$ & 33.3 & 18.5 & 3.6 & 2.7 & 50 & 01 & 01 & 01 & 11 & 06 & 97 & Minimally retouched \\
\hline $217-1$ & 6 & $170-180$ & 34.5 & 17.0 & 3.1 & 2.3 & 65 & 01 & 00 & 01 & 07 & 06 & 97 & Minimally retouched \\
\hline $121-4$ & 7 & $120-130$ & 43.5 & 25.8 & 8.9 & 11.6 & 45 & 01 & 00 & 03 & 07 & 06 & 97 & Expediently used \\
\hline $122-2$ & 10 & $110-120$ & 41.0 & 32.0 & 4.7 & 6.8 & 55 & 01 & 00 & 03 & 11 & 06 & 97 & Expediently used \\
\hline $126-2$ & 10 & $130-140$ & 41.5 & 40.6 & 5.9 & 7.7 & 60 & 01 & 00 & 01 & 07 & 06 & 97 & Expediently used \\
\hline $126-1$ & 10 & $130-140$ & 30.1 & 30.2 & 5.9 & 3.2 & 70 & 01 & 00 & 01 & 09 & 06 & 97 & Formal \\
\hline $128-2$ & 10 & $140-150$ & - & - & 4.2 & 4.3 & 65 & 08 & 00 & 03 & 00 & 06 & 97 & Minimally retouched \\
\hline $140-2$ & 10 & $160-170$ & 15.5 & 25.5 & 4.7 & 2.4 & 70 & 01 & 00 & 01 & 07 & 06 & 97 & Formal \\
\hline $140-3$ & 10 & $160-170$ & 30.5 & 43.8 & 9.4 & 12.2 & 70 & 01 & 01 & 03 & 09 & 06 & 97 & Formal \\
\hline $216-2$ & 10 & $170-180$ & 35.0 & 30.2 & 8.3 & 7.9 & 65 & 05 & 01 & 03 & 11 & 06 & 97 & Formal \\
\hline $216-3$ & 10 & $170-180$ & 31.8 & 26.4 & 7.4 & 5.2 & 55 & 01 & 00 & 01 & 11 & 06 & 97 & Formal \\
\hline $216-4$ & 10 & $170-180$ & 39.1 & 24.0 & 10.1 & 9.0 & 55 & 01 & 01 & 03 & 07 & 06 & 97 & Minimally retouched \\
\hline $130-1$ & 11 & $110-120$ & 60.3 & 38.8 & 34.4 & 84.0 & 80 & 01 & 00 & 01 & 09 & 06 & 97 & Formal (gouge) \\
\hline $132-1$ & 11 & $120-130$ & 34.8 & 27.1 & 7.9 & 9.3 & $65 / 75$ & 01 & 00 & $01 / 03$ & 11 & 06 & 97 & Expediently used \\
\hline $155-2$ & 11 & $150-160$ & 27.3 & 51.5 & 8.4 & 13.9 & 50 & 01 & 00 & 01 & 07 & 06 & 97 & Expediently used \\
\hline $155-1$ & 11 & $150-160$ & 25.8 & 24.3 & 8.8 & 5.4 & 75 & 01 & 00 & 03 & 09 & 06 & 97 & Minimally retouched \\
\hline $133-1$ & 12 & $110-120$ & 61.5 & 40.7 & 13.5 & 34.4 & $65 / 70$ & 01 & 00 & $03 / 02$ & 12 & 06 & 97 & Formal (unifacial Clear Fork tool) \\
\hline $138-1$ & 12 & $130-140$ & - & 2.7 & 5.3 & 3.5 & 65 & 03 & 00 & 03 & 09 & 06 & 97 & Formal \\
\hline $139-1$ & 12 & $140-150$ & - & 23.0 & 7.1 & 6.0 & 65 & 03 & 00 & 01 & 09 & 06 & 97 & Formal \\
\hline $150-2$ & 13 & $120-130$ & 26.3 & 31.7 & 5.6 & 4.6 & 70 & 01 & 00 & 01 & 07 & 06 & 97 & Formal \\
\hline $150-1$ & 13 & $120-130$ & 42.4 & 20.7 & 3.0 & 3.0 & 80 & 01 & 01 & 03 & 07 & 06 & 97 & Minimally retouched \\
\hline $218-3$ & 13 & $170-180$ & 51.1 & 46.0 & 15.4 & 31.9 & 60 & 01 & 00 & 01 & 09 & 06 & 97 & Minimally retouched \\
\hline $218-4$ & 13 & $170-180$ & 52.0 & 48.3 & 15.2 & 34.5 & 60 & 01 & 00 & 02 & 07 & 06 & 97 & Minimally retouched \\
\hline $179-1$ & 14 & $130-140$ & 39.5 & 30.4 & 14.8 & 20.3 & 60 & 01 & 01 & 03 & 09 & 06 & 97 & Formal (scraper) \\
\hline $147-1$ & 15 & $110-120$ & 22.4 & 21.7 & 2.9 & 1.5 & 60 & 01 & 00 & 01 & 09 & 06 & 97 & Formal \\
\hline $157-2$ & 17 & $130-140$ & - & - & 11.8 & 9.1 & 60 & 05 & 00 & 01 & 09 & 06 & 97 & Minimally retouched \\
\hline $278-1$ & 19 & $130-140$ & 36.0 & 54.1 & 8.9 & 6.9 & 55 & 01 & 02 & 03 & 09 & 06 & 97 & Expediently used \\
\hline $278-2$ & 19 & $130-140$ & - & 46.2 & 19.7 & 23.2 & 55 & 04 & 01 & 01 & 09 & 06 & 97 & Expediently used \\
\hline $278-3$ & 19 & $130-140$ & 34.5 & 30.0 & 10.6 & 5.0 & 60 & 01 & 00 & 03 & 09 & 06 & 97 & Formal \\
\hline $278-4$ & 19 & $130-140$ & 57.9 & 54.2 & 27.0 & 56.5 & 70 & 01 & 00 & 02 & 09 & 06 & 97 & Minimally retouched \\
\hline $282-1$ & 19 & $150-160$ & - & - & 10.0 & 5.5 & 65 & 04 & 00 & 02 & 09 & 06 & 97 & Formal \\
\hline $189-1$ & 20 & $130-140$ & 45.8 & 30.5 & 8.6 & 3.8 & 55 & 01 & 02 & 05 & 08 & 06 & 97 & Minimally retouched \\
\hline 194-1 & 22 & $130-140$ & 35.7 & 29.5 & 11.3 & 15.9 & 60 & 01 & 00 & 02 & 09 & 06 & 97 & Minimally retouched \\
\hline $255-1$ & 23 & $130-140$ & 36.0 & 33.1 & 5.0 & 6.3 & 50 & 01 & 00 & 01 & 07 & 06 & 97 & Expediently used \\
\hline $255-2$ & 23 & $130-140$ & 23.5 & 30.4 & 8.4 & 6.7 & 60 & 01 & 01 & 03 & 09 & 06 & 97 & Expediently used \\
\hline $172-1$ & 24 & $110-120$ & - & 27.7 & 8.8 & 11.4 & 70 & 05 & 00 & 01 & 08 & 06 & 97 & Minimally retouched \\
\hline $197-4$ & 24 & $150-160$ & 16.8 & 22.7 & 5.6 & 2.3 & 60 & 01 & 00 & 01 & 09 & 06 & 97 & Formal \\
\hline $197-6$ & 24 & $150-160$ & - & - & 8.7 & 15.6 & 60 & 08 & 00 & 01 & 00 & 06 & 97 & Formal \\
\hline $197-5$ & 24 & $150-160$ & 41.7 & 44.6 & 16.7 & 28.3 & 70 & 01 & 00 & 03 & 09 & 06 & 97 & Formal (scraper) \\
\hline 201-1 & 25 & $110-120$ & 61.5 & 29.4 & 9.6 & 14.9 & 65 & 01 & 01 & 03 & 09 & 06 & 97 & Minimally retouched \\
\hline $221-3$ & 25 & $130-140$ & 32.5 & 40.1 & 8.8 & 9.9 & 65 & 01 & 00 & 02 & 07 & 06 & 97 & Minimally retouched \\
\hline $235-3$ & 25 & $150-160$ & - & - & 9.2 & 7.4 & 70 & 08 & 00 & 02 & 09 & 06 & 97 & Formal \\
\hline $235-4$ & 25 & $150-160$ & - & 21.5 & 18.3 & 19.5 & 70 & 05 & 00 & 03 & 09 & 06 & 97 & Formal (scraper) \\
\hline $186-1$ & 26 & $110-120$ & 19.2 & 34.4 & 6.2 & 5.2 & 80 & 01 & 01 & 03 & 07 & 06 & 97 & Minimally retouched \\
\hline $202-1$ & 26 & $120-130$ & 31.5 & 27.1 & 12.1 & 9.6 & 80 & 01 & 00 & 02 & 07 & 06 & 97 & Minimally retouched \\
\hline $202-2$ & 26 & $120-130$ & 30.0 & 42.2 & 7.2 & 7.3 & 80 & 01 & 00 & 03 & 09 & 06 & 97 & Minimally retouched \\
\hline $261-3$ & 28 & $140-150$ & 44.6 & 25.0 & 7.4 & 7.2 & 65 & 01 & 02 & 03 & 10 & 06 & 97 & Expediently used \\
\hline $261-5$ & 28 & $140-150$ & 47.1 & 32.2 & 23.3 & 38.0 & 70 & 01 & 02 & 02 & 07 & 06 & 97 & Formal (gouge/scraper) \\
\hline $261-2$ & 28 & $140-150$ & 29.1 & - & 11.4 & 17.4 & 80 & 05 & 00 & 01 & 07 & 06 & 97 & Minimally retouched \\
\hline $261-4$ & 28 & $140-150$ & 33.3 & 27.3 & 4.9 & 5.3 & 65 & 01 & 02 & 02 & 09 & 06 & 97 & Minimally retouched \\
\hline
\end{tabular}


Table B-5 Key:

\begin{tabular}{|c|c|c|c|c|c|}
\hline Portion & Alteration & (D\&L\&R) & Edge Construction Type & Lithology & Source Identification \\
\hline $00=$ Indeterminate & $00=$ Indeterminate & $00=$ Indeterminate & $00=$ Indeterminate & $06=$ Chert & $97=$ Unidentified local \\
\hline $01=$ Complete & $01=$ Thermal & $01=$ Straight & $01=$ Bifacial-Distal & & \\
\hline $02=$ Distal & $02=$ White Patina & $02=$ Concave & $02=$ Bifacial-Bilateral & & \\
\hline $03=$ Distal-Medial & $03=$ Black Patina & $03=$ Convex & $03=$ Bifacial-Unilateral & & \\
\hline $04=$ Medial & (Yellowing) & $04=$ Recurved & 04 = Bifacial-Distal-Bilateral & & \\
\hline $05=$ Proximal-Medial & $05=$ Pigment Staining & $05=$ Serrated & $05=$ Bifacial-Distal-Unilateral & & \\
\hline $06=$ Proximal & $06=$ Carbonate Build - Up & $99=$ Not Applicable & $06=$ Bifacial-Circumferential & & \\
\hline Missing & $99=$ Other & & $07=$ Unifacial-Distal & & \\
\hline $08=$ Fragment & & & $08=$ Unifacial-Bilateral & & \\
\hline $09=$ Barb/Shoulder & & & $09=$ Unifacial-Unilateral & & \\
\hline $10=\mathrm{Ear} /$ Tang & & & $10=$ Unifacial-Distal-Bilateral & & \\
\hline \multirow[t]{4}{*}{$11=$ Stem } & & & $11=$ Unifacial-Distal-Unilateral & & \\
\hline & & & $12=$ Unifacial-Circumferential & & \\
\hline & & & $13=$ Other & & \\
\hline & & & $99=$ Not Applicable & & \\
\hline
\end{tabular}

Table B-6. Catalog of Hammerstones.

\begin{tabular}{cccccc}
\hline Lot \# & Unit \# & Depth (cmbs) & Total & Weight (g) & Heated \\
\hline $116-1$ & 2 & $170-180$ & 1 & 137.6 & $\mathrm{~N}$ \\
$249-2$ & 27 & $100-110$ & 1 & 406.3 & $\mathrm{~N}$ \\
\hline
\end{tabular}

Table B-7. Catalog of Groundstones.

\begin{tabular}{cccccc}
\hline Lot \# & Unit \# & Depth (cmbs) & Total & Weight $(\mathrm{g})$ & Notes \\
\hline $79-1$ & 4 & $120-130$ & 2 & 75.8 & metate fragment \\
$176-1$ & 21 & $140-150$ & 1 & 99.9 & metate fragment \\
$247-1$ & 28 & $110-120$ & 1 & 60.4 & poss. mono fragment \\
$253-2$ & 28 & $120-130$ & 2 & 44.7 & metate fragment \\
\hline
\end{tabular}


Table B-8. Catalog of Whole and Proximal Flakes 100-200 cmbs.

\begin{tabular}{|c|c|c|c|c|c|c|c|c|c|c|c|c|}
\hline 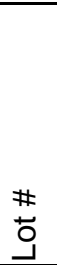 & 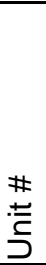 & 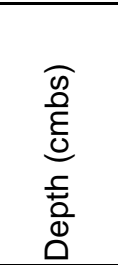 & 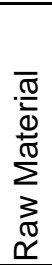 & $\begin{array}{l}0 \\
\mathbb{d} \\
\frac{\mathbf{0}}{\mathbb{0}} \\
\frac{0}{1} \\
\frac{0}{0} \\
\frac{0}{3}\end{array}$ & 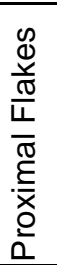 & $\begin{array}{l}\frac{0}{0} \\
\frac{\pi}{0} \\
\mathbb{N} \\
\frac{N}{\omega}\end{array}$ & 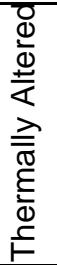 & 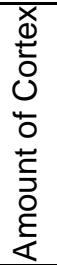 & $\begin{array}{l}\stackrel{0}{2} \\
\stackrel{1}{1} \\
\frac{E}{0} \\
\frac{0}{ \pm} \\
\frac{\pi}{\alpha}\end{array}$ & 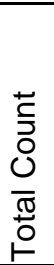 & 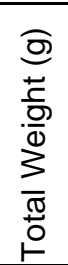 & $Z_{\Sigma}^{Z}$ \\
\hline 61 & 1 & $100-110$ & 1 & $x$ & & 02 & 02 & 00 & 04 & 1 & 0.4 & 1 \\
\hline 61 & 1 & $100-110$ & 1 & & $x$ & 04 & - & 01 & 04 & 1 & 0.1 & 1 \\
\hline 64 & 1 & $110-120$ & 1 & $x$ & & 02 & 01 & 01 & 08 & 1 & 1.7 & 1 \\
\hline 64 & 1 & $110-120$ & 1 & $x$ & & 03 & - & 00 & 02 & 1 & 0.6 & 1 \\
\hline 64 & 1 & $110-120$ & 1 & $x$ & & 04 & - & 00 & 05 & 1 & 0.3 & 1 \\
\hline 71 & 1 & $130-140$ & 1 & & $x$ & 01 & 02 & 02 & 02 & 1 & 12.9 & 1 \\
\hline 71 & 1 & $130-140$ & 1 & & $x$ & 01 & 02 & 00 & 06 & 1 & 4.6 & 1 \\
\hline 71 & 1 & $130-140$ & 1 & & $x$ & 01 & 01 & 01 & 01 & 1 & 9 & 1 \\
\hline 71 & 1 & $130-140$ & 1 & & $x$ & 02 & 01 & 00 & 05 & 2 & 3.4 & 1 \\
\hline 71 & 1 & $130-140$ & 1 & & $x$ & 04 & - & 00 & 06 & 1 & 0.2 & 1 \\
\hline 76 & 1 & $140-150$ & 1 & & $x$ & 03 & 02 & 01 & 01 & 1 & 1 & 1 \\
\hline 76 & 1 & $140-150$ & 1 & $x$ & & 03 & 02 & 00 & 05 & 1 & 0.4 & 1 \\
\hline 76 & 1 & $140-150$ & 1 & $x$ & & 02 & 02 & 01 & 08 & 1 & 2.8 & 1 \\
\hline 76 & 1 & $140-150$ & 1 & $x$ & & 02 & 01 & 00 & 02 & 1 & 0.8 & 1 \\
\hline 83 & 1 & $150-160$ & 1 & & $x$ & 03 & 02 & 00 & 04 & 1 & 0.3 & 1 \\
\hline 83 & 1 & $150-160$ & 1 & $x$ & & 01 & 02 & 01 & 02 & 1 & 17.0 & 1 \\
\hline 87 & 1 & $160-170$ & 1 & $x$ & & 03 & 01 & 01 & 04 & 1 & 0.5 & 1 \\
\hline 87 & 1 & $160-170$ & 1 & $x$ & & 01 & 02 & 01 & 04 & 1 & 1.5 & 1 \\
\hline 42 & 2 & $120-130$ & 1 & & $x$ & 01 & 02 & 01 & 02 & 1 & 7.6 & 1 \\
\hline 114 & 2 & $160-170$ & 1 & & $x$ & 04 & - & 01 & 04 & 1 & 0.1 & 1 \\
\hline 114 & 2 & $160-170$ & 1 & $x$ & & 03 & 01 & 00 & 02 & 1 & 0.7 & 1 \\
\hline 114 & 2 & $160-170$ & 1 & $x$ & & 02 & 01 & 01 & 08 & 1 & 2.2 & 1 \\
\hline 114 & 2 & $160-170$ & 1 & $x$ & & 01 & 01 & 03 & 01 & 1 & 3.3 & 1 \\
\hline 116 & 2 & $170-180$ & 1 & $x$ & & 04 & - & 00 & 02 & 1 & 0.2 & 1 \\
\hline 116 & 2 & $170-180$ & 1 & $x$ & & 02 & 02 & 01 & 02 & 1 & 2.4 & 1 \\
\hline 116 & 2 & $170-180$ & 1 & $x$ & & 02 & 02 & 00 & 02 & 1 & 2.7 & 1 \\
\hline 116 & 2 & $170-180$ & 1 & & $x$ & 02 & 01 & 00 & 05 & 1 & 2.1 & 1 \\
\hline 116 & 2 & $170-180$ & 1 & & $x$ & 01 & 02 & 00 & 00 & 1 & 2.7 & 1 \\
\hline 116 & 2 & $170-180$ & 1 & & $x$ & 01 & 01 & 00 & 05 & 1 & 1.7 & 1 \\
\hline 119 & 2 & $180-190$ & 1 & & $x$ & 02 & 02 & 01 & 02 & 1 & 1.3 & 1 \\
\hline 119 & 2 & $180-190$ & 1 & $x$ & & 01 & 02 & 01 & 02 & 1 & 7.0 & 1 \\
\hline 40 & 3 & $100-110$ & & $x$ & & 04 & - & 00 & 05 & 1 & 0.0 & 1 \\
\hline 40 & 3 & $100-110$ & 1 & $x$ & & 02 & 02 & 01 & 02 & 1 & 1.2 & 1 \\
\hline 40 & 3 & $100-110$ & 1 & $x$ & & 02 & 01 & 00 & 02 & 1 & 3.1 & 1 \\
\hline 45 & 3 & $110-120$ & 1 & & $x$ & 02 & 02 & 02 & 01 & 1 & 2.2 & 1 \\
\hline 45 & 3 & $110-120$ & 1 & & $x$ & 02 & 01 & 00 & 04 & 1 & 1.5 & 1 \\
\hline 45 & 3 & $110-120$ & 1 & & $x$ & 02 & 01 & 02 & 04 & 1 & 3.8 & 1 \\
\hline 49 & 3 & $120-130$ & 1 & & $x$ & 04 & - & 00 & 05 & 1 & 0.0 & 1 \\
\hline 49 & 3 & $120-130$ & 1 & & $x$ & 04 & - & 00 & 00 & 1 & 0.0 & 1 \\
\hline 49 & 3 & $120-130$ & 1 & & $x$ & 02 & 01 & 00 & 02 & 1 & 1.0 & 1 \\
\hline 49 & 3 & $120-130$ & 1 & & $x$ & 02 & 01 & 01 & 02 & 1 & 1.2 & 1 \\
\hline 55 & 3 & $130-140$ & 1 & $x$ & & 04 & - & 01 & 03 & 1 & 0.2 & 1 \\
\hline 55 & 3 & $130-140$ & 1 & $x$ & & 04 & - & 00 & 04 & 1 & 0.2 & 1 \\
\hline 55 & 3 & $130-140$ & 1 & & $x$ & 04 & - & 01 & 05 & 1 & 0.4 & 1 \\
\hline 55 & 3 & $130-140$ & 1 & $x$ & & 03 & - & 00 & 02 & 1 & 1.0 & 1 \\
\hline
\end{tabular}


Table B-8 (continued). Catalog of Whole and Proximal Flakes 100-200 cmbs.

\begin{tabular}{|c|c|c|c|c|c|c|c|c|c|c|c|c|}
\hline \# & 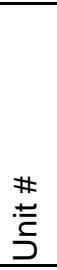 & 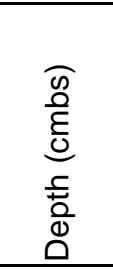 & 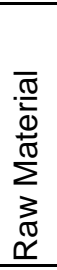 & $\begin{array}{l}0 \\
\mathbb{Q} \\
\frac{2}{\sigma} \\
\frac{0}{1} \\
\frac{0}{0} \\
\frac{0}{3} \\
\frac{1}{3}\end{array}$ & 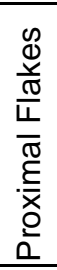 & $\begin{array}{l}\frac{0}{0} \\
\frac{\pi}{0} \\
\bar{\sigma} \\
\mathbb{N} \\
\frac{N}{\omega}\end{array}$ & 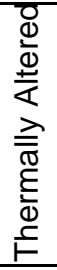 & 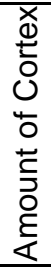 & 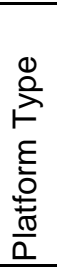 & 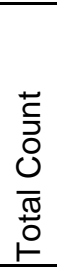 & 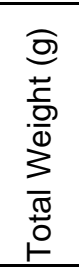 & $\sum_{\Sigma}^{z}$ \\
\hline 55 & 3 & $130-140$ & 1 & & $x$ & 03 & - & 00 & 05 & 1 & 0.8 & 1 \\
\hline 55 & 3 & $130-140$ & 1 & $x$ & & 01 & 00 & 00 & 02 & 1 & 3.5 & 1 \\
\hline 58 & 3 & $140-150$ & 1 & $x$ & & 04 & - & 00 & 04 & 1 & 0.0 & 1 \\
\hline 58 & 3 & $140-150$ & 1 & $x$ & & 03 & - & 02 & 02 & 1 & 1.6 & 1 \\
\hline 58 & 3 & $140-150$ & 1 & $x$ & & 03 & - & 02 & 04 & 1 & 0.4 & 1 \\
\hline 99 & 3 & $150-160$ & 1 & $x$ & & 01 & 01 & 01 & 01 & 1 & 1.6 & 1 \\
\hline 101 & 3 & $160-170$ & 1 & & $x$ & 02 & 01 & 00 & 02 & 1 & 2.1 & 1 \\
\hline 107 & 3 & $170-180$ & 1 & $x$ & & 04 & - & 00 & 02 & 1 & 0.2 & 1 \\
\hline 107 & 3 & $170-180$ & 1 & $x$ & & 03 & - & 02 & 02 & 1 & 1.5 & 1 \\
\hline 25 & 4 & $100-110$ & 1 & $x$ & & 03 & - & 00 & 02 & 1 & 1.0 & 1 \\
\hline 25 & 4 & $100-110$ & 1 & & $x$ & 02 & 01 & 00 & 04 & 1 & 0.7 & 1 \\
\hline 25 & 4 & $100-110$ & 1 & & $x$ & 02 & 01 & 01 & 01 & 1 & 1.0 & 1 \\
\hline- & 4 & $110-120$ & 1 & $x$ & & 01 & 01 & 01 & 04 & 1 & 8.2 & 1 \\
\hline 79 & 4 & $120-130$ & 1 & $x$ & & 01 & 02 & 02 & 02 & 3 & 45.7 & 2 \\
\hline 79 & 4 & $120-130$ & 1 & $x$ & & 01 & 02 & 02 & 01 & 1 & 9.2 & 1 \\
\hline 79 & 4 & $120-130$ & 1 & & $x$ & 01 & 02 & 02 & 04 & 1 & 10.5 & 1 \\
\hline 79 & 4 & $120-130$ & 1 & $x$ & & 02 & 02 & 01 & 03 & 1 & 2.3 & 1 \\
\hline 84 & 4 & $130-140$ & 1 & $x$ & & 01 & 01 & 01 & 05 & 1 & 4.9 & 1 \\
\hline 84 & 4 & $130-140$ & 1 & & $x$ & 02 & 01 & 01 & 00 & 1 & 1.7 & 1 \\
\hline 86 & 4 & $140-150$ & 1 & & $x$ & 03 & - & 00 & 04 & 1 & 1.0 & 1 \\
\hline 86 & 4 & $140-150$ & 1 & $x$ & & 01 & 02 & 02 & 04 & 2 & 5.2 & 2 \\
\hline 86 & 4 & $140-150$ & 1 & & $x$ & 01 & 02 & 01 & 02 & 1 & 17.5 & 1 \\
\hline 102 & 5 & $110-120$ & 1 & & $x$ & 03 & - & 01 & 02 & 1 & 1.2 & 1 \\
\hline 102 & 5 & $110-120$ & 1 & & $x$ & 02 & 02 & 02 & 04 & 1 & 2.9 & 1 \\
\hline 102 & 5 & $110-120$ & 1 & & $x$ & 02 & 01 & 00 & 02 & 1 & 3.0 & 1 \\
\hline 109 & 5 & $120-130$ & 1 & & $x$ & 03 & - & 00 & 05 & 2 & 1.9 & 2 \\
\hline 109 & 5 & $120-130$ & 1 & & $x$ & 01 & 02 & 02 & 02 & 1 & 20.9 & 1 \\
\hline 109 & 5 & $120-130$ & 1 & $x$ & & 01 & 02 & 00 & 05 & 1 & 1.9 & 1 \\
\hline 109 & 5 & $120-130$ & 1 & $x$ & & 01 & 02 & 01 & 04 & 1 & 4.9 & 1 \\
\hline 109 & 5 & $120-130$ & 1 & $x$ & & 01 & 01 & 00 & 02 & 1 & 3.8 & 1 \\
\hline 110 & 5 & $130-140$ & 1 & & $x$ & 04 & - & 00 & 00 & 1 & 0.1 & 1 \\
\hline 110 & 5 & $130-140$ & 1 & & $x$ & 03 & - & 02 & 01 & 1 & 1.9 & 1 \\
\hline 110 & 5 & $130-140$ & 1 & $x$ & & 03 & - & 00 & 03 & 1 & 0.4 & 1 \\
\hline 110 & 5 & $130-140$ & 1 & $x$ & & 03 & - & 00 & 02 & 1 & 0.6 & 1 \\
\hline 110 & 5 & $130-140$ & 1 & & $x$ & 02 & 02 & 01 & 02 & 1 & 2.8 & 1 \\
\hline 110 & 5 & $130-140$ & 1 & $x$ & & 01 & 02 & 00 & 02 & 1 & 6.2 & 1 \\
\hline 115 & 5 & $140-150$ & 1 & & $x$ & 04 & - & 00 & 04 & 1 & 0.3 & 1 \\
\hline 115 & 5 & $140-150$ & 1 & $x$ & & 04 & - & 00 & 04 & 1 & 0.4 & 1 \\
\hline 115 & 5 & $140-150$ & 1 & & $x$ & 04 & - & 00 & 05 & 1 & 0.0 & 1 \\
\hline 115 & 5 & $140-150$ & 1 & & $x$ & 03 & - & 00 & 04 & 1 & 0.4 & 1 \\
\hline 115 & 5 & $140-150$ & 1 & $x$ & & 02 & 02 & 00 & 02 & 1 & 2.3 & 1 \\
\hline 115 & 5 & $140-150$ & 1 & $x$ & & 02 & 01 & 02 & 04 & 1 & 9.7 & 1 \\
\hline 115 & 5 & $140-150$ & 1 & & $x$ & 01 & 02 & 01 & 02 & 1 & 28.4 & 1 \\
\hline 115 & 5 & $140-150$ & 1 & $x$ & & 01 & 02 & 00 & 04 & 1 & 3.2 & 1 \\
\hline 115 & 5 & $140-150$ & 1 & $x$ & & 01 & 02 & 02 & 02 & 1 & 9.8 & 1 \\
\hline
\end{tabular}


Table B-8 (continued). Catalog of Whole and Proximal Flakes 100-200 cmbs.

\begin{tabular}{|c|c|c|c|c|c|c|c|c|c|c|c|c|}
\hline $\begin{array}{l}\# \\
\text { \# } \\
\end{array}$ & $\begin{array}{l}\# \\
\stackrel{ \pm}{ \pm} \\
.\end{array}$ & 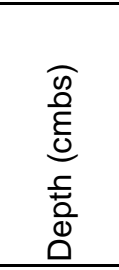 & 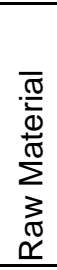 & $\begin{array}{l}0 \\
\mathbb{d} \\
\frac{1}{\omega} \\
\frac{1}{1} \\
\frac{0}{0} \\
\frac{0}{3}\end{array}$ & 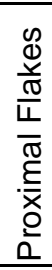 & $\begin{array}{l}0 \\
\frac{0}{\pi} \\
\frac{\pi}{\pi} \\
0 \\
\stackrel{N}{\omega} \\
\end{array}$ & 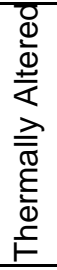 & 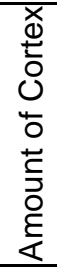 & 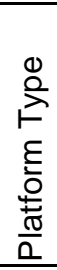 & 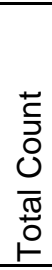 & 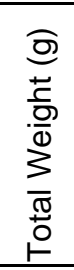 & $\underset{z}{Z}$ \\
\hline 75 & 6 & $100-110$ & 1 & & $x$ & 04 & - & 00 & 03 & 1 & 0.1 & 1 \\
\hline 75 & 6 & $100-110$ & 1 & $x$ & & 03 & - & 00 & 02 & 1 & 0.7 & 1 \\
\hline 82 & 6 & $110-120$ & 1 & $x$ & & 04 & - & 00 & 05 & 1 & 0.3 & 1 \\
\hline 82 & 6 & $110-120$ & 1 & & $x$ & 03 & - & 00 & 04 & 1 & 0.8 & 1 \\
\hline 82 & 6 & $110-120$ & 1 & $x$ & & 01 & 02 & 02 & 08 & 1 & 4.4 & 1 \\
\hline 89 & 6 & $120-125$ & 1 & & $x$ & 04 & - & 01 & 02 & 1 & & 1 \\
\hline 89 & 6 & $120-125$ & 1 & & $x$ & 03 & - & 01 & 05 & 1 & & 1 \\
\hline 90 & 6 & $125-130$ & 1 & & $x$ & 03 & - & 00 & 04 & 3 & 2.6 & 3 \\
\hline 90 & 6 & $125-130$ & 1 & & $x$ & 01 & 02 & 01 & 02 & 1 & 16.6 & 1 \\
\hline 94 & 6 & $130-140$ & 1 & & $x$ & 04 & - & 00 & 04 & 1 & 0.4 & 1 \\
\hline 94 & 6 & $130-140$ & 1 & & $x$ & 04 & - & 01 & 03 & 1 & 0.6 & 1 \\
\hline 94 & 6 & $130-140$ & 1 & & $x$ & 02 & 01 & 02 & 02 & 1 & 1.7 & 1 \\
\hline 94 & 6 & $130-140$ & 1 & & $x$ & 02 & 02 & 01 & 02 & 1 & 4.8 & 1 \\
\hline 94 & 6 & $130-140$ & 1 & $x$ & & 02 & 01 & 00 & 04 & 1 & 1.4 & 1 \\
\hline 94 & 6 & $130-140$ & 1 & & $x$ & 01 & 02 & 00 & 02 & 1 & 7.4 & 1 \\
\hline 103 & 6 & $140-150$ & 1 & & $x$ & 01 & 02 & 00 & 04 & 1 & 5.8 & 1 \\
\hline 103 & 6 & $140-150$ & 1 & & $x$ & 01 & 02 & 01 & 02 & 1 & 7.7 & 1 \\
\hline 103 & 6 & $140-150$ & 1 & & $x$ & 01 & 01 & 01 & 02 & 1 & 9.5 & 1 \\
\hline 103 & 6 & $140-150$ & 1 & & $x$ & 01 & 02 & 01 & 01 & 1 & 6.0 & 1 \\
\hline 103 & 6 & $140-150$ & 1 & $x$ & & 01 & 02 & 00 & 02 & 1 & 19.6 & 1 \\
\hline 103 & 6 & $140-150$ & 1 & & $x$ & 01 & 02 & 02 & 02 & 2 & 45.1 & 2 \\
\hline- & 6 & $150-160$ & 1 & $x$ & & 04 & - & 00 & 05 & 1 & 0.1 & 1 \\
\hline- & 6 & $150-160$ & 1 & & $x$ & 04 & - & 00 & 04 & 1 & 0.1 & 1 \\
\hline- & 6 & $150-160$ & 1 & & $x$ & 02 & 01 & 00 & 03 & 1 & 1.6 & 1 \\
\hline- & 6 & $150-160$ & 1 & $x$ & & 01 & 01 & 00 & 03 & 1 & 7.9 & 1 \\
\hline- & 6 & $150-160$ & 1 & $x$ & & 01 & 02 & 01 & 02 & 1 & 11.9 & 1 \\
\hline- & 6 & $150-160$ & 1 & & $x$ & 01 & 02 & 01 & 03 & 1 & 24.8 & 1 \\
\hline 174 & 6 & $160-170$ & 1 & $x$ & & 03 & - & 00 & 04 & 1 & 1.3 & 1 \\
\hline 174 & 6 & $160-170$ & 1 & $x$ & & 03 & - & 00 & 03 & 1 & 1.8 & 1 \\
\hline 174 & 6 & $160-170$ & 1 & $x$ & & 02 & 02 & 00 & 04 & 1 & 5.1 & 1 \\
\hline 174 & 6 & $160-170$ & 1 & & $x$ & 02 & 02 & 01 & 04 & 1 & 2.7 & 1 \\
\hline 174 & 6 & $160-170$ & 1 & $x$ & & 01 & 02 & 01 & 02 & 1 & 5.8 & 1 \\
\hline 217 & 6 & $170-180$ & 1 & $x$ & & 04 & - & 00 & 03 & 02 & 0.6 & 2 \\
\hline 217 & 6 & $170-180$ & 1 & $x$ & & 04 & - & 00 & 02 & 1 & 0.7 & 1 \\
\hline 217 & 6 & $170-180$ & 1 & $x$ & & 04 & - & 00 & 00 & 1 & 0.3 & 1 \\
\hline 217 & 6 & $170-180$ & 1 & & $x$ & 04 & - & 00 & 04 & 2 & 1.5 & 2 \\
\hline 217 & 6 & $170-180$ & 1 & & $x$ & 04 & - & 00 & 02 & 1 & 0.2 & 1 \\
\hline 217 & 6 & $170-180$ & 1 & $x$ & & 04 & - & 01 & 01 & 1 & 1.0 & 1 \\
\hline 217 & 6 & $170-180$ & 1 & $x$ & & 04 & - & 02 & 04 & 1 & 1.3 & 1 \\
\hline 217 & 6 & $170-180$ & 1 & $x$ & & 03 & - & 01 & 01 & 1 & 1.8 & 1 \\
\hline 217 & 6 & $170-180$ & 1 & $x$ & & 03 & - & 01 & 03 & 2 & 5.5 & 2 \\
\hline 217 & 6 & $170-180$ & 1 & & $x$ & 03 & - & 01 & 04 & 2 & 2.7 & 2 \\
\hline 217 & 6 & $170-180$ & 1 & $x$ & & 03 & - & 02 & 02 & 1 & 4.3 & 1 \\
\hline 217 & 6 & $170-180$ & 1 & & $x$ & 03 & - & 02 & 03 & 1 & 1.3 & 1 \\
\hline 217 & 6 & $170-180$ & 1 & $x$ & & 03 & - & 00 & 05 & 1 & 1.5 & 1 \\
\hline
\end{tabular}


Table B-8 (continued). Catalog of Whole and Proximal Flakes 100-200 cmbs.

\begin{tabular}{|c|c|c|c|c|c|c|c|c|c|c|c|c|}
\hline 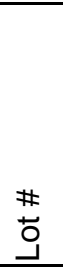 & $\begin{array}{l}\text { \# } \\
\stackrel{ \pm}{\underline{\underline{\prime}}} \\
\end{array}$ & 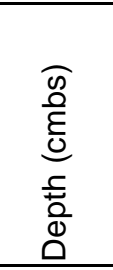 & 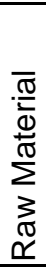 & $\begin{array}{l}0 \\
\Phi \\
\frac{1}{0} \\
\frac{\pi}{1} \\
\frac{0}{0} \\
\frac{0}{3} \\
\frac{1}{3}\end{array}$ & 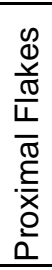 & $\begin{array}{l}\frac{0}{0} \\
\frac{\pi}{0} \\
\overline{0} \\
\stackrel{N}{N} \\
\frac{N}{\omega}\end{array}$ & 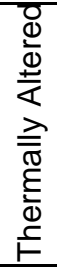 & 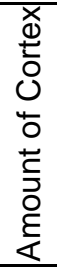 & 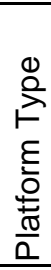 & 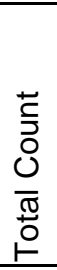 & 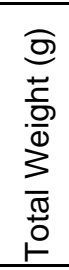 & $\frac{Z}{z}$ \\
\hline 217 & 6 & $170-180$ & 1 & $x$ & & 03 & - & 00 & 02 & 3 & 1.2 & 3 \\
\hline 217 & 6 & $170-180$ & 1 & & $x$ & 03 & - & 00 & 02 & 1 & 3.4 & 1 \\
\hline 217 & 6 & $170-180$ & 1 & & $x$ & 03 & - & 00 & 03 & 1 & 1.2 & 1 \\
\hline 217 & 6 & $170-180$ & 1 & & $x$ & 03 & - & 00 & 04 & 1 & 1.3 & 1 \\
\hline 217 & 6 & $170-180$ & 1 & & $x$ & 03 & - & 00 & 05 & 2 & 3.0 & 2 \\
\hline 217 & 6 & $170-180$ & 1 & $x$ & & 02 & 01 & 00 & 02 & 1 & 5.6 & 1 \\
\hline 217 & 6 & $170-180$ & 1 & $x$ & & 02 & 02 & 00 & 03 & 1 & 1.8 & 1 \\
\hline 217 & 6 & $170-180$ & 1 & & $x$ & 02 & 02 & 02 & 02 & 1 & 4.8 & 1 \\
\hline 217 & 6 & $170-180$ & 1 & $x$ & & 01 & 02 & 01 & 02 & 4 & 86.8 & 4 \\
\hline 217 & 6 & $170-180$ & 1 & $x$ & & 01 & 02 & 02 & 02 & 1 & 7.3 & 1 \\
\hline 217 & 6 & $170-180$ & 1 & $x$ & & 01 & 01 & 01 & 04 & 1 & 9.7 & 1 \\
\hline 217 & 6 & $170-180$ & 1 & $x$ & & 01 & 02 & 00 & 02 & 1 & 15.9 & 1 \\
\hline 217 & 6 & $170-180$ & 1 & $x$ & & 01 & 02 & 01 & 01 & 1 & 7.2 & 1 \\
\hline 217 & 6 & $170-180$ & 1 & & $x$ & 01 & 02 & 02 & 01 & 1 & 14.8 & 1 \\
\hline 217 & 6 & $170-180$ & 1 & & $x$ & 01 & 01 & 00 & 02 & 1 & 15.3 & 1 \\
\hline 229 & 6 & $180-190$ & 1 & $x$ & & 04 & - & 00 & 00 & 1 & 0.0 & 1 \\
\hline 229 & 6 & $180-190$ & 1 & & $x$ & 02 & 02 & 00 & 03 & 1 & 3.6 & 1 \\
\hline 234 & 6 & $190-200$ & 1 & & $x$ & 04 & - & 00 & 04 & 1 & 0.5 & 1 \\
\hline 234 & 6 & $190-200$ & 1 & & $x$ & 04 & - & 00 & 02 & 1 & 0.4 & 1 \\
\hline 234 & 6 & $190-200$ & 1 & $x$ & & 03 & - & 00 & 04 & 1 & 1.0 & 1 \\
\hline 234 & 6 & $190-200$ & 1 & & $x$ & 03 & - & 00 & 04 & 1 & 1.5 & 1 \\
\hline 234 & 6 & $190-200$ & 1 & & $x$ & 01 & 01 & 01 & 02 & 1 & 11.6 & 1 \\
\hline 217 & 6 & $170-180$ & 1 & & $x$ & 01 & 01 & 00 & 02 & 1 & 15.3 & 1 \\
\hline 59 & 6 & $100-110$ & 1 & $x$ & & 04 & - & 00 & 02 & 1 & 0.0 & 1 \\
\hline 118 & 7 & $110-120$ & 1 & & $x$ & 02 & 01 & 02 & 01 & 1 & 2.3 & 1 \\
\hline 118 & 7 & $110-120$ & 1 & & $x$ & 01 & 02 & 01 & 02 & 1 & 26.3 & 1 \\
\hline 121 & 7 & $120-130$ & 1 & $x$ & & 03 & - & 01 & 01 & 1 & 1.0 & 1 \\
\hline 121 & 7 & $120-130$ & 1 & & $x$ & 03 & - & 00 & 04 & 1 & 0.7 & 1 \\
\hline 121 & 7 & $120-130$ & 1 & & $x$ & 01 & 02 & 02 & 02 & 1 & 25.8 & 1 \\
\hline 125 & 7 & $130-140$ & 1 & & $x$ & 03 & - & 00 & 03 & 1 & 0.9 & 1 \\
\hline 125 & 7 & $130-140$ & 1 & & $x$ & 03 & - & 02 & 04 & 1 & 2.0 & 1 \\
\hline 125 & 7 & $130-140$ & 1 & & $x$ & 03 & - & 01 & 01 & 1 & 2.7 & 1 \\
\hline 125 & 7 & $130-140$ & 1 & $\mathrm{x}$ & & 03 & - & 01 & 04 & 1 & 3.8 & 1 \\
\hline 125 & 7 & $130-140$ & 1 & $x$ & & 03 & - & 01 & 02 & 1 & 2.9 & 1 \\
\hline 125 & 7 & $130-140$ & 1 & & $x$ & 02 & 01 & 00 & 06 & 1 & 1.4 & 1 \\
\hline 127 & 7 & $140-150$ & 1 & $x$ & & 04 & - & 00 & 02 & 1 & 0.3 & 1 \\
\hline 127 & 7 & $140-150$ & 1 & & $x$ & 04 & - & 01 & 01 & 1 & 0.2 & 1 \\
\hline 127 & 7 & $140-150$ & 1 & & $x$ & 04 & - & 00 & 03 & 2 & 0.6 & 2 \\
\hline 127 & 7 & $140-150$ & 1 & & $x$ & 04 & - & 01 & 02 & 2 & 0.8 & 2 \\
\hline 127 & 7 & $140-150$ & 1 & & $x$ & 04 & - & 00 & 04 & 3 & 0.6 & 3 \\
\hline 127 & 7 & $140-150$ & 1 & $x$ & & 03 & - & 00 & 06 & 1 & 1.4 & 1 \\
\hline 127 & 7 & $140-150$ & 1 & $x$ & & 03 & - & 00 & 02 & 2 & 3.0 & 2 \\
\hline 127 & 7 & $140-150$ & 1 & & $x$ & 03 & - & 00 & 04 & 3 & 1.8 & 3 \\
\hline 127 & 7 & $140-150$ & 1 & & $x$ & 03 & - & 01 & 04 & 1 & 1.0 & 1 \\
\hline 127 & 7 & $140-150$ & 1 & $x$ & & 02 & 01 & 00 & 02 & 1 & 2.3 & 1 \\
\hline
\end{tabular}


Table B-8 (continued). Catalog of Whole and Proximal Flakes 100-200 cmbs.

\begin{tabular}{|c|c|c|c|c|c|c|c|c|c|c|c|c|}
\hline $\begin{array}{l}\# \\
\text { \# } \\
\end{array}$ & 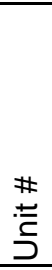 & 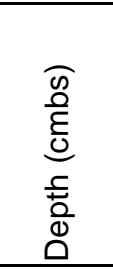 & 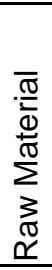 & 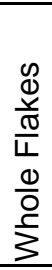 & 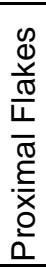 & $\begin{array}{l}0 \\
\frac{0}{0} \\
\frac{\pi}{0} \\
\stackrel{N}{0} \\
\stackrel{N}{\omega}\end{array}$ & 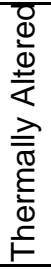 & 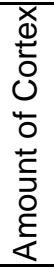 & 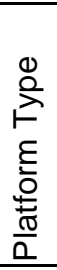 & 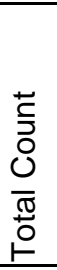 & 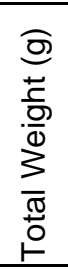 & $\sum_{\Sigma}^{Z}$ \\
\hline 127 & 7 & $140-150$ & 1 & $x$ & & 02 & 02 & 00 & 02 & 1 & 3.8 & 1 \\
\hline 127 & 7 & $140-150$ & 1 & $x$ & & 02 & 02 & 00 & 04 & 1 & 2.1 & 1 \\
\hline 127 & 7 & $140-150$ & 1 & $x$ & & 02 & 02 & 01 & 01 & 1 & 3.0 & 1 \\
\hline 127 & 7 & $140-150$ & 1 & & $x$ & 02 & 02 & 02 & 01 & 1 & 2.7 & 1 \\
\hline 127 & 7 & $140-150$ & 1 & & $x$ & 02 & 02 & 00 & 04 & 1 & 3.8 & 1 \\
\hline 127 & 7 & $140-150$ & 1 & & $x$ & 02 & 02 & 00 & 02 & 1 & 2.1 & 1 \\
\hline 127 & 7 & $140-150$ & 1 & & $x$ & 02 & 01 & 00 & 06 & 1 & 1.8 & 1 \\
\hline 127 & 7 & $140-150$ & 1 & $x$ & & 01 & 02 & 01 & 02 & 1 & 10.0 & 1 \\
\hline 127 & 7 & $140-150$ & 1 & & $x$ & 01 & 02 & 01 & 03 & 1 & 10.7 & 1 \\
\hline 127 & 7 & $140-150$ & 1 & & $x$ & 01 & 02 & 02 & 01 & 1 & 13.0 & 1 \\
\hline 73 & 8 & $100-110$ & 1 & $x$ & & 03 & - & 00 & 04 & 2 & 1.0 & 1 \\
\hline 104 & 8 & $110-120$ & 1 & & $x$ & 02 & 02 & 01 & 04 & 1 & 6.5 & 1 \\
\hline 104 & 8 & $100-120$ & 1 & & $x$ & 02 & 02 & 01 & 02 & 1 & 7.7 & 1 \\
\hline 104 & 8 & $100-120$ & 1 & & $x$ & 02 & 01 & 01 & 01 & 1 & 7.0 & 1 \\
\hline 104 & 8 & $100-120$ & 1 & & $x$ & 02 & 01 & 01 & 03 & 1 & 3.2 & 1 \\
\hline 97 & 8 & $120-130$ & 1 & $x$ & & 02 & 02 & 01 & 02 & 1 & 4.2 & 1 \\
\hline 97 & 8 & $120-130$ & 1 & & $x$ & 01 & 01 & 02 & 02 & 1 & 7.2 & 1 \\
\hline 105 & 8 & $130-140$ & 1 & $x$ & & 03 & - & 00 & 03 & 1 & 1.7 & 1 \\
\hline 105 & 8 & $130-140$ & 1 & & $x$ & 02 & 01 & 01 & 03 & 1 & 4.3 & 1 \\
\hline 105 & 8 & $130-140$ & 1 & & $x$ & 02 & 01 & 02 & 04 & 1 & 5.2 & 1 \\
\hline 105 & 8 & $130-140$ & 1 & $x$ & & 02 & 02 & 02 & 04 & 1 & 5.4 & 1 \\
\hline 105 & 8 & $130-140$ & 1 & $x$ & & 01 & 02 & 01 & 03 & 1 & 18.3 & 1 \\
\hline 105 & 8 & $130-140$ & 1 & & $x$ & 01 & 02 & 02 & 02 & 1 & 14.4 & 1 \\
\hline 120 & 8 & $140-150$ & 1 & & $x$ & 03 & - & 01 & 04 & 1 & 0.9 & 1 \\
\hline 120 & 8 & $140-150$ & 1 & & $x$ & 03 & - & 00 & 04 & 1 & 1.3 & 1 \\
\hline 120 & 8 & $140-150$ & 1 & $x$ & & 03 & - & 00 & 02 & 1 & 1.0 & 1 \\
\hline 120 & 8 & $140-150$ & 1 & $x$ & & 02 & 02 & 00 & 03 & 1 & 3.1 & 1 \\
\hline 120 & 8 & $140-150$ & 1 & & $x$ & 02 & 02 & 00 & 04 & 2 & 5.0 & 2 \\
\hline 120 & 8 & $140-150$ & 1 & & $x$ & 02 & 02 & 01 & 03 & 1 & 4.7 & 1 \\
\hline 120 & 8 & $140-150$ & 1 & & $x$ & 02 & 01 & 01 & 03 & 1 & 6.2 & 1 \\
\hline 120 & 8 & $140-150$ & 1 & $x$ & & 01 & 02 & 01 & 02 & 2 & 16.2 & 2 \\
\hline 120 & 8 & $140-150$ & 1 & & $x$ & 01 & 01 & 01 & 02 & 1 & 8.1 & 1 \\
\hline 120 & 8 & $140-150$ & 1 & $x$ & & 01 & 02 & 02 & 02 & 1 & 14.4 & 1 \\
\hline 120 & 8 & $140-150$ & 1 & & $x$ & 01 & 02 & 02 & 02 & 1 & 12.5 & 1 \\
\hline 117 & 8 & $150-160$ & 1 & $x$ & & 03 & - & 00 & 05 & 1 & 1.4 & 1 \\
\hline 117 & 8 & $150-160$ & 1 & & $x$ & 03 & - & 01 & 01 & 1 & 0.9 & 1 \\
\hline 117 & 8 & $150-160$ & 1 & $x$ & & 02 & 02 & 01 & 02 & 1 & 6.2 & 1 \\
\hline 96 & 9 & $100-110$ & 1 & $x$ & & 03 & - & 01 & 01 & 1 & 1.9 & 1 \\
\hline 100 & 9 & $110-120$ & 1 & & $x$ & 04 & - & 00 & 04 & 2 & 1.1 & 2 \\
\hline 100 & 9 & $110-120$ & 1 & & $x$ & 02 & 01 & 01 & 02 & 1 & 3.2 & 1 \\
\hline 100 & 9 & $110-120$ & 1 & & $x$ & 01 & 02 & 01 & 02 & 1 & 6.6 & 1 \\
\hline 108 & 9 & $120-130$ & 1 & & $x$ & 03 & - & 01 & 02 & 1 & 2.3 & 1 \\
\hline 108 & 9 & $120-130$ & 1 & $x$ & & 03 & - & 01 & 01 & 1 & 1.8 & 1 \\
\hline 108 & 9 & $120-130$ & 1 & $x$ & & 02 & 02 & 01 & 03 & 1 & 4.8 & 1 \\
\hline 108 & 9 & $120-130$ & 1 & $x$ & & 02 & 02 & 00 & 04 & 1 & 3.2 & 1 \\
\hline
\end{tabular}


Table B-8 (continued). Catalog of Whole and Proximal Flakes 100-200 cmbs.

\begin{tabular}{|c|c|c|c|c|c|c|c|c|c|c|c|c|}
\hline 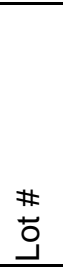 & $\begin{array}{l}\# \\
\text { \# } \\
\text { 言 } \\
\end{array}$ & 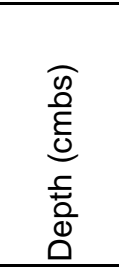 & 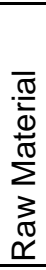 & $\begin{array}{l}0 \\
\Phi \\
\frac{1}{0} \\
\frac{\pi}{1} \\
\frac{0}{0} \\
\frac{0}{3} \\
\frac{1}{3}\end{array}$ & 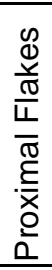 & $\begin{array}{l}\frac{0}{0} \\
\frac{\pi}{0} \\
\overline{0} \\
\stackrel{N}{N} \\
\frac{N}{\omega}\end{array}$ & 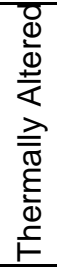 & 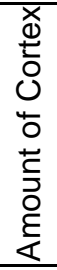 & 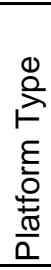 & 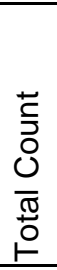 & 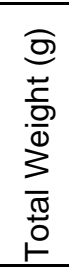 & $\frac{Z}{z}$ \\
\hline 108 & 9 & $120-130$ & 1 & $x$ & & 02 & 01 & 02 & 02 & 1 & 5.8 & 1 \\
\hline 108 & 9 & $120-130$ & 1 & $x$ & & 01 & 01 & 01 & 03 & 1 & 4.3 & 1 \\
\hline 111 & 9 & $130-140$ & 1 & $x$ & & 04 & - & 01 & 04 & 1 & 0.0 & 1 \\
\hline 122 & 10 & $110-120$ & 1 & & $x$ & 02 & 02 & 01 & 04 & 2 & 6.1 & 2 \\
\hline 129 & 10 & $120-130$ & 1 & & $x$ & 03 & - & 00 & 03 & 1 & 1.8 & 1 \\
\hline 129 & 10 & $120-130$ & 1 & & $x$ & 02 & 01 & 00 & 04 & 1 & 5.3 & 1 \\
\hline 126 & 10 & $130-140$ & 1 & & $x$ & 04 & - & 00 & 04 & 2 & 0.7 & 2 \\
\hline 126 & 10 & $130-140$ & 1 & & $x$ & 03 & - & 01 & 02 & 1 & 4.1 & 1 \\
\hline 126 & 10 & $130-140$ & 1 & $x$ & & 03 & - & 01 & 03 & 1 & 1.2 & 1 \\
\hline 126 & 10 & $130-140$ & 1 & & $x$ & 03 & - & 00 & 04 & 1 & 1.3 & 1 \\
\hline 126 & 10 & $130-140$ & 1 & $x$ & & 02 & 02 & 00 & 04 & 1 & 4.9 & 1 \\
\hline 126 & 10 & $130-140$ & 1 & & $x$ & 01 & 02 & 02 & 02 & 1 & 25.6 & 1 \\
\hline 128 & 10 & $140-150$ & 1 & $x$ & & 03 & - & 00 & 05 & 1 & 0.7 & 1 \\
\hline 128 & 10 & $140-150$ & 1 & & $x$ & 03 & - & 00 & 03 & 1 & 1.5 & 1 \\
\hline 128 & 10 & $140-150$ & 1 & $x$ & & 03 & - & 01 & 01 & 2 & 3.4 & 2 \\
\hline 128 & 10 & $140-150$ & 1 & $x$ & & 03 & - & 01 & 05 & 1 & 0.5 & 1 \\
\hline 128 & 10 & $140-150$ & 1 & $x$ & & 03 & - & 01 & 02 & 1 & 1.5 & 1 \\
\hline 128 & 10 & $140-150$ & 1 & $x$ & & 01 & 02 & 00 & 02 & 1 & 6.0 & 1 \\
\hline 128 & 10 & $140-150$ & 1 & $x$ & & 01 & 02 & 02 & 01 & 1 & 15.0 & 1 \\
\hline 134 & 10 & $150-160$ & 1 & & $x$ & 04 & - & 01 & 01 & 1 & 0.4 & 1 \\
\hline 134 & 10 & $150-160$ & 1 & & $x$ & 04 & - & 00 & 05 & 1 & 0.0 & 1 \\
\hline 134 & 10 & $150-160$ & 1 & $\mathrm{x}$ & & 03 & - & 01 & 02 & 1 & 4.6 & 1 \\
\hline 134 & 10 & $150-160$ & 1 & & $x$ & 03 & - & 00 & 03 & 1 & 1.4 & 1 \\
\hline 134 & 10 & $150-160$ & 1 & & $x$ & 02 & 01 & 00 & 05 & 1 & 0.8 & 1 \\
\hline 134 & 10 & $150-160$ & 1 & & $x$ & 01 & 01 & 01 & 02 & 1 & 14.4 & 1 \\
\hline 134 & 10 & $150-160$ & 1 & & $x$ & 01 & 01 & 00 & 02 & 1 & 10.2 & 1 \\
\hline- & 10 & $160-170$ & 1 & & $x$ & 04 & - & 00 & 03 & 1 & 0.4 & 1 \\
\hline- & 10 & $160-170$ & 1 & & $x$ & 04 & - & 02 & 03 & 1 & 0.7 & 1 \\
\hline- & 10 & $160-170$ & 1 & $x$ & & 03 & - & 01 & 01 & 1 & 2.3 & 1 \\
\hline- & 10 & $160-170$ & 1 & $x$ & & 03 & - & 01 & 02 & 1 & 2.6 & 1 \\
\hline- & 10 & $160-170$ & 1 & $x$ & & 02 & 01 & 00 & 02 & 1 & 4.6 & 1 \\
\hline- & 10 & $160-170$ & 1 & $x$ & & 02 & 01 & 01 & 02 & 1 & 11.3 & 1 \\
\hline- & 10 & $160-170$ & 1 & $x$ & & 02 & 02 & 01 & 05 & 1 & 4.6 & 1 \\
\hline- & 10 & $160-170$ & 1 & $x$ & & 02 & 02 & 01 & 04 & 1 & 8.6 & 1 \\
\hline- & 10 & $160-170$ & 1 & $x$ & & 02 & 02 & 01 & 01 & 1 & 5.5 & 1 \\
\hline- & 10 & $160-170$ & 1 & & $x$ & 02 & 02 & 01 & 02 & 1 & 11.6 & 1 \\
\hline- & 10 & $160-170$ & 1 & $\mathrm{x}$ & & 01 & 02 & 01 & 02 & 2 & 42.7 & 2 \\
\hline- & 10 & $160-170$ & 1 & $x$ & & 01 & 02 & 02 & 01 & 1 & 49.9 & 1 \\
\hline- & 10 & $160-170$ & 1 & & $x$ & 01 & 01 & 00 & 00 & 1 & 18.7 & 1 \\
\hline- & 10 & $160-170$ & 1 & & $x$ & 01 & 02 & 02 & 02 & 1 & 12.5 & 1 \\
\hline 216 & 10 & $170-180$ & 1 & $x$ & & 04 & - & 00 & 02 & 2 & 0.4 & 2 \\
\hline 216 & 10 & $170-180$ & 1 & $x$ & & 04 & - & 01 & 01 & 1 & 0.8 & \\
\hline 216 & 10 & $170-180$ & 1 & & $x$ & 04 & - & 00 & 03 & 2 & 0.7 & 2 \\
\hline 216 & 10 & $170-180$ & 1 & & $x$ & 04 & - & 00 & 05 & 1 & 1.1 & 1 \\
\hline 216 & 10 & $170-180$ & 1 & $x$ & & 03 & - & 00 & 05 & 1 & 0.5 & 1 \\
\hline
\end{tabular}


Table B-8 (continued). Catalog of Whole and Proximal Flakes 100-200 cmbs.

\begin{tabular}{|c|c|c|c|c|c|c|c|c|c|c|c|c|}
\hline $\begin{array}{l}\# \\
\text { \# } \\
\end{array}$ & 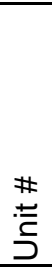 & 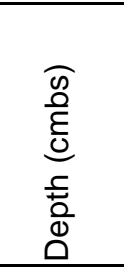 & 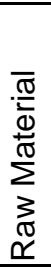 & 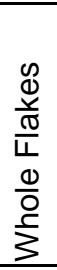 & 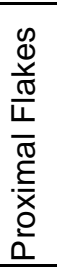 & $\begin{array}{l}\frac{0}{0} \\
\frac{\pi}{0} \\
0 \\
0 \\
\mathbb{N} \\
0\end{array}$ & 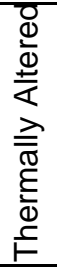 & 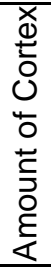 & 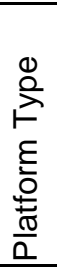 & 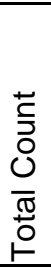 & 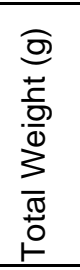 & 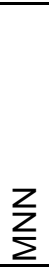 \\
\hline 216 & 10 & $170-180$ & 1 & $x$ & & 03 & - & 00 & 04 & 2 & 3.3 & 2 \\
\hline 216 & 10 & $170-180$ & 1 & $x$ & & 03 & - & 00 & 03 & 4 & 6.6 & 4 \\
\hline 216 & 10 & $170-180$ & 1 & $x$ & & 03 & - & 00 & 02 & 2 & 2.5 & 2 \\
\hline 216 & 10 & $170-180$ & 1 & $x$ & & 03 & - & 01 & 01 & 1 & 1.5 & 1 \\
\hline 216 & 10 & $170-180$ & 1 & $x$ & & 03 & - & 02 & 04 & 1 & 1.3 & 1 \\
\hline 216 & 10 & $170-180$ & 1 & $x$ & & 03 & - & 02 & 01 & 1 & 2.1 & 1 \\
\hline 216 & 10 & $170-180$ & 1 & & $x$ & 03 & - & 00 & 05 & 1 & 0.5 & 1 \\
\hline 216 & 10 & $170-180$ & 1 & & $x$ & 03 & - & 00 & 04 & 1 & 0.6 & 1 \\
\hline 216 & 10 & $170-180$ & 1 & & $x$ & 03 & - & 00 & 03 & 3 & 7.4 & 3 \\
\hline 216 & 10 & $170-180$ & 1 & & $x$ & 03 & - & 00 & 00 & 1 & 3.8 & 1 \\
\hline 216 & 10 & $170-180$ & 1 & & $x$ & 03 & - & 01 & 03 & 1 & 3.1 & 1 \\
\hline 216 & 10 & $170-180$ & 1 & & $x$ & 03 & - & 01 & 02 & 1 & 0.8 & 1 \\
\hline 216 & 10 & $170-180$ & 1 & $x$ & & 02 & 01 & 00 & 06 & 1 & 5.6 & 1 \\
\hline 216 & 10 & $170-180$ & 1 & $x$ & & 02 & 02 & 00 & 02 & 1 & 11.9 & 1 \\
\hline 216 & 10 & $170-180$ & 1 & & $x$ & 02 & 02 & 00 & 02 & 1 & 6.0 & 1 \\
\hline 216 & 10 & $170-180$ & 1 & $x$ & & 02 & 02 & 01 & 04 & 1 & 9.6 & 1 \\
\hline 216 & 10 & $170-180$ & 1 & $x$ & & 02 & 02 & 01 & 02 & 2 & 18.0 & 2 \\
\hline 216 & 10 & $170-180$ & 1 & & $x$ & 02 & 02 & 01 & 04 & 1 & 6.4 & 1 \\
\hline 216 & 10 & $170-180$ & 1 & $x$ & & 02 & 01 & 01 & 04 & 1 & 2.9 & 1 \\
\hline 216 & 10 & $170-180$ & 1 & $x$ & & 02 & 01 & 01 & 02 & 1 & 3.9 & 1 \\
\hline 216 & 10 & $170-180$ & 1 & $x$ & & 02 & 01 & 01 & 01 & 02 & 15.0 & 2 \\
\hline 216 & 10 & $170-180$ & 1 & $x$ & & 02 & 01 & 00 & 02 & 1 & 9.0 & 1 \\
\hline 216 & 10 & $170-180$ & 1 & $x$ & & 01 & 02 & 02 & 02 & 1 & 19.0 & 1 \\
\hline 216 & 10 & $170-180$ & 1 & & $x$ & 01 & 02 & 02 & 02 & 1 & 23.0 & 1 \\
\hline 216 & 10 & $170-180$ & 3 & $x$ & & 01 & 02 & 01 & 02 & 1 & 22.1 & 1 \\
\hline 216 & 10 & $170-180$ & 1 & $x$ & & 01 & 02 & 01 & 01 & 2 & 30.7 & 2 \\
\hline 216 & 10 & $170-180$ & 1 & $x$ & & 01 & 02 & 01 & 02 & 1 & 41.5 & 1 \\
\hline 216 & 10 & $170-180$ & 1 & $x$ & & 01 & 01 & 01 & 01 & 1 & 11.6 & 1 \\
\hline 216 & 10 & $170-180$ & 1 & & $x$ & 01 & 01 & 02 & 00 & 1 & 22.0 & 1 \\
\hline 219 & 10 & $180-190$ & 1 & & $x$ & 02 & - & 01 & 01 & 1 & 1.3 & 1 \\
\hline 219 & 10 & $180-190$ & 1 & & $x$ & 02 & - & 00 & 04 & 1 & 1.3 & 1 \\
\hline 219 & 10 & $180-190$ & 1 & $x$ & & 02 & 01 & 02 & 01 & 1 & 5.5 & 1 \\
\hline 219 & 10 & $180-190$ & 1 & & $x$ & 01 & 02 & 01 & 01 & 1 & 15.4 & 1 \\
\hline 228 & 10 & $190-200$ & 1 & & $x$ & 03 & - & 00 & 04 & 1 & 1.0 & 1 \\
\hline 228 & 10 & $190-200$ & 1 & & $x$ & 02 & 02 & 02 & 02 & 1 & 7.1 & 1 \\
\hline 228 & 10 & $190-200$ & 1 & $x$ & & 01 & 08 & 02 & 02 & 1 & 45.3 & 1 \\
\hline 130 & 11 & $110-120$ & 1 & $x$ & & 03 & - & 01 & 02 & 1 & 1.8 & 1 \\
\hline 132 & 11 & $120-130$ & 1 & & $x$ & 03 & - & 01 & 01 & 1 & 2.4 & 1 \\
\hline 132 & 11 & $120-130$ & 1 & $x$ & & 02 & 01 & 00 & 02 & 1 & 3.4 & 1 \\
\hline 135 & 11 & $130-140$ & 1 & $x$ & & 04 & - & 00 & 02 & 1 & 0.2 & 1 \\
\hline 135 & 11 & $130-140$ & 1 & & $x$ & 03 & - & 02 & 01 & 1 & 0.8 & 1 \\
\hline- & 11 & $140-150$ & 1 & & $x$ & 04 & - & 01 & 02 & 1 & 0.4 & 1 \\
\hline 155 & 11 & $150-160$ & 1 & & $x$ & 03 & - & 00 & 02 & 1 & 2.8 & 1 \\
\hline 155 & 11 & $150-160$ & 1 & & $x$ & 02 & 01 & 01 & 02 & 1 & 4.5 & 1 \\
\hline 155 & 11 & $150-160$ & 1 & $x$ & & 01 & 01 & 00 & 03 & 1 & 9.1 & 1 \\
\hline
\end{tabular}


Table B-8 (continued). Catalog of Whole and Proximal Flakes 100-200 cmbs.

\begin{tabular}{|c|c|c|c|c|c|c|c|c|c|c|c|c|}
\hline \begin{tabular}{l}
$\#$ \\
\multirow{2}{*}{}
\end{tabular} & $\begin{array}{l}\# \\
\text { \# } \\
\text { 言 } \\
\end{array}$ & 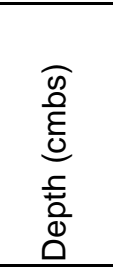 & 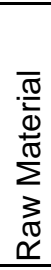 & $\begin{array}{l}0 \\
\Phi \\
\frac{1}{0} \\
\frac{\pi}{1} \\
\frac{0}{0} \\
\frac{0}{3} \\
\frac{1}{3}\end{array}$ & 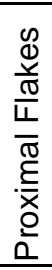 & $\begin{array}{l}\frac{0}{0} \\
\frac{\pi}{0} \\
\mathbb{U} \\
0 \\
\frac{N}{\omega}\end{array}$ & 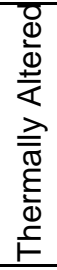 & 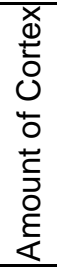 & 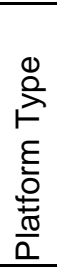 & 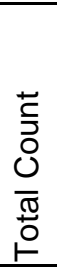 & 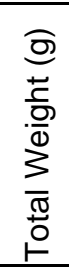 & $\frac{Z}{z}$ \\
\hline 131 & 12 & $100-110$ & 1 & $x$ & & 04 & - & 00 & 03 & 1 & 0.6 & 1 \\
\hline 131 & 12 & $100-110$ & 1 & $x$ & & 04 & - & 01 & 01 & 1 & 0.3 & 1 \\
\hline 131 & 12 & $100-110$ & 1 & $x$ & & 03 & - & 01 & 03 & 1 & 2.2 & 1 \\
\hline 131 & 12 & $100-110$ & 1 & $x$ & & 03 & - & 01 & 01 & 1 & 2.9 & 1 \\
\hline 133 & 12 & $110-120$ & 1 & $x$ & & 01 & 02 & 01 & 03 & 1 & 10.2 & 1 \\
\hline 136 & 12 & $120-130$ & 1 & $x$ & & 03 & - & 01 & 01 & 1 & 2.3 & 1 \\
\hline 138 & 12 & $130-140$ & 1 & $x$ & & 04 & - & 00 & 04 & 1 & 0.4 & 1 \\
\hline 138 & 12 & $130-140$ & 1 & $x$ & & 04 & - & 00 & 02 & 1 & 1.2 & 1 \\
\hline 138 & 12 & $130-140$ & 1 & & $x$ & 04 & - & 01 & 04 & 2 & 1.4 & 2 \\
\hline 138 & 12 & $130-140$ & 1 & & $x$ & 02 & 02 & 00 & 03 & 1 & 3.6 & 1 \\
\hline 138 & 12 & $130-140$ & 1 & $x$ & & 02 & 02 & 01 & 04 & 1 & 4.2 & 1 \\
\hline 138 & 12 & $130-140$ & 1 & $x$ & & 01 & 02 & 01 & 02 & 1 & 12.1 & 1 \\
\hline 138 & 12 & $130-140$ & 1 & $x$ & & 01 & 02 & 01 & 01 & 1 & 49.3 & 1 \\
\hline 139 & 12 & $140-150$ & 1 & $x$ & & 04 & - & 00 & 04 & 3 & 0.7 & 3 \\
\hline 139 & 12 & $140-150$ & 1 & & $x$ & 04 & - & 00 & 05 & 1 & 0.2 & 1 \\
\hline 139 & 12 & $140-150$ & 1 & & $x$ & 04 & - & 01 & 01 & 1 & 0.6 & 1 \\
\hline 139 & 12 & $140-150$ & 1 & $x$ & & 03 & - & 00 & 05 & 1 & 0.9 & 1 \\
\hline 139 & 12 & $140-150$ & 1 & $x$ & & 03 & - & 00 & 03 & 1 & 1.8 & 1 \\
\hline 139 & 12 & $140-150$ & 1 & & $x$ & 03 & - & 00 & 03 & 1 & 1.0 & 1 \\
\hline 139 & 12 & $140-150$ & 1 & & $x$ & 03 & - & 02 & 03 & 1 & 0.7 & 1 \\
\hline 139 & 12 & $140-150$ & 1 & & $x$ & 03 & - & 01 & 02 & 1 & 1.0 & 1 \\
\hline 139 & 12 & $140-150$ & 1 & $\mathrm{x}$ & & 02 & 02 & 01 & 02 & 1 & 3.7 & 1 \\
\hline 139 & 12 & $140-150$ & 1 & & $x$ & 02 & 02 & 00 & 04 & 1 & 1.8 & 1 \\
\hline 139 & 12 & $140-150$ & 1 & & $x$ & 02 & 02 & 01 & 04 & 1 & 2.6 & 1 \\
\hline 139 & 12 & $140-150$ & 1 & $x$ & & 02 & 01 & 00 & 03 & 1 & 4.1 & 1 \\
\hline 139 & 12 & $140-150$ & 1 & $x$ & & 02 & 01 & 00 & 02 & 1 & 2.4 & 1 \\
\hline 139 & 12 & $140-150$ & 1 & & $x$ & 01 & 02 & 02 & 02 & 1 & 15.9 & 1 \\
\hline 139 & 12 & $140-150$ & 1 & & & 01 & 02 & 02 & 03 & 1 & 21.1 & 1 \\
\hline 146 & 13 & $110-120$ & 1 & $x$ & & 04 & - & 00 & 05 & 1 & 0.0 & 1 \\
\hline 146 & 13 & $110-120$ & 1 & $x$ & & 04 & - & 00 & 04 & 1 & 0.1 & 1 \\
\hline 146 & 13 & $110-120$ & 1 & $x$ & & 04 & - & 00 & 00 & 1 & 0.0 & 1 \\
\hline 146 & 13 & $110-120$ & 1 & & $x$ & 04 & - & 00 & 02 & 1 & 0.0 & 1 \\
\hline 146 & 13 & $110-120$ & 1 & & $x$ & 04 & - & 00 & 05 & 2 & 0.2 & 2 \\
\hline 146 & 13 & $110-120$ & 1 & & $x$ & 03 & - & 00 & 02 & 2 & 2.7 & 2 \\
\hline 146 & 13 & $110-120$ & 1 & & $x$ & 03 & - & 00 & 05 & 1 & 1.5 & 1 \\
\hline 146 & 13 & $110-120$ & 1 & & $x$ & 02 & 02 & 00 & 02 & 1 & 5.7 & 1 \\
\hline 146 & 13 & $110-120$ & 1 & & $x$ & 02 & 02 & 01 & 02 & 1 & 5.5 & 1 \\
\hline 146 & 13 & $110-120$ & 1 & $x$ & & 01 & 01 & 01 & 00 & 1 & 6.0 & 1 \\
\hline 150 & 13 & $120-130$ & 1 & $x$ & & 04 & - & 01 & 01 & 1 & 1.1 & 1 \\
\hline 150 & 13 & $120-130$ & 1 & & $x$ & 04 & - & 00 & 04 & 1 & 0.8 & 1 \\
\hline 150 & 13 & $120-130$ & 1 & & $x$ & 04 & - & 00 & 05 & 1 & 0.7 & 1 \\
\hline 150 & 13 & $120-130$ & 1 & & $x$ & 04 & - & 00 & 02 & 1 & 0.2 & 1 \\
\hline 150 & 13 & $120-130$ & 1 & & $x$ & 03 & - & 01 & 04 & 1 & 2.5 & 1 \\
\hline 150 & 13 & $120-130$ & 1 & & $x$ & 03 & - & 01 & 04 & 2 & 3.2 & 2 \\
\hline 150 & 13 & $120-130$ & 1 & $x$ & & 02 & 02 & 01 & 05 & 1 & 2.1 & 1 \\
\hline
\end{tabular}


Table B-8 (continued). Catalog of Whole and Proximal Flakes 100-200 cmbs.

\begin{tabular}{|c|c|c|c|c|c|c|c|c|c|c|c|c|}
\hline $\begin{array}{l}\# \\
\text { \# } \\
\end{array}$ & 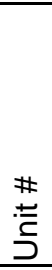 & 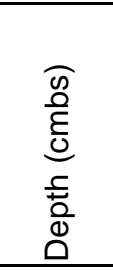 & 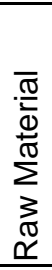 & 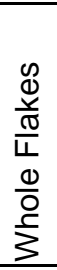 & 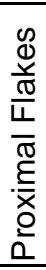 & $\begin{array}{l}0 \\
\frac{0}{0} \\
\frac{\pi}{0} \\
\stackrel{N}{0} \\
\stackrel{N}{\omega}\end{array}$ & 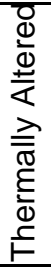 & 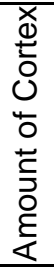 & 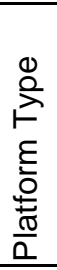 & 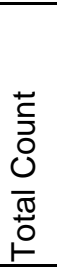 & 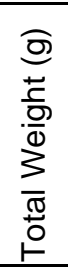 & $\sum_{\Sigma}^{Z}$ \\
\hline 150 & 13 & $120-130$ & 1 & $x$ & & 01 & 02 & 00 & 05 & 1 & 11.0 & 1 \\
\hline 150 & 13 & $120-130$ & 1 & $x$ & & 01 & 02 & 01 & 03 & 1 & 8.6 & 1 \\
\hline 158 & 13 & $130-140$ & 1 & $x$ & & 04 & - & 00 & 02 & 1 & 0.1 & 1 \\
\hline 158 & 13 & $130-140$ & 1 & & $x$ & 04 & - & 00 & 04 & 1 & 0.0 & 1 \\
\hline 158 & 13 & $130-140$ & 1 & & $x$ & 03 & - & 00 & 05 & 1 & 0.7 & 1 \\
\hline 158 & 13 & $130-140$ & 1 & $x$ & & 03 & - & 01 & 00 & 1 & 3.8 & 1 \\
\hline 158 & 13 & $130-140$ & 1 & $x$ & & 02 & 02 & 01 & 01 & 1 & 5.3 & 1 \\
\hline 158 & 13 & $130-140$ & 1 & & $x$ & 02 & 02 & 01 & 02 & 1 & 7.2 & 1 \\
\hline 158 & 13 & $130-140$ & 1 & $x$ & & 02 & 02 & 02 & 00 & 1 & 9.9 & 1 \\
\hline 158 & 13 & $130-140$ & 1 & $x$ & & 01 & 02 & 00 & 03 & 1 & 17.4 & 1 \\
\hline 158 & 13 & $130-140$ & 1 & $x$ & & 01 & 02 & 01 & 01 & 1 & 8.9 & 1 \\
\hline 163 & 13 & $140-150$ & 1 & $x$ & & 03 & - & 00 & 02 & 1 & 1.8 & 1 \\
\hline 163 & 13 & $140-150$ & 1 & & $x$ & 03 & - & 00 & 02 & 1 & 4.9 & 1 \\
\hline 163 & 13 & $140-150$ & 1 & $x$ & & 02 & 01 & 01 & 02 & 1 & 10.9 & 1 \\
\hline 170 & 13 & $150-160$ & 1 & $x$ & & 03 & - & 00 & 02 & 1 & 0.4 & 1 \\
\hline 170 & 13 & $150-160$ & 1 & $x$ & & 03 & - & 00 & 04 & 1 & 0.9 & 1 \\
\hline 170 & 13 & $150-160$ & 1 & & $x$ & 03 & - & 01 & 03 & 1 & 1.2 & 1 \\
\hline 170 & 13 & $150-160$ & 1 & & $x$ & 02 & 02 & 02 & 03 & 1 & 5.5 & 1 \\
\hline 170 & 13 & $150-160$ & 1 & $x$ & & 02 & 01 & 00 & 03 & 1 & 10.2 & 1 \\
\hline 170 & 13 & $150-160$ & 1 & & $x$ & 01 & 01 & 00 & 02 & 1 & 13.9 & 1 \\
\hline 170 & 13 & $150-160$ & 1 & $x$ & & 01 & 02 & 01 & 01 & 1 & 17.1 & 1 \\
\hline 184 & 13 & $160-170$ & 1 & $x$ & & 04 & - & 00 & 04 & 1 & 0.0 & 1 \\
\hline 184 & 13 & $160-170$ & 1 & & $x$ & 04 & - & 00 & 02 & 2 & 1.4 & 2 \\
\hline 184 & 13 & $160-170$ & 1 & & $x$ & 04 & - & 00 & 03 & 1 & 0.4 & 1 \\
\hline 184 & 13 & $160-170$ & 1 & & $x$ & 04 & - & 00 & 04 & 1 & 0.5 & 1 \\
\hline 184 & 13 & $160-170$ & 1 & & $x$ & 04 & - & 00 & 05 & 1 & 0.7 & 1 \\
\hline 184 & 13 & $160-170$ & 1 & & $x$ & 04 & - & 01 & 02 & 1 & 1.1 & 1 \\
\hline 184 & 13 & $160-170$ & 1 & $x$ & & 03 & - & 00 & 02 & 1 & 1.3 & 1 \\
\hline 184 & 13 & $160-170$ & 1 & $x$ & & 03 & - & 00 & 04 & 1 & 1.5 & 1 \\
\hline 184 & 13 & $160-170$ & 1 & $x$ & & 03 & - & 00 & 06 & 1 & 0.7 & 1 \\
\hline 184 & 13 & $160-170$ & 1 & & $x$ & 03 & - & 00 & 02 & 1 & 1.5 & 1 \\
\hline 184 & 13 & $160-170$ & 1 & $x$ & & 03 & - & 01 & 02 & 1 & 1.3 & 1 \\
\hline 184 & 13 & $160-170$ & 1 & & $x$ & 03 & - & 02 & 02 & 1 & 3.2 & 1 \\
\hline 184 & 13 & $160-170$ & 1 & & $x$ & 03 & - & 02 & 03 & 1 & 1.8 & 1 \\
\hline 184 & 13 & $160-170$ & 1 & $x$ & & 02 & 02 & 00 & 02 & 1 & 5.2 & 1 \\
\hline 184 & 13 & $160-170$ & 1 & $x$ & & 02 & 02 & 00 & 04 & 1 & 2.7 & 1 \\
\hline 184 & 13 & $160-170$ & 1 & & $x$ & 02 & 02 & 00 & 04 & 1 & 3.1 & 1 \\
\hline 184 & 13 & $160-170$ & 1 & & $x$ & 02 & 02 & 00 & 02 & 1 & 4.1 & 1 \\
\hline 184 & 13 & $160-170$ & 1 & $x$ & & 02 & 02 & 01 & 02 & 1 & 3.4 & 1 \\
\hline 184 & 13 & $160-170$ & 1 & & $x$ & 02 & 02 & 01 & 02 & 1 & 5.2 & 1 \\
\hline 184 & 13 & $160-170$ & 1 & & $x$ & 02 & 02 & 01 & 04 & 1 & 3.5 & 1 \\
\hline 184 & 13 & $160-170$ & 1 & $x$ & & 01 & 02 & 00 & 06 & 1 & 5.6 & 1 \\
\hline 184 & 13 & $160-170$ & 1 & $x$ & & 01 & 02 & 01 & 01 & 1 & 9.7 & 1 \\
\hline 184 & 13 & $160-170$ & 1 & $x$ & & 01 & 02 & 02 & 01 & 1 & 7.2 & 1 \\
\hline 184 & 13 & $160-170$ & 1 & & $x$ & 01 & 02 & 01 & 01 & 1 & 9.1 & 1 \\
\hline
\end{tabular}


Table B-8 (continued). Catalog of Whole and Proximal Flakes 100-200 cmbs.

\begin{tabular}{|c|c|c|c|c|c|c|c|c|c|c|c|c|}
\hline \# & 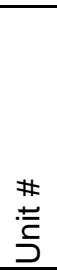 & 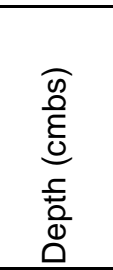 & 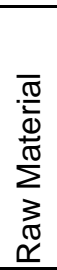 & 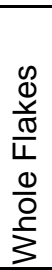 & 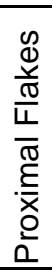 & $\begin{array}{l}\frac{0}{0} \\
\frac{\pi}{\pi} \\
\mathbb{N} \\
\frac{N}{\omega}\end{array}$ & 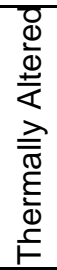 & 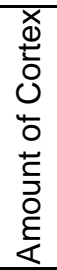 & 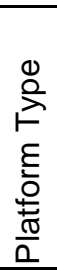 & 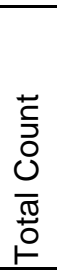 & 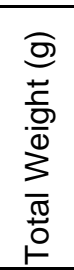 & $\frac{Z}{Z}$ \\
\hline 218 & 13 & $170-180$ & 1 & $x$ & & 04 & - & 00 & 02 & 3 & 0.4 & 3 \\
\hline 218 & 13 & $170-180$ & 1 & $x$ & & 04 & - & 00 & 03 & 1 & 0.0 & 1 \\
\hline 218 & 13 & $170-180$ & 1 & $x$ & & 04 & - & 00 & 03 & 1 & 0.3 & 1 \\
\hline 218 & 13 & $170-180$ & 1 & & $x$ & 04 & - & 00 & 02 & 1 & 0.0 & 1 \\
\hline 218 & 13 & $170-180$ & 1 & & $x$ & 04 & - & 00 & 04 & 1 & 0.3 & 1 \\
\hline 218 & 13 & $170-180$ & 1 & $x$ & & 04 & - & 02 & 02 & 1 & 0.4 & 1 \\
\hline 218 & 13 & $170-180$ & 1 & $x$ & & 04 & - & 01 & 02 & 1 & 0.3 & 1 \\
\hline 218 & 13 & $170-180$ & 1 & & $x$ & 04 & - & 01 & 04 & 1 & 0.4 & 1 \\
\hline 218 & 13 & $170-180$ & 1 & $x$ & & 03 & - & 00 & 04 & 2 & 2.7 & 2 \\
\hline 218 & 13 & $170-180$ & 1 & $x$ & & 03 & - & 00 & 02 & 1 & 1.8 & 1 \\
\hline 218 & 13 & $170-180$ & 1 & & $x$ & 03 & - & 00 & 02 & 2 & 3.6 & 2 \\
\hline 218 & 13 & $170-180$ & 1 & & $x$ & 03 & - & 00 & 04 & 1 & 0.8 & 1 \\
\hline 218 & 13 & $170-180$ & 1 & & $x$ & 03 & - & 01 & 02 & 1 & 1.8 & 1 \\
\hline 218 & 13 & $170-180$ & 1 & & $x$ & 03 & - & 02 & 01 & 1 & 1.5 & 1 \\
\hline 218 & 13 & $170-180$ & 1 & $x$ & & 03 & - & 01 & 01 & 1 & 1.3 & 1 \\
\hline 218 & 13 & $170-180$ & 1 & $x$ & & 02 & 02 & 00 & 05 & 1 & 2.6 & 1 \\
\hline 218 & 13 & $170-180$ & 1 & $x$ & & 02 & 02 & 01 & 02 & 2 & 11.3 & 2 \\
\hline 218 & 13 & $170-180$ & 1 & & $x$ & 02 & 02 & 01 & 04 & 2 & 10.2 & 2 \\
\hline 218 & 13 & $170-180$ & 1 & & $x$ & 02 & 02 & 02 & 01 & 1 & 8.0 & 1 \\
\hline 218 & 13 & $170-180$ & 1 & & $x$ & 01 & 02 & 01 & 02 & 1 & 22.7 & 1 \\
\hline 218 & 13 & $170-180$ & 1 & & $x$ & 01 & 02 & 01 & 01 & 1 & 23.9 & 1 \\
\hline 277 & 13 & $180-190$ & 1 & $x$ & & 03 & - & 00 & 02 & 1 & 1.2 & 1 \\
\hline 277 & 13 & $180-190$ & 1 & & $x$ & 03 & - & 01 & 04 & 1 & 1.5 & 1 \\
\hline 277 & 13 & $180-190$ & 1 & $x$ & & 02 & 02 & 00 & 02 & 1 & 5.3 & 1 \\
\hline 156 & 14 & $110-120$ & 1 & & $x$ & 04 & - & 00 & 02 & 1 & 0.3 & 1 \\
\hline 156 & 14 & $110-120$ & 1 & & $x$ & 04 & - & 00 & 03 & 1 & 0.5 & 1 \\
\hline 156 & 14 & $110-120$ & 1 & & $x$ & 04 & - & 00 & 04 & 1 & 0.0 & 1 \\
\hline 156 & 14 & $110-120$ & 1 & & $x$ & 04 & - & 00 & 05 & 1 & 0.1 & 1 \\
\hline 156 & 14 & $110-120$ & 1 & $x$ & & 04 & - & 01 & 01 & 1 & 0.1 & 1 \\
\hline 156 & 14 & $110-120$ & 1 & & $x$ & 03 & - & 00 & 04 & 1 & 1.3 & 1 \\
\hline 156 & 14 & $110-120$ & 1 & $x$ & & 03 & - & 01 & 01 & 1 & 3.5 & 1 \\
\hline 178 & 14 & $120-130$ & 1 & & $x$ & 04 & - & 00 & 04 & 1 & 0.0 & 1 \\
\hline 179 & 14 & $130-140$ & 1 & & $x$ & 03 & 02 & 00 & 02 & 1 & 2.9 & 1 \\
\hline 179 & 14 & $130-140$ & 1 & $x$ & & 01 & 02 & 00 & 02 & 1 & 11.9 & 1 \\
\hline 192 & 14 & $140-150$ & 1 & $x$ & & 03 & - & 01 & 02 & 1 & 2.9 & 1 \\
\hline 192 & 14 & $140-150$ & 1 & $x$ & & 03 & - & 00 & 02 & 1 & 2.9 & 1 \\
\hline 192 & 14 & $150-150$ & 1 & $x$ & & 02 & 02 & 00 & 04 & 1 & 5.0 & 1 \\
\hline 192 & 14 & $150-150$ & 1 & & $x$ & 02 & 01 & 00 & 02 & 1 & 5.8 & 1 \\
\hline 192 & 14 & $140-150$ & 1 & & $x$ & 02 & 02 & 02 & 02 & 1 & 5.0 & 1 \\
\hline 193 & 14 & $150-160$ & 1 & $x$ & & 01 & 02 & 01 & 02 & 1 & 21.4 & 1 \\
\hline 203 & 14 & $160-170$ & 1 & $x$ & & 03 & 02 & 00 & 02 & 1 & 1.3 & 1 \\
\hline 203 & 14 & $160-170$ & 1 & & $x$ & 03 & 02 & 01 & 02 & 1 & 1.4 & 1 \\
\hline 203 & 14 & $160-170$ & 1 & $x$ & & 01 & 02 & 00 & 02 & 1 & 9.0 & 1 \\
\hline 205 & 14 & $160-170$ & 1 & $x$ & & 03 & - & 00 & 02 & 1 & 3.7 & 1 \\
\hline 205 & 14 & $160-170$ & 1 & & $x$ & 02 & 01 & 01 & 00 & 1 & 11.4 & 1 \\
\hline
\end{tabular}


Table B-8 (continued). Catalog of Whole and Proximal Flakes 100-200 cmbs.

\begin{tabular}{|c|c|c|c|c|c|c|c|c|c|c|c|c|}
\hline $\begin{array}{l}\# \\
\text { \# } \\
\end{array}$ & 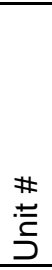 & 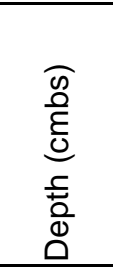 & 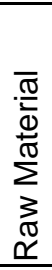 & 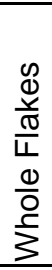 & 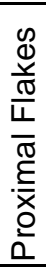 & $\begin{array}{l}0 \\
\frac{0}{0} \\
\frac{\pi}{0} \\
\stackrel{N}{0} \\
\stackrel{N}{\omega}\end{array}$ & 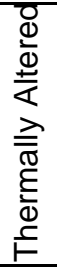 & 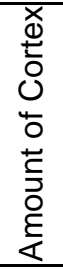 & 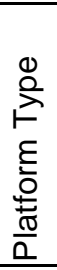 & 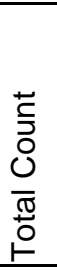 & 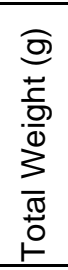 & $\sum_{\Sigma}^{Z}$ \\
\hline 205 & 14 & $160-170$ & 2 & $x$ & & 01 & 02 & 01 & 01 & 1 & 20.6 & 1 \\
\hline 148 & 15 & $120-130$ & 1 & $x$ & & 02 & 02 & 02 & 03 & 1 & 10.2 & 1 \\
\hline 150 & 15 & $130-140$ & 4 & & $x$ & 04 & - & 00 & 04 & 1 & 0.1 & 1 \\
\hline 150 & 15 & $130-140$ & 1 & $x$ & & 04 & - & 00 & 05 & 1 & 0.0 & 1 \\
\hline 151 & 15 & $140-150$ & 1 & & $x$ & 02 & 01 & 00 & 00 & 1 & 7.0 & 1 \\
\hline 154 & 15 & $150-160$ & 1 & & $x$ & 04 & - & 00 & 02 & 1 & 0.4 & 1 \\
\hline 154 & 15 & $150-160$ & 1 & $x$ & & 04 & - & 00 & 06 & 1 & 0.3 & 1 \\
\hline 154 & 15 & $150-160$ & 3 & $x$ & & 01 & 02 & 01 & 04 & 1 & 15.0 & 1 \\
\hline 188 & 15 & $170-180$ & 1 & & $x$ & 04 & - & 01 & 01 & 1 & 0.1 & 1 \\
\hline 188 & 15 & $170-180$ & 1 & & $x$ & 04 & - & 00 & 02 & 1 & 0.8 & 1 \\
\hline 188 & 15 & $170-180$ & 1 & & $x$ & 04 & - & 00 & 04 & 1 & 0.2 & 1 \\
\hline 188 & 15 & $170-180$ & 1 & $x$ & & 03 & - & 02 & 02 & 1 & 1.3 & 1 \\
\hline 188 & 15 & $170-180$ & 1 & $x$ & & 03 & - & 00 & 03 & 1 & 2.4 & 1 \\
\hline 188 & 15 & $170-180$ & 1 & $x$ & & 03 & - & 02 & 04 & 1 & 1.6 & 1 \\
\hline 141 & 16 & $110-120$ & 1 & & $x$ & 04 & - & 01 & 03 & 1 & 0.5 & 1 \\
\hline 141 & 16 & $110-120$ & 1 & $x$ & & 01 & 02 & 001 & 02 & 1 & 10.8 & 1 \\
\hline 142 & 16 & $120-130$ & 1 & $x$ & & 01 & 01 & 02 & 01 & 1 & 11.5 & 1 \\
\hline 142 & 16 & $120-130$ & 1 & & $x$ & 01 & 02 & 00 & 02 & 1 & 4.0 & 1 \\
\hline 143 & 16 & $130-140$ & 1 & $x$ & & 04 & - & 00 & 04 & 1 & 0.1 & 1 \\
\hline 143 & 16 & $130-140$ & 1 & & $x$ & 03 & - & 00 & 04 & 1 & 0.8 & 1 \\
\hline 143 & 16 & $130-140$ & 1 & & $x$ & 03 & - & 01 & 01 & 1 & 1.8 & 1 \\
\hline 147 & 17 & $110-120$ & 1 & & $x$ & 03 & - & 00 & 04 & 1 & 0.7 & 1 \\
\hline 147 & 17 & $110-120$ & 1 & & $x$ & 03 & - & 00 & 00 & 1 & 0.8 & 1 \\
\hline 147 & 17 & $110-120$ & 1 & & $x$ & 01 & 02 & 02 & 02 & 1 & 11.4 & 1 \\
\hline 147 & 17 & $110-120$ & 1 & & $x$ & 01 & 02 & 01 & 02 & 1 & 10.2 & 1 \\
\hline 153 & 17 & $120-130$ & 1 & $x$ & & 03 & - & 00 & 02 & 1 & 2.2 & 1 \\
\hline 153 & 17 & $120-130$ & 1 & & $x$ & 02 & 01 & 02 & 01 & 1 & 11.8 & 1 \\
\hline 153 & 17 & $120-130$ & 1 & $x$ & & 01 & 02 & 01 & 01 & 1 & 7.2 & 1 \\
\hline 153 & 17 & $120-130$ & 2 & & $x$ & 01 & 02 & 01 & 01 & 1 & 11.6 & 1 \\
\hline 157 & 17 & $130-140$ & 1 & $x$ & & 04 & - & 01 & 06 & 1 & 1.3 & 1 \\
\hline 157 & 17 & $130-140$ & 1 & $x$ & & 04 & - & 01 & 02 & 1 & 1.1 & 1 \\
\hline 157 & 17 & $130-140$ & 1 & & $x$ & 04 & - & 00 & 03 & 1 & 0.0 & 1 \\
\hline 157 & 17 & $130-140$ & 1 & & $x$ & 04 & - & 01 & 04 & 1 & 1.0 & 1 \\
\hline 157 & 17 & $130-140$ & 1 & & $x$ & 04 & - & 01 & 01 & 1 & 0.0 & 1 \\
\hline 157 & 17 & $130-140$ & 1 & & $x$ & 04 & - & 00 & 04 & 2 & 1.5 & 2 \\
\hline 157 & 17 & $130-140$ & 1 & & $x$ & 04 & - & 00 & 05 & 3 & 1.2 & 3 \\
\hline 157 & 17 & $130-140$ & 1 & $x$ & & 03 & - & 00 & 02 & 2 & 3.9 & 2 \\
\hline 157 & 17 & $130-140$ & 1 & $x$ & & 03 & - & 00 & 04 & 1 & 1.1 & 1 \\
\hline 157 & 17 & $130-140$ & 1 & & $x$ & 03 & - & 00 & 04 & 2 & 2.2 & 2 \\
\hline 157 & 17 & $130-140$ & 1 & $x$ & & 03 & - & 01 & 02 & 3 & 5.1 & 3 \\
\hline 157 & 17 & $130-140$ & 1 & & $x$ & 03 & - & 02 & 00 & 1 & 2.4 & 1 \\
\hline 157 & 17 & $130-140$ & 1 & & $x$ & 03 & - & 02 & 04 & 1 & 2.4 & 1 \\
\hline 157 & 17 & $130-140$ & 1 & $x$ & & 02 & 02 & 00 & 00 & 1 & 3.4 & 1 \\
\hline 157 & 17 & $130-140$ & 1 & $x$ & & 02 & 02 & 00 & 03 & 1 & 3.5 & 1 \\
\hline 157 & 17 & $130-140$ & 1 & $x$ & & 02 & 02 & 01 & 02 & 1 & 4.1 & 1 \\
\hline
\end{tabular}


Table B-8 (continued). Catalog of Whole and Proximal Flakes 100-200 cmbs.

\begin{tabular}{|c|c|c|c|c|c|c|c|c|c|c|c|c|}
\hline \# & 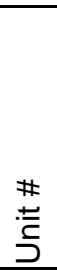 & 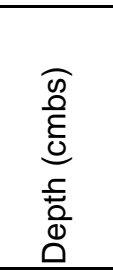 & 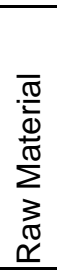 & 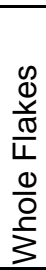 & 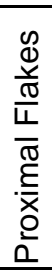 & $\begin{array}{l}\frac{0}{0} \\
\frac{\pi}{\pi} \\
\mathbb{N} \\
\frac{N}{\omega}\end{array}$ & 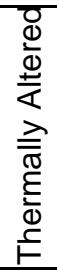 & 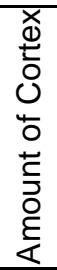 & 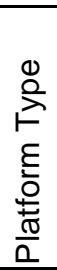 & 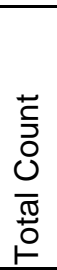 & 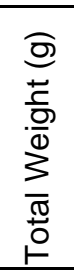 & $\underset{z}{Z}$ \\
\hline 159 & 17 & $130-140$ & 1 & $x$ & $x$ & 04 & - & 00 & 04 & 1 & 0.2 & 1 \\
\hline 159 & 17 & $130-140$ & 1 & & $x$ & 04 & - & 00 & 05 & 1 & 0.4 & 1 \\
\hline 159 & 17 & $130-140$ & 1 & & $x$ & 04 & - & 00 & 02 & 1 & 0.7 & 1 \\
\hline 159 & 17 & $130-140$ & 1 & & $x$ & 04 & - & 01 & 02 & 1 & 0.6 & 1 \\
\hline 159 & 17 & $130-140$ & 1 & & $x$ & 04 & - & 01 & 01 & 1 & 0.5 & 1 \\
\hline 159 & 17 & $130-140$ & 1 & & $x$ & 04 & - & 02 & 04 & 1 & 0.7 & 1 \\
\hline 159 & 17 & $130-140$ & 1 & & $x$ & 03 & - & 00 & 04 & 1 & 0.9 & 1 \\
\hline 159 & 17 & $130-140$ & 1 & & $x$ & 03 & - & 00 & 03 & 1 & 1.0 & 1 \\
\hline 159 & 17 & $130-140$ & 1 & $x$ & & 03 & - & 01 & 02 & 1 & 2.0 & 1 \\
\hline 159 & 17 & $130-140$ & 1 & & $x$ & 03 & - & 02 & 02 & 1 & 1.2 & 1 \\
\hline 159 & 17 & $140-150$ & 1 & & $x$ & 03 & - & 02 & 04 & 1 & 1.8 & 1 \\
\hline 159 & 17 & $140-150$ & 1 & & $x$ & 02 & 02 & 00 & 05 & 1 & 2.4 & 1 \\
\hline 166 & 18 & $100-110$ & 1 & $x$ & & 01 & 01 & 01 & 01 & 1 & 4.1 & 1 \\
\hline 167 & 18 & $110-120$ & 1 & $x$ & & 03 & - & 01 & 03 & 1 & 1.7 & 1 \\
\hline 167 & 18 & $110-120$ & 2 & & $x$ & 03 & - & 02 & 01 & 1 & 1.0 & 1 \\
\hline 167 & 18 & $110-120$ & 1 & & $x$ & 02 & 01 & 00 & 02 & 1 & 3.8 & 1 \\
\hline- & 19 & $110-120$ & 1 & & $x$ & 04 & - & 02 & 03 & 1 & 0.3 & 1 \\
\hline - & 19 & $110-120$ & 1 & & $x$ & 03 & - & 00 & 04 & 1 & 2.1 & 1 \\
\hline- & 19 & $120-130$ & 1 & & $x$ & 03 & - & 01 & 04 & 1 & 1.1 & 1 \\
\hline- & 19 & $120-130$ & 1 & & $x$ & 03 & - & 01 & 02 & 1 & 7.4 & 1 \\
\hline- & 19 & $130-140$ & 1 & $x$ & & 04 & - & 02 & 03 & 1 & 1.2 & 1 \\
\hline- & 19 & $130-140$ & 1 & & $x$ & 04 & - & 00 & 02 & 1 & 0.0 & 1 \\
\hline- & 19 & $130-140$ & 1 & $x$ & & 03 & - & 00 & 03 & 1 & 1.5 & 1 \\
\hline- & 19 & $130-140$ & 1 & $x$ & & 03 & - & 00 & 00 & 1 & 1.0 & 1 \\
\hline- & 19 & $130-140$ & 1 & & $x$ & 03 & - & 01 & 02 & 1 & 1.2 & 1 \\
\hline- & 19 & $130-140$ & 1 & & $x$ & 03 & - & 01 & 01 & 1 & 1.1 & 1 \\
\hline- & 19 & $130-140$ & 1 & $x$ & & 03 & - & 01 & 01 & 1 & 2.4 & 1 \\
\hline- & 19 & $130-140$ & 1 & $x$ & & 02 & 02 & 00 & 02 & 1 & 3.4 & 1 \\
\hline- & 19 & $130-140$ & 1 & $x$ & & 02 & 02 & 01 & 02 & 2 & 9.4 & 2 \\
\hline- & 19 & $130-140$ & 1 & $x$ & & 01 & 01 & 01 & 02 & 1 & 12.0 & 1 \\
\hline- & 19 & $140-150$ & 1 & $x$ & & 04 & - & 00 & 02 & 1 & 0.0 & 1 \\
\hline- & 19 & $140-150$ & 1 & & $x$ & 04 & - & 00 & 04 & 1 & 0.0 & 1 \\
\hline- & 19 & $140-150$ & 1 & & $x$ & 04 & - & 00 & 02 & 1 & 0.0 & 1 \\
\hline- & 19 & $140-150$ & 1 & & $x$ & 04 & - & 01 & 01 & 2 & 1.0 & 2 \\
\hline- & 19 & $140-150$ & 1 & $x$ & & 03 & - & 00 & 04 & 2 & 2.4 & 2 \\
\hline- & 19 & $140-150$ & 1 & & $x$ & 03 & - & 00 & 02 & 1 & 1.7 & 1 \\
\hline- & 19 & $140-150$ & 1 & $x$ & & 02 & 02 & 01 & 01 & 1 & 3.0 & 1 \\
\hline- & 19 & $140-150$ & 1 & $x$ & & 02 & 02 & 01 & 02 & 1 & 7.1 & 1 \\
\hline- & 19 & $140-150$ & 1 & $x$ & & 02 & 02 & 01 & 01 & 1 & 3.4 & 1 \\
\hline- & 19 & $140-150$ & 1 & & $x$ & 02 & 02 & 02 & 01 & 2 & 15.1 & 2 \\
\hline- & 19 & $140-150$ & 1 & $x$ & & 01 & 02 & 01 & 02 & 1 & 6.6 & 1 \\
\hline- & 19 & $140-150$ & 1 & $x$ & & 01 & 02 & 01 & 01 & 1 & 14.6 & 1 \\
\hline- & 19 & $150-160$ & 1 & $x$ & & 04 & - & 00 & 04 & 1 & 0.6 & 1 \\
\hline- & 19 & $150-160$ & 1 & & $x$ & 04 & - & 00 & 00 & 1 & 0.2 & 1 \\
\hline - & 19 & $150-160$ & 1 & $x$ & & 03 & - & 00 & 04 & 1 & 0.7 & 1 \\
\hline
\end{tabular}


Table B-8 (continued). Catalog of Whole and Proximal Flakes 100-200 cmbs.

\begin{tabular}{|c|c|c|c|c|c|c|c|c|c|c|c|c|}
\hline $\begin{array}{l}\# \\
\text { \# } \\
\end{array}$ & $\begin{array}{l}\# \\
\stackrel{ \pm}{ \pm} \\
د \\
د\end{array}$ & 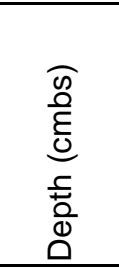 & 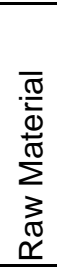 & $\begin{array}{l}0 \\
\mathbb{d} \\
\frac{1}{\omega} \\
\frac{1}{1} \\
\frac{0}{0} \\
\frac{0}{3}\end{array}$ & 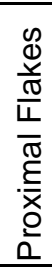 & $\begin{array}{l}0 \\
\frac{0}{\pi} \\
\frac{\pi}{\pi} \\
0 \\
\stackrel{N}{\omega} \\
\end{array}$ & 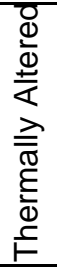 & 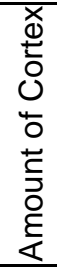 & 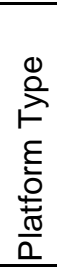 & 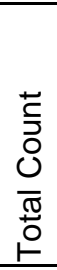 & 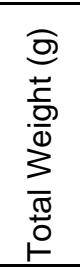 & $\underset{z}{Z}$ \\
\hline- & 19 & $150-160$ & 1 & $x$ & & 03 & - & 01 & 01 & 2 & 4.8 & 2 \\
\hline- & 20 & $110-120$ & 1 & $x$ & & 04 & - & 00 & 04 & 1 & 0.1 & 1 \\
\hline- & 20 & $110-120$ & 1 & $x$ & & 02 & 01 & 01 & 02 & 1 & 4.1 & 1 \\
\hline- & 20 & $120-130$ & 1 & $x$ & & 04 & - & 01 & 03 & 1 & 1.5 & 1 \\
\hline- & 20 & $120-130$ & 1 & & $x$ & 04 & - & 00 & 02 & 1 & 0.1 & 1 \\
\hline- & 20 & $120-130$ & 1 & $x$ & & 02 & 02 & 01 & 02 & 1 & 4.6 & 1 \\
\hline- & 20 & $120-130$ & 1 & $x$ & & 01 & 02 & 01 & 02 & 1 & 19.1 & 1 \\
\hline 189 & 20 & $130-140$ & 1 & $x$ & & 04 & - & 00 & 02 & 1 & 0.6 & 1 \\
\hline 189 & 20 & $130-140$ & 1 & $x$ & & 03 & - & 00 & 04 & 2 & 2.6 & 2 \\
\hline 189 & 20 & $130-140$ & 1 & & $x$ & 02 & 02 & 00 & 05 & 1 & 2.3 & 1 \\
\hline 189 & 20 & $130-140$ & 1 & $x$ & & 02 & 02 & 01 & 02 & 1 & 3.4 & 1 \\
\hline 189 & 20 & $130-140$ & 1 & $x$ & & 02 & 01 & 02 & 01 & 1 & 4.1 & 1 \\
\hline 191 & 20 & $140-150$ & 1 & $x$ & & 04 & - & 00 & 02 & 2 & 1.5 & 1 \\
\hline 191 & 20 & $140-150$ & 1 & $x$ & & 04 & - & 00 & 04 & 1 & 0.4 & 1 \\
\hline 191 & 20 & $140-150$ & 1 & & $x$ & 04 & - & 00 & 04 & 3 & 1.0 & 3 \\
\hline 191 & 20 & $140-150$ & 1 & $x$ & & 04 & - & 01 & 02 & 1 & 1.4 & 1 \\
\hline 191 & 20 & $140-150$ & 1 & $x$ & & 03 & - & 00 & 02 & 1 & 0.7 & 1 \\
\hline 191 & 20 & $140-150$ & 1 & & $x$ & 03 & - & 00 & 02 & 1 & 1.7 & 1 \\
\hline 191 & 20 & $140-150$ & 1 & & $x$ & 03 & - & 00 & 05 & 1 & 0.6 & 1 \\
\hline 191 & 20 & $140-150$ & 1 & $x$ & & 03 & - & 01 & 02 & 2 & 1.8 & 2 \\
\hline 191 & 20 & $140-150$ & 1 & $x$ & & 03 & - & 01 & 01 & 1 & 1.1 & 1 \\
\hline 191 & 20 & $140-150$ & 1 & $x$ & & 02 & 02 & 02 & 02 & 1 & 7.2 & 1 \\
\hline 195 & 20 & $150-160$ & 3 & & $x$ & 04 & - & 00 & 02 & 1 & 0.2 & 1 \\
\hline 195 & 20 & $150-160$ & 1 & $x$ & & 03 & - & 00 & 02 & 1 & 4.7 & 1 \\
\hline 195 & 20 & $150-160$ & 1 & $x$ & & 03 & - & 00 & 04 & 1 & 1.5 & 1 \\
\hline 195 & 20 & $150-160$ & 1 & $x$ & & 03 & - & 01 & 04 & 1 & 1.8 & 1 \\
\hline 195 & 20 & $150-160$ & 1 & $x$ & & 02 & 01 & 01 & 02 & 1 & 8.7 & 1 \\
\hline 195 & 20 & $150-160$ & 1 & $x$ & & 01 & 02 & 01 & 01 & 1 & 22.4 & 1 \\
\hline 204 & 20 & $160-170$ & 1 & & $x$ & 04 & - & 00 & 02 & 1 & 0.7 & 1 \\
\hline 164 & 21 & $110-120$ & 1 & & $x$ & 03 & - & 00 & 05 & 1 & 1.6 & 1 \\
\hline 164 & 21 & $110-120$ & 1 & & $x$ & 02 & 02 & 00 & 02 & 1 & 5.2 & 1 \\
\hline 168 & 21 & $120-130$ & 1 & & $x$ & 04 & - & 00 & 04 & 1 & 0.2 & 1 \\
\hline 168 & 21 & $120-130$ & 1 & & $x$ & 03 & - & 00 & 04 & 1 & 4.1 & 1 \\
\hline 168 & 21 & $120-130$ & 1 & $x$ & & 02 & 02 & 01 & 01 & 1 & 4.1 & 1 \\
\hline 168 & 21 & $120-130$ & 1 & & $x$ & 01 & 02 & 01 & 02 & 1 & 9.1 & 1 \\
\hline 168 & 21 & $120-130$ & 1 & $x$ & & 01 & 02 & 01 & 02 & 1 & 3.9 & 1 \\
\hline 175 & 21 & $130-140$ & 1 & $x$ & & 04 & - & 00 & 03 & 1 & 1.1 & 1 \\
\hline 175 & 21 & $130-140$ & 1 & & $x$ & 04 & - & 00 & 05 & 1 & 0.7 & 1 \\
\hline 175 & 21 & $130-140$ & 1 & & $x$ & 04 & - & 00 & 02 & 1 & 0.0 & 1 \\
\hline 175 & 21 & $130-140$ & 1 & $x$ & & 03 & - & 01 & 04 & 1 & 3.1 & 1 \\
\hline 175 & 21 & $130-140$ & 1 & $x$ & & 03 & - & 01 & 02 & 2 & 5.2 & 2 \\
\hline 175 & 21 & $130-140$ & 1 & & $x$ & 02 & 02 & 02 & 02 & 1 & 9.2 & 1 \\
\hline 175 & 21 & $130-140$ & 1 & $x$ & & 01 & 01 & 02 & 04 & 1 & 4.9 & 1 \\
\hline 175 & 21 & $130-140$ & 1 & & $x$ & 01 & 02 & 00 & 04 & 1 & 10.1 & 1 \\
\hline 176 & 21 & $140-150$ & 1 & $x$ & & 03 & - & 01 & 02 & 1 & 5.9 & 1 \\
\hline
\end{tabular}


Table B-8 (continued). Catalog of Whole and Proximal Flakes 100-200 cmbs.

\begin{tabular}{|c|c|c|c|c|c|c|c|c|c|c|c|c|}
\hline \# & 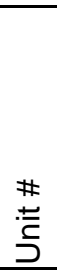 & 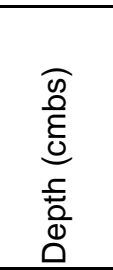 & 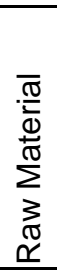 & 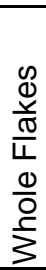 & 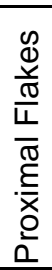 & $\begin{array}{l}\frac{0}{0} \\
\frac{\pi}{\pi} \\
\mathbb{N} \\
\frac{N}{\omega}\end{array}$ & 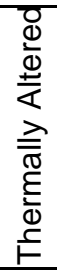 & 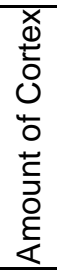 & 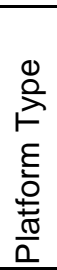 & 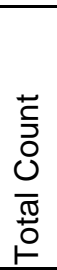 & 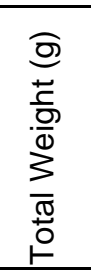 & $\frac{Z}{Z}$ \\
\hline 177 & 21 & $150-160$ & 1 & $x$ & & 04 & - & 00 & 02 & 1 & 0.7 & 1 \\
\hline 177 & 21 & $150-160$ & 1 & & $x$ & 03 & - & 01 & 04 & 1 & 1.6 & 1 \\
\hline 177 & 21 & $150-160$ & 1 & $x$ & & 03 & - & 01 & 01 & 1 & 3.8 & 1 \\
\hline 181 & 22 & $110-120$ & 1 & $x$ & & 03 & - & 00 & 02 & 1 & 1.7 & 1 \\
\hline 181 & 22 & $110-120$ & 1 & $x$ & & 03 & - & 01 & 02 & 1 & 2.9 & 1 \\
\hline 181 & 22 & $110-120$ & 1 & & $x$ & 03 & - & 01 & 01 & 1 & 1.2 & 1 \\
\hline 181 & 22 & $110-120$ & 1 & $x$ & & 02 & 02 & 00 & 05 & 1 & 3.8 & 1 \\
\hline 190 & 22 & $120-130$ & 1 & & $x$ & 04 & - & 00 & 05 & 1 & 0.7 & 1 \\
\hline 190 & 22 & $120-130$ & 1 & $x$ & & 04 & - & 00 & 02 & 1 & 1.7 & 1 \\
\hline 190 & 22 & $120-130$ & 1 & $x$ & & 04 & - & 02 & 01 & 1 & 2.1 & 1 \\
\hline 190 & 22 & $120-130$ & 1 & $x$ & & 03 & - & 00 & 04 & 1 & 2.4 & 1 \\
\hline 194 & 22 & $130-140$ & 1 & $x$ & & 04 & - & 00 & 05 & 2 & 1.2 & 1 \\
\hline 194 & 22 & $130-140$ & 1 & $x$ & & 04 & - & 00 & 00 & 1 & 0.2 & 1 \\
\hline 194 & 22 & $130-140$ & 1 & & $x$ & 04 & - & 00 & 00 & 1 & 0.2 & 1 \\
\hline 194 & 22 & $130-140$ & 1 & $x$ & & 03 & - & 00 & 04 & 2 & 4.0 & 2 \\
\hline 194 & 22 & $130-140$ & 1 & $x$ & & 02 & 02 & 00 & 04 & 1 & 4.0 & 1 \\
\hline 194 & 22 & $130-140$ & 1 & & $x$ & 02 & 02 & 01 & 01 & 1 & 5.5 & 1 \\
\hline 194 & 22 & $130-140$ & 2 & $x$ & & 02 & 02 & 01 & 01 & 1 & 6.4 & 1 \\
\hline 194 & 22 & $130-140$ & 1 & $x$ & & 02 & 01 & 01 & 01 & 1 & 4.2 & 1 \\
\hline 194 & 22 & $130-140$ & 1 & $x$ & & 02 & 02 & 01 & 02 & 1 & 6.1 & 1 \\
\hline 194 & 22 & $130-140$ & 1 & $x$ & & 01 & 02 & 02 & 01 & 1 & 28.5 & 1 \\
\hline 196 & 22 & $140-150$ & 1 & $x$ & & 04 & - & 00 & 05 & 1 & 0.7 & 1 \\
\hline 196 & 22 & $140-150$ & 1 & $x$ & & 04 & - & 00 & 02 & 1 & 0.7 & 1 \\
\hline 196 & 22 & $140-150$ & 1 & $x$ & & 04 & - & 01 & 00 & 1 & 0.8 & 1 \\
\hline 196 & 22 & $140-150$ & 1 & $x$ & & 03 & - & 00 & 05 & 1 & 3.2 & 1 \\
\hline 196 & 22 & $140-150$ & 1 & & $x$ & 03 & - & 00 & 05 & 1 & 2.0 & 1 \\
\hline 196 & 22 & $140-150$ & 1 & $x$ & & 03 & - & 01 & 05 & 1 & 2.6 & 1 \\
\hline 196 & 22 & $140-150$ & 1 & $x$ & & 03 & - & 01 & 02 & 1 & 5.6 & 1 \\
\hline 196 & 22 & $140-150$ & 1 & $x$ & & 03 & - & 01 & 01 & 2 & 5.1 & 2 \\
\hline 196 & 22 & $140-150$ & 1 & & $x$ & 03 & - & 01 & 02 & 1 & 1.7 & 1 \\
\hline 196 & 22 & $140-150$ & 1 & $x$ & & 01 & 02 & 02 & 02 & 2 & 115.9 & 2 \\
\hline 207 & 22 & $150-160$ & 1 & & $x$ & 04 & - & 00 & 04 & 1 & 0.0 & 1 \\
\hline 242 & 23 & $100-110$ & 1 & & $x$ & 04 & - & 00 & 05 & 1 & 0.2 & 1 \\
\hline 242 & 23 & $100-110$ & 1 & $x$ & & 03 & - & 01 & 02 & 1 & 7.3 & 1 \\
\hline 242 & 23 & $100-110$ & 1 & & $x$ & 01 & 01 & 00 & 03 & 1 & 17.9 & 1 \\
\hline 244 & 23 & $110-120$ & 1 & & $x$ & 04 & - & 01 & 02 & 1 & 0.7 & 1 \\
\hline 244 & 23 & $110-120$ & 1 & $x$ & & 03 & - & 01 & 02 & 1 & 2.9 & 1 \\
\hline 248 & 23 & $120-130$ & 1 & $x$ & & 02 & 02 & 01 & 01 & 1 & 13.5 & 1 \\
\hline 255 & 23 & $130-140$ & 1 & $x$ & & 04 & - & 01 & 03 & 2 & 1.4 & 1 \\
\hline 255 & 23 & $130-140$ & 1 & & $x$ & 04 & - & 00 & 06 & 1 & 0.2 & 1 \\
\hline 255 & 23 & $160-140$ & 1 & & $x$ & 03 & - & 00 & 04 & 1 & 2.2 & 1 \\
\hline 255 & 23 & $130-140$ & 1 & & $x$ & 03 & - & 01 & 02 & 1 & 1.9 & 1 \\
\hline 255 & 23 & $130-140$ & 1 & & $x$ & 03 & - & 01 & 03 & 1 & 1.8 & 1 \\
\hline 259 & 23 & $140-150$ & 1 & $x$ & & 04 & - & 00 & 04 & 1 & 0.0 & 1 \\
\hline 259 & 23 & $140-150$ & 1 & $x$ & & 03 & - & 00 & 04 & 1 & 0.9 & 1 \\
\hline
\end{tabular}


Table B-8 (continued). Catalog of Whole and Proximal Flakes 100-200 cmbs.

\begin{tabular}{|c|c|c|c|c|c|c|c|c|c|c|c|c|}
\hline $\begin{array}{l}\# \\
\text { \# } \\
\end{array}$ & 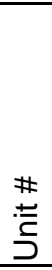 & 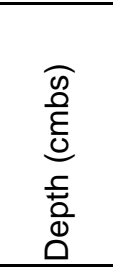 & 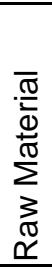 & 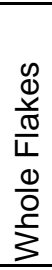 & 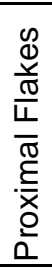 & 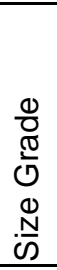 & 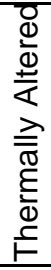 & 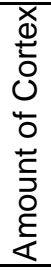 & 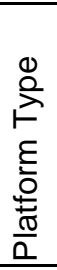 & 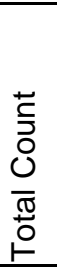 & 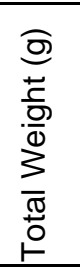 & $\underset{z}{Z}$ \\
\hline 259 & 23 & $140-150$ & 1 & & $x$ & 03 & - & 00 & 04 & 1 & 1.4 & 1 \\
\hline 259 & 23 & $140-150$ & 1 & & $x$ & 03 & - & 01 & 01 & 1 & 1.9 & 1 \\
\hline 171 & 24 & $100-110$ & 1 & & $x$ & 04 & - & 00 & 04 & 1 & 0.0 & 1 \\
\hline 171 & 24 & $100-110$ & 1 & & $x$ & 04 & - & 00 & 02 & 1 & 0.6 & 1 \\
\hline 171 & 24 & $100-110$ & 1 & & $x$ & 03 & - & 00 & 05 & 1 & 1.0 & 1 \\
\hline 171 & 24 & $100-110$ & 1 & & $x$ & 02 & 02 & 02 & 02 & 1 & 3.4 & 1 \\
\hline 172 & 24 & $110-120$ & 1 & $x$ & & 04 & - & 00 & 02 & 1 & 0.7 & 1 \\
\hline 172 & 24 & $110-120$ & 1 & $x$ & & 01 & 02 & 01 & 02 & 1 & 49.6 & 1 \\
\hline 182 & 24 & $130-140$ & 1 & $x$ & & 03 & - & 01 & 01 & 1 & 4.3 & 1 \\
\hline 182 & 24 & $130-140$ & 1 & & $x$ & 02 & 02 & 00 & 02 & 1 & 15.1 & 1 \\
\hline 183 & 24 & $140-150$ & 1 & $x$ & & 04 & - & 00 & 05 & 1 & 0.7 & 1 \\
\hline 183 & 24 & $140-150$ & 1 & & $x$ & 03 & - & 01 & 01 & 1 & 5.8 & 1 \\
\hline 183 & 24 & $140-150$ & 1 & $x$ & & 02 & 02 & 01 & 01 & 1 & 32.2 & 1 \\
\hline 197 & 24 & $150-160$ & 1 & $x$ & & 04 & - & 00 & 02 & 1 & 0.9 & 1 \\
\hline 197 & 24 & $150-160$ & 1 & & $x$ & 03 & - & 00 & 05 & 1 & 1.4 & 1 \\
\hline 197 & 24 & $150-160$ & 1 & & $x$ & 03 & - & 00 & 02 & 1 & 3.2 & 1 \\
\hline 197 & 24 & $150-160$ & 1 & & $x$ & 03 & - & 00 & 03 & 1 & 5.4 & 1 \\
\hline 197 & 24 & $150-160$ & 1 & $x$ & & 03 & - & 01 & 02 & 4 & 15.3 & 4 \\
\hline 197 & 24 & $150-160$ & 1 & $x$ & & 03 & - & 01 & 01 & 3 & 10.9 & 3 \\
\hline 197 & 24 & $150-160$ & 1 & $x$ & & 02 & 02 & 00 & 08 & 1 & 4.2 & 1 \\
\hline 197 & 24 & $150-160$ & 1 & $x$ & & 02 & 01 & 01 & 02 & 1 & 10.8 & 1 \\
\hline 197 & 24 & $150-160$ & 1 & & $x$ & 02 & 02 & 01 & 01 & 1 & 7.7 & 1 \\
\hline 197 & 24 & $150-160$ & 1 & & $x$ & 02 & 02 & 02 & 03 & 1 & 7.9 & 1 \\
\hline 198 & 24 & $160-170$ & 1 & $x$ & & 04 & - & 00 & 04 & 2 & 1.4 & 2 \\
\hline 198 & 24 & $160-170$ & 1 & & $x$ & 03 & - & 00 & 04 & 1 & 1.6 & 1 \\
\hline 198 & 24 & $160-170$ & 1 & & $x$ & 02 & 02 & 02 & 00 & 1 & 4.6 & 1 \\
\hline 198 & 24 & $160-170$ & 1 & & $x$ & 02 & 02 & 00 & 03 & 1 & 13.6 & 1 \\
\hline 211 & 24 & $180-190$ & 1 & $x$ & & 02 & 02 & 00 & 04 & 1 & 6.9 & 1 \\
\hline 200 & 25 & $100-110$ & 1 & & $x$ & 04 & - & 00 & 05 & 1 & 0.3 & 1 \\
\hline 201 & 25 & $110-120$ & 1 & & $x$ & 04 & - & 00 & 04 & 2 & 0.2 & 2 \\
\hline 201 & 25 & $110-120$ & 1 & & $x$ & 04 & - & 02 & 04 & 1 & 0.4 & 1 \\
\hline 201 & 25 & $110-120$ & 1 & $x$ & & 03 & - & 01 & 01 & 2 & 4.7 & 2 \\
\hline 201 & 25 & $110-120$ & 1 & $x$ & & 03 & - & 02 & 04 & 1 & 1.5 & 1 \\
\hline 201 & 25 & $110-120$ & 1 & & $x$ & 03 & - & 02 & 01 & 1 & 4.8 & 1 \\
\hline 201 & 25 & $110-120$ & 1 & $x$ & & 01 & 02 & 02 & 02 & 1 & 12.5 & 1 \\
\hline 220 & 25 & $120-130$ & 1 & $x$ & & 04 & - & 00 & 02 & 1 & 0.0 & 1 \\
\hline 220 & 25 & $120-130$ & 1 & & $x$ & 03 & - & 00 & 05 & 1 & 1.0 & 1 \\
\hline 220 & 25 & $120-130$ & 1 & & $x$ & 03 & - & 01 & 01 & 1 & 1.3 & 1 \\
\hline 220 & 25 & $120-130$ & 1 & & $x$ & 02 & 01 & 02 & 02 & 1 & 25.9 & 1 \\
\hline 220 & 25 & $120-130$ & 1 & & $x$ & 02 & 02 & 02 & 02 & 1 & 16.7 & 1 \\
\hline 221 & 25 & $130-140$ & 1 & $x$ & & 04 & - & 00 & 04 & 1 & 0.1 & 1 \\
\hline 221 & 25 & $130-140$ & 1 & $x$ & & 04 & - & 01 & 04 & 1 & 1.1 & 1 \\
\hline 221 & 25 & $130-140$ & 1 & & $x$ & 04 & - & 02 & 02 & 1 & 0.0 & 1 \\
\hline 221 & 25 & $130-140$ & 1 & $x$ & & 03 & - & 01 & 01 & 1 & 4.8 & 1 \\
\hline 221 & 25 & $130-140$ & 1 & $x$ & & 02 & 00 & 01 & 03 & 1 & 16.7 & 1 \\
\hline
\end{tabular}


Table B-8 (continued). Catalog of Whole and Proximal Flakes 100-200 cmbs.

\begin{tabular}{|c|c|c|c|c|c|c|c|c|c|c|c|c|}
\hline 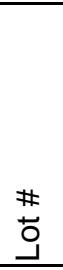 & $\begin{array}{l}\text { \# } \\
\stackrel{ \pm}{\underline{\underline{\prime}}} \\
\end{array}$ & 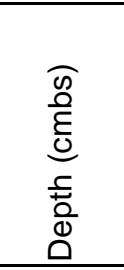 & 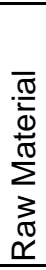 & $\begin{array}{l}0 \\
\Phi \\
\frac{1}{0} \\
\frac{\pi}{1} \\
\frac{0}{0} \\
\frac{0}{3} \\
\frac{1}{3}\end{array}$ & 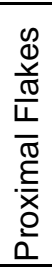 & $\begin{array}{l}\frac{0}{0} \\
\frac{\pi}{0} \\
\overline{0} \\
\stackrel{N}{N} \\
\frac{N}{\omega}\end{array}$ & 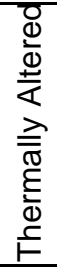 & 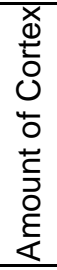 & $\begin{array}{l}\stackrel{0}{2} \\
\stackrel{2}{2} \\
\varepsilon \\
\frac{5}{0} \\
\frac{0}{ \pm} \\
\frac{\pi}{\alpha}\end{array}$ & 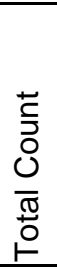 & 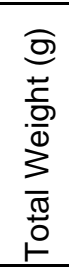 & $\frac{Z}{z}$ \\
\hline 221 & 25 & $130-140$ & 1 & $x$ & & 02 & 01 & 01 & 02 & 1 & 10.7 & 1 \\
\hline 221 & 25 & $130-140$ & 1 & $x$ & & 02 & 02 & 01 & 00 & 1 & 7.9 & 1 \\
\hline 221 & 25 & $130-140$ & 1 & $x$ & & 02 & 02 & 02 & 02 & 2 & 26.8 & 2 \\
\hline 221 & 25 & $130-140$ & 1 & $x$ & & 02 & 02 & 02 & 01 & 1 & 9.5 & 1 \\
\hline 221 & 25 & $130-140$ & 1 & $x$ & & 01 & 02 & 02 & 02 & 1 & 36.5 & 1 \\
\hline 222 & 25 & $140-150$ & 1 & $x$ & & 04 & - & 00 & 02 & 1 & 0.4 & 1 \\
\hline 222 & 25 & $140-150$ & 1 & $x$ & & 04 & - & 01 & 04 & 1 & 2.0 & 1 \\
\hline 222 & 25 & $140-150$ & 1 & $x$ & & 04 & - & 01 & 01 & 1 & 0.2 & 1 \\
\hline 222 & 25 & $140-150$ & 1 & $x$ & & 03 & - & 00 & 03 & 1 & 1.7 & 1 \\
\hline 222 & 25 & $140-150$ & 1 & & $x$ & 03 & - & 00 & 03 & 1 & 1.7 & 1 \\
\hline 222 & 25 & $140-150$ & 1 & & $x$ & 03 & - & 00 & 04 & 1 & 1.5 & 1 \\
\hline 222 & 25 & $140-150$ & 1 & $x$ & & 02 & 02 & 01 & 04 & 1 & 3.9 & 1 \\
\hline 222 & 25 & $140-150$ & 1 & $x$ & & 02 & 02 & 01 & 03 & 1 & 11.1 & 1 \\
\hline 222 & 25 & $140-150$ & 1 & $x$ & & 02 & 02 & 02 & 02 & 1 & 13.3 & 1 \\
\hline 222 & 25 & $140-150$ & 1 & $x$ & & 02 & 01 & 01 & 02 & 2 & 19.0 & 2 \\
\hline 235 & 25 & $150-160$ & 1 & $x$ & & 04 & - & 00 & 04 & 3 & 2.1 & 3 \\
\hline 235 & 25 & $150-160$ & 1 & & $x$ & 04 & - & 00 & 05 & 2 & 0.7 & 2 \\
\hline 235 & 25 & $150-160$ & 1 & & $x$ & 04 & - & 00 & 04 & 2 & 0.0 & 2 \\
\hline 235 & 25 & $150-160$ & 1 & & $x$ & 04 & - & 00 & 03 & 1 & 1.0 & 1 \\
\hline 235 & 25 & $150-160$ & 1 & & $x$ & 04 & - & 00 & 02 & 1 & 0.6 & 1 \\
\hline 235 & 25 & $150-160$ & 1 & $x$ & & 04 & - & 01 & 04 & 1 & 1.3 & 1 \\
\hline 235 & 25 & $150-160$ & 1 & & $x$ & 03 & - & 00 & 02 & 1 & 4.7 & 1 \\
\hline 235 & 25 & $-150-160$ & 1 & $x$ & & 03 & - & 00 & 00 & 1 & 2.1 & 1 \\
\hline 235 & 25 & $150-160$ & 1 & $x$ & & 03 & - & 01 & 02 & 1 & 2.1 & 1 \\
\hline 235 & 25 & $150-160$ & 1 & $x$ & & 03 & - & 01 & 01 & 1 & 4.6 & 1 \\
\hline 235 & 25 & $150-160$ & 1 & $x$ & & 03 & - & 01 & 04 & 1 & 2.3 & 1 \\
\hline 235 & 25 & $150-160$ & 1 & & $x$ & 03 & - & 01 & 02 & 1 & 2.5 & 1 \\
\hline 235 & 25 & $150-160$ & 1 & & $x$ & 03 & - & 01 & 01 & 1 & 3.8 & 1 \\
\hline 235 & 25 & $150-160$ & 1 & $x$ & & 02 & 02 & 00 & 04 & 3 & 12.1 & 3 \\
\hline 235 & 25 & $150-160$ & 3 & $x$ & & 02 & 02 & 00 & 02 & 1 & 3.3 & 1 \\
\hline 235 & 25 & $150-160$ & 1 & & $x$ & 02 & 02 & 01 & 02 & 1 & 4.3 & 1 \\
\hline 235 & 25 & $150-160$ & 1 & $x$ & & 02 & 02 & 02 & 01 & 1 & 18.1 & 1 \\
\hline 235 & 25 & $150-160$ & 1 & $x$ & & 01 & 02 & 00 & 04 & 1 & 11.5 & 1 \\
\hline 235 & 25 & $150-160$ & 1 & & $x$ & 01 & 02 & 02 & 01 & 1 & 21.5 & 1 \\
\hline 235 & 25 & $150-160$ & 1 & $x$ & & 01 & 02 & 02 & 04 & 1 & 28.3 & 1 \\
\hline 236 & 25 & $160-170$ & 1 & & $x$ & 04 & - & 00 & 04 & 1 & 0.2 & 1 \\
\hline 236 & 25 & $160-170$ & 1 & $x$ & & 04 & - & 01 & 01 & 1 & 0.7 & 1 \\
\hline 236 & 25 & $160-170$ & 1 & $x$ & & 03 & - & 00 & 02 & 1 & 2.9 & 1 \\
\hline 185 & 26 & $100-110$ & 1 & & $x$ & 04 & - & 00 & 04 & 1 & 0.0 & 1 \\
\hline 186 & 26 & $110-120$ & 1 & $x$ & & 03 & - & 00 & 04 & 1 & 3.8 & 1 \\
\hline 186 & 26 & $110-120$ & 1 & & $x$ & 03 & - & 00 & 08 & 1 & 2.7 & 1 \\
\hline 202 & 26 & $120-130$ & 1 & & $x$ & 04 & - & 00 & 04 & 1 & 0.6 & 1 \\
\hline 202 & 26 & $120-130$ & 1 & & $x$ & 04 & - & 00 & 05 & 1 & 0.3 & 1 \\
\hline 202 & 26 & $120-130$ & 1 & $x$ & & 03 & - & 01 & 00 & 1 & 1.9 & 1 \\
\hline 202 & 26 & $120-130$ & 1 & $x$ & & 03 & - & 02 & 02 & 1 & 8.2 & 1 \\
\hline
\end{tabular}


Table B-8 (continued). Catalog of Whole and Proximal Flakes 100-200 cmbs.

\begin{tabular}{|c|c|c|c|c|c|c|c|c|c|c|c|c|}
\hline 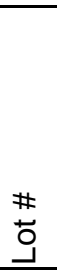 & 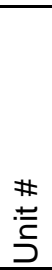 & 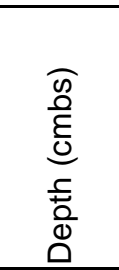 & 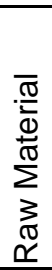 & 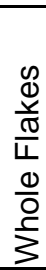 & 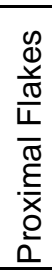 & $\begin{array}{l}\frac{0}{0} \\
\frac{\pi}{0} \\
\mathbb{N} \\
0 \\
\frac{N}{\omega}\end{array}$ & 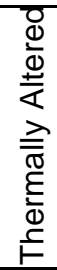 & 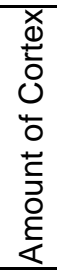 & 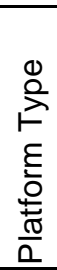 & 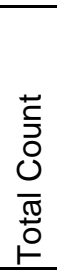 & 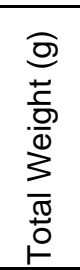 & $\underline{Z}$ \\
\hline 249 & 22 & $100-110$ & 1 & $x$ & & 04 & - & 00 & 04 & 2 & 0.9 & 2 \\
\hline 249 & 22 & $100-110$ & 1 & $x$ & & 02 & 02 & 02 & 02 & 1 & 17.8 & 1 \\
\hline 252 & 27 & $110-120$ & 1 & $x$ & & 03 & - & 01 & 02 & 1 & 4.1 & 1 \\
\hline 256 & 27 & $120-130$ & 1 & $x$ & & 03 & - & 01 & 02 & 1 & 3.2 & 1 \\
\hline 256 & 27 & $120-130$ & 1 & & $x$ & 03 & - & 00 & 02 & 1 & 2.6 & 1 \\
\hline 256 & 27 & $120-130$ & 1 & & $x$ & 03 & - & 01 & 08 & 1 & 3.3 & 1 \\
\hline 266 & 27 & $130-140$ & 1 & $x$ & & 04 & - & 00 & 02 & 1 & 0.0 & 1 \\
\hline 266 & 27 & $130-140$ & 1 & $x$ & & 04 & - & 00 & 04 & 1 & 0.0 & 1 \\
\hline 266 & 27 & $130-140$ & 1 & & $x$ & 04 & - & 00 & 04 & 3 & 1.4 & 3 \\
\hline 266 & 27 & $130-140$ & 1 & $x$ & & 04 & - & 01 & 02 & 1 & 1.3 & 1 \\
\hline 266 & 27 & $130-140$ & 1 & & $x$ & 04 & - & 01 & 02 & 1 & 0.7 & 1 \\
\hline 266 & 27 & $130-140$ & 1 & & $x$ & 04 & - & 02 & 01 & 1 & 1.3 & 1 \\
\hline 266 & 27 & $130-140$ & 1 & $x$ & & 03 & - & 00 & 05 & 1 & 1.4 & 1 \\
\hline 266 & 27 & $130-140$ & 1 & $x$ & & 03 & - & 00 & 04 & 1 & 2.8 & 1 \\
\hline 266 & 27 & $130-140$ & 1 & & $x$ & 03 & - & 00 & 02 & 1 & 3.2 & 1 \\
\hline 266 & 27 & $130-140$ & 1 & $x$ & & 03 & - & 01 & 05 & 1 & 2.7 & 1 \\
\hline 266 & 27 & $130-140$ & 1 & & $x$ & 03 & - & 01 & 02 & 1 & 2.5 & 1 \\
\hline 266 & 27 & $130-140$ & 1 & & $x$ & 03 & - & 01 & 01 & 2 & 4.1 & 2 \\
\hline 266 & 27 & $130-140$ & 1 & $x$ & & 03 & - & 02 & 02 & 1 & 2.8 & 1 \\
\hline 266 & 27 & $130-140$ & 1 & $x$ & & 03 & - & 02 & 04 & 1 & 2.7 & 1 \\
\hline 266 & 27 & $130-140$ & 1 & $x$ & & 02 & 02 & 00 & 03 & 1 & 8.7 & 1 \\
\hline 266 & 27 & $130-140$ & 1 & & $x$ & 02 & 02 & 00 & 00 & 1 & 3.8 & 1 \\
\hline 266 & 27 & $130-140$ & 1 & $x$ & & 02 & 02 & 01 & 01 & 1 & 5.9 & 1 \\
\hline 266 & 27 & $130-140$ & 1 & & $x$ & 02 & 02 & 02 & 01 & 1 & 11.1 & 1 \\
\hline 266 & 27 & $130-140$ & 1 & $x$ & & 01 & 02 & 02 & 02 & 1 & 15.0 & 1 \\
\hline 266 & 27 & $130-140$ & 1 & $x$ & & 01 & 02 & 02 & 04 & 1 & 14.2 & 1 \\
\hline 247 & 28 & $110-120$ & 1 & & $x$ & 04 & - & 00 & 05 & 1 & 0.8 & 1 \\
\hline 247 & 28 & $110-120$ & 1 & & $x$ & 04 & - & 00 & 04 & 1 & 0.4 & 1 \\
\hline 247 & 28 & $110-120$ & 1 & $x$ & & 03 & - & 00 & 05 & 1 & 1.8 & 1 \\
\hline 247 & 28 & $110-120$ & 1 & $x$ & & 03 & - & 01 & 01 & 1 & 3.5 & 1 \\
\hline 253 & 28 & $120-130$ & 1 & & $x$ & 04 & - & 00 & 04 & 1 & 0.4 & 1 \\
\hline 253 & 28 & $120-130$ & 1 & & $x$ & 04 & - & 00 & 08 & 1 & 0.2 & 1 \\
\hline 253 & 28 & $120-130$ & 1 & & $x$ & 03 & - & 01 & 02 & 2 & 7.5 & 2 \\
\hline 253 & 28 & $120-130$ & 1 & & $x$ & 03 & - & 01 & 01 & 1 & 2.7 & 1 \\
\hline 253 & 28 & $120-130$ & 1 & $x$ & & 02 & 02 & 01 & 01 & 1 & 9.2 & 1 \\
\hline 254 & 28 & $130-140$ & 1 & & $x$ & 03 & - & 00 & 04 & 1 & 2.1 & 1 \\
\hline 254 & 28 & $130-140$ & 1 & & $x$ & 03 & - & 01 & 01 & 1 & 2.6 & 1 \\
\hline 254 & 28 & $130-140$ & 1 & & $x$ & 02 & 01 & 01 & 01 & 1 & 5.2 & 1 \\
\hline 254 & 28 & $130-140$ & 1 & $x$ & & 02 & 02 & 01 & 03 & 1 & 7.7 & 1 \\
\hline 261 & 28 & $140-150$ & 1 & & $x$ & 03 & - & 00 & 02 & 1 & 14.6 & 1 \\
\hline 261 & 28 & $140-150$ & 1 & $x$ & & 03 & - & 01 & 02 & 1 & 2.6 & 1 \\
\hline 261 & 28 & $140-150$ & 2 & $x$ & & 03 & - & 01 & 04 & 1 & 3.3 & 1 \\
\hline 261 & 28 & $140-150$ & 1 & $x$ & & 02 & 02 & 00 & 02 & 1 & 11.1 & 1 \\
\hline 261 & 28 & $140-150$ & 3 & & $x$ & 02 & 02 & 00 & 02 & 1 & 8.8 & 1 \\
\hline 261 & 28 & $140-150$ & 2 & & $x$ & 02 & 02 & 01 & 02 & 1 & 10.0 & 1 \\
\hline
\end{tabular}


Table B-8 (continued). Catalog of Whole and Proximal Flakes 100-200 cmbs.

\begin{tabular}{|c|c|c|c|c|c|c|c|c|c|c|c|c|}
\hline \# & $\begin{array}{l}\text { \# } \\
\stackrel{ \pm}{\underline{\underline{c}}} \\
\end{array}$ & 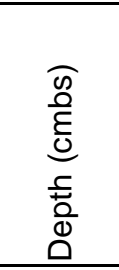 & 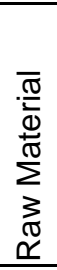 & $\begin{array}{l}0 \\
\mathbb{d} \\
\frac{\tilde{\sigma}}{0} \\
\frac{1}{1} \\
\frac{0}{0} \\
\frac{0}{3}\end{array}$ & 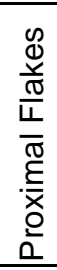 & $\begin{array}{l}\frac{0}{0} \\
\frac{\pi}{\pi} \\
\mathbb{N} \\
\mathbb{N} \\
\frac{N}{\omega}\end{array}$ & 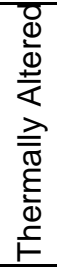 & 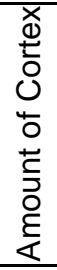 & 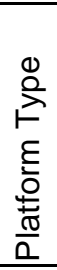 & 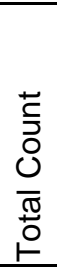 & 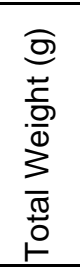 & $\underset{z}{Z}$ \\
\hline 261 & 28 & $140-150$ & 2 & $x$ & & 02 & 02 & 02 & 02 & 1 & 13.7 & 1 \\
\hline 262 & 28 & $150-160$ & 1 & $x$ & & 04 & - & 00 & 02 & 1 & 0.9 & 1 \\
\hline 262 & 28 & $150-160$ & 1 & $x$ & & 04 & - & 00 & 04 & 2 & 1.8 & 2 \\
\hline 262 & 28 & $150-160$ & 1 & & $x$ & 04 & - & 00 & 05 & 2 & 0.9 & 2 \\
\hline 262 & 28 & $150-160$ & 1 & $x$ & & 04 & - & 01 & 03 & 1 & 0.7 & 1 \\
\hline 262 & 28 & $150-160$ & 1 & $x$ & & 03 & - & 00 & 04 & 2 & 4.7 & 2 \\
\hline 262 & 28 & $150-160$ & 1 & & $x$ & 03 & - & 00 & 02 & 2 & 9.4 & 2 \\
\hline 262 & 28 & $150-160$ & 1 & $x$ & & 03 & - & 01 & 02 & 1 & 2.9 & 1 \\
\hline 262 & 28 & $150-160$ & 1 & & $x$ & 03 & - & 02 & 04 & 1 & 2.9 & 1 \\
\hline 262 & 28 & $150-160$ & 1 & $x$ & & 02 & 02 & 01 & 02 & 2 & 14.4 & 2 \\
\hline 262 & 28 & $150-160$ & 1 & $x$ & & 02 & 02 & 01 & 01 & 1 & 14.0 & 1 \\
\hline 262 & 28 & $150-160$ & 1 & & $x$ & 02 & 01 & 02 & 02 & 1 & 7.0 & 1 \\
\hline 251 & 29 & $100-110$ & 1 & & $x$ & 04 & - & 00 & 08 & 1 & 0.6 & 1 \\
\hline 251 & 29 & $100-110$ & 1 & & $x$ & 04 & - & 00 & 04 & 1 & 0.0 & 1 \\
\hline 251 & 29 & $100-110$ & 1 & $x$ & & 04 & - & 01 & 02 & 1 & 0.1 & 1 \\
\hline 251 & 29 & $100-110$ & 1 & & $x$ & 02 & 01 & 01 & 02 & 1 & 14.2 & 1 \\
\hline 258 & 29 & $110-120$ & 1 & & $x$ & 04 & - & 00 & 04 & 2 & 0.5 & 2 \\
\hline 258 & 29 & $110-120$ & 1 & & $x$ & 04 & - & 01 & 04 & 1 & 1.2 & 1 \\
\hline 258 & 29 & $110-120$ & 1 & $x$ & & 03 & - & 00 & 04 & 1 & 2.3 & 1 \\
\hline 258 & 29 & $110-120$ & 1 & & $x$ & 03 & - & 01 & 04 & 1 & 6.2 & 1 \\
\hline 258 & 29 & $110-120$ & 1 & $x$ & & 02 & 01 & 01 & 05 & 1 & 8.6 & 1 \\
\hline 258 & 29 & $110-120$ & 1 & & $x$ & 02 & 02 & 01 & 01 & 1 & 5.8 & 1 \\
\hline 260 & 29 & $120-130$ & 1 & $x$ & & 04 & - & 01 & 01 & 1 & 0.4 & 1 \\
\hline 260 & 29 & $120-130$ & 1 & $x$ & & 04 & - & 00 & 03 & 1 & 0.7 & 1 \\
\hline 271 & 29 & $130-140$ & 1 & & $x$ & 04 & - & 00 & 04 & 1 & 0.0 & 1 \\
\hline 271 & 29 & $130-140$ & 1 & & $x$ & 04 & - & 00 & 08 & 1 & 0.0 & 1 \\
\hline 271 & 29 & $130-140$ & 1 & & $x$ & 04 & - & 01 & 01 & 1 & 1.2 & 1 \\
\hline Feat. 1 & $6 / 10$ & - & 1 & $x$ & & 03 & 02 & 01 & 01 & 1 & 11.0 & 1 \\
\hline
\end{tabular}

Table B-8 Key:

\begin{tabular}{lllll}
\hline \multicolumn{1}{c}{ Raw Material } & \multicolumn{1}{c}{ Size Grade } & \multicolumn{1}{c}{ Thermally Altered } & Amount of Cortex & Platform Type \\
\hline $01=$ Unidentified Silex & $01=1$-inch sieve & $00=$ no & $00=0 \%$ & $00=$ indeterminate \\
$02=$ Microcrystalline Quartz & $02=3 / 4$-inch sieve & $01=$ yes & $01=1-25 \%$ & $01=$ cortical \\
$03=$ Macrocrystalline Quartz & $03=1 / 2$-inch sieve & $02=$ indeterminate & $02=26-50 \%$ & $02=$ flat \\
$04=$ Chalcedony & $04=1 / 4$-inch sieve & & $03=51-75 \%$ & $03=$ faceted \\
& & $04=76-100 \%$ & $04=$ multifaceted \\
& & & $05=$ abraded \\
& & & $06=$ complex \\
& & & $07=$ rejuventaed \\
& & & $08=$ missing \\
\hline
\end{tabular}


Table B-9. Catalog of Incomplete Flakes 100-200 cmbs.

\begin{tabular}{|c|c|c|c|c|c|}
\hline Lot \# & Unit \# & Depth (cmbs) & Total & Weight (g) & Heated \\
\hline 115 & 5 & $140-150$ & 2 & 1.2 & $Y$ \\
\hline 75 & 6 & $100-110$ & 2 & 1.8 & $Y$ \\
\hline 75 & 6 & $100-110$ & 1 & 0.2 & $\mathrm{~N}$ \\
\hline 82 & 6 & $110-120$ & 3 & 4.7 & $\mathrm{~N}$ \\
\hline 89 & 6 & $120-125$ & 2 & 0.8 & $\mathrm{~N}$ \\
\hline 94 & 6 & $130-140$ & 4 & 1.8 & Y \\
\hline 94 & 6 & $130-140$ & 3 & 1.0 & $\mathrm{~N}$ \\
\hline - & 6 & $150-160$ & 1 & 0.2 & $\mathrm{~N}$ \\
\hline 174 & 6 & $160-170$ & 2 & 4.5 & $\mathrm{~N}$ \\
\hline 174 & 6 & $160-170$ & 2 & 5.6 & Y \\
\hline 217 & 6 & $170-180$ & 14 & 26.4 & $\mathrm{~N}$ \\
\hline 217 & 6 & $170-180$ & 10 & 11.7 & Y \\
\hline 229 & 6 & $180-190$ & 2 & 2.8 & Y \\
\hline 229 & 6 & $180-190$ & 4 & 5.1 & $\mathrm{~N}$ \\
\hline 234 & 6 & $190-200$ & 1 & 0.1 & Y \\
\hline 234 & 6 & $190-200$ & 4 & 5.2 & $\mathrm{~N}$ \\
\hline 90 & 6 & $125-130$ & 4 & 1.3 & Y \\
\hline 90 & 6 & $125-150$ & 1 & 1.9 & $\mathrm{~N}$ \\
\hline 59 & 7 & $100-110$ & 2 & 5.4 & $\mathrm{~N}$ \\
\hline 59 & 7 & $100-110$ & 3 & 1.5 & Y \\
\hline 118 & 7 & $110-120$ & 1 & 3.1 & Y \\
\hline 121 & 7 & $120-130$ & 1 & 0.3 & $\mathrm{~N}$ \\
\hline 121 & 7 & $120-130$ & 1 & 5.2 & $\mathrm{Y}$ \\
\hline 125 & 7 & $130-140$ & 3 & 18.8 & $Y$ \\
\hline 125 & 7 & $130-140$ & 1 & 3.2 & $\mathrm{~N}$ \\
\hline 127 & 7 & $140-150$ & 10 & 11.6 & $Y$ \\
\hline 127 & 7 & $140-150$ & 10 & 19.7 & $\mathrm{~N}$ \\
\hline 73 & 7 & $100-110$ & 2 & 2.9 & $\mathrm{Y}$ \\
\hline 73 & 7 & $100-110$ & 4 & 1.6 & $\mathrm{~N}$ \\
\hline 97 & 8 & $120-130$ & 1 & 0.4 & Y \\
\hline 105 & 8 & $130-140$ & 3 & 21.2 & $\mathrm{~N}$ \\
\hline 105 & 8 & $130-140$ & 2 & 14.9 & Y \\
\hline 120 & 8 & $140-150$ & 2 & 10.5 & Y \\
\hline 120 & 8 & $140-150$ & 3 & 15.8 & $\mathrm{~N}$ \\
\hline 96 & 9 & $100-110$ & 1 & 0.4 & $Y$ \\
\hline 100 & 9 & $110-120$ & 3 & 13.8 & Y \\
\hline 108 & 9 & $120-130$ & 1 & 1.3 & $\mathrm{~N}$ \\
\hline 108 & 9 & $120-130$ & 4 & 5.3 & $Y$ \\
\hline 122 & 10 & $110-120$ & 4 & 2.7 & Y \\
\hline 122 & 10 & $110-120$ & 2 & 6.9 & $\mathrm{~N}$ \\
\hline 126 & 10 & $130-140$ & 1 & 1.3 & Y \\
\hline 126 & 10 & $130-140$ & 1 & 1.0 & $\mathrm{~N}$ \\
\hline 128 & 10 & $140-150$ & 5 & 5.3 & Y \\
\hline 128 & 10 & $140-150$ & 5 & 6.9 & $\mathrm{~N}$ \\
\hline 134 & 10 & $150-160$ & 4 & 32.3 & $\mathrm{~N}$ \\
\hline 134 & 10 & $150-160$ & 1 & 0.3 & Y \\
\hline- & 10 & $160-170$ & 2 & 1.3 & \\
\hline 216 & 10 & $170-180$ & 26 & 38.5 & $\mathrm{~N}$ \\
\hline 216 & 10 & $170-180$ & 9 & 15.8 & Y \\
\hline 219 & 10 & $180-190$ & 4 & 0.1 & $\mathrm{~N}$ \\
\hline 219 & 10 & $180-190$ & 1 & 1.3 & Y \\
\hline 130 & 11 & $110-120$ & 3 & 1.2 & $\mathrm{~N}$ \\
\hline 130 & 11 & $110-120$ & 1 & 2.1 & Y \\
\hline 132 & 11 & $120-130$ & 1 & 0.5 & Y \\
\hline 135 & 11 & $130-140$ & 2 & 0.7 & $\mathrm{~N}$ \\
\hline
\end{tabular}


Table B-9 (continued). Catalog of Incomplete Flakes 100-200 cmbs.

\begin{tabular}{|c|c|c|c|c|c|}
\hline Lot \# & Unit \# & Depth (cmbs) & Total & Weight $(\mathrm{g})$ & Heated \\
\hline 135 & 11 & $130-140$ & 1 & 0.4 & Y \\
\hline- & 11 & $140-150$ & 3 & 1.4 & Y \\
\hline- & 11 & $140-150$ & 2 & 2.1 & $\mathrm{~N}$ \\
\hline 131 & 12 & $100-110$ & 1 & 0.6 & $\mathrm{~N}$ \\
\hline 131 & 12 & $100-110$ & 2 & 0.7 & Y \\
\hline 133 & 12 & $110-120$ & 4 & 1.8 & Y \\
\hline 136 & 12 & $120-130$ & 3 & 2.4 & Y \\
\hline 138 & 12 & $130-140$ & 5 & 12.5 & $\mathrm{~N}$ \\
\hline 138 & 12 & $130-140$ & 1 & 1.2 & Y \\
\hline 139 & 12 & $140-150$ & 2 & 4.8 & Y \\
\hline 139 & 12 & $140-150$ & 4 & 6.3 & $\mathrm{~N}$ \\
\hline 146 & 13 & $110-120$ & 5 & 4.6 & Y \\
\hline 146 & 13 & $110-120$ & 4 & 7.0 & $\mathrm{~N}$ \\
\hline 150 & 13 & $120-130$ & 12 & 20.1 & $\mathrm{~N}$ \\
\hline 150 & 13 & $120-130$ & 1 & 0.0 & Y \\
\hline 158 & 13 & $130-140$ & 9 & 46.7 & $\mathrm{~N}$ \\
\hline 158 & 13 & $130-140$ & 5 & 9.0 & Y \\
\hline 163 & 13 & $140-150$ & 1 & 14.8 & $\mathrm{~N}$ \\
\hline 163 & 13 & $140-150$ & 2 & 7.7 & Y \\
\hline 170 & 13 & $150-160$ & 3 & 2.2 & Y \\
\hline 170 & 13 & $150-160$ & 3 & 3.2 & $N$ \\
\hline 184 & 13 & $160-170$ & 5 & 17.5 & Y \\
\hline 184 & 13 & $160-170$ & 6 & 14.4 & $N$ \\
\hline 218 & 13 & $170-180$ & 16 & 28.5 & $N$ \\
\hline 218 & 13 & $170-180$ & 7 & 4.0 & Y \\
\hline 156 & 14 & $110-120$ & 8 & 8.1 & $N$ \\
\hline 156 & 14 & $110-120$ & 5 & 3.8 & Y \\
\hline 179 & 14 & $130-140$ & 1 & 1.8 & $N$ \\
\hline 192 & 14 & $140-150$ & 1 & 0.4 & Y \\
\hline 203 & 14 & $160-170$ & 4 & 27.8 & $N$ \\
\hline 203 & 14 & $160-170$ & 1 & 0.7 & Y \\
\hline 205 & 14 & $160-170$ & 2 & 12.2 & $N$ \\
\hline 150 & 15 & $130-140$ & 1 & 0.4 & $N$ \\
\hline 216 & 10 & $170-180$ & 15 & 91.7 & $N$ \\
\hline 216 & 10 & $170-180$ & 57 & 298.2 & Y \\
\hline 219 & 10 & $180-190$ & 5 & 4.1 & Y \\
\hline 132 & 11 & $120-130$ & 2 & 3.2 & Y \\
\hline 135 & 11 & $130-140$ & 2 & 23.7 & Y \\
\hline 135 & 11 & $130-140$ & 1 & 0.1 & $N$ \\
\hline 131 & 12 & $100-110$ & 1 & 5.2 & $\mathrm{~N}$ \\
\hline 133 & 12 & $110-120$ & 1 & 21.5 & $\mathrm{~N}$ \\
\hline 133 & 12 & $110-120$ & 4 & 17.3 & Y \\
\hline 138 & 12 & $130-140$ & 2 & 1.0 & $\mathrm{~N}$ \\
\hline 138 & 12 & $130-140$ & 2 & 5.7 & Y \\
\hline 139 & 12 & $140-150$ & 5 & 46.5 & $\mathrm{~N}$ \\
\hline 139 & 12 & $140-150$ & 10 & 32.7 & Y \\
\hline 146 & 13 & $110-120$ & 4 & 9.7 & $Y$ \\
\hline 146 & 13 & $110-120$ & 1 & 1.8 & $N$ \\
\hline 150 & 13 & $120-130$ & 9 & 11.9 & $Y$ \\
\hline 150 & 13 & $120-130$ & 1 & 1.6 & $N$ \\
\hline 158 & 13 & $130-140$ & 9 & 8.8 & $Y$ \\
\hline 158 & 13 & $130-140$ & 4 & 4.3 & $N$ \\
\hline 163 & 13 & $140-150$ & 4 & 6.7 & $Y$ \\
\hline 163 & 13 & $140-150$ & 1 & 23.1 & $N$ \\
\hline 170 & 13 & $150-160$ & 3 & 25.5 & Y \\
\hline
\end{tabular}


Table B-9 (continued). Catalog of Incomplete Flakes 100-200 cmbs.

\begin{tabular}{|c|c|c|c|c|c|}
\hline Lot \# & Unit \# & Depth (cmbs) & Total & Weight (g) & Heated \\
\hline 170 & 13 & $150-160$ & 6 & 30.6 & $N$ \\
\hline 184 & 13 & $160-170$ & 3 & 29.6 & $\mathrm{~N}$ \\
\hline 184 & 13 & $160-170$ & 28 & 286.2 & Y \\
\hline 218 & 13 & $170-180$ & 21 & 119.4 & Y \\
\hline 218 & 13 & $170-180$ & 3 & 22.3 & $\mathrm{~N}$ \\
\hline 277 & 13 & $170-180$ & 2 & 43.6 & $\mathrm{~N}$ \\
\hline 277 & 13 & $170-180$ & 3 & 13.9 & Y \\
\hline 156 & 14 & $110-120$ & 2 & 0.4 & Y \\
\hline 178 & 14 & $120-130$ & 1 & 0.1 & Y \\
\hline 179 & 14 & $130-140$ & 4 & 59.6 & $\mathrm{~N}$ \\
\hline 179 & 14 & $130-140$ & 4 & 24.8 & Y \\
\hline 192 & 14 & $140-150$ & 1 & 12.3 & Y \\
\hline 193 & 14 & $150-160$ & 2 & 10.2 & $\mathrm{~N}$ \\
\hline 193 & 14 & $150-160$ & 2 & 19.2 & Y \\
\hline 203 & 14 & $160-170$ & 3 & 18.1 & Y \\
\hline 203 & 14 & $160-170$ & 2 & 42.7 & $\mathrm{~N}$ \\
\hline 205 & 14 & $160-170$ & 1 & 3.6 & Y \\
\hline 150 & 15 & $130-140$ & 2 & 31.6 & Y \\
\hline 151 & 15 & $140-150$ & 2 & 3.3 & Y \\
\hline 151 & 15 & $140-150$ & 2 & 1.5 & $\mathrm{~N}$ \\
\hline 187 & 15 & $160-170$ & 1 & 1.6 & Y \\
\hline 188 & 15 & $170-180$ & 2 & 16.9 & $\mathrm{~N}$ \\
\hline 151 & 15 & $140-150$ & 1 & 1.8 & $N$ \\
\hline 187 & 15 & $160-170$ & 2 & 4.1 & $\mathrm{~N}$ \\
\hline 188 & 15 & $170-180$ & 2 & 0.7 & $N$ \\
\hline 141 & 16 & $110-120$ & 1 & 0.7 & Y \\
\hline 142 & 16 & $120-130$ & 1 & 2.8 & Y \\
\hline 143 & 16 & $130-140$ & 1 & 0.8 & Y \\
\hline 147 & 17 & $110-120$ & 3 & 3.0 & $N$ \\
\hline 147 & 17 & $110-120$ & 1 & 1.8 & Y \\
\hline 153 & 17 & $120-130$ & 1 & 0.1 & \\
\hline 157 & 17 & $130-140$ & 8 & 9.8 & $N$ \\
\hline 157 & 17 & $130-140$ & 5 & 3.6 & Y \\
\hline 159 & 17 & $140-150$ & 6 & 19.7 & $N$ \\
\hline 167 & 18 & $110-120$ & 1 & 0.6 & $N$ \\
\hline- & 19 & $130-140$ & 1 & 2.5 & Y \\
\hline- & 19 & $130-140$ & 5 & 7.3 & $N$ \\
\hline- & 19 & $140-150$ & 4 & 9.2 & Y \\
\hline- & 19 & $140-150$ & 6 & 30.0 & $N$ \\
\hline- & 19 & $150-160$ & 1 & 2.1 & $N$ \\
\hline- & 20 & $110-120$ & 1 & 0.2 & Y \\
\hline- & 20 & $110-120$ & 2 & 1.7 & $N$ \\
\hline- & 20 & $120-130$ & 1 & 0.0 & Y \\
\hline- & 20 & $120-130$ & 1 & 0.0 & $N$ \\
\hline 189 & 20 & $130-140$ & 1 & 0.3 & $N$ \\
\hline 189 & 20 & $130-140$ & 3 & 0.7 & Y \\
\hline 191 & 20 & $140-150$ & 1 & 0.4 & Y \\
\hline 191 & 20 & $140-150$ & 7 & 4.0 & $N$ \\
\hline 195 & 20 & $150-160$ & 3 & 1.9 & $N$ \\
\hline 168 & 21 & $120-130$ & 2 & 2.4 & $N$ \\
\hline 175 & 21 & $130-140$ & 6 & 14.5 & $N$ \\
\hline 175 & 21 & $130-140$ & 2 & 3.0 & Y \\
\hline 176 & 21 & $140-150$ & 1 & 1.7 & $N$ \\
\hline 177 & 21 & $150-160$ & 2 & 4.1 & $N$ \\
\hline 181 & 22 & $110-120$ & 2 & 4.0 & $\mathrm{Y}$ \\
\hline
\end{tabular}


Table B-9 (continued). Catalog of Incomplete Flakes 100-200 cmbs.

\begin{tabular}{|c|c|c|c|c|c|}
\hline Lot \# & Unit \# & Depth (cmbs) & Total & Weight $(\mathrm{g})$ & Heated \\
\hline 190 & 22 & $120-130$ & 2 & 1.3 & $N$ \\
\hline 194 & 22 & $130-140$ & 6 & 10.2 & $\mathrm{~N}$ \\
\hline 194 & 22 & $130-140$ & 2 & 1.4 & Y \\
\hline 196 & 22 & $140-150$ & 6 & 8.7 & $N$ \\
\hline 196 & 22 & $140-150$ & 2 & 1.3 & Y \\
\hline 207 & 22 & $150-160$ & 4 & 6.3 & $\mathrm{~N}$ \\
\hline 244 & 23 & $110-120$ & 1 & 0.0 & $\mathrm{~N}$ \\
\hline 248 & 23 & $120-130$ & 1 & 0.0 & $N$ \\
\hline 255 & 23 & $130-140$ & 2 & 0.5 & $\mathrm{~N}$ \\
\hline 259 & 23 & $140-150$ & 1 & 0.7 & Y \\
\hline 259 & 23 & $140-150$ & 1 & 4.4 & $N$ \\
\hline 171 & 24 & $100-110$ & 2 & 1.1 & $N$ \\
\hline 183 & 24 & $140-150$ & 1 & 0.5 & Y \\
\hline 197 & 24 & $150-160$ & 1 & 0.4 & $N$ \\
\hline 197 & 24 & $150-160$ & 2 & 5.4 & Y \\
\hline 200 & 25 & $100-110$ & 1 & 0.0 & Y \\
\hline 200 & 25 & $100-110$ & 2 & 0.3 & $N$ \\
\hline 201 & 25 & $110-120$ & 2 & 0.7 & $N$ \\
\hline 201 & 25 & $110-120$ & 2 & 6.6 & Y \\
\hline 220 & 25 & $120-130$ & 2 & 4.5 & $N$ \\
\hline 221 & 25 & $130-140$ & 3 & 28.9 & $N$ \\
\hline 221 & 25 & $130-140$ & 1 & 12.8 & Y \\
\hline 222 & 25 & $140-150$ & 2 & 1.8 & Y \\
\hline 222 & 25 & $140-150$ & 3 & 11.2 & $N$ \\
\hline 235 & 25 & $150-160$ & 7 & 7.9 & $N$ \\
\hline 236 & 25 & $150-160$ & 3 & 2.1 & $N$ \\
\hline 185 & 26 & $100-110$ & 1 & 1.4 & $N$ \\
\hline 185 & 26 & $100-110$ & 1 & 1.0 & Y \\
\hline 186 & 26 & $110-120$ & 4 & 12.4 & $N$ \\
\hline 186 & 26 & $110-120$ & 2 & 1.8 & Y \\
\hline 202 & 26 & $120-130$ & 2 & 1.0 & Y \\
\hline 202 & 26 & $120-130$ & 3 & 5.2 & $N$ \\
\hline 249 & 27 & $100-110$ & 4 & 4.0 & $N$ \\
\hline 252 & 27 & $110-120$ & 1 & 0.6 & $N$ \\
\hline 252 & 27 & $110-120$ & 1 & 0.1 & Y \\
\hline 266 & 27 & $130-140$ & 4 & 7.8 & $N$ \\
\hline 266 & 27 & $130-140$ & 3 & 5.5 & Y \\
\hline 246 & 28 & $100-110$ & 2 & 3.1 & $N$ \\
\hline 247 & 28 & $110-120$ & 1 & 0.0 & $N$ \\
\hline 253 & 28 & $120-130$ & 8 & 9.5 & $N$ \\
\hline 253 & 28 & $120-130$ & 1 & 6.6 & Y \\
\hline 254 & 28 & $130-140$ & 4 & 17.8 & $N$ \\
\hline 261 & 28 & $140-150$ & 2 & 2.9 & $N$ \\
\hline 262 & 28 & $150-160$ & 6 & 16.1 & Y \\
\hline 262 & 28 & $150-160$ & 2 & 2.1 & $N$ \\
\hline 260 & 29 & $120-130$ & 2 & 1.6 & Y \\
\hline 260 & 29 & $120-130$ & 1 & 0.8 & $N$ \\
\hline 271 & 29 & $130-140$ & 1 & 1.8 & Y \\
\hline 251 & 29 & $100-110$ & 2 & 3.8 & $\mathrm{~N}$ \\
\hline
\end{tabular}


Table B-10. Catalog of Debitage 100-200 cmbs.

\begin{tabular}{|c|c|c|c|c|c|}
\hline Lot \# & Unit \# & Depth (cmbs) & Total & Weight $(\mathrm{g})$ & Heated \\
\hline 64 & 1 & $110-120$ & 2 & 5.7 & $\mathrm{~N}$ \\
\hline 67 & 1 & $120-130$ & 3 & 10.5 & Y \\
\hline 71 & 1 & $130-140$ & 4 & 2.4 & $\mathrm{~N}$ \\
\hline 71 & 1 & $130-140$ & 9 & 10.0 & Y \\
\hline 76 & 1 & $140-150$ & 6 & 20.9 & $\mathrm{~N}$ \\
\hline 83 & 1 & $150-160$ & 6 & 6.9 & $\mathrm{~N}$ \\
\hline 83 & 1 & $150-160$ & 1 & 2.8 & Y \\
\hline 87 & 1 & $160-170$ & 1 & 1.8 & Y \\
\hline 42 & 2 & $120-130$ & 1 & 2.6 & Y \\
\hline 47 & 2 & $130-140$ & 2 & 31.1 & Y \\
\hline 47 & 2 & $130-140$ & 1 & 16.4 & $\mathrm{~N}$ \\
\hline 113 & 2 & $150-160$ & 1 & 0.4 & $\mathrm{~N}$ \\
\hline 114 & 2 & $160-170$ & 8 & 76.0 & Y \\
\hline 116 & 2 & $170-180$ & 4 & 25.1 & Y \\
\hline 116 & 2 & $170-180$ & 2 & 7.6 & $\mathrm{~N}$ \\
\hline 119 & 2 & $180-190$ & 1 & 8.3 & $\mathrm{~N}$ \\
\hline 119 & 2 & $180-190$ & 3 & 13.8 & Y \\
\hline 40 & 3 & $100-110$ & 4 & 7.1 & $\mathrm{~N}$ \\
\hline 40 & 3 & $100-110$ & 3 & 2.5 & Y \\
\hline 45 & 3 & $110-120$ & 5 & 3.0 & Y \\
\hline 49 & 3 & $120-130$ & 9 & 9.1 & $Y$ \\
\hline 55 & 3 & $130-140$ & 5 & 2.4 & Y \\
\hline 58 & 3 & $140-150$ & 5 & 1.3 & $Y$ \\
\hline 99 & 3 & $150-160$ & 4 & 3.6 & $Y$ \\
\hline 107 & 3 & $70-180$ & 6 & 13.0 & $Y$ \\
\hline 25 & 4 & $100-110$ & 1 & 0.8 & $\mathrm{~N}$ \\
\hline 25 & 4 & $100-110$ & 1 & 0.2 & $Y$ \\
\hline- & 4 & $110-120$ & 1 & 4.3 & $Y$ \\
\hline 84 & 4 & $130-140$ & 2 & 21.2 & $Y$ \\
\hline 84 & 4 & $130-140$ & 1 & 1.0 & $\mathrm{~N}$ \\
\hline 86 & 4 & $140-150$ & 11 & 22.8 & Y \\
\hline 86 & 4 & $140-150$ & 3 & 0.9 & $\mathrm{~N}$ \\
\hline 102 & 5 & $110-120$ & 3 & 49.2 & $\mathrm{~N}$ \\
\hline 102 & 5 & $110-120$ & 1 & 1.3 & $Y$ \\
\hline 109 & 5 & $120-130$ & 3 & 30.2 & $Y$ \\
\hline 109 & 5 & $120-130$ & 2 & 1.8 & $\mathrm{~N}$ \\
\hline 110 & 5 & $130-140$ & 4 & 8.8 & $Y$ \\
\hline 110 & 5 & $130-140$ & 1 & 0.5 & $\mathrm{~N}$ \\
\hline 115 & 5 & $140-150$ & 2 & 2.7 & $\mathrm{~N}$ \\
\hline 115 & 5 & $140-150$ & 22 & 74.4 & $Y$ \\
\hline 75 & 6 & $100-110$ & 1 & 3.2 & $Y$ \\
\hline 82 & 6 & $110-120$ & 1 & 0.1 & $Y$ \\
\hline 89 & 6 & $120-125$ & 2 & 4.3 & $Y$ \\
\hline 94 & 6 & $130-140$ & 5 & 29.0 & $Y$ \\
\hline 103 & 6 & $140-150$ & 1 & 0.4 & $\mathrm{~N}$ \\
\hline 103 & 6 & $140-150$ & 3 & 31.3 & Y \\
\hline- & 6 & $150-160$ & 1 & 10.8 & $\mathrm{~N}$ \\
\hline- & 6 & $150-160$ & 6 & 66.8 & $Y$ \\
\hline 174 & 6 & $160-170$ & 5 & 4.9 & $Y$ \\
\hline 217 & 6 & $170-180$ & 6 & 64.6 & $\mathrm{~N}$ \\
\hline 217 & 6 & $170-180$ & 36 & 112.4 & $\mathrm{Y}$ \\
\hline 229 & 6 & $180-190$ & 2 & 3.0 & $Y$ \\
\hline 229 & 6 & $180-190$ & 1 & 0.8 & $\mathrm{~N}$ \\
\hline 234 & 6 & $190-200$ & 2 & 9.9 & $Y$ \\
\hline 234 & 6 & $190-200$ & 4 & 15.8 & $\mathrm{~N}$ \\
\hline
\end{tabular}


Table B-10 (continued). Catalog of Debitage 100-200 cmbs.

\begin{tabular}{|c|c|c|c|c|c|}
\hline Lot \# & Unit \# & Depth (cmbs) & Total & Weight $(\mathrm{g})$ & Heated \\
\hline 90 & 6 & $125-130$ & 4 & 18.9 & $\mathrm{Y}$ \\
\hline 90 & 6 & $125-130$ & 1 & 1.7 & $\mathrm{~N}$ \\
\hline 59 & 7 & $100-110$ & 1 & 2.4 & $\mathrm{~N}$ \\
\hline 59 & 7 & $100-110$ & 4 & 8.8 & Y \\
\hline 121 & 7 & $120-130$ & 1 & 0.6 & Y \\
\hline 127 & 7 & $140-150$ & 17 & 38.0 & $\mathrm{~N}$ \\
\hline 127 & 7 & $140-150$ & 14 & 18.2 & Y \\
\hline 73 & 8 & $100-110$ & 1 & 0.4 & Y \\
\hline 97 & 8 & $120-130$ & 3 & 51.8 & $N$ \\
\hline 105 & 8 & $130-140$ & 1 & 2.7 & $N$ \\
\hline 105 & 8 & $130-140$ & 4 & 26.0 & Y \\
\hline 120 & 8 & $140-150$ & 4 & 17.6 & $N$ \\
\hline 120 & 8 & $140-150$ & 11 & 7.0 & Y \\
\hline 117 & 8 & $150-160$ & 3 & 2.6 & $N$ \\
\hline 117 & 8 & $150-160$ & 1 & 0.3 & Y \\
\hline 96 & 9 & $100-110$ & 8 & 7.4 & Y \\
\hline 100 & 9 & $110-120$ & 2 & 8.4 & $\mathrm{~N}$ \\
\hline 100 & 9 & $110-120$ & 6 & 5.9 & Y \\
\hline 108 & 9 & $120-130$ & 2 & 3.8 & $\mathrm{~N}$ \\
\hline 108 & 9 & $120-130$ & 19 & 24.8 & Y \\
\hline 111 & 9 & $130-140$ & 1 & 0.2 & $N$ \\
\hline 111 & 9 & $130-140$ & 8 & 13.8 & Y \\
\hline 122 & 10 & $110-120$ & 2 & 2.4 & $N$ \\
\hline 129 & 10 & $120-130$ & 1 & 3.4 & Y \\
\hline 126 & 10 & $130-140$ & 6 & 5.8 & Y \\
\hline 126 & 10 & $130-140$ & 4 & 9.1 & $N$ \\
\hline 128 & 10 & $140-150$ & 1 & 1.0 & Y \\
\hline 128 & 10 & $140-150$ & 14 & 42.2 & Y \\
\hline 128 & 10 & $140-150$ & 2 & 15.2 & $N$ \\
\hline 134 & 10 & $150-160$ & 1 & 7.2 & $N$ \\
\hline 134 & 10 & $150-160$ & 8 & 30.2 & Y \\
\hline- & 10 & $160-170$ & 4 & 29.5 & $N$ \\
\hline- & 10 & $160-170$ & 14 & 133.6 & Y \\
\hline 188 & 15 & $170-180$ & 7 & 52.9 & Y \\
\hline 141 & 16 & $110-120$ & 2 & 95.6 & Y \\
\hline 142 & 16 & $120-130$ & 1 & 0.8 & $N$ \\
\hline 143 & 16 & $130-140$ & 2 & 6.7 & Y \\
\hline 143 & 16 & $130-140$ & 1 & 2.2 & $N$ \\
\hline 147 & 17 & $110-120$ & 2 & 21.2 & $N$ \\
\hline 153 & 17 & $120-130$ & 2 & 7.5 & Y \\
\hline 157 & 17 & $130-140$ & 6 & 11.0 & $N$ \\
\hline 157 & 17 & $130-140$ & 13 & 49.4 & Y \\
\hline 159 & 17 & $140-150$ & 2 & 1.6 & $N$ \\
\hline 159 & 17 & $140-150$ & 4 & 16.3 & Y \\
\hline 167 & 18 & $110-120$ & 1 & 3.2 & Y \\
\hline 170 & 18 & $130-140$ & 1 & 0.4 & $N$ \\
\hline- & 19 & $110-120$ & 1 & 0.4 & Y \\
\hline- & 19 & $120-130$ & 1 & 1.5 & Y \\
\hline- & 19 & $130-140$ & 6 & 3.3 & $N$ \\
\hline- & 19 & $130-140$ & 10 & 44.6 & Y \\
\hline- & 19 & $140-150$ & 4 & 1.6 & Y \\
\hline- & 19 & $140-150$ & 4 & 17.0 & $N$ \\
\hline- & 19 & $150-160$ & 1 & 0.4 & $N$ \\
\hline- & 20 & $120-130$ & 1 & 0.5 & Y \\
\hline 189 & 20 & $130-140$ & 2 & 4.0 & Y \\
\hline
\end{tabular}


Table B-10 (continued). Catalog of Debitage 100-200 cmbs.

\begin{tabular}{|c|c|c|c|c|c|}
\hline Lot \# & Unit \# & Depth (cmbs) & Total & Weight (g) & Heated \\
\hline 189 & 20 & $130-140$ & 3 & 13.0 & $\mathrm{~N}$ \\
\hline 191 & 20 & $140-150$ & 13 & 10.4 & Y \\
\hline 191 & 20 & $140-150$ & 11 & 41.7 & $\mathrm{~N}$ \\
\hline 195 & 20 & $150-160$ & 2 & 11.1 & $\mathrm{~N}$ \\
\hline 164 & 21 & $110-120$ & 3 & 11.9 & $\mathrm{~N}$ \\
\hline 164 & 21 & $110-120$ & 3 & 22.4 & Y \\
\hline 168 & 21 & $120-130$ & 2 & 2.3 & $\mathrm{~N}$ \\
\hline 168 & 21 & $120-130$ & 1 & 1.4 & Y \\
\hline 175 & 21 & $130-140$ & 4 & 16.4 & Y \\
\hline 175 & 21 & $130-140$ & 4 & 15.4 & $\mathrm{~N}$ \\
\hline 176 & 21 & $140-150$ & 2 & 11.0 & Y \\
\hline 176 & 21 & $140-150$ & 3 & 36.7 & $\mathrm{~N}$ \\
\hline 181 & 22 & $110-120$ & 2 & 40.0 & Y \\
\hline 190 & 22 & $120-130$ & 2 & 4.6 & Y \\
\hline 190 & 22 & $120-130$ & 1 & 11.1 & $\mathrm{~N}$ \\
\hline 194 & 22 & $130-140$ & 6 & 8.7 & Y \\
\hline 194 & 22 & $130-140$ & 7 & 38.4 & $\mathrm{~N}$ \\
\hline 196 & 22 & $140-150$ & 2 & 1.8 & Y \\
\hline 196 & 22 & $140-150$ & 1 & 9.6 & $\mathrm{~N}$ \\
\hline 207 & 22 & $150-160$ & 3 & 22.1 & $\mathrm{~N}$ \\
\hline 207 & 22 & $150-160$ & 5 & 9.7 & Y \\
\hline 242 & 23 & $100-110$ & 3 & 14.0 & $\mathrm{~N}$ \\
\hline 242 & 23 & $100-110$ & 2 & 3.7 & Y \\
\hline 244 & 23 & $110-120$ & 3 & 37.6 & Y \\
\hline 255 & 23 & $130-140$ & 2 & 5.8 & Y \\
\hline 255 & 23 & $130-140$ & 7 & 44.7 & $\mathrm{~N}$ \\
\hline 259 & 23 & $140-150$ & 11 & 89.9 & $Y$ \\
\hline 259 & 23 & $140-150$ & 5 & 46.4 & $\mathrm{~N}$ \\
\hline 171 & 24 & $100-110$ & 2 & 3.2 & Y \\
\hline 171 & 24 & $100-110$ & 1 & 0.9 & $\mathrm{~N}$ \\
\hline 172 & 24 & $110-120$ & 2 & 7.4 & $\mathrm{~N}$ \\
\hline 182 & 24 & $130-140$ & 2 & 4.5 & $\mathrm{~N}$ \\
\hline 182 & 24 & $130-140$ & 1 & 3.2 & Y \\
\hline 197 & 24 & $150-160$ & 6 & 66.3 & $\mathrm{~N}$ \\
\hline 197 & 24 & $150-160$ & 21 & 269.1 & Y \\
\hline 198 & 24 & $160-170$ & 2 & 27.6 & Y \\
\hline 198 & 24 & $160-170$ & 3 & 33.9 & $\mathrm{~N}$ \\
\hline 200 & 25 & $100-110$ & 1 & 0.6 & $\mathrm{~N}$ \\
\hline 200 & 25 & $100-110$ & 1 & 1.1 & Y \\
\hline 201 & 25 & $110-120$ & 1 & 0.7 & $N$ \\
\hline 201 & 25 & $110-120$ & 3 & 12.9 & $Y$ \\
\hline 220 & 25 & $120-130$ & 1 & 0.4 & $\mathrm{~N}$ \\
\hline 220 & 25 & $120-130$ & 11 & 34.2 & Y \\
\hline 221 & 25 & $130-140$ & 7 & 117.0 & Y \\
\hline 221 & 25 & $130-140$ & 3 & 8.2 & $\mathrm{~N}$ \\
\hline 222 & 25 & $140-150$ & 10 & 31.7 & Y \\
\hline 222 & 25 & $140-150$ & 2 & 0.7 & $\mathrm{~N}$ \\
\hline 235 & 25 & $150-160$ & 18 & 114.7 & $\mathrm{~N}$ \\
\hline 235 & 25 & $150-160$ & 36 & 118.9 & Y \\
\hline 185 & 26 & $100-110$ & 1 & 14.6 & Y \\
\hline 202 & 26 & $120-130$ & 2 & 4.1 & Y \\
\hline 249 & 27 & $100-110$ & 1 & 14.7 & $Y$ \\
\hline 266 & 27 & $130-140$ & 4 & 12.5 & Y \\
\hline 266 & 27 & $130-140$ & 1 & 0.0 & $\mathrm{~N}$ \\
\hline 246 & 28 & $100-110$ & 5 & 14.4 & Y \\
\hline
\end{tabular}


Table B-10 (continued). Catalog of Debitage 100-200 cmbs.

\begin{tabular}{cccccc}
\hline Lot \# & Unit \# & Depth (cmbs) & Total & Weight $(\mathrm{g})$ & Heated \\
\hline 246 & 28 & $100-110$ & 2 & 12.3 & $\mathrm{~N}$ \\
247 & 28 & $110-120$ & 3 & 29.4 & $\mathrm{Y}$ \\
247 & 28 & $110-120$ & 1 & 4.7 & $\mathrm{~N}$ \\
253 & 28 & $120-130$ & 2 & 0.4 & $\mathrm{Y}$ \\
253 & 28 & $120-130$ & 2 & 32.5 & $\mathrm{~N}$ \\
254 & 28 & $130-140$ & 2 & 6.4 & $\mathrm{~N}$ \\
261 & 28 & $140-150$ & 5 & 7.9 & $\mathrm{Y}$ \\
261 & 28 & $140-150$ & 3 & 19.5 & $\mathrm{~N}$ \\
262 & 28 & $150-160$ & 11 & 44.2 & $\mathrm{Y}$ \\
262 & 28 & $150-160$ & 2 & 3.8 & $\mathrm{~N}$ \\
251 & 29 & $100-110$ & 4 & 13.8 & $\mathrm{Y}$ \\
258 & 29 & $110-120$ & 3 & 4.7 & $\mathrm{Y}$ \\
260 & 29 & $120-130$ & 1 & 35.3 & $\mathrm{Y}$ \\
260 & 29 & $120-130$ & 1 & 11.0 & $\mathrm{~N}$ \\
271 & 29 & $130-140$ & 1 & 0.4 & $\mathrm{Y}$ \\
\hline
\end{tabular}




\section{Appendix C \\ Freshwater Mussel Shell Analysis}

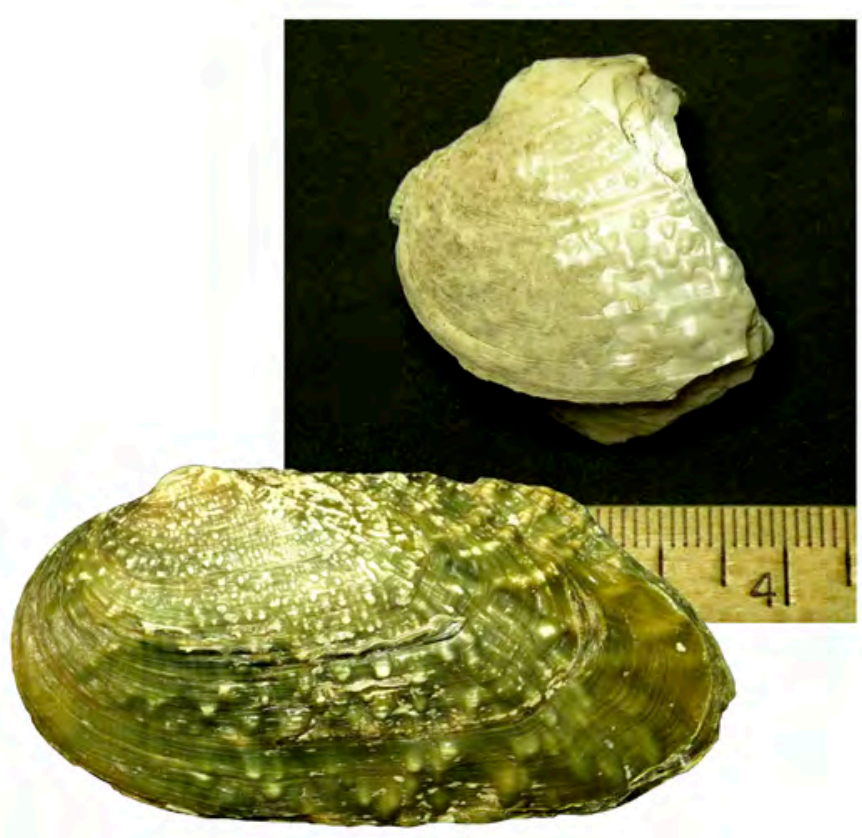

Robert G. Howells

BioStudies, Kerrville, Texas

Prepared for:

Ecological Communications Corp.

Austin, Texas

September 2011 


\section{FRESHWATER MUSSEL SHELL REMAINS:}

\section{DW277, DeWitt County, Texas}

\section{INTRODUCTION}

Freshwater mussels (Unionidae) are important elements of aquatic ecosystems in Texas (Howells et al. 1996; Howells 2010a) and throughout North America (Parmalee and Bogan 1998; Williams et al. 2008; Watters et al. 2009). This group has also played an important roll in Native American activities in many areas (Parmalee and Bogan 1998; Williams et al. 2008; Watters et al. 2009), including many sites in Texas (e.g., Neck 1982; Murray 1982; Howells 1998, 2001, 2002a, 2002b, 2009; Howells et al. 2003). Shells, valves, and fragments of many species were not only harvested by Native Americans, but preserve well and therefore provide a record of species present, those harvested, and related environmental conditions.

An archaeological survey conducted by Ecological Communications Corporation, Inc. (EComm), Austin, Texas, at a site in DeWitt County, Texas, in the lower Guadalupe River drainage, produced an array of freshwater mussels valve fragments. These were delivered to BioStudies, Kerrville, Texas, in late summer 2011 for examination, identification, and analysis. Results are reported herein.

\section{Materials ANd Methods}

Identification of freshwater mussel fragments follows Howells et al. (1996) and Howells (2010a). Species terminology follows Williams et al. (1993), Turgeon et al. (1998), and Howells et al. (1996), except for more recent changes in species terminology (Howells 2010a).

Selected representative specimens from the 41DW277 Site were photographed (Figs. 1-15) during processing to demonstrate some diagnostic features used in making identifications. Additional photographs of recent specimens of the unionid taxa recovered at 41DW277 were also taken and included for reference (Figs. 16-24).

\section{RESUlTS AND Discussion}

Over 50 freshwater mussel species have been reported in Texas (Howells et al. 1996; Howells 2101a, b), with at least 25 confirmed in waters of the Guadalupe-San Antonio basin (Howells 2010b) (Table 1). However, among these 25 unionids, two species, and probably a third, were non-native introductions that would not be expected among archaeological remains.

EComm recovered 1,513 mussel shell remains from Site 41DW277 (Sub-Appendix Table 1). Among these, were nine mussel species and two other taxa (Table 2) including: threeridge (Amblema plicata), Tampico pearlymussel (Cyrtonaias tampicoensis), Louisiana fatmucket (Lampsilis hydiana), yellow sandshell (L. teres), an unidentified lampsiliid (either Louisiana fatmucket or yellow sandshell), washboard (Megalonaias nervosa), southern mapleleaf (Quadrula apiculata), golden orb (Q. aurea), false spike (Q. mitchelli), pistolgrip (Q. verrucosa), and unidentified quadrulid fragments (most probably southern mapleleaf or golden orb, but possibly pistolgrip or Texas pimpleback Q. petrina), as well as unidentified and unidentifiable shell and valve fragments. 


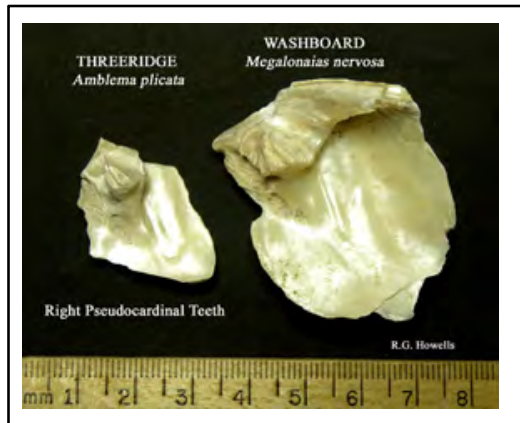

Figure C-1. Threeridge (Amblema plicata) and washboard (Megalonaias nervosa) right pseudocardinal teeth. Although this tooth is similar in both species, its major axis angles more posteriorly in threeridge and the posterio-ventral tooth base is not as broad as that of washboard.

Figures C-4 and C-5. Golden orb (Quadrula aurea) right valve interior and exterior views. This species typically has little or no disk sculpturing and hinge teeth that are often less massive than many other quadrulids.

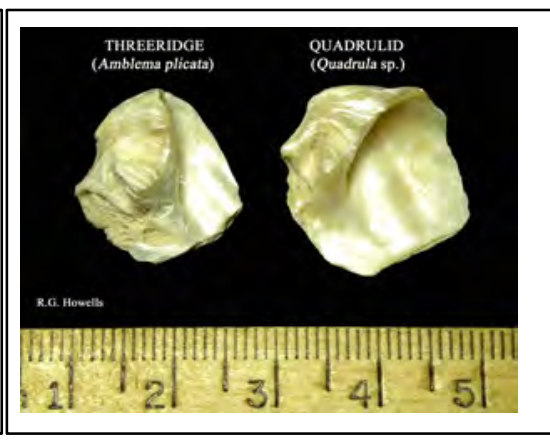

Figure C-2. Threeridge (Amblema plicata) and quadrulid (Quadrula sp.) right pseudocardinal teeth. The major axis of this tooth in threeridge angles toward the posterio-ventral corner of the shell, but angles downward in many quadrulids. This tooth has a nearly flat anterior surface in golden orb (Q. aurea) and some other members of the genus.
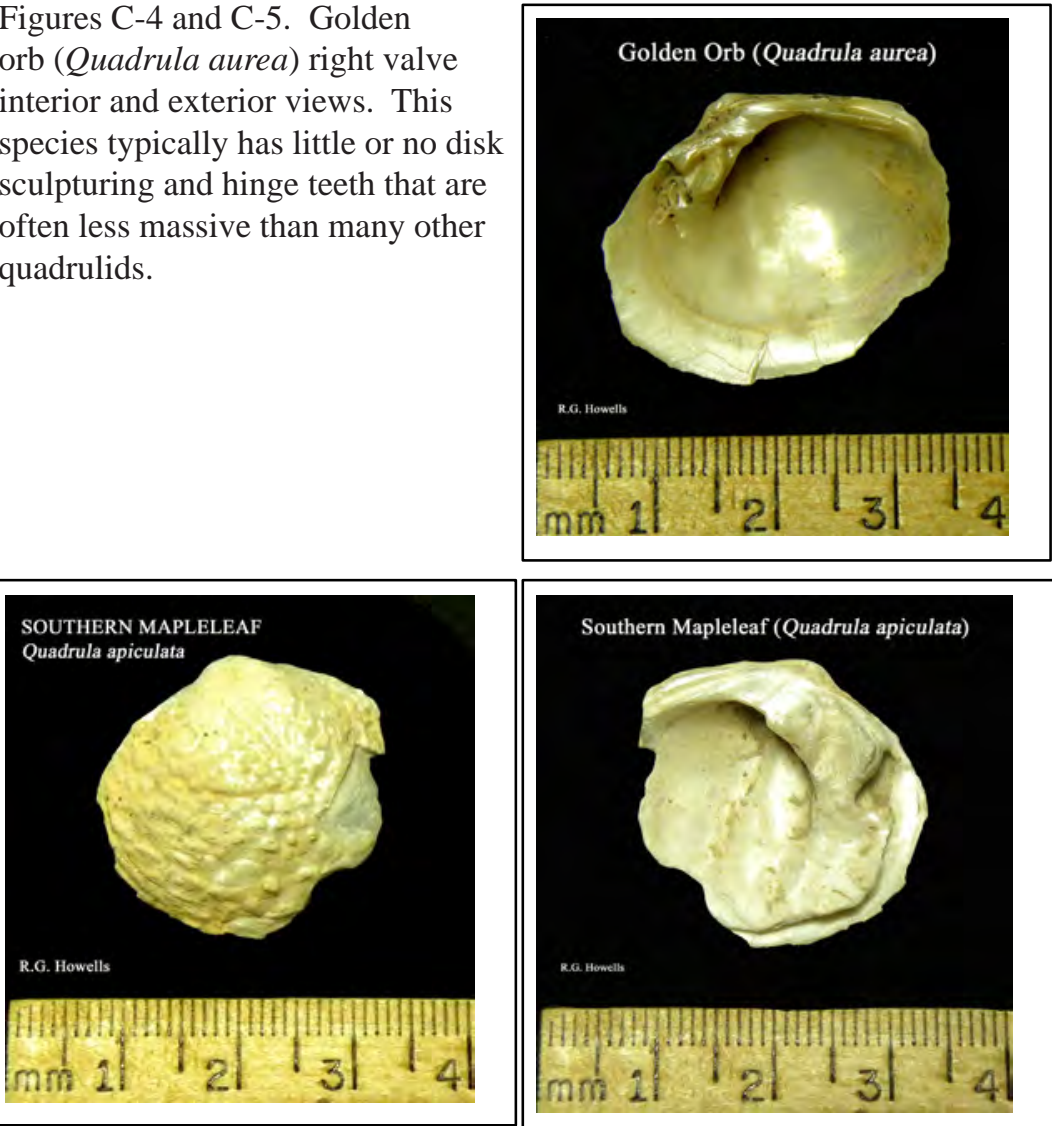

Figures C-6 and C-7. Southern mapleleaf (Quadrula apiculata) left valve fragment. This is one of the few unionid species in the Guadalupe-San Antonio drainage basin that has numerous small pustules on the shell periostracum (exterior) that allow identification of disk fragments when beaks and hinge teeth are lacking.

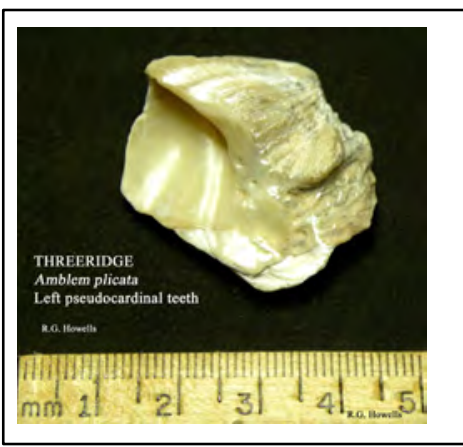

Figure C-3. Threeridge (Amblema plicata) left pseudocardinal teeth. The posterior left pseudocardinal tooth in threeridge is typically larger than the corresponding tooth in washboard (Megalonaias nervosa).
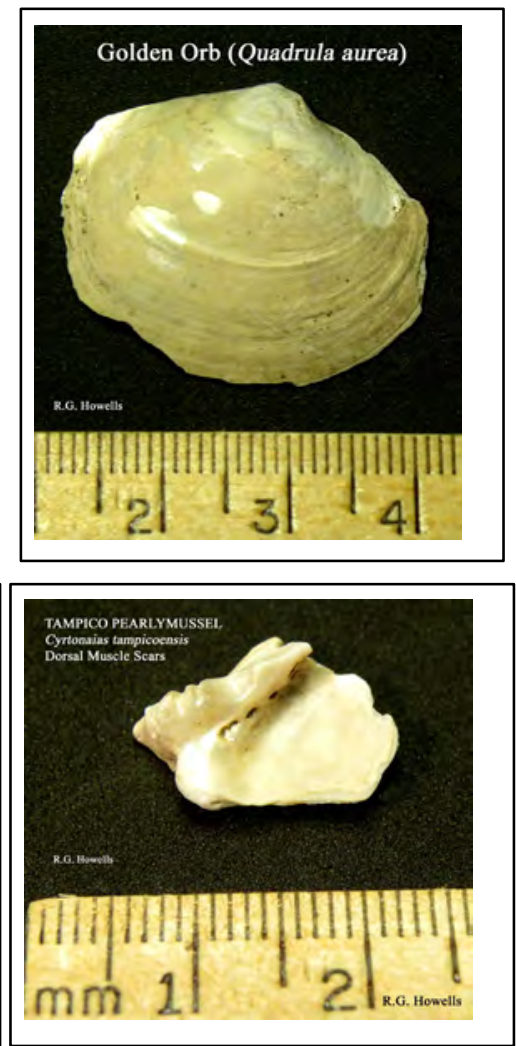

Figure C-8. Tampico pearlymussel (Cyrtonaias tampicoensis) showing dorsal muscle scars in the beak cavity. 

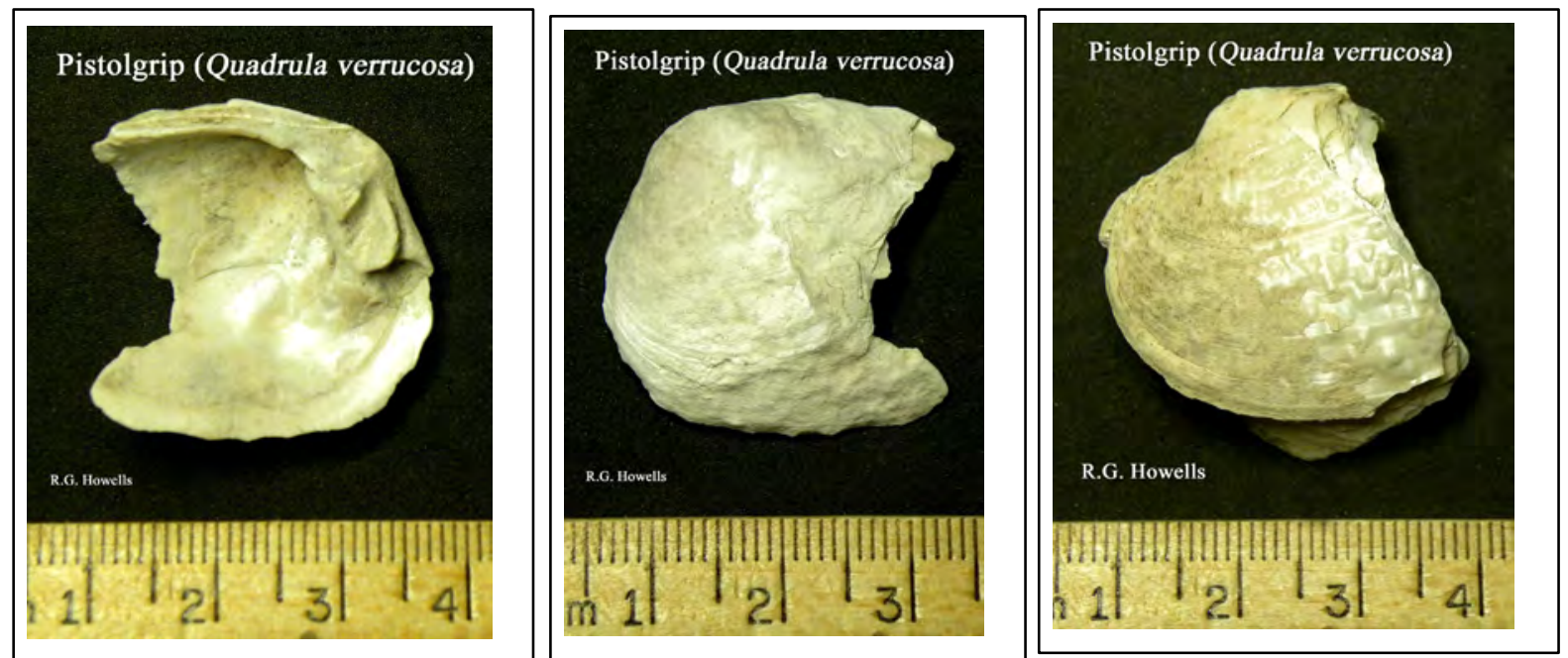

Figures C-9, C-10, and C-11. Pistolgrip (Quadrula verrucosa) left valve fragments. Like southern mapleleaf (Q. apiculata), this species also has external sculpturing on the disk that can allow identification of disk fragments. Although this species is strongly sexually dimorphic (females are longer than males), the posterior portion of the shell (absent in these specimens) is necessary to make that identification.
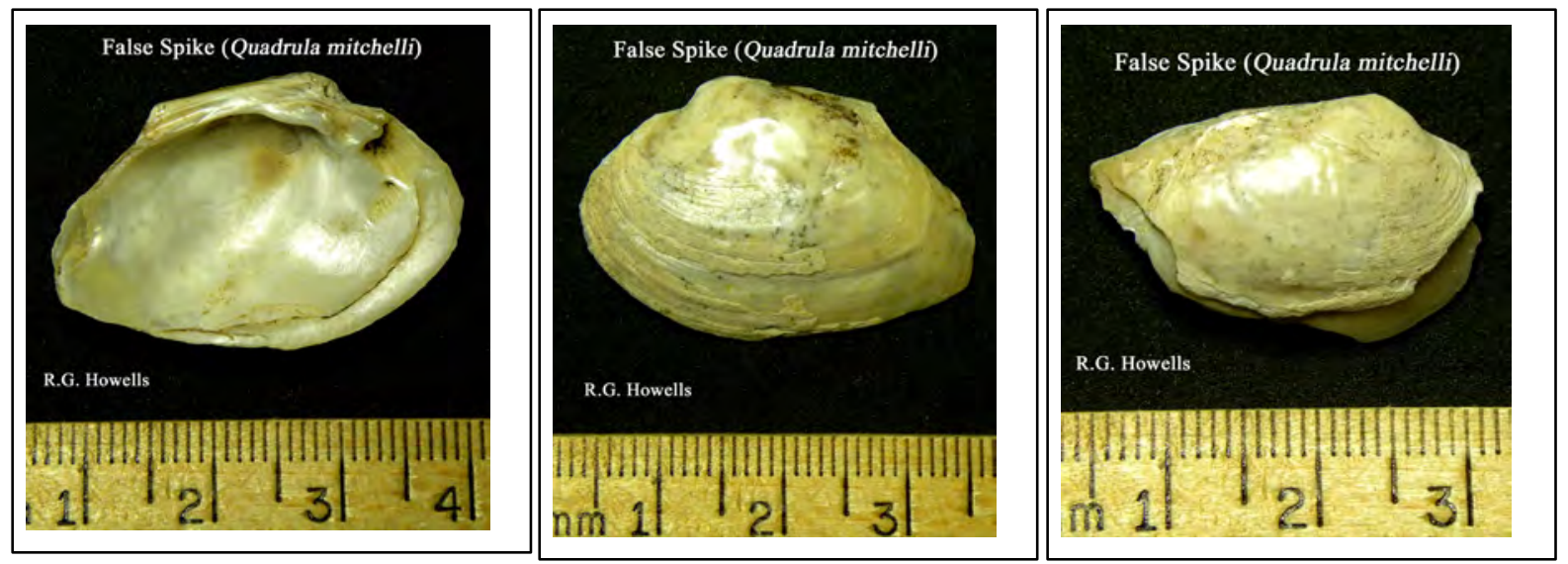

Figures C-12, C-13, and C-14. False spike (Quadrula mitchelli) left valves (above left and center) and right valve fragment (above right). This morphologically variable species may or may not have external disk sculpture. However, many specimens show a series of vertical grooves in the mid-disk area (apparent in the image above right).

Figure C-15. Right and left pseudocardinal teeth of several unionid taxa that appear to have been burnt based on the grayish coloration present here rather than the chalky white typical of unburned material.

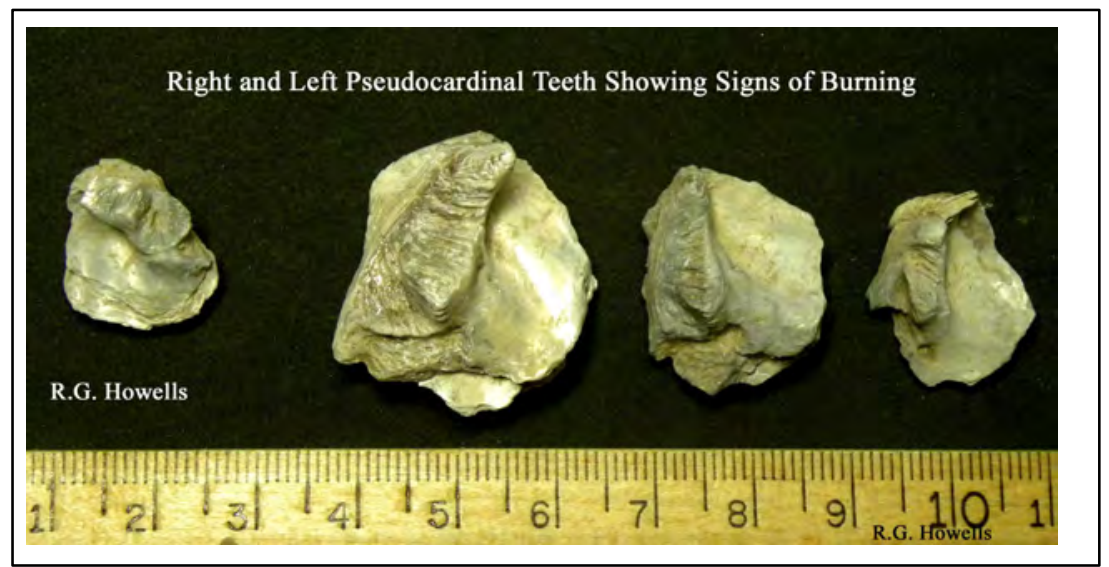




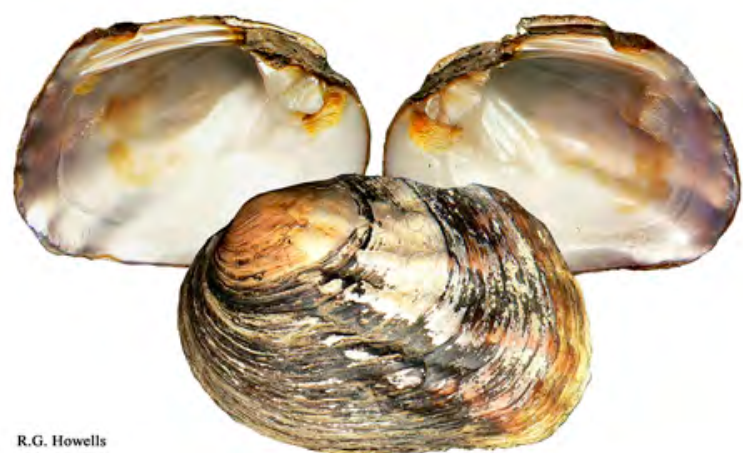

Figure C-16. Threeridge (Amblema plicata).

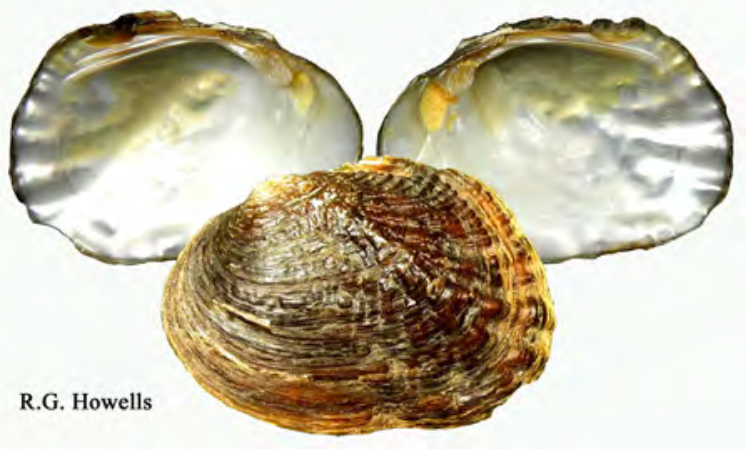

Figure C-17. Washboard (Megalonaias nervosa).

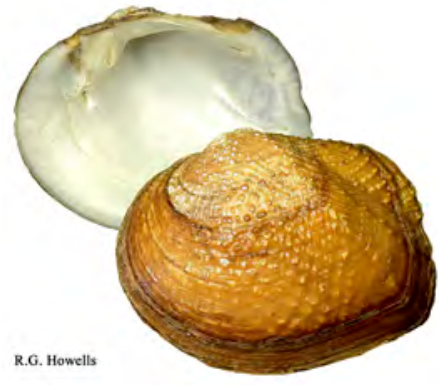

Figure C-18. Southern mapleleaf (Quadrula apiculata).

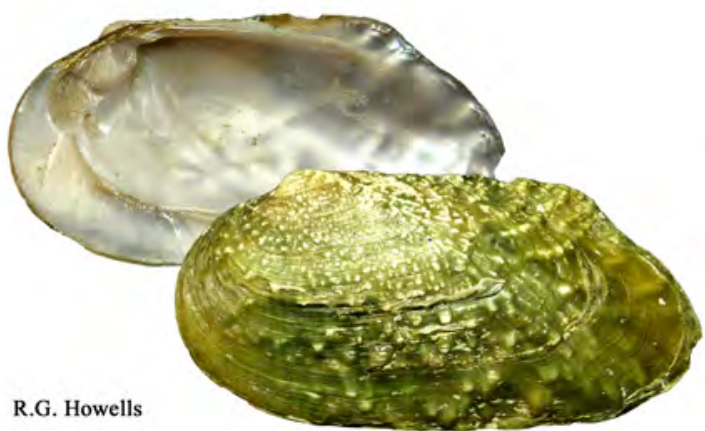

Figure C-21. Pistolgrip (Quadrula verrucosa).

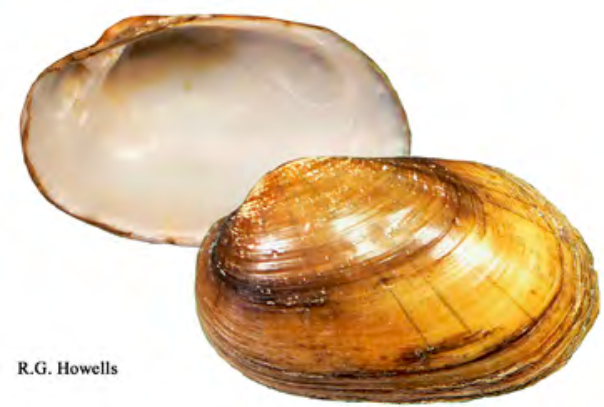

Figure C-23. Louisiana fatmucket (Lampsilis hydiana).
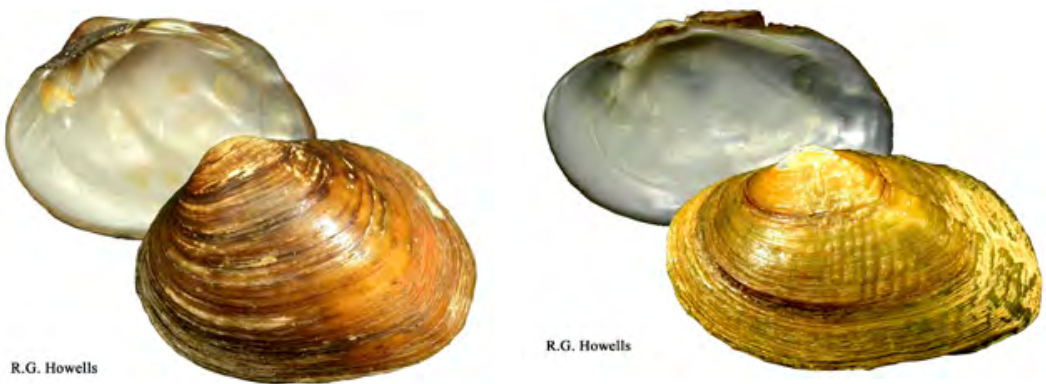

Figure C-20. False spike (Quadrula mitchelli).

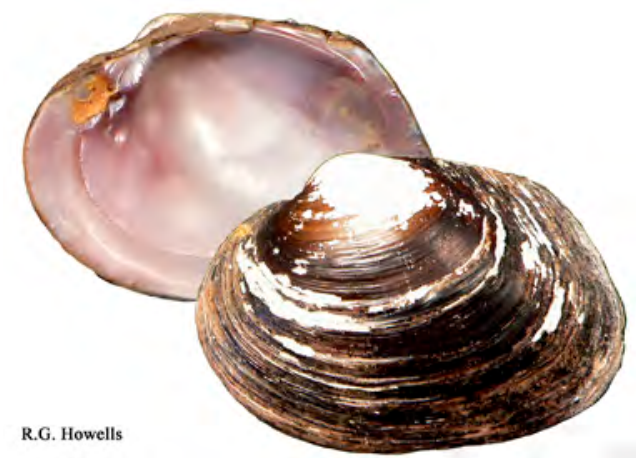

Figure C-22. Tampico pearlymussel (Cyrtonaias tampicoensis).

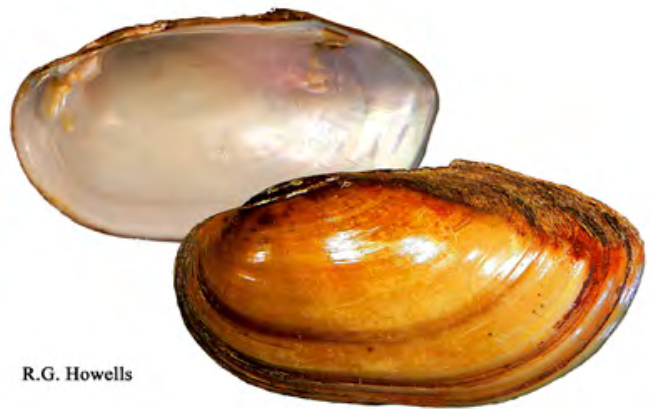

Figure C-24. Yellow sandshell (Lampsilis teres). 
Table C-1. Freshwater mussels (Family Unionidae) documented in the Guadalupe-San Antonio River drainage, Texas, based on Howells (2010a, b).

\begin{tabular}{lll}
\hline \multicolumn{1}{c}{ Common name } & \multicolumn{1}{c}{ Scientific name } & Comments \\
\hline Threeridge & Amblema plicata & \\
Rock-pocketbook & Arcidens confragosus & \\
Tampico pearlymussel & Cyrtonaias tampicoensis & \\
Spike & Elliptio dilatata & unsuccessful introduction record \\
Round pearlshell & Glebula rotundata & lower reaches only \\
Texas fatmucket & Lampsilis bracteata & upper reaches only \\
Louisiana fatmucket & Lampsilis hydiana & \\
Yellow sandshell & Lampsilis teres & \\
White heelpslitter & Lasmigona complanata & unsuccessful introduction record \\
Fragile papershell & Leptodea fragilis & one enigmatic record \\
Pondmussel & Ligumia subrostrata & \\
Washboard & Megalonaias nervosa & \\
Bleufer & Potamilus purpuratus & several questionable records \\
Giant floater & Pyganodon grandis & \\
Southern mapleleaf & Quadrula apiculata & \\
Golden orb & Quadrula aurea & \\
False spike & Quadrula mitchelli & \\
Texas pimpleback & Quadrula petrina & \\
Pistolgrip & Quadrula verrucosa & \\
Creeper & Strophitus undulatus & \\
Lilliput & Toxolasma parvum & \\
Texas lilliput & Toxolasma texasense & \\
Tapered pondhorn & Uniomerus declivis & \\
Pondhorn & Uniomerus tetralasmus & \\
Paper pondshell & Utterbackia imbecillis & \\
& & \\
\hline
\end{tabular}

Table C-2. Freshwater mussel (Family Unionidae) species remains found at Site 41DW277 and previously reported archaeological records from Site 41DW270 (Howells 2002a).

\begin{tabular}{lll}
\hline \multirow{2}{*}{ Species } & Present study & Howells (2002) \\
& Date unstated & 1997-1998 \\
\hline Threeridge (Amblema plicata) & $\mathrm{X}$ & $\mathrm{X}$ \\
Tampico pearlymussel (Cyrtonaias tampicoensis) & $\mathrm{X}$ & $\mathrm{X}$ \\
Louisiana fatmucket (Lampsilis hydiana) & $\mathrm{X}$ & $\mathrm{X}$ \\
Yellow sandshell (Lampsilis teres) & $\mathrm{X}$ & $\mathrm{X}$ \\
Lampsiliid (Lampsilis hydiana, & $\mathrm{X}$ & $\mathrm{X}$ \\
Lampsilis teres, or both) & $\mathrm{X}$ & $\mathrm{X}$ \\
Washboard (Megalonaias nervosa) & $\mathrm{X}$ & \\
Southern mapleleaf (Quadrula apiculata) & $\mathrm{X}$ & \\
Golden orb (Quadrula aurea) & $\mathrm{X}$ & $\mathrm{X}$ \\
False spike (Quadrula mitchelli) & $\mathrm{X}$ & \\
Pistolgrip (Quadrula verrucosa) & $\mathrm{X}$ & \\
Quadrulid (primarily Quadrula apiculata, & & $\mathrm{X}$ \\
Q. aurea, or both; less likely, Texas & & \\
pimpleback Q. petrina or Q. verrucosa) & & \\
Texas lilliput (Toxolasma texasense) & & \\
\end{tabular}




\section{Species Accounts}

Threeridge (Amblema plicata) (see Figures C-1-C-3, and C-16). Threeridge ranges from the lower Nueces River north to the Red River in Texas and then throughout much of the central U.S.; it reaches $180 \mathrm{~mm}$ sl (shell length); and is often common to abundant (Howells et al. 1996; Howells 2010a). Heavy shells and fragments of this species often preserve well and persist in natural and archaeological deposits. Threeridge was the most abundant of the identified mussel shells remains recovered at the site, with 268 specimens found. It occurred in 24 units, at 19 levels, and at depth ranges from 90-200 cmbs (Table C-3). This species was most abundant at 100-190 cmbs depths, with only three at 90-100, 10 at 190-200, and none less than 90 cmbs (Table C-4).

Tampico pearlymussel (Cyrtonaias tampicoensis) (see Figures C-8 and C-22). Tampico pearlymussel ranges from the Brazos and Colorado drainages south and west into the Rio Grande and northeastern Mexico; it reaches 160 mm sl (Howells et al. 1996; Howells 2010a). The ecophenotype in the GuadalupeSan Antonio basin are somewhat less robust than those in the Brazos and Colorado rivers, with less massive hinge teeth. When hinge teeth are broken away from the valve and eroded they can resemble those of other unionids (e.g., Lampsilis) therefore confounding positive identification. A total of 15 fragments of Tampico pearlymussel was found at the site, including in eight units, at eight levels, and at depths from 90-190 cmbs (see Table C-3). Too few specimens were recovered at individual depth groupings to allow comment on depth associations other than to note that none were taken at less than 90 cmbs (see Table C-4).

Louisiana fatmucket (Lampsilis hydiana) (see Figure C-23). Louisiana fatmucket ranges from the lower Nueces River along the coast plain north to San Antonio, Austin, and Waco, then east into eastern Texas and western Louisiana; it reaches $127 \mathrm{~mm}$ sl, but is usually much less (Howells et al. 1996; Howells 2010a). The ecophenotype found on the coastal plain area of Texas is significantly less robust than populations in eastern Texas waters. Only a single specimen was identified (one unit, one level) and it was collected at 180-190 cmbs (see Tables C-3 and C-4).

Yellow sandshell (Lampsilis teres) (see Figure C-24). Yellow sandshell occurs from the Rio Grande north and northeast throughout much of Texas and the Mississippi River valley; it reaches $185 \mathrm{~mm}$ sl (Howells et al. 1996; Howells 2010a). Shells can vary from relatively thin to rather heavy such that broken fragments can be confused with a number of other unionid taxa. Three yellow sandshell remains were found at the site among three units, at two levels, and at depth ranges from 110-130 cmbs (see Tables C-3 and C-4).

Unidentified Lampsiliid (Lampsilis spp.). A single fragment (one unit, one level, 170-180 cmbs) that could either have been Louisiana fatmucket or yellow sandshell was recovered. However, this specimen was too worn and incomplete to allow positive identification (see Tables C-3 and C-4). The only other member of the genus in the Guadalupe-San Antonio basin is Texas fatmucket (L. bracteata), but that species occurs only in the Texas Hill Country and Edwards Plateau (Howells 2010c), would not be expected on the coastal plain, so can be eliminated from consideration at this site.

Washboard (Megalonaias nervosa) (see Figures C-1 and C-17). Washboard occurs from the Rio Grande to the Red River in Texas and throughout much of the central U.S.; it is the largest North American unionid and reaches lengths of $280 \mathrm{~mm}$ sl; and can be locally common (Howells et al. 1996; Howells 2010a). Heavy shells and fragments preserve well and may endure in natural and archaeological deposits. A total of 45 washboard specimens was identified from 15 units, at 13 levels, and at a depth 
Table C-3. Freshwater mussel (Family Unionidae) species remains found at Site 41DW277, DeWitt County, Texas, collected by Ecological Communications Corporation, date unstated, including number of specimens recovered, units and levels in which they occurred, and range in depths.

\begin{tabular}{lcccc}
\hline Species & $\begin{array}{c}\text { N } \\
\text { specimens }\end{array}$ & $\begin{array}{c}\text { N } \\
\text { units }\end{array}$ & $\begin{array}{c}\text { N } \\
\text { levels }\end{array}$ & $\begin{array}{c}\text { Depth } \\
\text { range (cmbs) }\end{array}$ \\
\hline $\begin{array}{l}\text { Threeridge } \\
\text { (Amblema plicata) }\end{array}$ & 268 & 24 & 19 & $90-200$ \\
$\begin{array}{l}\text { Tampico pearlymussel } \\
\text { (Cyrtonaias tampicoensis) }\end{array}$ & 15 & 8 & 8 & $90-190$ \\
$\begin{array}{l}\text { Louisiana fatmucket } \\
\text { (Lampsilis hydiana) }\end{array}$ & 1 & 1 & 1 & $180-190$ \\
$\begin{array}{l}\text { Yellow sandshell } \\
\text { (Lampsilis teres) }\end{array}$ & 3 & 3 & 2 & $110-130$ \\
$\begin{array}{l}\text { Lampsiliid } \\
\text { (Lampsilis spp.) }\end{array}$ & 1 & 1 & 1 & $170-180$ \\
$\begin{array}{l}\text { Washboard } \\
\text { (Megalonaias nervosa) }\end{array}$ & 45 & 15 & 13 & $110-190$ \\
$\begin{array}{l}\text { Southern mapleleaf } \\
\text { (Quadrula apiculata) }\end{array}$ & 4 & 2 & 2 & $170-200$ \\
$\begin{array}{l}\text { Golden orb } \\
\text { (Quadrula aurea) }\end{array}$ & 2 & 2 & 2 & $120-140$ \\
$\begin{array}{l}\text { False spike } \\
\text { (Quadrula mitchelli) }\end{array}$ & 2 & 2 & 2 & $90-140$ \\
$\begin{array}{l}\text { Pistolgrip } \\
\text { (Quadrula verrucosa) }\end{array}$ & 2 & 2 & 2 & $40-200$ \\
$\begin{array}{l}\text { Quadrulid } \\
\text { Quadrula spp.) }\end{array}$ & 84 & 29 & 18 & $0-200$ \\
$\begin{array}{l}\text { Unidentified } \\
\quad\end{array}$ & 1086 & 22 & & \\
\hline
\end{tabular}

range from 110-190 cmbs (Table C-3), with the greatest number (18) found at 170-180 cmbs (see Table C-4).

Southern mapleleaf (Quadrula apiculata) (see Figures C-6-C-7, C-18). Southern mapleleaf ranges from the Nueces-Frio drainage north and northeast in Texas, into southern Oklahoma and the eastern Gulf states, with an introduction in the lower Rio Grande; it reaches over $120 \mathrm{~mm}$ sl (Howells et al. 1996; Howells 2010a). It has a number of ecophenotypes in various Texas drainage basins, with the form in the Guadalupe-San Antonio system being smaller and less robust than some other forms. This less-heavy morph in the Guadalupe River can confound identification of pseudocardinal tooth fragments when not associated with the remainder of the disk. Four fragments of southern mapleleaf were recovered at the site from two units, at two levels, and a depth range from 170-200 cmbs (see Table C-3). Although the only recognizable southern mapleleaf fragments were taken in deeper areas (170-180 and 190-200 cmbs), too few were found to allow comment on occurrence and depth (see Table C-4).

Golden orb (Quadrula aurea) (see Figures C-4-C-5, C-19). Golden orb is endemic to the GuadalupeSan Antonio and Nueces-Frio systems; it reaches $82 \mathrm{~mm}$ sl (Howells et al. 1996; Howells 2010a). Two fragments of golden orb were obtained at the site each from a distinct unit and level with a depth range 
Table C-4. Number of freshwater mussel (Family Unionidae) species remains found at designated depths (cmbs) at Site 41DW277, DeWitt County, Texas, collected by Ecological Communications Corporation, date unstated.

\begin{tabular}{|c|c|c|c|c|c|c|}
\hline $\begin{array}{l}\text { Depth } \\
\text { (cmbs) }\end{array}$ & $\begin{array}{c}\text { Threeridge } \\
\text { Amblema } \\
\text { Nervosa }\end{array}$ & $\begin{array}{c}\text { Tampico } \\
\text { pearlymussel } \\
\text { Cyrtonaias } \\
\text { tampicoensis }\end{array}$ & $\begin{array}{c}\text { Louisiana } \\
\text { fatmucket } \\
\text { Lampsilis } \\
\text { hydiana }\end{array}$ & $\begin{array}{l}\text { Yellow } \\
\text { sandshell } \\
\text { Lampsilis } \\
\text { teres }\end{array}$ & $\begin{array}{l}\text { Unidentified } \\
\text { Lampsiliid } \\
\text { Lampsilis } \\
\text { sp. }\end{array}$ & $\begin{array}{c}\text { Washboard } \\
\text { Megalonaias } \\
\text { nervosa }\end{array}$ \\
\hline $0-20$ & 0 & 0 & 0 & 0 & 0 & 0 \\
\hline $20-40$ & 0 & 0 & 0 & 0 & 0 & 0 \\
\hline $30-40$ & 0 & 0 & 0 & 0 & 0 & 0 \\
\hline $40-50$ & 0 & 0 & 0 & 0 & 0 & 0 \\
\hline $50-60$ & 0 & 0 & 0 & 0 & 0 & 0 \\
\hline $70-80$ & 0 & 0 & 0 & 0 & 0 & 0 \\
\hline $80-20$ & 0 & 0 & 0 & 0 & 0 & 0 \\
\hline $90-100$ & 3 & 1 & 0 & 0 & 0 & 0 \\
\hline $100-110$ & 21 & 2 & 0 & 0 & 0 & 0 \\
\hline $110-120$ & 31 & 0 & 0 & 2 & 0 & 6 \\
\hline $120-130$ & 39 & 3 & 0 & 1 & 0 & 6 \\
\hline $130-140$ & 30 & 4 & 0 & 0 & 0 & 4 \\
\hline $140-150$ & 26 & 2 & 0 & 0 & 0 & 3 \\
\hline $150-160$ & 14 & 1 & 0 & 0 & 0 & 2 \\
\hline $160-170$ & 19 & 1 & 0 & 0 & 0 & 4 \\
\hline $170-180$ & 61 & 0 & 0 & 0 & 1 & 18 \\
\hline 180-190 & 14 & 1 & 1 & 0 & 0 & 2 \\
\hline $190-200$ & 10 & 0 & 0 & 0 & 0 & 0 \\
\hline $\begin{array}{l}\text { Depth } \\
\text { (cmbs) }\end{array}$ & $\begin{array}{l}\text { Southern } \\
\text { mapleleaf } \\
\text { Quadrula } \\
\text { apiculata }\end{array}$ & $\begin{array}{l}\text { Golden } \\
\text { orb } \\
\text { Quadrula } \\
\text { aurea }\end{array}$ & $\begin{array}{c}\text { False } \\
\text { spike } \\
\text { Quadrula } \\
\text { mitchelli }\end{array}$ & $\begin{array}{l}\text { Pistolgrip } \\
\text { Quadrula } \\
\text { verrucosa }\end{array}$ & $\begin{array}{l}\text { Unidentified } \\
\text { quadrulid } \\
\text { Quadrula } \\
\text { spp. }\end{array}$ & Unidentified \\
\hline $0-20$ & 0 & 0 & 0 & 0 & 0 & 2 \\
\hline $20-40$ & 0 & 0 & 0 & 0 & 1 & 2 \\
\hline $30-40$ & 0 & 0 & 0 & 0 & 0 & 1 \\
\hline $40-50$ & 0 & 0 & 0 & 0 & 1 & 1 \\
\hline $50-60$ & 0 & 0 & 0 & 0 & 0 & 1 \\
\hline $70-80$ & 0 & 0 & 0 & 0 & 0 & 6 \\
\hline $80-20$ & 0 & 0 & 0 & 0 & 0 & 15 \\
\hline $90-100$ & 0 & 0 & 0 & 1 & 1 & 46 \\
\hline $100-110$ & 0 & 1 & 0 & 0 & 5 & 181 \\
\hline $110-120$ & 0 & 0 & 0 & 0 & 5 & 210 \\
\hline $120-130$ & 0 & 0 & 1 & 0 & 11 & 158 \\
\hline $130-140$ & 0 & 1 & 1 & 1 & 14 & 116 \\
\hline $140-150$ & 0 & 0 & 0 & 0 & 11 & 93 \\
\hline $150-160$ & 0 & 0 & 0 & 0 & 6 & 71 \\
\hline $160-170$ & 0 & 0 & 0 & 0 & 2 & 54 \\
\hline $170-180$ & 1 & 0 & 0 & 0 & 15 & 102 \\
\hline $180-190$ & 0 & 0 & 0 & 0 & 8 & 17 \\
\hline $190-200$ & 3 & 0 & 0 & 0 & 4 & 10 \\
\hline
\end{tabular}


of 100-140 cmbs (see Table C-3). Too few specimens were recovered to allow comment on occurrence and depth (see Table C-4).

False spike (Quadrula mitchelli; previously Quincuncina mitchelli) (see Figures C-12-C-14, C-20). False spike occurred in two areas with a population in the Brazos, Colorado, and Guadalupe-San Antonio drainages of Central Texas and another in the Rio Grande; it reaches $132 \mathrm{~mm}$ sl, but is usually much less (Howells et al. 1996; Howells 2010a). Two fragments of false spike were obtained at the site each from a distinct unit and level with a depth range of 120-140 cmbs (see Table C-3). Too few specimens were recovered to allow comment on occurrence and depth (see Table C-4).

Pistolgrip (Quadrula verrucosa; previously Tritogonia verrucosa) (see Figures C-9-C-11, C-21). Pistolgrip ranges from the Guadalupe-San Antonio drainage north and east in Texas and throughout much of the Mississippi River valley; maximum size reaches over $200 \mathrm{~mm}$ sl (Howells et al. 1996; Howells 2010a). Two fragments of pistolgrip were obtained at the site each from a distinct unit and level with a depth range of $90-140$ cmbs (see Table C-3). Too few specimens were recovered to allow comment on occurrence and depth (see Table C-4).

Quadrulid (Quadrula spp.) (se Figure C-2). Unidentified quadrulid remains recovered from the site included 84 fragments from 22 units, 13 levels, and a depth range from 40-200 cmbs (see Table C-3). These remains occurred nearly throughout the depth of the column excavated, though few were found above 100 cmbs and most were located between 120-150 cmbs and 170-180 cmbs (see Table C-4). Given that this group likely includes at least two species and could include as many as five species, depth associations could be obscured by varying contributions of these taxa.

\section{Unidentified Unionid Fragments}

A total of 1,086 unidentified or unidentifiable mussel shell fragments were obtained from the site and these occurred in 29 units, at 18 levels, with depth ranges of $-200 \mathrm{cmbs}$ (see Table C-3). These remains occurred virtually throughout the depth of the excavated column, but were most abundant between 90-180 cmbs (see Table C-4). Again, give that various genera and species undoubtedly contributed to these counts, significance of numbers at various depths could be confounded by differing species involvements.

\section{Human Influence on Mussel Shell Remains}

Among 1,513 mussel shell fragments obtained at 41DW277, 12 specimens appeared to have been burnt (see Sub Appendix, Table 1). These were recovered from 7 units, 8 levels, and a depth range of 100-200 cmbs. Aside from these examples, none of the other material displayed definitive signs of human manipulation.

Although several pseudocardinal teeth, beaks, and disk fragments did come from larger, adult mussel specimens (shells over $100 \mathrm{~mm}$ in shell length when intact), the vast majority of specimens recovered were smaller individuals or species that attain relatively small maximum sizes. This finding it typical of other archaeological sites in Texas that are also dominated by remains of smaller unionids rather than adults of larger species. Species size distribution can vary over time. However, the preponderance of smaller species and small specimens of larger species at archaeological sites suggests selection for these smaller individuals. 


\section{Summary ANd Conclusions}

The species assemblage here was similar to that found at the Smith Creek Site 41DW270 in DeWitt County, Texas, but quadrulid species were not as clearly enumerated in that report and Texas lilliput (a species more typical of ponds, backwaters, and streams) was also taken (Howells 2002a). Other species present in the Guadalupe River drainage (see Table C-1) that were not found at 41DW277 are typically either rather rare (e.g. rock-pocketbook Arcidens confragosus) in this system (only two collection records); species with thin, frail shells that preserve poorly (e.g., giant floater Pyganodon grandis and paper pondshell Utterbackia imbecillis); or pond and oxbow species that would not be abundant in mainchannel areas (e.g., pondmussel Ligumia subrostrata and pondhorn Uniomerus tetralasmus). Washboard is a species characteristicly of larger, permanent rivers and streams and threeridge often occurs with it. Neither is typical of smaller streams, ponds, or temporary waters. Further, within the Guadalupe River at present, Tampico pearlymussel, southern mapleleaf, golden orb, pistolgrip, Louisiana fatmucket, and yellow sandshell often occur in washboard and threeridge beds and appear to have done so in the past. Therefore, mussel shell remains recovered at 41DW277 represent species taken in the main channel of the Guadalupe River or at least the lower reaches of major tributaries. Further, the 41DW277 species assemblage likely occurred on substrates of firm mud, sand, and light to moderately large gravels rather than deep silts or scoured cobble and bedrock.

\section{REFERENCES}

Howells, R.G. 1998. Freshwater mussel (Unionidae) shell remains associated with archeological site 41MV120, near Eagle Pass, Maverick County, Texas. In B.V. Vierra. 41MV120: a stratified Late Archaic site in Maverick County, Texas. Center for Archaeological Research, University of Texas at San Antonio, Archaeological Survey Report 251, San Antonio.

Howells, R.G. 2001. Appendix D: Freshwater mussel shell. Pages 94-97 in R.B. Mahoney and S.A. Tomka. National Register eligibility testing of 41MM340 and 41MM341, along Little River, Milam County, Texas. Center for Archeological Research, The University of Texas at San Antonio, Archaeological Survey Report 303, San Antonio.

Howells, R.G. 2002a. Appendix E: Freshwater mussel shell remains. Pages 195-209 in D. Hudler, K. Prilliman, and T. Gustavson. The Smith Creek Bridge Site (41DW270): a terrace site in DeWitt County, Texas. Texas Archeological Research Laboratory, The University of Texas at Austin, Austin.

Howells, R.G. 2002b. Appendix G: Freshwater mussel (Bivalvia: Unionidae) shell remains associated with Site 41CW54. Pages 277-290 in E.A. Schroeder and E.R. Oksanen. Data recovery at the Armstrong Site (41CW54) Caldwell County, Texas. Volume I.: Background methods, and site context - Antiquities Permit 2250. Paul Price Associates, Inc., Austin, Texas.

Howells, R.G. 2009. Freshwater mussel shell remains associated with the Vara Daniel Site (41MV1364): Zilker Park, Austin, Texas. BioStudies, Kerrville, Texas. Prepared for Ecological Communications Corporation, Austin, Texas. 
Howells, R.G. 2010a. Guide to Texas freshwater mussels. BioStudies, Kerrville, Texas.

Howells, R.G. 2010b. Freshwater mussels of Texas and the western Gulf Coast. Pages 161174 in Freshwater Mollusk Conservation Society (FMCS). Regional Fauna Identification and sampling: 'show me your umbones'. FMCS, Kirkwood, Missouri.

Howells, R.G. 2010c. Texas fatmucket Lampsilis bracteata (Gould 1855): summary of selected biological and ecological data for Texas. BioStudies, Kerrville, Texas. Prepared for Save Our Springs Alliance, Austin, Texas.

Howells, R.G., R.W. Neck, and H.D. Murray. 1996. Freshwater mussels of Texas. Texas Parks and Wildlife Press, Austin.

Howells, R.G., J. Neel-Hartman, and S.A. Wagner. 2003. Appendix G: Freshwater mussel shell from 41MM340. Pages 345-370 in R.B. Mahoney and six coauthors. Data recovery excavations at 41MM340: a Late Archaic site along Little River, Milam County, Texas. Center for Archaeological Research, The University of Texas at San Antonio, Archaeological Survey Report 340, San Antonio.

Murray, H.D. 1982. Unionids from Indian sites in McMullen and Live Oak counties, Texas. Bulletin of the American Malacological Union 1981:10-11.

Neck, R.W. 1982. A review of the interactions between humans and freshwater mussels in Texas. Pages 169-182 in J.R. Davis, editor. Proceedings on the Symposium on Recent Benthological Investigations in Texas and Adjacent States. Texas Academy of Science, Austin.

Turgeon, D.D., and 13 Coauthors. 1998. Common and scientific names of aquatic invertebrates of the United States and Canada: mollusks. American Fisheries Society, Bethesda, Maryland.

Parmalee, P.W., and A.E. Bogan. 1998. The freshwater mussels of Tennessee. The University of Tennessee Press, Knoxville.

Watters, G.T., M.A. Hoggarth, and D.H. Stansbery. 2009. The freshwater mussels of Ohio. Ohio State University Press, Columbus.

Williams, J.D., A.E. Bogan, and J.T. Garner. 2008. Freshwater mussels of Alabama \& the Mobile Basin in Georgia, Mississippi \& Tennessee. The University of Alabama Press, Tuscaloosa.

Williams, J.D., M.L. Warren, Jr., K.S. Cummings, J.L. Harris, and R.J. Neves. 1993. Conservation status of the freshwater mussels of the United States and Canada. Fisheries (Bethesda) 18(9):6-22. 
Sub-Appendix Table 1. Freshwater mussel (Family Unionidae) species remains found at Site 41DW277, DeWitt County, Texas, collected by Ecological Communications Corporation, date unstated.

\begin{tabular}{|c|c|c|c|c|c|c|}
\hline Unit & Level & CMBS & Lot & $N$ & Species/Taxon & Shell Structure or Fragment \\
\hline 1 & 11 & $100-110$ & 61 & 3 & Unidentified & 2 left pseudocardinal teeth; 1 right pseudocardinal tooth \\
\hline 1 & 12 & $110-120$ & 64 & 1 & Unidentified & right pseudocardinal tooth (possibly Lampsilis teres) \\
\hline 1 & 14 & $130-140$ & 71 & 1 & Unidentified & fragment \\
\hline 1 & 14 & $130-140$ & 71 & 1 & $\begin{array}{l}\text { Threeridge } \\
\text { Amblema plicata }\end{array}$ & right pseudocardinal tooth \\
\hline 1 & 14 & $130-140$ & 71 & 3 & Unidentified & pseudocardinal teeth (includes two species) \\
\hline 1 & 13 & $120-130$ & 67 & 1 & Unidentified & right pseudocardinal tooth (possibly Lampsilis teres) \\
\hline 1 & 15 & $140-150$ & 76 & 1 & $\begin{array}{l}\text { Threeridge } \\
\text { Amblema plicata }\end{array}$ & left pseudocardinal teeth \\
\hline 1 & 16 & $150-160$ & 83 & 1 & $\begin{array}{l}\text { Tampico pearlymussel } \\
\text { Cyrtonaias tampicoensis }\end{array}$ & left pseudocardinal teeth \\
\hline 2 & 8 & $70-80$ & 22 & 1 & Unidentified & fragment \\
\hline 2 & 9 & $80-90$ & 26 & 4 & Unidentified & pseudocardinal teeth \\
\hline 2 & 10 & $90-100$ & 29 & 2 & Unidentified & fragment \\
\hline 2 & 11 & $100-110$ & 33 & 2 & $\begin{array}{l}\text { Threeridge } \\
\text { Amblema plicata }\end{array}$ & 1 right pseudocardinal tooth, 1 left pseudocardinal tooth \\
\hline 2 & 11 & $100-110$ & 33 & 2 & Unidentified & fragment \\
\hline 2 & 12 & $110-120$ & 37 & 8 & Unidentified & pseudocardinal teeth \\
\hline 2 & 13 & $120-130$ & 42 & 1 & Unidentified & right pseudocardinal tooth \\
\hline 2 & 13 & $120-130$ & 42 & 1 & Unidentified & left pseudocardinal teeth (possibly Lampsilis teres) \\
\hline 2 & 17 & $160-170$ & 114 & 1 & $\begin{array}{l}\text { Tampico pearlymussel } \\
\text { Cyrtonaias tampicoensis }\end{array}$ & left pseudocardinal teeth \\
\hline 2 & 18 & $170-180$ & 116 & 1 & $\begin{array}{l}\text { Threeridge } \\
\text { Amblema plicata }\end{array}$ & right pseudocardinal tooth \\
\hline 2 & 18 & $170-180$ & 116 & 1 & Quadrulid & right pseudocardinal tooth \\
\hline 2 & 19 & $180-190$ & 119 & 1 & $\begin{array}{l}\text { Quadrula sp. } \\
\text { Threeridge } \\
\text { Amblema plicata }\end{array}$ & right pseudocardinal tooth \\
\hline 2 & 19 & $190-200$ & 119 & 1 & $\begin{array}{l}\text { Threeridge } \\
\text { Amblema plicata }\end{array}$ & right pseudocardinal tooth \\
\hline 3 & 6 & $40-50$ & 20 & 1 & Unidentified & fragment \\
\hline 3 & 6 & $40-50$ & 20 & 1 & $\begin{array}{l}\text { Quadrulid } \\
\text { Quadrula sp. }\end{array}$ & left pseudocardinal teeth \\
\hline 3 & 7 & $50-60$ & 23 & 1 & Unidentified & fragment \\
\hline 3 & 9 & $70-80$ & 30 & 1 & Unidentified & fragment \\
\hline 3 & 12 & $100-110$ & 40 & 1 & Unidentified & fragment \\
\hline 3 & 12 & $100-110$ & 40 & 3 & $\begin{array}{l}\text { Threeridge } \\
\text { Amblema plicata }\end{array}$ & 1 right pseudocardinal teeth, 2 left pseudocardinal tooth \\
\hline 3 & 13 & $110-120$ & 45 & 2 & Unidentified & fragments \\
\hline 3 & 13 & $110-120$ & 45 & 1 & $\begin{array}{l}\text { Threeridge } \\
\text { Amblema plicata }\end{array}$ & left pseudocardinal teeth \\
\hline 3 & 14 & $120-130$ & 49 & 3 & Unidentified & fragments \\
\hline 3 & 14 & $120-130$ & 49 & 1 & $\begin{array}{l}\text { Threeridge } \\
\text { Amblema plicata }\end{array}$ & right pseudocardinal tooth \\
\hline
\end{tabular}


Sub-Appendix Table 1 (continued). Freshwater mussel (Family Unionidae) species remains found at Site 41DW277, DeWitt County, Texas, collected by Ecological Communications Corporation, date unstated.

\begin{tabular}{|c|c|c|c|c|c|c|}
\hline Unit & Level & CMBS & Lot & $N$ & Species/Taxon & Shell Structure or Fragment \\
\hline 3 & 16 & $140-150$ & 58 & 2 & Unidentified & fragments \\
\hline 4 & 10 & $90-100$ & 19 & 1 & $\begin{array}{l}\text { Tampico pearlymussel } \\
\text { Cyrtonaias tampicoensis }\end{array}$ & left pseudocardinal teeth \\
\hline 4 & 10 & $90-100$ & 19 & 2 & Unidentified & pseudocardinal teeth \\
\hline 4 & 11 & $100-110$ & 25 & 1 & $\begin{array}{l}\text { Golden Orb } \\
\text { Quadrula aurea }\end{array}$ & right pseudocardinal tooth and disk fragment \\
\hline 4 & 11 & $100-110$ & 25 & 9 & Unidentified & fragments and pseudocardinal teeth \\
\hline 4 & 12 & $110-120$ & $?$ & 5 & Unidentified & fragments and pseudocardinal teeth \\
\hline 4 & 13 & $120-130$ & 79 & 6 & Unidentified & fragments and pseudocardinal teeth \\
\hline 4 & 15 & $140-150$ & 86 & 7 & Unidentified & fragments and pseudocardinal teeth \\
\hline 4 & 17 & $160-170$ & $?$ & 1 & Unidentified & fragment \\
\hline 5 & 7 & $90-100$ & 95 & 1 & Unidentified & left pseudocardinal teeth \\
\hline 5 & 9 & $110-120$ & 102 & 1 & $\begin{array}{l}\text { Yellow sandshell } \\
\text { Lampsilis teres }\end{array}$ & right pseudocardinal tooth \\
\hline 5 & 9 & $110-120$ & 102 & 2 & Unidentified & right pseudocardinal teeth \\
\hline 5 & 10 & $120-130$ & 109 & 2 & $\begin{array}{l}\text { Threeridge } \\
\text { Amblema plicata }\end{array}$ & right pseudocardinal teeth \\
\hline 5 & 10 & $120-130$ & 109 & 1 & $\begin{array}{l}\text { Tampico pearlymussel } \\
\text { Cyrtonaias tampicoensis }\end{array}$ & right pseudocardinal tooth \\
\hline 5 & 10 & $120-130$ & 109 & 2 & Unidentified & disk fragments \\
\hline 5 & 10 & $120-130$ & 109 & 3 & Unidentified & pseudocardinal teeth \\
\hline 5 & 8 & $100-110$ & 98 & 1 & $\begin{array}{l}\text { Threeridge } \\
\text { Amblema plicata }\end{array}$ & right pseudocardinal tooth \\
\hline 5 & 8 & $100-110$ & 98 & 3 & Unidentified & fragments and pseudocardinal teeth \\
\hline 5 & 11 & $130-140$ & 110 & 2 & Unidentified & pseudocardinal teeth \\
\hline 5 & 11 & $130-140$ & 110 & 1 & $\begin{array}{l}\text { Washboard } \\
\text { Megalonaias nervosa }\end{array}$ & right pseudocardinal tooth \\
\hline 5 & 12 & $140-150$ & 115 & 1 & Unidentified & fragment \\
\hline 6 & 8 & $80-90$ & 63 & 6 & Unidentified & pseudocardinal teeth \\
\hline 6 & 10 & $100-110$ & 75 & 15 & Unidentified & pseudocardinal teeth \\
\hline 6 & 10 & $100-110$ & 75 & 2 & Unidentified & disk fragments \\
\hline 6 & 11 & $110-120$ & 82 & 17 & Unidentified & pseudocardinal teeth (probably Amblema plicata) \\
\hline 6 & 11 & $110-120$ & 82 & 1 & Unidentified & disk fragment \\
\hline 6 & 12 & $130-140$ & 89 & 3 & Unidentified & pseudocardinal teeth \\
\hline 6 & 12 & $130-140$ & 90 & 1 & $\begin{array}{l}\text { Threeridge } \\
\text { Amblema plicata }\end{array}$ & right pseudocardinal tooth \\
\hline 6 & 12 & $130-140$ & 90 & 1 & $\begin{array}{l}\text { Tampico pearlymussel } \\
\text { Cyrtonaias tampicoensis }\end{array}$ & right pseudocardinal tooth \\
\hline 6 & 12 & $130-140$ & 90 & 1 & Unidentified & pseudocardinal teeth \\
\hline 6 & 9 & $90-100$ & 70 & 8 & Unidentified & pseudocardinal teeth \\
\hline 6 & 9 & $90-100$ & 70 & 1 & Unidentified & disk fragment \\
\hline 6 & 9 & $90-100$ & 70 & 1 & Unidentified & hinge fragment \\
\hline 6 & 13 & $140-150$ & 94 & 3 & $\begin{array}{l}\text { Threeridge } \\
\text { Amblema plicata }\end{array}$ & right pseudocardinal teeth \\
\hline 6 & 13 & $140-150$ & 94 & 1 & $\begin{array}{l}\text { Washboard } \\
\text { Megalonaias nervosa }\end{array}$ & right pseudocardinal tooth \\
\hline 6 & 14 & $140-150$ & 103 & 1 & Unidentified & $\begin{array}{l}\text { left pseudocardinal tooth (probably Cyrtonaias } \\
\text { tampicoensis) }\end{array}$ \\
\hline
\end{tabular}


Sub-Appendix Table 1 (continued). Freshwater mussel (Family Unionidae) species remains found at Site 41DW277, DeWitt County, Texas, collected by Ecological Communications Corporation, date unstated.

\begin{tabular}{|c|c|c|c|c|c|c|}
\hline Unit & Level & CMBS & Lot & $N$ & Species/Taxon & Shell Structure or Fragment \\
\hline 6 & 15 & $160-170$ & 137 & 2 & $\begin{array}{l}\text { Threeridge } \\
\text { Amblema plicata }\end{array}$ & left pseudocardinal teeth \\
\hline 6 & 15 & $160-170$ & 137 & 1 & $\begin{array}{l}\text { Threeridge } \\
\text { Amblema plicata }\end{array}$ & right pseudocardinal tooth \& disk fragment \\
\hline 6 & 15 & $160-170$ & 137 & 2 & Unidentified & disk fragments \\
\hline 6 & 15 & $160-170$ & 174 & 2 & Unidentified & disk fragments \\
\hline 6 & 15 & $160-170$ & 174 & 1 & Unidentified & left pseudocardinal teeth \\
\hline 6 & 16 & $170-180$ & 217 & 13 & Unidentified & disk fragments \\
\hline 6 & 16 & $170-180$ & 217 & 20 & Unidentified & pseudocardinal teeth (4 burnt) \\
\hline 6 & 16 & $170-180$ & 217 & 1 & $\begin{array}{l}\text { Southern mapleleaf } \\
\text { Quadrula apiculata }\end{array}$ & left pseudocardinal teeth \& valve fragment \\
\hline 6 & 16 & $170-180$ & 217 & 1 & $\begin{array}{l}\text { Fatmucket/Sandshell } \\
\text { Lampsilis sp. }\end{array}$ & right pseudocardinal tooth \\
\hline 6 & 16 & $170-180$ & 217 & 11 & $\begin{array}{l}\text { Quadrulid } \\
\text { Quadrula spp. }\end{array}$ & 5 right $\& 6$ left pseudocardinal teeth \\
\hline 6 & 16 & $170-180$ & 217 & 20 & $\begin{array}{l}\text { Threeridge } \\
\text { Amblema plicata }\end{array}$ & 8 right \& 12 left pseudocardinal teeth \\
\hline 6 & 16 & $170-180$ & 217 & 11 & $\begin{array}{l}\text { Washboard } \\
\text { Megalonaias nervosa }\end{array}$ & 8 right $\& 3$ left pseudocardinal teeth \\
\hline 6 & 17 & $180-190$ & 229 & 4 & Unidentified & disk \& hinge fragments \\
\hline 6 & 17 & $180-190$ & 229 & 5 & Unidentified & pseudocardinal teeth \\
\hline 6 & 17 & $180-190$ & 229 & 7 & Quadrulid & 3 right $\& 4$ left pseudocardinal teeth \\
\hline 6 & 17 & $180-190$ & 229 & 1 & $\begin{array}{l}\text { Tampico pearlymussel } \\
\text { Cyrtonaias tampicoensis }\end{array}$ & left pseudocardinal teeth \\
\hline 6 & 17 & $180-190$ & 229 & 1 & $\begin{array}{l}\text { Louisiana fatmucket } \\
\text { Lampsilis hydiana }\end{array}$ & right pseudocardinal tooth \\
\hline 6 & 17 & $180-190$ & 229 & 2 & $\begin{array}{l}\text { Washboard } \\
\text { Megalonaias nervosa }\end{array}$ & right pseudocardinal teeth \\
\hline 6 & 17 & $180-190$ & 229 & 6 & $\begin{array}{l}\text { Threeridge } \\
\text { Amblema plicata }\end{array}$ & 1 right \& 5 left pseudocardinal teeth \\
\hline 6 & 18 & $190-200$ & 234 & 8 & $\begin{array}{l}\text { Threeridge } \\
\text { Amblema plicata }\end{array}$ & 2 right $\& 6$ left pseudocardinal teeth ( 1 burnt) \\
\hline 6 & 18 & $190-200$ & 234 & 4 & $\begin{array}{l}\text { Quadrulid } \\
\text { Quadrula spp. }\end{array}$ & right pseudocardinal teeth \\
\hline 6 & 18 & $190-200$ & 234 & 3 & $\begin{array}{l}\text { Southern mapleleaf } \\
\text { Quadrula apiculata }\end{array}$ & 1 right $\& 2$ left pseudocardinal teeth ( 1 burnt) \\
\hline 6 & 18 & $190-200$ & 234 & 2 & Unidentified & disk fragments \\
\hline 6 & 18 & $190-200$ & 234 & 5 & Unidentified & pseudocardinal teeth \\
\hline 7 & 8 & $90-100$ & 52 & 1 & Unidentified & pseudocardinal teeth \\
\hline 7 & 9 & $100-110$ & 59 & 2 & Unidentified & pseudocardinal teeth \\
\hline 7 & 10 & $110-120$ & 118 & 1 & $\begin{array}{l}\text { Threeridge } \\
\text { Amblema plicata }\end{array}$ & left pseudocardinal teeth \\
\hline 7 & 10 & $110-120$ & 118 & 5 & Unidentified & 2 right \& 3 left pseudocardinal teeth \\
\hline 7 & 11 & $120-130$ & 121 & 1 & $\begin{array}{l}\text { Quadrulid } \\
\text { Quadrula sp. }\end{array}$ & right pseudocardinal tooth \\
\hline 7 & 11 & $120-130$ & 121 & 2 & $\begin{array}{l}\text { Threeridge } \\
\text { Amblema plicata }\end{array}$ & left pseudocardinal teeth \\
\hline 7 & 11 & $120-130$ & 121 & 1 & Unidentified & left pseudocardinal teeth \\
\hline 7 & 12 & $130-140$ & 125 & 2 & Unidentified & pseudocardinal teeth \\
\hline 7 & 13 & $140-150$ & 127 & 2 & $\begin{array}{l}\text { Threeridge } \\
\text { Amblema plicata }\end{array}$ & 1 right pseudocardinal tooth, 1 left pseudocardinal tooth \\
\hline 7 & 13 & $140-150$ & 127 & 2 & Washboard & 1 right pseudocardinal tooth, 1 left pseudocardinal tooth \\
\hline 7 & 13 & $140-150$ & 127 & 1 & Unidentified & left pseudocardinal tooth \\
\hline
\end{tabular}


Sub-Appendix Table 1 (continued). Freshwater mussel (Family Unionidae) species remains found at Site 41DW277, DeWitt County, Texas, collected by Ecological Communications Corporation, date unstated.

\begin{tabular}{|c|c|c|c|c|c|c|}
\hline Unit & Level & CMBS & Lot & $N$ & Species/Taxon & Shell Structure or Fragment \\
\hline 7 & 13 & $120-130$ & $?$ & 1 & $\begin{array}{l}\text { Quadrulid } \\
\text { Quadrula sp. }\end{array}$ & pseudocardinal teeth \\
\hline 8 & 2 & $20-40$ & 35 & 1 & $\begin{array}{l}\text { Quadrulid } \\
\text { Quadrula sp. }\end{array}$ & left pseudocardinal teeth \\
\hline 8 & 2 & $20-40$ & 35 & 1 & Unidentified & left pseudocardinal teeth \\
\hline 8 & 8 & $90-100$ & 66 & 12 & Unidentified & fragments ( 1 burnt) \\
\hline 8 & 9 & $100-110$ & 73 & 3 & Unidentified & disk fragments \\
\hline 8 & 9 & $100-110$ & 73 & 31 & Unidentified & right and left pseudocardinal teeth ( 1 burnt) \\
\hline 8 & 9 & $100-110$ & 73 & 2 & $\begin{array}{l}\text { Tampico pearlymussel } \\
\text { Cyrtonaias tampicoensis }\end{array}$ & 1 right pseudocardinal tooth, 1 left pseudocardinal tooth \\
\hline 8 & 9 & $100-110$ & 73 & 2 & $\begin{array}{l}\text { Quadrulid } \\
\text { Quadrula spp. }\end{array}$ & 1 right pseudocardinal tooth, 1 left pseudocardinal tooth \\
\hline 8 & 9 & $100-110$ & 73 & 2 & $\begin{array}{l}\text { Threeridge } \\
\text { Amblema plicata }\end{array}$ & right pseudocardinal teeth \\
\hline 8 & 10 & $110-120$ & 104 & 12 & Unidentified & right and left pseudocardinal teeth \\
\hline 8 & 10 & $110-120$ & 104 & 1 & Unidentified & disk fragment \\
\hline 8 & 10 & $110-120$ & 104 & 1 & $\begin{array}{l}\text { Washboard } \\
\text { Megalonaias nervosa }\end{array}$ & right pseudocardinal tooth \\
\hline 8 & 10 & $110-120$ & 104 & 2 & $\begin{array}{l}\text { Threeridge } \\
\text { Amblema plicata }\end{array}$ & 1 right pseudocardinal tooth, 1 left pseudocardinal tooth \\
\hline 8 & 10 & $110-120$ & 104 & 1 & $\begin{array}{l}\text { Quadrulid } \\
\text { Quadrula sp. }\end{array}$ & right pseudocardinal tooth \\
\hline 8 & 11 & $120-130$ & 97 & 2 & $\begin{array}{l}\text { Threeridge } \\
\text { Amblema plicata }\end{array}$ & right pseudocardinal teeth \\
\hline 8 & 11 & $120-130$ & 97 & 2 & Unidentified & 1 right pseudocardinal tooth, 1 left pseudocardinal tooth \\
\hline 8 & 12 & $130-140$ & 105 & 3 & Unidentified & disk fragments \\
\hline 8 & 12 & $130-140$ & 105 & 1 & Unidentified & beak and pseudocardinal teeth (deformed) \\
\hline 8 & 12 & $130-140$ & 105 & 2 & $\begin{array}{l}\text { Washboard } \\
\text { Megalonaias nervosa }\end{array}$ & right pseudocardinal tooth \\
\hline 8 & 12 & $130-140$ & 105 & 2 & $\begin{array}{l}\text { Quadrulid } \\
\text { Quadrula spp. }\end{array}$ & 1 right pseudocardinal tooth, 1 left pseudocardinal tooth \\
\hline 8 & 13 & $140-150$ & 120 & 1 & Unidentified & disk fragment \\
\hline 8 & 13 & $140-150$ & 120 & 4 & Unidentified & right and left pseudocardinal teeth \\
\hline 8 & 13 & $140-150$ & 120 & 1 & $\begin{array}{l}\text { Quadrulid } \\
\text { Quadrula sp. }\end{array}$ & right pseudocardinal tooth \\
\hline 9 & 1 & $0-20$ & 65 & 2 & Unidentified & 1 right pseudocardinal tooth, 1 left pseudocardinal tooth \\
\hline 9 & 3 & $30-40$ & 72 & 1 & Unidentified & left pseudocardinal teeth \\
\hline 9 & 7 & $70-80$ & 85 & 4 & Unidentified & pseudocardinal teeth \\
\hline 9 & 8 & $80-90$ & 88 & 2 & Unidentified & right pseudocardinal teeth \\
\hline 9 & 9 & $90-100$ & 93 & 1 & Unidentified & right pseudocardinal teeth \\
\hline 9 & 10 & $100-110$ & 96 & 3 & Unidentified & right and left pseudocardinal teeth \\
\hline 9 & 10 & $100-110$ & 96 & 1 & Unidentified & $\begin{array}{l}\text { right pseudocardinal teeth (probably Megalonaias } \\
\text { nervosa) }\end{array}$ \\
\hline 9 & 10 & $100-110$ & 96 & 1 & $\begin{array}{l}\text { Quadrulid } \\
\text { Quadrula sp. }\end{array}$ & left pseudocardinal teeth \\
\hline 9 & 13 & $130-140$ & 111 & 2 & Unidentified & 1 right pseudocardinal tooth, 1 left pseudocardinal tooth \\
\hline 9 & 13 & $130-140$ & 111 & 1 & $\begin{array}{l}\text { Quadrulid } \\
\text { Quadrula sp. }\end{array}$ & right pseudocardial tooth \\
\hline 10 & 1 & $110-120$ & 122 & 7 & Unidentified & right and left pseudocardinal teeth ( 1 burnt) \\
\hline 10 & 1 & $110-120$ & 122 & 1 & $\begin{array}{l}\text { Washboard } \\
\text { Megalonaias nervosa }\end{array}$ & right pseudocardinal tooth \\
\hline 10 & 2 & $120-130$ & 129 & 2 & Unidentified & disk fragments \\
\hline
\end{tabular}


Sub-Appendix Table 1 (continued). Freshwater mussel (Family Unionidae) species remains found at Site 41DW277, DeWitt County, Texas, collected by Ecological Communications Corporation, date unstated.

\begin{tabular}{|c|c|c|c|c|c|c|}
\hline Unit & Level & CMBS & Lot & $N$ & Species/Taxon & Shell Structure or Fragment \\
\hline 10 & 2 & $120-130$ & 129 & 16 & Unidentified & right and left pseudocardinal teeth \\
\hline 10 & 2 & $120-130$ & 129 & 1 & $\begin{array}{l}\text { Threeridge } \\
\text { Amblema plicata }\end{array}$ & left pseudocardinal teeth \\
\hline 10 & 2 & $120-130$ & 129 & 2 & $\begin{array}{l}\text { Tampico pearlymussel } \\
\text { Cyrtonaias tampicoensis }\end{array}$ & 1 right pseudocardinal tooth, 1 left pseudocardinal tooth \\
\hline 10 & 3 & $130-140$ & 126 & 11 & Unidentified & right and left pseudocardinal teeth \\
\hline 10 & 3 & $130-140$ & 126 & 1 & $\begin{array}{l}\text { Threeridge } \\
\text { Amblema plicata }\end{array}$ & right pseudocardinal tooth \\
\hline 10 & 3 & $130-140$ & 126 & 1 & Quadrulid & right pseudocardinal tooth \\
\hline 10 & 3 & $130-140$ & 126 & 1 & $\begin{array}{l}\text { Golden Orb } \\
\text { Quadrula aurea }\end{array}$ & right pseudocardinal tooth, umbo, and disk fragment \\
\hline 10 & 4 & $140-150$ & 128 & 3 & Unidentified & disk fragments \\
\hline 10 & 4 & $140-150$ & 128 & 2 & Unidentified & pseudocardinal teeth \\
\hline 10 & 4 & $140-150$ & 128 & 3 & Threeridge & 1 right pseudocardinal tooth, 2 left pseudocardinal teeth \\
\hline 10 & 4 & $140-150$ & 128 & 1 & $\begin{array}{l}\text { Quadrulid } \\
\text { Quadrula sp. }\end{array}$ & right pseudocardinal tooth \\
\hline 10 & 4 & $140-150$ & 128 & 2 & $\begin{array}{l}\text { Tampico pearlymussel } \\
\text { Cyrtonaias tampicoensis }\end{array}$ & 1 right pseudocardinal tooth, 1 left pseudocardinal tooth \\
\hline 10 & 5 & $150-160$ & 134 & 1 & $\begin{array}{l}\text { Washboard } \\
\text { Megalonaias nervosa }\end{array}$ & left pseudocardinal tooth, umbo, and disk fragment \\
\hline 10 & 5 & $150-160$ & 134 & 4 & $\begin{array}{l}\text { Threeridge } \\
\text { Amblema plicata }\end{array}$ & 1 right pseudocardinal tooth, 3 left pseudocardinal teeth \\
\hline 10 & 5 & $150-160$ & 134 & 1 & $\begin{array}{l}\text { Quadrulid } \\
\text { Quadrula sp. }\end{array}$ & right pseudocardinal tooth \\
\hline 10 & 5 & $150-160$ & 134 & 1 & Unidentified & disk fragment \\
\hline 10 & 5 & $150-160$ & 134 & 8 & Unidentified & right and left pseudocardinal teeth \\
\hline 10 & 6 & $160-170$ & $?$ & 1 & $\begin{array}{l}\text { Washboard } \\
\text { Megalonaias nervosa }\end{array}$ & left pseudocardinal teeth \\
\hline 10 & 6 & $160-170$ & $?$ & 1 & Unidentified & disk fragment \\
\hline 10 & 6 & $160-170$ & $?$ & 8 & Unidentified & right and left pseudocardinal teeth \\
\hline 10 & 6 & $160-170$ & $?$ & 1 & Unidentified & left valve fragment \\
\hline 10 & 7 & $170-180$ & 216 & 28 & $\begin{array}{l}\text { Threeridge } \\
\text { Amblema plicata }\end{array}$ & $\begin{array}{l}11 \text { right pseudocardinal teeth, } 17 \text { left pseudocardinal } \\
\text { teeth }\end{array}$ \\
\hline 10 & 7 & $170-180$ & 216 & 7 & Washboard & I left pseudocardinal tooth, 6 right pseudocardinal teeth \\
\hline 10 & 7 & $170-180$ & 216 & 3 & $\begin{array}{l}\text { Quadrulid } \\
\text { Quadrula spp. }\end{array}$ & right pseudocardinal teeth \\
\hline 10 & 7 & $170-180$ & 216 & 43 & Unidentified & right and left pseudocardinal teeth \\
\hline 10 & 8 & $180-190$ & 219 & 4 & Unidentified & right and left pseudocardinal teeth \\
\hline 10 & 8 & $180-190$ & 219 & 1 & $\begin{array}{l}\text { Quadrulid } \\
\text { Quadrula sp. }\end{array}$ & left pseudocardinal teeth \\
\hline 10 & 9 & $190-200$ & 228 & 2 & Unidentified & disk fragments \\
\hline 10 & 9 & $190-200$ & 228 & 1 & Unidentified & right pseudocardinal tooth \\
\hline 10 & 9 & $190-200$ & 228 & 1 & $\begin{array}{l}\text { Threeridge } \\
\text { Amblema plicata }\end{array}$ & left pseudocardinal teeth \\
\hline 11 & 1 & $110-120$ & 130 & 8 & Unidentified & pseudocardinal teeth \\
\hline 11 & 1 & $110-120$ & 130 & 1 & $\begin{array}{l}\text { Washboard } \\
\text { Megalonaias nervosa }\end{array}$ & right pseudocardinal tooth \\
\hline 11 & 2 & $120-130$ & 132 & 3 & Unidentified & disk fragments \\
\hline 11 & 2 & $120-130$ & 132 & 1 & Unidentified & right pseudocardinal tooth \\
\hline 11 & 2 & $120-130$ & 132 & 5 & $\begin{array}{l}\text { Threeridge } \\
\text { Amblema plicata }\end{array}$ & 3 right pseudocardinal teeth, 2 left pseudocardinal teeth \\
\hline
\end{tabular}


Sub-Appendix Table 1 (continued). Freshwater mussel (Family Unionidae) species remains found at Site 41DW277, DeWitt County, Texas, collected by Ecological Communications Corporation, date unstated.

\begin{tabular}{|c|c|c|c|c|c|c|}
\hline Unit & Level & CMBS & Lot & $N$ & Species/Taxon & Shell Structure or Fragment \\
\hline 11 & 3 & $130-140$ & 135 & 2 & Unidentified & 1 right pseudocardinal tooth, 1 left pseudocardinal tooth \\
\hline 11 & 3 & $130-140$ & 135 & 1 & $\begin{array}{l}\text { Quadrulid } \\
\text { Quadrula sp. }\end{array}$ & right pseudocardinal tooth \\
\hline 11 & 4 & $140-150$ & $?$ & 1 & Unidentified & disk fragment \\
\hline 11 & 4 & $140-150$ & $?$ & 1 & $\begin{array}{l}\text { Threeridge } \\
\text { Amblema plicata }\end{array}$ & right pseudocardinal tooth \\
\hline 11 & 4 & $140-150$ & $?$ & 1 & Unidentified & left pseudocardinal teeth (burnt) \\
\hline 11 & 5 & $150-160$ & 155 & 4 & $\begin{array}{l}\text { Threeridge } \\
\text { Amblema plicata }\end{array}$ & left pseudocardinal teeth \\
\hline 11 & 5 & $150-160$ & 155 & 1 & Unidentified & disk fragment \\
\hline 11 & 6 & $160-170$ & 205 & 4 & $\begin{array}{l}\text { Threeridge } \\
\text { Amblema plicata }\end{array}$ & $\begin{array}{l}3 \text { right pseudocardinal teeth, } 1 \text { left pseudocardinal } \\
\text { tooth }\end{array}$ \\
\hline 11 & 6 & $160-170$ & 205 & 7 & Unidentified & right and left pseudocardinal teeth \\
\hline 11 & 6 & $160-170$ & 203 & 4 & Threeridge & 2 right pseudocardinal teeth, 2 left pseudocardinal teeth \\
\hline 11 & 6 & $160-170$ & 203 & 2 & Unidentified & left pseudocardinal teeth \\
\hline 12 & 1 & $90-100$ & 129 & 2 & Unidentified & left pseudocardinal teeth \\
\hline 12 & 1 & $90-100$ & 129 & 1 & $\begin{array}{l}\text { Threeridge } \\
\text { Amblema plicata }\end{array}$ & left pseudocardinal teeth \\
\hline 12 & 1 & $90-100$ & 129 & 1 & $\begin{array}{l}\text { Pistolgrip } \\
\text { Quadrula verrucosa }\end{array}$ & left valve fragment \\
\hline 12 & 2 & $100-110$ & 131 & 2 & $\begin{array}{l}\text { Threeridge } \\
\text { Amblema plicata }\end{array}$ & right pseudocardinal teeth \\
\hline 12 & 2 & $100-110$ & 131 & 11 & Unidentified & right and left pseudocardinal teeth ( 1 burnt) \\
\hline 12 & 3 & $110-120$ & 133 & 12 & Unidentified & right and left pseudocardinal teeth \\
\hline 12 & 3 & $110-120$ & 133 & 1 & $\begin{array}{l}\text { Quadrulid } \\
\text { Quadrula sp. }\end{array}$ & right pseudocardinal tooth \\
\hline 12 & 3 & $110-120$ & 133 & 3 & Unidentified & valve fragments \\
\hline 12 & 4 & $120-130$ & 136 & 1 & $\begin{array}{l}\text { Threeridge } \\
\text { Amblema plicata }\end{array}$ & left valve fragment (larger adult) \\
\hline 12 & 4 & $120-130$ & 136 & 1 & $\begin{array}{l}\text { Threeridge } \\
\text { Amblema plicata }\end{array}$ & left pseudocardinal teeth \\
\hline 12 & 4 & $120-130$ & 136 & 1 & $\begin{array}{l}\text { Washboard } \\
\text { Megalonaias nervosa }\end{array}$ & right pseudocardinal tooth \\
\hline 12 & 4 & $120-130$ & 136 & 1 & $\begin{array}{l}\text { Quadrulid } \\
\text { Quadrula sp. }\end{array}$ & right pseudocardinal tooth \\
\hline 12 & 4 & $120-130$ & 136 & 3 & Unidentified & pseudocardinal teeth \\
\hline 12 & 4 & $120-130$ & 136 & 1 & Unidentified & disk fragment \\
\hline 12 & 5 & $130-140$ & 138 & 1 & $\begin{array}{l}\text { Threeridge } \\
\text { Amblema plicata }\end{array}$ & right pseudocardinal tooth \\
\hline 12 & 5 & $130-140$ & 138 & 5 & Unidentified & pseudocardinal teeth \\
\hline 12 & 6 & $140-150$ & 139 & 3 & $\begin{array}{l}\text { Quadrulid } \\
\text { Quadrula spp. }\end{array}$ & right pseudocardinal teeth \\
\hline 12 & 6 & $140-150$ & 139 & 2 & Unidentified & left pseudocardinal teeth \\
\hline 13 & 1 & $110-120$ & 146 & 1 & $\begin{array}{l}\text { Threeridge } \\
\text { Amblema plicata }\end{array}$ & left pseudocardinal teeth \\
\hline 13 & 1 & $110-120$ & 146 & 25 & Unidentified & right and left pseudocardinal teeth \\
\hline 13 & 1 & $110-120$ & 146 & 2 & Unidentified & disk fragments \\
\hline 13 & 2 & $120-130$ & 150 & 5 & Unidentified & disk fragments \\
\hline 13 & 2 & $120-130$ & 150 & 1 & $\begin{array}{l}\text { Threeridge } \\
\text { Amblema plicata }\end{array}$ & right pseudocardinal tooth \\
\hline 13 & 2 & $120-130$ & 150 & 1 & $\begin{array}{l}\text { Washboard } \\
\text { Megalonaias nervosa }\end{array}$ & right pseudocardinal tooth \\
\hline
\end{tabular}


Sub-Appendix Table 1 (continued). Freshwater mussel (Family Unionidae) species remains found at Site 41DW277, DeWitt County, Texas, collected by Ecological Communications Corporation, date unstated.

\begin{tabular}{|c|c|c|c|c|c|c|}
\hline Unit & Level & CMBS & Lot & $N$ & Species/Taxon & Shell Structure or Fragment \\
\hline 13 & 2 & $120-130$ & 150 & 4 & $\begin{array}{l}\text { Quadrulid } \\
\text { Quadrula spp. }\end{array}$ & right pseudocardinal teeth \\
\hline 13 & 2 & $120-130$ & 150 & 30 & Unidentified & right and left pseudocardinal teeth \\
\hline 13 & 3 & $130-140$ & 158 & 3 & Unidentified & disk fragments \\
\hline 13 & 3 & $130-140$ & 158 & 6 & Unidentified & right and left pseudocardinal teeth \\
\hline 13 & 3 & $130-140$ & 158 & 6 & $\begin{array}{l}\text { Threeridge } \\
\text { Amblema plicata }\end{array}$ & 3 right pseudocardinal teeth, 3 left pseudocardinal tooth \\
\hline 13 & 3 & $130-140$ & 158 & 3 & $\begin{array}{l}\text { Tampico pearlymussel } \\
\text { Cyrtonaias tampicoensis }\end{array}$ & 1 right pseudocardinal tooth, 2 left pseudocardinal teeth \\
\hline 13 & 3 & $130-140$ & 158 & 1 & $\begin{array}{l}\text { Quadrulid } \\
\text { Quadrula sp. }\end{array}$ & fragment (Q. apiculata or $Q$. verrucosa) \\
\hline 13 & 4 & $140-150$ & 163 & 2 & $\begin{array}{l}\text { Threeridge } \\
\text { Amblema plicata }\end{array}$ & 1 right pseudocardinal tooth, 1 left pseudocardinal tooth \\
\hline 13 & 4 & $140-150$ & 163 & 2 & $\begin{array}{l}\text { Quadrulid } \\
\text { Quadrula spp. }\end{array}$ & right pseudocardinal teeth \\
\hline 13 & 4 & $140-150$ & 163 & 2 & Unidentified & pseudocardinal teeth \\
\hline 13 & 4 & $140-150$ & 163 & 1 & Unidentified & disk fragment \\
\hline 13 & 5 & $150-160$ & 170 & 13 & Unidentified & right and left pseudocardinal teeth \\
\hline 13 & 5 & $150-160$ & 170 & 12 & Unidentified & disk fragments \\
\hline 13 & 5 & $150-160$ & 170 & 3 & $\begin{array}{l}\text { Threeridge } \\
\text { Amblema plicata }\end{array}$ & 1 right pseudocardinal tooth, 2 left pseudocardinal teeth \\
\hline 13 & 5 & $150-160$ & 170 & 1 & $\begin{array}{l}\text { Washboard } \\
\text { Megalonaias nervosa }\end{array}$ & right pseudocardinal tooth \\
\hline 13 & 6 & $160-170$ & 184 & 8 & $\begin{array}{l}\text { Threeridge } \\
\text { Amblema plicata }\end{array}$ & 5 right pseudocardinal teeth, 3 left pseudocardinal teeth \\
\hline 13 & 6 & $160-170$ & 184 & 2 & $\begin{array}{l}\text { Washboard } \\
\text { Megalonaias nervosa }\end{array}$ & 1 right pseudocardinal tooth, 1 left pseudocardinal tooth \\
\hline 13 & 6 & $160-170$ & 184 & 2 & $\begin{array}{l}\text { Quadrulid } \\
\text { Quadrula spp. }\end{array}$ & right pseudocardinal teeth \\
\hline 13 & 6 & $160-170$ & 184 & 7 & Unidentified & disk fragments \\
\hline 13 & 6 & $160-170$ & 184 & 16 & Unidentified & right and left pseudocardinal teeth \\
\hline 13 & 7 & $170-180$ & 218 & 6 & $\begin{array}{l}\text { Threeridge } \\
\text { Amblema plicata }\end{array}$ & 1 right pseudocardinal tooth, 5 left pseudocardinal teeth \\
\hline 13 & 7 & $170-180$ & 218 & 17 & Unidentified & right and left pseudocardinal teeth \\
\hline 13 & 7 & $170-180$ & 218 & 7 & Unidentified & disk fragments \\
\hline 13 & 8 & $180-190$ & 241 & 7 & $\begin{array}{l}\text { Threeridge } \\
\text { Amblema plicata }\end{array}$ & 4 right pseudocardinal teeth, 3 left pseudocardinal teeth \\
\hline 13 & 8 & $180-190$ & 241 & 1 & Unidentified & left pseudocardinal teeth \\
\hline 13 & 8 & $180-190$ & 241 & 3 & Unidentified & disk fragment \\
\hline 14 & 1 & $110-120$ & 156 & 1 & Threeridge & right pseudocardinal tooth \\
\hline 14 & 1 & $110-120$ & 156 & 1 & $\begin{array}{l}\text { Quadrulid } \\
\text { Quadrula sp. }\end{array}$ & right pseudocardinal tooth \\
\hline 14 & 1 & $110-120$ & 156 & 1 & $\begin{array}{l}\text { Yellow sandshell } \\
\text { Lampsilis teres }\end{array}$ & right pseudocardinal tooth \\
\hline 14 & 1 & $110-120$ & 156 & 11 & Unidentified & right and left pseudocardinal teeth \\
\hline 14 & 2 & $120-130$ & 178 & 8 & $\begin{array}{l}\text { Threeridge } \\
\text { Amblema plicata }\end{array}$ & 4 right pseudocardinal teeth, 4 left pseudocardinal teeth \\
\hline 14 & 2 & $120-130$ & 178 & 1 & Unidentified & right pseudocardinal tooth \\
\hline 14 & 3 & $130-140$ & 179 & 3 & Unidentified & $\begin{array}{l}\text { right and left pseudocardinal teeth (probably Amblema } \\
\text { plicata) }\end{array}$ \\
\hline 14 & 4 & $140-150$ & 192 & 3 & Unidentified & right and Ifet pseudocardinal teeth \\
\hline 14 & 5 & $150-160$ & 193 & 1 & $\begin{array}{l}\text { Quadrulid } \\
\text { Quadrula sp. }\end{array}$ & right pseudocardinal tooth \\
\hline 14 & 5 & $150-160$ & 193 & 5 & Unidentified & $\begin{array}{l}\text { right and left pseudocardinal teeth (Amblema or } \\
\text { Megalonaias) }\end{array}$ \\
\hline
\end{tabular}


Sub-Appendix Table 1 (continued). Freshwater mussel (Family Unionidae) species remains found at Site 41DW277, DeWitt County, Texas, collected by Ecological Communications Corporation, date unstated.

\begin{tabular}{|c|c|c|c|c|c|c|}
\hline Unit & Level & CMBS & Lot & $N$ & Species/Taxon & Shell Structure or Fragment \\
\hline 15 & 1 & $110-120$ & 147 & 1 & $\begin{array}{l}\text { Threeridge } \\
\text { Amblema plicata }\end{array}$ & left pseudocardinal teeth \\
\hline 15 & 1 & $110-120$ & 147 & 1 & Unidentified & left pseudocardinal teeth \\
\hline 15 & 6 & $160-170$ & 187 & 1 & $\begin{array}{l}\text { Washboard } \\
\text { Megalonaias nervosa }\end{array}$ & right pseudocardinal tooth \\
\hline 15 & 6 & $160-170$ & 187 & 5 & Unidentified & right and left pseudocardinal teeth \\
\hline 15 & 7 & $170-180$ & 188 & 6 & $\begin{array}{l}\text { Threeridge } \\
\text { Amblema plicata }\end{array}$ & 2 right pseudocardinal teeth, 4 left pseudocardinal teeth \\
\hline 15 & 7 & $170-180$ & 188 & 2 & Unidentified & pseudocardinal teeth \\
\hline 16 & 1 & $110-120$ & 141 & 3 & Unidentified & pseudocardinal teeth \\
\hline 16 & 2 & $120-130$ & 142 & 1 & Unidentified & fragment \\
\hline 16 & 3 & $130-140$ & 143 & 1 & Unidentified & left pseudocardinal teeth (probably Amblema plicata) \\
\hline 17 & 1 & $110-120$ & 147 & 3 & $\begin{array}{l}\text { Threeridge } \\
\text { Amblema plicata }\end{array}$ & 1 right pseudocardinal tooth, 2 left pseudocardinal teeth \\
\hline 17 & 1 & $110-120$ & 147 & 1 & $\begin{array}{l}\text { Washboard } \\
\text { Megalonaias nervosa }\end{array}$ & right pseudocardinal tooth \\
\hline 17 & 1 & $110-120$ & 147 & 9 & Unidentified & right and left pseudocardinal teeth \\
\hline 17 & 1 & $110-120$ & 147 & 4 & Unidentified & disk fragments \\
\hline 17 & 2 & $120-130$ & 153 & 1 & $\begin{array}{l}\text { Threeridge } \\
\text { Amblema plicata }\end{array}$ & left pseudocardinal teeth \\
\hline 17 & 2 & $120-130$ & 153 & 1 & $\begin{array}{l}\text { Quadrulid } \\
\text { Quadrula sp. }\end{array}$ & right pseudocardinal tooth \\
\hline 17 & 2 & $120-130$ & 153 & 2 & Unidentified & pseudocardinal teeth \\
\hline 17 & 3 & $130-140$ & 157 & 2 & Unidentified & left pseudocardinal teeth \\
\hline 17 & 4 & $140-150$ & 159 & 1 & Unidentified & left pseudocardinal teeth \\
\hline 17 & 4 & $140-150$ & 159 & 1 & Unidentified & pseudocardinal teeth \\
\hline 18 & 9 & $80-90$ & 162 & 3 & Unidentified & right and left pseudocardinal teeth \\
\hline 18 & 10 & $90-100$ & 165 & 2 & $\begin{array}{l}\text { Threeridge } \\
\text { Amblema plicata }\end{array}$ & 1 right pseudocardinal tooth, 1 left pseudocardinal tooth \\
\hline 18 & 10 & $90-100$ & 165 & 1 & $\begin{array}{l}\text { Quadrulid } \\
\text { Quadrula sp. }\end{array}$ & right pseudocardinal tooth \\
\hline 18 & 10 & $90-100$ & 165 & 1 & Unidentified & right pseudocardinal tooh \\
\hline 18 & 11 & $100-110$ & 166 & 1 & Unidentified & left pseudocardinal teeth \\
\hline 18 & 12 & $110-120$ & 197 & 4 & $\begin{array}{l}\text { Threeridge } \\
\text { Amblema plicata }\end{array}$ & 1 right pseudocardinal tooh, 3 left pseudocardinal teeth \\
\hline 18 & 12 & $110-120$ & 197 & 4 & Unidentified & pseudocardinal teeth \\
\hline 18 & 13 & $120-130$ & 169 & 1 & $\begin{array}{l}\text { Threeridge } \\
\text { Amblema plicata }\end{array}$ & right pseudocardinal teeth \\
\hline 18 & 13 & $120-130$ & 169 & 1 & $\begin{array}{l}\text { Yellow sandshell } \\
\text { Lampsilis teres }\end{array}$ & right pseudocardinal teeth \\
\hline 18 & 14 & $130-140$ & 170 & 1 & Unidentified & right pseudocardinal teeth \\
\hline 19 & 1 & $110-120$ & $?$ & 1 & $\begin{array}{l}\text { Threeridge } \\
\text { Amblema plicata }\end{array}$ & left pseudocardinal teeth \\
\hline 19 & 1 & $110-120$ & $?$ & 1 & $\begin{array}{l}\text { Washboard } \\
\text { Megalonaias nervosa }\end{array}$ & right pseudocardinal tooth \\
\hline 19 & 1 & $110-120$ & $?$ & 1 & $\begin{array}{l}\text { Quadrulid } \\
\text { Quadrula sp. }\end{array}$ & right pseudocardinal tooth \\
\hline 19 & 1 & $110-120$ & $?$ & 8 & Unidentified & right and left pseudocardinal teeth \\
\hline 19 & 3 & $130-140$ & $?$ & 1 & $\begin{array}{l}\text { Threeridge } \\
\text { Amblema plicata }\end{array}$ & left pseudocardinal teeth \\
\hline 19 & 3 & $130-140$ & $?$ & 4 & $\begin{array}{l}\text { Quadrulid } \\
\text { Quadrula spp. }\end{array}$ & 3 right pseudocardinal tooth, 1 left pseudocardinal tooth \\
\hline 19 & 3 & $130-140$ & $?$ & 26 & Unidentified & right and left pseudocardinal teeth \\
\hline
\end{tabular}


Sub-Appendix Table 1 (continued). Freshwater mussel (Family Unionidae) species remains found at Site 41DW277, DeWitt County, Texas, collected by Ecological Communications Corporation, date unstated.

\begin{tabular}{|c|c|c|c|c|c|c|}
\hline Unit & Level & CMBS & Lot & $N$ & Species/Taxon & Shell Structure or Fragment \\
\hline 19 & 4 & $140-150$ & $?$ & 2 & $\begin{array}{l}\text { Threeridge } \\
\text { Amblema plicata }\end{array}$ & left pseudocardinal teeth \\
\hline 19 & 4 & $140-150$ & $?$ & 4 & Unidentified & right and left pseudocardinal teeth \\
\hline 19 & 5 & $150-160$ & ? & 1 & Unidentified & pseudocardinal teeth \\
\hline 20 & 1 & $110-120$ & $?$ & 4 & Unidentified & right and left pseudocardinal teeth \\
\hline 20 & 2 & $120-130$ & $?$ & 1 & $\begin{array}{l}\text { Threeridge } \\
\text { Amblema plicata }\end{array}$ & right pseudocardinal teeth \\
\hline 20 & 2 & $120-130$ & $?$ & 6 & Unidentified & right and left pseudocardinal teeth \\
\hline 20 & 3 & $130-140$ & 189 & 3 & $\begin{array}{l}\text { Threeridge } \\
\text { Amblema plicata }\end{array}$ & left pseudocardinal teeth \\
\hline 20 & 3 & $130-140$ & 189 & 2 & $\begin{array}{l}\text { Quadrulid } \\
\text { Quadrula spp. }\end{array}$ & right pseudocardinal tooth \\
\hline 20 & 3 & $130-140$ & 189 & 15 & Unidentified & right and left pseudocardinal teeth \\
\hline 20 & 4 & $140-150$ & 191 & 3 & $\begin{array}{l}\text { Threeridge } \\
\text { Amblema plicata }\end{array}$ & 2 right pseudocardinal teeth, 1 left pseudocardinal tooth \\
\hline 20 & 4 & $140-150$ & 191 & 2 & $\begin{array}{l}\text { Quadrulid } \\
\text { Quadrula spp. }\end{array}$ & 1 right pseudocardinal tooth, 1 left pseudocardinal tooth \\
\hline 20 & 4 & $140-150$ & 191 & 11 & Unidentified & right and left pseudocardinal teeth \\
\hline 20 & 5 & $150-160$ & 195 & 1 & $\begin{array}{l}\text { Threeridge } \\
\text { Amblema plicata }\end{array}$ & right pseudocardinal tooth \\
\hline 20 & 5 & $150-160$ & 195 & 1 & $\begin{array}{l}\text { Quadrulid } \\
\text { Quadrula sp. }\end{array}$ & right pseudocardinal tooth \\
\hline 20 & 5 & $150-160$ & 195 & 3 & Unidentified & right and left pseudocardinal teeth \\
\hline 21 & 1 & $110-120$ & 164 & 3 & $\begin{array}{l}\text { Threeridge } \\
\text { Amblema plicata }\end{array}$ & 2 right pseudocardinal teeth, 1 left pseudocardinal tooth \\
\hline 21 & 1 & $110-120$ & 164 & 1 & $\begin{array}{l}\text { Quadrulid } \\
\text { Quadrula sp. }\end{array}$ & right pseudocardinal tooth \\
\hline 21 & 1 & $110-120$ & 164 & 4 & Unidentified & right and left pseudocardinal teeth \\
\hline 21 & 2 & $120-130$ & 168 & 1 & $\begin{array}{l}\text { Quadrulid } \\
\text { Quadrula sp. }\end{array}$ & right pseudocardinal tooth \\
\hline 21 & 2 & $120-130$ & 168 & 1 & Unidentified & left pseudocardinal teeth \\
\hline 21 & 3 & $130-140$ & 175 & 3 & Unidentified & right and left pseudocardinal teeth \\
\hline 21 & 3 & $130-140$ & 175 & 1 & $\begin{array}{l}\text { Threeridge } \\
\text { Amblema plicata }\end{array}$ & left pseudocardinal teeth \\
\hline 21 & 3 & $130-140$ & 175 & 1 & $\begin{array}{l}\text { Quadrulid } \\
\text { Quadrula sp. }\end{array}$ & right pseudocardinal tooth \\
\hline 21 & 3 & $130-140$ & 175 & 1 & $\begin{array}{l}\text { Washboard } \\
\text { Megalonaias nervosa }\end{array}$ & right pseudocardinal tooth \\
\hline 21 & 4 & $140-150$ & 176 & 2 & $\begin{array}{l}\text { Threeridge } \\
\text { Amblema plicata }\end{array}$ & right pseudocardinal teeth \\
\hline 22 & 1 & $110-120$ & 181 & 1 & Unidentified & right pseudocardinal tooth \\
\hline 22 & 2 & $120-130$ & 190 & 1 & $\begin{array}{l}\text { Threeridge } \\
\text { Amblema plicata }\end{array}$ & right pseudocardinal tooth \\
\hline 22 & 2 & $120-130$ & 190 & 2 & $\begin{array}{l}\text { Washboard } \\
\text { Megalonaias nervosa }\end{array}$ & right pseudocardinal teeth \\
\hline 22 & 2 & $120-130$ & 190 & 1 & $\begin{array}{l}\text { Quadrulid } \\
\text { Quadrula sp. }\end{array}$ & right pseudocardinal tooth \\
\hline 22 & 2 & $120-130$ & 190 & 5 & Unidentified & right and left pseudocardinal teeth \\
\hline 22 & 3 & $130-140$ & 194 & 1 & $\begin{array}{l}\text { False spike } \\
\text { Quadrula mitchelli }\end{array}$ & left valve fragment \\
\hline 22 & 3 & $130-140$ & 194 & 1 & $\begin{array}{l}\text { Quadrulid } \\
\text { Quadrula sp. }\end{array}$ & right pseudocardinal tooth \\
\hline 22 & 3 & $130-140$ & 194 & 2 & Unidentified & disk fragments \\
\hline 22 & 4 & $140-150$ & 196 & 1 & $\begin{array}{l}\text { Threeridge } \\
\text { Amblema plicata }\end{array}$ & left pseudocardinal teeth \\
\hline 22 & 4 & $140-150$ & 196 & 1 & Unidentified & right pseudocardinal teeth \\
\hline
\end{tabular}


Sub-Appendix Table 1 (continued). Freshwater mussel (Family Unionidae) species remains found at Site 41DW277, DeWitt County, Texas, collected by Ecological Communications Corporation, date unstated.

\begin{tabular}{|c|c|c|c|c|c|c|}
\hline Unit & Level & CMBS & Lot & $N$ & Species/Taxon & Shell Structure or Fragment \\
\hline 22 & 5 & $150-160$ & 207 & 5 & Unidentified & right and left pseudocardinal teeth \\
\hline 22 & 5 & $150-160$ & 207 & 1 & Unidentified & disk fragment \\
\hline 23 & 8 & $90-100$ & 230 & 10 & Unidentified & right and left pseudocardinal teeth \\
\hline 23 & 9 & $100-110$ & 242 & 2 & $\begin{array}{l}\text { Threeridge } \\
\text { Amblema plicata }\end{array}$ & right pseudocardinal teeth \\
\hline 23 & 9 & $100-110$ & 242 & 1 & $\begin{array}{l}\text { Quadrulid } \\
\text { Quadrula sp. }\end{array}$ & right pseudocardinal tooth \\
\hline 23 & 9 & $100-110$ & 242 & 32 & Unidentified & right and left pseudocardinal teeth \\
\hline 23 & 9 & $100-110$ & 242 & 1 & Unidentified & disk fragment \\
\hline 23 & 10 & $110-120$ & 244 & 12 & Unidentified & right and left pseudocardinal teeth \\
\hline 23 & 10 & $110-120$ & 244 & 2 & $\begin{array}{l}\text { Threeridge } \\
\text { Amblema plicata }\end{array}$ & right pseudocardinal teeth \\
\hline 23 & 10 & $110-120$ & 244 & 1 & Washboard & right pseudocardinal tooth \\
\hline 23 & 11 & $120-130$ & 248 & 5 & Unidentified & right and left pseudocardinal teeth \\
\hline 23 & 11 & $120-130$ & 256 & 2 & $\begin{array}{l}\text { Threeridge } \\
\text { Amblema plicata }\end{array}$ & 1 right pseudocardinal tooth, 1 left pseudocardinal tooth \\
\hline 23 & 11 & $120-130$ & 256 & 1 & $\begin{array}{l}\text { False spike } \\
\text { Quadrula mitchelli }\end{array}$ & right pseudocardinal tooth and disk fragment \\
\hline 23 & 12 & $130-140$ & 255 & 6 & Unidentified & right and left pseudocardinal teeth (1 burnt) \\
\hline 23 & 12 & $130-140$ & 255 & 1 & $\begin{array}{l}\text { Threeridge } \\
\text { Amblema plicata }\end{array}$ & left pseudocardinal teeth \\
\hline 23 & 13 & $140-150$ & 259 & 1 & $\begin{array}{l}\text { Threeridge } \\
\text { Amblema plicata }\end{array}$ & left pseudocardinal teeth \\
\hline 23 & 13 & $140-150$ & 259 & 1 & $\begin{array}{l}\text { Quadrulid } \\
\text { Quadrula sp. }\end{array}$ & right pseudocardinal tooth \\
\hline 23 & 13 & $140-150$ & 259 & 2 & Unidentified & left lateral teeth \\
\hline 24 & 1 & $100-110$ & 171 & 8 & Unidentified & right and left pseudocardinal teeth \\
\hline 24 & 2 & $110-120$ & 172 & 1 & Unidentified & right pseudocardinal tooth \\
\hline 24 & 2 & $110-120$ & 172 & 1 & Unidentified & disk fragment \\
\hline 24 & 4 & $130-140$ & 182 & 1 & $\begin{array}{l}\text { Pistolgrip } \\
\text { Quadrula verrucosa }\end{array}$ & left pseudocardinal teeth and umbo \\
\hline 24 & 5 & $140-150$ & 183 & 3 & Unidentified & right and left pseudocardinal teeth \\
\hline 24 & 5 & $140-150$ & 183 & 1 & $\begin{array}{l}\text { Quadrulid } \\
\text { Quadrula sp. }\end{array}$ & right pseudocardinal tooth \\
\hline 24 & 6 & $156-160$ & 197 & 1 & $\begin{array}{l}\text { Quadrulid } \\
\text { Quadrula sp. }\end{array}$ & right pseudocardinal tooth \\
\hline 24 & 6 & $156-160$ & 197 & 1 & Unidentified & left pseudocardinal teeth \\
\hline 25 & 1 & $100-110$ & 200 & 1 & $\begin{array}{l}\text { Quadrulid } \\
\text { Quadrula sp. }\end{array}$ & right pseudocardinal tooth \\
\hline 25 & 1 & $100-110$ & 200 & 14 & Unidentified & right and left pseudocardinal teeth \\
\hline 25 & 2 & $110-120$ & 201 & 2 & $\begin{array}{l}\text { Threeridge } \\
\text { Amblema plicata }\end{array}$ & right pseudocardinal teeth \\
\hline 25 & 2 & $110-120$ & 201 & 8 & Unidentified & right and left pseudocardinal teeth \\
\hline 25 & 2 & $110-120$ & 201 & 2 & Unidentified & disk fragments \\
\hline 25 & 3 & $120-130$ & 220 & 6 & $\begin{array}{l}\text { Threeridge } \\
\text { Amblema plicata }\end{array}$ & 4 right pseudocardinal teeth, 2 left pseudocardinal teeth \\
\hline 25 & 3 & $120-130$ & 220 & 2 & $\begin{array}{l}\text { Washboard } \\
\text { Megalonaias nervosa }\end{array}$ & 1 right pseudocardinal tooth, 1 left pseudocardinal tooth \\
\hline 25 & 3 & $120-130$ & 220 & 7 & Unidentified & disk fragments \\
\hline 25 & 3 & $120-130$ & 220 & 9 & Unidentified & right and left pseudocardinal teeth \\
\hline 25 & 3 & $120-130$ & 202 & 4 & Unidentified & disk fragments \\
\hline 25 & 3 & $120-130$ & 202 & 9 & Unidentified & right and left pseudocardinal teeth \\
\hline 25 & 4 & $130-140$ & 221 & 2 & Unidentified & disk fragments \\
\hline 25 & 4 & $130-140$ & 221 & 3 & Unidentified & right and left pseudocardinal teeth \\
\hline
\end{tabular}


Sub-Appendix Table 1 (continued). Freshwater mussel (Family Unionidae) species remains found at Site 41DW277, DeWitt County, Texas, collected by Ecological Communications Corporation, date unstated.

\begin{tabular}{|c|c|c|c|c|c|c|}
\hline Unit & Level & CMBS & Lot & $N$ & Species/Taxon & Shell Structure or Fragment \\
\hline 25 & 4 & $130-140$ & 221 & 2 & $\begin{array}{l}\text { Threeridge } \\
\text { Amblema plicata }\end{array}$ & 1 right pseudocardinal tooth, 1 left pseudocardinal tooth \\
\hline 25 & 5 & $140-150$ & 222 & 1 & $\begin{array}{l}\text { Threeridge } \\
\text { Amblema plicata }\end{array}$ & right pseudocardinal tooth \\
\hline 25 & 5 & $140-150$ & 222 & 11 & Unidentified & right and left pseudocardinal teeth \\
\hline 25 & 6 & $150-160$ & 235 & 2 & $\begin{array}{l}\text { Threeridge } \\
\text { Amblema plicata }\end{array}$ & right pseudocardinal teeth \\
\hline 25 & 6 & $150-160$ & 235 & 1 & $\begin{array}{l}\text { Quadrulid } \\
\text { Quadrula sp. }\end{array}$ & right pseudocardinal tooth \\
\hline 25 & 6 & $150-160$ & 235 & 6 & Unidentified & right and left pseudocardinal teeth \\
\hline 25 & 6 & $150-160$ & 235 & 8 & Unidentified & disk fragments \\
\hline 25 & 7 & $160-170$ & 236 & 1 & Unidentified & right pseudocardinal tooth \\
\hline 26 & 1 & $100-110$ & 185 & 2 & $\begin{array}{l}\text { Threeridge } \\
\text { Amblema plicata }\end{array}$ & left pseudocardinal teeth \\
\hline 26 & 1 & $100-110$ & 185 & 2 & Unidentified & right pseudocardinal teeth \\
\hline 26 & 2 & $110-120$ & 186 & 1 & $\begin{array}{l}\text { Threeridge } \\
\text { Amblema plicata }\end{array}$ & left pseudocardinal teeth \\
\hline 26 & 2 & $110-120$ & 186 & 4 & Unidentified & right and left pseudocardinal teeth \\
\hline 26 & 2 & $110-120$ & 186 & 3 & Unidentified & disk fragments \\
\hline 27 & 2 & $20-40$ & 215 & 1 & Unidentified & right pseudocardinal tooth \\
\hline 27 & 8 & $90-100$ & 243 & 1 & Unidentified & right pseudocardinal tooth \\
\hline 27 & 10 & $110-120$ & 252 & 3 & $\begin{array}{l}\text { Threeridge } \\
\text { Amblema plicata }\end{array}$ & 1 right pseudocardinal tooth, 2 left pseudocardinal teeth \\
\hline 27 & 10 & $120-130$ & 252 & 8 & Unidentified & right and left pseudocardinal teeth \\
\hline 27 & 12 & $130-140$ & 266 & 5 & $\begin{array}{l}\text { Threeridge } \\
\text { Amblema plicata }\end{array}$ & 2 right pseudocardinal teeth, 3 left pseudocardinal teeth \\
\hline 27 & 12 & $130-140$ & 266 & 2 & Unidentified & pseudocardinal teeth \\
\hline 28 & 8 & $90-100$ & 245 & 2 & Unidentified & pseudocardinal teeth \\
\hline 28 & 9 & $100-110$ & 277 & 6 & $\begin{array}{l}\text { Threeridge } \\
\text { Amblema plicata }\end{array}$ & 4 right pseudocardinal teeth, 2 left pseudocardinal teeth \\
\hline 28 & 9 & $100-110$ & 277 & 11 & Unidentified & right and left pseudocardinal teeth \\
\hline 28 & 10 & $100-110$ & 247 & 19 & Unidentified & right and left pseudocardinal teeth \\
\hline 28 & 10 & $110-120$ & 247 & 5 & $\begin{array}{l}\text { Threeridge } \\
\text { Amblema plicata }\end{array}$ & 1 right pseudocardinal tooth, 4 left pseudocardinal teeth \\
\hline 28 & 10 & $110-120$ & 247 & 1 & Unidentified & disk fragment \\
\hline 28 & 10 & $110-120$ & 247 & 1 & Unidentified & lateral teeth \\
\hline 28 & 10 & $110-120$ & 247 & 14 & Unidentified & right and left pseudocardinal teeth \\
\hline 28 & 11 & $120-130$ & 253 & 2 & $\begin{array}{l}\text { Threeridge } \\
\text { Amblema plicata }\end{array}$ & 1 right pseudocardinal tooh, 1 left pseudocardinal tooth \\
\hline 28 & 11 & $120-130$ & 253 & 1 & $\begin{array}{l}\text { Threeridge } \\
\text { Amblema plicata }\end{array}$ & left lateral teeth \\
\hline 28 & 11 & $120-130$ & 253 & 2 & Unidentified & disk fragments \\
\hline 28 & 11 & $120-130$ & 253 & 1 & Unidentified & lateral tooth fragment \\
\hline 28 & 11 & $120-130$ & 253 & 15 & Unidentified & right and left pseudocardinal teeth ( 1 burnt) \\
\hline 28 & 12 & $130-140$ & 254 & 3 & $\begin{array}{l}\text { Threeridge } \\
\text { Amblema plicata }\end{array}$ & 2 right pseudocardinal teeth, 1 left pseudocardinal tooth \\
\hline 28 & 13 & $140-150$ & 261 & 18 & Unidentified & disk fragments \\
\hline 28 & 13 & $140-150$ & 261 & 8 & Unidentified & right and left pseudocardinal teeth \\
\hline 28 & 13 & $140-150$ & 261 & 1 & Unidentified & right valve section \\
\hline 28 & 13 & $140-150$ & 261 & 4 & $\begin{array}{l}\text { Threeridge } \\
\text { Amblema plicata }\end{array}$ & right pseudocardinal teeth \\
\hline 28 & 14 & $150-160$ & 262 & 5 & Unidentified & right and left pseudocardinal teeth \\
\hline 28 & 14 & $150-160$ & 262 & 1 & $\begin{array}{l}\text { Quadrulid } \\
\text { Quadrula sp. }\end{array}$ & right pseudocardinal tooth \\
\hline
\end{tabular}


Sub-Appendix Table 1 (continued). Freshwater mussel (Family Unionidae) species remains found at Site 41DW277, DeWitt County, Texas, collected by Ecological Communications Corporation, date unstated.

\begin{tabular}{|c|c|c|c|c|c|c|}
\hline Unit & Level & CMBS & Lot & $N$ & Species/Taxon & Shell Structure or Fragment \\
\hline 28 & 14 & $150-160$ & 262 & 1 & Unidentified & disk fragment \\
\hline 29 & 8 & $90-100$ & 250 & 1 & Unidentified & pseudocardinal teeth \\
\hline 29 & 9 & $100-110$ & 251 & 7 & Unidentified & right and left pseudocardinal teeth \\
\hline 29 & 9 & $100-110$ & 251 & 1 & $\begin{array}{l}\text { Threeridge } \\
\text { Amblema plicata }\end{array}$ & left pseudocardinal teeth \\
\hline 29 & 10 & $110-120$ & 258 & 3 & Unidentified & right and left pseudocardinal teeth \\
\hline 29 & 11 & $120-130$ & 260 & 1 & $\begin{array}{l}\text { Quadrulid } \\
\text { Quadrula sp. }\end{array}$ & right pseudocardinal tooth \\
\hline 29 & 11 & $120-130$ & 260 & 1 & Unidentified & left pseudocardinal teeth \\
\hline 29 & 12 & $130-140$ & 271 & 4 & $\begin{array}{l}\text { Threeridge } \\
\text { Amblema plicata }\end{array}$ & 2 right pseudocardinal teeth, 2 left pseudocardinal teeth \\
\hline 29 & 12 & $130-140$ & 271 & 5 & Unidentified & disk fragments \\
\hline
\end{tabular}


Appendix D

\section{Flotation Analysis and Wet SCREENING Results}


Plant Remains

FROM

SITE 41DW277

August 25, 2011

Prepared for:

Rachel Feit, Principal Investigator

and

Mindy Bonine, Project Archaeologist

Ecological Communications Corporation

4009 Banister Lane, Suite 300

Austin, Texas 78704

Prepared by:

Leslie L. Bush, Ph.D., R.P.A.

Macrobotanical Analysis

12308 Twin Creeks Rd., B-106

Manchaca, TX 78652 
Six flotation samples were submitted for identification and analysis from Site 41DW277. The site is located in northern DeWitt county along the east bank of the Guadalupe River near the Highway 183 bridge crossing. The site is described as a broad prehistoric lithic scatter with areas of burned rock (THC Site Files 6/26/2009).

\section{VEGETATION}

Site 41DW277 today is located near the convergence of three major vegetation areas: the southernmost extents of the Blackland Prairie and Post Oak Savannah and the northeasternmost extent of the South Texas Plains.

\section{Blackland Prairie}

The most common prairie grasses in presettlement times would have been little bluestem (Schizachyrium scoparium), Indiangrass (Sorghastrum nutans), switchgrass (Panicum virgatum), and big bluestem (Andropogon gerardii), which are dominant over much of the Blackland Prairie. Community types vary in localized areas primarily due to differences in soil (Diggs et al. 1999:40). Wooded areas are occasionally present in the uplands and typical near larger rivers and streams. Wildfires tended to make smaller tributaries treeless. R. T. Hill listed some common trees in his 1901 description of the Blacklands in general:

The surfaces of the prairies are ordinarily clad with thick mantles of grass, liberally sprinkled with many-colored flowers, broken here and there by low growths of mesquite trees, or in exceptional places by 'mottes' or clumps of live oaks on uplands, pecan, bois d'arc, walnut and oaks in the streams bottoms; juniper and sumac where stony slopes exist, and post oak and black-jack in the sandy belts. (Diggs et al.1999:34)

\section{Post Oak Savannah}

Upland vegetation on the Post Oak Savannah is characterized by a mixture of trees and grasslands. Oaks and hickories are the dominant trees through most of the region, but true hickories become rare in the southeasternmost counties of the Post Oak Savannah (Diggs et al. 2006; Turner et al. 2003a). In the past, areas of tall grasses interspersed among the woodlands would have included species common to the Blackland Prairie. On sandier sites, sandjack oak (Quercus incana; also called bluejack oak) and sand post oak (Q. margaretta; also called runner oak) would be the more common oak trees, with yucca (Yucca louisianensis) and prickly pear (Opuntia humifusa) present in the understory (Diggs et al. 2006). Wetter areas may have been able to support sugarberry-elm communities where sugarberry and hackberry (Celtis laevigata; and C. pallida), cedar elm (Ulmus crassifolia), and green ash (Fraxinus pennsylvanica) dominate the canopy. Grape vines (Vitis spp.), poison ivy (Toxicodendron radicans), sedges (Cyperaceae), and wetland grasses such as wildrye (Elymus spp.) and wood oats (Chasmanthium spp.) would also have been common (Bezanson 2000:51; Diggs et al. 2006:122-3).

\section{South Texas Plains}

The South Texas Plains are part of the Tamaulipan Biotic Province, which is characterized by shrubs and thorny brush (Blair 1950). Although climate fluctuations during the Holocene have resulted in variation 
in temperature and moisture regimes, the species composition of the area has not changed radically. Typical vegetation in historic times includes honey mesquite (Prosopis glandulosa), various acacias (Acacia spp.), granjeno (Celtis pallida), guayacan (aka Texas lignum vitae; Guajacum angustifolia syn. Porlieria angustifolia), cenizo (aka Texas barometer bush; Leucophyllum frutescens), whitebrush (Aloysia gratissima), prickly pear (Opuntia spp.), tasajillo (Cylindropuntia spp.), condalias (Condalia spp.), and goatbush (aka allthorn; Castela erecta) (Gould 1962). Grasses are also important, especially in the western part of the Tamaulipan Biotic Province, where decreasing moisture results in a thinning of the woody vegetation.

\section{VEGETATION HistORY}

Pollen studies indicate that use of the modern vegetation zones described above is appropriate for understanding the plants and attendant animal resources available during most of the Holocene. Weakly Bog, situated in the Post Oak Savannah vegetation region in Leon County, provides some of the best data for vegetation reconstruction in the eastern half of Texas, at least during the last 3,000 years (Bousman 1998). Pollen profiles from this bog indicate oak and later oak/hickory woodlands, suggesting that modern plant communities generally provide good analogs for historical Texas plant communities. Some fluctuations in rainfall and temperature have taken place (Bousman 1998:204), but even decadeslong fluctuations in rainfall patterns seem to be part of the natural background of Late Holocene climate patterns (Stahle and Cleaveland 1992). The most notable changes since presettlement times include an increase in upland woody vegetation and the loss of "bottom prairie" communities along major rivers (Diggs et al. 2006:115-116; MacRoberts et al. 2002).

\section{Historical Food Resources}

Information about plant food resources in South Texas comes from the account of Álvar Núñez Cabeza de Vaca, whose travels took him very near Site 41DW277 (Krieger 2002). During his multi-year residency in sixteenth-century Texas, de Vaca became familiar with the South Texas plains as well as the coastal plains near Matagorda Bay. Typical plant foods he describes include prickly pear, nuts, and geophytes. Prickly pear (Opuntia spp.) provided both fresh green pads (nopalitos) and ripe fruits (tunas). Pecans (Carya illinoinensis) would have been the only tree nut available in most of the area of de Vaca's travels. Underground plant parts would have included bulbs of onions and garlic (Allium spp.), rain lily (Cooperia spp.), and possibly camas (Camassia scilloides), although DeWitt County is south of the current distribution of this important food plant (Turner 2003b). Wine cup roots (Callirhoe involucrate) and globeberry tubers (Ibervillea lindheimeri) would also have been available to people living at Site 41DW277 (Thoms et al., 2010).

\section{METHODS}

Flotation samples from 41DW277 were processed at EComm's Austin offices in a manual, bucket-tobucket flotation system. Light fractions were caught in chiffon fabric, and heavy fractions were passed through a 1/16" (1.6 mm) mesh. The heavy fraction was hand-separated at $16 \mathrm{X}$ magnification by EComm personnel, and lithics, charcoal, bone, Rabdotus spp., mussel, and otoliths/scales were stored in separate vials. All vials were examined for the presence of plant material at the Macrobotanical Analysis laboratory, and any plant material was added to the flotation light fractions before sorting. 
Flotation samples were sorted according to standard procedures at the Macrobotanical Analysis laboratory in Manchaca, Texas (Pearsall 2000). Each sample was weighed on an Ohaus Scout II 200 x 0.01 g electronic balance before being size-sorted through a stack of graduated geologic mesh. Material that did not pass through the No. 10 mesh ( $2 \mathrm{~mm}$ square openings) was completely sorted, and all carbonized botanical remains were counted, weighed, recorded, and labeled. Uncarbonized botanical material and non-botanical material such as gastropods and sediment that did not fall through the $2 \mathrm{~mm}$ mesh were weighed, recorded, and labeled as "contamination". Material that fell through the $2 \mathrm{~mm}$ mesh ("residue") was examined under a stereoscopic microscope at 7-45 X magnification for carbonized botanical remains. Because so few remains were present, any material identifiable as carbonized flora was removed from residue, counted, weighed, recorded, and labeled, even though wood charcoal fragments of this size are not typically included in macrobotanical analysis (Pearsall 2000). Modern seeds were recorded on a presence/absence basis.

Botanical materials were identified to the lowest possible taxonomic level by comparison to materials in the Macrobotanical Analysis comparative collection and through the use of standard reference works

(Core et al. 1979; Davis 1993; Hoadley 1990; Martin and Barkley 2000; Musil 1963; Panshin and de Zeeuw 1980). Botanical nomenclature follows that of the PLANTS Database (USDA, NRCS 2011).

\section{RESULTS AND DiscuSSION}

Plants recovered from the 41DW277 samples are shown in Table D-1. Botanical material was sparse, with wood charcoal the only archeological plant part present.

\section{Uncarbonized (Modern) Plants}

Uncarbonized plant parts were present in the flotation samples and consisted of roots, rootlets, and seeds. The roots and rootlets are easily interpreted as parts of modern plants currently or very recently growing on the site. Uncarbonized seeds were present in four of the six flotation samples. Uncarbonized seeds are also a common occurrence on most archeological sites, and they usually represent seeds of modern plants that have made their way into the soil either through their own dispersal mechanisms or by faunalturbation, floralturbation, or argilliturbation (Bryant 1985; Miksicek 1987). They are interpreted as modern here.

\section{Wood Charcoal}

Two fragments of wood charcoal from Site 41DW277 could be identified to genus. The fragment from Lot 128 belongs to the genus Condalia. Only one species of this genus occurs in DeWitt County in modern times: Condalia hookeri, known variously as bluewood condalia, capul negro, and brasil. Four other species of Condalia occur in Texas today, but they are largely species of the Trans-Pecos and southern Edwards Plateau that are unlikely to have been present in the site area even during the driest periods of the Holocene.

The wood charcoal fragment from Lot 137 was identifiable to the genus Colubrina. This is almost certainly Colubrina texensis, whose common names include Texas colubrina, hogplum, guayule, and snakewood. Two other Colubrina species have been recorded in Texas, but their distributions are limited to E1 Paseo and Cameron Counties (Turner 2003a). 
Table D-1. Plant Remains from Site 41DW277.

\begin{tabular}{|c|c|c|c|c|c|c|}
\hline Lot \# & 128 & 134 & 137 & 174 & 216 & 217 \\
\hline Unit & 10 & 10 & 6 & 6 & 10 & 6 \\
\hline Feature & 1 & 1 & 1 & 2 & 3 & 2 \\
\hline Depth (cmbs) & $140-150$ & $150-160$ & $150-160$ & $160-170$ & $170-180$ & $170-180$ \\
\hline L iters processed & 5.5 & 2 & 4.5 & 4 & 4 & 7 \\
\hline \multicolumn{7}{|l|}{ Wood Charcoal } \\
\hline Condalia (Condalia sp.) & $1(0.02)^{*}$ & - & - & - & - & - \\
\hline Colubrina (Colubrina sp.) & - & - & $1(0.01) *$ & - & - & - \\
\hline Hardwood flecks too small for identification & - & $2(<0.01)^{*}$ & - & $5(0.01)^{*}$ & $2(<0.01)^{*}$ & $4(<0.01)^{*}$ \\
\hline Indeterminable botanical & - & - & $1(<0.01)^{*}$ & - & - & - \\
\hline Indeterminable semi-carbonized material, probably fungus & - & - & - & - & $34(0.08) *$ & - \\
\hline \multicolumn{7}{|l|}{ Uncarbonized, modern seeds } \\
\hline Evening primrose (O enothera sp.) & - & $x$ & - & - & $\mathrm{X}$ & - \\
\hline Verbena (Verbena sp.) & - & - & $x$ & - & - & - \\
\hline B ristlegrass (Setaria sp.) & - & - & - & - & - & $X$ \\
\hline
\end{tabular}

Both bluewood condalia and Texas colubrina are thicket-forming shrubs of the Buckthorn family (Rhamnaceae), and both are common in South Texas today (Everitt et al. 2002). That a brush vegetation is indicated near the site suggests that vegetation (and climate) in the site area may have had a more southern character at the time of site occupation. It is somewhat surprising that the wood charcoal from a site so near the channel of the Guadalupe does not include trees such as hackberry or pecan that typically occur in gallery forests throughout south and east Texas. The wood of bluewood condalia and Texas colubrina is very dense, however, and other types of wood charcoals may have succumbed to the poor preservation conditions for charcoal at the site.

The dense wood tissue of bluewood condalia and Texas colubrina means that they burn at high temperatures (Graves 1919), but their utility as firewood is limited by the relatively small size of their stems and branches. Bluewood condalia has uses other than firewood. Its berries are edible and are known to have been consumed by Native groups (Moerman 1998). Bluewood condalia is also an excellent dye plant, with both berries and wood tissue said to produce good color, green-gold and blue respectively (Tull 1987).

\section{References Cited}

Bezanson, David

2000 Natural Vegetation Types of Texas and their Representation in Conservation Areas. M.A. thesis, Department of Geography, University of Texas at Austin.

Blair, W. F.

1950 The Biotic Provinces of Texas. Texas Journal of Science 2(1):93-117.

Bousman, C. Britt

1998 Paleoenvironmental Change in Central Texas: The Palynological Evidence. Plains Anthropologist 43(164):201-219. 
Bryant, John A.

1985 Seed Physiology. The Institute of Biology’s Studies in Biology No. 165. Edward Arnold, Ltd., London.

Core, H. A., W. A. Cote and A. C. Day

1979 Wood Structure and Identification. 2nd ed. Syracuse University Press, Syracuse, New York.

Davis, Linda W.

1993 Weed Seeds of the Great Plains: A Handbook for Identification. University Press of Kansas, Lawrence.

Diggs Jr., George M., Barney L. Lipscomb, and Robert J. O’Kennon

1999 Shinners and Mahler's Illustrated Flora of North Central Texas. Second printing, 2000, with minor corrections. Botanical Research Institute of Texas, Fort Worth.

Diggs Jr., George M., Barney L. Lipscomb, Monique D. Reed and Robert J. O’Kennon

2006 Illustrated Flora of East Texas, Volume One: Introduction, Pteridophytes, Gymnosperms, and Monocotyledons Sida, Botanical Miscellany, No. 26. Botanical Research Institute of Texas, Fort Worth.

Everitt, James H., D. Lynn Drawe, and Robert I. Lonard

2002 Trees, Shrubs and Cacti of South Texas. Revised ed. Texas Tech University Press, Lubbock.

Gould, Frank W.

1962 Texas Plants -- A Checklist and Ecological Summary. The Agricultural and Mechanical College of Texas, Texas Agricultural Experiment Station, College Station, Texas.

Graves, Henry S.

1919 The Use of Wood for Fuel. United States Department of Agriculture Bulletin No. 753, Washington, DC.

Hoadley, R. Bruce

1990 Identifying Wood: Accurate Results with Simple Tools. The Taunton Press, Newtown, Connecticut.

Krieger, Alex D.

2002 We Came Naked and Barefoot: The Journey of Cabeza de Vaca across North America. Edited by Margery H. Krieger. University of Texas Press, Austin.

MacRoberts, Barbara R., Michael H. MacRoberts, and James C. Cathey

2002 Floristics of Xeric Sandylands in the Post Oak Savanna Region of East Texas. Sida 20(1):373-386. 
Martin, Alexander C. and William D. Barkley

2000 Seed Identification Manual. The Blackburn Press.

Miksicek, Charles H.

1987 Formation Processes of the Archaeobotanical Record. In Advances in Archaeological Method and Theory, Vol. 10, edited by M. B. Schiffer, pp. 211-247. Academic Press, Inc.

Moerman, Daniel E.

1998 Native American Ethnobotany. Timber Press, Portland, Oregon.

Musil, Albina F.

1963 Identification of Crop and Weed Seeds Agriculture Handbook No. 219. U.S. Department of Agriculture, Washington, D.C.

Panshin, A. J. and Carol de Zeeuw

1980 Textbook of Wood Technology: Structure, Identification, Properties, and Uses of the Commercial Woods of the United States and Canada. Fourth ed. McGraw-Hill Book Company, New York.

Pearsall, Deborah M.

2000 Paleoethnobotany: A Handbook of Procedures. 2nd ed. Academic Press, San Diego.

Thoms, Alston, Susan Dial, and Heather Smith

2010 Learning from Cabeza de Vaca. Texas Beyond History, Texas Archeological Research Laboratory, University of Texas at Austin. http://www.texasbeyondhistory.net/cabeza-cooking/ index.html. Accessed 8/24/11.

Tull, Delena

1987 Edible and Useful Plants of Texas and the Southwest. University of Texas Press, Austin.

Turner, Billie L., Holly Nichols, Geoffrey Denny, and Oded Doron

2003a Atlas of the Vascular Plants of Texas, Volume 1:Dicots. Botanical Research Institute of Texas, Fort Worth.

Turner, Billie L., Holly Nichols, Geoffrey Denny, and Oded Doron

2003b Atlas of the Vascular Plants of Texas, Volume 2: Ferns, Gymnosperms, Monocots. Botanical Research Institute of Texas, Fort Worth.

USDA, NRCS (United States Department of Agriculture, Natural Resources Conservation Service)

2011 The PLANTS Database. http://plants.usda.gov. National Plant Data Center, Baton Rouge, LA 70874-4490. Accessed 8/24/2011. 

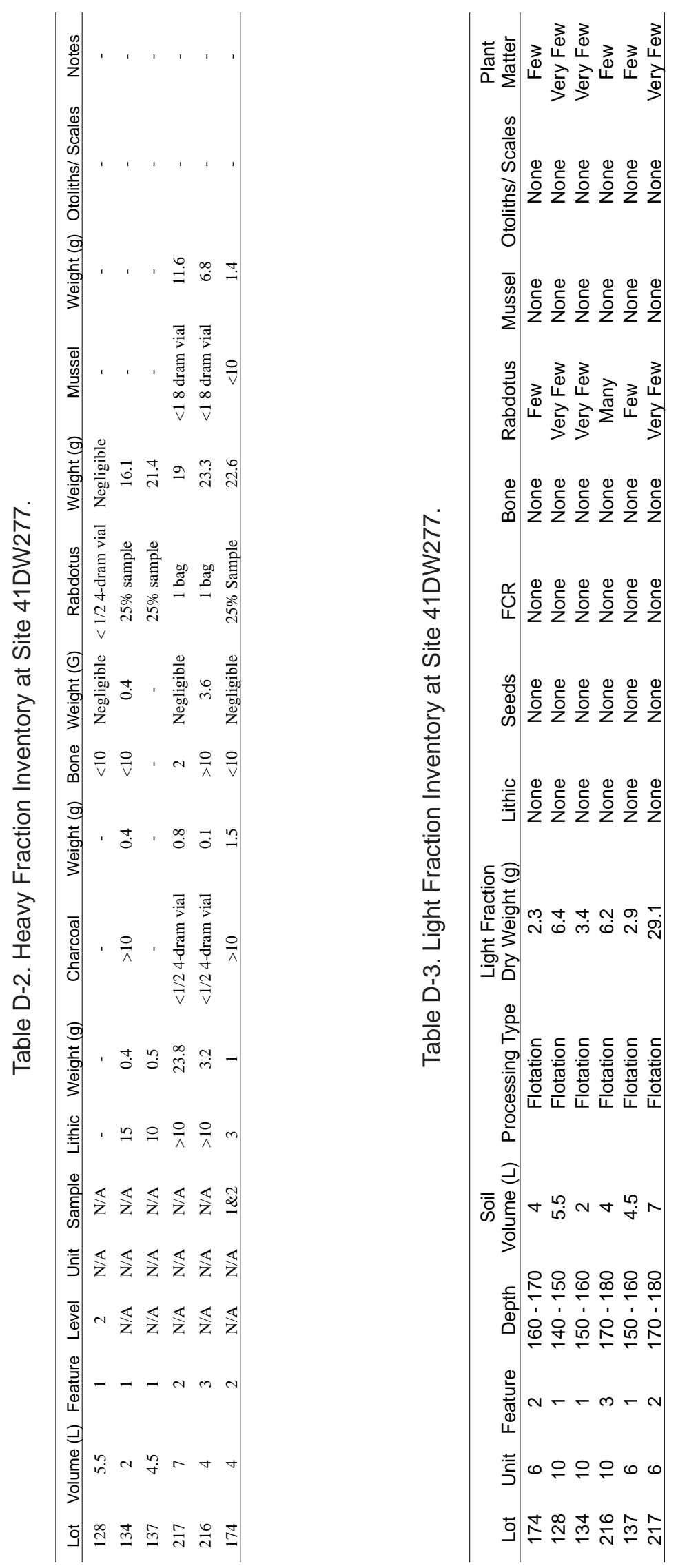
Table D-4. Wet Screen Inventory (0.25-inch Screen) at Site 41DW277.

\begin{tabular}{|c|c|c|c|c|c|c|c|c|c|c|c|c|}
\hline Lot & Unit & $\begin{array}{l}\text { Depth } \\
\text { (cmbs) }\end{array}$ & $\begin{array}{c}\text { Volume } \\
\text { (L) }\end{array}$ & $\begin{array}{l}\text { Lithic } \\
\text { Count }\end{array}$ & $\begin{array}{c}\text { Lithic } \\
\text { Weight }(\mathrm{g})\end{array}$ & $\begin{array}{l}\text { Bone } \\
\text { Count* }\end{array}$ & $\begin{array}{c}\text { Bone } \\
\text { Weight }(\mathrm{g})\end{array}$ & Rabdotus Count & $\begin{array}{l}\text { Rabdotus } \\
\text { Weight (g) }\end{array}$ & Mussel Count & $\begin{array}{c}\text { Mussel } \\
\text { Weight (g) }\end{array}$ & Notes \\
\hline 128 & 10 & $140-150$ & 4 & 7 & 0.7 & - & - & $<1 \mathrm{Bag}$ & 23 & - & - & - \\
\hline 135 & 10 & $160-170$ & 3 & 5 & 0.6 & - & - & $>15$ drams & 36 & $<1 / 2$ 4-dram vial & 2.9 & - \\
\hline 143 & 11 & $150-160$ & 3.5 & 10 & 0.6 & - & - & 14-dram vial & 7 & - & - & - \\
\hline 153 & 13 & $120-130$ & 3.5 & 7 & 0.4 & - & - & $<1$ 4-dram vial & 3.3 & $<1 / 2$ 4-dram vial & 3 & - \\
\hline 156 & 14 & $160-170$ & 2 & 1 & 0.2 & - & - & 14-dram vial & 9.4 & $<1 / 2$ 4-dram vial & 1.4 & - \\
\hline 164 & 15 & $150-160$ & 3 & 1 & Negligible & - & - & 14-dram vial & 7.5 & - & - & - \\
\hline 170 & 13 & $150-160$ & 4 & 4 & 0.7 & - & - & 14-dram vial & 10.2 & $<1 / 2$ 4-dram vial & 2.3 & - \\
\hline 173 & 24 & $120-130$ & 2.5 & 6 & 1.3 & - & - & 14 -dram vial & 4.7 & $<14$-dram vial & 3.7 & - \\
\hline 177 & 21 & $150-160$ & 3.5 & 5 & 0.3 & - & - & $<14$-dram vial & 5.2 & - & - & - \\
\hline 178 & 17 & $130-140$ & 3 & 4 & 8.4 & - & - & 14-dram vial & 4.8 & - & - & - \\
\hline 183 & 24 & $140-150$ & 1.6 & 3 & 1.2 & - & - & $<14$-dram vial & 4.2 & - & - & - \\
\hline 184 & 13 & $160-170$ & 4 & 34 & 13 & - & - & $>1 / 2$ 4-dram vial & 5.6 & $<1 / 24$-dram vial & 1 & - \\
\hline 185 & 26 & $100-110$ & 1.5 & 4 & 0.4 & - & - & $<1 / 2$ 4-dram vial & Negligible & - & - & - \\
\hline 188 & 20 & $140-150$ & 2.5 & 10 & 0.9 & - & - & $<1 / 2$ 4-dram vial & 3.3 & - & - & - \\
\hline 190 & 22 & $120-130$ & 2 & - & - & $<10$ & Negligible & <1 4-dram vial & 4.2 & - & - & - \\
\hline 192 & 14 & $140-150$ & 4 & 1 & Negligible & - & - & $<1 / 2$ 4-dram vial & 3.2 & $<1 / 2$ 4-dram vial & 0.5 & - \\
\hline 193 & 20 & $130-140$ & 3 & 1 & Negligible & - & - & 14-dram vial & 4.9 & $<1 / 2$ 4-dram vial & 2.5 & - \\
\hline 196 & 22 & $140-150$ & 2 & 13 & 4.7 & - & - & $<1 / 2$ 4-dram vial & 3.2 & - & - & - \\
\hline 197 & 24 & $150-160$ & 2 & 17 & 9.1 & - & - & $<1$ 4-dram vial & 4.1 & - & - & - \\
\hline 198 & 24 & $160-170$ & 2 & 7 & 1.3 & - & - & $<1 / 2$ 4-dram vial & 2.9 & $<1 / 24$-dram vial & 0.1 & - \\
\hline 199 & 24 & $170-180$ & 1.5 & 4 & 0.5 & - & - & $<1 / 2$ 4-dram vial & 0.9 & - & - & - \\
\hline 204 & 20 & $160-170$ & 3.5 & 3 & 2.2 & - & - & $<1 / 2$ 4-dram vial & 1.8 & - & - & - \\
\hline 207 & 22 & $150-160$ & 5 & 1 & Negligible & - & - & $<14$-dram vial & 4.1 & - & - & - \\
\hline 211 & 24 & $180-190$ & 2 & 2 & Negligible & - & - & $<1 / 2$ 4-dram vial & 0.5 & - & - & - \\
\hline 216 & 24 & $130-140$ & 2.5 & 12 & 2.9 & - & - & $<1 \mathrm{Bag}$ & 37 & - & - & - \\
\hline 217 & 6 & $170-180$ & 2 & 5 & 8.9 & - & - & 14 -dram vial & 8.3 & $<1 / 24$-dram vial & 4.9 & - \\
\hline 218 & 13 & $170-180$ & 3.5 & 9 & 3.9 & $<10$ & 2 & $>1 / 2$ 4-dram vial & 3.8 & - & - & - \\
\hline 219 & 10 & $180-190$ & 2 & 5 & 0.9 & - & - & $<14$-dram vial & 4.1 & - & - & - \\
\hline 222 & 25 & $140-150$ & 3 & 11 & 3.7 & - & - & 14-dram vial & 3 & - & - & - \\
\hline 228 & 25 & $150-160$ & 2 & 23 & 10.6 & - & - & 14-dram vial & 5.1 & - & - & - \\
\hline 229 & 6 & $180-190$ & 1.5 & 12 & 4.4 & - & - & 1/2 4-dram vial & 2.9 & $<1 / 2$ 7-dram vial & 10.5 & - \\
\hline 230 & 26 & $160-170$ & 2 & 1 & Negligible & - & - & $<1 / 2$ 4-dram vial & Negligible & $<1 / 2$ 4-dram vial & Negligible & - \\
\hline 234 & 6 & $190-200$ & 2 & 8 & 0.7 & - & - & $<1 / 2$ 4-dram vial & 3.3 & $<1 / 2$ 4-dram vial & 2.6 & - \\
\hline 236 & 25 & $160-170$ & 2 & 4 & 1.5 & - & - & $<1 / 2$ 4-dram vial & 1 & - & - & - \\
\hline 240 & 27 & $100-110$ & 3 & 1 & Negligible & - & - & $<1 / 24$-dram vial & 2.4 & - & - & - \\
\hline 241 & 13 & $180-190$ & 3 & 4 & 1.2 & $<20$ & 1.5 & $<1 / 2$ 4-dram vial & 0.5 & - & - & - \\
\hline 244 & 23 & $110-120$ & 3.5 & 5 & 1 & - & - & 14-dram vial & 2.5 & - & - & - \\
\hline 247 & 28 & $110-120$ & 4 & 4 & 0.4 & - & - & $<1 / 2$ 4-dram vial & 2.5 & $<1 / 2$ 4-dram vial & 3.1 & - \\
\hline 253 & 28 & $120-130$ & 3 & 5 & 0.2 & - & - & 14-dram vial & 2.8 & $<1 / 2$ 4-dram vial & 0.8 & - \\
\hline 258 & 29 & $110-120$ & 3.5 & 12 & 2.7 & - & - & $<1 / 2$ 4-dram vial & 1.4 & $<1 / 24$-dram vial & Negligible & - \\
\hline 259 & 23 & $140-150$ & 3 & 7 & 2.7 & - & - & 14-dram vial & 1.9 & - & - & - \\
\hline 260 & 29 & $120-130$ & 2 & 5 & 1 & - & - & $<1$ 4-dram vial & - & 4.2 & - & - \\
\hline 261 & 28 & $140-150$ & 3 & 3 & Negligible & - & - & $<1 / 2 \mathrm{Bag}$ & 12 & - & - & - \\
\hline 262 & 28 & $150-160$ & 3.5 & 8 & 1.4 & $<20$ & 1.3 & 14-dram vial & 3.2 & $<1 / 2$ 4-dram vial & 1.5 & - \\
\hline 271 & 29 & $130-140$ & 3.5 & 2 & Negligible & - & - & 14-dram vial & 2 & - & - & - \\
\hline 273 & 19 & $140-150$ & 3.5 & 10 & 2.1 & - & - & $<1 / 2$ 7-dram vial & 6.4 & - & - & - \\
\hline 279 & 20 & $120-130$ & 2 & 1 & Negligible & - & - & $<1 / 2$ 4-dram vial & 1.2 & $<1 / 2$ 4-dram vial & Negligible & - \\
\hline 280 & 14 & $160-170$ & 2 & 3 & 0.7 & - & - & 14-dram vial & 6.6 & $<1 / 2$ 4-dram vial & 2.7 & - \\
\hline 282 & 19 & $150-160$ & 4 & 1 & Negligible & - & - & $<14$-dram vial & 3.9 & - & - & - \\
\hline 285 & 20 & $120-130$ & 3 & - & - & - & - & $<1 / 24$-dram vial & 3.4 & - & - & - \\
\hline
\end{tabular}

* Pieces too small to identify with certainty 
Table D-5. Wet Screen Inventory (0.125-inch Screen) at Site 41DW277.

\begin{tabular}{|c|c|c|c|c|c|c|c|c|c|c|c|c|}
\hline Lot & Unit & $\begin{array}{l}\text { Depth } \\
\text { (cmbs) }\end{array}$ & Volume (L) & $\begin{array}{l}\text { Lithic } \\
\text { Count }^{\star}\end{array}$ & $\begin{array}{c}\text { Lithic } \\
\text { Weight }(\mathrm{g})\end{array}$ & $\begin{array}{l}\text { Bone } \\
\text { Count }\end{array}$ & $\begin{array}{c}\text { Bone } \\
\text { Weight (g) }\end{array}$ & $\begin{array}{c}\text { Rabdotus } \\
\text { Count }\end{array}$ & $\begin{array}{c}\text { Rab. } \\
\text { Weight }(\mathrm{g})\end{array}$ & $\begin{array}{c}\text { Mussel } \\
\text { Count }\end{array}$ & $\begin{array}{c}\text { Mussel } \\
\text { Weight (g) }\end{array}$ & Notes \\
\hline 128 & 10 & $140-150$ & 4 & $<15$ & Negligible & 1 & Negligible & 1/2 Bag & 100 & - & - & - \\
\hline 135 & 10 & $160-170$ & 3 & $<20$ & Negligible & - & - & 1/2 Bag & 52 & - & - & - \\
\hline 143 & 11 & $150-160$ & 3.5 & $<20$ & Negligible & - & - & 1/2 Bag & 66 & - & - & - \\
\hline 153 & 13 & $120-130$ & 3.5 & $<10$ & Negligible & - & - & $<1 / 3 \mathrm{Bag}$ & 41 & - & - & - \\
\hline 156 & 14 & $160-170$ & 2 & $<20$ & Negligible & - & - & $<1 / 2 \mathrm{Bag}$ & 35 & - & - & - \\
\hline 164 & 15 & $150-160$ & 3 & 10 & Negligible & - & - & 1/2 Bag & 69 & - & - & - \\
\hline 170 & 13 & $150-160$ & 4 & $<20$ & Negligible & - & - & $>1 / 2 \mathrm{Bag}$ & 82 & - & - & - \\
\hline 173 & 24 & $120-130$ & 2.5 & $<10$ & Negligible & - & - & 1/3 Bag & 35 & - & - & - \\
\hline 177 & 21 & $150-160$ & 3.5 & $<20$ & Negligible & - & - & 1/2 Bag & 69 & - & - & - \\
\hline 178 & 17 & $130-140$ & 3 & $<10$ & Negligible & - & - & 1/2 Bag & 68 & - & - & - \\
\hline 183 & 24 & $140-150$ & 1.6 & $<15$ & Negligible & 1 & Negligible & 1/3 Bag & 35 & - & - & - \\
\hline 184 & 13 & $160-170$ & 4 & $<20$ & Negligible & - & - & 1/2 Bag & 66 & - & - & - \\
\hline 185 & 26 & $100-110$ & 1.5 & $<10$ & Negligible & - & - & 1/2 7-dram vial & 10 & - & - & - \\
\hline 188 & 20 & $140-150$ & 2.5 & $<10$ & Negligible & - & - & 1/2 Bag & 56 & - & - & - \\
\hline 190 & 22 & $120-130$ & 2 & $<10$ & Negligible & - & - & $<1 / 3 \mathrm{Bag}$ & 34 & - & - & - \\
\hline 192 & 14 & $140-150$ & 4 & $<20$ & Negligible & - & - & 1/2 Bag & 67 & - & - & - \\
\hline 193 & 20 & $130-140$ & 3 & $<5$ & Negligible & - & - & $<1 / 2 \mathrm{Bag}$ & 47 & - & - & - \\
\hline 197 & 24 & $150-160$ & 2 & $<15$ & Negligible & - & - & 1/3 Bag & 29 & - & - & - \\
\hline 198 & 24 & $160-170$ & 2 & $<20$ & Negligible & - & - & 1/3 Bag & 50 & - & - & - \\
\hline 199 & 24 & $170-180$ & 1.5 & $<10$ & Negligible & - & - & 1/3 Bag & 34 & - & - & - \\
\hline 204 & 20 & $160-170$ & 3.5 & $<20$ & Negligible & - & - & 1/2 Bag & 78 & - & - & - \\
\hline 207 & 22 & $150-160$ & 5 & - & - & - & - & 1/2 Bag & 61 & - & - & - \\
\hline 211 & 24 & $180-190$ & 2 & $<20$ & Negligible & - & - & 1/3 Bag & 43 & - & - & - \\
\hline 216 & 24 & $130-140$ & 2.5 & $<10$ & Negligible & - & - & 1/2 Bag & 61 & - & - & - \\
\hline 217 & 6 & $170-180$ & 2 & $<10$ & Negligible & - & - & $<1 / 2 \mathrm{Bag}$ & 34 & - & - & - \\
\hline 196 & 22 & $140-150$ & 2 & $<20$ & Negligible & $<10^{*}$ & Negligible & 1/4 Bag & 22 & - & - & - \\
\hline 218 & 13 & $170-180$ & 3.5 & $<10$ & Negligible & - & - & 1/3 Bag & 50 & - & - & - \\
\hline 219 & 10 & $180-190$ & 2 & $<20$ & Negligible & $<5^{\star}$ & Negligible & 1/3 Bag & 53 & - & - & - \\
\hline 222 & 25 & $140-150$ & 3 & $<25$ & Negligible & - & - & $<1 \mathrm{Bag}$ & 67 & - & - & - \\
\hline 228 & 25 & $150-160$ & 2 & $<30$ & Negligible & - & - & 1/2 Bag & 54 & - & - & - \\
\hline 229 & 6 & $180-190$ & 1.5 & $<15$ & Negligible & - & - & 1/3 Bag & 32 & - & - & - \\
\hline 230 & 26 & $160-170$ & 2 & $<10$ & Negligible & - & - & $<1 / 3$ Bag & 15 & - & - & - \\
\hline 234 & 6 & $190-200$ & 2 & $<15$ & Negligible & - & - & 1/4 Bag & 37 & - & - & - \\
\hline 236 & 25 & $160-170$ & 2 & $<10$ & Negligible & - & - & 1/3 Bag & 42 & - & - & - \\
\hline 240 & 27 & $100-110$ & 3 & $<20$ & Negligible & - & - & $<1 / 4 \mathrm{Bag}$ & 14 & - & - & - \\
\hline 241 & 13 & $180-190$ & 3 & $<20$ & Negligible & - & - & 1/3 Bag & 48 & - & - & - \\
\hline 244 & 23 & $110-120$ & 3.5 & $<10$ & Negligible & - & - & 1/2 Bag & 51 & - & - & - \\
\hline 247 & 28 & $110-120$ & 4 & $<15$ & Negligible & - & - & $<1 / 3 \mathrm{Bag}$ & 24 & - & - & - \\
\hline 253 & 28 & $120-130$ & 3 & $<20$ & Negligible & - & - & 1/3 Bag & 40 & - & - & - \\
\hline 258 & 29 & $110-120$ & 3.5 & $<20$ & Negligible & - & - & 1/3 Bag & 38 & - & - & - \\
\hline 259 & 23 & $140-150$ & 3 & - & - & 1 & Negligible & 1/2 Bag & 61 & - & - & - \\
\hline 260 & 29 & $120-130$ & 2 & $<20$ & Negligible & - & - & $<1 / 3 \mathrm{Bag}$ & 30 & - & - & - \\
\hline 261 & 28 & $140-150$ & 3 & 11 & Negligible & - & - & 1/2 Bag & 65 & - & - & - \\
\hline 262 & 28 & $150-160$ & 3.5 & $<20$ & Negligible & $<10^{*}$ & Negligible & 1/2 Bag & 63 & - & - & - \\
\hline 271 & 29 & $130-140$ & 3.5 & $<20$ & Negligible & - & - & 1/2 Bag & 67 & - & - & - \\
\hline 273 & 19 & $140-150$ & 3.5 & $<20$ & Negligible & - & - & $>1 / 2 \mathrm{Bag}$ & 84 & - & - & - \\
\hline 279 & 20 & $120-130$ & 2 & $<20$ & Negligible & - & - & $<1 / 3 \mathrm{Bag}$ & 30 & - & - & - \\
\hline 280 & 14 & $160-170$ & 2 & $<20$ & Negligible & - & - & 1/3 Bag & 34 & - & - & - \\
\hline 282 & 19 & $150-160$ & 4 & $<5$ & Negligible & - & - & 1/2 Bag & 66 & - & - & - \\
\hline 285 & 20 & $120-130$ & 3 & $<15$ & Negligible & 1 & Negligible & $<1 / 4 \mathrm{Bag}$ & 22 & - & - & - \\
\hline
\end{tabular}

* Pieces too small to identify with certainty 
Table D-6. Wet Screen Inventory (0.0625-inch Screen) at Site 41DW277.

\begin{tabular}{ccccccc}
\hline Lot & Unit & Depth (cmbs) & Soil Volume $(\mathrm{L})$ & Sample Weight $(\mathrm{g})$ & Lithics* $^{*}$ & Weight $(\mathrm{g})$ \\
\hline 128 & 10 & $140-150$ & 4 & 256 & $<20$ & Negligible \\
156 & 14 & $160-170$ & 2 & 136 & $<15$ & Negligible \\
184 & 13 & $160-170$ & 4 & 303 & $<20$ & Negligible \\
185 & 26 & $100-110$ & 1.5 & 83 & $<20$ & Negligible \\
192 & 14 & $140-150$ & 4 & 235 & $<15$ & Negligible \\
204 & 20 & $160-170$ & 3.5 & 322 & $<15$ & Negligible \\
217 & 6 & $170-180$ & 2 & 108 & $<20$ & Negligible \\
222 & 25 & $140-150$ & 3 & 206 & $<15$ & Negligible \\
230 & 26 & $160-170$ & 2 & 113 & $<20$ & Negligible \\
244 & 23 & $110-120$ & 3.5 & 175 & $<10$ & Negligible \\
247 & 28 & $110-120$ & 4 & 110 & $<10$ & Negligible \\
258 & 29 & $110-120$ & 3.5 & 147 & $<20$ & Negligible \\
259 & 23 & $140-150$ & 3 & 176 & $<15$ & Negligible \\
273 & 19 & $140-150$ & 3.5 & 197 & $<15$ & Negligible \\
279 & 20 & $120-130$ & 2 & 125 & $<15$ & Negligible \\
\hline
\end{tabular}

* Pieces too small to identify with certainty 